
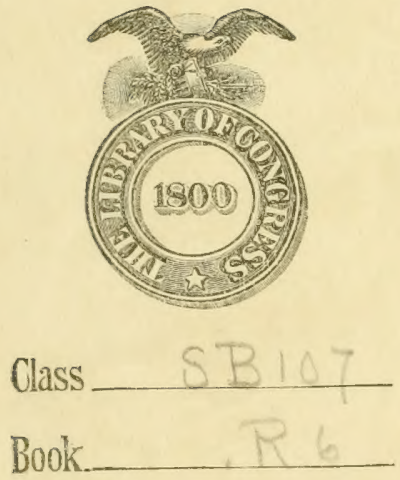

Copyighit No.

COPYRIGHT DEPOSET 




\section{THE BOTANY OF CROP PLANTS \\ R O B B I N S}





\title{
THE \\ BOTANY OF CROP PLANTS
}

A TEXT

AND REFERENCE BOOK

\author{
BY \\ WILFRED W. ROBBINS, PH. D. \\ PROFESSOR OF BOTANY, COLORADO AGRICULTURAL COLLEGE
}

ILLUSTRATED

\author{
PHILA DELPHIA \\ P. BLAKISTON'S SON \& CO. \\ 1012 WALNUT STREET
}




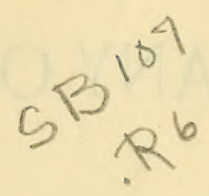

Copyright, igi7, By P. Blakiston's Son \& Co.

$1 \%$

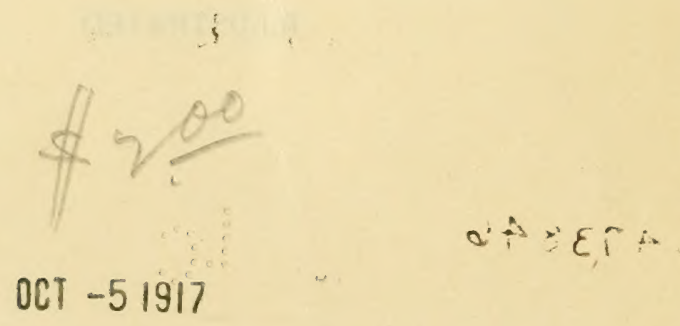

THE MAPLE PRESS YORK PA

(C) $\operatorname{CI} .4738846$

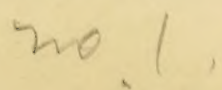




\section{PREFACE}

This book has grown out of a course of instruction extending over a number of successive years. Most of the material presented here, except Part I, has been used in mimeographed form in college freshmen classes, not only as a text from which to make assignments, but also as a guide and reference in the laboratory. The issuance of the book has been stimulated in part by the expressed need of a number of schools for a text and reference book which will give the student a knowledge of the botany of common orchard, garden and field crops, and it is the author's wish that the material brought together from many sources and organized in the present form will meet this need, at least in a measure.

It has seemed advisable to include chapters (Part I) which may be needed in some instances to refresh the student's knowledge of certain fundamentals, or prepare him for that which follows in Part II. But in many schools Part II will be preceded by a general course which aims to give the student a survey of the plant kingdom and an acquaintance with the large outstanding facts and principles of botany, and in this case Part I will be omitted. . The subject matter of Part II is sufficient for a course of one-half year involving one recitation and two laboratory (5) periods per week.

In the preparation of the book, the writer has had in mind non-agricultural as well as agricultural schools, for it cannot escape notice that there is a growing tendency, wherever botany is taught, to tie it up more closely with economic interests and to draw more and more upon economic plants in citing examples and in choosing objects of study in the laboratory. 
The bibliographies are obviously incomplete. Most of the titles were made use of by the writer in the preparation of the manuscript, and to the authors of these he is under obligation. Bailey's Cyclopedia of Horticulture has been indispensable and has been called into use frequently. The writer has also called upon the publications of the United States Department of Agriculture and of the various Experiment Stations. A number of the "keys" are original, many are adapted, and a few are taken verbatim. A majority of the illustrations are original. It is believed that the direct method adopted herein of labeling drawings will appeal to both students and teachers.

Almost all original illustrations, and also those copied or adapted are the work of Mr. N. Lee Foster. The writer is especially indebted to him, not only for the delineation, but for his helpful interest and valued coöperation throughout. Professor D. W. Frear, formelly Associate Professor of Agronomy at the Colorado Agricultural College, now of the North Dakota Experiment Station, is to be given credit for organizing and writing up portions of Chapters IX, XVII, XXX and XXXVIII. The text was planned and outlined by Professor Frear and the undersigned as joint authors, but unavoidable exigencies made it impossible for him to continue his connection as author. The entire manuscript was painstakingly read by Louise Falk Robbins, and her suggestions have added greatly to the accuracy in many places.

Colorado Agricultural College.

W. W. Robbins. 


\title{
CONTENTS
}

\author{
PART I
}

CHAPTER I.-The SeEd PLANT Body.

Principal Parts of the Seed Plant Body-Size and Form of the Seed Plant Body.......................

CHAPTER II.-Findmentil Intern.il Strlcture of Plint Body.

Organs and Tissues-The Plant Cell-The Cell as a Unit of Structure-The Cell as a Unit of Plant Activity--The Structure of the Plant Cell-The Cell Wall-Plastids-NucleusProtoplasm .......................... 4 4-9

CHAPTER III.-Roots.

Development of Root Systems-The Work of Roots-Effect of Environment upon Character of Root System-General Characteristics of Roots-Classification of Roots Based upon Their Medium of Growth-Structure of Roots-Root Hairs, the Absorbing Organs of a Plant-Root-hair Zone-Structure of a Root Hair-Effect of External Factors upon Development of Root Hairs - Length of Life of Roots........... I0-2I CHAPTER IV.-STEMS.

Development of Shoot System-Buds-Classification of Buds-Bud Variation-General Characteristics of StemsHow Does a Stem Grow in Length-Classification of Stems Based upon Their Medium of Growth- "Modified" StemsStructure of Stems-The Young Dicot Stem-Dicot Vascular Bundle-Growth in Thickness of Dicot Stem-Monocot Stems-Annual Rings-Bark-The Work of Stems....... . 22-4I

CHAPTER V.-LEAVES.

Development of Leaves-Parts of Leaf-Kinds of LeavesStructure of Leaves-The Work of Foliage Leaves.... . . 42-47 CHAPTER VI.-FLOWERS.

Parts of Representative Flower-Development of the Flower -Stamens-Mature Pollen Grain-Pistil-Ovule-Pollination-Fertilization-Placentation-Symmetry of FlowerRelative Positions of Flower Parts--Union of Flower PartsIncomplete Flowers-Inflorescence............ . 48-56 CHAPTER VII.-Fruits, SEed, AND SeEdings.

Development of the Seed-Development of the Fruit-Fruit and Seed Distinguished-Kinds of Fruits-Germination of the Seed 
CHAPTER VIII.-The Classification and Naming of Plants. Reproductive versus Vegetative Organs in ClassificationGroups of Plants-The Plant Kingdom-Plant Nomenclature - Scientific Name-Scientific Name versus Common NameGeneral References.......................... 60-67

\section{PART II}

CHAPTER IX.-Graminex (PoACE玉) Grass Family.

Habit of Plants-Roots-Stems-Lodging-Tillering-Bulbous Grasses-Rhizome-bearing Grasses-Stoloniferous Grasses-Leaves-Growth of Leaves-Scales and BractsLigule-Auricle-Inflorescence-Spikelet-Pollination-Fruit -Phylogeny of Grasses-Grass-like Plants-ReferencesCereals - Key to Groups of Important Cereals-Key to Smallgrain Seedlings-References ................. 68-90

CHAPTER X.-TRITICUM (WheAT).

Habit of Plant-Roots-Stems-Leaf-Inflorescence-Spikelet-Flower-Opening of Flower and Pollination-Artificial Cross Pollination-Fertilization and Maturing of GrainRipening Stages-The Mature Grain-Relative Proportions of the Parts of the Grain- "Hard" and "Soft" Wheats-Milling of Wheat-Kinds of Flour-Germination of Wheat-Classification of the Types of Wheat-Key to Economic Types of Wheat-Origin of Wheat-Environmental Relations-Uses of Wheat-Production of Wheat-References........... 9 I - I 2 I CHAPTER XI.-AvEnA (OATS).

Habit of Plant-Roots-Stems-Leaf-Inflorescence-Spikelet and Flower-Opening of Flower and Pollination-Fertilization and Maturing of Grain-The Mature Grain-Germination of Oats-Classification of Oats-Other Cultivated Oats -Avena fatua ("wild oats") - Origin of Oats-Environmental Relations-Uses of Oats-The Production of Oats References.............................. 2 . 34 CHAPTER XII.-HoRdEUM (BARLEY).

Habit of Plant, Roots, Stems, Leaves-Spikelet and FlowerOpening of Flower and Pollination-Fertilization and Maturing of Grain-Mature Grain of Barley-Color of GrainGermination of Barley-Classification of Barleys-Origin of Cultivated Barleys-Environmental Relations-Uses of Barley-The Brewing Process-Production of BarleyReferences ...................... . $355^{-1} 52$ 
CHAP'TER XIII.-SECALE CEREALE (RYE).

Habit of Plant, Roots-Stems, Leaves-Inflorescence-Spikelet-Opening of Flower, Pollination and Fertilization-Maturing of Grain, and Mature Grain-Germination of RyeClassification, and Origin of Rye-Environmental Relations -Uses of .Rye-Production of Rye-References......... I53-156 CHAPTER XIV.-ZEA (CORN, MAIZE).

Habit of Plant, Roots- "Prop" and "Brace" Roots-Stem -Leaves-Inflorescence-Staminate Inflorescence-Staminate Spikelet-Pistillate Inflorescence-Pistillate SpikeletHermaphroditic Flowers-Opening of the Flowers, and Pollination-Fertilization, and Development of the Grain-Xenia in Corn-Variation in the Corn Plant-Results of Self-fertiiization in Corn-The Mature Grain of Corn-Corn Starch Distinguished from the Other Common Starches-Germination of Corn-Classification-Key to "Species Groups" of Corn-Origin of Maize-Environmental Relations-Uses of Corn-Production of Corn-References.............. I57-I90 CHAPTER XV.-AnDRopogon Sorghum (SoRghuMs).

Habit of Plant, and Roots-Stems and Leaves-Inflorescence -Spikelets and Flowers-Fertile Spikelet-Staminate Spikelet-Opening of Flowers and Pollination-Fruit-VarietiesKey to Principal Groups of Sorghum-Origin of SorghumsEnvironmental Relations-Uses of Sorghums-References... I0I--20I CHAPTER XVI.-ORYZA SATIVA (RICE).

Habit, Roots, Stems, Leaves-Inflorescence and SpikeletPollination and Fertilization-Grain-Milling of Rice-Varieties-Distribution, and Closely Related Species-Uses of Rice -Environmental Relations-The Production of RiceReferences.............................202-200 CHAPTER XVII.-MILLET.

Key to Principal Economic Types (Species) of Millet and Some Closely Related Common Weed Grasses............. 2 I0-2I I Pennisetum glaucum (Pearl Millet)-Stem-Leaf-Inflorescence-Spikelet and Flower-Pollination-Mature GrainVarieties-Origin..................... $2 \mathrm{II}-2 \mathrm{I} 3$ Panicum miliaceum (Proso, Hog or Broom-corn Millet)Stem-Leaf-Inflorescence-Spikelet and Flower-Pollination-Mature Grain-Varieties-Origin.............2 23-2I6 Chætochloa italica (Foxtail Millets) - Steam-Leaf - Inflorescence-Spikelets and Flower-Pollination-Mature GrainTypes and Varieties of Foxtail Millet-Key to Principai Types of Foxtail Millets (Chxtochloa italica)-Origin of Foxtail Millet 216-219 
Echinochloa Crus-galli (Barnyard Grass or Barnyard Millet)-Habit, Stems, Leaves-Inflorescence, Spikelet, Flowers, and Fruit-Distribution................ I19-220

Echinochloa frumentacea (Japanese Barnyard Millet).....219-220

Environmental Relations-Uses of Millets-References.....220-22I CHAPTER XVIII.-PhLEUM PRATENSE (TIMOTHY).

Description-Environmental Relations-Closely Related Species-References......................... . . 222-224

CHAPTER XIX.-Saccharum officinarum (Sugar Cane).

Habit, Roots-Stems-Leaves-Inflorescence, Flowers, Fruit - Geographical-Sugar from Sugar Cane-Production of Cane Sugar ................................... 225-228

CHAPTER XX.-LILIACE (LILY FAMILY).

Habit, Roots-Leaves-Inflorescence and Flowers-Fruit and Seeds................................ . 229-230 Allium-Roots-Stems-Leaf-Inflorescence-Flower-Pollination-Fruit-Germination of Seed, and the SeedlingGeographical-Key to the Principal Cultivated Species of Genus Allium........................... . 23I-237

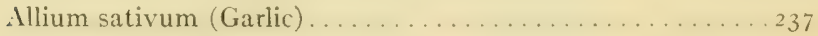

Allium porrum (Leek) . . . . . . . . . . . . . . . . 238

Allium schœnoprasum (Chives or Cives)............. 238

Allium ascalonicum (Shallot) . . . . . . . . . . . . . . . 238-239

Allium fistulosum (Welsh Onion or Ciboule). . . . . . . 239-240 Allium cepa (Onion) - Description-History-Types of Onions -Foreign and Domestic Onions-Composition of Onions-Uses of Onions........................... 240-244

Asparagus-Generic Description-Economic Importance of Genus... . . . . . . . . . . . . . . . . . . . . . . . . 244-246 Asparagus officinalis (Asparagus)-Roots-Stems-LeafFlower-Pollination-Fruit-Geographical-Types and Varieties - References......................... 246-25I

CHAPTER XXI.-MORACE (MULBERRY FAMILY).

Description-Key to Principal Genera.............. . 252-253

Morus (Mulberry) - Habit, Stems-Leaves-InflorescencesFruit-Other "Mulberries"-Geographical-Key to Principal Species of Genus Morus... . . . . . . . . . . . . . . 253-255

Morus alba (White Mulberry)-Description-meographical -Types and Varieties-Economic Importance-Early Attempts in the United States to Grow Silk-Uses....... 255-257 Morus nigra (Black Mulberry)-Description-Geographical -Varieties-Uses........................ . 257-258 Morus rubra (Red Mulberry)-Description-GeographicalVarieties and Uses........................... ${ }_{5} \mathrm{~S}$ 
Humulus (Hop). Humulus lupulus (Common Hop) - Root-Stems-Leaves-Inflorescences-Flowers-Pollination, Fertilization, and Development of the "Hops"- The Mature FruitLupulin Glands-Geographical-Closely Related SpeciesVarieties-Composition-Uses of Hops.............258-267 Ficus (Fig)-Habit, Roots, Stems-Leaves-InflorescenceGeographical Distribution, and Economic Importance.....26 $7-269$ Ficus carica (Common Fig)-Habit of Plant, and StemLeaves-Inflorescence, and Flowers-Pollination-Crops of Fruit in Caprifigs-Caprification-The Mature Fruit-Geographical-Types of Figs-Uses of Figs...........269-276 Cannabis sativa (Hemp) - Description-Geographical-Varieties - The Hemp Industry in the United States-Preparation of Hemp for Market-Uses of Hemp-Sisal HempReferences................................. $270_{2} 8_{3}$ CHAPTER XXII.-Polygonacee (Buckinheat Family).

Stems-Inflorescences-Flowers-Fruit-Key to Principal Genera................................... $88_{4}-286$

Rheum rhaponticum (Rhubarb, Pie Plant)-Roots, Stems, Leaves, Flowers - Fruit - Geographical, and Varieties Uses ................................ 286-289

Fagopyrum vulgare (Common Buckwheat) - Roots-StemsLeaves-Inflorescence-Flowers-Dimorphism and Pollination-Fruit-Seed-Geographical-Other Species-Varieties - Key to Varieties of Common Buckwheat-Environmental Relations-Uses-References.................. 289-295

CHAP'TER XXIII.-Chenopodiace

Habit, Stems, Leaves-Inflorescence and Flowers-Fruit-

Key to Principal Genera.....................296-298

Spinacia oleracea (Spinach)-Description-Other Plants Named "Spinach"-Groups of True Spinach-Key to Groups of Spinach............................. 29s-300 Beta vulgaris (Beet)--Botanical Groups-The IIild Beet...300-30I Sugar Beet-Habit-Root-Stems-Shape and Structure of Beet (Tap Root and Hypocotyl)-Leaves-InflorescenceFlowers-Pollination and Fertilization-Fruit and SeedSeed Production-Germination, and the Seedling-Types of Sugar Beets--Composition of Sugar Beets-Manufacture of Sugar-By-products of Manufacture................... $301-309$ Common Garden Beet-Types-Uses................ 310-312 Chard............................... 312-313 Mangel-wurzels or Mangels-Types-Composition and Uses-References .............................. $313-315$ 
CHAPTER XXIV.-Grossulariace. (Gooseberry Family).

Stems-Leaves-Inflorescence and Flowers-PollinationThe Mature Fruit-Seeds-Geographical-Key to Important

Species of Genus Ribes ....................... 316-3 I9

Currants-Species-Uses. ................... 320-32I

Gooseberries-Species-Uses .................... 32I-322

CHAPTER XXV.-Crucifere (MUstard Family).

Stems, Leaves-Inflorescence and Flowers-Fruit-Seeds-

Closely Related Families-Key to Principal Genera........323-326

Brassica-Generic Description-Pollination-Seedling-Geo-

graphical-Key to Principal Species of Genus Brassica.....327-328

Brassica oleracea (Cabbages, etc.) - Wild Cabbage-Cultivat-

ed Types of Cabbages-Key to Cultivated Types of Cabbage. 328-330

Brassica oleracea var. viridis............................ 330

Brassica oleracea var. gemmifera (Brussels Sprouts)-Types

-Uses................................. 330 . 33 I

Brassica oleracea var. capitata (Common Head Cabbage)-

Types-Key to Types of Head Cabbage-Uses........... 33I -333

Brassica oleracea var. caulo-rapa (Kohlrabi or Turnip-rooted

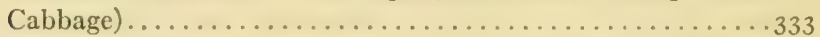

Brassica oleracea var. botrytis (Cauliflower, Broccoli).....334-335

Brassica rapa (Turnip)-Description-Geographical-Types

of Turnips-Structure and Uses................. 335-337

Brassica campestris (Rutabaga or Swede Turnip)-Descrip-

tion-Uses..................................... 3338

Brassica napus (Rape)-Description-Varieties and Uses...338-339

Brassica nigra (Black or Brown Mustard)-Description-

Related Species-Uses........................ 339-340

Brassica alba (White Mustard)................ 340-34I

Raphanus sativus (Garden Radish) - Habit-Root-Stem-

Leaves-Inflorescence and Flowers-Fruit-Seeds and Seedling-Geographical Distribution and Origin-Closely Related Species-Types of Radishes.................. $34 \mathrm{I}-344$ Radicula (Water Cress and Horse-radish)........... 344-345 Radicula armoracia (Horse-radish) -Description-Geographical-Uses......................................

Radicula nasturtium-aquaticum (Water Cress)--Description

-Geographical-References..................... 345-347

CHAPTER XXVI.-Rosace E (Rose Family).

Leaves-Inflorescence-Flowers-Fruit-Key to Important

Genera of Rosacex ........................

Rubus (Raspberry, Blackberry, Dewberry) - Stems -

Propagation-Leaves-Inflorescence-Flowers-Pollination- 
Fruit-Geographical-Classification-Key to Groups of Genus

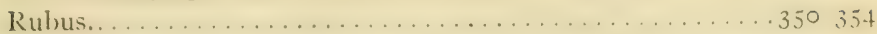

Blackberries-Key to Species of Blackberries-Rubus nigrobaccus - Rubus nigrobaccus $\times R$. villosus - Rubus argutusRubus cuncifolius. . . . . . . . . . . . . . . . . . 354-355 Dewberries-Key to Principal Species of Dewberries-Rubus trivialis - Rubus invisus - Rubus vitifolius-Rubus villosus . 355-357 Raspberries-Key to Principal Species of Raspberries-Rubus occidentalis-Rubus idæus-Rubus strigosus-Rubus strigosus $\times$ R. occidentalis - The Loganberry-Mayberry .....355-358 Fragaria (Strawberry)-Roots and Stems-Leaves-Inflorescence and Flowers-Fertilization, and Development of the Fruit-The Mature Fruit-Geographical-Principal Fruitbearing Species-Key to Principal Species of FragariaFragaria virginiana-Fragaria vesca-Fragaria chiloensisVarieties-Origin of New Varieties-Uses-Refcrences.....358-365 CHAPTER XXVII.-Pomacez (APple Family).

Habit, Leaves-Inflorescence-Flowers-Fruit-Geographical - Key to Important Genera of Pomaceæ... . . . . . . . . 366-367 Malus (Apples)-Stems-Leaves-Inflorescence-Flowers and Their Development-Pollination and Fertilization-Selfsterility and Self-fertility-Effects of Strange Pollen-Parthenocarpy-The Fruit and Its Development-Key to Principal Species of Malus-Malus floribunda-Malus baccata-Malus angustifolia-Malus coronaria-Malus ioensis - Malus soulardii-Malus sylvestris - The Classification of Apples-Composition-Cider and Vinegar-Dried Apples-Production of Apples in the United States. . . . . . . . . . . . . . . 367-384 Pyrus (Pear). 384

Pyrus communis (Common Pear)-Stem-Leaves and Flowers-Fruit-Geographical.................... $8_{5}$

Pyrus serotina culta (Sand, Japanese, or Chinese Pear)-Self -sterility in Pears-Dwarf Pears.................. $38_{5}-38$; Cydonia (Quince)-Cydonia oblonga (Common Quince)Stem-Leaves - Flowers - Fruit - Varieties - Uses - References................................... 38790

CHAPTER XXVIII.-DRUPACEA (PLUM FAMILY).

Habit, Stems-Leaves-Flowers-Fruit. . . . . . . . . 39 I-394

Prunus-Key to Main Groups of Genus Prunus. . . . . . . . 394 394

Plums-Stems-Leaves-Inflorescence-Flowers-Fertilization-Fruit-Classification of I'lums-Key to Principal Species of Plums... . . . . . . . . . . . . . . . . 394-397 Discussion of Species-Prunus domestica-Prunus insititia- 
Prunus cerasifera-Prunus triflora-Prunus americana-

Prunus hortulana-Prunus nigra-Prunus angustifolia....398-40I Cherries-Description-Groups of Cherries.............40I-402

Prunus avium (Sweet Cherry)-Description-Geographical

-Groups of Sweet Cherries....................402-403

Prunus cerasus (Sour Cherry)-Description-Geographical-

Groups of Sour Cherries-Other Species of Cherries-Uses...403-405

Apricots-Stems-Leaves-Inflorescence and Flowers-Fruit

-Description-Other Species-Uses............. 405-407

Peaches-Stems-Leaves-Inflorescence and Flowers-Fruit

- Geographical-Types of Peaches-Uses, and Production of

Peaches in the United States.................... 407-4IO

Almonds-Description-Types of Almonds-Uses-Almond

Oil-References......................... 4 IO-4I 2

CHAPTER XXIX.-Leguminose (Pea Family).

Root Tubercles-Habit-Leaves-Inflorescence-Flowers-

Fruit-Seeds-Key to Principal Genera of Leguminosæ...4 4I 3-4I 7

Pisum (Pea)-Description-Types of Peas--Peas and Men-

delism-Uses.........................

Phaseolus (Bean) - Description - Geographical, and Species-

Key to Principal Species of Phaseolus............... $42 \mathrm{I}-424$

Phaseolus lunatus (Sieva and Lima Beans)-Classification of

Types of Lima Beans-Table Showing Relationship of Types of

Lima Beans.

$424-426$

Phaseolus vulgaris (Kidney Bean)-Uses of Beans .......426

Vicia (Vetch, Broad Bean)-Generic Description-Geographical-Key to Important Species of Vicia-Less Common Species............................ .426-429

Vicia faba (Broad Bean, Windsor Bean).

Vicia sativa (Common Vetch or Tares) - Uses.......... 429-430

Vicia villosa (Hairy, Russian, Siberian, or Villous Vetch) ...430-432

Lathyrus (Vetchling, Wild Pea)....................... 432

Trifolium * (Clover)-Generic Description-Geographical-

Key to Principal Species of Trifolium............... 432-433

Trifolium repens (White or Dutch Clover)-Description-

Geographical, and Uses - Environmental Relations........ 433-434

Trifolium hybridum (Alsike, Alsatian, or Swedish Clover)-

Description - Geographical, and Uses............... 434-435

Trifolium incarnatum (Crimson, Scarlet, or Italian Clover)-

Description-Geographical, and Uses-Environmental Relations................................ $435^{-4} 43^{6}$

Trifolium pratense (Common Red or Purple Clover) Habit, Stems, Roots-Leaves-Inflorescence and Flowers- 
Fruit-Pollination-Geographical-Environmental Relations

-Mammoth Clover-Uses..................... $43^{0}+40$

Trifolium medium (Zigzag, Medium Red, White, Mammoth

or Meadow Clover)....................... 44 I

Medicago (Medics)-Generic Description-Geographical-

Key to Principal Species of Medicago............... 44I-442

Medicago sativa (Alfalfa, Lucerne)-Roots-Stems-"Cuttings" of Alfalfa-Leaves-Inflorescence-Flowers-Pollination-Factors Affecting Seed Production-Fruit-Germination and Seedling-Geographical-Types of Alfalfa-Environmental Relations-Uses and Production............ . 442-449

Medicago lupulina (Hop Clover, Black Medic, Yellow Trefoil).449

Medicago arabica (Spotted Bur Clover). . . . . . . . . . . 449-45 I

Medicago hispida (Toothed Bur Clover)............ $45^{2}$

Melilotus (Sweet Clover)-Generic Description-Species of Melilotus. . . . . . . . . . . . . . . . . . . 45 . $2-454$

Melilotus alba (White Sweet Clover)-Description........454

Melilotus officinalis (Yellow Sweet Clover)-Description-

Environmental Relations-Uses of Sweet Clovers)....... 454-455

Soja (Soy Bean) - Generic Description. . . . . . . . . . . 455-456

Soja max (Soy Bean, Soja Bean, Coffee Bean)-Description-

Uses. . . . . . . . . . . . . . . . . . . . 4 456-458

Vigna (Cowpea and Related Species)-Description-Species..458-460

Vigna sinensis (Cowpea)-Description-Environmental Rela-

tions-Uses...........................460-462

Arachis hypogoea (Peanut, Goober)-Habit, Stem-Leaves-

Flowers-Development of Fruit-Fruit-Types-Environ-

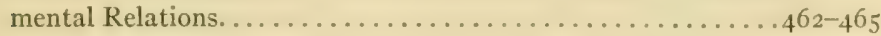

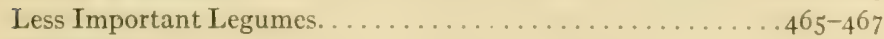

References.......................... . . . . . . . . . 468

CHAPTER XXX.-LINACE玉 (FLAX FAMLY)

Habit, Stem, Leaf-Inflorescence and Flowers-Fruit-The

Names Derived from "Linum"-Geographical, and Environ-

mental Relations......................469-470

Linum usitatissimum (Common Flax)-Habit, Root-Stem-

Flax Fibers-Leaves, Inflorescence and Flowers-Pollination

- Mature Fruit-Seeds-Geographical-Types and Varieties

-Uses-Preparation of Flax Fiber-Production of Flax...470-474

CHAPTER XXXI.-RUTACE (RUE FAMILY).

Description-Key to Important Genera of Rutacex. . . . . 475-476

Citrus (Citron, Lemon, Orange, etc.)-Habit, Roots-Leaves

-Flowers-Pollination and Fertilization-Fruit-Seeds-

Geographical-Key to Principal Species of Citrus........476-480 
Citrus medica (Citron)-Description-Geographical-" "Citron" ............................... $480-48 \mathrm{r}$

Citrus limonia (Lemon)-Description-Geographical-Color of Lemon Fruit-Uses....................... $48 \mathrm{I}-483$

Citrus aurantifolia (Lime)-Description-Geographical"Limequat".................................. $48_{3}$

Citrus sinensis (Common or Sweet Orange)-DescriptionGeographical-Types-Uses....................... $4_{4-4} 4^{8}$

Citrus nobilis (King Orange)—Description-Varieties.....485 Citrus grandis (Grapefruit, Pomelo, Shaddock) - Description - Geographical-Variety and Name.................. 485-487 Citrus aurantium (Sour or Seville Orange)-DescriptionGeographical-Other Species of Citrus................. 487

Fortunella (Kumquat or Kinkan)-Description-SpeciesUses.................................... $487-489$ Poncirus (Trifoliate Orange)-Description-A Hardy Orange.489 References..................................... 4890 CHAP'TER XXXII.-Vitace E (Grape Famly). Family Description-Geographical-Key to Important Genera................................. $49^{1-492}$ Vitis (Grape) - Stems-Leaves-Inflorescence and FlowersOpening of Flower and Pollination-Self-sterility-Grape Pollen-"Coulure" of Muscat Grape-Flowers of Wild Grape - Key to Most Important Species of Vitis-Vitis viniferaVitis rotundifolia-Vitis rupestris-Vitis riparia-Vitis aestivalis-Vitis labrusca-Varieties of Table Grapes-Wine and Raisin Grapes-Uses-References................. 492-504 CHAPTER XXXIII.-Malvace (Mallow Family).

Habit-Leaves-Flowers-Fruit and Seeds-GeographicalEconomic Importance-Key to Important Genera of Maivacer................................... $505-508$

Gossypium (Cotton) - Habit of Plants, and Roots-StemsLeaves-Flowers-Pollination, Fertilization, and Development of the Fruit-Fruit-Seeds-Cotton Fibers Distinguished from Other Common Textile Fibers-Species-Wild CottonsAmerican Cottons-Types and Varieties-Environmental Relations-Picking and Ginning of Cotton-Bleaching of Cotton-Uses of Cotton-Imiportance and Production of Cotton................................... $508-527$

Hibiscus esculentus (Okra, Gumbo)-Description-Geographical-Types-Uses..................... $527-528$ References.............................. 528-529 
CHAPTER XXXIV.-UMBLLITERA (CARRot FAMLY).

Stems and Leaves-Inflorescence and Flowers-Firuit-

Geographical-Key to Genera of Economic Importance... 530-533

Daucus carota (Carrot)-Habit, Root and Stems-Leaves-

Inflorescence and Flowers-Fruit and Seed-Geographical

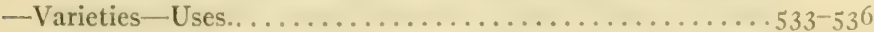

Pastinaca sativa (Parsnip) - Habit, Roots, and Stems-Leaves

-Inflorescence and Flowers-Fruit and Seed-Geographical

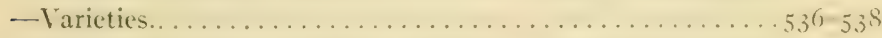

Apium (Celery and Parsley)-Generic Description-Geo-

graphical-Key to Principal Species of Apium......... 538-539

Apium petroselinum (Parsley)-Description-Varieties.... 339-540

Apium graveolens (Celery and Celeriac)-Description-Geo-

graphical-Types and Varieties-Uses............ . . 540-542

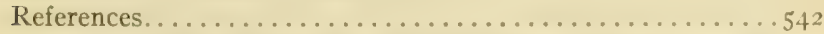

CHAPTER XXXV.-VACCINIACEX (HuckleberRy FaMILY).

Habit-Leaves-Inflorescence and Flowers-Fruit. . . . . . 543-545

Vaccinium-Pollination-Fruit-Geographical-Key to Chief

Fruit-bearing Species of Vaccinium............. . 545-547

Gaylussacia (Huckleberry, Tangleberry, Dangleberry)-

Description-Geographical-Key to North American Species

of Gaylussacia........................... . . 547

Cranberries-Vaccinium macrocarpon-Types-Vaccinium

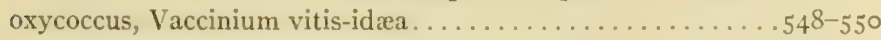

Huckleberries and Blueberries................... 550

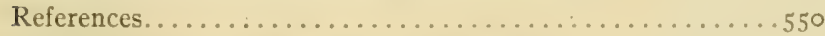

CHAPTER XXXVI.-OLEACE (Olive FamLy).

Family Description-Geographical, and Economic Impor-

tance.............................

Olea europoea (Olive)-Description-Seed Germination-

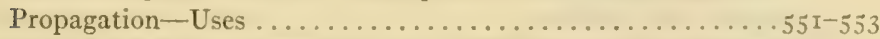

CIAPTER XXXVII-CONTOLULACE. (MORNING GLoRY FAMIL).

Habit-Leaves-Inflorescence and Flowers-Fruit-Key to

Important Genera. . . . . . . . . . . . . . . . . 554-555

Ipomoea batatas (Sweet Potato) - Roots and Stems- Leaves -

Inflorescence and Flowers-Geographical, and Environmental

Relations-Closely Related Species-Types and Varieties-

Leaf Shape as a Basis of Classification-Uses-References. . 555-558

CHAPTER XXXVIII.-Solanace (Potato FamLY).

Habit of Plants-Leaves-Inflorescence and Flowers-Fruit

- Key to Important Genera.. $550-5(10$

Solanum-Habit-Leaves-Inflorescence, and Flowers-

Fruit-Geographical-hey to Important Species of Solanum. .5(30-56) 
Solanum tuberosum (Potato)-Habit-Roots-StemsLeaves-Flower-Opening of Flower and Pollination-Fruit - Seed-Germination-Development of the Seedling-Tubers from Seedlings - Tuberization-Fungus Theory of Tuberization-History-Varieties-Tuber Morphology-Periderm or Skin-Vascular Ring-Paren ch y m a-Cortex-MedullaShape-Color-Eyes-Germination or Sprouting of Tuber - Physical Composition of Potatoes-Chemical Composition of Potatoes-Starch and Sugar-"Mealiness"-Quality of Potatoes-Degree of Maturity and Quality-Degeneracy of the Potato-Environmental Relations-Uses of PotatoesProduction of Potatoes..................... $56 \ldots$ Solanum melongena (Eggplant, Guinea Squash)-Description

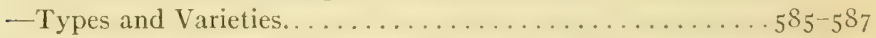
Lycopersicon (Tomato)-Habit of Growth, and Stems-Roots -Leaves-Inflorescence and Flowers-Pollination, Fertilization, and Development of the Fruit-Parthenocarpy-Abnormal Tomatoes-The Mature Fruit-Geographical-Important Species and Varieties-Key to Types of Cultivated Tomatoes - Closely Related Forms-History-Uses... . . . 587-592 Capsicum annuum (Peppers)-Description-GeographicalOther Species-Types-Key to Botanical Varieties of Capsicum annuum-Composition-Uses.............. . . 592-596

Nicotiana (Tobacco)-Habit-Leaves-Inflorescence and Flowers-Fruit-Geographical Distribution and Economic Importance . . . . . . . . . . . . . . . . 596-597 Nicotiana tabacum (Tobacco)-Habit, Roots, Stems-Leaves --Inflorescence and Flowers-Pollination and FertilizationFruit-Geographical-Closely Related Species-Types and Varieties-Composition-Curing Tobacco-The Tobacco Industry -References....................... 597-605

CHAPTER XXXIX.-CucurbitACE玉 (Gourd FAMILY).

Habit-Stems and Leaves-Flowers-Fruit-Germination of Cucurbit Seeds-Key to Principal Genera... . . . . . . . . . 6o6-6ro Cucurbita (Squash, Pumpkin, Gourd)-Stems, Leaves, Flowers-Pollination and Fertilization-Mature FruitGeographical-Key to Important Species of Cururbita......6 6ro-6 I 2 Cucurbita pepo-Description-Origin-Types and Varieties.6r 3 Cucurbita maxima-Description-Types and Varieties......6r4 Cucurbita moschata-Description-Types...........615 Cucumis (Muskmelon, Cantaloupe, Cucumber)-Stems, Leaves, Flowers-Pollination-Geographical-Key to Principal Species........................ 
Cucumis melo (Muskmelon, Cantaloupe, Melons)-Descrip-

tion-Botanical Varicties of Cucumis melo............618-620

Cucumis sativus (Cucumber)-Description-Geographical-

-Closely Related fiorms-Types-Pickles............620-622

Cucumis anguria-Description..................622

Citrullus (Watermelon, Citron, Colocynth)-Description-

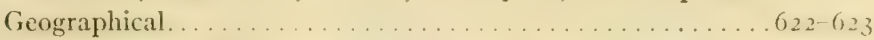

Citrullus vulgaris (Watermelon, Citron)-Description-Geo-

graphical-Types and Varicties..................622-624

References............................624

CHAPTER XL.-Compositæ (Tüstle FAMILY).

Habit-Leaves-Inflorescence-Flowers-Key to Important

Genera............................. $625^{-628}$

Lactuca sativa (Garden Lettuce)-Description-Origin, and

Geographical--Types of Lettuce-Key to Types of Lettuce. .629-633

Tragopogon porrifolius (Salsify or "Oyster Plant")-Descrip-

tion-Geographical, and Closely Related Species-Uses.....633-635

Cichorium (Chicory or Succory, and Endive)-Description-

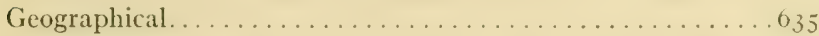

Cichorium intybus (Chicory or Succory) - Description-Uses, and Varieties.....................................

Cichorium endiva (Endive)-Description-Geographical

Distribution, and Economic Uses.................6.6.6.6.

Helianthus tuberosus (Jerusalem Artichoke)-Description-

Geographical-Closely Related Species-Uses...........639

References...............................639

Glossary.......................................

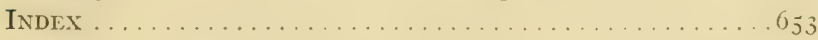





\section{BOTANY OF CROP PLANTS \\ PART I}

\section{CHAPTER I}

\section{THE SEED PLANT BODY}

The seed plant body, like the human body, is made up of a number of separate parts or members. In the lowest plant group, the Thallophytes (thallus plants), including algæ (pond scums, sea weeds, etc.), and fungi (molds, mildews, mushrooms, etc.), the plant body is relatively simple; it is not composed of distinct members, such as leaves, stems. roots and flowers. Such a simple, undifferentiated plant body is called a thallus. Between the typical thallus of algæ and fungi on the one hand, and the highly complex and welldifferentiated body of seed plants on the other, there are many intermediate forms, as for example, among the liverworts (Hepaticæ).

Principal Parts of Seed Plant Body.-The parts of the plant body may be classified according to the work they do, into two groups: (I) those that carry on vegctutive activity; and (2) those that carry on reproductive acticity. In seed plants, the stems, leaves and roots are chiefly concerned with maintaining the life of the individual plant, that is, carrying. on the vegetative (nutritive) functions, such as absorption of materials from the soil, manufacture of foods, respiration, 
transpiration, etc. while the flowers which produce seeds, (arry on, for the most part, the reproductive activities, and thus preserve the life of the race. However, we know that many seed plants, such as potatoes, asparagus, cane fruits, strawberries, and others may be propagated by using vegetative parts. of the plants.

'The above classification has a physiological basis.

We may also divide the seed plant body into two systems on a structural basis, as follows:

I. Shoot systcm, including stems, leaves, flowers, fruit and seerl. The stems may be in the air (acrial) or underground; the leaves may be ordinary joliage leaies, floral leaces flower parts), or scale leaves.

2. Root sy'stem, which may be in the soil, the aider or air.

The roots, stems, leaves and flowers are not always typical, lut may be modified or disguised, in some cases to such an cxtent as to be scarcely recognizable. For example, the tendril of the sweet pea is a leaf part. morphologically; the potato tuber, a modified stem; the sweet potato, a modified root.

Size and Form of the Seed Plant Body.-. There is a remarkable variety of forms and sizes of seed plants in the world. The duckweeds are very small, simple seed plants floating upon the surface of ponds. They are without leaves or with only very simple ones, they bear one or more rootlets, and extremely small flowers which usually consist of a single stamen or a single pistil. At the other extreme are the Giant Sequoias of California; one individual, the General Sherman "big tree," measures 279.9 feet in height and I02.8 feet about the base.

- We commonly make a distinction between trees, shrubs and herbs-plants which differ much in form and habit. Trees and shrubs are woody, while herbs possess less woody tissue 
and, consequently, are more soft and tender. The tree has a main trunk giving off branches at varying distances from the ground. The shrub may have a small main stem, but the shoots that arise at its base are equal to it in size. IV note differences in the shapes of plants. Contrast the apple tree with its oval shape with the cone shape of the pine or spruce. Observe the general columnar form of the corn plant, and note how different it is from the broadly oval form of a vigorous alfalfa clump. Again, we see that while most plants are erect, a number, like the strawberry and melons. are prostrate on the ground. Others, like the grape, are climhing, and gain mechanical support from other objects. 


\section{CHAPTER II}

\section{FUNDAMENTAL INTERNAL STRUCTURE OF PLANT BODY}

Organs and Tissues.-We have said that the seed plant body is composed of a number of members: roots, stems, leaves, and flowers, bearing the fruit and seed. We may say that the plant body is composed of a number of organs, that is, well-defined parts that perform some definite function or functions. For example, those parts of the plant concerned with absorption we call absorptive organs, those that carry on reproduction, reproductive organs, and so on. The roots are the chief absorptive organs of all common seed plants, and the stamens and pistils of the flower the reproductive organs. Now, if we study microscopically the structure of organs, they are seen to be made up of one or more different groups of cells. Each distinct group of cells within the organ that has a common origin and a common rôle to perform, is designated a tissue. For example, the pistil (a reproductive organ of a flower) is composed of several different tissues such as parenchyma tissue, conductive tissue, and epidermal tissue. Still deeper analysis of tissues shows all to be made up of small microscopic units-the cells.

The Plant Cell.--Discorery of the ('cll.- The discovery of the plant cell is attributed to Robert Hooke, an English lens manufacturer. In his microscopic study of thin sections of ordinary bottle cork, in I667, he observed the cork tissue to be composed of very small compartments, very much alike in size and shape, and fitting closely together. It happens 
that the separate units making up the cork tissue resemble the cells of a honeycomb, and hence Hooke gave the name "cell" to the units of cork tissue. Although an inappropriate name, in that the majority of plant cells have no resemblance to those of a honeycomb, the name still clings to botanical terminology. Hooke's discovery, although an epoch in the history of biology, was to be followed by others of far greater importance in that they tell us of the real nature of the cell, its marvelous inner structure, and most wonderful activities.

The Cell as a Unit of Structure.- Just as a brick house is made up of individual units, the bricks, so is a plant composed of individual units, the cells. A plant is made up of cells and the products of cells, and nothing clse. The wood, the root, the flower parts, the leaf, are made up of cells and cell products. This must not be understood to mean that all parts of a plant are alive; but the non-living portions are products of the living material within the cell.

The Cell as a Unit of Plant Activity.--The activities of a plant take place within the cells, for it is within them that we find the living material protoplasm. Some of the simplest plants are unicellulur, that is, one-celled. In such a case, the individual plant is simply one cell. That one cell, that individual, is capable of carrying on all the processesabsorption, respiration, digestion, assimilation, reproduction, etc--upon which its life and the life of the race to which that plant belongs are dependent. Somewhat higher in the scale of plant life, we find some plants, alga, for example, composed of a number of cells, several hundred, for instance. In this case, the individual plant is multicellular, and yet, in this plant, each cell is a unit of activity, and each carries on its activities quite independently of the others to which it is united, as is evidenced by the ability of the individual cells to live and reproduce when separated from its neighbors. In 
the higher seed plants, there are many different sorts of cells, both in structure and function, and the different cells are more dependent one upon another than are the cells that make up the simple algal filament. Yet, even in the seed plant, each cell is a unit of activity, and each is carrying on its functions more or less independently of its neighbors. The physiological unit of the plant is the cell.

The Structure of the Plant Cell (Fig. I).-It must be understood at the beginning that plant cells vary a good deal in size and shape. However, the fundamental structure of all plant cells is much the same. The plant cell consists of a living mass (protoplast) of protoplasm enclosed in a nonliving cell wall. The wall is manufactured by the protoplast, and serves as a protection to it. If we examine the protoplast, we see that it is composed of rather definite parts. There is an outer, thin, and transparent living membrane about the protoplast, which is only made manifest by treating the cell in a special manner. This membrane is known as the protoplasmic membrane, ectoplasm or hyaloplasm. It is allimportant in the intake and outgo of substances. If a plant tissue is immersed in a sugar or salt solution which has a greater concentration than the cell sap, water is drawn from the protoplast of each cell through the protoplasmic membrane, and the protoplast shrinks, thus pulling the membrane away from the cell wall and making it visible microscopically. Imbedded within the body of the protoplast there is a darker and denser mass of protoplasm, the mucleus, surrounded by its own living nuclear membrane. It may contain one to several small, darker bodies, the nucleoli. The protoplasm outside the nucleus is designated the cytoplasm. Hence we see that the protoplast is made up of three main parts: protoplasmic membrane, cytoplasm and nucleus. The protoplasm has spaces within it, which are filled with cell sap. 
These spaces are called iacuoles. However, one must not think of the cell-sap spaces in the protoplasm as vacuums, as the rather inappropriate name "vacuole" may suggest. Vacuoles are numerous and small in the young cells, but as
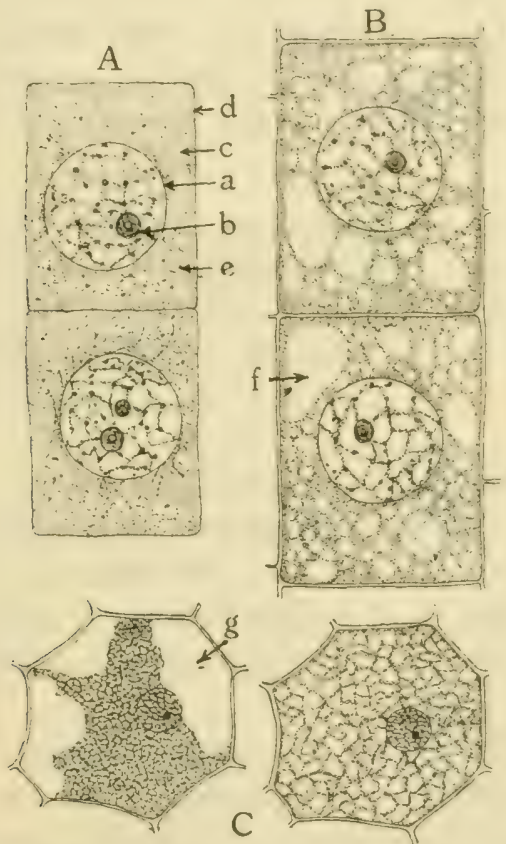

C

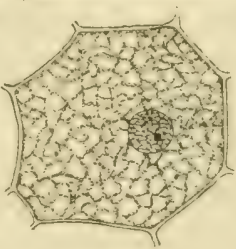

FIG. I.- $A$, young cells from onion root tip; $d$, protoplasmic membrane; $c$, cytoplasm; $a$, nuclear membrane; $d$, nucleolus; $e$, plastids (black dots). $B$. older cells farther back from the ront tip; $f$, vacuole; note that the cells have enlarged. $C$, epidermal cell of Tradescantia zebrina; in its natural condition of the right, and, on the left with the protoplast drawn from the cell wall as the result of immersing the cell in a solution the concentration of which is: greater than that of the cell sap. This phenomenon is called plasmolysis. $s$, contains the plasmolyzing solution. (After Stevens.)

the cell ages, they coalesce to form larger spaces. In some instances, there is one large central vacuole, while the cytoplasm and nucleus are squeezed out close to the cell wall. 
All vacuoles are bordered by a protoplasmic membrane, similar to the ectoplasm.

Suspended within the cytoplasm are specialized living bodies, the plastids, also numerous gramules, which may be of living material and insoluble food particles, such as starch or protein. The cytoplasm may hold insoluble crystals of salts, chiefly calcium oxalate. Let us arrange the parts of cell thus far described in outline form as follows:

$$
\text { Plant cell }\left\{\begin{array}{l}
\text { Cell wall (non-living) } \\
\text { Protoplast. }\left\{\begin{array}{l}
\text { Protoplasmic membrane (living) } \\
\text { Nucleus (living), containing one or more nucleoli }
\end{array}\right. \\
\text { Cytoplasm. } \begin{array}{l}
\text { plastids (living) } \\
\text { granules (living or non-living) } \\
\text { crystals (non-living) } \\
\text { vacuoles, containing cell sap. }
\end{array}
\end{array}\right.
$$

The Cell Wall.-The cell wall is a product of the protoplast. When young it is almost pure cellulose. As the cell grows older, its wall may thicken and become denser, and have added to it certain substances such as lignin, suberin, cutin and pectin which give it different physical and chemical qualities.

Plastids.- These are specialized masses of protoplasm suspended within the cytoplasm. They vary in size and form. There are three sorts of plastids based upon their color: (I) leucoplastids, colorless; (2) chloroplastids, green; and (3) chromoplastids, yellow, orange or red.

Nucleus.-All typical cells have a definite nucleus. It is wrong to regard the nucleus as the "seat of life" of the cell, for other portions of the cell are all-important, but it is a most essential part of the cell. If the nucleus is separated from the cytoplasm by artificial means, the cell dies. Its presence is needed, it seems, to stimulate respiratory activity. Moreover, reproduction of the cell-its division to form two 
cells-involves definite nuclear changes, which has led to the opinion that hereditary characteristics are carried by nuclear matter. The structure of the nucleus is indeed complex, and there is a wonderful chain of changes that it goes through at the time of cell division.

Protoplasm.--In I840, Hugo von Mohl drew attention to the fact that the slimy substance in the plant cell was responsible for its life, and that as soon as it was removed, the cell no longer had the properties of livingness. The name protoplasm was applied to the living portion of the plant cell. Somewhat later, 1850 , Ferdinand Cohn, gave positive evidence of the identity of the living material (protoplasm) in plant cells, and of the living material (socalled "sarcode") in animal cells.

If we examine a small bit of protoplasm under the microscope we see that it is a semi-transparent, jelly-like, rather granular substance, resembling very much the white of an egg. It feels slimy.

Protoplasm is a very complex chemical substance. Although no element has ever been found in protoplasm that is not also found in the common substances in the world about us, the exact arrangement and proportions of these elements has not been ascertained, except in a general way. It is quite clearly established that protoplasm is a proteid, of complex nature, with water as a solvent. Proteids form about one-half or two-thirds of the dry substance of protoplasm. The remainder is fat, sugar, and other carbohydrates, organic acids, organic bases, and some mineral substances. 


\section{CHAPTER III}

\section{ROOTS}

Development of Root Systems.-The root system of a plant is the entire collection of roots. Let us trace out the development of different root systems, starting with the seed. If we examine soaked grains of wheat, or bean seeds, or beet seeds, we observe that there is a young root already formed within the seed. Three germinating stages in wheat are shown in Fig. 2. The one principal root or primary root we see in the grain is the first to appear. It breaks through the root sheath (coleorhiza) which remains as a collar about the root where it breaks through the grain coat. Very soon two lateral roots appear; hence the primary root systcm or temporary root system consists of a whorl of three roots. Since these three roots were in the seed in the embryonic condition they are called seminal (seed), roots. The secondary roots appear in whorls at the joints on the stems some distance above the three temporary roots. The first whorl of permanent roots in wheat is generally about I inch below the soil surface, no matter at what depth the grain was planted (Fig. 3). One whorl of roots after another is formed above the first one, and as a result there is built up a fine network of roots, with their branches. A root system such as described in wheat is called a fibrous root system.

We spoke above of the three seminal or seed roots, and the development of whorls of roots from the nodes above as shown in Fig. 3. Roots not arising from the seed or as 
branches of seed roots, but from stems or leaves, are called adientitious roots. Hence the fibrous root system of wheat, and of all the other cereals and grasses, is in reality composed of roots that develop adventiliously. Adventitious root

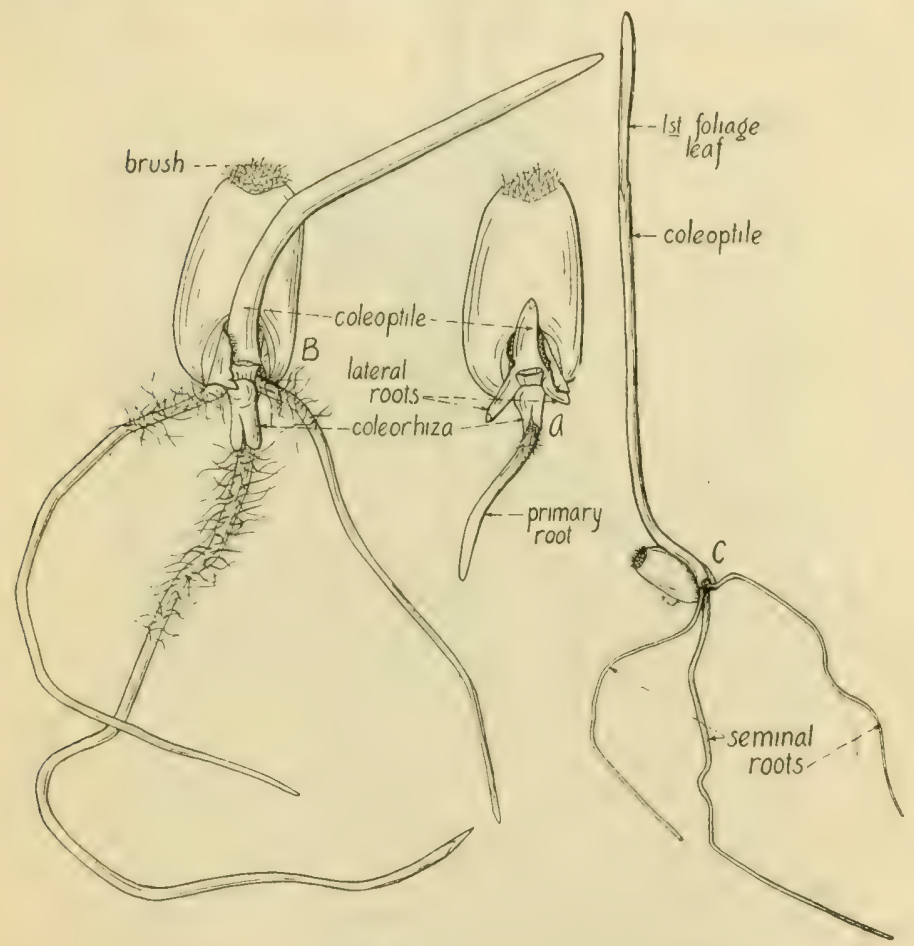

FIG. 2.-Three germinating stages in wheat.

systems may appear under a variety of conditions. When young onion "sets" are placed in the ground, a set of roots (adventitious roots) appears at their bases. If young oneyear-old twigs or stems (cuttings) of apple, raspberry, willow; geranium, carnation, chrysanthemum, rose, or of many other economic plants are placed in damp soil or sand, adventi- 
tious roots will appear at the cut surface, and by development, form the characteristic root system of the plant. Some

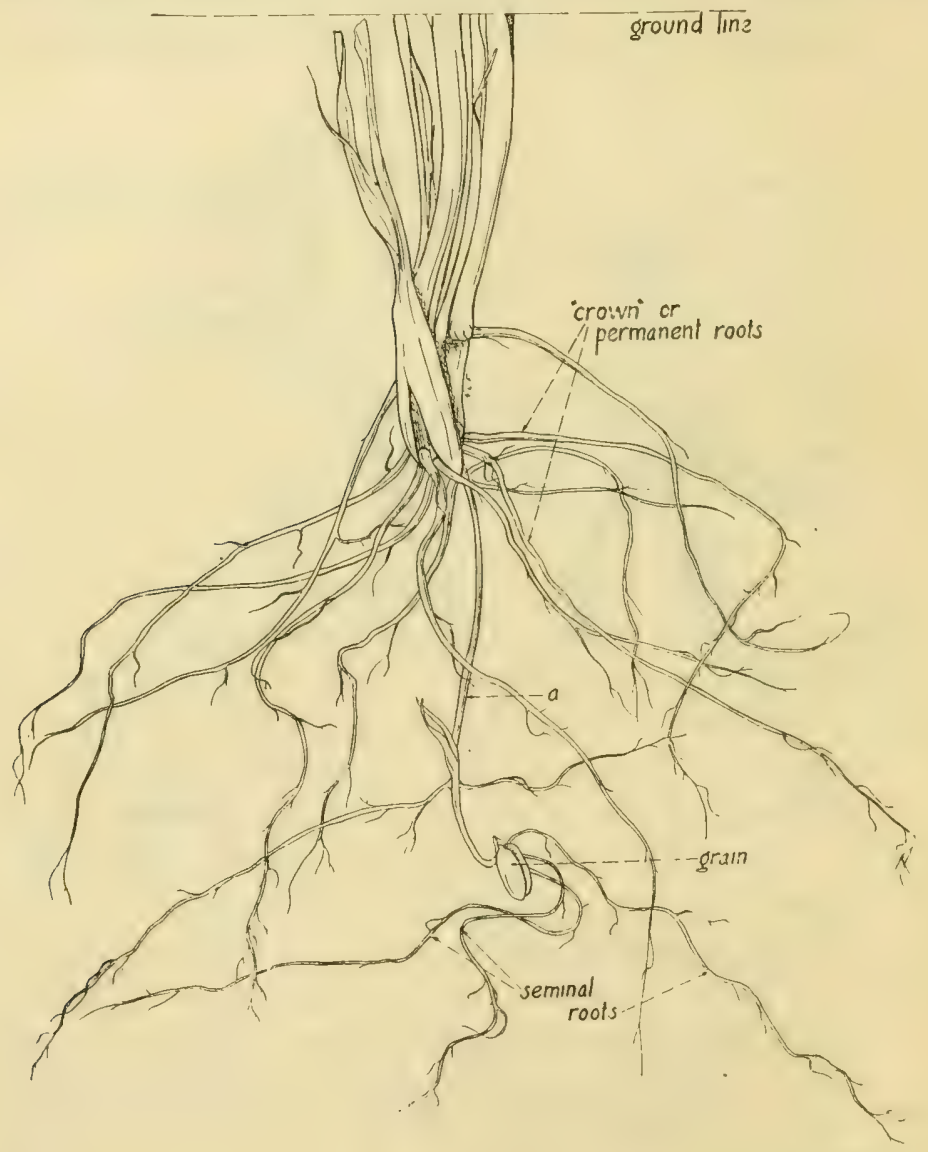

FIG. 3.-In spite of the fact that the grain of wheat was planted at too great a depth, the permanent roots were formed at about I inch below the soil surface.

leaves will even develop adventitious roots from cut or wounded leaf veins. This is true of such leaves as begonia, 
gloxinias, and bryophyllum. In the black-cap rasplberry and in dewberries, a shoot (stem) may bend over by its own weight, and where it strikes the ground, develop adventitious roots, and thus secure a foothold. When once the tip has rooted well, the stem may be cut loose from the

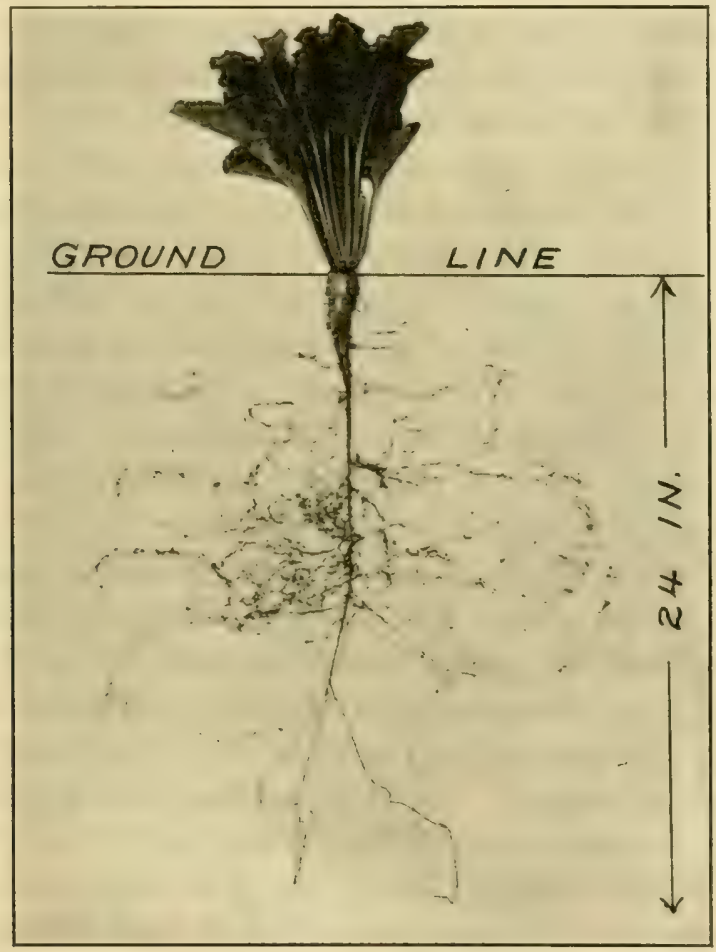

FIG. 4.-Tap-root system of young stigar beet. (Maxson.)

parent stem and such rooted tips used as "sets." Strawberries produce slender stems, called runners. Adventitious roots may be produced at the nodes.

A very different sort of root system develops in such plants 
as the beet, radish, turnip, parsnip and carrot. In the germination of the beet seed, for example, the primary root pushes out, takes a straight downward course, and gives off a few lateral roots. Hence, the primary root system of the beet consists of one main root extending downward, with a few fine laterals. Adventitious roots do not arise, as in wheat, nor does the primary root system die, as it does in wheat, but the main tap root of the young plant continues to elongate, and to give off lateral roots and rootlets (Fig. 4). The "beet" itself is for the most part an enlarged tap root. The tap root of the sugar beet may reach a depth of 4 feet, and often 6 or 7 feet. The upper laterals are the largest of the branch roots and extend farthest in the soil, spreading almost horizontally 2 to 3 feet. The lower laterals are more vertical and those near the very tip are almost parallel with the tap root. A root system such as possessed by the beet, radish, turnip, parsnip, carrot, dandelion, red clover, and many other plants is called a tap-root system.

The Work of Roots.-A root system absorbs, anchors, and serves as storage organ. The small, young, tender roots, with their root hairs, are largely absorption roots, but as the plant gets older, new absorptive roots are continually being formed, while the older ones become thick and woody and serve mainly as anchorage organs. Familiar storage roots are those of the beet, carrot, turnip, parsnip, sweet potato, and dandelion. The food material stored up by such plants for their own use furnishes a large proportion of the food supply of man. Irish potatoes (tubers) are not roots, but stems, and hence their discussion will be reserved for the proper section in the book.

Effect of Environment upon Character of Root System.It is noted, when roots make a vigorous growth, as they will under favorable soil conditions, that there is a very extensive 
system of rootlets developed. Corn is found to have a large part of its lateral root system in the surface layers when the soil is poor. The general form of a root system may be changed by transplanting. As a result of the necessary injury accompanying this process, there is developed a compact root system. Desert plants usually have an extensive root system, reaching to considerable depths. Swamp plants, even trees, develop a spreading, and comparatively shallow root system. The method and amount of watering affect the general shape of the root system. Fruit trees, for example, send their roots into the deeper soil layers if the surface layers are dry, but if the ground water level is close to the soil surface the root sy'stem will be more superficial. The character of the root system is often an index of soil conditions.

\section{General Characteristics} of Roots.-It will be recalled that the seed plant body possesses a number of members, each with more or less distinctive

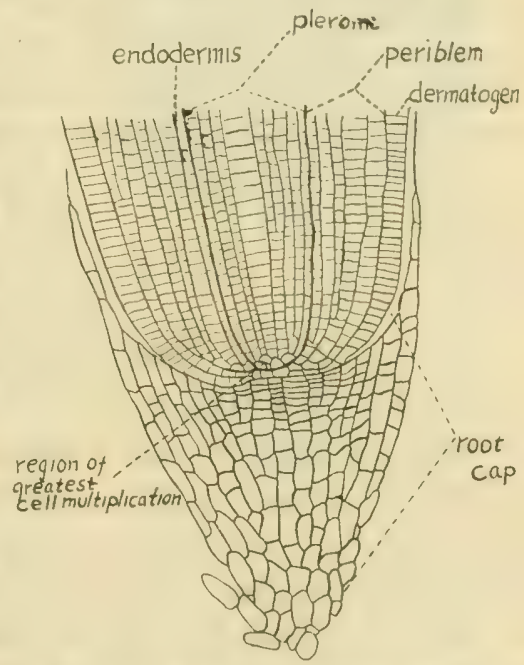

Fic. 5.-Median lengthwise section of the apex of a root of barley. (After Strasburger.)

characters. Roots have characteristics which stand out in quite marked contrast to those of other plant members. Roots do not give off their branches in a regular order, as stems do. They do not bear buds, except in very rare cases. Roots usually bear a root cap (Fig. 5) which protects the growing point, while the growing point in stems 
is either naked or surrounded by modified leaves (bud scales). There are other characters which will be mentioned further on.

Classification of Roots Based upon Their Medium of Growth.--The medium of growth of most roots is soil. Such roots may be called soil roots. It is customary for us to think of the root system of a plant as growing in the soil, just as we associate the shoot system with the air above ground. However, not all roots live in the soil, and not all shoots live in the air. There are water roots, and air roots, as well as the ordinary sort, soil roots. Water roots occur in such floating plants as the duckweeds, water hyacinth (Eichhornia speciosa). Water roots produce but a few branches. They possess no root hairs; absorption takes place through any cells on the surface. Air roots occur in many plants, such as corn (Fig. 56, B), Virginia creeper, tropical orchids, the banyan and other species of Ficus. Air roots are well shown in corn. In addition to the ordinary underground (soil) roots, corn develops aerial (air) roots, the so-called prop or brace roots (Fig. 56, B). These arise at successive levels above the surface, extending obliquely downward. As ærial roots, they are unbranched, but they branch profusely when they strike the soil. They have the rôle of absorption, then, as well as anchorage. In the banyan, for example, the air roots are often very large, and arise from branches far above the ground. They grow downward, and when they strike the ground, become firmly attached, and act as a support or prop to the heavy branches.

Hence, we learn that not all roots have soil as their medium of growth, but that air and water may be the media for some.

Structure of Roots.--Let us cut a median (middle) lengthwise section of a young root. It will appear as in Fig. 5 . We shall see then that the root has a cap of loose cells at the 
tip. This protective structure is called the root cap. Just back of the root cap is the region of greatest cell multiplicattion (Fig. 5), composed of cells that are actively growing. The very tip of the cap is continually sloughing off. while new cells are being added to it just in front of the growing point.

In addicion to the root cap we note that there are three distinct parts to the root, namely, (I) dermatogen, an outer layer or layers; (2) plerome (axis); and (3) periblem, between the dermatogen and plerome. The dermatogen becomes the epidermis, the plerome the stele or central cylinder, and the periblem the cortex. It is often possible to strip the cortex and epidermis from the central cylinder, which is composed of tough, fibrous tissue.

The cortex (Fig. 6) is composed of large, thin-walled cells, which do not fit closely together, but leave air spaces (inter-cellular spaces) between. The innermost cortex layer is called the endodermis. The outer cortex cells may become prolonged to the side to form root hairs. The central cylinder or stele (Fig. 6) is bounded

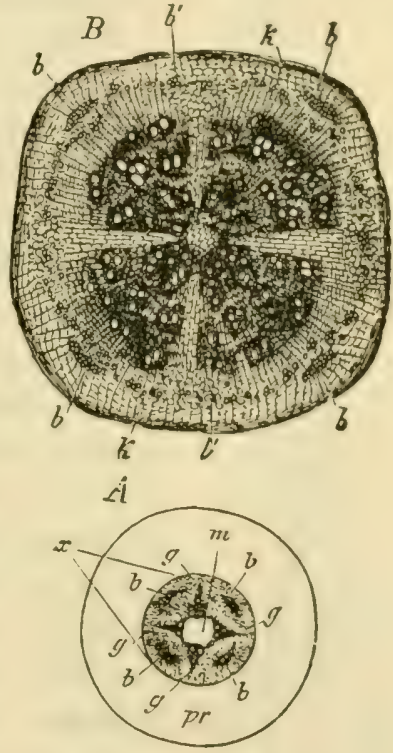

FIG. 6.-Cross-section of a young root of Phaseolus multiflorus. $A, p r$, cortex; $m$, pith; $x$, stele or central cylinder-all tissue within the pericycle, inclusive; $g$, primary xylem bundles; $b$, primary phloem bundles. $B$, crosssection of older portion of root; lettered as in $A ; b^{\prime}$, secondary phloem. (After Vines.)

by a single layer of cells, the pericycle, which lies adjacent to the endodermis. Within the stele are found alternating bundles or strands. The woody, water-conducting bun- 


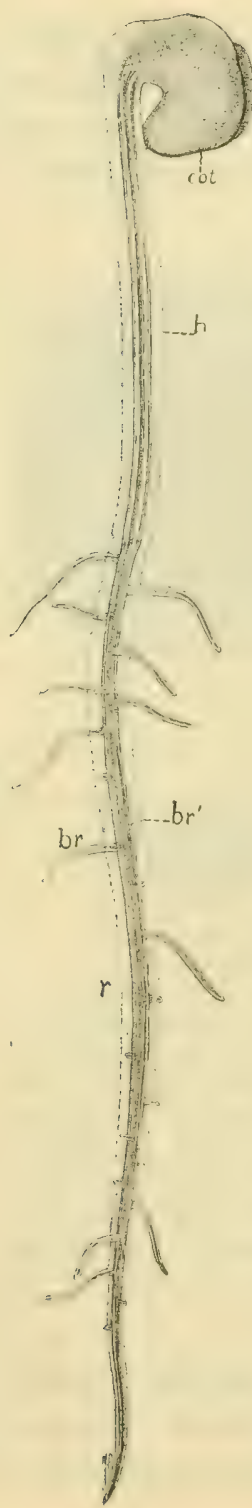

dles are called the xylem, the softer, foodconducting bundles, phloem. The central portion of the stele is composed of large, loosely fitting cells, making up the pith or medulla.

Side roots arise from the outer edge of the stele (central cylinder), and push their way through the cortex and epidermis (Fig. 7). This method of origin of side branches is characteristic of roots. In stems the side branches arise from the outer part of the cortex (Fig. I 5). Branch roots are said to have an endogenous origin, while branch shoots (except those in monocots) have an exogenous origin.

As the root grows older, new xylem and phloem are formed, and by and by, it becomes very tough and woody, serving as an efficient anchorage organ.

\section{Root Hairs - the Absorbing Organs of a} Plant.-The great problem of all our common plants is to take in as much water from the soil as they lose to the air, i.e., to maintain a balance between water intake and water outgo. We speak of the roots as the absorbing organs of the plant. In a sense this is true, but it must be understood that water and soil solutions are not taken in at all points on the surface of the root system. Practically all absorbed substances enter

FIG. 7.-Young root of white lupine showing origin of lateral roots from the stele. (After Gager.) 
the plant through root hairs, which are found near the tips of the smallest rootlets. In reality, the root hatirs are the absorbing organs of a plant. When we pull up any common herbaceous plant, we observe, as a rule, a large number of hair-like rootlets as branches of larger roots. These fine "hair roots" are sometimes mistaken for root hairs. But, closer examination, in which a hand lens may be necessary, shows us that these hair roots are the bearers of root hairs. In fact, root hairs are found only on the smallest and youngest rootlets.

Root-hair Zone.--Root hairs do not grow along the full length of a rootlet, but occupy a definite zone, designated the root-hair zone. This is clearly seen in young seedlings, grown on moist filter paper. The roothair zone appears as a white fuzzy coating. The root cap is free of root hairs. The length of the zone varies from a few millimeters to several centimeters. The roothair zone of seedlings grown in soil is plainly evident from the mass of soil particles held by the root hairs (Fig. 8). Each root hair in its growth flattens out over, and sometimes partially surrounds, the soil particles with which it comes into contact, thereby forming a close connection with the water and solutes that form a thin film around

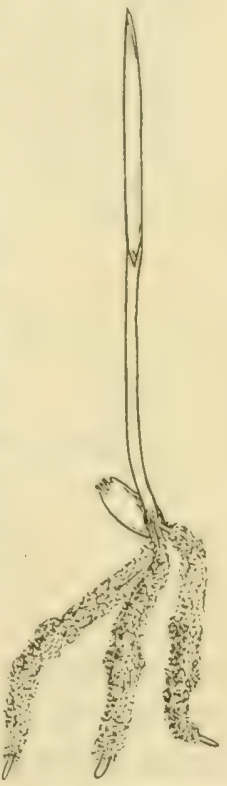

FIG. S.-Wheat seedling showing soil particles cling ing to root hairs; note that the root cai) is free of rout hairs. each soil particle (Fig. 9). Furthermore, the root hairs become mucilaginous, and this, along with their partial surrounding of particles, explains the presence of the mass of soil particles that clings to rootlets in the root-hair zone. Root hairs are short-lived, persisting for only a few days or 
weeks. New hairs are constantly formed anew at the anterior end of the root-hair zone, while those at the posterior end are dying. Root hairs do not become roots.

Structure of a Root Hair.- The root hair is a single cell. It is a simple, lateral prolongation of a border cell of the cortex (Fig. 9). It has the shape of a slender tube which may, however, become greatly contorted in its growth between and about soil particles. Root hairs vary in length from a fraction of a millimeter to 7 or 8 millimeters. The walls are thin

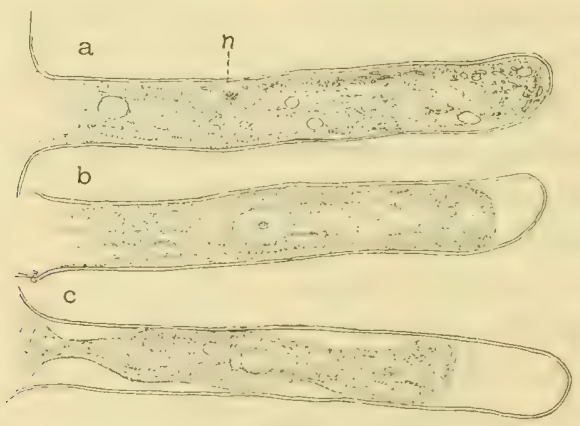

FIG. 9.-Root hairs. (After Ga ger.)

and of almost pure cellulose. A thin layer of protoplasm may line the walls, and the nucleus usually occupies a position near the apex. The central vacuole is large, and is filled with cell sap. The cell sap contains water, and various organic and inorganic substances in solution.

Effect of External Factors upon Development of Rcot $\mathrm{H}$ airs.-Most air and water roots have no root hairs. Soil roots, such as those of conifers, oaks, and others that are surrounded by a fungus (mycorrhizal growth) possess no root hairs. In the case of ordinary soil roots, root-hair development is usually meager in very wet soil. Corn roots develop root hairs in abundance in moist air, but none at all in water. The absence of root hairs in very wet soil, and in water, is probably to be attributed to poor oxygen supply. In at 
water-soaked soil. the air spates are tilled with water. ()ur ordinary crep) plants require a well-atired soil in oreler to develop root hatirs in abundiance. One of the chief objects of stirring the soil is to admit air to the roots. Orchard trees have been known to die as a result of the "puddling" of the soil. Trees are also sometimes killed by cattle tramping and packing the ground about them. such that the air supply to the roots is largely cut off. Root-hair development is often inhibited by a concentrated soil solution. High temperatures, and low temperatures, are inimical to root-hair growth. Root hairs develop in the light and dark about equally well. providing there is ample moisture.

Length of Life of Roots.-- Roots that live but one regetative period, that is, one season, are annual. All of our common cereals, such as wheat, oats, barley, rye, corn, rice, sorghum, and also such common crop plants as buckwheat, beans, peas, tomatoes, melons, etc., have annual roots. Biennial plants live two vegetative periods. Common biennials are beet, cabbage, carrot, and parsnip. From the seed of beet. for example. there is developed the first season a large fleshy tap root, and a short crown from which the leares arise. This fleshy structure ("beet"), stored with food, rests over the winter, and the next growing period sends up stout. branching stems to a height of 3 or 4 feet. which give rise to llowers and seed (Fig. I Ig). At the end of the second scatson of growth, after seed production, the entire plant dies. Under our cultural conditions winter wheat is a biennial. The roots of trees and shrubs arel some herbs live from year to year, increasing in size each season. Such plants are perennial in habit. In most cases the length of life of roots is the same as that of the shoot system. However, underground perennial stems, such as are possessed 1... quackgrass, Canada thistle, false Solomon's seal, etc. may have annual roots. 


\section{CHAPTER IV}

\section{STEMS}

Development of Shoot System.-When a grain of wheat germinates, the primary root is the first to appear. Very soon two lateral roots make their appearance, forming a primary root system of three roots. Also, the young stem (Fig. I) elongates, and there is formed the first shoot system of the plant. Elongation of the stem continues by growth at the tip, where the cells are young and active.

It is observed that the stem is divided into sections (internodes) (Fig. 25). The nodes, the enlarged joints between the internodes, give rise to leaves, and if we follow the wheat plant through its life, we observe that the stem terminates in an inflorescence (flower cluster). Now, in addition to the one main stem that arises as a prolongation of the embryonic stem in the seed, branches arise from the lower nodes. These branches arise in the axils of the lowermost leaves, in most cereals. In cereals, this branching is known as "stooling" or "tillering." Common cereals invariably produce a number of tillers or branches from the primary stem, and these in turn other tillers (lateral branches), so that under favorable conditions several dozen culms may result from a single seed. In the wheat plant, two or three weeks old, three or four buds (young stems) may be found, one in the axil of each leaf. Tillering results from the outgrowth of these lateral buds. Hence, as a result of the elongation of the main growing point, and of the lateral growing points into lateral 
branches of the primary stem, there is built up a shoot system, with its leaves and flowers.

Buds.-A bud is an undeveloped stem; it is simply a young shoot. In an ordinary shoot, an apple or peach twig for example, the internodes are considerably elongated. In rapidly growing water sprouts, internodes may be several inches in length. A bud is a very short, young shoot in which the internodes are few or are exceedingly short. That a bud is a young, individual shoot in itself is shown by the fact that buds may be removed from a branch and applied to the surface of the growing tissue (cambium) of another branch (stock) and successfully grown there. In fact, bud grafting is a common horticultural practice. The tip of the bud is usually protected by a series of overlapping scales (bud scales), which are in reality modified leaves. Naked buds are not protected by scales; they are found on woody plants of the moist tropics, and are the only sort on herbaceous plants the world over.

Classification of Buds.-Buds may be classified as to development into: (a) leaf, (b) flower, and (c) mixed buds. If we open up a leaf bud, we find a very much shortened axis or stem bearing a number of small leaves. As the leaf bud is a young shoot, it may as properly be called a branch bud. That is, it elongates into a branch which bears leaves. The new shoot, just as the old one from which it came, ends in a bud, and in the leaf axils other buds arise. If we open up a flower bud, we find one or more young flowers. In plums, for example, the number of flowers in a bud varies from one to five, two and three being the most common numbers (Fig. I66). Mixed buds contain both flowers and leaves. The terminal buds at the ends of the short "spurs" in the apple are mixed buds (Fig. I53).

It is not always possible to distinguish leaf from flower 
buds by their external appearance. In some cases, however, they have a different shape. In the apple, for example, fruit buds (here, really mixed buds) are rather thick and rounded, while leaf buds are smaller and more pointed. In all plums, the flower buds are lateral, and usually stand out at an angle of about $30^{\circ}$, while leaf buds are more appressed to the stem.

Buds may be classified as to their position on the stem into: (a) terminal, (b) lateral or axillary, (c) accessory or supernumerary, $(d)$ adventitious, and (e) dormant.

Most stems end in a bud. Such a terminal bud is almost always a leaf bud; occasionally it bears flowers, too, as in the apple. The terminal bud is normally the most vigorous of all on the stem, as is evidenced by the fact that it elongates into a shoot which exceeds in length those from the lateral buds. Lateral (side) buds arise in the leaf axils. They give rise to side branches or to flowers. Accessory or supernumerary buds are extra ones coming out in the leaf axils. They are best shown in the maples and box elder. Adventitious buds arise out of order, in unusual places, not in leaf axils or at the end of a stem. They are usually stimulated by injury. For example, when a branch is cut back, numerous adventitious buds develop about the edge of the cut surface. Dormant buds are ones that have arisen in a regular fashion in the leaf axil, but which, for some reason, do not develop. Hence, they may be grown over with the succeeding layers of wood and lie buried within the tissue in a latent condition. Such a bud may be called into activity later in the life of the plant and come to the surface. It would appear to be endogenous in its origin, while in reality it is exogenous. Irregular branching may result from the development of dormant buds, or as is more commonly the case, from the development of adventitious buds. 
Buds may be classified as to their arrangement on the stem into: (a) alternate, (b)opposite and (c) whorled. It is well to keep in mind that bud arrangement is the same as leaf arrangement, for the reason that buds normally develop in each leaf axil. Furthermore, as leaf buds develop into shoots, the method of branching, and hence the form of the plant, is largely determined by the bud arrangement.

When one bud occurs at each node, they are said to be alternate (Fig. Io). When two buds stand at a node, they are opposite (Fig. I03). When more than two buds stand at a node they are said to be whorled.

Bud Variation.-This is a more or less common occurrence in trees of all varieties. The buds on an apple, peach, or citrus tree, for example, differ from each other in important respects. That this differ-

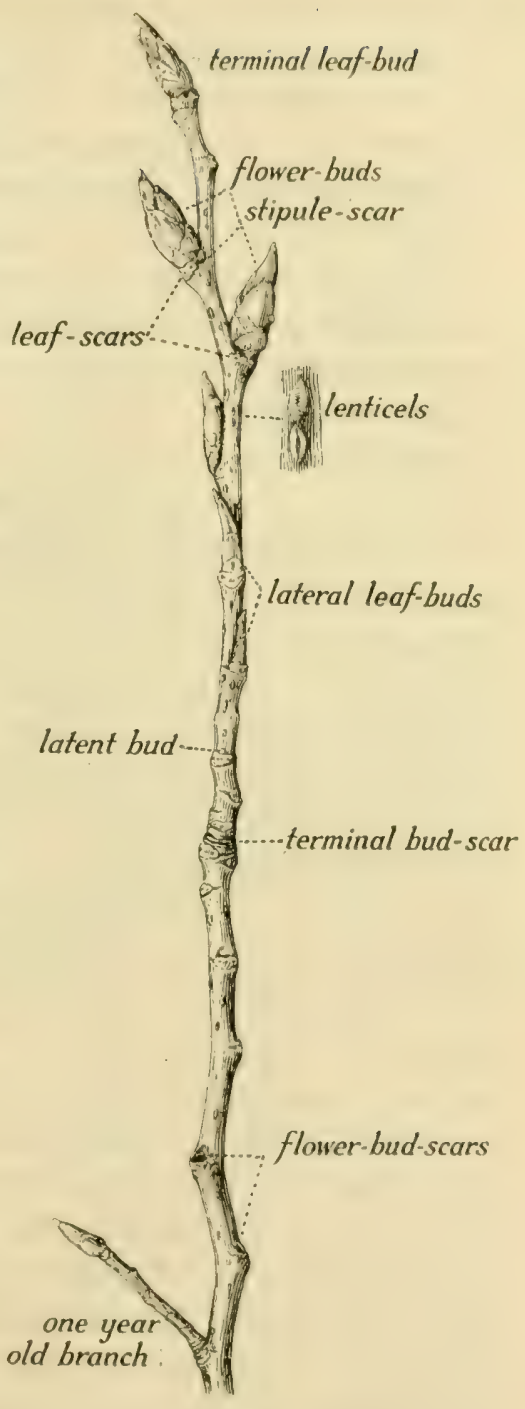

FIG. I0.-Cottonwood twig two years old. (After Longyear.) 
ence really exists can be well shown by removing branches or buds and growing them into independent plants. If we do this we will find that the individuals from the separate buds may vary in such respects as habit of growth, manner of branching, nature of foliage, form, color, texture and yield of fruits.

Nearly all our fruits are multiplied by bud propagation (asexual parts) and not by seed (sexual parts); and many of the varieties of fruits now in cultivation are in reality bud varieties or "sports." A certain branch on a tree is observed to differ from the rest in some marked respect; and this branch is taken off and propagated as a new variety.

General Characteristics of Stems.-Let us now examine a winter twig of the cottonwood, for example, that is several years old, such as pictured in Fig. ro. At the tip is a large terminal bud. If it is broken open, young overlapping leaves are found within. It develops into a leafy branch. The growth in length of the shoot results from the lengthening of the internodes in the bud. Along the side of the stem are latcral buds at regular intervals. These may be leaf buds or flower buds, as can be positively determined by breaking them open. Below each bud there is a half-moon-shaped leaf scar. Hence we see that leaf arrangement is also bud arrangement. By examining the leaf scar with a hand lens one sees several small bundle scars on the surface. Bundle scars are left by the vascular bundles that pass from the woody stem into the petiole (stem) of the leaf. Inflorescence scars are large circular or oval scars left by the falling off of flower clusters. A leaf scar is observed beneath each inflorescence scar. The twig growth of each year is clearly distinguished by a ring of scars. When the closely arranged bud scales of a terminal bud fall off in the spring they leave a number of scars so close together as to make a ring. Hence 
the limits of two successive years growth are marked by bud scale scars of terminal buds. In this way we may determine the age of a twig.

Close observation of the twig will reveal a number of whitish spots on the bark. These are lenticels (Fig. II), structures on the stem composed of a mass of loosely fitting cells which permit the diffusion of gases inward and outward. Except for the lenticels, the bark prevents the free passage of air, and also the loss of water from underlying stem parts.

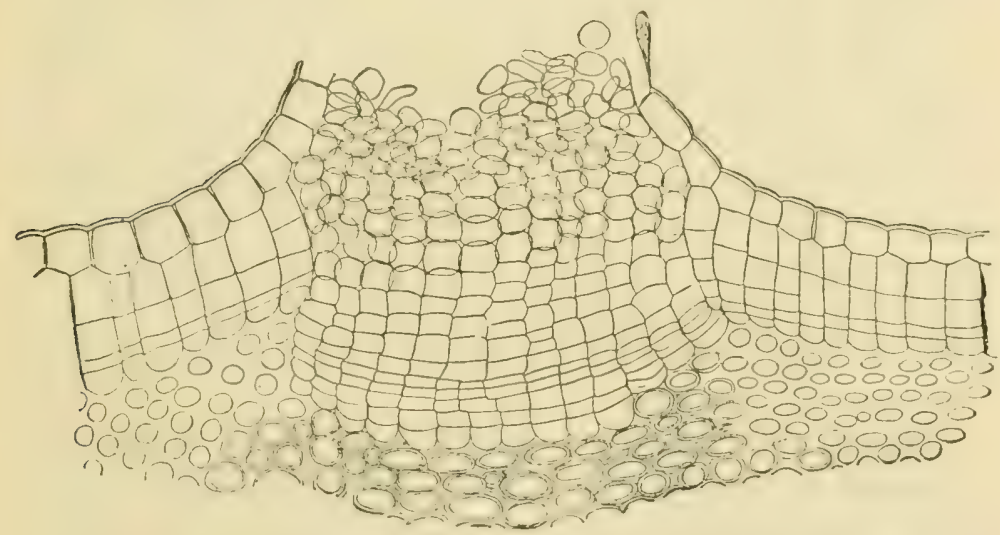

FIG. II.-Section of the lenticel of elder. (Afler Strasburger.) From A Text-book of Botany by Coulter, Barnes, and Cowles. Copyright, by the American Book Company, Publishers.

How Does a Stem Grow in Length?-A bud is a young shoot. A lengthwise section of a leaf bud shows a coneshaped growing point (young stem) upon which is a number of young leaves. These leaves come off at regular intervals, following identically the same arrangement as they do in the adult twig. The growing point, then, consists of a number of very much shortened internodes. Growth in length of the shoot consists in the elongation of these in- 
ternodes by increase in number and size of cells that compose internode tissue.

As a rule, the number of leaves that will be on a twig is already fixed in the bud. Seldom do new leaves originate during the growing season. This point is worthy of special mention: When a twig has made its year's growth, the internodes do not lengthen thereafter during subsequent years. Increase in length of that shoot is due to the addition of other "joints" at the end. The fixed length of old internodes is well proven by the common observation that nails driven into the trunk of a tree, or a small branch, are not elevated above the ground as the tree grows. It will become grown over with wood, but its height above the ground remains the same. A common impression prevails that the branches of a young tree should be started low to the ground, so that they will be at about the right elevation above the ground when the tree reaches maturity. The supposition here is that the limbs are raised by the growth of the tree. This notion is erroneous.

Classification of Stems Based upon Their Medium of Growth. - The medium of growth of most stems is air. Such stems may arise from the soil as in nearly all of ourordinary plants, or they may have no attachment with the soil at all, receiving mechanical support from other plants. The latter are called epiphytes. Tillandsia usneoides is probably the best epiphyte among seed plants. It is the so-called "Spanish moss." Many orchids of the moist tropics are epiphytic.

The entire shoot system of some plants is underground. This is the case in the ferns. Many plants produce both aerial and subterranean stems. For example, Canada thistle has horizontal underground stems, and from these are sent up aerial shoots bearing foliage leaves and flowers. Both 
underground and aterial stems are possessed by such common plants as Irish potato, onion and asparagus.

Water is also a medium of growth of stems, as is the case with such plants as Elodea, Polamogeton, water lilies, etc.

"Modified" Stems.-Undoubtedly, the ordinary cylindrical twig such as is found in trees and shrubs is the most common sort of stem. It is quite likely that we think of a stem as a plant part growing more or less erect, in fact, most stems do tend to grow erect. However, all stems are not as just described. As we take a survey of the plant kingdom, we discover many different forms of stems-stems that are so different from the ordinary sorts that they are scarcely recognizable as stems, and are identified as such, only by careful study of their origin and structure. Among such stems are the following:

I. Rootstocks or Rhizomes (Fig. I2).-These are underground, horizontally elongated stems. The rootstocks or rhizomes of Canada thistle are excellent examples. They bear reduced, scale leaves at the nodes. Lateral buds arise in the axils of these leaves, just as described in the cottonwood twig-a typical stem. They grow in length from a terminal bud, which is unprotected by tough scales. Adventitious roots are produced at the nodes. Rootstocks are efficient organs in the spreading of a plant. Here is a method of reproduction other than by seeds. Usually, acrial stems from the lateral buds of the rootstock are produced; they may die back to the ground each fall. The plant lives over the winter by means of the rootstocks. Hence, rootstocks or rhizome-bearing plants are perennial. Many of our worst weeds are perennials from a rootstock. We may prevent such plants from going to seed, but in spite of this, and the cutting back of the leafy shoots, new shoots are sent up from the rootstocks. Furthermore, if the root- 
stocks are broken into a number of separate pieces by cultivating implements, each piece may develop adventitious roots, establish itself, and send up leafy shoots. Frequent cultivation that has as its aim the destruction of new

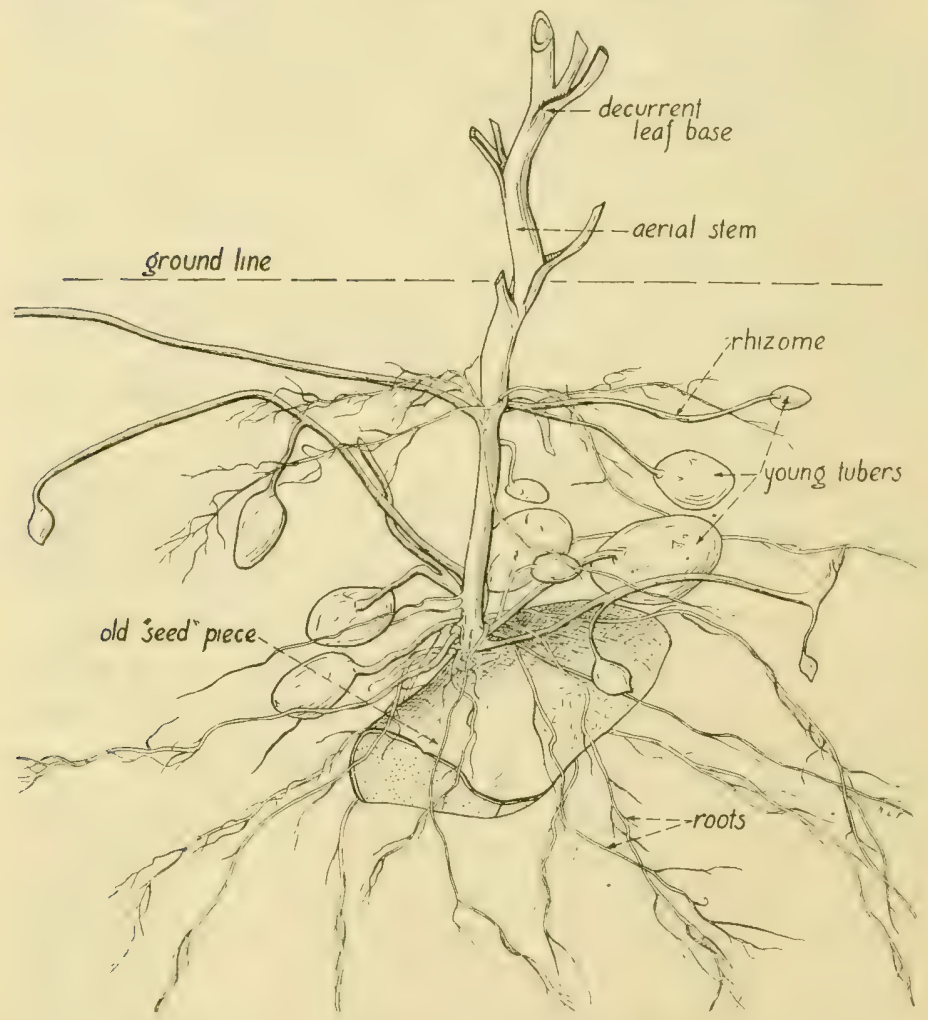

FIG. I2.-Portion of a sprouting potato tuber.

shoots as soon as they appear, may succeed in starving out the rootstock after a time. The period of time depends upon the amount of stored food material in the structure. This method of eradication is based upon the knowledge that the 
food of the plant is manufactured in the chlorophyll-beating (green) cells above ground.

2. Tubers.-These are fleshy, underground stems. 'The' best example is common Irish potato. Although the potato, ordinarily, would not be considered a stem, still if we follow through its development, and examine its structure, we are convinced that it is stem (Fig. I2). When we plant a slice of a potato, "sprouts" are soon sent out from the "eyes." These sprouts, with their nodes, and internodes, and their scale leaves, are quite obviously horizontal underground stems (rhizomes). Soon; the tip of a rhizome begins to enlarge, and a potato is formed; hence, the potato is seen to be a simple enlargement of the tip of an underground stem. Furthermore, examination of the tuber reveals the presence of a terminal bud ("seed end" of the potato), and lateral buds along the sides. The buds are the so-called "eyes." In an elongated potato, we may be able to detect the spiral arrangement of the buds. Lenticels may also be observed on the corky layer (skin) of the bark of the

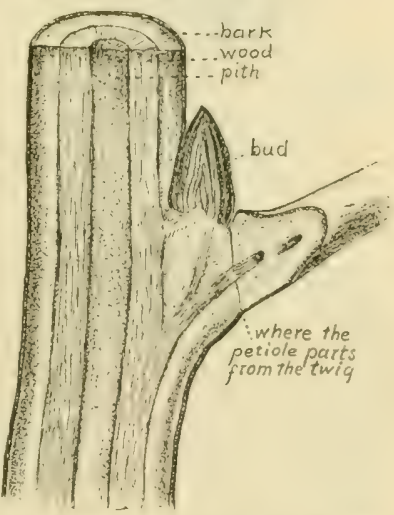

FIG. 13.-Section of stem showing a shedding leaf; also bark, wood and pith as seen in cross and longitudinal sections. (After Longyear.) potato.

A section of a tuber reveals a stem structure. The three principal parts of an ordinary stem are bark, wood and pith. This is shown in a cross-section of an ordinary twig (Fig. I.3). In the potato, these three distinct zones are visible, as indicated in Fig. 236. Hence, we see that the potato is in reality a modified stem. 
3. Bulbs. - A bulb is an underground stem. The common onion is a typical example. A median, lengthwise section (Fig. I4) of the onion bulb, shows a small, cone-shaped stem

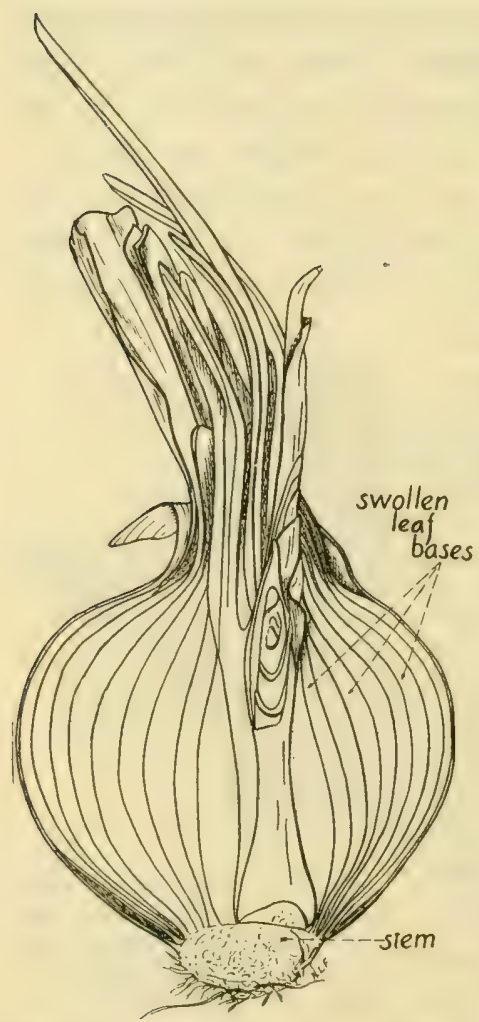

FIG. 14.-Median lengthwise section of common onion bulb. upon which are numerous, fleshy leaves that are overlapping and quite rich in food material. Here, too, there is a terminal bud, and lateral buds occasionally in the leaf axils. $B u^{-1 b s}$ are vertical stems, thus differing from the horizontal direction of growth of rhizomes.

4. Corms.-A colm is a short, solid, vertical, underground stem. It is typically exemplified in gladiolus. Corms are usually flattened from top to bottom, and bear a cluster of thick fibrous roots at the lower side, and a tuft of leaves on the upper side. Corms are storage organs.

5. Runners (stolons).These resemble rhizomes in that their direction of growth is horizontal. In the strawberry plant, the branches that arise from the axils of the closely set leaves are called "runners." They are slender stems, growing along the ground surface; they have long internodes, and produce leaves, flowers and roots at the nodes. Runners are used as a means of propagating the 
strawberry plant. They are attached to the old plant for but one season. Runners may branch.

6. Lianas.--A liana is a climbing stem, gaining mechanical support only from another plant. Common lianas are the grape, Virginia creeper, hop, Japan ivy (Psedra tricuspidata) and morning glory. The stems of lianas are slender, long, and have insufficient strengthening tissue to hold them perfectly erect. Hop stems always wind about the support clockwise (Fig. I02). Such a twiner is destrorse. The twining stem of Virginia creeper bears fleshy, yellowish air roots which may aid the plant in adhering to its support. Of greater value to the Virginia creeper plant, in this regard, however, are the highly specialized branches tendrils. In this case, a tendril ends in a knob which flattens out, when it comes into contact with a surface, and adheres to that surface by a mucilaginous disk-shaped structure.

7. Spines.-Some spines are reduced stem structures, as is the case in the honey-locust, hawthorn, wild crab, etc. Many small spines, such as are found in gooseberries, cacti, and roses, for example, are outgrowths of the stem. It seems that spines are induced by an excessive loss of water from the plant, and a low absorption rate, such as occur under desert and semi-desert conditions.

\section{STRUCTURE OF STEMS}

The Young Dicot Stem.--Let us cut a middle lengthwise section of a young dicot stem (Fig. I5). This section will cut the growing point (bud) of the stem, and the older parts back of the growing point. We see that the stem becomes progressively older farther and farther back from the tip. The cells at the growing point make up a tissue known as meristem tissue (undifferentiated tissue). Although they 
are similar in appearance, it is quite evident that they are capable of developing into different tissues. Just back of

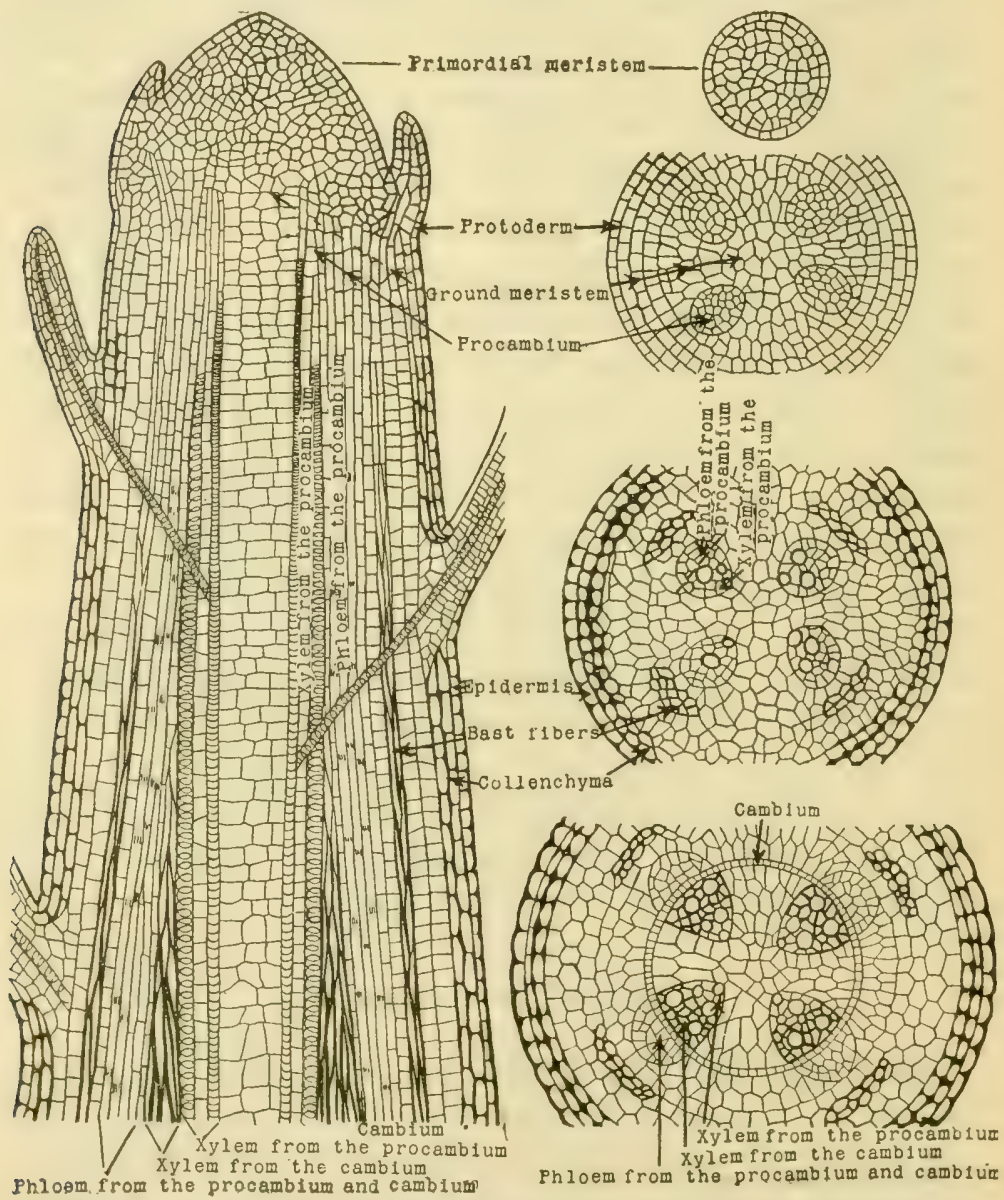

FIG. 15.-Diagram showing the evolution of tissues from the primordial meristem down to the beginning of cambial activity. (After Stevens.)

the growing point, we note that the cells have differentiated into three main regions: cpidermis, ground meristem, and 
procambium strands. These three regions are best shown in a cross-section (Fig. I5). In a little older portion of the stem, such as shown in a section further back (Fig. I5), further differentiation has taken place, which changes involve the ground meristem and the procambium. The vascular bundle is composed of three regions: phloem, cambium and xylem. The center of the stem is made up of large, loosely fitting cells which constitute the pith or medulla. Radiating from the medulla out between the vascular bundles are a number of cells which make up the medullary ray.

\section{Dicot Vascular Bundle.-De-} tailed examination of a dicot vascular bundle in cross- and longitudinal sections shows each of its three parts to be made up of characteristic structural elements.

Phloem.-In the phloem are sicie tubes, companion colls, and phloem parencliyma. Each sieve tube is a single cell, much elongated and modified for conduction. The end walls of sicve tubes (Fig. I6) are thickened, and perforated by a great number of holes,
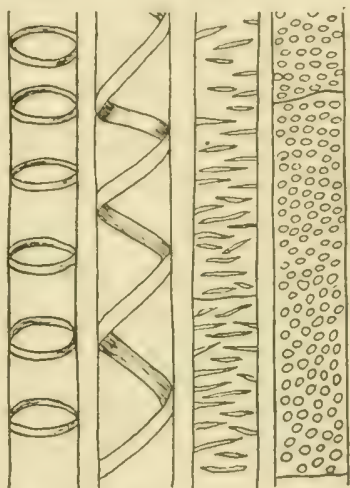

a

B

C

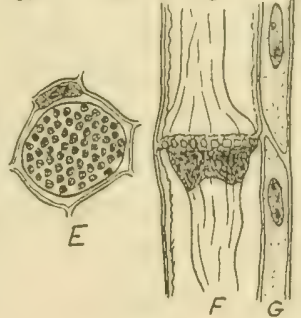

Fig. I6.-Vascular elements. $A$, annular tracheal tube; $B$, spiral tracheal tube; $C$, reticulated tracheal tube; $D$, pitted tracheal tube; $E$, cross-section through plate of sieve tube, and adjoining companion cell; $F$, lengthwise section of sieve tube; $G$, portions of two companion cells. (E, $F$, and $G$ after Strasburgir.) and thus resemble a sieve. Each sieve tube is adjoined by a single row of small cells, the companion cells, which run parallel to it. Phloem parenchyma cells are somewhat 
vertically elongated, but they do not reach any considerable size.

Functions of Phlocm Elcments. -The functions of these three elements of the phloem are as follows:

I. Sieve Tubes.-Conduction of soluble carbohydrates, amido-acids and proteins.

2. Companion Cells.-Although sieve tubes lose their nuclei before the end of the first year, they do not die; hence, it is thought that companion cells extend their influence to the sieve tubes, enabling them to carry on the life processes for which a nucleus seems necessary.

3. Phloem Parenchyma.-The cells of this region store food material or conduct it short distances in the stem.

Cambium.-The cambium layer is composed of one or more rows of small cells, flattened in planes that run at right angles to a radius of the stem. They are thin-walled cells, rich in protoplasm, and capable of rapid cell division and growth. The cambium is in fact the growing layer of the stem. In grafting, one stem, the scion, is inserted into another stem, the stock, in such a way as to bring the two cambium layers together. The cells of these layers possess the power of growth, and after a time there is a union.

Xylem (Wood).-The chief structural elements of the xylem or wood portion of the vascular bundle are: tracheal tubes, tracheids, wood fibers and wood parenchyma. The tracheal or water tubes are long, large, tubes with thick walls. They have been formed by the elongation and enlargement of rows of cells, the common end walls of which have totally or partially dissolved, leaving a duct of considerable length. The walls of the tracheal tubes become thickened, and the thickening material (lignin) is laid down on the inside of the walls in various patterns. 
Kinds of Tracheal Tubes (Fig. 16).-.There are the following sorts of tracheal tubes:

I. Annular Tracheal Tubes.-Here and there in the tube are thickened rings of lignin, which have the appearance of barrel hoops.

2. Spiral Tracheal Tubes.-The thickening material is in the form of a loose spiral.

3. Reticulated Tracheal Tubes.-In these, the strengthening material is laid down in such a fashion as to form a network on the wall.

4. Dotted or Pitted Tracheal Tubes.-In these, lignin has been deposited over the inner wall in such a manner as to leave numerous circular thin places, which give the tube a dotted or pitted appearance.

Tracheids (Fig. I7) are single cells, elongated and modified. They have thick, lignified walls with numerous bordered pits. In shape tracheids are like a spindle, and they fit closely together making up a strong supporting tissue.

Wood parenchyma cells are usually thin-walled and with unbordered pits.

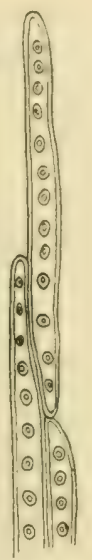

Fik. I 7 . Tracheids. with bordered pits.

Wood fibers are long, taper-pointed at the ends and thickwalled. The pits are unbordered.

Functions of Wood Elements.- The functions of the different wood (xylem) elements are as follows:

I. Tracheal Tubes.-(a) Carry water and solutes from the soil to and throughout the leaves; (b) give strength to the stem.

2. Tracheids.-(a) Carry water and solutes; (b) give strength to the stem.

3. Wood Parenchyma.-(a) Store water and foods; (b) and also conduct them short distances. 


\section{Wood Fibers.-Give strength to the stem.}

Growth in Thickness of Dicot Stem.-Medullary ray cells give rise to cambium that joins with the cambium in the vascular bundles. Thus there is formed a continuous cambium ring (Fig. I5). At the end of the first year of growth or the beginning of the second, another sort of cambium, called cork cambium, is differentiated in the outer cortex. Growth in thickness of the stem consists then in the production and growth of new cells from: (I) cambium of vascular ring, and (2) cork cambium. The cambium cells of the vascular ring may differentiate into xylem, or phloem, or remain cambium. Each cambium cell divides by a wall which is parallel with a tangent to the outside of the stem. If the inner cell resulting from the division becomes a xylem element, the outer usually remains cambium. On the other hand, if the outer cell resulting from the division becomes a phloem element, the inner remains cambium. Hence, by a division of cambium cells of the vascular ring, new xylem is laid down on the outside of the old xylem, and new phloem is laid down on the inside of the old phloem. Not only do the vascular bundles grow in a radial direction, but also somewhat laterally. This lateral growth of existing vascular bundles, together with the formation of new ones between the old ones, brings about a narrowing of the medullary rays, so that in an old stem they appear as mere lines or rays radiating from the pith or medulla. And, furthermore, the wood comes to form quite a solid ring, as does also the phloem.

In addition to the increase in stem thickness by the production of more xylem and phloem, the cork cambium cells aid in this process. Cork cambium cells which divide by a wall that is parallel to a tangent of the stem, give rise to cork tissue, and to secondary cortex. Hence, each year, there are produced in the dicot stem: 
I. Wood, on outside of old wood.

2. Phloem, on inside of old phloem.

3. Cork, on inside of old cork.

4. Secondary cortex, on outside of old cortex.

A two-year old woody dicot stem has the following general structure:

I. Bark, consisting of the following parts in orler from outside to inside: Cork, cork cambium, secondary cortex, primary cortex, primary phloem, secondary phloem.

2. Cambium of vascular bundle.

3. Wood, consisting of two layers, the youngest toward the outside.

4. Pitls.

5. Medullary rays, each ray of several rows of thin-walled cells running from the medulla to the outer edge of the phloem.

Monocot Stems.-The corn stalk is an excellent type of a monocot stem.

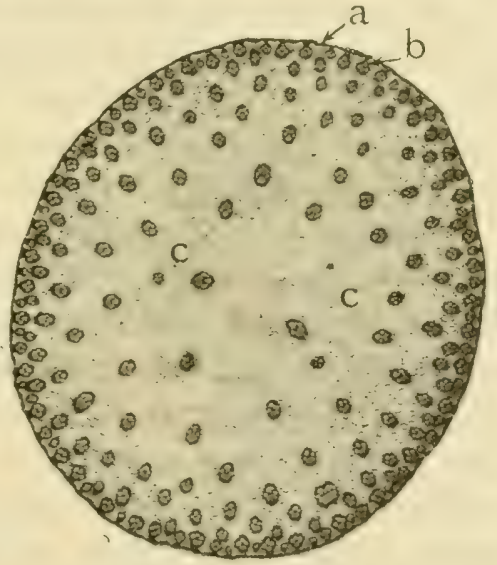

FIG. IS.-Cross-scction of cornstalk stem; $a$, epidermis; $b$, cortex and pericycle; $c$, ground tissue. (After Stevins.)

In this, as shown in cross-section of the stem in Fig. I8, the vascular bundles (fibers) are scattered throughout the ground tissue. They do not form a definite "vascular ring" as in dicot stems. Moreover, the vascular bundles of most monocots do not possess cambium, as in dicot stems. Hence, new phloem and xylem are not produced each season, and consequently there are no annual rings formed. Growth of monocot stems results from (I) simple enlargement of cells derived from primary meristem tissue, and in some instances 
from (2) the formation de novo of vascular bundles from cells that have retained their meristematic power.

Annual Rings.-An annual ring, as generally understood, is one year's growth of wood (xylem). The ring varies in width, depending upon the time in the life of the plant it was formed, and upon seasonal climatic conditions. Furthermore, it is known that some trees grow rapidly, producing wide annual rings, while it is a specific character of others to grow slowly, i.e., produce narrow annual rings.

There is usually a marked difference in the wood formed in the spring and early summer, and that produced in late summer and fall. In early or so-called "summer wood," tracheal tubes are large and quite numerous; in late or "autumn wood," tracheal tubes are smaller and fewer, and tracheids and wood fibers are relatively more abundant. Hence, "autumn wood" has more strength than summer wood. It is readily seen that the autumn wood of one year (say rgr6) is adjacent to the spring wood of the following year (I9I7). "Soft wood" is usually one which grows rapidly, and is diffuse porous, that is, tracheal tubes are rather small and uniform in size and evenly distributed throughout the year's growth. "Hard wood" is usually a comparatively slow-growing wood, and is ring porous, that is, the tracheal tubes of the spring and early summer are large and numerous, while the autumn wood is solid as a consequence of the relatively greater abundance of tracheids and wood fibers.

Bark. - The term "bark" with us includes all that portion of the stem down to the cambium layer. When the bark of a tree is peeled off, there are removed the following layers in order from outside to inside: cork, cork cambium, cortex, phloem, and portions of cambium. The cleavage line is the cambium zone. 
The Work of Stems. - (r) The stems of trees, shrubs and common herbs are mainly concerned in the conduction of water and solutes from the soil, and of food materials. The need for a conductive system first arose in the plant kingdom when the food-making organs of the plant became elevated above the soil or water surface. (2) The stem also is a support to the other organs of the plant, and it brings into display the leaves, and flowers. The leaves are brought into a position where they may receive the light to advantage, and flowers are placed where their pollen may be disseminated by wind or bees, and seeds may be more easily spread. (3) In addition to conduction and support, stems may store food material, water and various waste products. In our woody perennials, such as the apple or peach, for example, an abundance of food material is stored during the winter in the medullary ray cells, also, in wood parenchyma, and in that portion of the pith adjacent to wood, and sometimes in all of the pith cells; portions of the phloem and cortex may also store food. The stems of such plants as the giant cactus, and other cacti, store large quantities of water. Some stems, such as the potato tuber, bulb, corm and rootstock, are heavily loaded with stored food material. Young stems that contain chlorophyll in their outer layers possess the power of manufacturing carbohydrates, just as do green leaves. 


\section{CHAPTER V}

\section{LEAVES}

Development of Leaves.-Leaves appear at the growing point of a stem, as lateral protuberances (Fig. I5) consisting at first of a shapeless mass of cells. We call this group of cells the primordial leaf. By further cell division and differentiation (becoming different from each other) of these few cells the adult leaf arises. In the embryos of seeds the first few leaves are already formed, and even in this early stage may bear some resemblance in shape to the adult leaves.

Parts of Leaf.--Most leaves have two distinct parts: blade and petiole (leaf stalk). Some leaves, as those of peas and beans, have two small, leaf-like structures at the base of the petiole. These are stipules (Fig. I9). The petiole is sometimes absent, the blade being mounted directly on the stem. Such a leaf is said to be sessile. Vascular bundles run from the stem out through the petiole into the blade, where they branch to form the network of veins. The veins not only carry water, solutes and food materials, but also form a framework for the softer tissue of the leaf.

Kinds of Leaves.--It is possible to classify leaves in many different ways. Common green leaves that we are all familiar with are usually called foliage leaves. They are the chief food-making organs of all ordinary plants. However, there are many leaves that do not possess green coloring matter (chlorophyll) and hence, have no food-making power. 
As examples of the latter, may be mentioned the small, scale leaves on underground stems, the scales enwrapping the growing point in buds, the bracts in grass inflorescences, and the petals, stamens and carpels of flowers.

We look upon ordinary foliage leaves as the most common, and hence "normal," sorts of leaves. We would regard scale leaves, bracts, bud scales, and flower parts as "modified" leaves.

Leaves may function as (I) food-making organs (foliage leaves), (2) protective structures (scales), (3) reproductive organs (floral organs), and (4) as storage organs. The fleshy leaves that make up the bulb of onion are good examples of leaves used for storage.

Foliage leaves are either parallel-veined or netted-veined. In leaves with parallel venation, there are many veins, about equal in size, running parallel, and joined by inconspicuous veinlets. This type of venation is characteristic of the leaves of grasses, sedges, rushes, lilies and most all other monocotyledonous plants. In leaves with netted venation, which

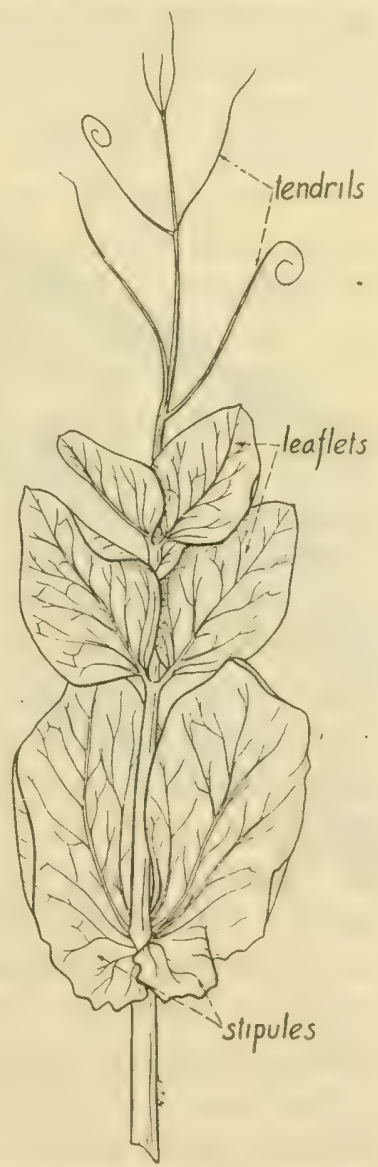

FIG. I9.-A single compound leaf of sweet pea. is so well illustrated in leares of apple, oak, maple, potato, cabbage and other dicotyledonous plants, there are a few 
prominent veins from which arise numerous minor veins, thus forming quite a conspicuous network.

Leaves are often classed as simple or compound. The apple leaf is an example of a simple leaf (Fig. I 59). In this there is an undivided blade. The bean, pea, carrot or parsnip leaf is compound (Fig. 19). The blade is divided into a number of segments, or leaflets.

We may classify leaves as to their arrangement on the stem. Leaf arrangement is the same as bud arrangement, for ordinarily a bud arises in the axil of each leaf. They may be alternate, opposite or whorled (see page 25).

Leaves vary widely in size, shape, character of margin, and base, texture, thickness, nature of epidermal coverings, etc. Some of these variations will be mentioned throughout the pages that follow.

Structure of Leaves.- The structure of a leaf is best shown in a cross-section (Fig. 20). The upper epidermis usually consists of a single row of cells. Below it, is the palisade layer, composed of one or more rows of cells the long axes of which are perpendicular to the leaf surface. Below the palisade cells is the spongy parenchyma, varying in thickness, and composed of rather irregularly shaped cells that fit together loosely, thus leaving intercellular spaces (air spaces). The lower epidermis is seldom more than one layer of cells thick. Chloroplastids are abundant in palisade and spongy parenchyma cells, but absent from all epidermal cells except the guard cells of stomata.

The outer wall of epidermal cells is normally thicker than radial or inner walls. Cutin, a fatty substance, highly impervious to water, is deposited on the outer wall, to form a layer called the cuticle. A thick cuticle is a common characteristic of leaves growing in arid situations. The same variety will develop a thicker cuticle under arid conditions 
than when growing where there is ample water. I thick cuticle is a good drought-resistant character.

The epidermal cells do not form a continuous layer over the two leaf surfaces. There are numerous pores or openings, the stomata (singular stoma, a mouth) (Fig. 20). Each stoma is bounded by two modified epidermal cells, differing

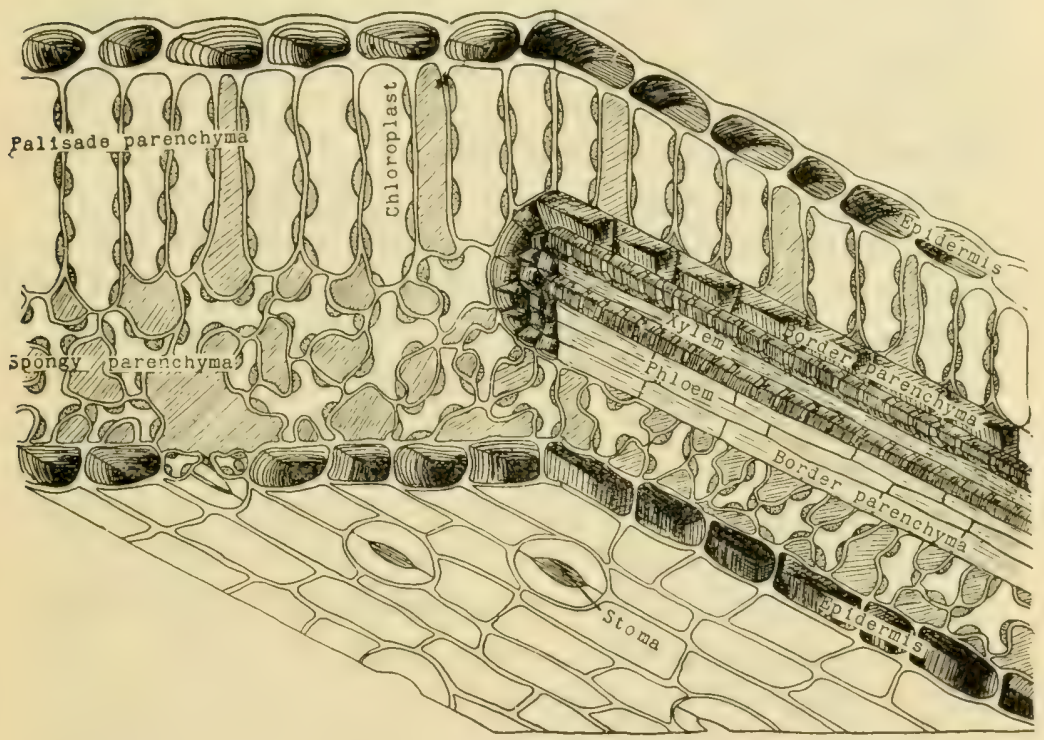

FIG. 20.-Diagram showing the structure of a representative leaf. (After Stevens.)

from ordinary epidermal cells in form, in their ability to change shape, and in the possession of chloroplastids. These are the guard cells.

Leaves possess many different kinds of surface peculiarities. such as hairs, scales, wax and resin deposits. These are features which tend to retard water loss from the leaf surface.

There is the widest variation in leaf structure. That 
described above is typical of dicot leares growing in situations with a moderate water supply. Water leaves are thin and have no palisade tissue. Palisade tissue is also absent in the leaves of grasses. The leaves of plants growing in arid situations are usually thick. The increased thickness is commonly due to an increase in the number of rows of palisade cells. Palisade may develop on both upper and lower surfaces. Some leaves have palisade tissue from epidermis to epidermis. The thickness of leaves growing in arid conditions may also be, in part, the result of the development of a very thick cuticle.

The Work of Foliage Leaves.-Leaves are very important organs of the plant. We are all familiar with the injury to a plant that results from defoliation through any cause, or from disease of leaves, or from their meager development. We have learned to associate an abundance of bright green leaves with plant vigor, just as we associate a rosy complexion with health in people. And, with but few exceptions, we may judge of the health of a plant by its leaf development and color.

Carbohydrates are made by green plants only, and only by those cells of green plants that possess chlorophyll. The cells of roots and other underground plant parts, and all those cells of the plant so far removed from the surface as to be beyond the influence of light, do not have chlorophyll, and hence, have no power of making carbohydrates. Other than that in the relatively small amount of green tissue in young stems and in the sepals of flowers, all the carbohydrate of the plant is made in the chlorophyll-bearing cells of leaves. The manufacture of carbohydrate by green tissue is called carbohydrate synthesis or photosynthesis. When we realize that carbohydrates form the basis of all the other more complex foods of the plant body, such as fats, amides and 
proteins, we see the great importance of a healthy l'al development.

In addition to their important work of carbohycluate synthesis, the synthesis of the fats, amides and proteins is carried on to a large extent in leaf cells. We may truly say, then, that leaves are the food-making organs of a plant.

Leaves are also the chief transpiring (water-losing) organs of the plant. Practically all of the water that escapes from a plant passes out through the leaves, chiefly through the stomata. When in a healthy growing condition, there is a continuous stream (transpiration stream) of water from the roots to the leaves.

The leaves of many succulent plants, such as Agare, Russian thistle, salt wort, stone crop, and others serve as storage places for water. Agave leaves may also store food. The onion bulb is made up of a very short stem bearing numerous, overlapping, fleshy leaves in which considerable quantities of food are stored.

The leaves of the sundew (Drosera), and pitcher plants (Sarracenia and Nepenthes) are highly modified as special organs that catch, digest and absorb insects. 


\section{CHAPTER VI}

\section{FLOWERS}

Parts of Representative Flower.-A representative flower

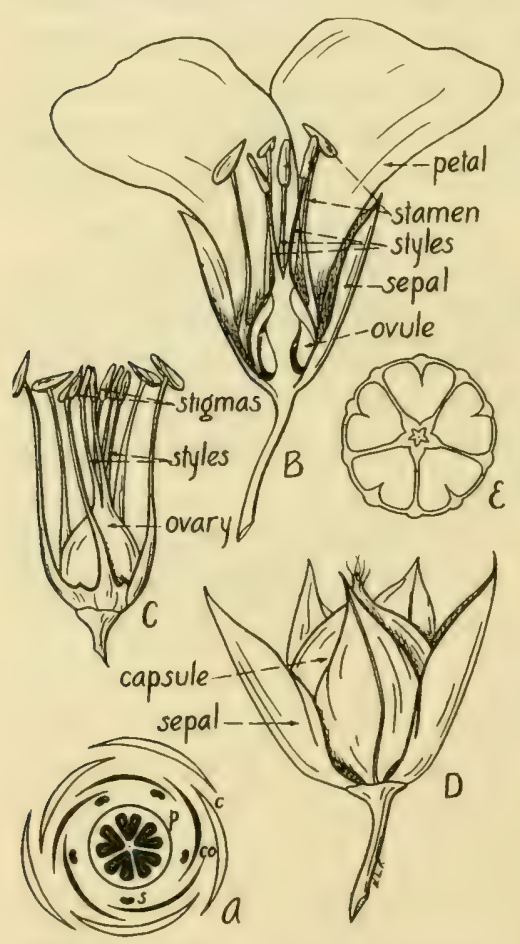

Fig. 21.-Flax. $A$, floral diagram$c$, calyx; $c o$, corolla; $s$, stamens; $p$, pistil. $B$, median lengthwise section of flower. $C$, calyx and corolla removed. $D$, fruit, external view. $E$, cross-section of fruit. such as shown in Fig. 2 I has the following parts taken in order from the outside to the inside:

I. Calyx, made up of sepals, which are green, and enclose the other flower parts in the bud.

2. Corolla, made up of petals, which are usually the colored portions of the flower.

3. Stamens, each made up of a stalk or filament at the tip of which is the anther, bearing pollen grains.

4. Pistil, which has a swollen basal portion, (I) the ovary, (2) a style, slender stalk leading from the ovary, and terminating in (3) a stigma, which is receptive to pollen. Within the ovary are the young ovules, the bodies which become seeds. 
All the flower parts mentioned above, in the representative flower, are attached to the end of the flower stalk, the receptacle or torus. The calyx and corolla taken together constitute the perianth.

We shall see that there are many different sorts of flowers in the families of seed plants. They differ widely in size, form, color, and in the shapes of the various parts.

Development of the Flower.-The primordia of flower parts arise as protuberances from the young receptacle (Fig. I5). As a rule, the sepals, petals, stamens and carpels

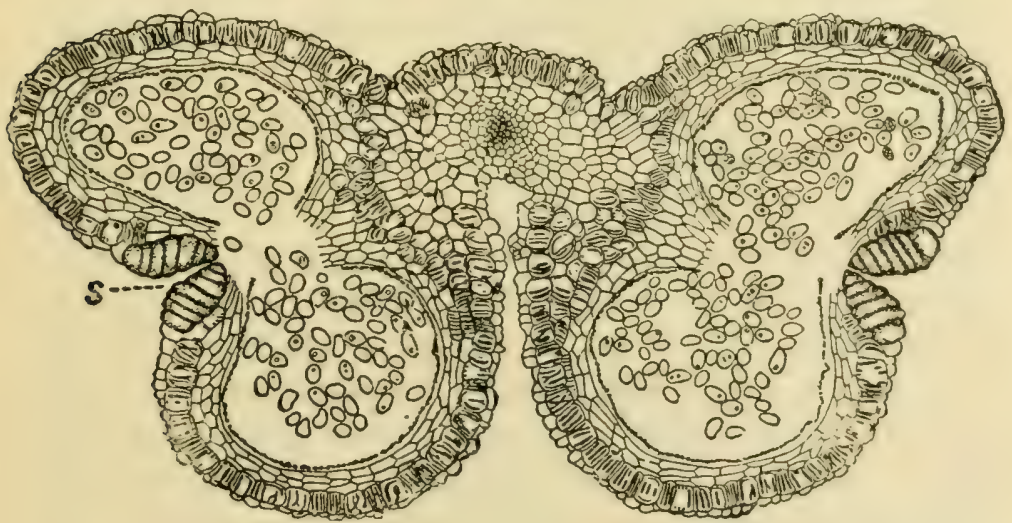

FIG. 22.-Cross-section of a mature lily anther. The pairs of pollen chambers unite to form two pollen sacs, filled with pollen grains; $s$, modified epidermal cells at line of splitting. (From a Text-book of Botany by Coulter, Barnes, and Cowles. Copyright by the American Book (ompany, Publishers.)

appear in the order named, as described in the case of the apple flower on page 366 . This order of floral succession is said to be acropetal. Although this is the prevailing order, there are different types. For example, in some mustards the petals are the last to appear, and in some roses the carpel primordia appear before the stamens.

Stamens.-Ordinarily, the anther is held upon a filament 
or stalk. When the filament is absent, the anther is said to be sessile. A cross-section of an immature anther is seen to have four chambers or locules, each with a number of pollen mother cells; each pollen mother cell normally divides to form four pollen grains. As the anther matures the pairs of locules unite, thus forming two pollen sacs in each anther. Finally, each sac splits open (dehisces) allowing the pollen to escape (Fig. 22).

Mature Pollen Grain.-When the pollen grain is mature, it consists of a wall surrounding a protoplasmic mass, the essential parts of which are a tube nucleus and a generative nucleus. At the time of pollen germination the latter divides into two sperm or male muclei.

Pistil.- The pistil usually consists of an ovary, style and stigma. The seeds are borne in the ovary. A cross-section of a simple ovary shows it to have one locule or chamber with one or more ovules attached to the wall. The tissue to which the ovule or ovules are attached is the placenta. A compound ovary (Figs. 2I and I3I) usually has two or more compartments, with an ovule-bearing tissue (placenta) in each. We may also speak of the pistil as simple or compound. A simple pistil has one carpel, which is in reality a modified leaf bearing one or more seeds. A compound pistil has two or more carpels. When the carpels are separate, as in the strawberry (Fig. I5I) the flower is said to be apocarpous; when united, as in asparagus (Fig. 99), syncarpous.

Ovule.-Fig. 23 shows an ovule just before fertilization. A central mass of tissue, the micellus, is surrounded by an inner and an outer integument, except for a small opening. the micropyle. Within the nucellus is the embryo sac, at this stage consisting of eight muclei: two synergids, one egg mucleus, three antipodals, and two polar nuclei. They occupy 
about the relative positions in the embryo sac as shown in Fig. 23 .

Pollination.-This is a mechanical process in which pollen is transferred from an anther to a stigma. Pollen maly be transferred from an anther to the stigma in the same flower.

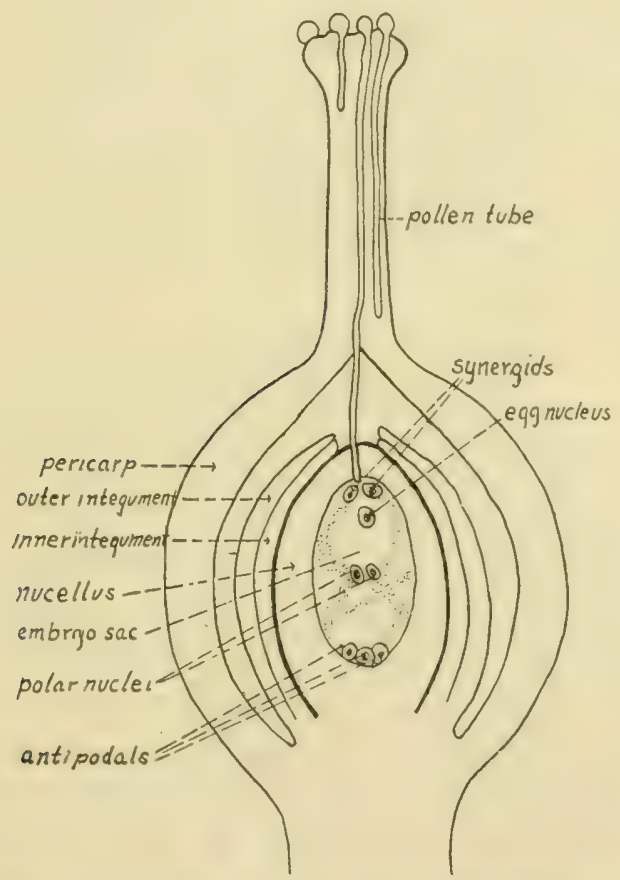

FIt. 23.-Diagram of a simple pistil as seen in lengthwise section showing a single ovule just prior to fertilization.

This is termed autogamy or close pollination. Or, pollen may be carried from an anther to a stigma of another flower on the same individual plant. This is called geitonogamy'. Again, pollen may be transferred from an anther to a stigma of a flower on another individual plant. This is termed 
xenogamy, or cross-pollination. Insects, wind and water are the chief agents in the spread of pollen.

Fertilization.-Fig. 23 is a diagram of an ovary with a single ovule cut lengthwise. It shows a stage of development of the ovule about at the time when the pollen grain has reached the stigma. As has been said, the mature pollen grain consists of a protoplasmic mass surrounded by a rather

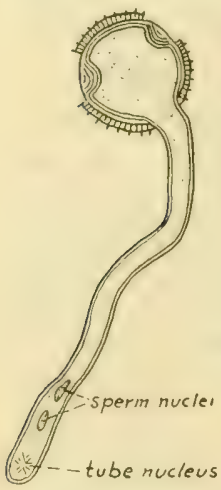

FIG. 24--Germinating pollen grain. (After Bergen and Caldwell.) thick wall. Three nuclei (Fig. 24) constitute the important structures in the pollen grain. It absorbs water and nutrient materials from the stigmatic surface, and grows by sending out a tube, known as the pollen tube. The tube grows downward through the stigma, sometimes in a tubular passage, or when necessary, secreting enzymes which digest (render soluble) the walls of cells that are in its path, at the same time deriving nourishment from this digested material. As the tube grows, the three nuclei keep pretty close to the tip, the tube nucleus in the lead, with the two sperm nuclei (male gametes) following. The tube finally reaches the ovule, takes a course through the micropyle and comes into contact with the nucellus. This nucellar tissue is penetrated, and after dissolution of the wall at the tip of the pollen tube, the three nuclei are discharged into the embryo sac. The tube nucleus is reabsorbed. One sperm nucleus unites with the egg nucleus (female gamete) to form the zygote, a nuclear mass which contains both the characters of the plant furnishing the pollen (paternal characters) and those of the plant fertilized (maternal characters). The union of the male gamete (sperm nucleus of pollen tube) with female gamete (egg nucleus of embryo sac) is fertilization. It is a 
sexual process. It is seen to differ fundamentally from pollination which is simply a mechanical process. The fertilized embryo nucleus now develops into a young plant (embryo). The synergids and antipodals are usually disorganized. In grasses and lilies and some other plants, socalled double fertilization has been observed. One sperm nucleus has been accounted for, as uniting with the embryo nucleus. The other unites with the two polar nuclei of the embryo sac. The body resulting from this triple fusion also carries both maternal and paternal characters. It grows and develops into the endosperm of the seed. Immediately following fertilization, there is a series of changes not only in the ovule which results in a seed, but in the ovary wall as well.

Just one pollen tube penetrates the embryo sac to bring about fertilization. Many pollen tubes, even hundreds, may penetrate the style, although comparatively few may function normally. Those which do not, wither and die. We may be sure that every ovule that develops into a seed has been visited by one, and only one, pollen tube.

Placentation. - Me said that the placenta is the tissue in the ovary to which the one or more ovules are attached. It is traversed by vascular bundles from which branches are given off to the ovules. In currants and gooseberries (Fig. 1 29) the placenta are on the ovary wall. Such placentation is said to be parietal. In lilies (Fig. 3IA), the placentation is axial, or central, that is, the placentx are on the ovary axis. I third kind of placentation is the free central, in which the ovules are attached to an up-growth of the floral axis in the center of the ovary, which is not connected to the ovary wall by radial partitions.

Symmetry of Flower. I flower such as the apple, cherry cr asparagus can be divided into two approximately sym- 
metrical halves by any diameter (Figs. I56 and I62). Such a flower is said to be radially symmetrical, or actinomorphic, or regular. Contrast this symmetry with that in such flowers as the pea or bean (Fig. I 72A), in which there is but one plane through which the flower can be divided to separate it into two symmetrical halves. Such a flower is said to be $b i$ laterally symmetrical, or zygomorphic, or irregular.

Relative Positions of Flower Parts.-In the gooseberry or currant flower (Fig. I29), for example, the ovary is below the stamens, corolla, and calyx, and is said to be inferior. A flower with an inferior ovary is said to be epigynous (above the gynocium or carpels). When the calyx, corolla, and stamens are inserted on the receptacle below the ovary, the ovary is superior, and the flower hypogynous (below the gynœeium). The flowers of mustards are hypogynous. There is a third intermediate type of flower, well illustrated by the cherry (Figs. 157 and 163 ), apple (Fig. I57), etc., in which the petals and stamens are inserted on a calyx rim and arise at about the level of the ovary. In such a case the ovary is half-inferior or half-superior, and the flower perigynous (around the gynocium).

Union of Flower Parts.- In the primitive flower type, such as the buttercup, the sepals, petals, stamens and carpels are all separate and distinct. A more or less complete union of the parts of each set of floral leaves may take place. For example, in gooseberries and currants, the sepals are united to form a calyw tube, in the potato flower the petals are united to form a corolla tube, in the cotton flower the stamen filaments are joined, and in many instances-onion, apple, orange, and others - the carpels are united. The adjectives to describe these various cases are as follows: 
Separate

Sepals........... aposepalous

Petals........... apopetalous

Stamens......... polydelphous

Carpels.......... apocarpous
United

synsepalous

sympetalous

diadelphous (2 groups)

monodelphous (I group)

syncarpous

Incomplete Flowers.--The representative flower described in a preceding paragraph had all four floral sets of organs present. However, one or more of these sets may be absent, and in this case, the flower is incomplete. Flowers lacking petals are called apelalous (buckwheat). When both sepals and petals are absent, the flower is naked (willows and cottonwoods). In the majority of flowers, both stamens and pistils, the essential organs of a flower, are present. Such a flower is said to be perfect or hermaphrodite. Some flowers have but one set of essential organs, either stamens, or a pistil. A flower with stamens only, and no pistil, or a flower cluster (inflorescence) composed of such flowers, is said to be staminate. On the other hand, a flower with a pistil but no stamens, or an inflorescence, composed of such flowers, is said to be pistillate. If staminate and pistillate inforescences are on different plants, the species is said to be "Jicecious." In some diœecious species (hops), the staminate and pistillate inflorescences are very unlike in appearance. while in other diœcious species (salt-grass. Dislichlis), the two unisexual inflorescences are very similar. If staminate and pistillate inflorescences are on the same individual plant, it is said to be "monocious." This is the case in corn, in which the "tassel" (staminate inflorescence) and the "ear" (pistillate inflorescence) are very dissimilar in appearance.

Inflorescence.--An inflorescence is a flower cluster. Its shape and the arrangement of the flowers in it differ with the kind of plant. There are three general classes of inflores- 
cences: (1) simple, (2) indeterminate or racemose, and (3) determinate or cymose.

The simple type is well represented by the calla lily or tulip, in which one flower terminates the stalk. Mustards and currants have a typical indeterminate or racemose inflorescence. In this, the older flowers are at the base or outside of the flower group and the younger appear in order above them. Moreover, the growth of the inflorescence may continue at the apex. For example, in a cabbage or radish inflorescence, flowers may be opening at the tip, while at the base pods are partially mature. Racemose types of inflorescences are the true raceme, panicle, corymb, umbel, spike, and head. These will be described when they are met with in the family descriptions that follow. The cymose flower cluster is one in which the older flowers are on the inside, and the younger appear in order toward the outside. The length of a flower shoot is determined by the terminal flower. The inflorescence of chickweeds is a cyme. 


\section{CHAP'TER VII}

\section{FRUITS, SEED, AND SEEDLINGS}

Development of the Seed.-We have seen how a male nucleus of the pollen tube unites with the egg or embryo (female) nucleus of the embryo sac. The fertilized egg then starts upon a series of divisions, and by growth and development, the young plant or embryo is formed. It may be partially or totally imbedded in the endosperm. In some seeds (bean), the endosperm is lacking, and the embryo occupies the entire space within the seed coats. The cells of the nucellus are in part absorbed by the developing embryo, and at most the nucellus is represented by a very thin and compressed layer just within the inner integument. The integuments of the ovule become harder, less permeable, and form the seed coats. The micropyle is still evident in the mature seed as a small opening.

The embryo or young plant has three main parts: (I) one or two cotyledons; (2) the hypocotyl, which includes all of the embryo below the cotyledons and terminates in the first root or radicle; and (3) the growing point of the shoot. upon which are a few leaves, making up a bud.

The parts of a representative mature seed may be summarized as follows:

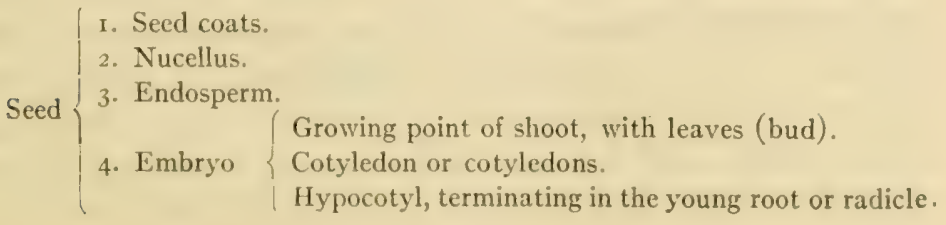


Development of-the Fruit.- The stimulus of fertilization, • which is not well understood, extends its influence not only to the ovule, but to the ovary as well. Coincident with the changes resulting in the mature seed, the ovary enlarges, and its walls become changed both physically and chemically. The ovary wall (pericarp) has three distinct layers. Named in order from the outside to the inside, these are the exocarp, mesocarp and endocarp. As the fruit develops the changes that occur in these layers may differ. For example, in the cherry or plum, the exocarp becomes the skin of the fruit, the mesocarp becomes thick and juicy to form the fleshy portion of the fruit, while the endocarp takes on a stony character.

Fruit and Seed Distinguished.-A fruit, botanically, is the matured ovary, with its seeds, and any parts of the flower which may be closely associated with it. The fruit contains the seed or seeds. For example, the entire bean pod is a fruit; the "beans" within are the seeds. It is in the case of dry, one-seeded fruits, particularly, that distinction needs to be made between fruit and seed. For example, the buckwheat fruit (achene) or grass fruit (grain) is commonly called a "seed." But, if development of these is traced and their structure carefully examined, they are seen to be true fruits, with a very thin pericarp (ovary wall) enclosing one seed (Figs. 35 and II 5).

Kinds of Fruits.- No attempt will be made at this place to give a complete classification of fruits. We will describe the different kinds as we meet with them in the discussions of crop plants. Fruits with a dry pericarp, such as the grain, achene, capsule and pod, are designated dry fruits. Dehiscent dry fruits (capsule, pod, follicle) split open at maturity in a definite way permitting the seeds to escape. Indehiscent dry fruits (achene, grain) do not split open at maturity 
-in any definite way. Fruits with a fleshy pericarp, such as the berry, are called flestry fruits.

Germination of Seed.- The seed must have an adequate supply of water, oxygen and a suitable temperature in order to germinate. The initiatory stages in germination are the absorption of water and the secretion of enzymes in the seed, which render soluble the stored food material necessary to nourish the growing embryo. This food may be stored in the endosperm, as in all grains, or in the cotyledons, as in beans and peas. The embryo is dependent upon stored food for its initial growth. The swelling of the seed, due to water absorption and growth of the embryo, ruptures the seed coats, and the young shoot and primary root make their appearance. The cotyledons are brought above ground in some plants (beans, squashes, etc.) and constitute the temporary or sced. leaies. They may develop chlorophyll and make food for a while. The true foliage leaves develop, partly at the expense of the food stored in the cotyledons, which gradually dwindle away. In many plants, e.g., all grasses, the cotyledon remains in the soil. In these the first leaves are true foliage leaves.

As soon as the first roots are established, making it possible for the plant to absorb water and mineral nutrients from the soil, and a few leaves are formed, the young plant is capable of making its own food and living an independent life. It has been tided through its early stages of development by food stored in the seed. (ienerally speaking, large seeds of any given species produce more vigorous seedlings than small ones, and this is probably correlated with a greater abundance of stored food in the former. 


\section{CHAPTER VIII}

\section{THE CLASSIFICATION AND NAMING OF PLANTS}

That subject which deals with the arrangement of plants into groups, based upon their structure and form, is designated Systematic Botany. From the earliest times, man has attempted to classify the large and varied assemblage of plants which he has found on the earth. There have been many systems of classification, some "artificial," some "natural." An artificial system of grouping plants may use purely arbitrary bases; it may be convenient, but fail to express the natural affinities of plants. For example, in an artificial system, we might choose to put all those plants with red flowers into one group, and those with blue flowers into another class, and so on, thus basing our classification on flower color. Or, we might put trees into one group, shrubs into another, and herbs into still another, thus basing the grouping on size and growth habit. Obviously, we would throw together plants which have no natural relationships, and in some cases, separate those which are naturally allied. An artificial system would not take into account the evolutionary tendencies in the plant world. It is agreed that one system of classification is better than another if it more accurately expresses the natural affinities and the evolutionary tendencies of the organisms dealt with.

In the early history of systematic botany, the systems of classification were largely artificial. As the knowledge of plants increased, one system supplanted another, and in most cases was an improvement over the old one. One of 
the first natural systems of classifying plants (and animals) was that of Linnaeus. The first edition of his notable work, Systema Nature, was published in 1735. There follow the systems of De Jussieu (I789), De Candolle (I8I9), Eichler (I883), Bentham and Hooker (I826-I883), and Engler and Prantl (I890-I896). Two recent systems are those of Bessey (I907), and of Schaffner (I9II).

\section{Reproductive versus Vegetative Organs in Classification.} - In all higher plants, reproductive and vegetative organs differ markedly from each other. Reproductive tissues are less influenced by environmental conditions than are vegetative tissues. There may be little resemblance between the vegetative portions of two species, although their reproductive structures may be very similar. For example, the strawberry and raspberry have quite different growth form. and their vegetative organs are quite dissimilar, yet the flowers of the two are constructed on the same general plan. On the other hand, two plants with very dissimilar reproductive structures, i.e., having little natural relationship, may resemble each other very closely in their general vegetative appearance. These conditions show that, although vegetative structures may be modified to a great degree under diverse environmental influences, these same influences do not modify, to an equal extent, the reproductive organs. Hence, on account of this greater stability of the reproductive structures of a plant, these are of relatively great value in showing actual relationships, and are of prime importance in classification.

\section{GROUPS OF PLANTS}

A survey of the plant kingdom shows it to be composed of a great variety of plants, differing in size, in structure, in habitat, and in method of living. 
The "thallus plants" (Thallophytes) include the simplest organisms. This group is divided into two large subdivisions, the Alge and Fungi. The Alga include the green scums so frequently observed upon the surface of pools, stagnant ponds, reservoirs, ditches and streams. They are also commonly. found in tanks and water troughs, and, in such places may render the water objectionable to stock, especially when decay sets in. The brown and red "sea weeds" are also Algæ. The Fungi are a large group of plants, probably the best known being the bacteria, the molds of bread, fruit, and cheese, the rusts and smuts of the cereals, the toadstools and mushrooms, the mildews, and the fungi causing such well-known diseases as blight of potato, alfalfa leaf spot, apple scab, wilt of cucurbit, etc.

The "moss plants" (Bryophytes) include the liverworts, peat mosses, black mosses, and common mosses. They are a group of comparatively slight economic importance.

The "fern plants" (Pteridopliytes) are represented by the true ferns, and closely allied plants such as the horsetails or scouring rushes, and club mosses. Like the preceding groups, fern plants do not produce seed but reproduce in a much simpler fashion, by spores.

The highest and most complex group is the "seed plants" (Spermatophytes). It includes the Gymnosperma (pines, spruces, firs, hemlocks, cedars, junipers and other cone-bearing plants) and the Angiosperme (higher seed plants or flowering plants). All the common crop plants, of field, orchard, and garden belong to the Angiospermæ. In the Gymnospermæ the seeds are exposed, while in Angiospermæ they are enclosed in a case, the ovary wall. Angiospermous plants fall into two groups (subclasses): (I) Monocotyledones, in which the seeds have one cotyledon, the flower parts are in threes, the leaves are parallel-veined, and 
the vascular bundles are scattered throughout the pith (examples: cereals, onions, asparagus, lilies); (2). Dicolyledones, in which the seeds have two cotyledons, the flower parts are in fours or fives, the leaves are netted-reined, and the vascular bundles are in the form of a cylinder about the pith (examples: buckwheat, beet, apple, cherry, mustard, cotton, melon, potato)!

Each of these subclasses is further subdivided. A complete classification of some plant, e.g., common alfalfa, will give the principal subdivisions:

Spermatophyta,

Angiospermæ,

Dicotyledones,

Order Rosales,

Family Leguminosæ,

Genus Medicago, Species Medicago sativa.

The order ending is usually "ales." Orders are subdivided into families. The family ending is commonly "acece" or "ce." Families are split up into genera, and genera into species. The number of families, genera, and species may be large or small.

THE PLANT KINGDOM

Thallophytes-"Thallus plants."

Myxomycetes - slime molds or slime fungi.

Schizophytes-"splitting plants."

Cyanophyceæ-blue-green algx.

Schizomycetes-bacteria.

Algæ - pond scums, sea weeds, etc.

Chlorophyceæ-green algæ.

Phæophyceæ - brown algæ.

Rhodophyceæ-red algæ. 
Fungi-molds, yeast, mildews, rusts, smuts, toadstools, lichens, etc.

Phycomycetes - algal-like fungi.

Ascomycetes-sac fungi.

Basidiomycetes-basidium fungi.

Bryophytes - "moss plants."

Hepaticæ-liverworts.

Musci-mosses.

Pteridophytes-"fern plants.".

Lycopodiales-club mosses, lycopods, quillworts.

Psilotales-two small living genera.

Sphenophyllales - a single Carboniferous genus.

Equisetales -horsetails.

Ophioglossales - adder's tongue, moonwort.

Filicales-true ferns and water ferns.

Spermatophytes - "seed plants."

Gymnospermæ-lower seed plants: cycads, ginkgo, conifers, joint-firs, etc.

Angiospermæ-higher seed plants.

Monocotyledones.

Dicotyledones.

\section{PLANT NOMENCLATURE}

Scientific Name.- The system of nomenclature in use by all biologists today is the so-called binomial system. The scientific name of each plant (and animal) is composed of two words. For example, the scientific name of the common garden bean is Phaseolus vulgaris L. The first word, Phaseolus, is the name of the gemus (pl. genera), or generic name; the second, vulgaris, is the name of the species (pl. species) or specific name. The letter " $L$ " following the scientific name of the common garden bean is the abbreviation for Linnaeus. Placed in this position after the name of the plant, it signifies 
that this species was first named and described by Linnaeus. This description may be found in published form. It is the practice of those engaged in the systematic study of plants and animals to record accurately the description, in some recognized scientific periodical, or in a monograph, of any new species they may find. When such is done, the one who names and describes the new plant affixes thereto his name, in full, if short, but usually abbreviated. In some instances, two abbreviations occur after a scientific name, for example, Echinochloa crus-galli (L.) Beauv. This illustrates a case in which a species has been transferred from one genus to another. Linnaeus named the common barnyard grass Panicum crus-galli L. In his revision, Beauvois transferred the common barnyard grass to the genus Echinochloa still retaining the specific name, crus-galli. Nomenclature rules state that when a species is transferred in this manner from one genus to another, the original author (in this case, Linnaeus) must always be cited in parenthesis, followed by the author (in this case, Beauvois) of the new binomial.

Botanical varieties or subspecies are often printed as trinomials, for example, the bush variety of Phaseolus vulgaris is written Phaseolus vulgaris nanus or Phaseolus vulgaris aar. namus. Agricultural "varieties" are designated by common names, for example, in beans, there are such varietal names as Early Bountiful, Black Valentine, Giant Stringless, Green-pod, etc.

Scientific names are in Latin. This is probably the most universal language, which fact was recognized by Linnaeus, and hence he adopted it in his system of nomenclature. The species and genus agree in gender. For example, Brassica rapa (turnip), Triticum aestivum (common wheat), and Rubus villosus (northern dewberry). 
Descriptive Nature of Specific Names.-Specific names are commonly descriptive. They may be descriptive of (I) some plant character or habit, (2) habitat, or (3) distribution; and, in some instances (4) the species may bear the name of an individual. By far the largest proportion of specific names is descriptive of some striking habit or character of the plant. For example, the trailing or procumbent Trifolium (clover) is Trifolium repens (repens, creeping); the sweet clover with white flowers is Melilotus alba (alba, white); the narrow-leafed crab-apple is Malus angustifolia (angustus, narrow-folium, leaf).

In Vitis riparia, the streamside grape, riparia is descriptive of this species' habitat. The common black-cap raspberry is Rubus occidentalis; here the specific name means "western." Again, in Vaccinium canadense, the Canada blueberry, the specific name indicates geographical distribution. The systematist frequently uses the name of an individual for the specific name. This may be done as a token of friendship, or recognition of distinction, or to indicate the finder of the new form. For example, Prumus besseyi, is after the well-known botanist, Charles Bessey. The $i$ ending is the Latin genitive, signifying "of Bessey."

Scientific Name versus Common Name.-There are distinct advantages connected with the knowledge and use of scientific names. Often the same species has many common names. Again, several distinct species often may go by the same common name. The use of one scientific name will do away with much misunderstanding as to what plant is actually referred to.

\section{General References}

Bailey, L. H.: The Standard Cyclopedia of Horticulture. The Macmillan Co., I9r4.

BaIlion, H.: Histoire des plantes. Paris, I894. 


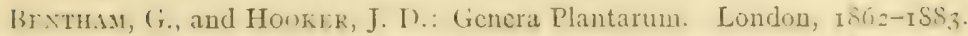
Bertrox.1No Brown: An Illustrated Flora of the Northem Statesand Canarlat.

Scribners, New York, I913.

CARD, Fred W.: Bush-fruits. 'The Macmillan Co., I909.

Corberr, L. C.: Garden Farming. Ginn \& Co., I9r3.

Colltrk, J. M., B.ıries, C. R., and Comi.s, H. C.: I Texthook of Butany. American Book Co., IgIr.

DE Caxdolle, Alphoss: The (Origin of ('ultivated l'lants. 1). Appleton \& Co., $\mathbf{r} 892$.

ENgler ANd Prantl: Die natürlichen Pflanzenfamilien.

Hunt, 'T. I.: Forage and Fiber Crops in America. Orange Judd Co., Igos. KNutr, Pst'L.: Handbook of Flower Pollination. 'Translation by J. R.

Ainsworth Davis. Oxford, Clarendon Press, I9o6.

Montcosery, E. G.: Productive larm Crops. Lippincott Co., ro I6.

Percrial, Jomn.: Agricultural Botany. Henry Holt \& Co., I905.

Piper, Ch.irles V.: Forage Plants and Their Culture. The Macmillan Co., I9I4.

Shepperd, J. H.: Root Systems of Field Crops. N. D). Igr. Exp. Sta. Bull. $64: 525-536$, I905.

Strasburger, E., Noll, li., Schexck, H., and Schmper, .1. I: II: : I Textbook of Botany. Macmillan Co., Igr2.

TeN ErCK, A. M.: The Roots of Plants. Kans. Agr. Exp. Sta. Bull. I27: I99-252, I904.

Vilmorin, M. M.: The Vegetable Garden. John Murray, London, ino5.

Wossidto, PAUL. Leitfaden der Botanik. Berlin, rgr I. 



\section{PART II}

\section{CHAPTER IX}

\section{GRAMINEE (POACEE), GRASS FAMILY}

No family of plants is of greater economic importance than the grass family. It has several thousand species, among which are the "grains" (such as wheat, oats, barley, corn, rice, and others) and the meadow, pasture and range grasses. The grasses grown for "grain" were the first plants to be cultivated by the human race. Members of this family are widely distributed over the surface of the earth, from tropical to polar regions and from low to very high altitudes. In many parts of the world, grasses form a dominant part of the plant covering. Examples of extensive grass associations are meadows, steppes, and savannahs. Meadows are moist grass lands and may occur in all climates. Steppes are dry grass lands. The Old World steppes of Russia, Hungary, Roumania, and Spain, the plains of the Western United States, and the pampas of South America are excellent examples. Savannahs are dry grass lands with scattered trees. The best examples of these are the llanos of Venezuela. and the patanas of Ceylon.

Habit of Plants.-Most grasses are low, erect herbs. A few, such as the bamboos, are shrubs or trees. Bamboo has a woody stem which may reach a height of roo feet or more. Some grasses are trailing, one or more being reported as climbing over trees roo feet high. ()thers, like 
rice cut grass (Homalocenchrus) are feeble climbers or support themselves by means of numerous hooked prickles on their leaves.

Many of our common pasture and meadow grasses, and all the cereals, complete their life period in one season. Such plants are said to be anmual. In cool climates, certain grasses behave as winter annuals, living through the winter as small plants and sending up flower stalks the following spring. So-called "winter" or "fall grasses" behave in this manner. A number of grasses, such as the pernicious quack grass (Agropyron repens), lawn grass (Poa pratensis), and others, are perennial, i.e., with a course of life extending over three or more seasons.

Roots.-The root system of grasses is fibrous, that is, composed of numerous slender roots of about equal diameter. No grasses, at maturity, possess a tap-root system, as that of radish, dandelion, beet, and others. In this there is a strong leading central root. The primary roots, those that arise directly from the seed, are temporary, dying after the permanent roots are able to support the plant. The permanent roots arise from that portion of the stem which extends from the germinating seed to the surface of the ground. These roots are always produced at about the same distance below the surface, regardless of the depth at which the seed is planted (Fig. 3).

Grasses are classed as shallow-rooted plants. However, great variation has been observed in the depth to which the roots penetrate, some extending to depths which cannot be considered as shallow. Roots of buffalo grass (Buchloe) sometimes go to a depth of 7 feet. Rye roots have been found penetrating to a depth of 3 feet, corn $3 \frac{1}{2}$ feet (Fig. $5^{6)}$, emmer and spelt $3 \frac{1}{2}$ feet, and wheat more than 4 feet.

Roots may break through the sheaths (that part of the 


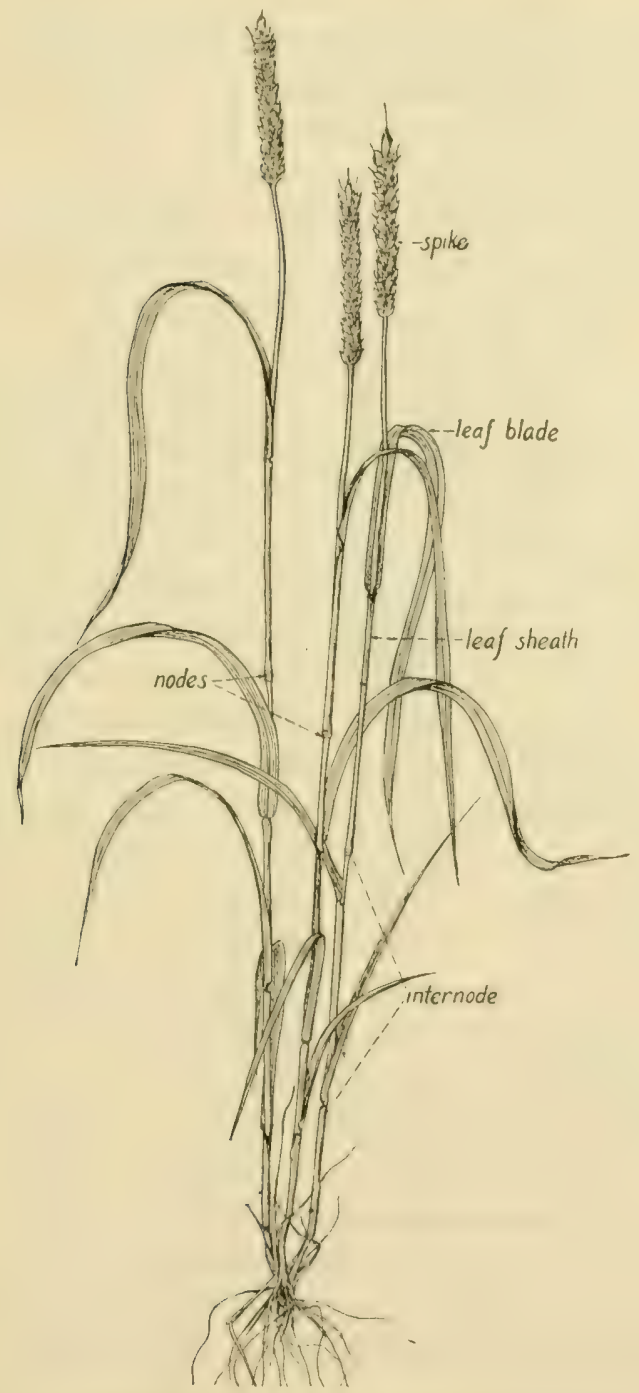

FIG. 25.- Wheat plant showing the general habit of grasses. 
leaf which is wrapped about the stem) of the first few leaves, or spring freely from underground stems. They may also arise from joints above the ground line, as in corn. If such aerial roots reach the ground they may serve as supporting or "prop" roots (Fig. 56).

Stems.-General Characteristics.-The stems of grasses are called culms. They are cylindrical (rarely flattened),

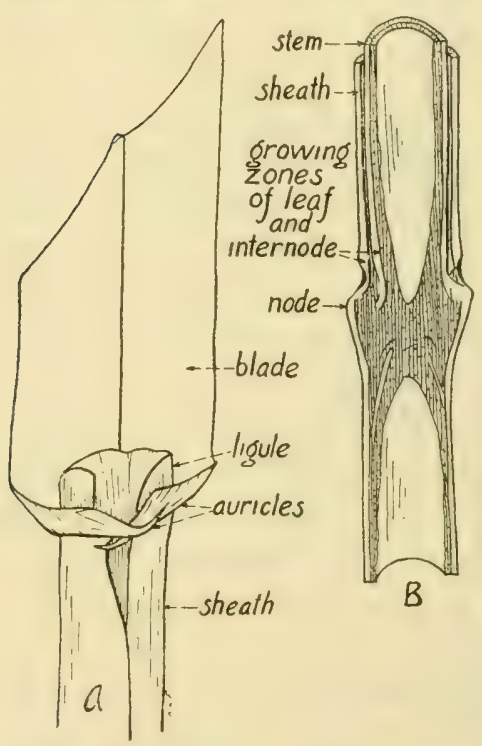

FIG. 26.-Barley. A; portion of leaf at juncture of leaf and blade; $B$, stem cut in median lengthwise section. $\times 21 \frac{1}{2}$. and divided into sections (internodes) (Fig. 25) which are usually hollow, but sometimes filled with pith, as in corn. When young, the internodes are solid, but, as the stem enlarges, the central portion is ruptured and a hollow is formed. The nodes (Fig. 25), the enlarged joints between the internodes, are solid. Enlargement of the nodes is due partly to a thickening of the leaf base at each node (Fig. 26) and partly to enlargement of the stem itself. In most grasses, the part of the culm within the sheath remains soft and continues to grow or retain the power of growth after the portion not in the sheath has ceased growth, or lost the ability to grow. The youngest part of each internode is at its base, surrounded by the basal swelling of the leaf sheath (Fig. 26). Each internode has its own growing zone.

Lodging.--It is customary to speak of a grass as "lodged" 
when its stems are bent over and caused to lie on the ground by the mechanical action of a high wind, or driving rain. Some grasses lodge more easily than others. This may be due either to their greater height, heavier fruiting head, or to a lack of strengthening material. Moreover, it has been shown that an excessive amount of available nitrates in the soil favors lodging. As it has been demonstrated that the application of nitrate fertilizers to a soil tends to suppress the amount of silicon taken in by the wheat plant, the greater frequency of lodging of plants grown on such a soil may result from a stem weakness caused by a lack of silicon within them. However, the causes of lodging are not well known.

The stems of lodged grain are not necessarily broken. The reverse is the case, as is shown by the fact that the lodged culm has the power of partially or entirely erecting itself. This power is exhibited more strongly in growing or immature culms than in old ones. When a grass stem is lodged, the cells on the lower side of each internode, at its base, grow more rapidly than those on the upper side, and, hence, the stem curves upward. This behavior is a response to the stimulus gravity. The manner in which gravity acts upon an organ as a stimulus has not been demonstrated. However, it has been experimentally determined that all plants make pronounced adjustments in their growth in response to gravitation. This property is called geotropism.

Tillering.- It is a common observation that trees, shrubs and most herbaceous plants produce side branches in regular order, and that these arise at the nodes along the stem. The side branches of the grasses are not so obvious as those in trees and shrubs, for example, for the reason that the culms of most grasses produce branches from the lower nodes only. This branching in grasses is known as "stooling," "tillering," or "mooting." The individual branches are known as " tillers" 
(Fig. 27), and the entire mass of branches is the "stool." Common cereals, such as wheat and oats, invariably produce a number of tillers, sometimes as many as 50 . The tillers from the primary culm may produce tillers (lateral branches) and these in turn other tillers, so that under favorable conditions several dozen culms may result from a single seed. As the internodes are much shortened, the branches

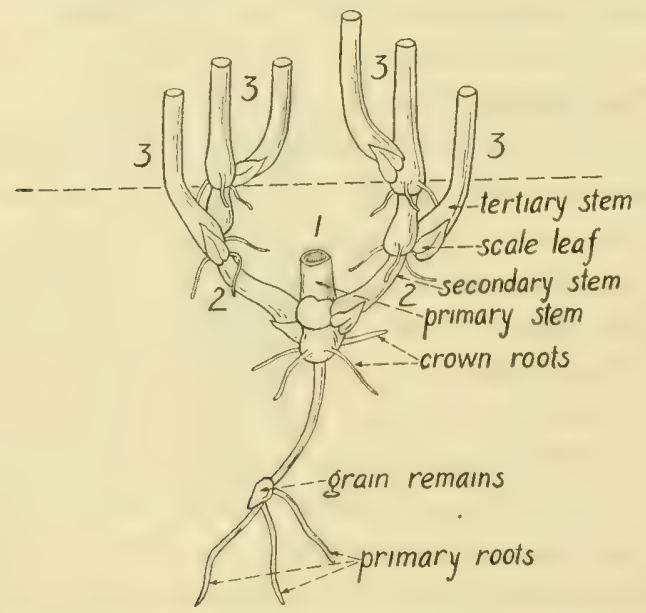

FrG. 27.-Diagrammatic representation of tillering in cereals.

(After Schindler.)

appear to come out at one point. In the wheat plant, two or three weeks old, three or four buds may be found, one in the axil of each leaf. Tillering results from the outgrowth of these lateral buds.

Tillering activity varies with the species, the individual, and environmental conditions. In general, winter grains tiller more than summer ones. It is dependent especially upon the depth of seeding. There seems to be an optimum depth, which varies with the sort of grass. The average depth of the tillering node in cereals is about $\mathrm{I}$ to 2 centi- 
meters. 'Tillers are produced freely in moderately warm, sandy soil. The number of tillers is also increased by a large amount of reserve material in the seed, and by high soil fertility, and by thin seeding. The effect of this last factor is well shown in the following data taken from the Nebraska Experiment Station Bulletin г 7 :

Tillering of OATs

\begin{tabular}{|c|c|c|}
\hline $\begin{array}{l}\text { Pecks of seed sown per } \\
\text { acre }\end{array}$ & Stems per 100 plants & $\begin{array}{c}\text { Total number of stems } \\
\text { per acre }\end{array}$ \\
\hline 4 & 466 & $1,419,000$ \\
\hline 8 & 279 & $1,732,000$ \\
\hline 16 & I 40 & $2,283,000$ \\
\hline
\end{tabular}

- The production of tillers in the small grains is altogether desirable from the farmer's standpoint, as it is an important factor determining yield.

Bulbous Grasses.- In a few species such as timothy (Phlcum pralcnse) and tall oat grass (Arrhenatherum elatius), some of the lower, short internodes are enlarged into bulblike bodies containing a store of nourishment.

Rhizome-bearing Grasses.-Perennial grasses usually have rhizomes or rootstocks, horizontally elongated underground stems, which give rise to erect annual stems that bear foliage leaves and flowers. These underground stems are very efficient as reproductive organs, for, as a result of their elongation in the soil, the plant is able to invade areas already occupied by other plants. Furthermore, each rootstock is capable of budding a new plant at every node, and should it be dragged from the ground by cultivating machinery and broken into a number of separate pieces, each piece will give rise, under favorable conditions, to a new plant. Quack grass (Agropyron repens), and many other of our 
worst weeds, owe their obnoxious character mainly to the possession of rootstocks. Such plants are not dependent upon seed production alone, but in addition spread by means of their rootstocks. The rootstock is a storehouse of food material, and although the leaves and stems above ground may be destroyed, new shoots are sent up from it, drawing upon the stored food supply. For this reason, perennial weeds of all kinds are difficult to eradicate. Any method of elimination adopted is based upon the knowledge that the food stored in the underground stems is made in the green leaves; therefore, the development of green leaves must not be allowed.

Rhizomes of grasses bear brown or colorless sheathing scales (rudimentary leaves) containing in their axils active buds which may develop into erect stems. Under favorable conditions, roots are produced at the nodes of the rhizomes. Grasses possessing rhizomes are rhizomatous.

When the internodes of the rhizomes are very short, the culms are close together, and the grass is known as a tufted grass or as bunch grass, as in meadow fescue (Festuca pralensis). Many of our most valued range grasses have the bunch habit. When the internodes are long, the culms are more widely separated, and a creeping grass, as awnless brome grass (Bromus inermis), is the result.

Stoloniferous Grasses.-When the horizontal stems are at or above the surface of the ground, they are called rmmers or stolons, as in buffalo grass (Buchloe dactyloides). Outside of the grass family, the runners or stolons of strawberry are very typical. Stolons are about as effective as rhizomes in propagation. They usually produce a more open, loose tuft. This is due to the long internodes. Stoloniferous grasses do not produce as solid and uniform a turf as most rhizomatous grasses. Neither is it likely that the former would produce a 
sod that would be as enduring under conditions affecting the sod surface, such as heavy trampling or close grazing.

Leaves.-Gencral Characteristics.--In grasses, a single leaf arises at each node. Leaves disposed in this fashion along a stem are said to be alternate. If one starts with a certain leaf, the leaf next above or next below, is on the opposite side of the stem, $180^{\circ}$ around the circumference. This arrangement gives two vertical rows of leaves opposite each other on the stem. Such an arrangement is said to be two-ranked, distichous, or one-half spiral. We shall have occasion further on to discuss other leaf arrangements, and to emphasize the fact that leaves are developed on a stem in a definite order.

The grass leaf in general appearance is unlike that of such common plants as apple, cottonwood, maple and beet. In these the leaf has a definite, narrow stalk or petiole and an expanded blade (Fig. I 59). The grass leaf is divided into two distinct parts, sheath and blade (Fig. 26). The sheath represents the leaf base, and forms a tube around the culm. At the base of the leaf sheath, there is a distinct swelling. The more or less flattened part of the leaf which spreads away from the culm is the blade (Iamina). The blades are parallel-veined, that is, have many veins, about equal in size, running parallel, and joined by inconspicuous veinlets. Parallel venation is characteristic of the leaves of grasses, sedges, rushes, lilies and most all other monocotyledonous plants.

Growth of Leaves.-In the early life of the grass plant, leaves grow faster than internodes. This results in a tuft of leaves. Some leaves elongate indefinitely. The tip of the leaf blade is the oldest portion. The growing point is at the base of the blade. This growing zone, as a rule, is marked by a whitish or light green semicircle (Fig. 26). 
The upper portion of the leaf may therefore be removed without permanent injury to the plant. This is well shown in the rapid recovery of the leaves of lawn grass after mowing, and of pasture grasses after grazing.

Scales and Bracts.- Reduced leaves in the form of scales and bracts occur in grasses. Such reduced leaves are termed "scales" when they appear lower on the stem than the foliage leaves, and "bracts" when higher. For example, the reduced leaves at tillering nodes are "scales" (Fig. 27), while the reduced leaves (glumes) in the inflorescence are "bracts" (Fig. 28). Scales and bracts seldom possess chlorophyll (green coloring material in plants), and, hence, are incapable of carrying on synthesis of carbohydrates. The scales and bracts in grasses have the same one-half spiral arrangement as the foliage leaves and although they may be very close together on the axis, careful observation shows them to have this typical arrangement of all grass leaves.

Ligule.-At the junction of the sheath and blade is a membranous or cartilaginous ring or fringe, the ligule (Fig. 26). It is next to the culm, and varies in size, shape, and hairiness in different species of grasses. The ligule is sometimes absent.

Auricle (Fig. 26).-This is a more or less pointed, thin, ear-like structure projecting from the leaf edge at the junction of sheath and blade. It often clasps the stem but may be more or less twisted and bent away from it. It varies greatly in size and shape. In the tribe Horder, the auricles are characteristic. They are entirely absent in some species.

Inflorescence.-The grass inflorescence (flower cluster) consists of a number of groups of flowers, each group being called a spikclet. The spikelet is, in fact, the unit of the 
grass inflorescence. 'The spikelets are attacherl ('ither directly or indirectly to a main axis, the rachis (Fig. 28).

The three common sorts of grass inflorescences are the spike, panicle, and raceme. When the rachis is unbranched, so that the spikelets are not borne on individual stalks, but are attached directly (sessile) to the rachis, the result is at spike. The inflorescences of wheat, barley, and rye are good examples of spikes. Usually, each culm bears a single spike. In the raceme, each spikelet is borne on a short branch of the rachis, as in sheep's fescue (Festuca ovina). In the panicle, the primary branches of the rachis branch one or more times (Fig. 44). These branches may be long and widely spreading, as in oats and brome grass, or short and rather appressed to the rachis, as in timothy, meadow foxtail (Alopecurus), and Kocleria.

Different types of inflorescences besides the spike, raceme and panicle will be met with in some of the following

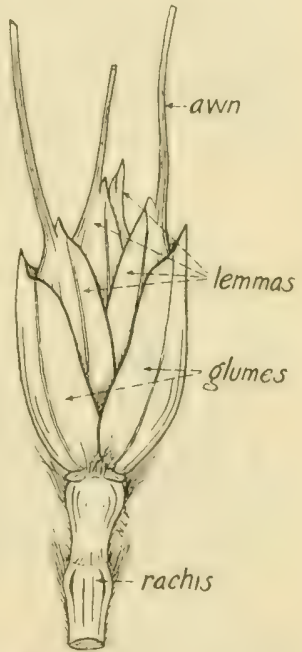

FIG. 28.--Single spikelet of common wheat (Triticum restivum). $\times 2$. families. We shall also see that these three types are not confined to the grass family; but are in fact exceedingly common among seed plants of all kinds.

Spikelet.-The spikelet is the unit of inflorescence in grasses. A typical spikelet, such as that of oats (Fig. 46), or wheat (Fig. 28), for example, consists of a shortened axis, the rachilla, bearing a number of chaff-like, two-ranked (distichous), overlapping bracts (glumes of some authors). The two lowermost bracts are empty, that is, do not bear flowers in their axils. Fig. 29 shows a dissected wheat 
spikelet with its parts removed in order. Each spikelet is subtended by these two empty bracts. Following the suggestion of Piper, we shall designate these two basal, empty bracts as "glumes." The lower of these is the "first glume," the upper the "second glume." Above the two glumes, on the rachilla, are one or more bracts; each one of these is known as a lemma (flowering glume and inferior palea of some authors). Normally, there is a flower in the axil of each lemma. Opposite each lemma is a two-nerved, twokeeled, bract-like structure, the palet (the palea, prophyllum,

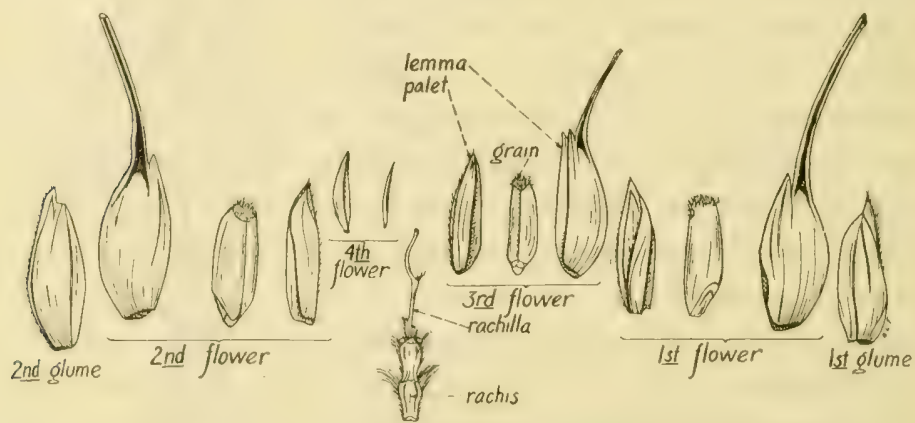

FIG. 29.--Spikelet of common wheat (Triticum æestivum) dissected, the parts removed in order.

bracteole, and superior palea of some authors). Its back is turned toward the rachilla. It frequently envelops the other parts of the flower with its infolded edges. The palet is never awned (bearded). While the glumes and lemmas are inserted on the rachilla, the palet is inserted on a very short flower stalk (pedicel). At the base of the ovary, on the side opposite the palet, are two minute scales, the (anterior) lodicules (Fig. 30). Inside the palet, and placed farther up on the flower stalk, are three stamens and a single pistil. Thus we see that in the typical spikelet there are two glumes 
subtending one or more lemmas; in the axil of each lemma is a flower, and each flower consists of a palet (outer perianth), two lodicules (inner perianth), three stamens, and a single pistil. Each stamen has a large anther. 'The filament (stalk) is attached at the base of the anther, but on account

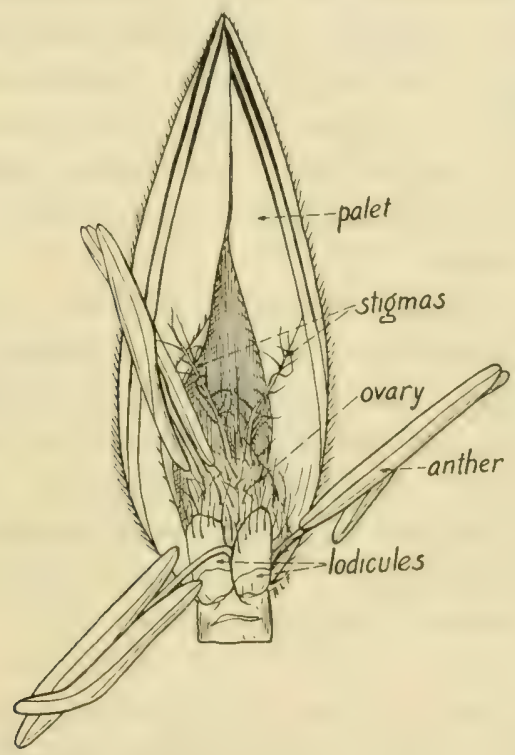

FIG. 30.-Wheat flower with lemma removed; considerably magnified.

of the extreme sagittate nature of the latter, it appears versatile. The ovary is one-celled, one-seeded, bears two. styles and two feathery stigmas.

There are many deviations from the typical form of spikelet. In Colcanlhus, the empty glumes are absent; in Vardus, solitary; in Homulocenchrus, mere rudiments. In some $A$ grostis species, the palet is rudimentary. It is not always two-keeled, but generally two-nerved. There is a third (posterior) lodicule in some grasses. Although the stamens are as a rule three, there are six in most bamboos and in rice (Orysa). In Sireplochete and Ory $\approx a$ (occasionally), there are three styles, and only one in Nardus. 
'I'he awns or beards are brittle-like structures on lemmas or glumes, usually on the former. They are commonly terminal, as in wheat, or dorsal (attached to back of lemma), as in oats. Zoebel and Mikosch, working with two-rowed and six-rowed barleys, arrived at the conclusion that awns are transpiring (water-losing) organs. They noted that bearded barley spikelets transpired more than artificially beardless ones of the same sort under similar conditions. They also observed that, at the time of kernel development, transpiration from the spikelet was most intense, probably corresponding to the time of greatest movement of reserve material to the kernel.

Up to i9o6, Hackel reports 67 species of cleistogamous grasses. As compared with flowers that open, cleistogamous ones generally have reduced lodicules, smaller anthers, a shorter pistil, and less pollen. In a few cases (Panicum clandestinum) for example, chasmogamous spikelets and cleistogamous spikelets may occur in the same inflorescence. According to Koernicke, two-rowed erect-eared barley (Hordeum distichon erectum) bears only cleistogamous flowers.

Pollination.-Wind is the chief agent in the dissemination of grass pollen. In all grasses the pollen is light and dry, and hence easily blown. Insects play a very unimportant part in this process.

Most grass flowers open to shed their pollen, that is show chasmogamy. In some grasses, however, the glumes do not spread apart, thus allowing the stamens and pistils to become exposed. Flowers that do not open are said to show cleistogamy.

Fruit.--In all grasses, the fruit is one-seeded, dry, and does not split open at maturity to allow the seed to escape. The pericarp (ovary wall) is firmly attached to the seed coat. 
The grass fruit is called a grain or caryopsis. There is an abundance of starchy endosperm. Sometimes the grain is closely adherent to the palet and lemma, as in most barleys and oats.

Phylogeny of Grasses.--The history of the evolution of a group of organisms is phylogeny. What is the origin of the grasses? Are they primitive forms, the progenitors of such closely related groups as the lilies and other common monocotyledonous plants; or are they a reduced group? By those who hold the latter view, which is more widely accepted, grasses are considered to have come from lily-like plants by a reduction and modification of a number of parts of the flower. Examination of the floral diagram of a typical lily flower is shown in Fig. $3 \mathbf{I}$. It has two sets of floral segments (which together constitute the perianth) which alternate, two whorls of stamens, three in each whorl, and a pistil divided into three chambers, hence tri-carpellary. The stamens of one whorl alternate with those in the other; those of the outer whorl alternate with the inner segments of the perianth. The three carpels alternate with the inner stamens. In Fig. $3 i$ is shown the floral diagram of
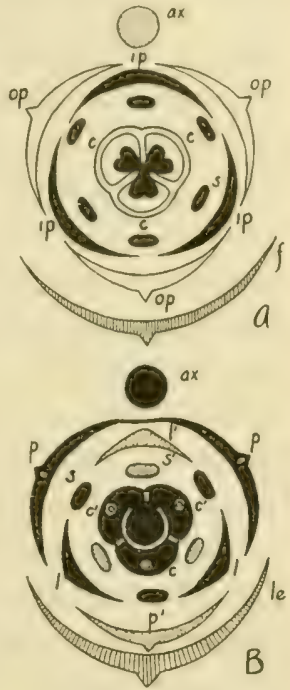

FIg. 31.-Diagram of $A$ lily flower, and $B$ grass flower showing homologous structures. $A, f$, bract; $a x$, axis; $o p$, outer perianth; ip, inner perianth; $s$, stamens; $c$, tricarpellary ovary. $B$, shaded structures are aborted; le, lemma (bract); ax, axis; $p$ and $p^{\prime}$, palet (outer perianth); $l$ and $l^{\prime}$, lodicules (inner perianth); $s$ and $s^{\prime}$, two whorls of stamens; $c$, tricarpellary ovary. (B after Schuster.) a grass flower with the rudimentary or missing parts shaded. According to the view that grasses are reduced lilies, there was a reduction in the lobes of 
the pistil from three to one, a loss of one whorl of stamens, and a reduction in the number of perianth lobes.

Although commonly assumed to be one-carpelled, the grass pistil is really tri-carpellary. This latter view is held by a number of morphologists (Doell and Goebel), and recently has been quite conclusively demonstrated by Walker and Schuster. In all grasses, the pistil has three fibro-vascular bundles. Two of these extend to the style branches and the third (dorsal) extends to the dorsal lobe of the pistil or to the third rudimentary style branch, when present. This third bundle bears the ovule. In Streptochata and Bambuse, there are three styles. Furthermore, it should be noted that the three vascular bundles stand in regular alternation with the second whorl of stamens and the inner whorl of the perianth.

Rowlee, in a study of Arundinaria, a bamboo, concluded that the lodicules represent the inner perianth whorl. The common view, as presented by Hackel, has been that lodicules are bracts. Schuster's researches substantiate those of Rowlee. He finds that, although two lodicules is the common number, a third (anterior) one occasionally occurs (in Bambusx); that the two (posterior) lodicules are not bound together at first but originate separately; that in one grass genus (Streptoclaaeta), at least, the three lodicules are independent. From these studies, it appears that the lodicules, morphologically, are to be considered as the inner perianth whorl. The same worker (Schuster) considers the palet to represent the outer perianth whorl of this lily-like flower. The palet is usually two-keeled or two-nerved. There are cases in which the palet is divided into two parts, and in which there is a third part in a rudimentary condition. In the majority of grasses, the two parts of the palet arise from separate primordia, later growing together to form a single 
structure; the third, outer perianth whorl aborts. In this comnection it should be noted that the paled of cinkorn (Triticum monococomm) divides into two parts, at maturity. on the merlian line, each half bearing a keel (Fig. 37).

According to the view presented above, the grass spikelet is interpreted as a modified branch, bearing a number of distichous bracts. The two lower bracts (glumes) are sterile. The flowers occur in the axils of the lemmas. The flower is of the lily type. The outer perianth whorl is represented by the palet, the inner by the lodicules; one whorl (inner) of stamens (usually, not always) is aborted; the pistil is three-carpelled. Hence, we see that grasses are derivates of a normal monocot flower.

Grass-like Plants.-Grasses are closely related to the sedges (Cyperacee). Sedges, however, have solid stems, usually three-angled, leaves with closed sheaths, and the fruit an achene. In the achene the pericarp or mature ovary wall is not firmly grown to the seed coat which immediately adjoins on its inner surface. The achene and the grain are both dry, one-seeded fruits that do not split (dehisce) at maturity, but in the grain the mature ovary wall is closely adherent to the seed coat. In grasses, as pointed out on page 77. the leaves are two-ranked or distichous. In sedges, however, the leaves are three-ranked, or one-third alternate. Sedges grow in wetter situations than grasses and are often harsher in texture, due to the deposition of silica in the stems and leaves. There are certain rushes (Juncace(e), other than rush-like sedges, which are grasslike in appearance. These, however, are distinguished from the grasses by the presence of a perianth of six distinct glumelike segments. 


\section{References}

Baillon, H.: L'evolution de l'inflorescence dans les Graminees. Bu\} Soc. Linn. Nord, France, I894, II23-II28.

BRUNS, E.: Der Grasembryo. Flora, 76: $1-33,1892$.

Chase, Agnes: Notes on the Cleistogamy of Grasses. Bot. Gaz., 45: 135I36, I908.

DoELl.: Untersuchungen über den Bau der Grasblute. Jahresber. Mann. Ver. f. Naturk., r868, xxxiv and I8jo, xxxvi.

Goebel, K.: Ein Beitrag zur Morphologie der Graser. Flora, I895, Erganzungsband.

Guerin, P.: Recherches sur le development du tegument seminal et du pericarpe des graminees. Ann. Sci. Nat. Bot., 9: I-59, I899.

HAckel, E.: Über das Aufblühen der Graser. Bot. Ztg., 33: 432, I880. Untersuchungen über die Lodiculie der Graser. Engler's Jahrb., r: $33^{6-}$ $36 \mathrm{r}, \mathrm{I} 88 \mathrm{r}$.

The true grasses. Transl. from German by F. L. Scribner and E. A. Southworth. Henry Holt \& Co., New York, I89o.

Über Kleistogamie bei den Gräsern. Osterr. Bot. Ztschr., 55: 8I-88, I43-I54, I80-I86, I906.

Hгтснсоск, A. S.: A Text-book of Grasses with Especial Reference to the Economic Species of the Unites States. The Macmillan Co., New York, I9r4.

Jumelle, Henri.: Note sur la constitution du fruit des Graminees. Compt. Rend. Acad. Sci. (Paris), 107: 285, 1888.

Kennedy, P. B.: The Structure of the Caryopsis of Grasses with Reference to Their Morphology and Classification. U.S. Dept. Agr., Div. Agros., Bul. I9, I900.

Lamb, William H.: The Phylogeny of Grasses. Plant World, 15: 264-270, I9I2.

Piper, C.: The Terminology of the Parts of the Grass Spikelet. Science, n. S., 23: 789-790, 1906.

RowleE, W. W.: The Morphological Significance of the Lodicules of Grasses. Bot. Gaz., 25: 199-203, 1898 .

Schuster, Julius: Über die Morphologie der Grasblüte. Flora, IO0: 213266, I9IO.

WALkeR, E. R.: On the Structure of the Pistils of Some Grasses. Thesis, Univ. Nebr., Igo6.

Ward, H. Marshall: Grasses, a Handbook for Use in the Field and Laboratory. Cambridge, I9or.

True, Rodney: On the Development of the Caryopsis. Bot. Gaz., i8: 212-226, I 893 (contains bibliography on development of grain). 


\section{CEREALS}

Cereals are those grasses which are grown for their grain. Buckwheat is sometimes considered a cereal because its fruit (achene) is ground into flour, but it is not so considered here.

Buckwheat, flax, and others, which are often raised for their seed or fruit, but are not grasses, are discussed wherever they happen to come in the botanical order of treatment followed here.

\section{Key to Groups (Genera) of Important Cereals ${ }^{1}$}

1 What is a "key," and how is it used? 'Throughout the following pages there will be a number of "keys." A "key" is a convenient form for distinguishing one plant from another, or one plant group from another. It presents in concise form the principal differences between the plants con sidered. It also enables one to determine the proper classification of an unknown plant. Most of the "keys" in the following pages are "artificial," that is, the characters used are obvious ones. The "keys" herein are constructed on the dichotomous plan, i.c. by twos. The entire number of groups under consideration, whether these be species, genera, families, or higher divisions, is first divided into two subgroups; each of the subgroups is subdivided into two groups, and so on. The alternatives are equally indented on the page. In the key to the genera of cereals, they are first divided into) two large groups, the first including Zea, Oryza, Andropogon and Millets: and the second, Avena, Secale, Triticum and Hordeum. It is seen that those genera of the first group have "spikelets falling from the inflorescence entire . . "while those of the second group have "spikelets falling from the inflorescence without the glumes. . ." Each of the two large groups is again separated into two subdivisions. For example, the genera diena, Secale, Triticum and Hordeum, are subdivided on the basis of their inflorescences. Avena has a panicle inflorescence, while Sccale, Triticum, and IIordeum have a spike inflorescence.

Let us suppose that we have a cereal in hand, the genus of which we wish to determine. First of all, it would be necessary to decide whether the "spikelets fall from the inflorescences entire... . ;" or "spikelets fall from the inflorescence without the glumes . . . ;" if it has the characters of the second alternative, we know it is either oats, rye, wheat or barley. Should the specimen in hand have a spike inflorescence, oats is eliminated from consideration, and the plant must be either rye, wheat or barley. If, 
by examination of this unknown plant, we find now that there are "three spikelets at each joint of the rachis," it must belong to the genus Hordcum (barley).

The "key" shows many of the characteristics of a group. Consider Triticum (wheat), for example. One can see by the key that "spikelets fall from the inflorescence without the glumes, which remain attached to the rachilla; spikelets one-many-flowered; rachilla often produced beyond the upper glume; grain with a longitudinal furrow; tuft of hairs at tip of ovary." Furthermore, that the "inflorescence is a spike"; that there is "one spikelet at each joint of the rachis," and the "glumes are not bristle-like, but broad."

Spikelets falling from the inflorescence entire (glumes attached to grain), oneflowered, or if two-flowered the lower one staminate; rachilla not produced beyond the flowers; grain without a longitudinal furrow; no tuft of hairs at tip of ovary.

Flowers staminate and pistillate; borne in separate inflorescences on the same plant, i.e., monœecious (Fig. 57), Zea (maize or Indian corn).

Flowers perfect or staminate; when the staminate are present, borne in same inflorescence with perfect.

Spikelets much compressed laterally (Fig. 75), Oryza (rice).

Spikelets cylindrical or somewhat compressed dorsally.

Lemma and palet thin and papery, much more delicate in texture than the empty glumes (Fig. 7I), Andropogon (sorghum, milo, broom corn, etc.)

Lemma and palet, at least of perfect flower, never thin and papery, parchment-like or leathery, hard and shiny, very different in color and appearance from the glumes (Fig. 83), Chretochloa, Echinochloa, Panicum, Pennisetum (millets).

Spikelets falling from the inflorescence without the glumes, which remain attached to the rachilla; spikelets one to many-flowered; rachilla often produced beyond the upper glume (Fig. 47); grain with a longitudinal furrow (Fig. 34); tuft of hairs at tip of ovary (Fig. 34).

Inflorescence a panicle (Fig. 45), Avena (oats).

Inflorescence a spike.

One spikelet at each joint of rachis.

Glumes bristle-like (Fig. 55), Secale (rye).

Glumes not bristle-like, broad (Fig. 28), Triticum (wheat).

Three spikelets at each joint of rachis (Fig 49), Hordeum (barley).

\section{Key to Small-grain Seedi.ings ${ }^{1}$}

1 This key is taken verbatim from Carrier. The "collar" is a narrow band, usually of different color from the sheath and blade, at the junction of leaf and blade. The "claw-like appendages" are the auricles. 
Collar without claw-like appendages, Oats (Avenu sativa).

Collar with claw-like appendages which clasp the stem more or less.

Claws hairy.

Sheaths and blarles finely pubescent, soft, and velvety, Emmer (Trilicum dicoccum).

Sheaths and blades not pubescent.

Collar and claws large, Spelt (Trilicum spelta).

Collar and claws slender, Wheat (Triticum astivum).

Claws not hairy.

Collar and claws large and prominent.

Nerves of blades not prominent, upper surface rough, Barley (IIordeum sativum).

Nerves of blades broad and prominent, smooth on upper surface, Polish wheat (Triticum polonicum).

Collar and claws slender.

Blades and sheaths sparsely hairy, Rye (Secale cereale).

Blades and sheaths free from hairs, Durum wheat (Triticum durum).

\section{References}

A.ronsonn, A.: Über die in Palistina und Syrien wildwachsend aufgefundenen Getreide-arten. Verhandl. K. K. Zool. Bot. Gesell. Wien., 59: $385-590$, r 909 .

Contribution á l'histoire des cereales. Bul. Soc. Bot. (France), r9og.

Atterberg, A.: Die Nachreife des Getreides. Landw. Versuchstat., 67 : I29-I43, I907.

Carleton, M. A.: The Small Grains. The Macmillan Co., igr6.

C.arrier, Lymax: The Identification of (rrasses by Their Vegetative (haracters. U. S. Dept. Agr. Bull. 46r: 1-30, 1917.

I)FHer.IN UXD DtpoNt: C'ber den Crsprung der Stärke im Getreidekorn.

Comp. Rend. Acad. Sci. (Paris), 133:774, 1902.

Desriot, A.: Les cereales, 2 ed., Paris, Igro, Hachette et cie.

Eкkert, F.: Über Keimung, Bestockung und Bewurzelung der (ietreidearten. Inaug. Diss. Leipzig, I873.

Fruwrth, C.: Das Blühen des (ietreides. Jahrb. Deut. Landw. (iesell., $22: 68-75,1907$.

Frowrth, W: Die Ziichtung der landwirtschaftlichen Kulturpflanzen. Berlin, Igro.

Koernicke, I: and Werner, H.: Handbuch des Getreidesbaues. I. Dic Arten und Varietäten des Getreides. II. Die Sorten und der Anbau des Getreides. Berlin, I885.

Über die Entstehung und dats Verhalten neuer Getreidevarietiten. Archivs für Biontologie, ז908. 
KraUS, C.: Die Lagerung der Getreide. Stuttgart, I908.

Knissing, L.: Untersuchungen über die Keimung der Getreide. Landw. Jahrb. (Bayern), I: 449-5I4, I9ri.

KudelKa, F.: Über die Entwicklung und den Bau der Frucht und Samenschale unserer Cerealien. Landw. Jahrb., 4: 46I-478, I875.

Hitier, H.: Les cereales secondaires. Seigle, Mais, Sarasin, Millet, Rhiz. Paris, rgro.

Hofrman: Das Getreidekorn. Berlin, I9I2.

Hunt, T. F.: The Cereals of America. Orange Judd Co., New York, I905. Nowackr, A.: Anleitung zum Getreidebau, IV. Berlin, I905.

Rrmpau, W.: Das Blühen des Getreides. Landw. Jahrb., I882 (contains the old literature on the blooming of grasses).

Untersuchungen über die Bestockungen des Getreides. Jahrb. Deut. Landw. Gesell., rgo3.

Schindler, Franz: Der Getreidebau. Berlin, I909.

Schmid, B.: Bau und Funktionen der Grannen unserer Getreide-arten. Bot. Centralbl., 76, I898.

Schmid, O.: Über den Entwicklungverlauf beim Getreide. Ein Beitrag zur Sortenkenntnis. Landw. Jahrb., 45: 267-324, I9r3.

Schulz, A.: Die Geschichte der kultivierten Getreide, I. Halle, rgr3.

Scrivlz, B.: Wurzelatlas. Darstellung natürlicher Wurzelbilder der Halmfrüchte in verschiedenen Stadien der Entwickelung. Berlin, Igr r.

Seelmorst, V.: Versuche über die Möglichkeit einer Bewurzelung und Adventivtriebbildung an oberirdischen Knoten von Getreidepflanzen. Jour. Landw., Igo2. 


\section{CHAP'TER X \\ TRITICUM (Wheat)}

Habit of Plant.- Wheat is an annual. Under our cultural conditions, there are two seasonal forms, winter annual, or winter wheat, and summer annual, or spring wheat.

Roots.- Wheat has a fibrous root system. In the germination of the grain, the primary root (Fig. 2) takes the lead; very soon, two secondary roots appear on either side of the primary, thus forming a whorl of three. Later, other roots may be added to these. This whorl constitutes the primary or temporary rool system. It usually dies before the plant is fully grown. Permanent roots appear in whorls at the nodes some distance above the three temporary roots. The first whorl of permanent roots is generally about I inch below the soil surface, no matter at what depth the grain was planted (Fig. 3). In their growth, the whorls of permanent roots curve outward and then downward, taking an almost vertical course. They branch very freely near the soil surface and form within the first foot a fine network, which constitutes a large absorbing surface. However, many of the roots of wheat reach a depth of 4 feet, or even more under favorable soil conditions. Nobbe observed that the aggregate length of all the roots of a one-year-old wheat plant amounts to 500 to 600 meters. The number of roots increases with the number of tillers.

Stems.--The stems of wheat are of the general grass type. In wheat, there are usually six joints (internodes), the sixth being the spike-bearing one. The lowest joint usually re- 
mains short, sometimes less than i millimeter long; the second joint also remains short; the sixth one is the longest.

Leaf. The wheat leaf is of the ordinary grass type. 'The blade varies considerably; the sheath is split; the ligule is thin and transparent; the auricles are conspicuous, although not as prominent as those in barley.

Inflorescence.-Wheat flowers are arranged in spikelets and the spikelets into a "head" or spike (Fig. 38). The spike varies in size, compactness and form in the different types of wheat. Fifteen to twenty fertile spikelets in a head is a fair average, but spikes have been observed with a number considerably greater. An abundance of water in the soil during the early stages of development has been found to increase the number of spikelets in a head. The rachis or main axis of the spikelet is zigzag in shape (Fig. 48). Each joint of the rachis is flattened and curved, the concave surface being on the side next to the spikelet. There is but one spikelet at each joint of the rachis. There are usually numerous short so-called "basal hairs" at the base of each spikelet. The lower spikelets of the head are often sterile; less frequently, the terminal spikelet is sterile (as in einkorn).

Spikelet.-The number of flowers in a wheat spikelet varies from two to five. It has been shown that the number of flowers that reach maturity in a spikelet may be increased by an ample supply of water during the period when the flowers are dereloping. It is quite probable that there is a "critical period" in the life of the plant at which time the supply of moisture coming to the plant has the maximum effect in the production of flowers. This critical period is probably during the early stages of flower formation, quite a while before the time of heading.

The wheat spikelet dissected in Fig. 29 has four flowers, three of which have matured grain. The fourth flower is 
sterile. In lig. 28 , the lemmas of four flowers are visible. As a rule, but two grains mature. In some varieties, most of the spikelets mature three grains, and less frequently four.

The glumes are broal, varying much in shape, color, smoothness or hairiness, width and distinctness of kecel. length and sharpness of tip. It has been shown that, in general, the second kernel of a spikelet is the heaviest, the first next heaviest, then the third, fourth, etc.

Flower (Fig. 30). - There are three stamens with threadlike filaments and rather large anthers. The single ovary has two feathery stigmas. There are two lodicules. As was pointed out on page. 84 , the palet represents the outer perianth whorl, and the lodicules the inner perianth whorl.

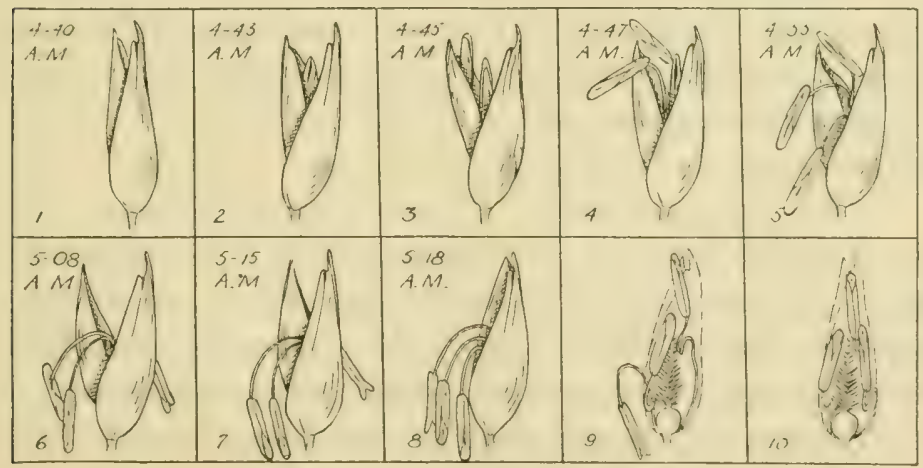

FIG. 32,-Opening of wheat flower. (After Hays.)

Opening of Flower and Pollination.-Hays has shown (in a variety of spring wheat) that the flowers open early in the morning, the entire process of pollination taking place within about an hour (Fig. 32). Fruwirth notes that, in warm weather, blooming begins at 4:30 a.m., and continues at a rapid rate until 5:30 $\mathrm{a.m}$. From this latter hour until ():00 
a.m., there is less blooming; this is followed by a period from 9:00 a.m. to 10:00 a.m. of more rapid blooming, which in turn is followed by an interval of less rapid rate up to $2: 30$ p.m.; after this there is an increase in the rate again until 3:30 p.m., and from this hour up to $7: 00$ p.m., only a slight amount of blooming takes place. Fluctuation in the time of blooming is less noticeable in einkorn than in other wheats, and less marked on sultry days following rainy days in all types of wheat. Polish wheat shows the most marked fluctuations. Temperature and moisture are certainly the important external factors determining the time of blooming. There appears to be considerable variation even in the same variety.

It is stated that the swelling of the lodicules brings about the separation of the lemma and palet and hence the opening of the flower. Grass flowers in which the lodicules are membranous or wanting remain closed, while those in which there is only slight swelling of the lodicules open but to a small extent.

In the unopened wheat flower, the filaments are short, the stigmas erect and in contact. The palet and lemma separate, first slowly and then quickly. The filaments then elongate rapidly, pushing the anthers up and outside of the glumes. The anthers are shedding pollen before the flower is fully open, and they continue to do so until it closes again. All three anthers do not always protrude from the flower, and, in some instances, none may escape before the flower closes. The first flowers to open are those situated about one-third of the way from the tip of the spike. The others follow in succession above and below this point. Each flower remains open from a half hour to one hour. The head completes its flowering usually in several days.

In northern cold or wet climates, close pollination (auto- 
$g(a m y)$ is the rule in nearly all wheats. I) urum wheat, how ever, has the habit of cross-pollination (xenogamy), and it has been suggested that this behavior is partly responsible for its better adaptation to dry climates, and for its greater disease resistance and vigor. Cross-pollination is quite common in the primitive wheat, which is an inhabitant of a dry, warm country. It appears that cross-pollination is the rule in hot, dry localities, such as certain parts of India.

Artificial Cross-pollination.-One of the chicf means of wheat improvement is hybridization. This necessitates the operation of artificial cross-pollination. In this process, the glumes of the flower of the female parent are spread apart and the three stamens removed; this is done just before the anthers are mature. On the same day, or on the following morning, pollen is taken from the mature anthers of the plant to serve as the male parent, and placed between the glumes of the flower from which the stamens have been removed. The chances are that the pollen will reach the stigma branches of the emasculated flower, germinate, and effect cross-fertilization.

Fertilization and Maturing of Grain.-Brenchley states that fertilization in wheat normally occurs between one and two days after pollination. This interval represents the time necessary for the pollen grain to germinate, and for the pollen tube to grow down through the stigma to the embryo sac in the developing ovule. This interval no doubt varies in different varieties and under different environmental conditions, particularly temperature. Cool weather will retard germination of the grain, and growth of the pollen tube, and thus affect the "setting" of grain.

After fertilization, the embryo begins to develop, the endosperm to store reserve material, and the seed and fruit walls to undergo marked changes. 
Embryo.--In the very young stage, prior to fertilization, the axis of the ovule is parallel with that of the ovary. Soon in its development, the ovule turns so that its micropyle is directed downward (Fig. 33). At first, the young ovule does not fill the ovary cavity, but soon does so by further growth. The ovule is attached along its side to the ovary. The groove indicates the position and extent of this at-

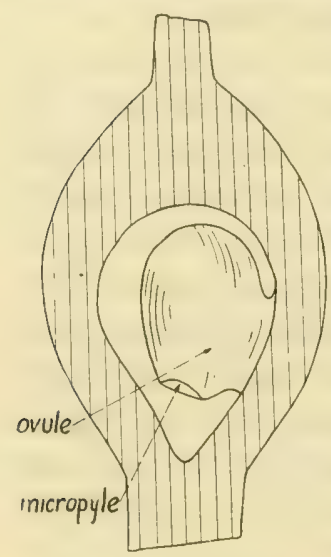

FIG. 33.-Diagrammatic section of young ovary of wheat. (After Bessey.) tachment. The first pair of seminal (seed) rootlets appears in the embryo about four weeks after pollination. About a week later, two other rootlets appear above the first pair, and Brenchley describes a fifth lateral rootlet, which does not appear until quite late.

Endosperm.-In about a week or ten days after fertilization, a definite tissue is formed within the embryo sac. This is the endosperm. About seven or eight days later, the aleurone layer is marked off, appearing first on the dorsal side. According to Brenchley, starch first begins to appear in the "flank" cells about the eleventh day after pollination. Eckerson points out that the actual time of the beginning of deposition depends upon the relative activity of the leaves in making sugar and of the embryo in assimilating it. Infiltration of starch is complete in about five weeks after pollination. It is held that reserve nitrogenous matter enters the endosperm at the same time as the starch.

Grain Coats.-Before fertilization, the grain coats are as follows: 
I. Outer epidermis-one row of cells.

2. Parenchyma layer-many rows of colorless cells.

3. Chlorophyll layer-one row of cubical cells, sometimes two, and several in the groove region.

4. Inner epidermis - one row of small cells.

5. Outer integument-two layers.

6. Inner integument-two layers.

7. Vucellus-several layers of thin-walled parenchyma cells, all bounded by a distinct nucellar epidermis.

The first four regions listed above constitute the ovary wall (pericarp). After fertilization, marked changes take place in these coats. The nucellar tissue, except its epidermis, is absorbed by the enlarging embryo. The outer in tegument (5) and the inner epidermis (4) soon disappear. It first, starch is deposited in the entire ovary wall. It the time of resorption of the ovary wall, deposition of starch within it ceases, and its appearance begins in the endosperm. Resorption of the ovary wall begins in the layer just outside the chlorophyll-bearing layer and extends slowly out to the epidermis. Two to four layers next to the epidermis persist in the mature grain. The chlorophyll cells become longer, lose their chlorophyll, and thicken their walls. In the process of maturation, the ovary wall or pericarp becomes firmly attached to the outer layer of the inner integument of the ovule. This behavior seems to be well demonstrated in all grasses investigater. The firm attachment of the pericarp to the orule distinguishes the grain or caryopsis from the achene.

Ripening Stages.--It is customary to speak of four stages in the ripening of the grain: ( I) milk-ripe or green-ripe stage; (2) yellow-ripe, gold-ripe, or " lough" stage; (3) full-ripe stage, and (4) dead-ripe stage. 
In the milk-ripe or grecn-ripe stage, the embryo is already fully developed. The grain changes from pale green to dark green in color, which change Nowacki explains as being due to the resorption of several layers of the ovary wall, through which the chlorophyll layer now shows. The endosperm cells are filled with a watery sap in which are suspended a number of starch grains; hence, when the grain is squeezed a white, milky juice comes out.

In the yellow-ripe, gold-ripe, or "dough" stage, the cells of the ovary wall become thicker. The lumina of inner integument cells decrease in size, due to an increase in the thickness of their walls. The color of the grain changes from green to yellow, and the endosperm becomes tough and waxy.

The full-ripe stage follows close upon the preceding. As a result of water loss, the different cell layers become distorted. The grain becomes harder and firmer. Grain is usually harvested while in this stage.

If the crop is now left in the field, the grain becomes brittle; it is then said to be in the dead-ripe stage.

Nowacki gives the following analyses of grains of wheat at different stages of development:

\begin{tabular}{|c|c|c|c|}
\hline & $\begin{array}{c}\text { Water content } \\
\text { of grain }\end{array}$ & $\begin{array}{l}\text { Volume of Ioo } \\
\text { grains, } \mathrm{cm}^{2} \text {. }\end{array}$ & $\begin{array}{c}\text { Dry substance } \\
\text { in Ioo grains, } \\
\text { grams }\end{array}$ \\
\hline$\ldots$ & $\cdots-$ & - & —-_- - - \\
\hline Milk-ripe (a) July $9 \ldots .$. & 5 I. 47 & $5 \cdot 3 I$ & 2.86 \\
\hline Milk-ripe (b) July $13 \ldots . .$. & 47.69 & 5.17 & $3 \cdot 58$ \\
\hline & $34 \cdot 37$ & 5.07 & $4 \cdot 44$ \\
\hline Yellow-ripe July $20 . . . .$. . & $25 \cdot 73$ & $4 \cdot 28$ & $4 \cdot 19$ \\
\hline & I $2.9 I$ & 3.08 & 3.80 \\
\hline July $23 \ldots . .$. & 12.97 & $3 \cdot 52$ & 4.22 \\
\hline
\end{tabular}

The maturity of the grain appears to affect its vitality. Kedzie has shown that wheat collected in the dough stage 
yielded 25 bushels per acre; in the full-ripe stage, 30 bushels per acre, and in the dead-ripe, 28 bushels. The dead-ripe stage produced the most vigorous seed, as was determined by the length to which the plumule would grow. For example, in the above experiment wheat collected in the dough stage produced a plumule 9 inches long, in the full-ripe stage IO.I inches long, and in the dead-ripe stage I I inches long. Similar experiments with rye have shown that plants from immature seeds lack vigor, and also that a large percentage fail to germinate. There is some experimental evidence that by continually planting immature seeds an earlier ripening strain may be obtained.

The Mature Grain.--The average weight of roo kernels of common bread wheat is about 3.866 grams. Durum wheats weigh more per roo grains. Although the results are conflicting, there are insufficient positive results to warrant the belief that large plump seeds will give uniformly greater yields than small seeds, especially when such seeds are secured by means of the ordinary fanning mill. It is known that not all the grains in a spikelet are the same size and weightthe second is the heaviest, the first and third about equal in weight, and the fourth and fifth, if present, are lightest of all. It is obvious that all grains from a spikelet regardless of their size, have the same heredity. And a light seed from a spikelet usually will, under similar environmental conditions, develop into a plant with as much vigor as one from a heavy seed from the same spikelet. In the selection of seed wheat, the individual plant should be the basis of selection, when such method is practicable, rather than to depend upon seed from the bin or sack, which is the offspring of many different parent plants.

There is a tuft of hairs, the brush (Fig. 34) at the small (stigmatic) end of the grain, and at the opposite end the 
cmbryo. Along the side of the grain, facing the palet, is a groove or furrow. This groove marks the region of attachment of seed to ovary. The position of the embryo may be seen easily at the base of the grain. Fig. 34 shows a cross-

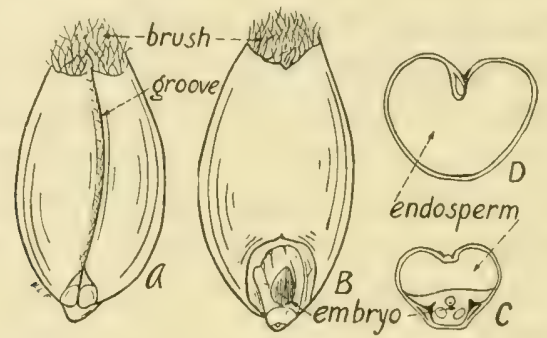

FIG. 34.-Common wheat (Triticum æstivum). $A$, grain, groove side; $B$, grain, embryo side; $C$, cross-section of grain through the embryo; $D$, crosssection of grain beyond the embryo.

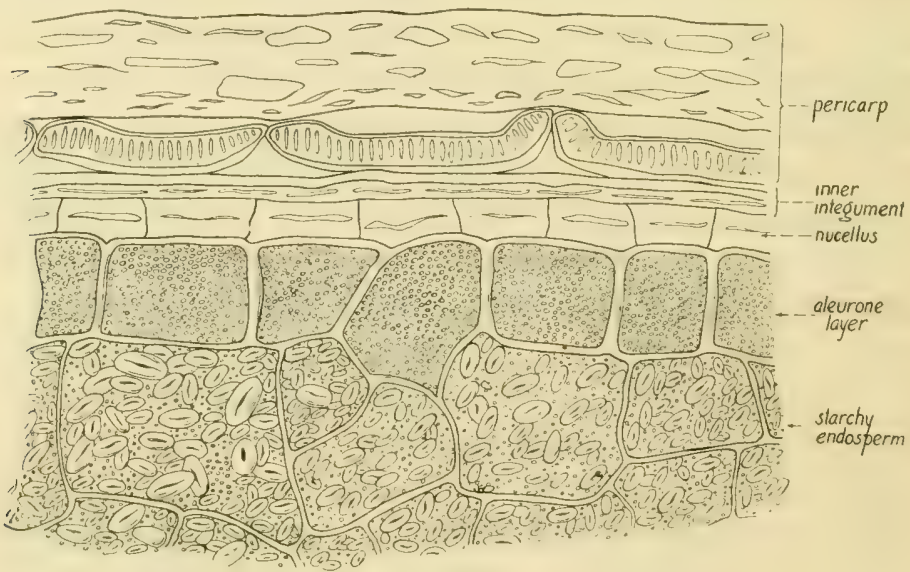

FIG. 35.-Microscopic section of wheat grain.

section of a mature grain of wheat through the embryo region. The three primary roots are seen in section.

In a cross-section of a mature wheat grain, cut at right angles to its length, so as not to include the embryo, the following layers may be recognized (Fig. 35): 
I. Ovary wall or pericarp, of several cell layers.

2. Testa, two layers of inner integument.

3. Nucellus.

t. Heurone layer, outermost layer of endosperm.

5. Starchy endosperm.

Oiary Wall or Pericarp.-The pericarp of the mature grain is composed of several layers of highly compressed cells, the original cavities of which can scarcely be distinguished. The walls are thickened, cuticularized and lignified. The chlorophyll-bearing layer, now colorless, is below these layers. Its cells are marked by numerous narrow transverse pits. The outside wall of chlorophyll cells is thin, while the inside wall, next to the integument, is thick. In tangential view, chlorophyll-bearing cells appear strongly thickened, rounded at the ends, and closely fitting, thus leaving no intercellular spaces. In rye, these same cells as seen in tangential section are pointed at the ends.

The grains of spelt, emmer, and einkorn have the palet and lemma attached, and in these the pericarp is more weakly developed than in the types of wheat with naked grains. In all wheats, the layers of the grain, both fruit and seed, are much thinner at the embryo end than in the other parts of the fruit. It is known that the greatest amount of absorption of water takes place at the embryo end.

Testa (episperm).- It has been noted that, in the developing wheat grain, the testa is composed of two integuments of two layers each. In the ripening process, the outer integument is entirely absorbed, so that in the mature grain the testa consists of two rows of cells, belonging to the inner integument. The walls are slightly lignified.

The coloring matter of the grain is found in the inner layer of the testa. It is of two kinds, pale yellow and orange 
yellow. The proportions of these colors determine whether the wheat is white, yellow, or red.

Brown found in Triticum, as well as in Avena, Secale, and Hordeum, that the semi-permeability of the grain coats is localized in the testa. It is very probable that the epidermal membrane of the nucellus also has semi-permeable properties.

Nucellus (perisperm).-The epidermis of the nucellus surrounds the aleurone layer. It is the only remaining portion of the nucellar tissue, which was comparatively large in the undeveloped ovule. The mature nucellus consists of cells with strongly thickened walls, and with indistinct cavities. It is possible that in some cases the nucellus is completely absorbed, and hence wanting in the mature grain.

Endosperm.-The endosperm consists of two portions, starchy or floury endosperm, and aleurone layer. The endosperm constitutes about 92 per cent. of the grain's volume. The cereals are cultivated chiefly for the food material stored in the grain. In all of them, the bulk of this food is found in the endosperm. The chief food materials stored in the endosperm of grains are starch and proteins. The germinating embryo makes use of these foods in the first few days of its growth, or until its roots are taking substances from the soil, and the young leaves are manufacturing food, or, in other words, until the young plant has established its independence.

Aleurone Layer.-This is a single layer of large cells immediately within the nucellus. The cells are rather uniformly square or rectangular when viewed in transverse or longitudinal section, but irregular in shape when viewed perpendicular to the surface. They are stored largely with aleurone grains. This layer is often erroneously called the gluten layer. The term "gluten" is only properly applied 
so the principal protein found in the starchy endosperm, and thould not be used in connection with the aleurone layer.

Starchy Endosperm.-This is made up of large, somewhat elongated, thin-walled cells. The longer axes of the cells are usually at right angles to the grain surface. They are filled for the most part with starch grains. Protein granules may be seen among the starch grains by appropriate staining. Most, if not all, of the wheat starch and all of the

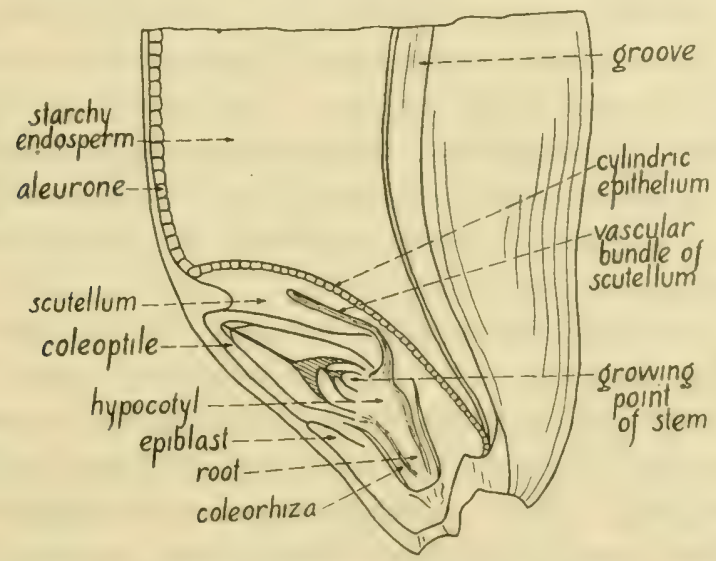

FIG. 36.-Part of a median lengthwise section of a grain of wheat; much enlarged. (After Strasburger.)

gluten occur in this part of the endosperm. The percentage of gluten increases from the center outward; those cells next to the aleurone layer contain the largest amount.

Embryo.-A median lengthwise section of the grain of wheat shows well the structure of the embryo (Fig. 36). The seminal roots point toward the micropylar end. They consist of a primary rootlet with two pairs of laterals. According to Brenchley, a fifth lateral rootlet is formed in addition to the two pairs usually described. These rootlets are surrounded by the root sheath or coleorhiza. A very short 
stem, the hypocolyl, is between the primary root and the growing point. In other words, the embryonic stem, or hypocotyl, terminates at the anterior end in a growing point and at the posterior end it is prolonged into the primary root. There are several immature foliage leaves surrounding the growing point and attached to the upper end of the hypocotyl. The growing point and foliage leaves are surrounded by a leaf sheath, the colcoptile or pileole. At the point where the root sheath merges into hypocotyledonary tissue, there is a small projection, the epiblast. Lying next to the endosperm is a specialized structure, the scutellum, which is attached to the hypocotyl. It has been suggested that the scutellum and epiblast represent two cotyledons, one of which (scutellum) is highly modified, the other (epiblast) suppressed.

We are all familiar with the seedlings of bean or squash. In these, there are two cotyledons (seed leaves) which are brought above ground and function for a while as green leaves. Plants with two cotyledons are said to be dicotyledonous. The scutellum of grasses is regarded as a cotyledon, morphologically. Plants like grasses, sedges, rushes, lilies, etc., which have one cotyledon are said to be monocotylcdonous. If the epiblast represents a rudimentary second cotyledon, as its position on the embryo would seem to indicate, it stands as evidence of the fact that monocotyledonous plants had dicotyledonous ancestry. Rudimentary structures are a great aid in tracing the racial history of all organisms.

The scutellum remains in the seed during germination, serving in the absorption of and transfer of food from the endosperm to the growing regions. The outermost layer of the scutellum, where it adjoins the endosperm, is a columnar epithelium. It is probably this layer which secretes 
the enzymes through the action of which the starches and proteins in the endosperm are rendered soluble (digested). and which in a soluble form, are enabled to pass from cell to cell to the tissues in the growing points.

The embryo is rich in fat or oil, mineral matter and protein, and contains considerable quantities of soluble carbohydrates, but probably no or very little starch. About onesixth of the embryo is fat and one-third protein, the two constituting about one-half of its weight.

Bran Laver.- The bran of wheat includes the three outer layers of tissue, viz.. pericarp, testa, and nucellus. The pericarp constitutes the larger proportion of the bran and consists largely of mineral and lignified material. The protein content of the bran is due to aleurone cells and starch cells which adhere to bran layers in the milling process.

Commercially speaking, bran consists of the scale-like, flaky outside covering which is removed from the wheat in the milling process. It ordinarily contains, in addition to the pericarp, testa, and nucellus, all or part of the aleurone layer and some starchy endosperm which may adhere to it.

Wheat bran varies considerably in chemical composition, and hence in feeding value, according to the kind of wheat used and the milling process employed in grinding it. It may contain as low as I 4 per cent. and as high as i 8 per cent crucle protein, with an average of about i 6 per cent.

Protein of Wheal.-According to analyses of American wheats compiled in 1890 , the protein (nitrogen $\times 6.25$ ) varies from 8. I per cent. to I 7.2 per cent., with an average of I I.9 per cent. This was in samples containing 10.5 per cent. water, thus making the protein 13.3 per cent. of the dry matter of the grain.

Osbourne and Vorhees have recognized the following five wheat proteins: slobulin, albumin, proleose, gliadin, and 
glutenin. The latter two proteins compose gluten. Gliadin is the sticky substance in gluten.

As a general rule, grains that have a marked glutenous or horny or flinty appearance are higher in protein than those that have a starchy or dull appearance. However, it is known that a given variety may produce a grain that is hard and rich in gluten; or one that is soft and low in gluten, depending on the environmental factors. But it seems true, nevertheless, that the term "quality" refers to both the physical characteristics and chemical composition of the grain.

\section{Relative Proportions of the Parts of the Grain.-}

I. Bran (pericarp, testa, nucellus), 8 to 9 per cent.

2. Aleurone layer, 3 to 4 per cent.

3. Starchy or floury endosperm, 82 to 86 per cent.

4. Embryo or germ, about 6 per cent.

"Hard" and "Soft" Wheats.-A "hard" wheat is one with a horny or flinty texture, and quite high in protein. Hard wheats, as a result of their high gluten content, make a "strong" flour, which is adapted for making light bread. A "soft" wheat is more easily crushed than a hard wheat, has a starchy or dull appearance, and is relatively rich in starch. The "soft" wheats have been regarded with favor for the making of bread and pastry flours. However, the flour from soft wheats is said to be "weak," that is incapable of making a large heavy loaf. At first there was much opposition to hard wheats, because of difficulties in milling and baking. In recent years, however, this opposition has been largely overcome.

There are three classes of hard wheats in this country: (I) hard spring wheat, (2) hard winter wheat, and (3) durum wheat. The principal hard spring wheats are Fife 
and Bluestem. Turkey and Kharkov are the chief hard winter wheats, and Kubankil the most important durum wheat. On account of its highly glutenous character, durum is used extensively in the manufacture of macaroni and vermicelli. The flour of this hard, glutenous wheat is being mixed with that from the softer wheats, and the result is a flour of excellent bread-making qualities.

Much emphasis has been placed upon the great influence of climate upon the composition, hardness and quality of wheat. In fact, it is claimed that the soil has little or no effect upon these characters. In general, a hot, dry climate produces a fine-stemmed plant the grain of which is hard, glassy and rich in nitrogen, while a cool, moist climate produces a coarser-stemmed plant the grain of which is relatively soft, mealy and poor in nitrogen. Headden, however, has been able to produce starchy and flinty kernels at will in the same variety growing under identical climatic conditions, by controlling the ratio of nitrogen to potassium. An abundance of nitrates produced a flinty grain, while a scarcity of nitrates in proportion to potash gave a starchy, mealy grain. This work establishes the fact that the soil, as well as the climate, is a factor in determining the quality of wheat.

Milling of Wheat.-The wheat is first thoroughly cleaned and scoured to remove sticks, straw, fine dust particles, and hairs of the brush. It is then slightly moistened with water, in order to prevent the pericarp from grinding up fine. This is known as tempering. Then comes the process of breaking. This consists in removing the bran coats and embryo from the endosperm, and the gradual reduction of the latter to finer and finer particles. In this process the grain is passed between successive pairs of corrugated iron rolls. The product of each set of rolls is sifted, and the particles are graded 
according to size, the coarser particles passing on to the next set of rolls. Finally, the pericarp layers are completely separated from the adhering layers of aleurone and starchy endosperm cells. The finely ground parts of the endosperm are sifted and bolted. The material that will pass through fine silk bolting cloth is called flour. The larger and coarser particles that remain behind are known as middlings. The middlings are then freed of particles of bran, i.e., purified, and passed between several sets of smooth rolls; the product of each set of rolls is taken to a machine which separates out the fine flour. The number of grades of flour, and of other products, will depend upon the number of sets of rolls, and the mesh of the bolts to which the grain and its ground products are subjected. Mills differ much in the grades of material turned out.

Kinds of Flour.- There are three general sorts of flour: graham, entire wheat, and patent or straight bread flour. "Graham flour" is the product obtained by grinding the entire kernel of wheat. Its name is after that of Sylvester Graham (I794-1851), a physician and writer on dietetics. "Entire wheat flour" contains about one-half of the coarse bran. In patent grades of flour all of the bran is removed. There are several grades of patent flour, but the most common one on the market is the "straight" or "standard patent." It is usually a combination of the so-called "first patent," "second patent," and "first clear" flours. About 72 to 75 per cent. of the total wheat is recovered as "straight" or "standard patent" flour. It is composed of floury endosperm alone. The ordinary bread flours belong to this grade. Other products of the milling process are known as "second clear" flour, used for low-grade bread, "red dog" also used for low-grade bread or for cattle feed, and "shorts," "middlings" and "bran." About 25 per cent. of the grain 
is returned as shorts, middlings and bran. The composition of these varies somewhat with the milling process.

Germination of Wheat.-The time required for germination depends upon external conditions. The optimum temperature for the germination of wheat is close to $84^{\circ} \mathrm{F}$, the minimum $40^{\circ}$ to $43^{\circ} \mathrm{F}$, and the maximum $108^{\circ} \mathrm{F}$. Germination will take place under field conditions usually within from four to ten days. Nobbe finds that wheat will begin to germinate in one and three-fourth days at $65^{\circ} \mathrm{F}$, two days at $60^{\circ} \mathrm{F}$, three days at $50^{\circ} \mathrm{F}$, and six days at $40^{\circ} \mathrm{F}$.

Three germinating stages in wheat are shown in Fig. 2. The primary root is the first to appear. It ruptures the coleorhiza which remains as a collar about the root where it breaks through the grain coats. Very soon two lateral roots appear; hence the primary root system consists of a whorl of three roots. The growing point elongates, the first young leaf being enclosed by the leaf sheath or coleoptile, a closed and pointed organ. The coleoptile protects the growing point and serves as a boring organ. The coleoptile of wheat has the greatest soil-penetrating ability of the common cereals. Its length varies with the variety and with the depth of seeding. The closed end of the coleoptile is broken by the first foliage leaf. The cotyledon (scutellum) is left beneath the ground.

Repeated Germination.- The grains of wheat, and the seeds of a number of other agricultural plants, are capable of repeated germination. A grain may start to sprout, the process be stopped by dryness, and sprout again if moisture is available. Beal germinated wheat and buckwheat six times, each time allowing the root and stem to grow to the length of the grain, with the following results: 
Repeated Germination

Kind of seed

Per cent. germinated

Kind of seed

\begin{tabular}{r|r|r|r|r|r} 
Ist & 2d & 3d & 4th & 5th & 6th \\
\hline & & & & & \\
100 & 100 & 90 & 87 & 67 & 8 \\
100 & 100 & 97 & 98 & 84 & 38 \\
100 & 100 & 100 & 98 & 65 & 39 \\
\hline
\end{tabular}

Classification of the Types of Wheat.- Hackel divides the genus Triticum into two sections, Aegilops and Sitopyros. In the first, the glumes are flat or rounded on the back; in the second, keeled. T. ovata is the principal species in the Aegilops section. It occurs in southern Europe, as far east as Turkestan in Asia. The cultivated wheats belong to the Sitopyros section.

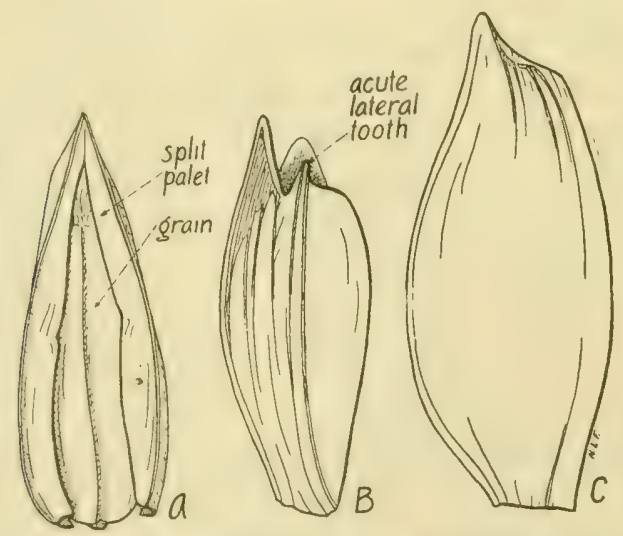

FIG. 37.-A, split palet of einkorn (Triticum monococcum) surrounding the grain; $B$, glume of einkorn; $C$, glume of club wheat (T. compactum). $\times 5$.

\section{Key to Economic Types of Wheat}

Spikelets two-flowered, one sterile, one fertile; terminal spikelet aborted; lateral teeth of glumes acute (Fig. 37); palet dividing lengthwise when mature. T. monococcum (einkorn). 
Spikelets more than two-flowered, two or more fertile; terminal spikelet developed; lateral têcth of glumes obtuse; palet remaining entire at maturity.

Glumes as long or usually longer than lemma; palet about two-thirds as long as lemma. T. polonicum (Polish wheat).

Glumes shorter than lemma; palet nearly as long as lemma.

Rachis brittle, articulated, breaking at nodes when threshed, the segments remaining attached to spikelets; spikelets two-yrained (sometimes three in spelt).

Spikelets not set thickly on stem; arched on inner side; adhering portion of rachis thick, blunt; stem above with central canal. $T$. spelta (spelt).

Spikelets set thickly on stem; flattened on inner side; adhering portion of rachis slender, pointed; stem above, with exception of narrow canal, filled with pith. T. dicoccum (emmer).

Rachis tenacious, not articulated, remaining entire in threshing; spikelets usually more than two-grained.

Empty glumes sharply and broadly keeled to the base; lemma bearded.

Spike with sides parallel or nearly so; glumes with a bloom, usually' glabrous; grain very hard, horny, long. T. durum (durum wheat).

Spike short, crowded, long-ovate; glumes usually pubescent; grain short, blunt and softer than that of T. durum. T. turgidum (Poulard wheat).

Empty glumes keeled in upper half; rounded below (sometimes slightly keeled in lower half); lemma sometimes bearded.

Spikes very short (rarely over 2 inches); very compact or crowded; thicker at apex than center or base; grains small, short. $T$. compactum (club wheat).

Spikes longer than 2 inches, open; sides usually parallel or nearly so. T. astivum (common bread wheat).

The types of wheat fall into two natural groups, as to attachment of lemma and palet to grain, as follows:

I. "Naked wheats," in which the grain comes free from the lemma and palet, and the rachis is tenacious ( $T$. durum, turgidum, compactum, astium, and polonicum).

2. "Spelt wheats," in which the grain remains attached to the lemma and palet, and the rachis is fragile ( $T$. monococcum, dicoccum, and spelta). 
Beyerinck has succeeded in producing crosses of einkorn with dicoccum, none of which were fertile, however. Aaronsohn says that $T$. polonicum hybridizes with the other species, $T$. cestioum and $T$. monococcum, but the offspring are not fertile.

T. monocnccum (einkorn) is a small-headed species of no economic importance in this country. It is cultivated to some extent in Spain, Germany,

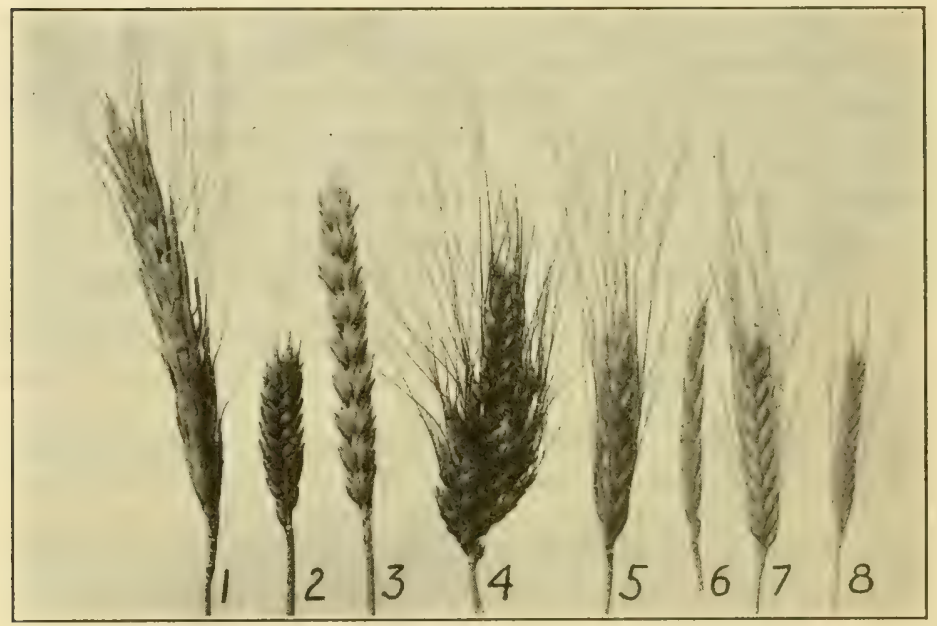

FIG. 38.- Spikes of the types of wheat. I, Polish wheat (Triticum polonicum); 2, club wheat (T. compactum);3, common bread wheat (T. æstivum); 4, Poulard wheat (T. turgidum); 5, durum wheat (T. durum); 6 , spelt (T. spelta); 7 , emmer (T. dicoccum); , einkorn (T. monococcum).

and Switzerland. Grains in the ear have been found in the remains near the homes of Swiss lake-dwellers of the Stone Age. It is a native of Asia Minor. Triticum agilopoides is considered to be the wild form of our cultivated einkorn. This wild species is divided into the two subspecies: T. thaoudar and $T$. boeoticum. In the first, only the lower flower is fertile, as a rule, but both bear awns, while in bocoticum only the lower flower is fertile and awm-bearing. There is a difference of opinion as to which of these stem forms is nearest to our cultivated einkorn. T. agilopoides differs from cultivated forms of einkorn in that its spikes are more fragile, and the grains smaller and lighter in color. 
T. polonicum (T'olish wheat) is not a native of l'oland, but occurs in Italy and Abysinia in Africa. It is cultivated to some extent in this country.

T. spella (spelt) is the oldest grain cultivated in Greece, Egypt, and the Roman Empire. It is of slight economic importance in the United states.

T. dicoccum (emmer) is of some economic importance in this country, - especially in the Western States.

T. durum (durum) varieties are also known as "goose," "wild goose," and "macaroni" wheats. They are hard wheats, particularly adapted to the arid regions, where they are better yielders than cslivum wheats.

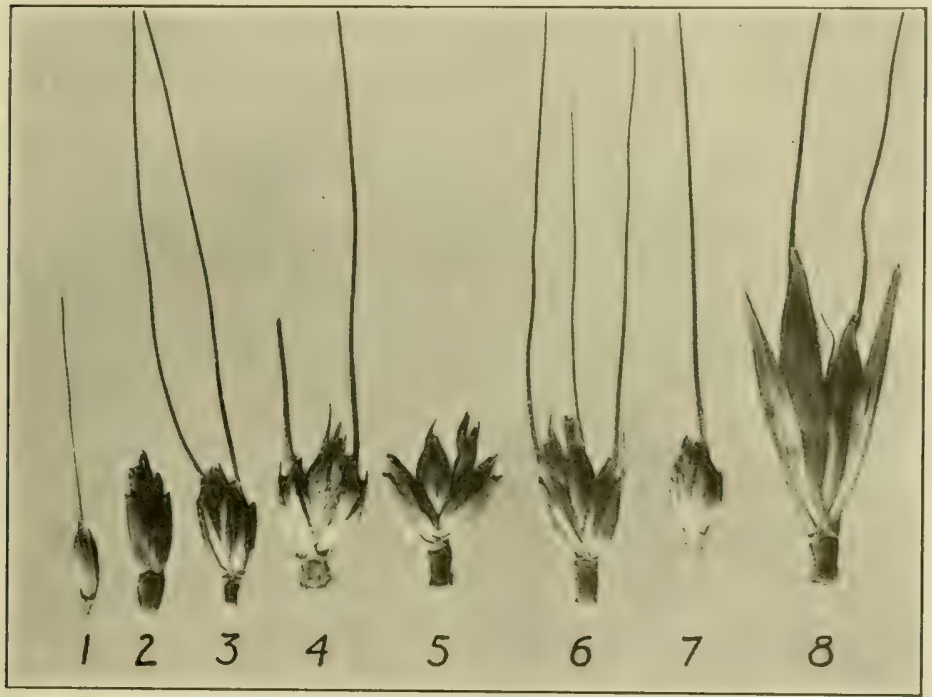

FIG. 39.- Spikelets of the types of wheat. I, einkorn (Triticum monococcum); 2 , spelt ( $T$. spelta); 3 , emmer ( $T$. dicoccum); , common bread wheat (T. astivum); 5, club wheat (T. compactum); 6 , durum wheat (T. durum); 7 , Poulard wheat (T. turgidum); 8 , Polish wheat (T. polonicum). About natural size.

Durum wheat resembles barley. Its heads are the longest among the wheats. The grains are hard, glassy, often translucent and rather large.

$T$. turgidum (Poulard wheat) is of little consequence in this country. The spikes are quadrangular or rectangular in cross-section. There is a tendency to form branching spikes, as in Alaskan and Seven-headed or Egyptian varieties. Such varieties also go under such common names as Stoner, Miracle, Eldorado, Jerusalem, Many-headed, Many-spiked, Mild coose, etc. 
T. compuctum (club wheat) varieties are said to be adapted to the Pacific Coast and Rocky Mountain States. In club wheats, the spikes are only two or three times as long as broad, and typically broader at the top than at the base, thus appearing somewhat club-shaped. The joints of the rachis are very short, so that the spikelets are crowded and often stand outright.

T. astivum (common wheat).-The bread wheats of the world are largely varieties of restivum.

Origin of Wheat.-A few years ago, Aaronsohn brought from Syria a wild emmer which was named by Koernicke Triticum dicoccum dicoccoides (T. hermonis Cook) (Fig. 40). Later, in an expedition in Upper Galilee to the north of Lake Tiberias, he found this wild emmer again, and, on Mount Hermon near the village of Arny, he found it very common and in a variety of forms. This was at an altitude of $\mathrm{x}, 500$ to 2,000 meters. Chodat concludes that wheat is indigenous to Syria. He considers that $T$. dicoccum dicoccoides, a form with a fragile rachis, is the primitive type of wheat. It is interesting to note that the grains of this "wild wheat" are not inferior in weight or size to those of the best cultivated varieties.

It is well agreed that the prototype of our cultivated wheats, whatever it is, is one with a fragile rachis. The rigid rachis is considered to be developed by man. It is known that the wheats cultivated in most ancient times were those with fragile rachises, such as emmer. Furthermore, all genera and species related to wheat, such as Aegilops and Agropyron, etc., have a fragile rachis. The only cultivated wheats of today with brittle rachises are einkorn, emmer, and spelt.

It is observed that cross-pollination is more prevalent in Aaronsohn's primitive wheat than in cultivated forms. This may be due to the fact that it grows in a warm, dry climate, while most cultivated wheats belong to northern climates, 


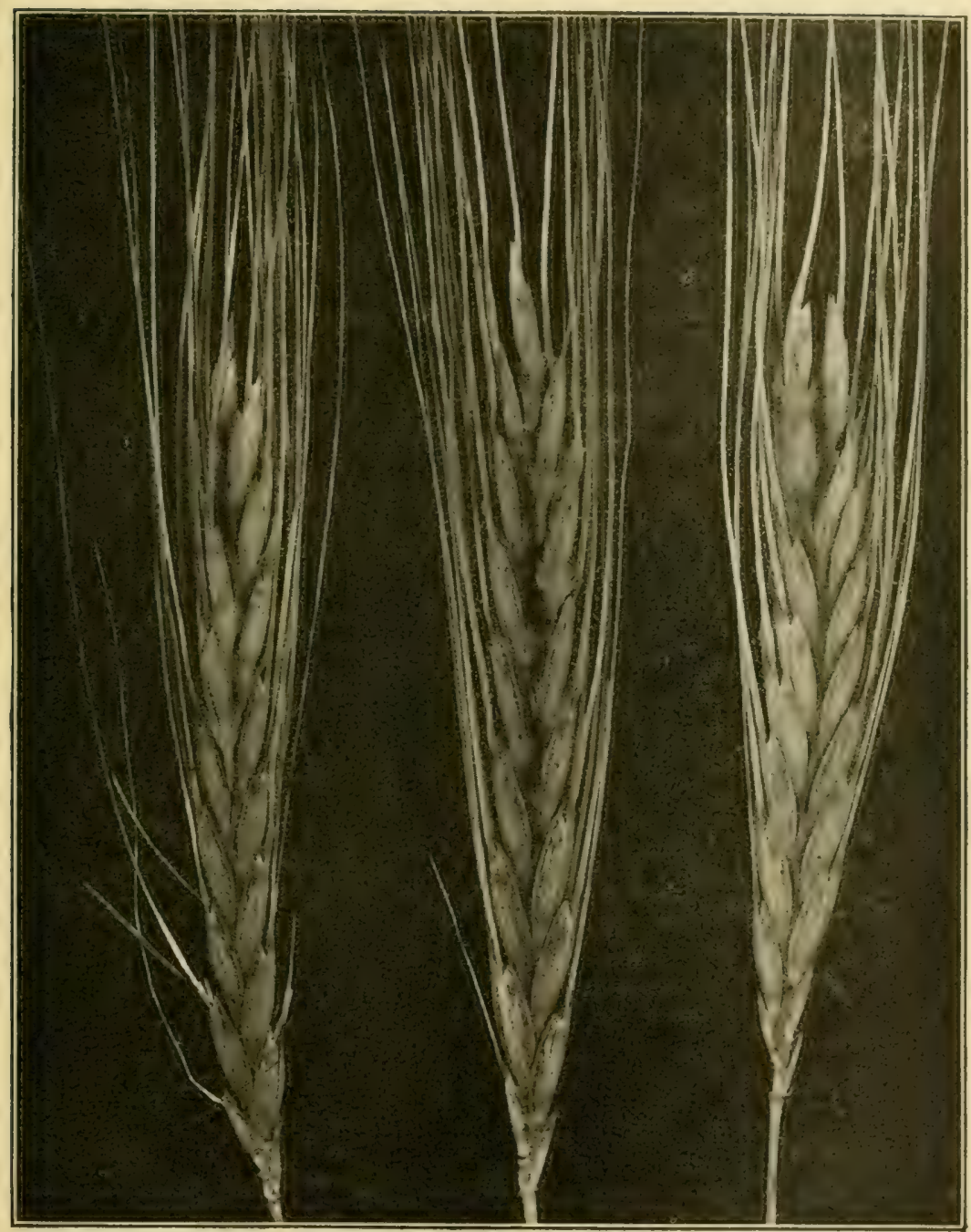

F1G. 40.-Wild emmer of Palestine (Triticum dicoccum dicoccoides), grown in experimental plat at Bard, California. (Cook, U. S. Dept. of Agr.) 
where cold or wet weather prevents flower opening. In India, it has been observed that cross-pollination in wheat is more frequent than in northern climates.

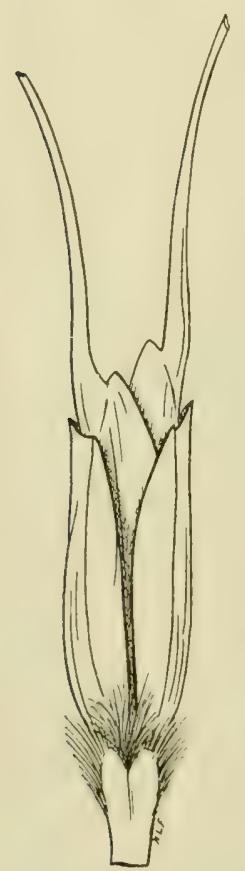

Fig. 4T.-Spikelet of wild emmer (Triticum dicoccum dicoccoides). $\times 21 / 2$.

In the wild wheat of Palestine, the kernels are normally retained by the spikelet. It differs also from domesticated wheat in the order of maturity of the spikelets. In domesticated wheat, the first spikelets to develop flowers are those near the middle of the head, while in the primitive wheat the terminal spikelets are the first ones. Primitive wheat also shows some indications of sexual dimorphism. Some plants have been observed to bear protogynous, others protandrous, flowers. The spikelets of this wild form never mature more than two grains (Fig. 4I), and those of the same spikelet are unequal in size. The smaller grain is borne by the lower flower in the spikelet; this flower has the longer awn too.

A. Schulz thinks that many, but not all, of the primitive wheat individuals found by Aaronsohn are hybrids between $T$. agilopoides thaoudar and dicoccoides. The origin of the different types of cultivated wheats, as given by Schulz, is shown in the following:

I. Einkorn series, of which $T$. agilopoides is the prototype.

2. Emmer scries, of which $T$. dicoccoides is the stem form. From this have come dicocum, durum, turgidum, and polonicum.

3. Spelt series, of which the stem form is unknown. From this have come spelta, compactum, cestivum, and capitatum.

Environmental Relations. - Wheat is grown under a wide range of temperature conditions. Some varieties come to maturity and yield well as far as $64^{\circ} \mathrm{N}$. latitude in Norway, 
and up to S,000 feet elevation in the Central Rocky Mountains. In this last-mentioned section wheat will yield a crop), except in unusual years, where the mean temperature for the year is not below $38^{\circ} \mathrm{F}$, and that for the summer season is not below $58^{\circ} \mathrm{F}$. Winter wheats are able to resist low temperatures for longer periods than spring wheats.

Plants differ widely in their water economy. Some require much more water than others to produce a unit of dry matter. The i'ater requirement of a plant is defined as the number of units of water absorbed by the plant in the production of a unit of dry matter. The following data are taken from Briggs and Shantz:

Water-requirement Determinitions at Akron, Colorado, igit, ílz, and igr3, Based on the Production of Dry Matter

\begin{tabular}{|c|c|}
\hline Plant & Mean of genus \\
\hline Proso...................... & 293 \\
\hline Millet.................. & 310 \\
\hline 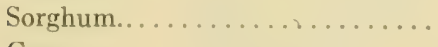 & 322 \\
\hline Corn.................... & 368 \\
\hline 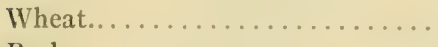 & 513 \\
\hline 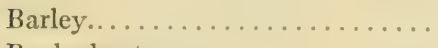 & 534 \\
\hline Buckwheat................ & 578 \\
\hline 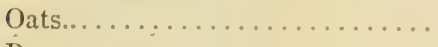 & 597 \\
\hline 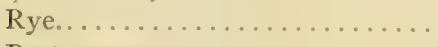 & 685 \\
\hline Beet, sugar................. & 397 \\
\hline Potato...................... & $6_{36}$ \\
\hline Pea, Canada field............. & 788 \\
\hline Alfalfa................... & 831 \\
\hline
\end{tabular}

If the water requirement of proso millet is regarded as I, the water requirement for the following crops is as follows: millet I.06; sorghum I. Io; corn, I.26; wheat I.76; barley I.83; oats 2.04 ; rye, 2.34 ; rice, 2.42 .

The water requirement of a plant is dependent upon a number of conditions, chief of which is the fertility of the soii. The water requirement is greater in an unfertile than 
in a fertile soil. The application of fertilizers may increase the total amount of water taken in by the plant, due to increased plant growth, but the requirement per unit of dry matter is lowered.

The effect of climate and soil on the composition of the grain has been discussed.

Uses of Wheat.-By far the largest proportion of the world's supply of flour is made from wheat. As already stated, the hard wheats, particularly durum varieties, are used extensively in the manufacture of macaroni and allied products. In the mamifacture of macaroni, the wheat is first ground into a course product known as "semolina."

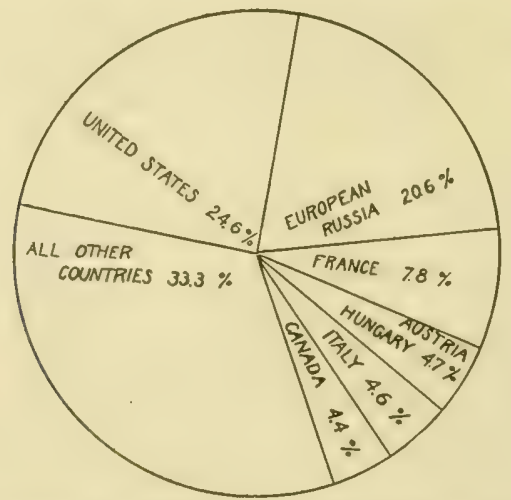

FIG. 42.-Diagram showing the percentage of the world's wheat crop produced by the different countries in I9I 5 .

It is freed then of any adhering particles of fine flour and bran. The semolina is mixed with about 30 per cent. of water, worked into a stiff dough, and given a thorough kneeding. The dough is then forced through a press, from which it issues in long hollow tubes. These tubes of moist dough are then carefully dried in a manner to prevent them from becoming too brittle or sour. Vermicelli and spaghetti 
are also made from semolina and water, but dies of different form are used, and drying is done on frames. Many sorts of breakfast foods are made from wheat. A very recent product is puffed wheat, in the preparation of which the kernels are expanded by heating to a high temperature under pressure, and then the pressure is suddenly released. The whole grain, screenings, bran, shorts, middlings and "red dog" are fed to animals. Sometimes wheat is sown with retch and the two together used for silage purposes. Wheat, as well as other cercals, finds use in the manufacture of whiskey. It is employed also in the making of weiss-beer malt.

Production of Wheat.-The leading wheat-producing countries of the world are shown graphically in Fig. 42 . The following table gives the wheat production in the United States for I9I5.

Wheat Production in the United States, I9I5

\begin{tabular}{|c|c|c|c|}
\hline State & Acres & Bushels & $\begin{array}{l}\text { Total value } \\
\text { dollars }\end{array}$ \\
\hline North Dakota..... & $8,350,000$ & I $51,970,000$ & $I_{32}, 2$ I 4,000 \\
\hline Kansas........... & $8,525,000$ & I06, 538,000 & 94,8 I 9,000 \\
\hline Minnesota........ & $4,310,000$ & $73,420,000$ & $66,678,000$ \\
\hline Nebraska......... & $3,947,000$ & $72,154,000$ & $60,609,000$ \\
\hline South Dakota...... & $3,725,000$ & $60,762,000$ & $54,835,000$ \\
\hline Illinois. . . . . . . . . . & $2,800,000$ & $53,200,000$ & $53,200,000$ \\
\hline Washington......... & $2,000,000$ & $50,394,000$ & $41,324,000$ \\
\hline Indiana.......... & $2,750,000$ & $47,300,000$ & $48,246,000$ \\
\hline Ohio............. & $1,980,000$ & $40,194,000$ & $4 \mathrm{I}, 802,000$ \\
\hline All other States... . & $2 \mathrm{I}, 5 \mathrm{II}, 000$ & $352,573,000$ & $336,575,000$ \\
\hline United States...... & $59,898,000$ & $\mathrm{I}, \mathrm{OII}, 505,000$ & $930,302,000$ \\
\hline
\end{tabular}

\section{References}

Aaronsohn, A., and Schweinfurtir, G.: Die Aufindung des wilden Emmers (Triticum dicoccum) in Nord Palästina. Altneuland Monatsschr. für die wirtschaftliche Erschliessung Palästinas, Berlin, Nors. $7^{-S,} \mathrm{II}_{3}$ $220,1906$. 


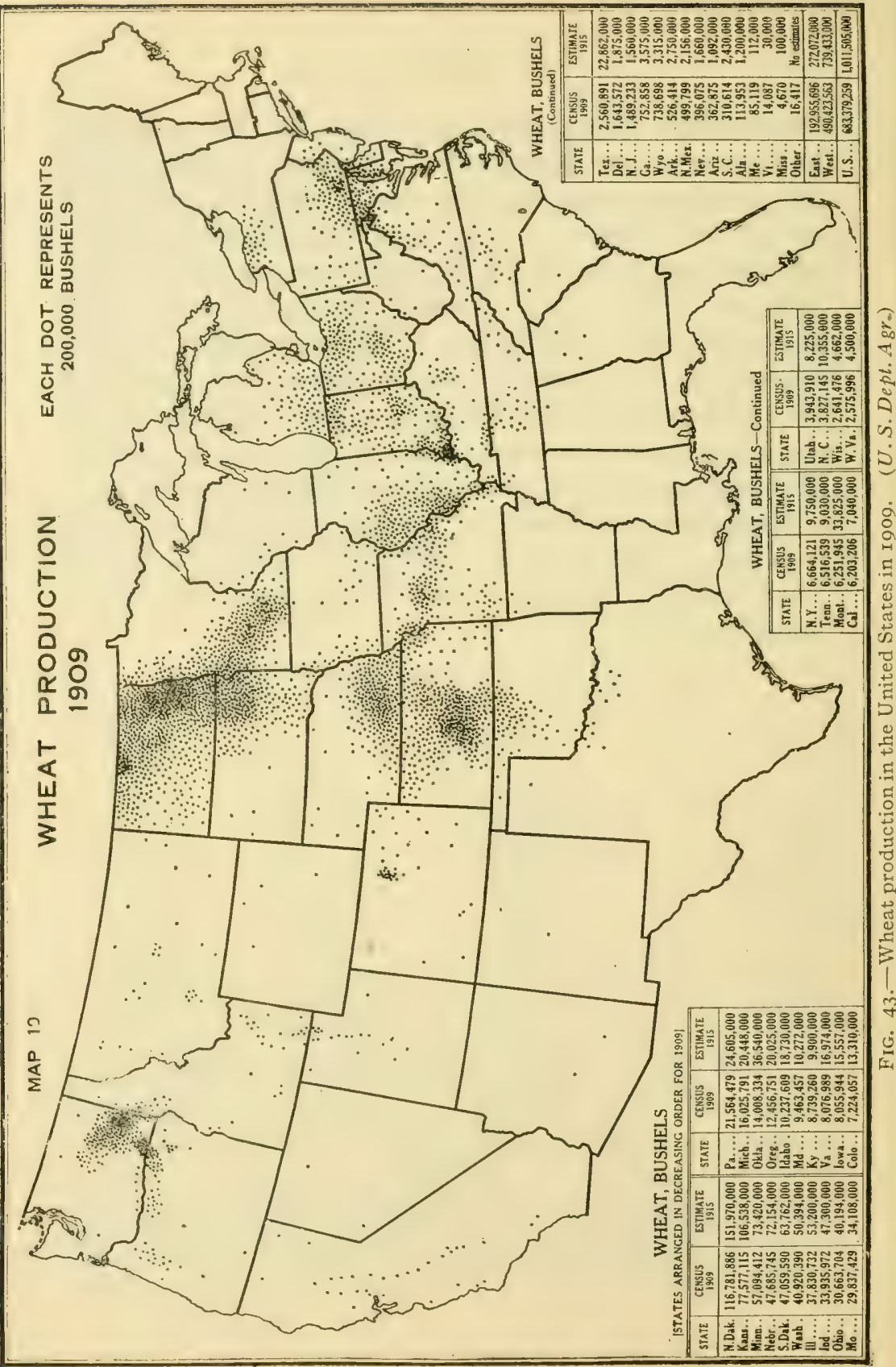


AARonsonn, AARon: Agricultural and Botanical Exploration in Pálestine: Wild Prototypes of Wheat and Other Cereals in Palestine. U. S. Dept. Agr. Bur. Plant Ind. Bull. $180: 36-52$, x 9 Io.

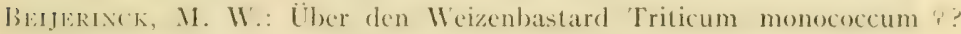
Triticum dicoccum ơ. Nederlandsch Kruidkundig Archief., ser. 2, 'T. 4: I 89-20I, I 886 .

Bessey, C. E.: The Structure of the Wheat Grain. Nebr. Agr. Exp. Sta. Bull. 32: 100-II4, I894.

Bloomfield, L. M.: Contributions to the Life History of the Wheat Plant

(T. vulgare). Ann. Rep. Ohio State Acad. Sci., 2: I 2-r4, r894.

IBRFNCHLEY, W. E.: (On the Strength and Development of the Grain of Wheat

(T. vulgare), Ann. Bot., 23: II7-I39, I909.

BRENCHLEY, W. E., and HALL, A. D.: The Development of the Grain of

Wheat. Jour. Agr. Sci., 3: 195-217, I909.

Cirodat, R.: A Grain of Wheat. Pop. Sci. Mo., 82:33-46, r9r3.

Совв, N. A.: Universal Nomenclature of Wheat. N. S. W. Dept. Agr. Misc. Pub. 539, I905.

Cook, O. F.: Wild Wheat in Palestine. U. S. Dept. Agr, Bur. Plant Ind. Bull. 274: $1-56$, I9I3.

Dondinger, P. T.: The Book of Wheat. Orange Judd Co., I9o8.

Errkssox, J.: Beiträge zur Systematik des cultivierten Weizens. Landw.

Versuchsstat., 45:37-I35, I894.

Fruwtith, ( . : Dils Bliben von Weizen und Hafer. Deut. Landw. Presse, 32: $737-739,747-748,1905$.

H.IYs, WILlet M., and Bosis, INDREw: Some Botanical Characteristics of Wheat. Minn. Agr. Exp. Sta. Bull. 62:39I-42 I, I899.

Headden, W. P.: Yellow-berry in Wheat. Colorado Agr. Exp. Sta. Bull. 205 ; $1-38$, r915.

Kondo, M.: Studies on Ireads of Wheat and Spelt as a Contribution to Exact Classification. Landw. Jahrb., 45: 713-8I 7, I913. .

Kritst, Ersit, H. S.: Dic Heimat des Spelzes. Naturw. Wchenschr., 25: 4I2-4I 4, I 9 IO.

Mäßıs, I : : Untersuchungen über die Sorteneinteilung bei Triticum vulgare. Inaug. Diss., Giessen, I913. Druck von F. Stollberg, Merseburg. ():Bor.a., T. B.: The Protein of Wheat Kernel. Carnegie Inst. Washington Pub. 84: I-II9, I907.

Somliz, Aeglst: Mbstammung und Heimat des Weizens. 39 Jahrsber. Westfäl. Prov. Ver. Wiss. u. Kunst (zu Münster) für I0Io-roII, S. I47-152, 19 II.

Die Geschichte des Weizens. Ztschr. Naturw., 83: I-68, I9 I I.

Die Abstammung des Weizens. Mitt. Naturf. Gesell. Halle, I: 14-I7, I0I 2 .

Fokerson, Sophid H.. Microchemical Studies in the Progressive Development of the Wheat Plant. Wash. Agr. Exp. Sta. Bull. I39; I-20, I9I7. 
Die Abstammung des Einkorns (T. munococcum L.). Mitt. Naturf. Gesell. Halle, 2: I2-I6, I9r3.

Triticum aegilopoides Thaoudar X dicoccoides. Mitt. Naturf. Gesell. Halle, 2: $\mathrm{I}_{7}-20$, I9r3.

Scofield, CARL S.: The Algerian Durum Wheats: A classified list, with descriptions. U. S. Dept. Agr. Bur. Plant Ind. Bull. 7: I-48, Igoz.

Ten Eyck, A. M.: The Roots of Plants. Kans. Agr. Exp. Sta. Bull. I27: I99-252, I904.

Thatcher, R. W.: The Progressive Development of the Wheat Kernel. Jour. Amer. Soc. Agron., 5: 203-2 I3, I9I3.

Woods, Charles, and Merrill, L. H.: Entire Wheat Flour. Me. Agr. Exp. Sta. Bull. I03: 61-80, I904. 


\section{CHAP'TER XI}

\section{AVENA (Oats)}

Habit of Plant.-Oats are annual. The large majority of varieties are summer annuals; a very few are winter annuals.

Roots.- The root system of oats is very similar to that of wheat. The dense, fibrous growth, which in wheat occurs in about the first foot of soil, is somewhat decper in oats. The roots of oats extend to a depth of 4 or 5 feet. To quote from Ten Eyck, "Extending down from the center of the root crown of each plant in this example was observed a short rudimentary root stem which ended abruptly with a slight enlargement from which radiated a few short, fine, wire-like roots. Often the old seed coat was found clinging to the enlarged terminus. The depth at which the seed was planted determined the length of the lower root stem. The explanation of this rudimentary growth is that the seed was planted too deep, or below the point at which soil conditions were most farorable for starting the young roots; hence, the root crown formed considerably above the seed, the lower root stem remaining rudimentary and the little rootlets which started from it ceasing to grow early in the season."

Stems.-As compared with wheat, the stems of oats are larger in diameter and softer. The number of joints in the culm varies from four to eight.

Leaf.-Oats produce abundant leaves. They are broader, as a rule, than those of wheat. The leaf sheath is closed. The ligule is short, oral, and with distinct teeth, thereby differing from wheat, rye, and barley. The young leaves are 
rolled to the left. The auricles are lacking, which also distinguishes it from the other cereals.

Inflorescence.- The spikelets of oats are arranged in a panicle. The branching on the main axis is racemose, that

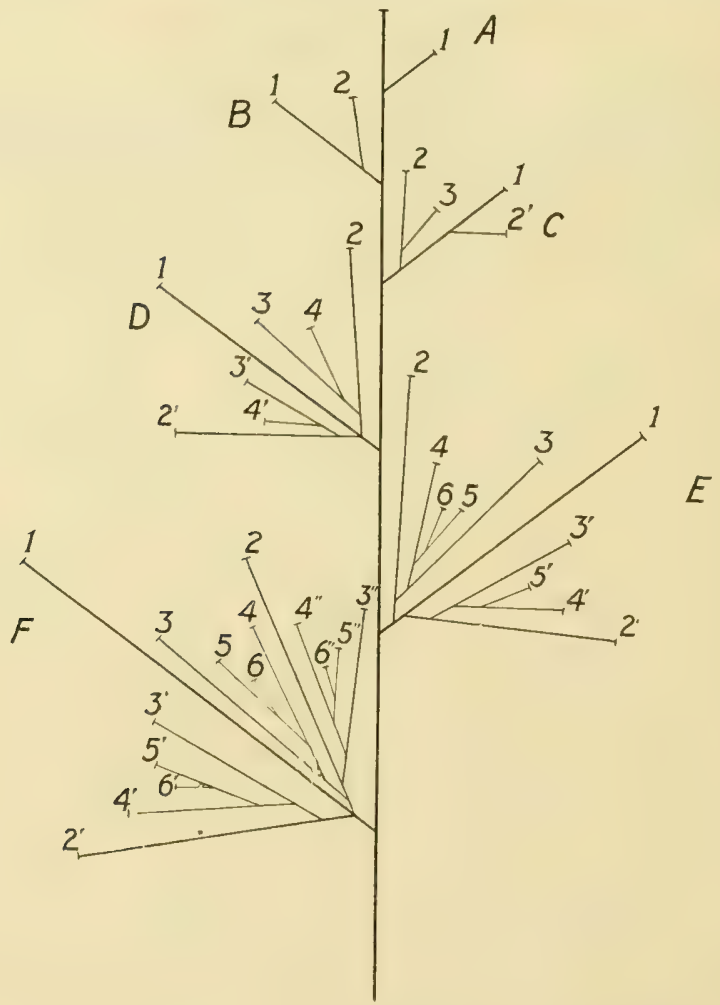

FIG. 44.-Diagram of oat inflorescence. (After Broili.)

of a higher order is cymose (Fig. 44). The number of whorls in a panicle ranges from four to nine, mostly five or six. Apparently, there are a number of primary branches arising" at a node. However, there is only one primary branch, 
the others being branches of higher order, arising at the batse of the primary. The branching decreases from bottom to top).

In banner oats (Aicna oricnlalis), the panicle is onesided. In ordinary panicle or spreading oats (Asena sativa),

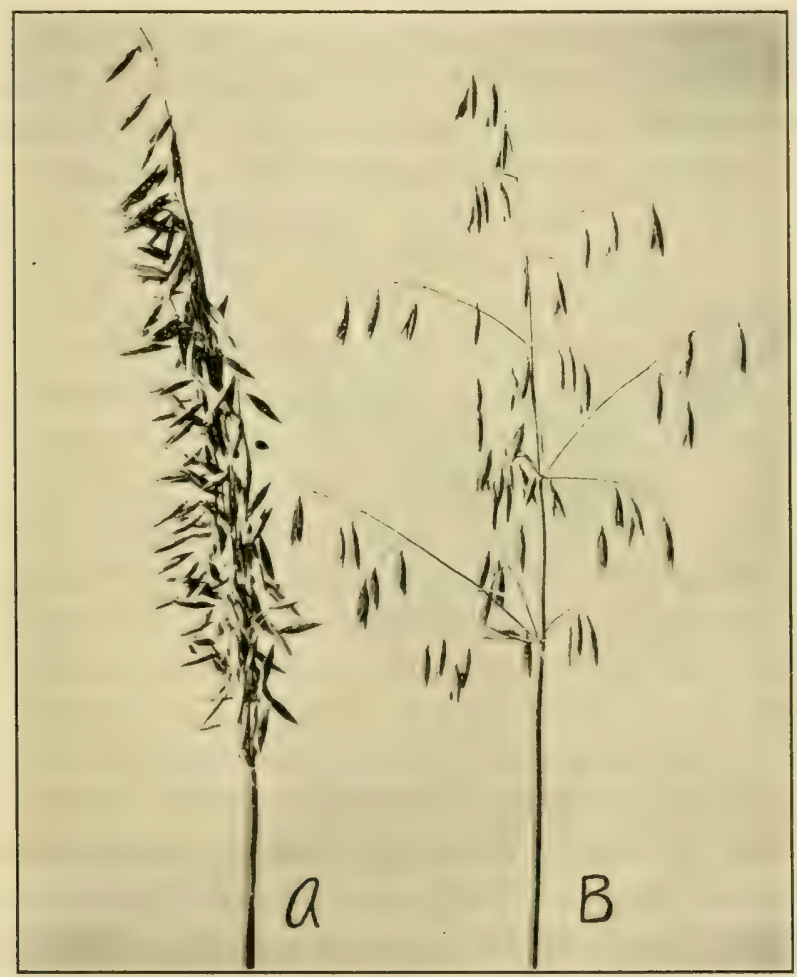

FIG. 45.-A, contracted, one-sided panicle of banner oats (Avena orientalis); $B$, spreading inflorescence of panicle oats (Avena sativa).

the branches spread toward all sides (Fig. 45). Four main types of panicle oats have been distinguished at the Svalof Experiment Station, as follows: (I) Panicle stiff and upright, (2) panicle pyramidal, the branches long, slender, and rising 
wcakly, (3) panicle widely spreading, (4) panicle with branches weak and drooping.

The number of spikelets in a panicle varies, an average number being near 75. The rachis is straight or only slightly undulating. A single spikelet is borne at the end of a slender pedicel, which varies in length.

Spikelet and Flower (Fig. 46).-The number of flowers in in oat spikelet varies from two to five, rarely it is one. Three, however, is the usual number. In the so-called "single

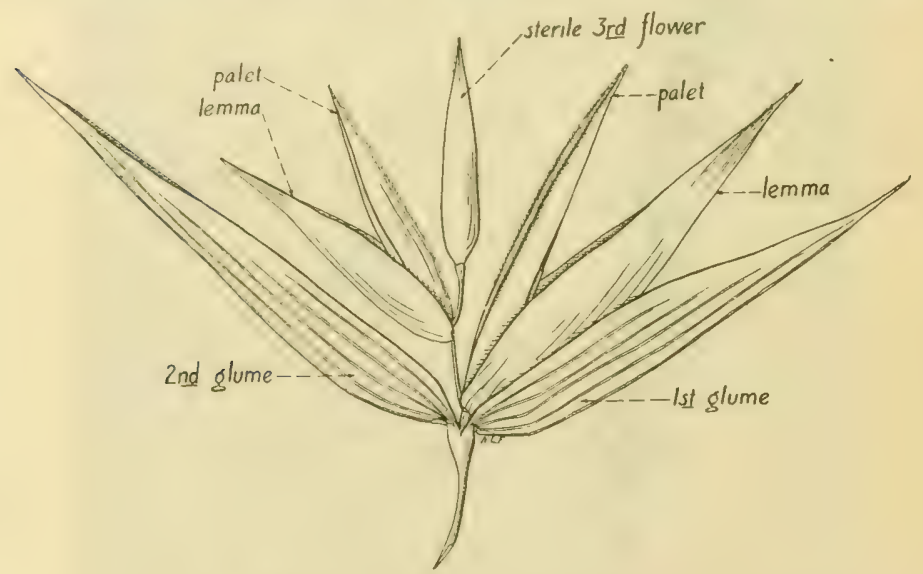

FIG. 46. - Spikelet of panicle oats (Avena sativa), $\times 21 / 2$.

oals," but one flower, the basal, matures. In "twin oats," two flowers mature. Three kernels occasionally mature. The upper flowers of the spikelet are often staminate or imperfect. If a large number of spikelets bear three kernels, there is usually a reduction in the number of spikelets in the panicle, as well as in the total weight of grain from that panicle.

The two empty glumes are unequal, and longer than the lemma. The lemma is rounded on the back, acute, and usually bears an awn which is dorsally attached. As a rule, 
the lower flower is the only one to bear an awn. The palet is two-toothed, and shorter than the lemma. It fits closely about the grain. Stamens three. Style branches two, plumose. Lodicules two, very evident at flowering time.

Opening of Flower and Pollination.-The inflorescence opens at the tip first. In oats, as in other paniculate types of inflorescences, there are a number of cells in the axils of the primary branches which become turgid and bring about the opening of the inflorescence. The first flowers to open in the panicle are in the middle spikelets. The blooming of the entire panicle is completed in six to seven days. In the spikelet, the lower flower opens first, then the second and third in order. The chief blooming time of oats is from $2: 00$ to $4: 00$ p.m. Blooming may continue at slackened speed until 7:00 or 8:00 p.m. A flower usually remains open from fifty to seventy minutes. Hence cross-pollination is not excluded. Self-pollination is the rule, however, due to the fact that all three anthers seldom project from the flower. In cool or rainy weather, flowers may not open at all.

Fertilization, and Maturing of Grain.-Oats and wheat are very similar as to fertilization. The oat grain passes through the milk and waxy stages to maturity, as in wheat. After the resorption of the outer integuments, resorption of the parenchyma layer begins. 'There is a complete resorption of the chlorophyll layer and the inner epidermis. There seems to be a less marked fusion of pericarp and seed coats than in wheat.

The Mature Grain.-The kernel is firmly surrounded by: the lemma and palet, except in "naked oats." The lemma and palet form the "hull" (Fig. 47). The quality of oats is judged largely on the basis of per cent. hull and kernel. Hull usually forms from 25 to 33 per cent. of grain weight, but may be as low as 20 per cent. or as high as 45 per cent. 
The percentage of hull in the upper grains of a spikelet is less than that of lower grains. It is also stated that earlyripening sorts have a greater percentage of hull than lateripening ones. The reports are conflicting concerning the percentage of hull in short plump grains and in long slender

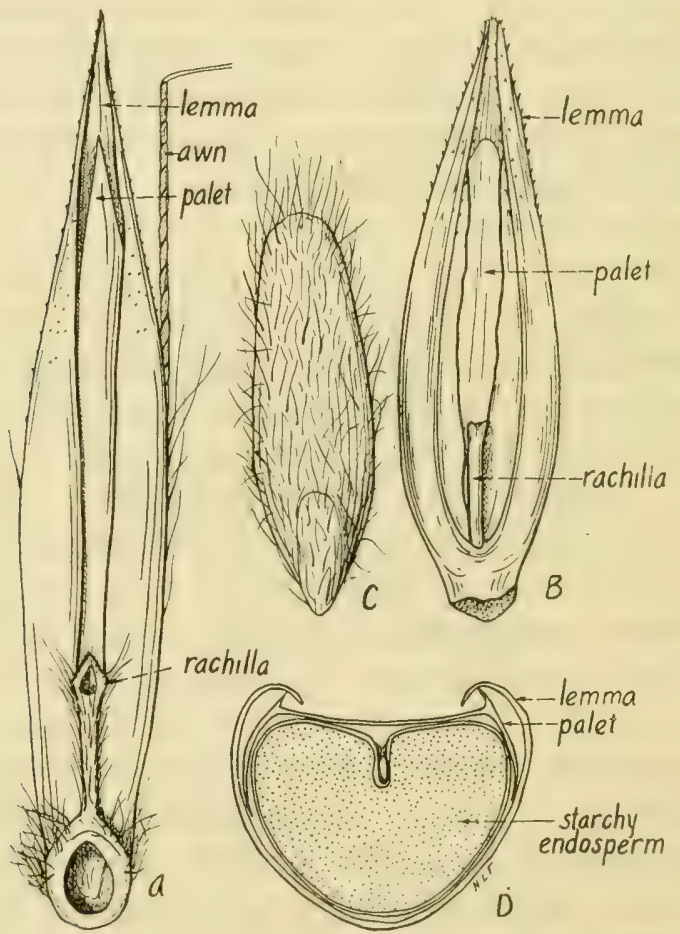

FrG. 47.- $A$, mature grain of wild oats (Avena fatua); $B$, mature grain of cultivated panicle oats (Avena sativa); $C$, grain of same with "hull " removed; $D$, cross-section of grain with the "hull." $A, B$ and $C, \times 5 ; D, \times 10$.

ones. Furthermore, there is no constant relation between weight of grain per bushel and per cent. of hull. However, if an oat variety is well adapted to a certain region, the per cent. of hull is quite generally lower than if it is poorly adapted. 
There are marked differences in the basal and upper grains of a spikelet. The basal grain is the largest and usually bears an awn; the upper ones rarely have awns. A short rachilla (Fig. 47), which bears the second grain, is at the base of the lower kernel. This rachilla varies in length, shape and hairiness in the different oat varieties. The second grain commonly carries no rachilla, or only a fine, thread-like one at the end of which is an immature grain or the mere remnants of a third flower. The base of the outer grain is blunt, while that of the inner is pointed.

The oat kernel (Fig. 47) is elongated and has a hairy surface. As in wheat, the embryo forms a very small portion of the kernel. A cross-section of the grain shows the following coats: (I) lemma; (2) palet, of six to eight cell layers; (3) pericarp, a thin layer of two or three rows of cells; (4) testa, two layers of inner integument; (5) nucellus, one layer; (6) aleurone layer, two rows of cubical cells (sometimes one); (7) starchy endosperm.

The starchy endosperm of oats, unlike that of wheat, possesses no gluten, and hence it cannot be made into light bread. In this respect it resembles barley. The double row of aleurone cells also distinguishes the oat grain from the wheat grain. The other grain coats and the embryo are very similar.

Germination of Oats.-The cardinal temperatures (maximum, optimum and maximum) for oats are about the same as they are for wheat.

The young shoot breaks out at the germ end, grows underneath the lemma, and comes out at the brush end. This method of growth is necessitated by the persistence of the palet and lemma. The primary root, however, ruptures the hull. The coleoptile is closed. The first foliage leaf is rolled. 
Classification of Oats. The common oat varieties in the United States fall into three species: Arena saliva, $A$. orientulis, and $A$. mudu. The latter two are sometimes given as varieties of $A$. sativa.

Avena sativa (panicle oats).-The common oats belong to this species. In these, the panicles are spreading in all directions (Fig. 45). A considerable number of forms are recognized. Four main types, based upon character of panicle, were given on page 125. As to color of grain, there are white, yellow, gray (winter oats), brown and black sorts. Some are bearded and some are beardless.

Avena orientalis (banner, side, mane, or Tatarian oats).The panicles of these species have erect branches which are close to the main axis (Fig. 45). The inflorescence is onesided, which character has suggested the common names ascribed to it. There are beardless-white, bearded-white, beardless-yellow, beardless-brown, and bearded-brown varieties.

Avena muda (naked or hull-less oats).-The grains of this oat fall from the hull when threshed. It may be either a spreading or side type.

Other Cultivated Oats.--In addition to the three common species of oats given above, the following species are recognized and cultivated in various parts of the Old World: Aiena strigosa (rough oats), A. brevis (short oats), A. byzantina (Mediterranean oats) and A abyssinica (Abyssinian oats).

Avena fatua ("wild oats").--The so-called "wild oat" is often found in oat fields, and the "seed" may frequently occur as an impurity in farm seed. The plant has slender stems, which are long, and hence it usually stands above the cultirated oats. It has three flowers to a spikelet, and the awns on the lemmas are strongly bent (Fig. 47), thus differing from common oats. Again, it is distinguished from the 
latter by the long reddish-brown hairs at the batse of the lemma and on the rachilla.

In cultivated sorts, there appears occasionally the so-called "false wild oats," differing in its characteristics hoth irom the cultivated varieties and the true wild oats. It differs from the cultivated varieties in having the long twisted and bent awns. The kernels, however, are similar to those of the cultivated varieties.

Origin of Oats.- It is held by Haussknecht, 'Thellungr. Trabut, and others that all the varieties belonging to 1 . sativa, A. orientalis, and A. mada have originated from $A$. fatua. Under cultivation, 1. fatua has lost the fragility of its articulations, its hairs and, in some instances, its awns. A. strigosa and $A$. breis are derived from A. barbala, a species growing wild in the Mediterranean region, Persia. Mesopotamia, west to Atlantic Europe and Great Britain. A. abyssinica is originated from A. wiestii, a species indigenous to North Africa and Arabia. A. byamtina has come from $A$. sterilis, the so-called "animated" or "fly" oats, a wild form frequent in the Mediterranean region. Trabut has found in this region all forms of Acend sterilis ("sterile" oats), beginning with those that are small and useless and ending with the forms now cultivated there. Algerian oat (A. algeriensis) is the common cultivated variety. of the sterile oat.

All the forms of oats derived from 4 . falua are characterized by the easy separation of the second flower from the rachilla, which persists above the lower flower. In those forms of oats derived from 1 . sterilis, on the other hand the second flower does not separate from the lower flower without carrying away the rachilla at its base.

Environmental Relations.-- ()ats is adapted to a humid, moderately cool climate, such as is found in the region north 
of the corn belt in the United States. Cool summers favor the ripening of the grain; oats is a better crop than wheat at high latitudes and altitudes. The white and black oats are grown at higher latitudes than red and yellow sorts; the latter are raised in the Southern States, some varieties being sown as winter oats. Practically all of the oats grown in the Northern States is spring-sown.

The water requirement of oats is greater than that of any of the other common cereals. It will thrive on soils too wet for corn and in general is better adapted to heavier soils.

Uses of Oats.-Large quantities of oats are consumed annually in the form of rolled oats or oatmeal. The grain is also a much valued horse feed, and not infrequently it is fed to poultry. Oats are sometimes grown for pasture, and also cut before reaching maturity as hay. It makes an excellent nurse crop. Oat straw is used as roughage for stock, and as a bedding.

The Production of Oats.-As is the case with wheat and corn, the United States also leads all other countries in the production of oats. Russia is a close second. Iowa, Illinois and Minnesota were the leading States in I9 5.

Leading Countries in the Production of Oats, Showing Acreage and PRODUCTION, I9I 5

\begin{tabular}{|c|c|c|}
\hline Countries & Acres & Bushels \\
\hline United States................. & $40,780,000$ & $\mathrm{I}, 540,362,000$ \\
\hline Russia, European................ & $44,787,000$ & $1,006,983,000$ \\
\hline Germany..................... & $* \ldots \ldots \ldots$ & $650,000,000$ \\
\hline Canada............. & I I , 365,000 & $481,035,000$ \\
\hline France................. & $9,05 \mathrm{x}, 000$ & $234,924,000$ \\
\hline Austria-Hungary.............. & $* \ldots \ldots \ldots$ & $234,924,000$ \\
\hline United Kingdom............. & $4,149,000$ & I95, I 69,000 \\
\hline Sweden..................... & $* \ldots \ldots \ldots$ & $70,000,000$ \\
\hline 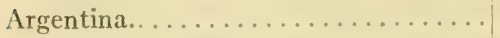 & $2,869,000$ & $62,392,000$ \\
\hline
\end{tabular}

* No official statistics. 
TH: Promuction of OATS in THE UNITED States, 1015

\begin{tabular}{|c|c|c|c|}
\hline States & Acres & Bushels & $\begin{array}{l}\text { Total valuc, } \\
\text { dollars }\end{array}$ \\
\hline Iowa............. & $4,950,000$ & $198,000,000$ & $63,360,000$ \\
\hline Illinois............ & $4,343,000$ & I $95,435,000$ & $68,402,000$ \\
\hline Minnesota........ & $3,125,000$ & $\mathrm{r} 34,375,000$ & $43,000,000$ \\
\hline Wisconsin........ & $2,150,000$ & $99,975,000$ & $35,99 \mathrm{r}, 000$ \\
\hline North Dakota..... & $2,450,000$ & $98,000,000$ & $26,460,000$ \\
\hline South Dakota.... & $1,725,000$ & $72,450,000$ & $20,286,000$ \\
\hline Nebraska... . . . . . . & $2,200,000$ & $70,400,000$ & $2 \mathrm{I}, 824,000$ \\
\hline Ohio............. & $\mathrm{I}, 683,000$ & $69,003,000$ & $24,841,000$ \\
\hline Indiana.......... & $\mathbf{I}, 638,000$ & $65,520,000$ & $22,277,000$ \\
\hline Michigan......... & I,530,000 & $64,260,000$ & $22,490,000$ \\
\hline All other States.... & $14,986,000$ & $472,944,000$ & $206,638,000$ \\
\hline United States..... & $40,780,000$ & $\mathrm{I}, 540,362,000$ & $555,569,000$ \\
\hline
\end{tabular}

\section{References}

Atterberg, 1.: Neues System der Hafervarietäten nebst Beschreibung der nordischen Haferformen. Landw. Vers. Stat., 39: I 7I-204, I88I. BöHMER, C.: Uber die Systematik der Hafersorten sowie über einige zuchterisch wichtige Eigenschaften der Haferispe. Berlin, Igoo, P. Parey. Hafer im Bilde. Fühling's Landw. Ztg., 609-6г6, IgIr.

BroILI, J.: Beitrage zur Hafer Morphologie. Jour. Landw., 58: 20,5-2 zo. I9Io.

Hafer im Bilde. Arb. Deut. Landw. Gesell. Heft, r94, Berlin, I9II. P. Parey.

Canvox, WI. A.: A Morphological Study of the Flower and Embryo of the

Wild Oat, Avena fatua L. Proc. Cal. Acad. Sci. Ser. 3, I, No. 10: 329-364, I900.

Cridder, N.: The So-called White Wild Oats and What They Are. Ottawa Nat., 23: 127, I909.

Wild Oats and False Wild Oats; Their Nature and Distinctive (haracters. Canada Dept. Agr. Bull. 7: I-Ir, I9I2.

Denaffe And Sirodot: L'avoine, etc. Paris, I902, 210 figures, pp. 848. Fruwert, C.: Die Iaferrispe bei der Beurteilung der Sorten und in der Züchtung. Fühling's Landw. Ztg., S. 289, 1007.

Haselfoff, E.: Vergleichende Untersuchungen deutscher und amerikanischer Haferkorner. Landw. Vers. Stat., 65:339-349, I907. 
Haussknecht, E.: Über die Abstammung des Saathafers. Mitt. Thüring. Bot. Ver. N. F. Heft, 2: 45-49, I892.

Raum, H.: Zur Systematisierung der Hafersorten. Fühling's Landw. Ztg., 58: 496-501, I909.

RıмPAU, W.: Die genetische Entwicklung der verschiedenen Formen unserer Saatgerste. Landw. Jahrb., 21: 699-702, I892.

Scinulz, A.: Die Geschichte des Saathafers I und II. Jahrsber. Westfal.

Prov. Vers. Wiss. W. Kunst. Munster., 4I: 204-217, I9I3.

Alstammung und Heimat des Saathafers. Mitt. Thuring. Bot. Ver. N.

F. Weimar., 3I: 6-II, I9I4.

Tinnert, Pall: Entwickelung und Bau von Blüte und Frucht von Avena sativa L. Inaug. Diss. Zurich, 1905 .

Thellung, A.: Über die Abstammung, den systematischen Wert und die Kulturgeschichte der Saathafer-Arten (Avena sativa Coss.) Vrtljschr. Naturf. Gesell. Zurich, 56:293-350, I9Ir.

Trabut, L.: Origin of Cultivated Oats. (Translation) Jour. Hered., 5: 74-85, I9I 5 .

Contribution a l'etude de l'origine des avoines cultivees. Compt. Rend., I49:227-229, I909.

Vieritapper, F.: Zur Systematik der Gattung Avena. Verhandi. K. K. Zool. Bot. Gesell. Wein., 56:369-370, I906.

Z.DE: Die Zwischenformen von Flughafer (Avena fatua) und Kulturhafer (Avena sativa). Fühling's Landw. Żtg., 369-384, I9x.2. 


\section{CHAP'TER XII \\ HORDEUM (Barley)}

Habit of Plant, Roots, Stems, Leaves.- Barley is urrown ats .either a summer or winter annual. It has been observed that two-rowed barley ( $H$. disticlion), has a distinct tendency toward the perennial habit like rye. Plants that were mowed down in July sent up new sprouts which developed inflorescences the following September, and after removing these, a third set of sprouts was sent up. It has been suggested that our cultivated barleys are derived from a perennial form and that in the course of time this habit has been lost.

The root system of barley resembles that of oats. The culm has from five to seven joints, sometimes eight, the length of which increases from below upward. Barley does not tiller as abundantly as oats and winter wheat. The leaves resemble those of wheat. The auricles, however, are usually very much pro-

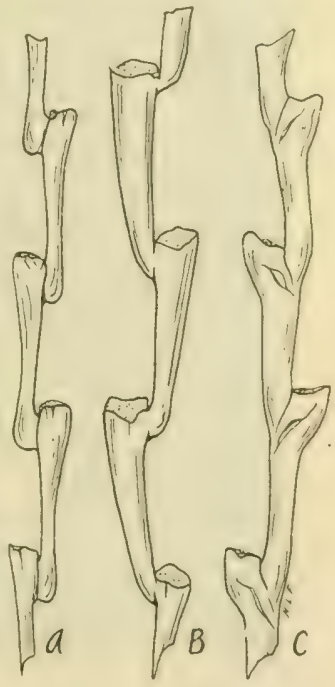

FIG. 48.- Rachises of three common cereals. $A$, bariey; $B$, wheat; $C$, rye. $\times 5$. nounced, and may be used as a basis of distinction between the straws (Fig. 26).

Inflorescence.- The inflorescence is a cylindrical spike, the shape of which varies slightly in the different barley 
types. The rachis is strongly compressed. Opposite each point on the rachis where the spikelets stand, there is a sharply defined horizontal cushion (Fig. 48). This distinguishes the barley rachis from that of wheat and rye. Furthermore, the single joints of the barley rachis are straight, while in wheat and rye they are bent.

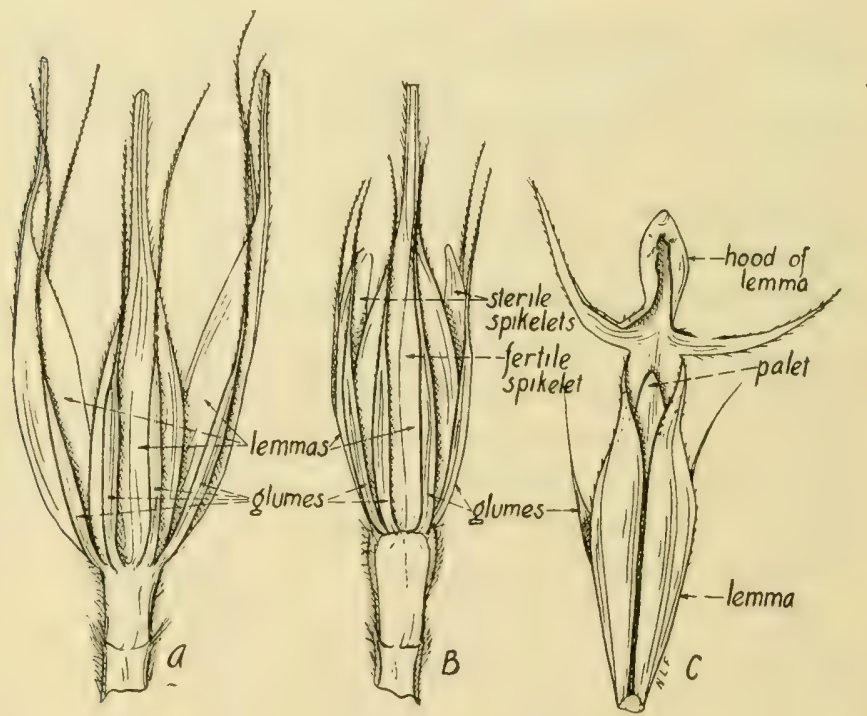

FIG. 49.-A, triplet of spikelets of six-rowed barley (Hordeum vulgare hexastichon); note that there are three fertile spikelets at the rachis joint; $B$, triplet of spikelets of two-rowed barley ( $H$. distichon); the two lateral spikelets are sterile; $C$, single spikelet of hooded barley ( $H$. vulgare trifurcatum).

At each joint of the rachis, there are three spikelets, each one-flowered (Figs. 49 and 50). The lateral spikelets of each triplet are sometimes imperfect, as in two-rowed barley. Each spikelet is on a short branch or rachilla, which is produced beyond the flower and appears as a bristle (Fig. 5I) lying within the groove of the grain. As in wheat, there is 
no apical spikelet in barley. The groups of spikelets are arranged alternately on the rachis.

Spikelet and Flower.-Each spikelet is one-flowered. The' glumes are narrow and awn-like, forming an apparent in-

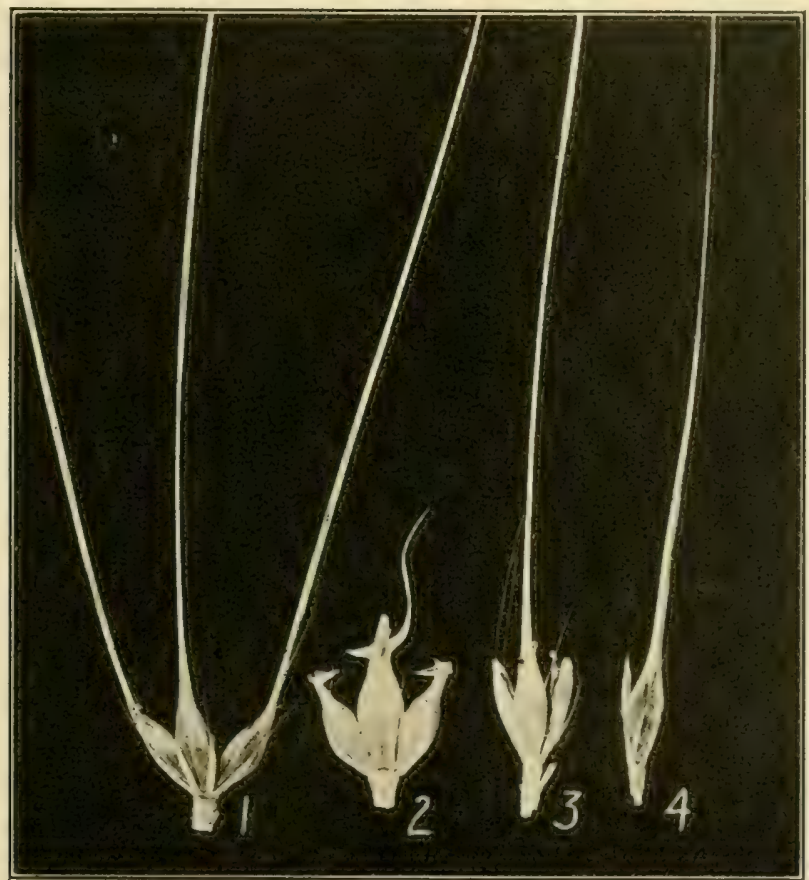

FIG. 50.-I, triplet of spikelets of six-rowed barley (Hordeum vulgare hexastichon); 2 , of hooded barley $(\mathrm{H}$. vulgare trifurcatum); 3 , of medium barley (H. vulgare intermedium); 4 , of two-rowed barley (H. distichon). Nat. size.

volucre about the spikelets. The lemma is broad, rounded on the back, five-nerved at the apex and bears a long awn with strongly barbed edges. In threshing barley care is taken not to break the awn so close that the end of the kernel 
is exposed, for by so doing, a point of attack for molds is furnished.

The palet is about the same length as the lemma, and bears two ridges. The styles are short, and the two lodicules are
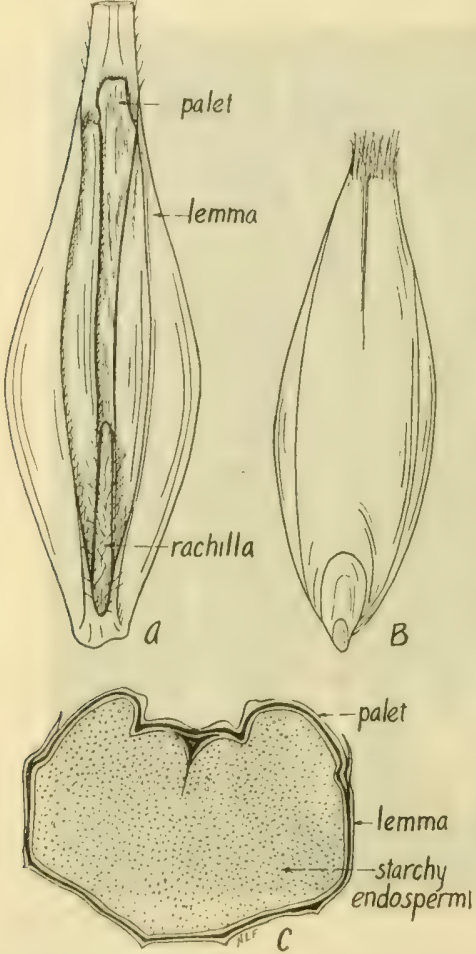

FIG. $51,-A$, barley grain with the "hull;" $B$, with "hull" removed; $C$, grain in cross-section. conspicuous and vagry in the different types.

Opening of Flower and Pollination.-The blooming of a spike begins slightly above the middle and proceeds from this point upward and downward. The middle flowers of a triplet come to maturity earlier than the laterals. The duration of blooming varies. Three to four days is a good average for a single spike, and seven to nine days for all spikes of a plant. The glumes of a flower remain open from twenty to thirty minutes. This period depends upon weather conditions.

In two-rowed nodding barley, the lateral flowers bloom with open glumes, while the middle ones seldom open. Four-rowed barley almost always blooms with open flowers, both middle and side. In two-rowed erect barley, six-rowed barley and peacock barley, the flowers bloom with closed glumes. It is claimed that, in such cases, the lodicules are too 
weak to force the glumes apart. In four-rowed barley. in which open flowers are the rule, lodicules are well developed. It would seem, then, that in four-rowerl barley and two-rowed nodding barley, there is a possibility of cross-pollination, while in six-rowed, peacock, and two-rowed erect barleys this possibility is excluded. However, very few positive cases of natural hybridization of barleys have been observed. The reason for this probably is that the styles are short and do not protrude beyond the glumes. Rimpau examined a large number of sorts, and in all, found but eight sure cases of crossing, and these were in four-rowed barleys. Self-pollination is the rule, which means that under field conditions there is little danger that a pure strain will become impure through the introduction of characters brought in by the pollen grains of undesirable strains.

Blooming in barley begins between 5:30 and $6: 00 \mathrm{a.m.}$ increasing in intensity up to $8: 00$ a.m. Very little blooming occurs in the middle of the day. There is a slight amount between 3 and 5 o'clock in the afternoon, but by 8 in the evening all blooming has ceased.

As in all cereals, blooming is dependent upon the weather. Barleys that normally bloom with open glumes on a day with high temperature and dry atmosphere, may bloom with closed or only slightly open glumes on a cool, moist day.

Fertilization and Maturing of Grain.--The immature grain has much the same structure as that of wheat. Kudelka finds that, in barley, the chlorophyll-bearing layer consists of two rows of cells, however. As in wheat, there is an carly resorption of the two layers of the outer integument. and of pericarp and nucellar cells. The barley grain passes through the milk-ripe, yellow-ripe, full-ripe, and dearl-ripe stages. 
Mature Grain of Barley.--In hulled barleys, the palet and lemma are firmly attached to the kernel (Fig. 5I). In the so-called "naked" or hull-less barley, these scales come loose from the kernel, as in common wheat. The kernel of naked barley resembles that of wheat. It is, however, pointed at both ends (Fig. 5 $\mathrm{I}$ ). The kernels are broadest at the middle, in two-rowed barleys, while in the four-rowed types the kernels from the outer rows of the head are slightly twisted and those from the middle rows are broadest near the tip.

In the hulled barleys, a rachilla ("basal bristle") persists at the base of the grain on the side adjacent to the palet (Fig. 5I). The character of this bristle is of some systematic importance.

The hull may form from 10 to 25 per cent. of the grain, being greater in. six-rowed types than in two-rowed types. Variation in percentage of glumes may depend upon season, soil, grain shape, and perhaps fertilizers. Furthermore, Haberlandt has shown that barleys of northern regions have a smaller percentage of hull than those of southern localities.

In a cross-section of the mature grain of hulled barley, the following coats are seen:

I. Lemma and palet, five to seven rows of cells.

2. Pericarp, consisting of several rows of parenchyma cells and two rows of chlorophyll-bearing cells.

3. Testa, two layers of inner integument.

4. Nucellus, one row of cells.

5. Aleurone layer, usually of three (two to four) rows of thick-walled cells.

6. Starchy endosperm.

As in rye and wheat, the fruit and seed coats are more weakly developed at the embryo end than in other parts of the grain. 
The embryo of barley is very similar to that of wheat. It occupies but a small part of the grain. Five to eight secondary rootlets occur. The epiblast is absent in the genus Hordeum. The endosperm varies from mealy to glassy or translucent. Mealiness is the result of a high percentage of starch, while translucency indicates a high percentage of protein. The relative amounts of starch and protein in the different types vary. The two-rowed barleys are used almost exclusively in brewing.

There is no gluten in barley grains, and for this reason light bread cannot be made from the flour.

Color of Grain.- Harlan has made a study of the color of barley grains. He says: "There are two coloring materials in barley: One, anthocyanin, is red in its acid and blue in its alkaline condition; the other, a melanin-like compound, is black. The pigments may occur in the hulls, the pericarp, the aleurone layer, and occasionally in the starch endosperm. The resulting colors of the grain are quite complicated. White denotes the absence of all pigment; a heary deposit of the melanin-like compound in the hulls results in black; a light deposit, brown. Anthocyanin in the hulls results in a light violet-red. In naked forms the melaninlike compound in the pericarp results in a black kernel; anthocyanin produces a violet one. The acid condition of anthocyanin in the pericarp superimposed upon the alkaline condition in the aleurone layer gives the effect of a purple color, while a blue aleurone beneath a colorless pericarp is blue-gray. White hulls over a blue aleurone cause the grain to appear bluish or bluish gray. Black hulls over a blue aleurone give, of course, a black appearance. The anthocyanin is always violet in the hulls and in the pericarp, showing that these tissues are in an acid condition, and always blue in the aleurone layer, showing an alkaline condition. The 
occurrence of anthocyanin in the pericarp of hull-less barleys is more significant than its production in the aleurone layer."

Germination of Barley.- Haberlandt gives the following as the germinating temperatures of barley: optimum $68^{\circ} \mathrm{F}$, minimum $37.4^{\circ}$ to $39.2^{\circ} \mathrm{F}$, maximum $82.4^{\circ}$ to $86^{\circ} \mathrm{F}$. In brewing, much emphasis is placed upon the "germinating energy" of the grain. By this is meant its ability to germinate within a specified time. A high germinating energy is 96 per cent. in seventy-two hours when kept at $64.4^{\circ}$ to $68^{\circ} \mathrm{F}$.

Much importance is attached to the secretion of enzymes and the conversion of endosperm in the germinating of barley grain. A barley of high diastatic power is preferred; by this is meant the ability to produce an abundance of the starchdissolving enzyme-diastase. Small grains, with a high nitrogen content have a high power of forming the enzymatic secretions. The enzymes secreted during germination are chiefly diastase, cytase, and proteases, and it is quite probable that the epithelial layer of the scutellum is the secreting organ. It has been pointed out by Mann and Harlan that "the greatest secreting area for a given grain is secured with a scutellum extending well over the edges of the adjacent endosperm; the greatest vigor in an epithelial layer of long, narrow cells, the highest condition of efficiency in a well-matured, well-cured grain." As has been indicated, the principal enzyme secreted by the germinating embryo is diastase. It has the specific property of changing starch to sugar. Hence, the reserve starch in the embryo, converted to soluble and diffusible sugar, serves to nourish the young plant. Cytase is a cellulose-dissolving enzyme. Protease renders the insoluble proteins soluble.

The primary root is the first to appear. This is followed by the secondary ones, and the young shoot. The shoot 
grows under the lemmat and palet to the anterior end of the grain and there becomes free. The coleoptile then opens

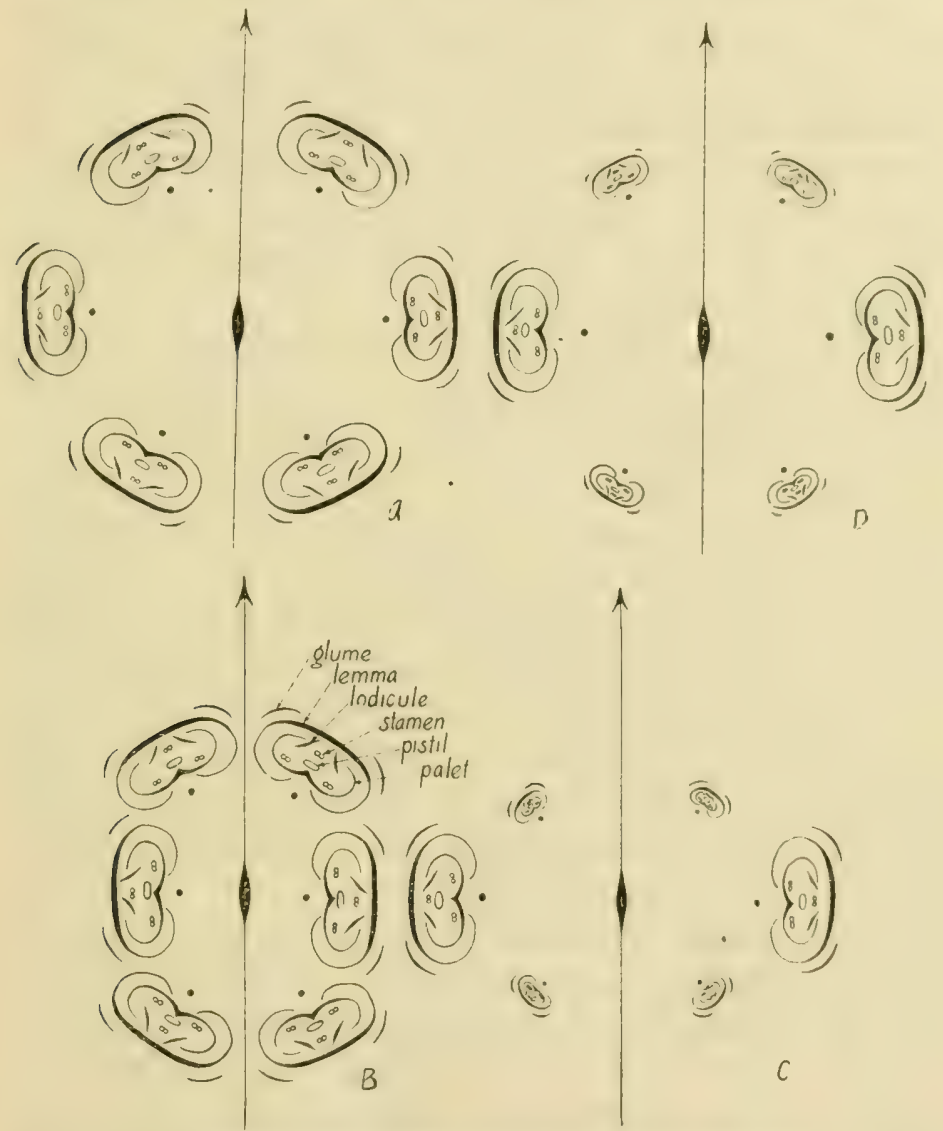

FIG. 52,-Diagrams showing the relative position of spikelets in barleys. 1. six-rowed (Hordeum vulgare hexastichon); $B$, four-rowed barley (II. vulgare pallidum); $C$, two-rowed barley ( $\mathrm{H}$. distichon); $D$, medium barley $(\mathrm{H}$. vulgare intermedium). (After Broili.)

and the first foliage leaf appears. In the germination of barley, the young leaves become twisterl. This is character- 
istic of barley. The term "acrospire" is sometimes applied to these leaves.

The crown roots are formed at a rather constant soil level. If the grain is planted deep, a long internode is formed, such that adventitious roots are produced at the proper level.

Classification of Barleys.-There is much difference of opinion concerning the classification of the cultivated barleys. There are at least two distinct species: Hordeum vulgare, including the six-rowed barleys, and Hordeum distichon, including the two-rowed barleys.

IIordeum vulgare hexastichon (six-rowed barley). - It will be recalled that, in the barleys, there are three one-flowered spikelets at each joint of the rachis. In the six-rowed type, every flower of a triplet is fertile. The spikelets are in six distinct rows and stand out equidistant from the rachis. Furthermore, the rows are equal distances from each other about the axis. These points are shown in Fig. 52. The lemmas of all three spikelets are bearded. The rachis internodes are very short, from 2.I to 2.7 millimeters long. The kernels from the outer rows are twisted, those from the middle row broadest near the tip, and symmetrical. The "hull" is thick. These are both winter and spring sorts. Six-rowed types are food barleys.

Hordeum anlgare (common six-rowed barley). - This is sometimes called a four-rowed barley. Every spikelet is fertile; the lemmas of all spikelets are bearded or hooded; the "hull" is thick; and there is a high percentage of protein. It differs from six-rowed barley in that the rows of grains are not equal distances from each other about the axis (Fig. $5^{2}$ ). The lateral grains of one triplet tend to overlap with the lateral grains of the triplet on the opposite side of the rachis. Hence, there will be found often four rows of grains, the central grains of each triplet forming two rows and the 
overlapping laterals also forming two rows. Furthermore, in four-rowed barley, the rachis internodes are longer (2.8 to 3.5 millimeters) than those in six-rowed barley, and this results in a more loosely arranged spike.

A form of four-rowed barley, Hordeum vulgare pallidum, is the common barley in northern Europe, Asia, and America. There are both winter and summer forms. Hordeum vulgare trifurcatum is the four-rowed Nepal barley. In this, the lemmas each have three pronged awns which bend back in the form of small horns or hoods (Fig. 49). It is also often called "hooded barley." There are both naked and hulled hooded barleys. Hordeum vulgare coerulescens is blue barley, $H$. vulgare nigrum, black barley, and $H$. vulgare coeleste, the hull-less Jerusalem barley.

Hordeum vulgare intermedium (medium or hybrid barley).Under this name are included those barleys that are transition forms between the two- and many-rowed types (Fig. 52). In these intermediate forms, only the two middle rows are normally formed, the four lateral ones being beardless and smaller. It is quite probable that the intermedium forms are segregates of the hybrids of certain two-rowed and many-rowed forms.

Hordeum distichon (two-rowed barley).- In this, the spikes bear two longitudinal rows of grains. As in six-rowed barley, the spikelets occur in groups of three on opposite sides of the rachis, but in the case of two-rowed barley, the lateral spikelets of each triplet do not mature, only the middle one of each maturing its grain (Figs. 49 and 52). However, the glumes of the lateral spikelets develop normally. The anthers of side spikelets may be either dwarfed or well developed. The kernels of two-rowed barleys are symmetrical and broadest in the middle. The hull is thin. There is a low percentage of protein and a mealy endosperm.

There are four rather common types of two-rowed barleys: 
I. Mordeum dislichon seocriton (peacock or fan barley) (Fig. 5.3). The spikes are very dense and short, about 6

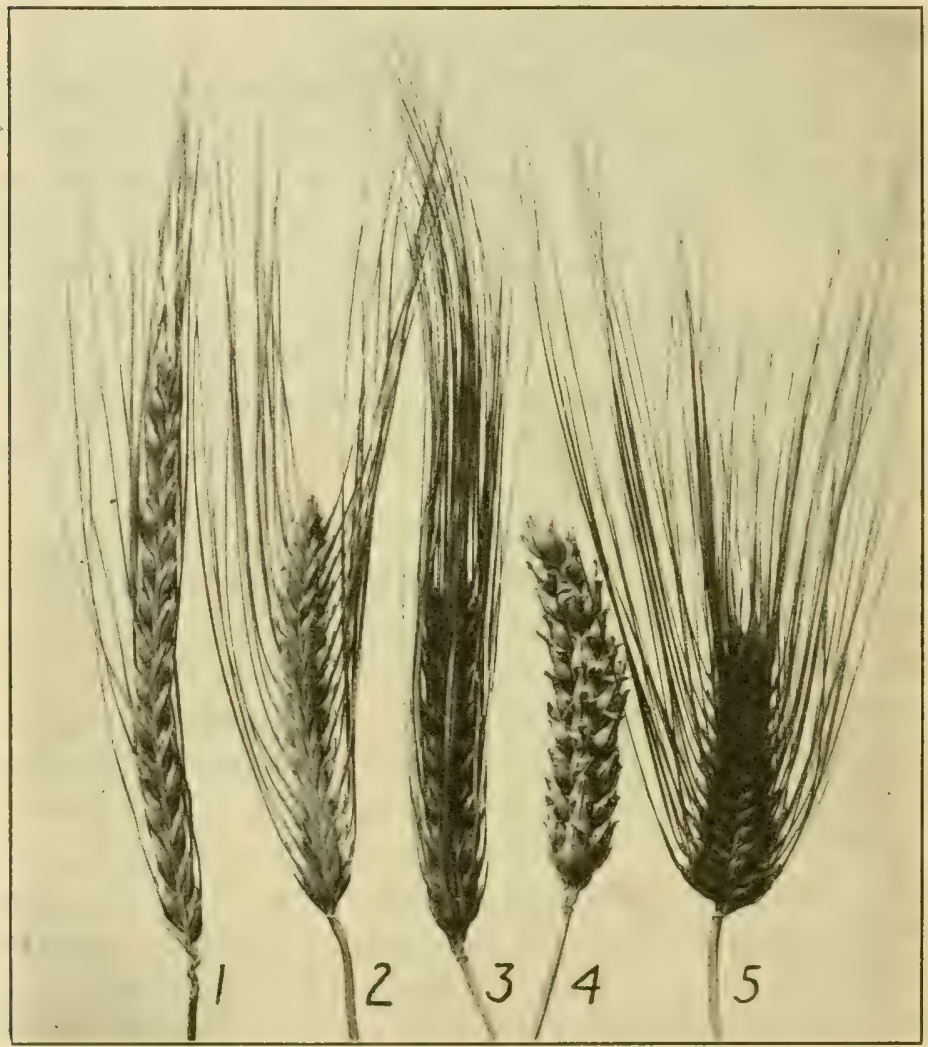

FIG. 53.- Spikes of barleys. I, two-rowed nodding barley (Hordeum distichon nutans); 2, medium barley ( $H$. vulgare intermedium); 3 , four-rowed barley (H. vulgare pallidum); 4 , hooded barley (H. vulgare trifurcatum); 5 , six-rowed barley (H. vulgare hexastichon).

centimeters long, broad at the base and narrow at the tip, and with widely spreading beards.

2. Hordeum distichon nudum (two-rowed naked barley). 
3. IIordeum distichon crechm (erect-eared barley).-In this the heads are erect and broad. ()n the dorsal side of the grain at the base, there is a characteristic crown furrow, so that in longitudinal section a rounded hump) show's (Fig. 54). Rachis joints are from 2.I to 2.7 millimeters long. The rachilla is hairy and broadened.
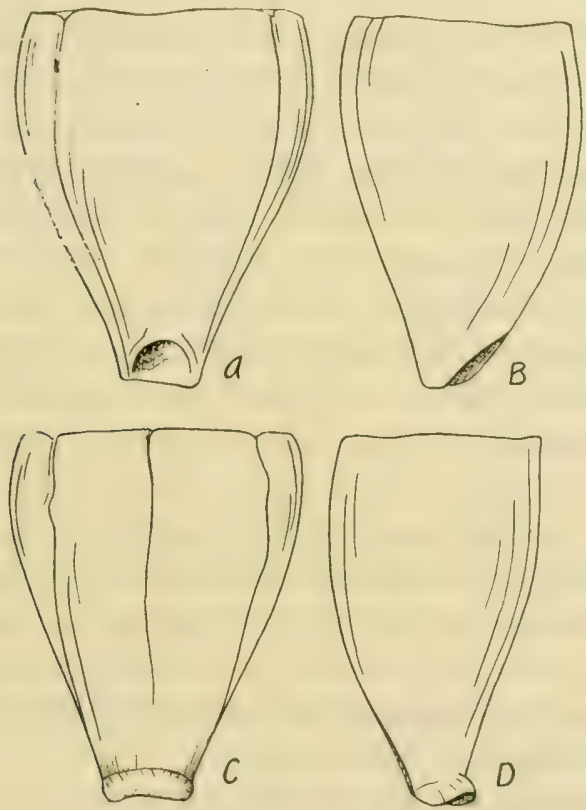

FIG. 54.--Bases of the grains of two-rowed barleys. $A, B$, nodding barley (Hordeum distichon nutans); $C, D$, erect-eared barley (H. distichon erectum). (After Newman.)

4. Hordeum dislichon nutans (bent or nodding barley).In this the heads hang down when ripe. On the dorsal side of the grain at the base, there is a slight horseshoe-shaped depression. In lengthwise section, the base of the kernel slopes off (Fig. 54). Rachis joints are 2.8 to 3.5 millimeters 
long. The rachilla is broom-form or very hairy. The noted malt barley, Chevalier, belongs to this type.

Origin of Cultivated Barleys.- There are two principal opinions regarding the origin of cultivated barley, that of Koernicke and that of Rimpau. Koernicke considers Hordeum spontaneum to be the prototype of all our cultural forms. This wild barley is nearest related to the mutans form of two-rowed barley, being distinguished from the latter by its more fragile rachis, less compressed spike, stronger awns, larger side spikelets, perennial habit, and its stronger tendency to tiller. The variety mutans first arose from the wild form. From this came erectum, by a shortening of the rachis joints. From erectum, came zeocriton by still greater shortening of rachis joints, and an enlargement of the fruit toward the base. From mulans also, there arose the four-rowed barley, by the side spikelets becoming fertile. From erectum and zeocriton, there came six-rowed barleys.

Rimpau, on the other hand, considers the six-rowed bearded barley as the prototype of all other barley types. Through a process in which side spikelets become rudimentary, there arose the various four- and two-rowed types. Rimpau bases his opinion on the nature of the offspring between zeocriton and trifurcatum.

Environmental Relations.-Winter barleys are less resistant to winter cold than either winter wheat or winter rye. Consequently, in the Northern States practically all barley is spring-sown. As a spring-sown crop it has a wide geographical range. It is grown as far as $65^{\circ} \mathrm{N}$. latitude in Alaska, and to an altitude of 7,500 feet in the Rocky Mountains. At higher elevations it is grown as a hay, the chief variety being "bald barley." Barley also does well in southern California. 
Barley stands between oats and wheat in its water requirement.

Uses of Barley. Barley has a great variety of uses. Its greatest use is in the preparation of malt. 'The two-rowed barleys have larger and softer grains than six-rowed barleys and therefore are preferred for malting purposes. Smaller quantities are ground into flour from which bread is made. "Pearl barley" (grains with the lemma and palet removed) is used for soups. Barley enters into a few cereal breakfast foods. It is a valuable stock feed, especially for hogs, sheep, dairy cows, and poultry. The six-rowed barleys are regarded as valuable sorts for feeding. The hooded varieties, chiefly. are grown as hay. Barley is sometimes grown as a pasture crop, as a nurse crop and as a smother crop. A paslure crop is used for grazing. A nurse crop is a temporary one often planted with a forage plant such as clover or alfalfa in order to secure a greater return from the land the first year, also to inhibit weed growth, and to prevent the blowing or washing of the soil. A smother crop is used to prevent the growth of weeds. The straw of barley is fed, and also serves as a bedding for stock. Malt sprouts and "brewers' grains" are now and then utilized as stock food.

The Brewing Process.-Brewing operations vary considerably in the different countries, and with the character of the product. The brewing materials employed are malt. hops and water. The malt is made from germinating barley, and to this are sometimes added unmalted cereals such as corn, wheat and rice.

Malting.-- In this process, barley is prepared for brewing purposes. The barley grains are steeped for about fortyeight hours in water, and then spread out on the malting floor. The temperature of the air in the malting room is inween 50 and $60^{\circ} \mathrm{F}$. Germination is not allowed to pro- 
ceed to the point when the young shoot (acrospire) breaks out from under the lemma and palet, but the process is checked by transferring the germinating grain to a kiln where it is kept for about twelve hours at a temperature sufficient to thoroughly dry it out. During germination, there is secreted from the epithelial layer of the scutellum a diastase which converts the starch to maltose sugar. Peptase is also secreted by the germinating barley; this enzyme modifies the albuminoids of the malt.

Mashing.-The malt, prepared as above, is cleaned, and crushed in a roller mill. It is then mixed with water, and in some cases with unmalted cereals. The mash is then held at the proper temperature for the action of diastase and peptase, which chemically invert the starch into maltose, maltodextrin and dextrin, and change the insoluble albuminoids to a soluble form.

Boiling the IVort.- The product of the mashing machine is called "wort." During the boiling process, hops are added. Boiling serves not only to extract desirable products from the hops, but to render harmless certain undesirable constituents. After boiling, the wort is strained into coolers.

Fermentation.-. Yeast is now added to the wort. This introduction of yeast is called "pitching." Through the activity of yeast, the sugar in the wort is changed to alcohol and carbon dioxicle. The wort has been changed to beer. It is removed from the fermenting vat, stored for a period to allow certain products to settle, and also to permit of afterfermentation, and then clarified, filtered, and packed for the market.

Production of Barley.- The four leading countries, in T9I5, in the production of barley were: Russia, United States, fiermany, and Austria-Hungary, producing respectively $475,109,000 ; 277,009,000$; I 50,000,000; and I 36, I 86,000 bushels. 


\section{Acreage, Production and Farm Value of Barley in Various States, I9I 5}

\begin{tabular}{|c|c|c|c|}
\hline States & Acres & Bushels & $\begin{array}{c}\text { Farm value, Dec. } \\
\text { I, dollars }\end{array}$ \\
\hline North Dakota...... & $\mathbf{I}, 400,000$ & $44,800,000$ & I9,7 12,000 \\
\hline Minnesota......... & $\mathbf{I}, 350,000$ & $4 \pi, I 75,000$ & $20,176,000$ \\
\hline California. . . . . . . & $I, 360,000$ & $39,440,000$ & $24,453,000$ \\
\hline South Dakota..... & 750,000 & $24,000,000$ & II $, 040,000$ \\
\hline Wisconsin ........ & 656,000 & $23,288,000$ & I3, O4I, 000 \\
\hline Iowa.............. & 353,000 & $10,943,000$ & $5,362,000$ \\
\hline Kansas............ & 270,000 & $8,370,000$ & $3,515,000$ \\
\hline All other States... & $\mathbf{I}, 256,000$ & $44,993,000$ & $25,200,000$ \\
\hline United States...... & $7,395,000$ & $237,009,000$ & I 22,499,000 \\
\hline
\end{tabular}

\section{References}

Attizblire, 1.: Die Erkennung der Haupt-varietaiten der Gerste in den \ordeuropäischen Saat- und Malzgerstan. Landw. Versuchstat., 36: $23-27$, I 889 .

Die Varietäten und Formen der Gerste. Jour. Landw., 47: I-44, I899.

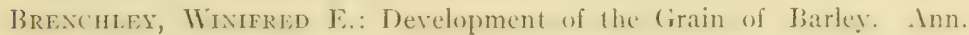
Bot., 26: 903-928, I9 2 .

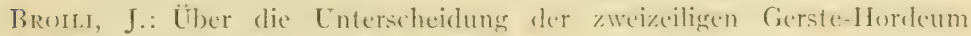
distichum-am Korne. Inaug. I)iss. Univ. Jena, I go6.

Das Gernstenkorn im Bilde. Stuttgart, I 908.

Brown, H. T., and Escombe, F.: On the Depletion of the Endosperm of Hordeum Vulgare during Germination. Proc. Roy. Soc. (London), $63: 3^{-25}, \mathrm{x} 898$.

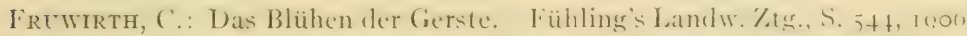

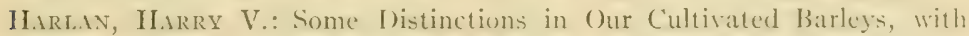
Reference to Their Use in Plant Breeding. U. S. Dept. Agr. Bull. I37, $\mathrm{I}-38$, I9I4.

Hexinga, E.: Beobachtungen über das Blühen der Gerste (Schwedisch. Bot. Notiser., 1905.

Hemar, .1.: Dic botaṇischen Lnterscheidungsmerkmale bei zweizeiliger Gerste. Illus. Landw. Ztg., 830-839, I900.

Jom.nNsex, WI: Entwickelung und Konstitution des Endosferms der Gerste. Ztschr. Gesam. Brauw., I905.

Krats, C.: Die Gliederung des Gersten- und IIaferhalmes und heren Beziehungen zu den Fruchtständen. Bciheft I der Naturwis. Zitsch. für Land- und Forstwirthschaft. München, I905. 
Mann, Albert, and Harlan, H. V.: Morphology of the Barley Grain with Reference to its Enzyme-secreting Areas. U. S. Dept. Agr. Bull. r83: I-32, I9I 5 .

Quante, Hugo: Die Gerste, ihre botanischen und brautechnischen Eigenschaften und ihre Anbau. Berlin, rgr3.

RimpaU, W.: Die genetische Entwicklung der verschiedenen Formen unserer Saatgerste. Landw. Jahrb., 2I: 699-702, I892.

Schulz, A.: Die Geschichte der Saatgerste. Ztschr. Naturw., 83: I97-233, IgI2.

Die Abstammung der Saatgerste, Hordeum sativum I-II. Mott. Naturf. Gesell. Halle, I: 18-27, I912.

TscherMak, E.: Die Blüh- und Fruchtbarkeitsverhältnisse bei Roggen und Gerste und das Auftreten von Mutterkorn. Fühling's Landw. Ztg.. S. I94, I906.

Voss, A.: Versuch einer neuen Systematik der Saatgerste. Jour. Landw., 33: $271-282,1885$.

Zobl, A., and Mikosch, C.: Die Funktion der Grannen der Gerstenahre, Zitzber. Akad. Wiss. (Vienna) Math. Naturw. Kl., IoI: Abt. I, I0331060, I892. 


\section{CHAPTER XIII \\ SECALE CEREALE (Rye)}

Habit of Plant, Roots.- Rye is an annual. It is reported. however, that rye stubble in a field may sprout after long standing, or that close pasturing for a season may cause it to live through a second winter. This is no doubt a reversion to the perennial habit displayed by the species from which our cultivated rye came.

Rye throws out a whorl of four primary roots, thus differing from the other cereals. The root system branches profusely in the first foot of soil and extends to a depth of 4 or 5 feet.

Stems, Leaves.-As compared with wheat, oats and barley, the stems of rye are tougher, slenderer, and longer. There are commonly five to six, rarely four to seven stem joints. The leaves are similar to those of wheat. The ligule is short and somewhat rounded. The auricles are white, narrow and wither early; sometimes they are absent altogether.

Inflorescence.--This is a spike. It is usually somewhat longer than the wheat spike, and is rather uniformly fourrowed. There are from 20 to 30 rachis joints. There is a single spikelet at each joint. All the spikelets, from base to tip, are fertile. The spikes have no terminal spikelet.

Spikelet.--Each spikelet (Fig. 55) consists of three flowers. The two lateral flowers mature grains, the middle one aborts. The glumes are very narrow; the lemma is broad, keeled, and bears a long, terminal awn; the keel is strongly barbed; the palet is thin, blunt and two-keelerl. The lodlicules are 
small, membranous, and ciliate on the upper margins. 'There are three stamens, and a single pistil with two feathery stigmas.

Opening of the Flower, Pollination and Fertilization.Rye is the only common cereal, besides corn, that is regularly cross-fertilized. These two cereals cannot be self-fertilized without a reduction in vigor and productivity. Apparently,

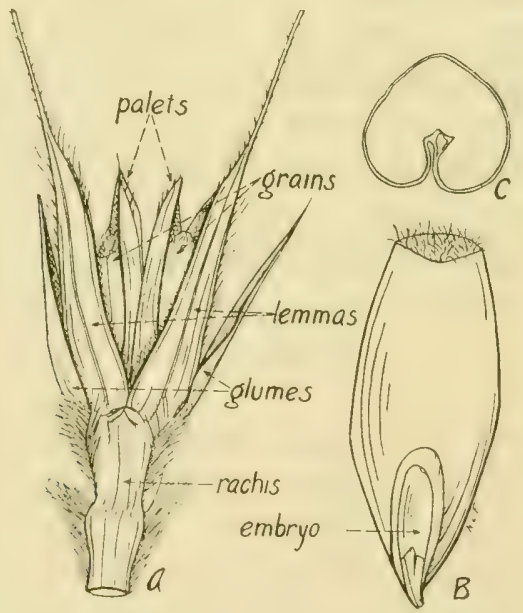

Frg. 55-Ryè (Secale cereale). A, a single spikelet at a joint on the rachis; $B$, grain, external view; $C$, grain in cross-section. $A, \times 2 \frac{1}{2} ; B$ and $C$, $\times 5$.

no ill effects result from self-fertilization of barley, wheat and oats. According to some observers, the pollen of rye is impotent on the stigma of the same flower. Fruwirth notes that the flower is completely closed within twenty-five to thirty minutes after it begins to open, providing the stigmas receive pollen. In case the stigmas are not dusted, the flowers remain open much longer. Blooming begins between 5:00 and 6:00 a.m. and continues until 0:00 or I r:00 a.m. Then bloming decreases throughout the afternoon, becoming 
more ratpid again in the evening. The first flowers to open are slightly above the middle of the spike. It has been ol)served that the flowers of rye can be induced to open by rubbing with the hand, or by other mechanical stimulation.

Maturing of Grain, and Mature Grain.-The anatomical structure of the ovary at blooming time is similar to that of wheat, as are also the changes which take place in the grain during its ripening.

The mature grain (Fig. 5.5) is free from the lemma and palet. It is long. narrow, and usually darker in color than wheat. The cross-section of the mature grain shows layers similar to those in wheat, although different from it in details.

Rye protein usually forms about 6 to r 2 per cent. of the grain. Gluten is present in the protein, hence, the flour may be made into porous bread. It will be recalled at this point that of the common small cereals, wheat and rye possess gluten, while oats and barley do not. The flour from rye is more starchy than that from wheat.

Germination of Rye.- Under favorable conditions, germination will take place in thirty-six to forty-eight hours. The optimum germinating temperature is $77^{\circ} \mathrm{F}$. maximum $87^{\circ} \mathrm{F}$, and minimum $33.8^{\circ} \mathrm{F}$, to $35.6^{\circ} \mathrm{F}$.

By deep seeding, rye may send out roots and tillers at the second, third, or even fourth node. As a result rye can be planted deeper than wheat. The coleoptile is closed; the first leaf is rolled and brownish-red, which color distinguishes the rye seedling from other cereals.

Classification, and Origin of Rye.--The cultivated sorts of rye all belong to the one species, Secale cereale. This originated from Secale anatolicum, one of the subspecies of $S$. montanum. This stem form differs from $S$. cereale in the fragile ratchis, the smaller, narrower fruit, and perennial rootstock.

Environmental Relations.-- Rje is arlapted to colder and 
drier climates than wheat, and will thrive on poorer soils and more sandy soils than any of the other cereals.

Uses of Rye.-Rye flour is made into bread. A few breakfast foods include rye as a minor component. Mixed with barley, or corn, or shorts, or oats, rye grain is fed to stock. In some sections it is grown for hay, or as a pasture crop, and now and then as green manure. The straw finds considerable use as a stable bedding, as a packing material for nursery stock, as a stuffing for horse collars, and it is also used in the manufacture of paper, strawboard, hats, and other coarse straw articles.

Production of Rye.- Russia produced 861,097,000 bushels of rye in I9I5; Germany ranked second, with 470,000,000 bushels, Austria-Hungary third, with $154,075,000$ bushels, and the United States fourth, with 49,190,000 bushels. The five leading States in the order of their production for the year r 915 are Wisconsin, Michigan, Minnesota, Pennsylvania, and Nebraska.

\section{References}

Batalin, A.: Das Perennieren des Roggens. Acta. Horti. Petropolitani, II : 299-303, I89o. Also Verhandl. Bot. Ver. Brand., 32:29-32, I89I. Rimpau, W.: Die Selbst Sterilität des Roggens. Landw. Jahrb., 6, I877. Schulz; August.: Die Geschichte des Roggens. Jahresbericht des Westfälischen Provinzial-Vereins für Wissenschaft und Kunst (zu Münster) für I9I0-I9II, 39: r53-I63, I9II.

Beitrage zur Kenntnis der kultivierten Getreide und ihrer Geschichte, I.

Die Abstammung des Roggens. Zeitschr. Naturw., 84:339-347, I9I3. 'Гsсиекмak, E.: Über künstliche Auslösung des Blühen beim Roggen.

Ber. Deut. Bot. Gesell., 22:445-449, 1904 .

Das Blühen des Roggens (Secale cereale). Östrk. Landw. Wchnbl., I906, p. 163 .

Die Blüh- und Fruchtbarkeitverhältnisse bei Roggen und Gerste und das Auftreten von Mutterhorn. Fuhlings Landw. Ztg., 55: 194-199, I906. Ulrich, C.: Die Bestäubung und Befruchtung des Roggens. Inaug. Diss., Jena, I902.

Witmack, L.: Über die Stammpflanze des gemeinen Roggens, Secale cereale. Verhandl. Bot. Ver. Brand., 32:32-34, I89o. 


\section{CHAP'TER XIV}

\section{ZEA (Corn, Maize)}

Habit of Plant, Roots.-Corn is distinctly a summer annual.

The root system is fibrous. Corn generally has been consiclered a shallow-rooted plant. The contrary is the case. At maturity the roots come to fill the upper 3 feet of soil and, under some conditions, may reach to a depth of 4 or 5 feet (Fig. 56). The depth of planting appears to bear no relation to the depth of rooting, for the first whorl of roots usually forms about $\mathrm{I}$ inch below the soil surface, no matter how deep the seed is planted. It will be remembered that this is true for the other cereals too. The roots of corn are thrown off in whorls, varying in number from two to ten, one whorl above another. The internodes between whorls are very short. The entire group of whorls constitutes the root crown.

Two kinds of roots are developed (Ten Eyck): (a) main vertical roots and (b) main lateral roots. Vertical roots curve out slightly from the crown and go directly downward. The laterals curve downward, as they leave the crown, then extend horizontally for a distance, finally taking a downward course. Laterals that leave the crown at about the soil level slope gradually downward, as indicated above. Midway between the rows of planted grain, about 22 inches from the 
hill, these laterals are aboul for 5 inches below the soil level. The laterals may be shallower than given, in heavy soils

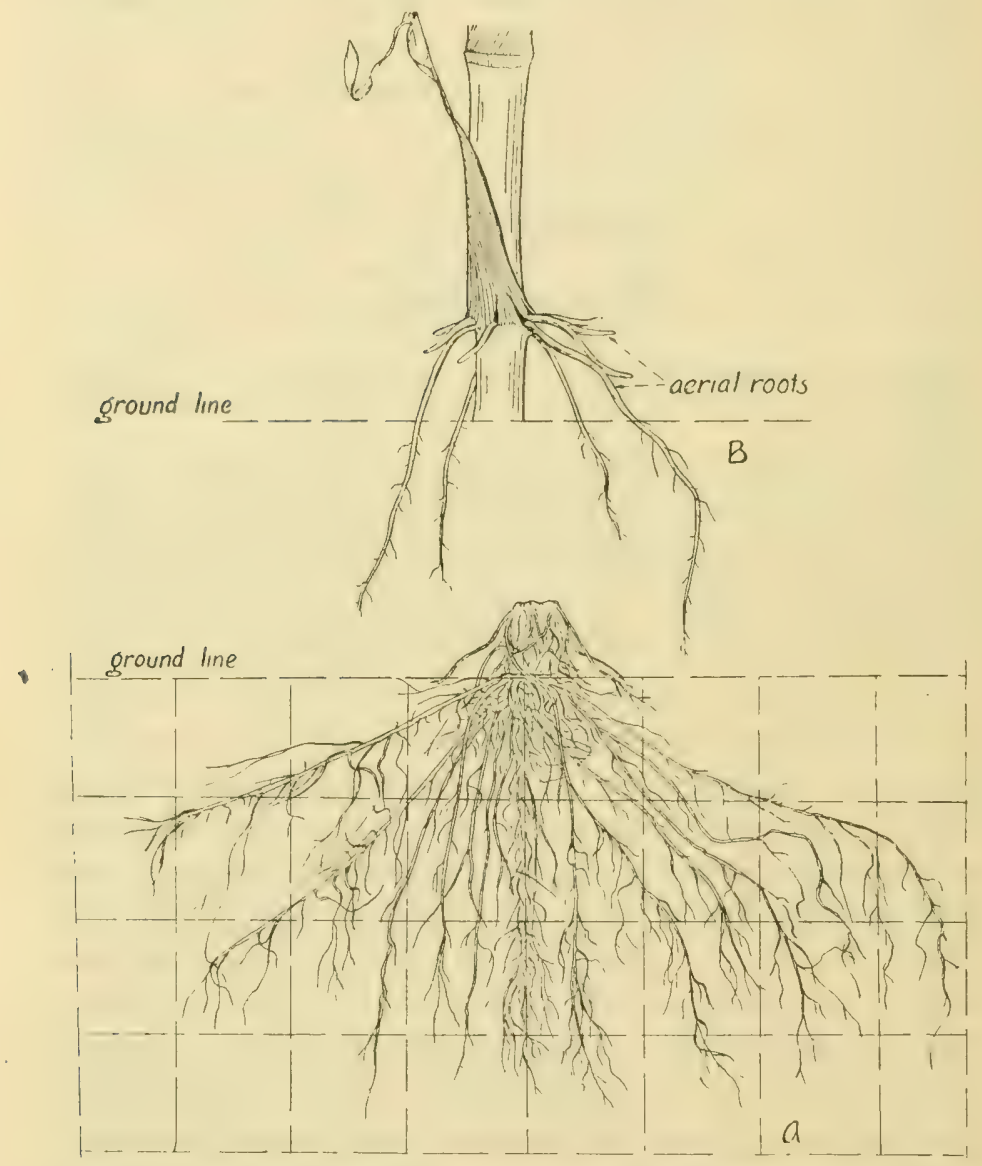

FIG. 56. $-A$, root system of corn (Zea mays); the squares are one foot on a side; $B$, prop or aerial roots of corn. (A, redrawn from U. S. Dept. Agri.; B, somerwhat modified after Bailey.)

and wet seasons. The roots of most plants are more superficial in a heavy or wet soil than in a light and drier soil. 


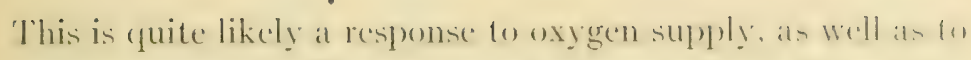
moisture supply. The amount of oxygen in the sobl flereaties ats the depth increases. Moreover, the rate of decreatice is greater in heavy or wet soils than in light or dry soils. When it is understood that every living root cell derives its oxyen for respiration from the soil air immediately surrounding and that the oxygen does not diffuse to any extent from the aterial parts of the plant down through the stem to the roots. we see the probable explanation of the fact that a shallow root system is peculiar to a heavy or wet soil. In this connection, it should be stated that an important result of tillage is the loosening of the soil so that oxygen may more easily diffuse to the roots of the plant. All main roots grive ofi numerous finer branches and these in turn branch, so that at maturity there is an interlacing mass of roots in the soil. Fully two-thirds of the entire root system occurs in the first + inches of soil. This statement is based on records of a number of observers (Sturtevant, Hunt, Newman, 'Ten Eyck, Hays). Ten Eyck has observed that, although the main laterals are several inches below the soil surface, they may send upward finer branches to within 1, inch of the surface. The depth of the corn roots determines the deptin of cultivation. If it is so deep as to destroy roots, the yicld is decreased.

"Prop" or "Brace" Roots.-In addition to the ordinary underground roots, corn develops aerial roots, the so-called "prop" or "brace" roots (Fig. 56). These arise in whorls at successive levels above the surface, extending obliguely. downward. They are covered with a mucilaginous sub)stance which protects them from drying out. Is acrial roots, they are unbranched, but they branch profusely when they strike the soil. They have the rôle of absorption, then, as well as anchorage. 
Stem.- ('orn is the largest of the common cereals. However, no other cereal varies so in size. There are dwarf forms scarcely 3 feet high, while some are 15 or more feet high. The stem is jointed as in all grasses. The internodes, however, are not hollow, but are filled with a soft pith through which run numerous vascular bundles, the fibers. The nodes are solid as in other grasses. The internodes are furrowed on the side next the leaf blade. The corn plant produces "suckers" which correspond to the "stools" of wheat, as to their morphology. "Suckers" are secondary stems or branches arising from the lower nodes. These branches develop their own roots. "Suckers" of corn are undesirable, for they do not, as a rule, produce ears, although they are heavy soil "feeders."

Leaves.- The leaves are arranged alternately on opposite sides of the stem as in all grasses. They vary in number from 8 to 20 . The blade is long and flat; the ligule closely invests the stalk, acting as a rain-guard. Water that runs down the stem and leaf blade is prevented from entering the space between the culm and leaf sheath by this tightly fitting ligule.

The corn leaf is thrown into a number of folds along the edges and at the base. This is due to the more rapid growth of the cells at these points. The corn plant is moderately well adapted to dry conditions. An examination of the leaf structure explains this. On the upper surface of the leaf blade, along either side of the midrib, are a number of large wedge-shaped cells; these absorb water readily in moist weather, become turgid, and thus flatten the leaf out. In dry weather, these cells lose their turgor. Hence the leaf rolls up, presenting a smaller evaporating surface. In addition to this adaptation to dry conditions, the cuticle of the lower surface of the leaf is much thickened, and the water 
requirement of the plant is low as compared with vats, clover, or alfalfa. It has been computed that an atverage acre of well-adapted corn, grown at the Nebraska Agricul-

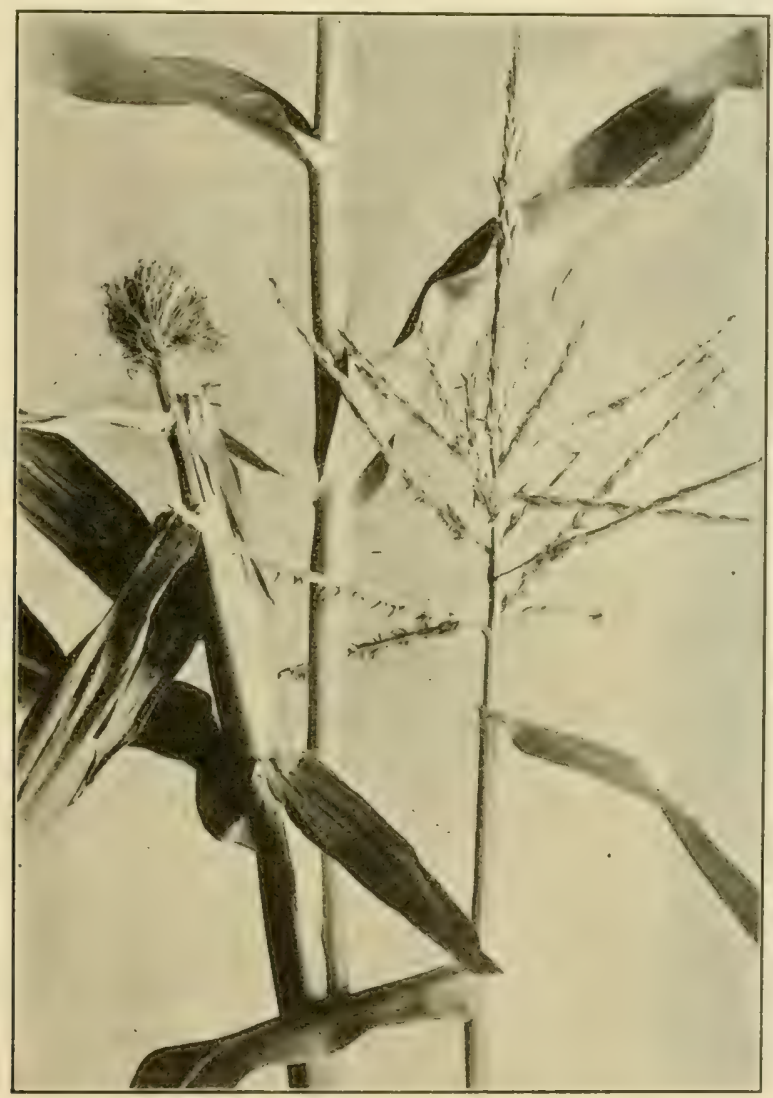

FIG. 57--Pistillate and staminate inflorescences of corn (Zea mays).

tural Experiment Station, has 4 acres of leaf space, counting both sides.

Inflorescence.-Ordinarily, corn is monnecious, that is, 
the stamens and pistils are borne in separate inflorescences on

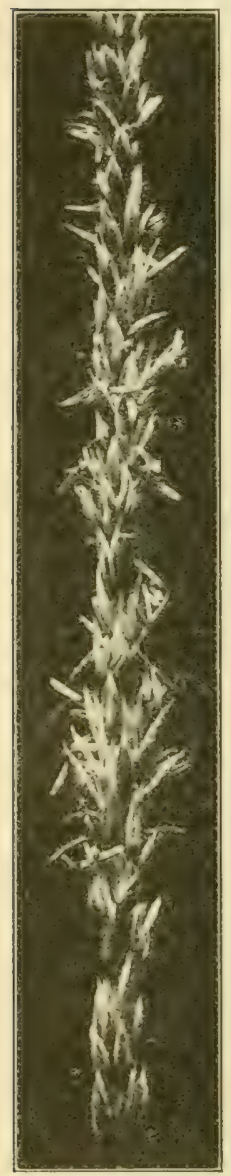

FIG. $58 .-\mathrm{A}$ single branch of the staminate infiorescence of corn (Zea mays). the same plant (Fig. 57). The staminate flowers are in a panicle at the top of the stalk; this inflorescence is known as the "tassel." The pistillate flowers are borne in a spike which is placed in the axil of a leaf lower down on the stem. When mature, the pistillate inflorescence is called the "ear."

Staminate Inflorescence ("tassel").--The rachises of the panicle are long, slender, and spike-like. One may distinguish between the central and lateral spikes of the panicle. In the central spike (Fig. 58), there are usually from four to eleven rows of spikelets, in pairs. Lateral branches usually have only two rows of spikelets, in pairs. One spikelet of each pair is pedicellate, the other sessile (Fig. 59), or in some cases both may be sessile. The groups of spikelets may overlap.

Staminate Spikelet.-Each normal staminate spikelet bears two flowers, each producing three perfect stamens and a rudimentary pistil (Fig. 60). The glumes are seven- to twelve-nerved, and about equal in size. The lemma is three- to five-nerved and the palet two-nerved. The two lodicules are fleshý and truncate. The anthers are long. The upper flower of a spikelet matures first; its palet is larger than the lemma, while in the lower flower, the lemma is larger than the palet.

Pistillate Inflorescence ("ear") Gcneral Characteristics.-The ear (Fig. 6I) is borne on a short 
branch, the so-called "shank." 'This branch consists of at number of very short internodes with one modified leaf at each node. The blades of the modified leaves have beem

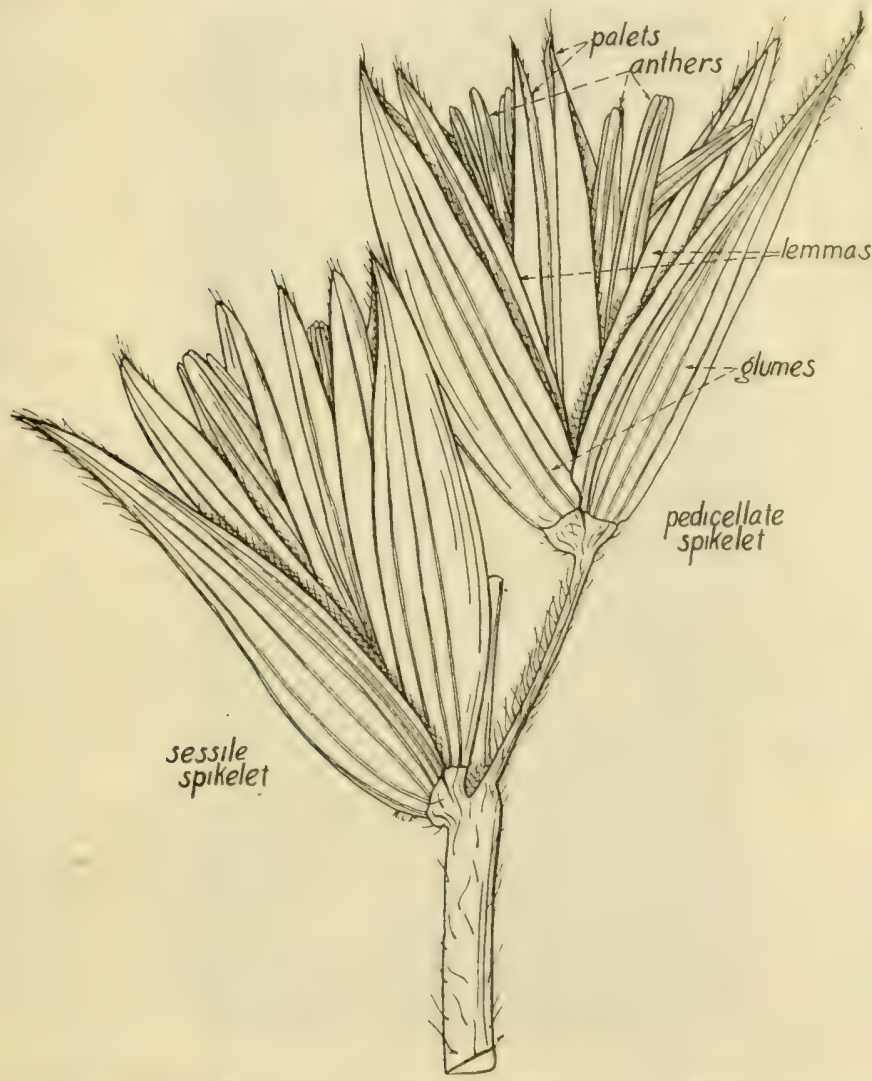

FIG. 59.-A pair of staminate spikelets of corn (Zea mays).

reduced, the leaf sheaths alone remaining. The collection of leaf sheaths on the shank forms the "husk" of the ear. The pistillate spikelets are arranged in rows along a fleshy" axis, the "cob." 
What Is the "Ear," Morphologically?-There are two theories as to the morphology of the car of corn. The view of Hackel and of Harshberger is that the ear is the result of

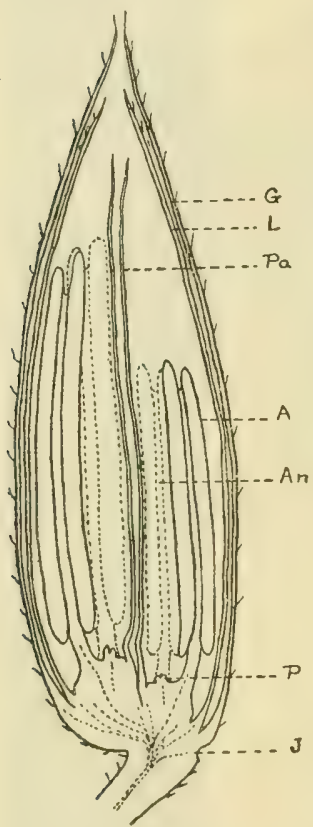

FIG. 60.-Longitudinal section of staminate spikelet of Country Gentleman sweet corn, $\times$ I 5 . $G$, glume; $P a$, palet; $A n$, position of one of the lateral anthers; $L$, lemma; $A$, dorsal anther. $P$, rudimentary pistil; $J$, joint of rachilla. (Afier Weatherwax.)

spike has the greater number of rows of spikelets.

4. He has observed the development of pistillate flowers from staminate ones. This development is as follows: pistillate spikes. Since each spikelet is two-flowered, and the lower abortive, there are often formed the two distinctly paired rows. The cob is said to be formed by the fusion of separate rachises. Opposed to the above theory is that of Montgomery, who holds that the ear develops "directly from the central spike of some tassel-like structure similar to the well-known corn tassel." His evidence for this belief may be summarized as follows:

I. He has found tassels in which a few pistillate flowers were found on the central spike, also tassels in which the central spike had developed into a fairsized ear of corn.

2. He observed a case in which the lateral spikes as well as the central one had developed pistillate flowers, forming a number of four-rowed "nubbins" surrounding a central well-developed twelve-rowed ear.

3. The central spike develops pistillate flowers much more readily than the lateral ones of the tassel. The central

a fusion of a number of two-rowed 
(a) Pedicellate spikelet shortens and beromes sessile; the difference between the two flowers of this becomes greater.

(b) The lower glume shortens and thickens.

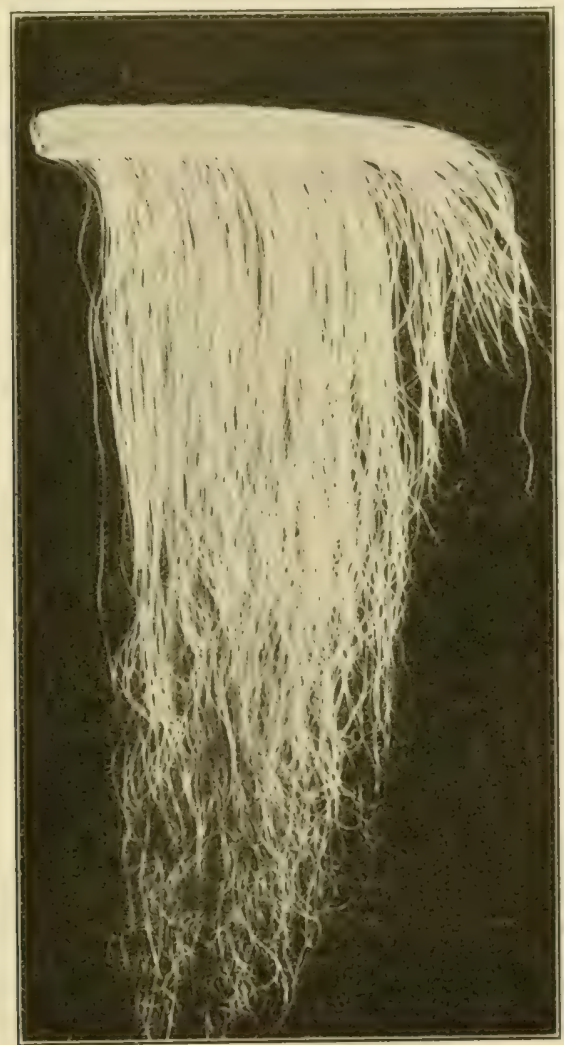

FIG. 6r.-Corn (Zea mays). Young pistillate inflorescence ("ear"), showing the long styles ("silks").

(c) Lemma and palet of upper flower become reduced while the lower flower becomes abortive.

(d) Sessile flower becomes pistillate.

(e) Both flowers become pistillate. 
Recently East and Hayes have expressed an opinion very similar to that of Montgomery. Quoting from them, "The car of maize, then, is a meristic variation produced from the central spike of the tassel of the lateral branches of teosinte or of a teosinte-like plant, and not a fusion of the lateral spikelets." Montgomery suggests that teosinte and corn had a common ancestor, which was a "large, much-branched grass, each branch being terminated by a tassel-like structure,

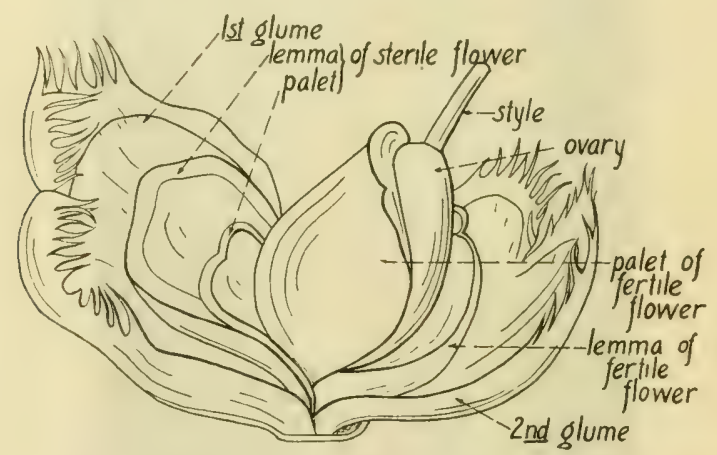

FIG. 62.-Pistillate spikelet of corn, much enlarged. (After Nees.)

bearing hermaphrodite flowers." He says further: "As evolution progressed, the central tassel came to produce only staminate flowers, these being higher and in a better position to fertilize the flowers on the lower branches. At the same time, the lateral branches came to produce only pistillate flowers, their position not being favorable as pollen producers, while, on the contrary, they were favorably placed to receive pollen. This differentiation in the flowers was accompanied by a shortening of the internodes of the lateral branches until they were entirely enclosed in the leaf sheaths" (the husks).

Pistillate Spikelet.-Each normal pistillate spikelet has two 
Howers, the lower one of which is abortive (Figs. 62 and 0,3 ). The palet and lemma of the abortive flower remain, and form a part of the "chaff" on the cob. The spikelet is subtenterl

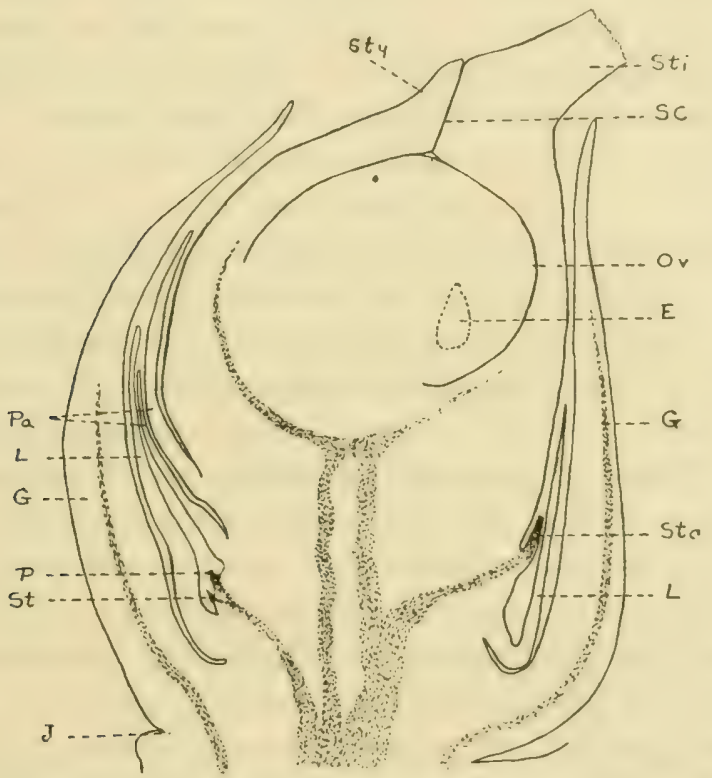

FIG. 63.-Longitudinal section of pistillate spikelet of Black Mexican sweet corn, $\times 25$. Sti, base of stigma; Sty, style; $E$, outline of embryo sac; $L$, lemma; $P a$, palet; $S t$, stamen of aborted flower; $S c$, stylar canal; $O z$, functional ovule; $G$, glume; Sta, rudimentary stamen; $P$, pistil of aborted flower; $J$, joint of rachilla. (After Weatherwax.)

by two glumes that are shorter than the ovary, very broad and fleshy at the base, thin membranous above and fringed

${ }^{1}$ Stewart has noted, in the Country (ientleman variety of corn, that some spikelets bear two well-developed flowers inside each pair of glumes. He further points out that the irregularity in the arrangement of grains on the ear may be due to the development of the second llower in some of the spike lets, which tends to throw some of the grains out of line. The same has been noted by Sturtevant and Kempton. 
on the edges. The lemma and palet of the fertile flower are short, broad and membranous. In pod corn, glumes, lemma, and palet attain a considerable size and enclose the grain. The single ovary bears one long style, the corn "silk," which is forked at the tip. It is well to remember that there is one silk for each grain on the cob. Weatherwax considers the corn silk a compound stigma rather than a style. The silk is incleed receptive to pollen a good portion of its length, possibly all. A hot, dry wind may wither the silks, thus destroying their receptivity to pollen. Fertilization of the ovules consequently does not take place, and the ovules do not mature. The short protuberance at the top of the ovary is considered by Weatherwax to be the style. It is traversed - by a canal, the stylar canal. Three small rudimentary stamens have been observed by Baillon, and Weatherwax, in the fertile flower; the lodicules are absent. The small aborted flower has rudimentary stamens and pistil about equally developed; the lodicules are present.

Hermaphroditic Flowers.--Ordinarily in corn the flowers are imperfect, that is either staminate or pistillate. Perfect or hermaphroditic flowers sometimes occur, however. Hermaphroditic flowers are far more common on the tassel than on the ear. East and Hayes record a sterile dwarf mutation which had nothing but hermaphroditic flowers. Hermaphroditic flowers have the stamens reduced. Lodicules are well developed in staminate flowers, reduced in hermaphroditic flowers, and altogether absent in fertile pistillate flowers. Montgomery observed hermaphroditic flowers on normal types of ears. The plants from these seeds came true to type. The seed was normal in every respect except that it had three fully developed stamens coming from near the base of the ovary. There were also three small stamens in the aborted flower of each pistillate spikelet. The plants 
were of unusual appearance, being 5 feet high, with short internodes and broad leaves.

Opening of the Flowers, and Pollination.-Cross-pollination, consequently cross-fertilization, is the rule in corn but self-fertilization frequently occurs. Wind and gravity are the chief factors in pollen dissemination, although bees visit the flowers and are evidently concerned in pollen dispersal; they are relatively of far less importance than wind.

In the case of the staminate inflorescence, the first flowers to open are those near the upper part of the central spike; blooming spreads both upward and downward, more rapidly downward. The same order of blooming occurs on the branches of the tassel.

The time of pollen shedding depends upon weather conditions. Cold, wet, weather retards or even prevents the shedding of pollen. On the other hand, droughty conditions hasten the shedding of pollen, but delay the appearance of silks. Hence it may happen that under these conditions much of the pollen is scattered before the stigmas are protruded and receptive, and an incomplete filling of the ear results. On sunshiny days, most of the pollen is shed during the forenoon and, in some instances, late in the afternoon of the same day. Individual tassels usually remain in blossom from four to ten days or even more, depending upon the weather. Furthermore, the anther does not shed all its pollen as soon as it opens, but discharges it a little at a time. In investigating a number (59) of varieties of corn as to the time elapsing between the appearance of anthers and appearance of first silks, Gernert finds marked variation. Both dichogamy (maturation of pollen and stigmas at different times) and homogamy (simultaneous maturity of pollen and stigmas) may occur. Furthermore, in dichogamous indi- 
viduals, protandry (anthers mature first) or protogyny (stigmas mature first) may occur. Out of 2,794 individuals in 59 varieties examined, he found 243 individuals homogamous, 92 protogynous, and 2,459 protandrous. It appears, then, that protandry is the rule in corn. In protandrous individuals, the first appearance of silks occurred from one to twenty-three days after pollen shedding, although the average is two days. Varieties of corn dealt with in the above were pod, pop, flint, dent, soft, and sweet. Collins records the discovery of the protogynous habit in a variety of maize introduced from Granada, Spain. Ordinarily, however. dichogamy is seldom pronounced enough to completely exclude self-pollination.

Gernert has also made observations as to the number of days intervening between the appearance of tassel and anthers. He finds, out of 3,319 individuals in 57 varieties, that, in the greatest number (5I4), the anthers appeared nine days after the tassel, and that in more than half of the individuals the first anthers appeared in seven to ten days after the tassels bearing them appeared.

Pollen is produced in great quantities. It is estimated that each tassel produces $20,000,000$ to $50,000,000$ grains of pollen. Lazenby estimated that for each ovule in dent maize there are about 45,000 pollen grains produced.

The size of pollen grains in corn varies. Pollen produced by central spikes is larger than that produced by laterals. Livingston observed that in Leaming corn the pollen grains from the central spikes were 0.02 millimeter larger on the average than those from lateral spikes. Of I2 varieties examined, Gernert finds that the average diameter of the pollen grain of corn varies from o.os to o.I millimeter. They are rather ellipsoidal in shape. Corn pollen soon shrivels after being shed, but its germinating power is not 
destroyed by this. However, pollen does not remain viable much longer than twenty-four hours after shedding.

Corn "silks" are long and plumose. The first silks to . appear on the ear are those from grains slightly above the base. Generally, four or live days intervene between the appearance of lowest and uppermost silks. Hence, it will require four or five days to pollinate all the silks of an ear. Unfavorable climatic conditions, such as cold, wet weather or extremely hot days, may account for the incomplete "filling out" of ears.

The silks are receptive throughout their length. Best results are obtained when silk receives the pollen within a few days after its emergence from the husk. Silk exposed by splitting down the husks proved receptive. Again, fertilization is not prevented when tips of silks are cut off.

\section{Fertilization, and Development of the Grain.- Just prior} to fertilization, the ovary of corn is bent from the perpendicular so that the silk, instead of pointing directly out from the cob, points in a direction longitudinal to the cob. The orary is on a stalk (rachilla) about 2.5 millimeters long. The ovule almost fills the ovary carity. It is attached to the wall of the ovary by more than one-third its circumference. The outer integument is incomplete while the inner covers the entire orule, except the micropyle. This opening is just above the point of attachment of the lemma.

The ovary wall at this time, that is before fertilization, possesses the following coats:

I. Single row of epidermal cells.

2. Many layers of parenchyma tisucue, varying somewhat in size.

3. Single layer of inner epidermal cells.

True records the presence of a pit "a short distance from 
the base of the style, on the posterior side." This is probably the "stylar canal" described by Poindexter.

The outer and inner integuments vary in thickness from two to four layers. The very large embryo sac is located at the base of the nucellus.

After fertilization, the following changes take place in the maturing grain:

I. Outer integument disappears.

2. Cells of inner integument become flattened, due to pressure from within.

3. The middle and inner cells of pericarp become compacted.

4. Cells of nucellus disappear to a large extent.

5. Hardening of the cell walls of the pericarp.

6. Fusion of pericarp and inner integument.

Xenia in Corn.-Xenia is the term applied to the phenomenon in which some character of the male appears at once in the seed. For example, in crossing a strain of corn having yellow endosperm with a strain having white endosperm, the grains produced are all yellow in every case, no matter which is used as the male parent. Xenia is shown only in case the parent having yellow endosperm is used as the male parent. The yellow endosperm character is dominant over white endosperm. Pollen from the plant bearing yellow endosperm will carry this character; pollen from the plant bearing white endosperm will carry the white character. When pollen, bearing the yellow endosperm character, is placed on the stigma of the grain having white endosperm, the pollen tube will discharge into the ovule two male nuclei, each bearing the character for yellow endosperm. One sperm nucleus fuses with the egg nucleus, the other sperm nucleus fuses with the two polar nuclei. The result of this triple fusion (second sperm nucleus and two polar nuclei) is the endosperm. Now, since yellow is dominant, 
the grain that is formed by this double fertilization will have a yellow endosperm. Thus double fertilization explains the phenomena of xenia. It is of course true that, if in the above, pollen from the white endosperm-bearing plant were used, xenia would not be shown. Xenia, the visible effects of double fertilization, has been found in the following conspicuous cases in corn - in each case below, the plant mentioned first is the female:

Non-starchy-seeded plants crossed with starchy-seeded plants always give starchiness.

Non-yellow endosperm crossed with yellow shows yellow.

Non-colored aleurone layer crossed with purple gives purple.

Non-colored aleurone layer crossed with red gives red.

Variation in the Corn Plant.-There are marked individual differences in the plants of an ordinary field of corn. The plants may vary in height, vigor, leaf production, height of ears on the stalk, shape of ears, composition of kernel, etc. Moreover, there is scarcely any other crop plant in which we find more abnormalities or monstrosities than we do in corn. We have mentioned hermaphroditic flowers, both in the tassel and ear as one abnormality; to these we may add branched ears, tassels with a few or many kernels, variegated leaves, and variegated ears. In corn it is possible for the different kernels of an ear to receive pollen from many different plants, and from its own tassel. Hence, it usually happens that the grains on the same ear have different hereditary characters as shown by their varied progeny. This is well shown in variegated ears. If xenia occurs, the effects of this crossing may be evident the same season. For example, if pollen from dent corn fertilizes some of the ovules on an ear of sweet corn, those ovules appear starchy, while the other grains of the ear of corn, fertilized with sweet corn 
pollen are wrinkled. If xenial does not occur, the results of the mixing will not show up until the second year. Hence, ordinarily even though an ear of corn appears uniform, the separate kernels may have different heredity. The only way of testing its purity is to plant the grains and observe their progeny. Of course in this test, care must be taken to prevent strange pollen from blowing in. This is practically accomplished by isolating the test plots.

Results of Self-fertilization in Corn.-If our ordinary field strains of corn are self-fertilized for several generations the yield is considerably reduced. However, as a result of this inbreeding, we may be sure that all the kernels on an ear

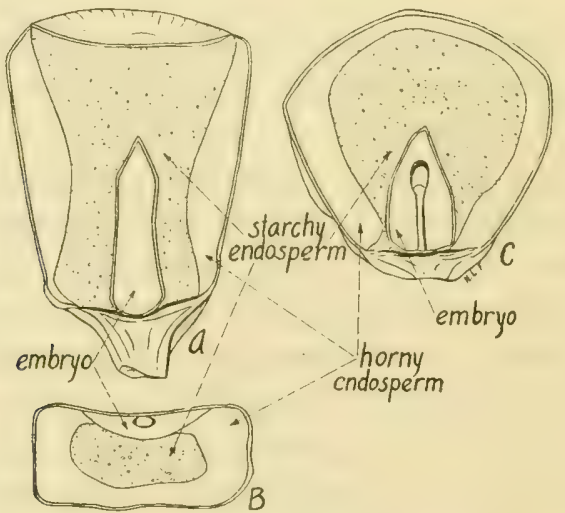

FIG. 64-Corn (Zea mays). A, median lengthwise section, cut parallel to broad surface, of grain of dent corn; $B$, cross-section of same through the embryo; $C$, section as in $A$ of flint corn.

have the same hereditary qualities. Furthermore, artificial self-fertilization for five or more successive years results in a strain that is not so complex in its characters, that is, a race which is comparatively uniform and pure.

The Mature Grain of Corn.-The mature grain of corn varies considerably in shape (Fig. 64). In most varieties, 
it is llattened in a plane at right angles to the length of the cob. The broater surface is roughly triangulat in outline, being broater above than at the batse. The gronere indicates the position of the embryo. It the "(ip)" of a mature gratin, may still be found the papery remains (" chatf") of the palet. lemma, and glumes of the pistillate spikelets. 'The point of the grain, where it was attached to the col), is the poluncle of the flower. The opposite indented end of the grain is often marked by a small point which is the remmant of the style. A longitudinal section of the corn grain parallel with the broad surface will show, with magnification, the following parts.

I. Pericarp, of several layers.

2. Testa, inner integument, of two layers.

3. Nucellar tissue.

4. Aleurone layer, outermost layer of endosperm, a single row of cells.

5. Starchy endosperm.

6. Horny endosperm.

7. Embryo.

8. Tip cap.

The pericarp and testa form the hull. It is possible to separate mechanically the starchy endosperm into two parts: the crown starch and tip starch.

The following is a fair average of the relative proportions of the divisions of the grain, as given by Hopkins, Smith, and East:

Embryo

Per cent.

"Tip cap.

I I . O

"Hull"

I. 5

6.0

Aleurone layer.

8.0 to $14: 0$

Horny endosperm.

45.0

Starchy endosperm. 
Of course, there is a marked variation in the proportions of these parts, and in their chemical composition.

Chemical analysis of the above parts shows that the hull contains less protein (about 4 per cent.) than any other part of the grain. The endosperm is richest in protein, containing 20 to 25 per cent. The horny endosperm contains about 90 per cent. starch and ro per cent. protein. The starchy endosperm is poor in total amount of protein $(5$ to 8 per

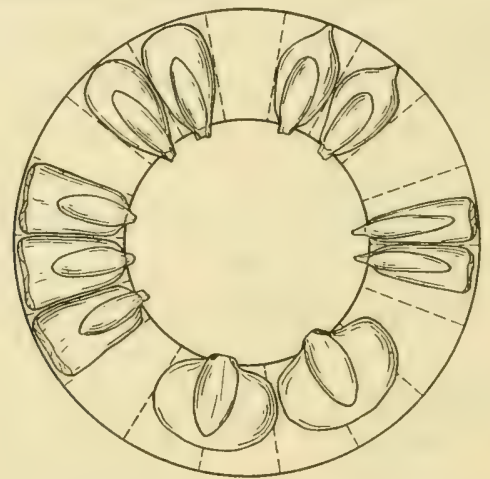

FIG. 65.-Variation in the shape of corn grains. Which is the best proportioned kernel? Why? (After Mich. Agr. Exp. Sta. Bull. 34-)

cent.). The germ is rich in oil, being composed of about 35 to 40 per cent. of oil and 19 to 20 per cent. protein. As much as 80 to 85 per cent. of the total oil content of the kernel occurs in the embryo.

In high-protein corn kernels, the horny endosperm extends up to and comes into contact with the embryo, the tip starch being entirely separated by it from the crown starch. In low-protein corn kernels, the amount of horny endosperm is reduced, tip and crown starch being continuous between it and the embryo. The embryo is much larger in high-oil kernels than in low-oil kernels. 
Embryo. - In the normal flower, the embryo of corn is on the side of the grain toward the tip of the ear. Inverted grains have been found, however. 'This inversion is due to the development of the lower flower of the pair in the pistillate spikelet. The embryo has the same structure as that of wheat. On account of its large size, the parts are readily made out. Its structure is best studied in a longitudinal section cut at right angles to the broad surface. The primary root is conspicuous; the two laterals may be recognized as two swollen areas near its base. The scutellum, or single cotyledon, is traversed by a vascular system. The hypocotyl is just beneath the plumule, being terminated at its base by the primary root.

Color.-Purple, blue, black, and red grains owe their color largely to a pigment located in the sap of aleurone cells. In some grains, there is a red sap in the pericarp. There is an absence of pericarp, aleurone and endosperm colors in white corn. In yellow maize, the coloring matter occurs both in the aleurone layer and in the endosperm.

Corn Starch Distinguished from the Other Common Starches.-The following key, adapted from Winton's Microscopy of Vegetable Foods, gives the characteristic microscopic differences between the common commercial starches.

All or most of the grains rounded, not from aggregates.

Grains rounded, with central hilum; small grains globular or angular, Wheat.

Grains large, of various shapes, with excentric hilum, Polalo.

Grains polygonal or rounded, with one or more facets, mostly from aggregites. Grains very small, sharply angular, Rice.

Grains large, polygonal or rounded; hilum with clefts, Maizc.

Germination of Corn.-The germination of corn may be judged from the following data: Sachs salys optimum $9{ }^{\circ} \mathrm{F}$.. 
maximum $154.8^{\circ} \mathrm{F}$, and minimum $+\mathrm{I}^{\circ} \mathrm{F}$. Sturterant further shows that corn germinates in from ten to twenty days at a temperature of $43.7^{\circ} \mathrm{F}$., while at from $48.6^{\circ} \mathrm{F}$, to $58.5^{\circ} \mathrm{F}$, it germinates in from five to ten days. In germination, the primary root appears first, at the tip of grain; soon the plumule breaks through the pericarp at about the middle of the grain. The young germinating grain consists of a primary root projecting at the peduncle end, and the plumule emerging through a slit in the pericarp at about the middle of the grain, and pointing in the opposite direction. On the sides of the primary root, two secondary ones soon appear, making a total of three roots in the primary root system.

In the seedling, there is, as in other cereals, a more or less clongated axis between the base of the coleoptile and the grain. This has been named the mesocotyl by some morphologists. Collins described seedlings of maize grown by the Indian tribes of the southwestern United States, that may develop, under conditions of deep planting, a mesocotyl up to 36 centimeters in length.

Classification. - The many different varieties of cultivated corn are all included under the one name, Zea mays $\mathrm{L}$. Sturtevant has divided this species up into "species groups" (subspecies), the most important of which are the following:*

I. Zea tumicata, pod corn.

2. Zea everta, pop corn.

3. Zea indurata, flint corn.

4. Zea indentata, dent corn.

5. Zea amylacea, soft corn.

6. Zea saccharata, sweet corn.

7. Zea amylea-saccharata, starchy sweet corn.

*'The specific name "mays" is omitted, for convenience, from the following. 
Gemert describes a type of corn with branching cars and highly branching tassels, which he considers ats a distimet subspecies and for which he suggests the name Zed may's ramosa. Collins describes a new tỹpe of Indian corn from China. This has erect leaf blades, some upper leaves arranged in a monostichous manner, silks developing insicle the leaf sheath, and grains with a peculiar waxy endosperm. Zou

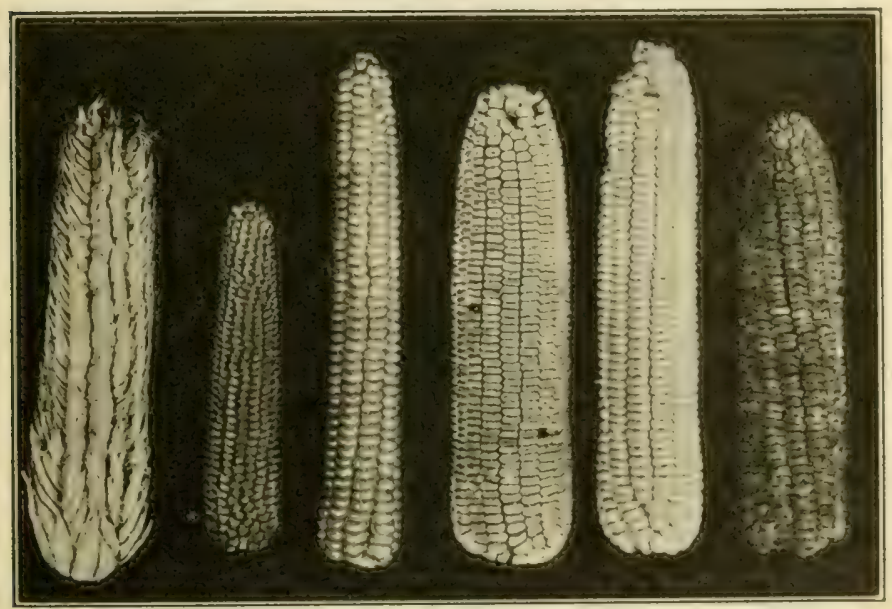

FIG. 66.-The six principal types of corn. From left to right, pod corn, pop corn, flint corn, dent corn, soft corn, and sweet corn. (After Monlgomery.)

canina Watson, the Maiz de Coyote, is a branching plant producing many small ears ( 2 to 4 inches long) on lateral branches. It has been produced artificially by crossing a common maize and teosints. It is said to grow wild in Mexico at the present time. Zea mays japonica is an ormamental sort with small, flinty grains. Zea mays hirla is a hairy, South American corn. Zea mal's curagua is a form with serrate leaves. 
The distinguishing characteristics of the seren groups above are shown in the following key:

\section{Key to "Species Groups" of Corn}

Each kernel enclosed in husks (glumes, lemma, palet); the ear is also enclosed in husks; a rare form, considered by some to be the primitive type, Zea tunicata (pod corn).

Each kernel naked, not enclosed in pod or husk:

Grains with popping properties; popping is due to the turning inside out of the kernel through the explosion of the contained moisture when heat is applied; pericarp is thick and tough; excessive proportion of horny (corneous) endosperm; kernels and ears small, Zea everta (pop corn).

Grains without popping properties.

No corneous endosperm, hence grains are soft; shaped like flint corn; no indentation; the mummy corns of Peru, Mexico, and southern United States probably belong to this group, Zea amylacea (soft corn).

Corneous endosperm present.

Grains more or less wrinkled or shrivelled; kernels horny and translucent in appearance.

Grains horny throughout, Zea saccharala (sweet corn).

Grains with upper half horny and translucent, the lower half starchy, Zea amylea-saccharata (starchy sweet corn).

Grains not wrinkled, smooth.

Starchy endosperm extending to top of kernel; corneous endosperm at sides; shrinkage of starchy endosperm at top of grain causes a drawing in of pericarp and hence the characterist c dent formed (Fig. 64), Zea indentala (dent corn).

Starchy endosperm enclosed by the corneous endosperm; hence there is no shrinkage of top of grain and no dent formed (Fig. 64), Zea indurata (flint corn).

Zea amylea-saccharuta (starchy sweet corn) is a group of only botanical interest. Some seed of this was found in the San Padro Indian collection by Dr. Palmer and sent to Sturtevant in I886. This seed was planted at Geneva, New York, but the crop failed and the seed was lost.

In Zea saccharata, the power to develop starch grains to maturity has been lost. The starch that is formed remains 
small, angular, and does not have the appearance of the typical corn starch granule. Sweet corns may be regarded

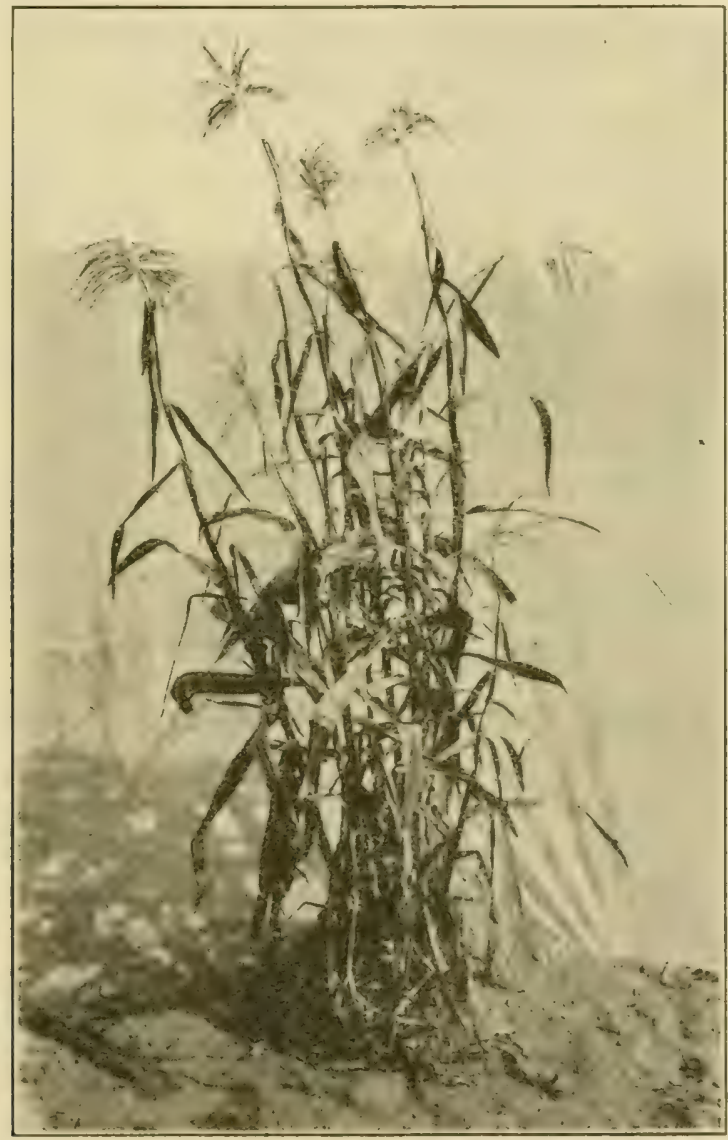

Fig. 67.-Teosinte (Euchlaena mexicana). (After Collins and Kemplon in Journal of Heredity.)

as dent, flint, and pop corns that have lost the power to mature starch normally.

Origin of Maize.-Although maize or Indian corn has been 
in cultivation since prehistoric times, it is unknown in the wild state. It is generally agreed, however, that it is distinctly of American origin. The nearest known wild relative of maize is a Mexican grass, teosinte (Euchlana mexicana), with which it is known to hybridize (Fig. 67).

Harshberger is inclined to believe "that Indian corn is the result of a cross between teosinte and a race or variety of the plant produced by successive cultivation of the wild plant until its characters as a variety or a race have become fixed." Collins produces evidence to show that maize originated as a hybrid between teosinte and as unknown grass belonging to the tribe Andropogoneæ. He believes this grass to be much like the earless varieties of pod corn (Zea tunicata). Montgomery suggests that teosinte and corn had a common ancestor, which was a "large, much-branched grass, each branch being terminated by a tassel-like structure, bearing hermaphrodite flowers." His views coincide with those of East and Hayes (see page I64).

Environmental Relations.-Corn is a native of semi-tropical America. Its range of distribution has been extended widely through culture. A number of varieties will mature grain as far north as southern Canada, and as a green fodder it is raised in still colder regions, where the season is too short to mature the grain.

Flint varieties are now grown quite abundantly throughout northern Wisconsin; they are better adapted to cool climates than dent corn. In general, corn is not a big crop north of the summer isotherm of $69^{\circ} \mathrm{F}$. The principal corn belt of the United States is a strip running from eastern Tebraska to western Ohio, the northern limit being southern Wisconsin and Minnesota. This is a region with warm summer days and nights. The chief limiting factor to corn growing in the northern tier of States is cool nights. 
Reference to page in 7 shows that the water recpuirement of corn stands between that of sorghum and wheat. There is a significant difference in the water requirement of the varieties of corn, indicating that some may be more droughtresistant than others. ('orn is being raised with profit on the dry lands of the West.

There is a close correlation between the yield of corn and the rainfall for June and July. The critical month is July. Smith says that the most critical ten-day period for corn. in Ohio, is from August r to to, the period following blossoming. when the weather must be wet and moderately cool.

In the corn districts west of the 95th meridian, hot winds sometimes prove fatal to corn. These winds are particularly harmful during the critical periods of "tasseling" and "silking."

Corn thrives best in a well-drained, medium loam soil, such as is found in the river bottoms of the Mississippi Valley. It will grow on soils so rich in nitrogen as to cause the lorlging of the small grains.

Uses of Corn.-- Vo other cereal is put to such a variety of uses as is corn. Some economical use has been found for nearly every part of the plant. 'There are numerous manufactured corn products and by-products. Corn meal, both yellow and white. is one of the chief forms in which the grain is used as a food for man. Whole meal includes the embryo. endosperm and hull, while new process meal has the embryo and hull removed. Other forms in which corn ats a human food is used are: hominy, green corn, canned corn, corn oil. corn flakes. pop corn, starch, and glucose. The sweet corn canning industry is a large one. Corn starch from which the protein and mineral matter hatse loeen removed by treatment with dilute alkaline solutions gives at flour which is used largely in the preparation of purddings, blane manges. ete. 
Corn oil is obtained from the embryo. When freshly prepared, it is pale yellow in color. It is employed in the manufacture of soap, and paints, and when mixed with linseed oil, it has some value as a grinding oil. Corn oil is also sometimes vulcanized into a cheap grade of rubber.

Corn Starch.-About 50,000,000 bushels of corn are used annually in the United States in the manufacture of commercial starches, and products derived from them. In the manufacture of corn starch, the corn is steeped from two to four days in warm water containing about 0.2 per cent. of sulphurous acid. Steeping is instituted in large wooden vats holding about 2,000 bushels of corn. When the grains are softened sufficiently, they are lead through a Fuss mill which thoroughly breaks up the grain. The embryos are separated from the rest of the grain material, and removed to another receptacle. The disintegrated grains are freed from the embryos, mixed with water, more finely ground and then shaken through bolting-cloth sieves. Starch and gluten pass through the sieves, while the courser materials, such as fragments of the pericarp, are caught by the sieve. The liquor containing starch and gluten is passed over tables, very slightly inclined, and as the liquid slowly flows down these tables, the starch granules settle, while the lighter particles of gluten are carried off the lower end. The starch is removed from the tables, washed, and kiln-dried.

Glucose. -The commercial "glucose" is a thick syrup-a product of the partial hydrolysis of starch. The manufacture of corn starch has been described. The "green starch" from the tables is made into a thick cream by mixing with water. This is then passed to converters where the starch is treated with hydrochloric acid to bring about its partial hydrolysis. The converted liquor is blown out of the converters into the neutralizer, where it is treated 
with a dilute solution of sodium carbonate, which neutralizes the acid, and precipitates the dissolved iron, and coagulates the colloidal albuminoids. The neutral liquor is then filtered, first in bag filters, and then in bone-char filters. From the first bone-char filters, there issues a light liquor. This is evaporated to increase its concentration, and passed on as heavy liquor to the bone-char filter again. The liquor that results from this second filtering is boiled down in vacuum pans, whence it comes as the finished glucose.

Pure glucose syrup has little flavor, and but half the sweetness of cane syrup. Maize syrup is mixed with varying quantities of cane syrup and sold as a substitute for golden syrup and molasses. It is the basis of many manufactured jellies and preserved fruits.

Grape Sugar.-This is a crude sugar made from starch, in a manner very similar to that employed in the manufacture of glucose. However, hydrolysis is more complete, the process of conversion being carried to the point that no dextrin is precipitated when a sample is placed in strong alcohol. Grape sugar appears on the market as a hard, waxy solid. It finds considerable use in the manufacture of sparkling ales; and, also, as a reducing agent in indigo dyeing, and other industries.

Artificial Gums.-These are known as dextrins and Brilish gums, and are made from starch. Starch is heated to a temperature varying from 170 to $270^{\circ} \mathrm{C}$. During this process, the starch may be treated with dilute nitric acid to bring about hydrolysis, although if high temperatures are used, the addition of acid is unnecessary, as the starch itself contains enough acid and water to effect hydrolysis. Dextrins and British gums are used on envelopes and postage stamps, and also in many of the textile industries.

Stock Food.-Corn fodder includes the whole plant-stalks, 
leaves, and ears-and in this form is fed to stock. Corn stover is the stalks of corn from which the ears have been husked; the stalks may be fed in the bundle form or shredded. Fodder is an important silage crop. In the form of silage, it makes a highly nutritious, succulent feed throughout the winter. Silage is a forage prepared by fermenting green, fresh, plants in a specially constructed air-tight receptacle, called a silo. The material to be ensilaged is cut into fine pieces and packed into the silo. Forage crops include, according to common usage, those plants which are grown for their vegetative parts and which are eaten, either in the green or dry state, by herbivorous animals. Some plants, such as sorghums, are grown for their grain and also for their herbage, that is, they are both a cereal and a forage crop. Corn is also both a cereal and a forage crop. The grass family (Graminex) and the pea family (Leguminosx) furnish the great majority of forage plants. Corn grain and corn bran are important stock foods.

Other Corn Products. - The pith from the stalks is made into explosives and also employed as a packing material where extreme lightness of weight is required. Corn cobs are still in demand for pipes. A fine grade of charcoal is manufactured from corn cobs. Paper is made from the stalks, and packing for mattresses from the husks. When oil is pressed from the embryos, there is left the corn cake, which may be utilized as a food for stock. Gluten meal, a byproduct from starch factories, is also not infrequently fed to stock. Corn is the most economical source of starch for alcohol manufacture in the United States. One ton of corn gives about 90 gallons of 94 per cent. alcohol.

Production of Corn.--In I9 r 4, the United States produced $2,672,804,000$ bushels of corn, which was over 70 per cent. of total production for the world. The country ranking 
second in its corn output wats Argentine with 338,235,c00 bushels. The ten learling States in the order of their production of corn in I915 were Illinois, Iowa, Nebraska, Missouri, Indiana, Texas, Kansats, Ohio, Oklahoma, and Kentucky. The total acreage in corn in the United states that year was $108.321,000$ and the total farm value of the I 915 corn crop), on the basis of the price of corn I)ecember I, was $\$ 1,755,859,000$.

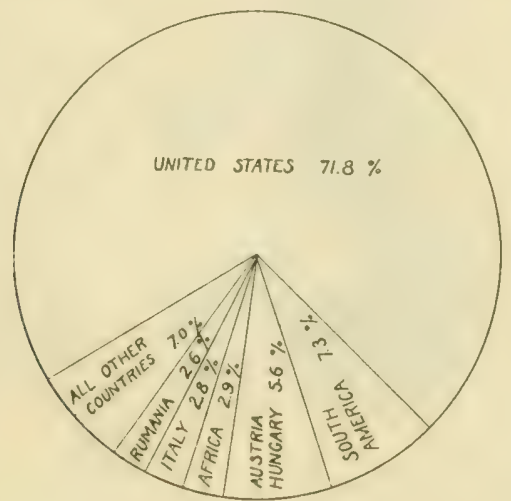

Fig. 68.-Percentage of the world's supply of corn produced in the varions countries in 1914 .

\section{References}

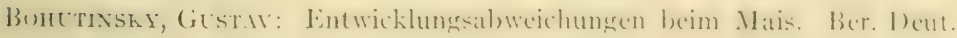
Bot. Gesell., 32: 179-188, 1914.

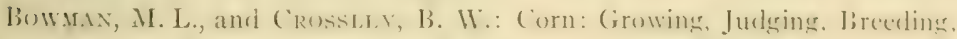
Fceding, Marketing. Waterloo, Iowa, I9II.

Bưtr, Davy J.: Botanical Characters of the Maize Plant. Transvaal Agr. Jour., 7: 348-395, I909.

Incomplete Dichogamy in Zea Mays. Jour. Bot. (London), 47:180-182, 1900 .

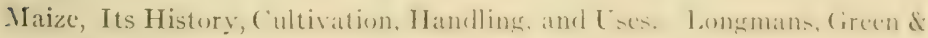
Co., I9I4.

Colutss, G. N.: $\Lambda$ New Type of Indian Corn from China. U.S. 1)ept. Agr: Bur. Plant Ind. Bul. I6I: I-25, I909. 


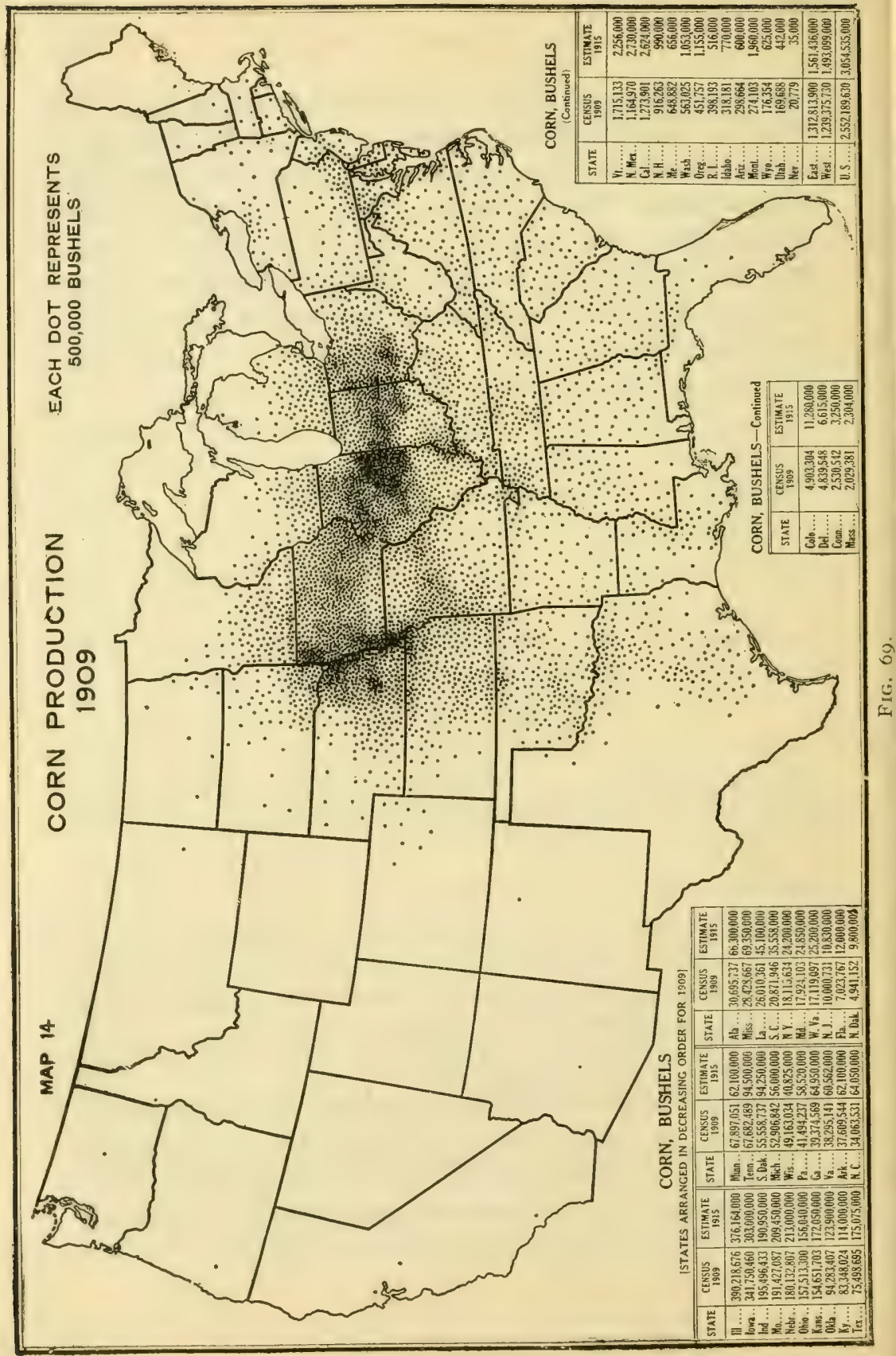


Apogamy in the Matze Plant. U. S. Nat. Mus Contrib. Nat. Herbarium, 1 2: 453-455, 1909 .

The Origin of Maize. Jour. Washington Acad. Sci, 2: 520-530, I 912.

A Variety of Maize with Silks Maturing Before the Tassels. U. S. Dept. Agr. Bur. Plant Ind. Cir. I07: I-I I, I9I3.

A Drought-resisting Adaptation in Seedlings of Hopi Maize. U. S. Dept. Agr. Jour. Agr. Research, I:293-302, I914.

Correns, C.: Untersuchungen über die Xenien bei Zea mays. Ber. Deut. Bot. Gesell., I $7: 410-417$, I899.

Crozier, A. A.: Silk-seeking Pollen. Bot. Gaz., I $3: 24 \dot{2}$, I 888.

E.Ast, E. M.: Inheritance of Color in the Aleurone Cells of Maize. Amer. Nat., 46:363-365, I9 I 2 .

A Chronicle of the Tribe of Corn. Pop. Sci. Mo., 82:225-236, I9I3.

EAst, E. M., and Hayes, H. K.: Inheritance in Maize. Conn. Agr. Exp. Sta. Bull. I67: I-142, I9I I.

Fisher, M. L.: Report of Work in Corn Pollination, I. Proc. Ind. Acad. Sci., I 908.

Report of Work in Corn Pollination, II. Proc. Ind. Acad. Sci., Igro.

Report of Work in Corn Pollination, III. Proc. Ind. Acad. Sci, I9I I. GAger, C. S.: An Occurrence of Glands in the Embryo of Zea Mays. Bull. Torrey Bot. Club, 34: I25-137, 1907.

Gernert, W. B.: Methods in the Artificial Pollination of Corn. Am. Breeders' Assn., 7: 353-36\%, I9r I.

A New Subspecies of Zea Mays. Am. Nat., 47:616-622, I9 2.

Guignard, L.: La double fécondation dans le mais. Jour. Bot. (Paris), I $5: 37-50$, I 901 .

Harsmberger, J. W.: Maize: A Botanical and Economic Study. Contrib. Bot. Lab. Univ. Pa., I : 75-202, 1893 .

Fertile Crosses of Teosinite and Maize. Gard. and Forest, 9: 522-523, 1896.

A Study of the Fertile Hybrids Produced by Crossing Teosinte and Maize. Contrib. Bot. Lab. Pa., 2, I9ot.

Hopkins, C. G., Smith, L. H., and E.Ast, E. M.: The Structure of the Corn Kernel and the Composition of its l)ifferent Parts. Ill. Agr. Exp. Sta. Bull. $87: 77-$ I 2, IgO3.

Hus, H., and Murdock, A. W.: Inheritance of Fasciation in Zea Mays. Plant World, r4: 88-96, г9г r.

Kellerman, W. A., and Swingle, W. T.: Preliminary Study of the Receptivity of Corn Silk. 2d Ann. Rept. Kans. Agr. Exp. Sta., 353-355, I 890 .

Bibliography of Cross-fertilization of Varieties of Corn. 2d Ann. Rept. Kans. Agr. Exp. Sta., 346-353, I89o. 
Experiments in Cross-fertilization of Corn. 2d Ann. Rept. Kans. Agr. Exp. Sta., 288-334, 1890.

Experiments in Crossing Varieties of Corn. 2d Ann. Rept. Kans. Agr. Exp. Sta., 2: 288-334, r89o.

Kempton, James H.: Floral Abnormalities in Maize. U. S. Dept. Agr. Bur. Plant Ind. Bull. 278: I-I6, I913.

Montgomery, E. G.: What is an Ear of Corn? Pop. Sci. Mo., 68: 55-62, igo6.

Perfect Flowers in Maize. Pop. Sci. Mo., 79:346-349, I9I I.

The Corn Crops. "The Macmillan Co., New York, igr3.

Perrsox, Henry: Ahormal Development in Maize. Jour. Bot. (London), 49: $347-348$, I9 I I.

Poindexter, C. C.: The Development of the Spikelet and Grain of Corn. Ohio Nat., 6, I903.

Sargent, Ethel, and Robertson, Agnes: The Anatomy of the Scutellum in Zea Mays. Ann. Bot., I9: II 5-123, I905.

Shoesmith, V. M.: The Study of Corn. Kans. Agr. Exp. Sta. Bull. I39: 223-249, I906.

The Study of Corn. Orange Judd Co., Igro.

Stewart, Alban: The Pistillate Spikelet in Zea Mays. Science, n.s. 42: 694 , I9I5.

Sturtevant, E. L.: Notes on Maize. Torrey Bot. Bull. 21 : 319-343, i894. Varieties of Corn. U. S. Dept. Agr. Office Expt. Stats. Bull. 57: I-103, IS99.

Weatherwax, Paul: Morphology of the Flowers of Zea Mays. Bull. Torrey Bot. Club, 43: I27-I44, I9I6.

Webrer, H. J.: Xenia, or the Immediate Effect of Pollen in Maize. U. S. Dept. Agr. Div. Veg. Path. and Veg. Phys., 22: I-44, 1900. 


\section{CHAPTER XV}

\section{ANDROPOGON SORGHUM (Sorghums ${ }^{1}$ )}

Habit of Plant, and Roots.-All sorghums are annual. The root system is well developed. The roots are generally finer and more fibrous than those of maize. The root crowns and laterals show a vigorous growth. Sorghum is more of a surface feeder than corn, its roots being chiefly in the first I 8 inches. The roots of all sorghums are tough and wiry.

Stems and Leaves.- The culms vary in height from 3 to 15 feet. They are solid; the internodes and leaf sheaths are about equal in length. Sorghums produce both "suckers" and side branches from buds placed in the axils of the leaves. As many as io or I5 suckers may be produced from one plant; they differ from the main stalk in that they are less tall, and mature later. Side branches do not appear until the main stem is headed out. The heads on these branches are smaller and less productive than those on the main stalk. and they mature much later.

The leaves are very similar to those of corn.

Inflorescence.-This is a panicle, which, with a few exceptions (e.g., broom corn), is rather compact. It is called the "head." These heads may vary (Fig. 73) a great deal in shape and color. The axis of the inflorescence is rather angular. The side branches are in apparent whorls, one above the other. The spikelets usually occur in pairs (Fig. 70), although toward the tip of the inflorescence they maty occur in threes.

1 The term "sorghum" includes all the groups known in the United States as milo, kowliang, shallu, durra, broom corn, and kafir. 
Spikelets and Flowers.- It was stated that the spikelets usually occur in pairs. One is sessile, the other pedicelled. The sessile one is broad, thick, and fertile; the pedicelled narrow, long, and staminate. Whenever three spikelets are in a group, one is sessile and perfect, and two are pedicelled and staminate; sometimes one of the two stalked spikelets may be perfect.

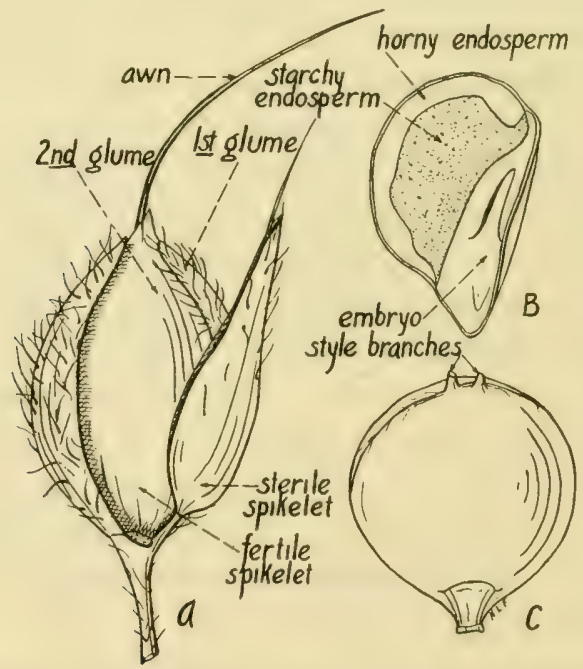

FIG. 70.--Sorghum (Andropogon sorghum). $A$, pair of spikelets; $B$, grain in section; $C$, grain, external. $\times 5$.

Fertile Spikelet (Fig. 7I).-The sessile spikelet has thick, leathery glumes of about equal length. The outer one partially wraps about the inner. The latter is narrower and more gradually tapering at the tip. Within the two glumes of this sessile spikelet, are two flowers; the lower sterile, the upper with both stamens and pistil. The so-called "third glume" of some descriptions is the lemma of the lower, sterile flower. Moreover, it is the only remnant of this flower. It 
encloses the parts of the fertile flower. The lemma of the fertile flower is broad, hairy, and two-cleft at the tip; there arises in the cleft, as a rule, a long awn which projects from the spikelet. The awn may be very short or only represented by a bristle. The palet is frequently absent; when pres-

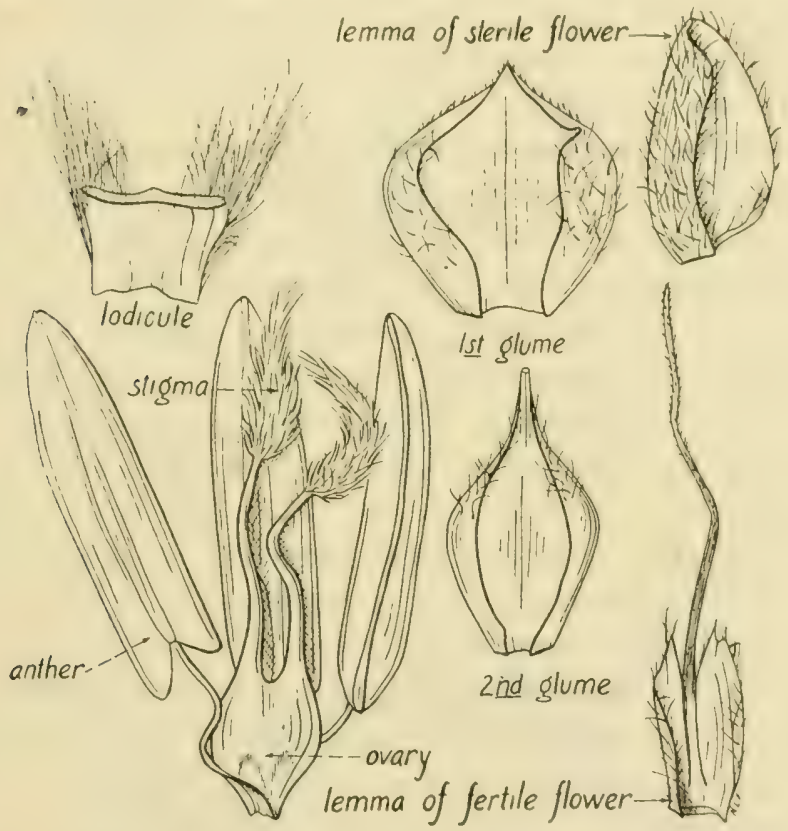

FIG. 7I.- Spikelet of sorghum (Andropogon sorghum) dissected. Lodicule $\times 10$, all others $\times 5$.

ent, it is small and thin. There are two lodicules, which are much broader than long, truncate, fleshy, and usually thickly hairy. Three stamens are present. The sessile, ovate ovary does not bear a tuft of hairs at the tip, such as is found in wheat, oats, rye, and barley. The two styles are thread-like and bare for the lower two-thirds of their length, and then spread out into bushy stigmas. 
Staminate Spikelet.-The stalked spikelet is narrower, and more pointed than the fertile one. It is two-flowered. It is subtended by two leathery glumes. Immediately within this pair is the lemma of the sterile flower of the spikelet. Then comes the lemma of the staminate flower; it may be short-awned or awnless; the palet of this flower is absent. The lodicules and stamens resemble those of the fertile spikelet. There is no pistil.

Opening of Flowers and Pollination.-Flowers do not begin to open on the inflorescence until the latter is entirely out of the leaf sheath. The first flowers to open are those near the tip of the head. Blooming proceeds from the tip downward. As a rule, flowers at the tip of an inflorescence have shed their pollen, and closed, when the lower flowers of the head are just beginning to bloom. Flowers on branches belonging to one whorl are usually in about the same stage of blooming. In nearly all cases, the sessile spikelet of a pair is the first to open. The stalked spikelets may sometimes fail to protrude their stamens. Most of the flowers open in the early morning; there is but very slight amount of blooming during the day. The stigmas may protrude to a slight extent first. (Fig 72). They are followed by the anthers. When the flower starts to open, the whole process takes place within from ten to fifteen minutes. The spreading of the glumes, and the emergence of anthers and styles may be so rapid in some instances as to be seen with the hand lens. The stamens extend their full length, as a rule, and the anthers swing on long filaments. In some cases, however, the anthers never fully project from between the glumes, but shed their pollen, and dry up, half or one-fourth caught by the glumes. When the anthers are partly out, the stigmas are fully protruded. No sooner are the anthers visible than they begin to dehisce by two narrow slits at the tip only. The stigmas and pollen- 
shedding anthers may be in contact at time of ofening, and since the stigma is receptive at this time, some self-pollination must take place. Pollination between flowers of the same
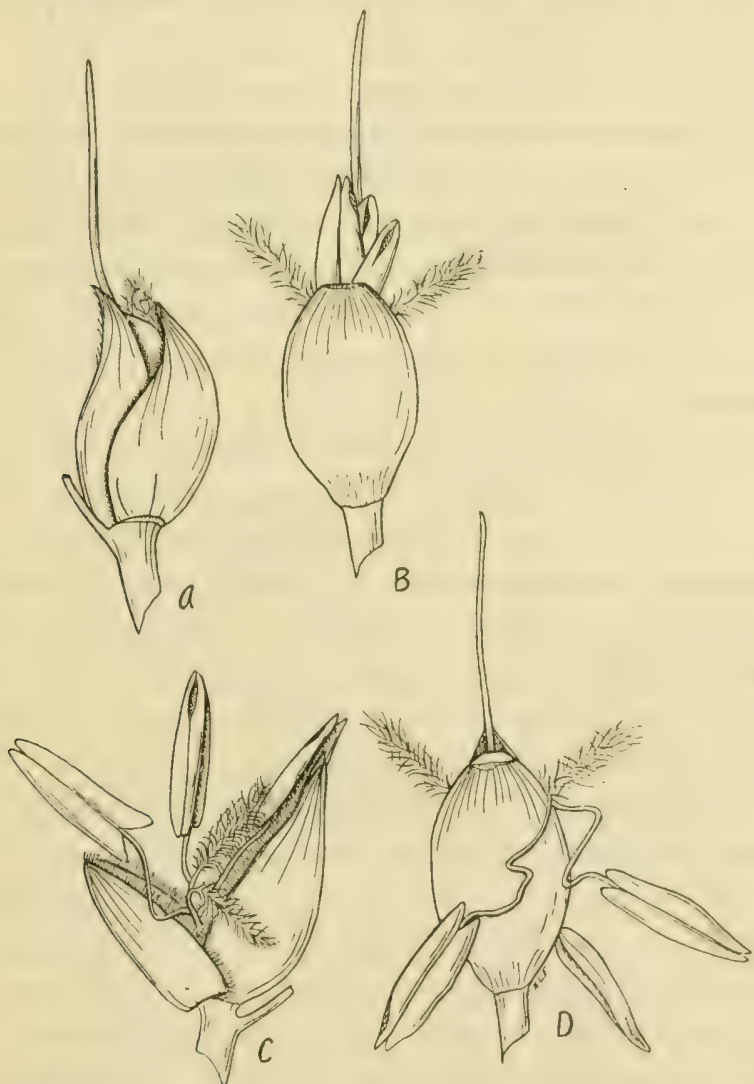

Fir. 72.- Four stages in the opening of the spikelet of sorghum (Andropugum sorghum). $\times 5$.

plant is very common. The upper flowers are shedling pollen in abundance, as the receptive stigmas of lower flowers are opening. And, in the light breeze of the morning, the head is 
moved enough to shake pollen out. Cross-pollination is also very common. Individual flowers do not, as a rule, remain open longer than the evening of the day they open. The brown and withered stamens and stigmas commonly protrude from between the closed glumes.

The different types of sorghum cross readily.

Fruit.- The mature grain may be entirely or in part enclosed by the "glumes." It is oval, a little longer than broad, smooth, and tipped with the remains of two style branches. The position of the embryo is seen at the base of the grain on one of the flat surfaces. The point of attachment-an oval, brown area - is found at the base of the grain on the other flat surface.

The seed is flattened in the durras, pyriform in some of the sorgos, and globular in kafir, kowliang, and shallu.

In some types of sorghum, the pericarp bears starch. The aleurone layer consists of one row of small cells. The starchy endosperm is mealy within and more or less horny without.

Varieties. - The sorghums are divided into two main divisions: (I) saccharine or sweet sorghums, and (2) non-saccharine sorghums. Saccharine sorghums are tall, leafy, and have an abundance of sweet juice, and a light crop of seed. The chief varieties are Amber, Orange, and Sumac. Nonsaccharine sorghums are more stocky, as a rule, contain less juice, and have a heavy crop of seed. Non-saccharine sorghums are divided into three groups; (I) kafir group, including those with erect, long cylindrical heads full of obovate seeds (kafirs, white milo, etc.); (2) durra group. including those with thick, compact, ovate, pendant inflorescences, and large, flattened seeds (yellow milo, durra, feterita); and (3) broom corn group, in which the heads are loose and spreading. Frequently the heads are on recurved stems, called "goose necks." 


\section{Key to the Principal Groups of Sorghum ${ }^{1}$}

Pith juicy.

Juice abundant and very sweet.

Internodes elongated; sheaths scarcely overlapping; leaves 12 to 15 (except in Amber varieties); spikelets elliptic-oval to obovate, 2.5 to 3.5 millimeters wide; seeds reddish brown, Sorgo.

Juice scanty, slightly sweet to subacid.

Internodes short; sheaths strongly overlapping; leaves i 2 to 15 ; peduncles crect; panicles cylindrical; spikelets obovate, 3 to + millineters wide: lemmas awnless, Kafir.

Internodes medium; sheaths scarcely overlapping; leaves S to I I per uncles mostly inclined, often recurved; panicles ovate; spikelets broad. Pith dry.

Iy obovate, 4.5 to 6 millimeters wide; lemmas awned, Milo.

Panicle lax, 2.5 to 7 decimeters Ioner; peduncles erect; spikelets ellipticoval or obovate, 2.5 to 3.5 millimeters wide; lemmas awned.

Panicle 4 to 7 decimeters long; rachis less than one-fifth as long as the panicle.

Panicle umbelliform, the branches greatly elongated, the tips droop)ing; seeds reddish, included, Broom Corn.

Panicle 2.5 to + decimeters long; rachis more than two-thirds as long as the panicle.

Panicle conical, the branches strongly drooping; glumes at maturity spreading and involute; seeds white or somewhat buff, Shallu.

Panicle oval or obovate, the branches spreading; glumes at maturity appressed, not involute; seeds white, brown, or reddish, Kowliang.

Panicle compact, I to 2.5 decimeters long; peduncles erect or recurved; rachis more than two-thirds as long as the panicle.

Spikelets elliptic-oval or obovate, 2.5 to 3.5 millimeters wide; lemmas awned, Kowliang.

Spikelets broadly obovate, 4.5 to 6 millimeters wide.

Glumes gray or greenish, not wrinkled; densely pubescent; Iemmas awned or awnless; seeds strongly flattened, Durra.

Glumes deep brown or black, transversely wrinkled; thinly pubecent; lemmas awned; seeds slightly flattened, Mrilo.

Origin of Sorghums.- The wild form from which our cultirated sorghums have been derived is Andropogon hulepensis (Johnson grass). This species is native to tropical and sui)tropical parts of the Old World. The view is now quite

1 Taken from Ball. 


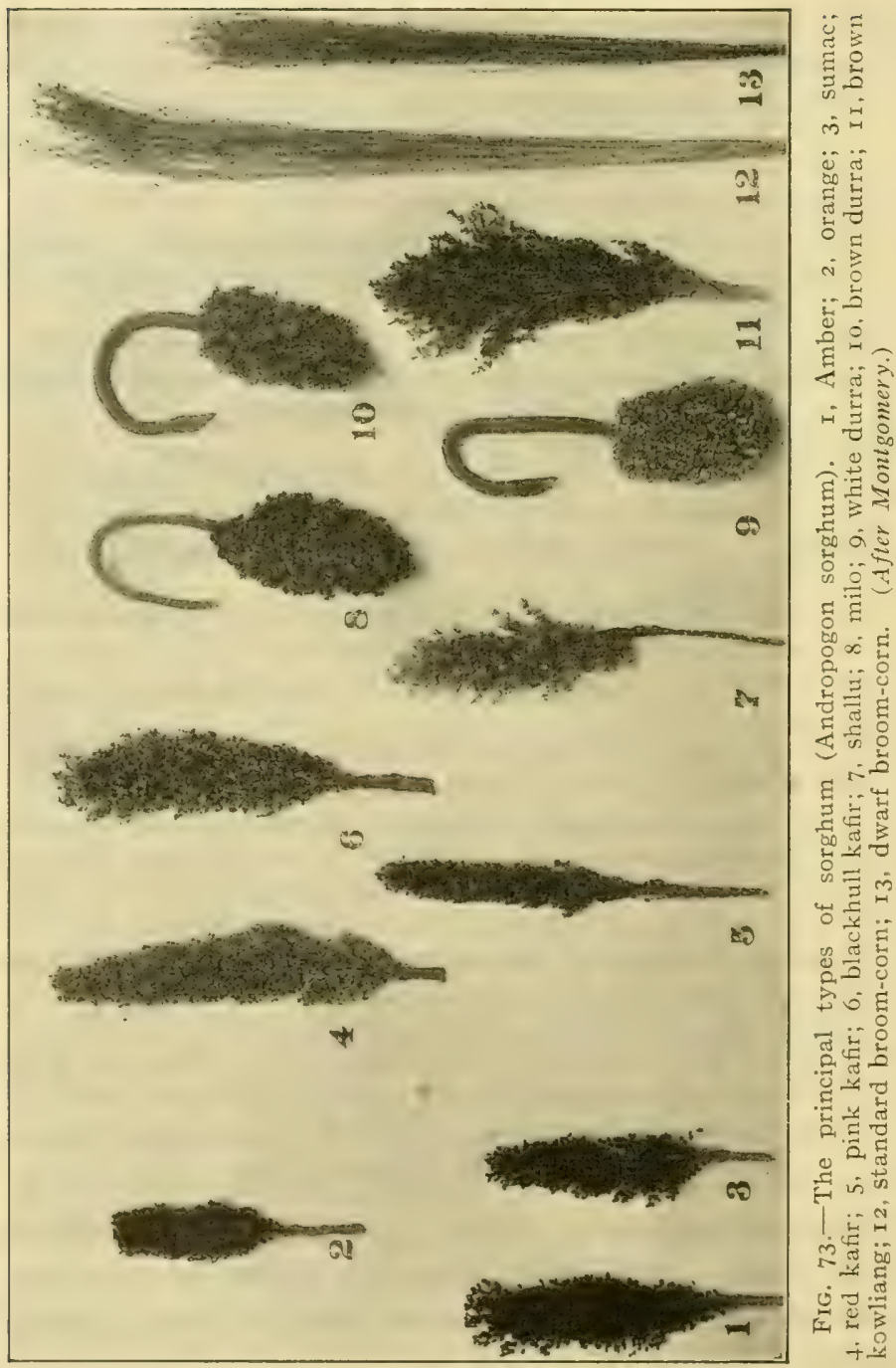


generally adopted that the present-day cultivated sorghums can be divided into two groups, each of which hat an independent origin in Asia and Africa respectively.

Environmental Relations.--Sorghums are of tropical origin, and are more at home in regions with warm, sunshiny summers. The plant will undergo high temperatures. It is sensitive to low temperatures, and consequently cannot be planted as early in the season as the other small cereals.

The sorghums are either able to resist or to escape drought. For this reason they have become one of the principal crops on the non-irrigated lands of the West. Their resistance to drought is due largely to their low water requirement, along with their ability to roll the leaves with approaching dry periods, and thus reduce the water-losing surface, and also to their ability to remain alive during a period of drought and quickly resume growth when moisture is available. In this last respect the sorghums differ from corn, for corn is unable to remain in a dormant state for a very long time. The sorghums are not as easily affected by hot winds as corn. This is an important characteristic adapting them to the semi-arid regions.

Sorghums will grow on a variety of soils. They are somewhat more resistant to alkali salts than the other grain crops.

Uses of Sorghums. - The saccharine or sweet sorghums are grown for syrup and for forage. The juice is extracted from the canes. The leading State in sorghum-syrup production is Tennessee. The non-saccharine sorghums are grown chiefly for their grain, but also for forage. The Chinese and Manchus put the grain sorghums to a great variety of uses. For example, a fermented drink is made from the seed, the heads are used for fuel and brooms, the leaves for fodder and for mats, the stalks for the construction of baskets. fences, building material, laths, playthings, posts, thatchings. 
wind breaks, and window shades, and even the roots and stubble are used as fuel. The broom-corn groups of sorghums are grown for their grain, and certain varieties with long rachi are made into brooms. For this purpose the heads are used. Brooms are made from two different groups of broom corn: tall-growing or Standard, and diearf. Fully two-thirds of the total broom-corn crop of the United States is dwarf broom corn. It produces a fiber that is finer than that of the tall-growing sort; and, too the head is not so firmly attached to the upper node. This latter character permits the "brush" (inflorescence) to be harvested by pulling. After threshing the grain from the heads, they are cured in sheds or out of doors in ricks. They are then graded and baled, and either stored or shipped directly to the broom factory. The "straws" of a broom are the rachises of the sorghum inflorescence. Oklahoma, Kansas, and Texas, in the order named, are the leading broom-corn States.

\section{References}

Ball, Carletbr R.: Saccharine Sorghums for Forage. U. S. Dept. Agr. Farmers' Bull. 246: 7-18, 1906.

Three Much Misrepresented Sorghums. U. S. Dept. Agr. Bur. Plant Ind. Cir. 50: I-I4, I9IO.

The History and Distribution of Sorghum. U. S. Dept. Agr. Bur. Plant Ind. Bull. I75: $1-63$, I910.

Better Grain-sorghum Crops. U. S. Dept. Agr. Farmers' Bull. 448: I-36, I9II.

The Importance and Improvement of the Grain Sorghums. U. S. Dept. Agr. Bur. Plant Ind. Bull. 203: I-45, I9II.

The Grain Sorghums, Immigrant Crops that Have Made Good. U. S. Dept. Agr. Yearbook, I9I3: 22I-238.

H.ıckel, E.: Die kultivirten Sorghum-Formen und ihre Abstammung. Jahrb. (Engler), 7: I I 5-I26, I885.

Piper, C. V.: The Prototype of the Cultivated Sorghums. Jour. Am. Soc. Agron., 7: 109-117, 1915. 
Hartley, Charles P.: Broom Corn. U. S. Dept. Agr. Farmers' Bull. I 74: $1-30,1903$.

Rotugen, B. E.: Dwarf Broom Corns. U. S. Dept. Agr. Farmers' Bull. 768: I-I6, I9I6.

Warburton, C. W.: The Non-saccharine Sorghums. U. S. Dept. Agr. Farmers' Bull. 288: I-28, I907. 


\section{CHAPTER XVI \\ ORYZA SATIVA (Rice)}

Habit, Roots, Stems, Leaves.-Common cultivated rice is an anmual plant, which grows best under swampy or very moist conditions. There are upland varieties produced with irrigation, but the lowland type is the sort almost entirely grown in the United States. The seedling has one seed root. The root system is fibrous; the first, second, and third nodes give rise to adventitious roots. The first whorl of permanent roots is close to $1 / 2$ inch above the lower end of the culm. It is more shallow in very moist ground than in dry soil. The plant tillers freely, sending up usually four or five hollow stems to a height of 2 to 6 feet. The leaf sheaths are open, and the blades are from 8 to $\mathrm{I} 2$ inches long and $3 / 4$ to $\mathrm{r}$ inch wide. The ligule is long, acute or obtuse, and easily splits into two parts. It is much shorter and more rounded on the upper leaves than on the lower. The auricle is white or green, cartilaginous or membranous, and hairy.

Inflorescence and Spikelet.-The inflorescence is a panicle (Fig. 74). Its branches are either single or in pairs. The spikelet (Fig. 75) is compressed laterally. It is oneflowered. There are two small scale-like or bristle-like glumes, underneath each of which is a very minute, rudimentary glume. The lemma is compressed, parchment-like and five-nerved. The palet is similar to the lemma in size and texture, but is only three-nerved. Both may be awned or awnless. The broadly oval lodicules are small, thick, and 
fleshy. Rice differs markedly from the other common cereal: in having six well-developed and functioning stamens. The ovary is somewhat longer than broad, smooth, and bears two

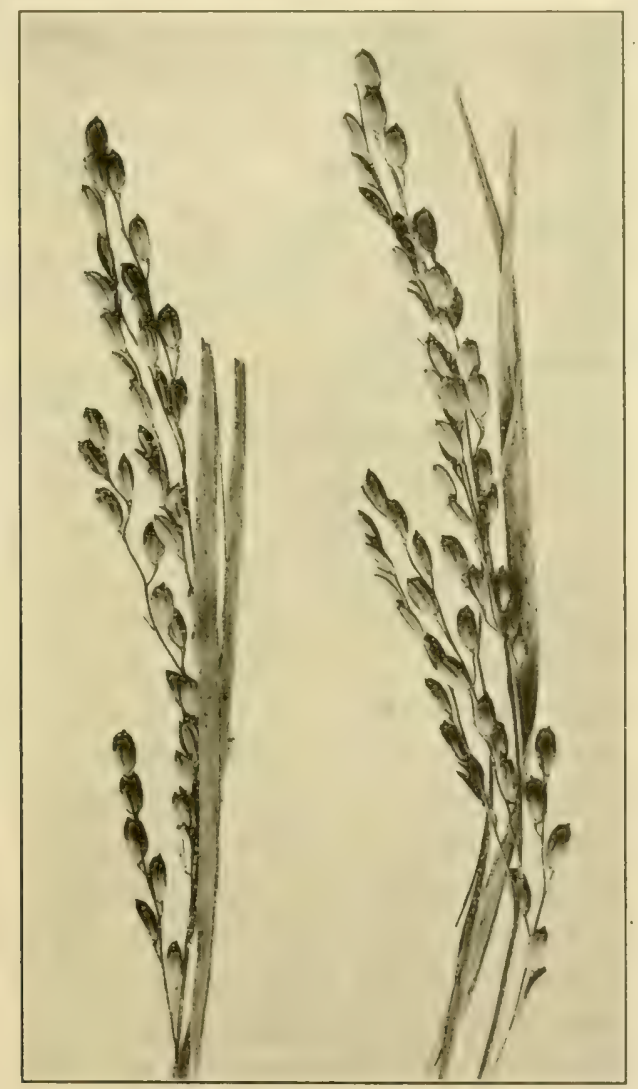

FIG. 74.-Panicle of rice (Oryza sativa).

styles, and sometimes a short, rudimentary third one. These three are sometimes grown together at the batse.

Pollination and Fertilization.--Rice is normally self-polli- 
nated. The flowers at the tip of the inflorescence are the first to open. Flower opening continues throughout the day.

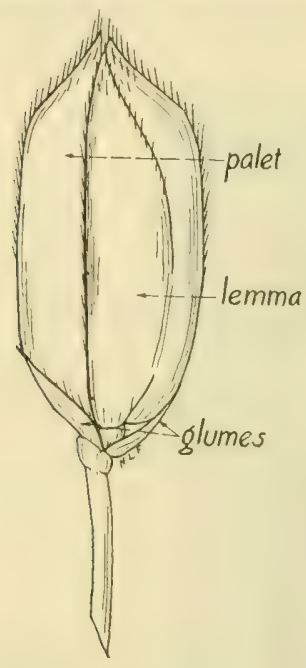

FIC. 75.-Spikelet of rice (Oryza sativa). The stamens are the first flower parts to appear. After they are extended full length, the lemma and palet open wider; and the stigmas protrude. Usually the stigmas draw back between the palet and lemma after pollination, although they may remain outside. Although self-fertilization is the normal process, cross-fertilization is not altogether precluded.

Grain.-The rice grain (caryopsis) is surrounded by the lemma and palet, or palet alone. These two structures form the "hull." Rice enclosed in the hull is known as "paddy." Rice from which the hull has been removed is "cleaned rice." The rice grain (Fig. 76) is smooth, longer than broad, and elliptical in cross-section. There are two longitudinal parallel ridges on each of the flat surfaces. The grain of common rice is shiny and transparent. This appearance is due to the glassy endosperm. Occasionally there are grains that appear dull; in such, the endosperm is starchy on the outside and horny within. Grains with dull areas here and there are not uncommon. An interesting rice is Oryza glutinosa, the grains of which always appear dull. A cut surface of this rice is described as paraffin-like in appearance. The

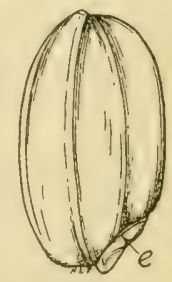

Fig. 76.Kernel of rice (Oryza sativa). $e$, e mbryo. $\times 5$. starch grains behave quite differently from those of common rice. They color yellow-brown with iodine instead of violet. 
When it is cooked, there is formed a mass the particles of which stick closely together; the single grains do not remain separate. There are rices with grains pale green in color, reddish-brown, dark brown, and white with red or dark stripes.

In cross-section of the rice grain, the layers are very similar to those in wheat. There is the pericarp of several layers, the testa, the nucellus (perisperm), and the aleurone layer, usually of one row of cells. The embryo is about one-third the length of the fruit. During the milling process, the lemma and palet, the embryo, pericarp, testa, nucellus, and in many cases all or a portion of the aleurone layer are removed. This "scouring process," in the case of Honduras and Japan rices, removes about io per cent. of the weight of the grain, and a considerable quantity of ash, fat, crude fiber, protein, and pentosans. The color of red rice is located in the seed coat, or throughout the endosperm.

Milling of Rice.-The threshed rice from the field is called "paddy rice." The grains are enclosed by the glumes, lemma, and palet, which together constitute the "hull." The hulls are removed by passing the grains between revolying millstones, set apart about two-thirds the length of a rice kernel. The hulls are then removed by a fanning device, and this process followed by the separation of the rough (unhulled) from the clean rice in the "paddy machine." The next process removes a part of the bran layer (pericarp, testa and nucellus) and most of the embryo. After a separation of the powdery bran from the cleaned rice, the grains are then led into the "pearling cone" where they are scoured. This is followed by a thorough polishing between pieces of pigskin. The grains then receive a coating of glucose and tale, and are ready to be graded and packed for the market. 
Beriberi.-This is a disease resulting from a diet consisting chiefly of polished rice. Asiatic laborers who have been fed upon polished rice develop this disease, while, if the rice is not polished, the disease does not appear. When rice is polished, there is removed a large proportion of the phosphates of the grain, and hence, when rice is almost the sole food, there is a deficiency of phosphates in the ration, which lack results in the disease, beriberi. Of course, those who have a mixed diet get the requisite amount of phosphates from a number of clifferent foods, and hence may eat polished rice without any ill effects.

Varieties.-Carleton gives the following provisional arrangement of wild and cultivated rices:

I. Oryza granulata (wild rice).

2. Oryza officinalis (wild rice).

3. Oryza sativa (cultivated rice).

(a) utilissima.

I. communis (large-kerneled rice).

2. minuta (small-kerneled rice).

(b) glutinosa (glutinous rice).

American varieties are comparatively few in number. Three main types are grown: Honduras, Carolina and Japan. The hulls of Honduras and Japan rice are yellowish-brown, those of Carolina rice mostly a golden yellow. Lowland types of rice form, almost exclusively, the sorts grown in this country. Japan rice has smaller grains, a thinner hull, and tillers more than the other types in the United States. Honduras and Carolina belong to the communis group, and Japan to the minuta group.

Distribution and Closely Related Species.-There is is a great number of Ory $\approx a$ species found growing wild in tropical regions of both hemispheres. The native home of $O$. satici is the warm parts of Asia and Africa. Cultivated rice probably originated in eastern Asia.

In this country, there are two quite common native plants termed "rice." These are, Canada rice (Zizania 
aquatica), and wild rice (Zizania miliacea). Both are tall aquatic grasses belonging to the same tribe (Oryzea als cultivated rice. Both species of Zizania differ from Oryza in having monocious spikelets.

Uses of Rice.-Rice is a food for more human beings than is any other grain. It is the principal food of the densely populated regions of China, India, and the neighboring islands. The consumption of rice per capita in the Uniterl

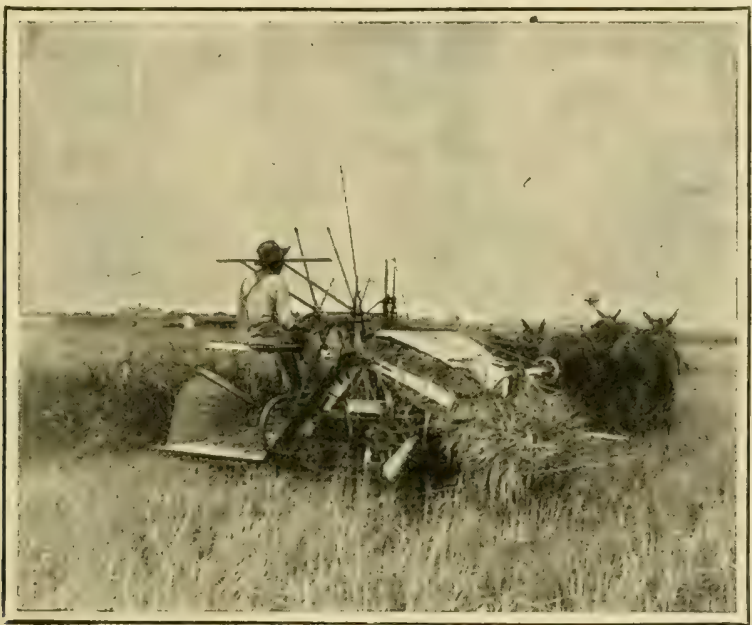

FIG. 77.- Harvesting rice in Arkansas. (From Essentials of Geography, Second Book. Copyright 1916, by Albert Perry Brigham and Charles $T$. McFarlane. American Book Company, Publishers.)

States is steadily increasing. Orientals do not polish their rice, while all the rice that comes on the market in this country has had the hull removed, and has been polished. Rice hulls and rice flour or polish, removed in the milling process, are used as stock food. Rice straw is also used as a food for stock, and in the manufacture of paper, straw hats, straw board, etc. In Japan, a drink called "sake," similar to beer, is made from rice. 
Environmental Relations.- Rice has a climatic range similar to that of cotton; it is seldom raised north of that region in which the average summer (June, July, August) tempera-

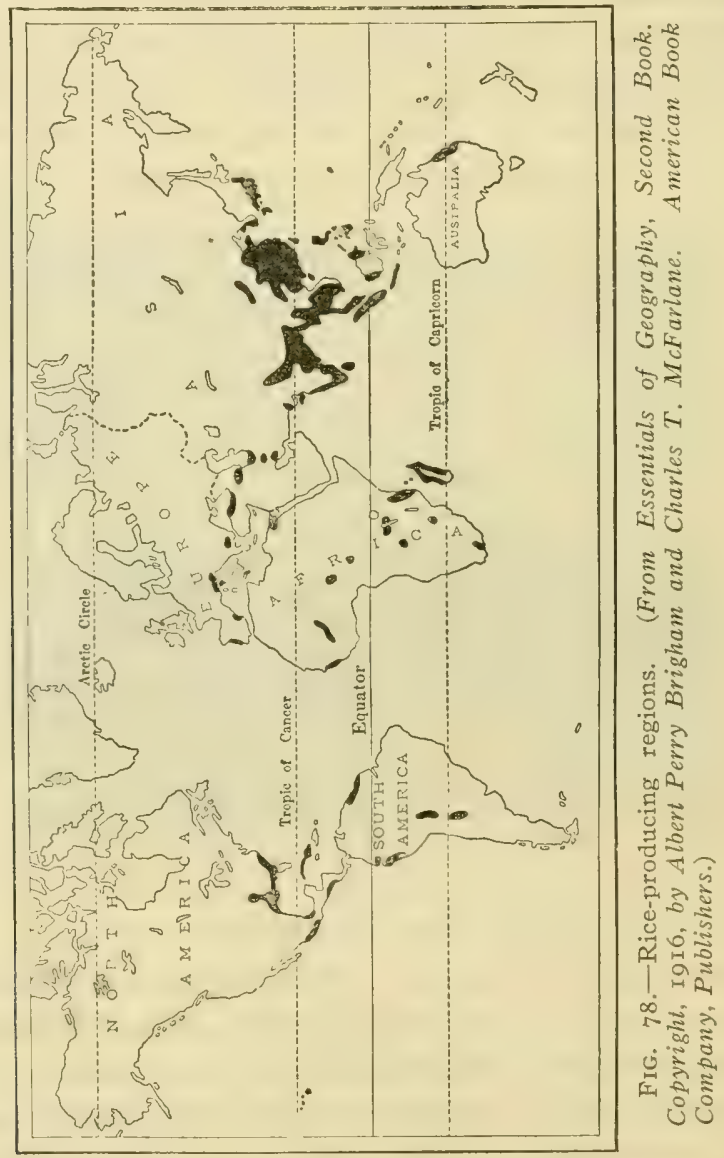

ture is lower than $77^{\circ} \mathrm{F}$. It reaches its best development in moist regions. Certain sorts of upland rice are planted, cultivated and harvested like oats. But, most of the rice 
is raised on low delta or alluvial lands that will permit of inundation. In lowland rice culture, flooding of the field is usually resorted to in order to hasten germination; after the plants have attained a height of several inches, from 3 to 6 inches of water are turned on to the field and kept there continuously for twenty, thirty, or more, days, depending upon the region. The water is renewed occasionally to prevent it from becoming stagnant. It is drained off just prior to the ripening of the grain.

The Production of Rice.-British India produced 62,638,9 I 2,000 pounds of rice in I9I 4. During the same period, Japan raised I7,826,240,000 pounds, Java and Madura ( I 9 I 3) 7.951,049,000 pounds, Korea 3.678,878,000 pounds, the Philippine Islands I,403,5 I6,000 pounds, Italy 74 I,263,oo pounds, and the United States 656,9 I7,000 pounds.

There are four commercial rice-growing districts in the United States: (I) The Carolina district. (2) the TexasLouisiana district. (3) The Arkansas district, and (4) the California district. The heaviest producer is the TexasLouisiana district. Louisiana produced I3.714,000 bushels of rice in 1915 , or about one-half of the total product for the entire United States. Texas ranked second with 7,930,000 bushels, Arkansas third with 4,840,000 bushels, and California fourth with 2,268,000 bushels.

\section{References}

Akemine, M.: On the Flowers and Flowering of O. sativa. Agric. Gaz. Nôgyô-Sekai, rgro-rr.

(ik.m.m, R. J. 1).: Preliminary Note on the Classification of Rice in the (entral Provinces. Mem. Dept. Agr. in India, Bot. ser. 6, No. 7: 209-230, I0I3.

Iector, P. G.: Notes on Pollination and Cross-fertilization in the Common Rice Plant, Oryza sativa, Mem. Dept. Agr. in India, Böt. ser. VI, I : $1-10$, I 913 .

Kikn.sw, S.: On the Classification of Cultivated Rice. Imp. Univ. Tokyo, Coll. Agr. Bull. III, No. 2, II-I08, I9I 2. 


\section{CHAPTER XVII}

\section{MILLET}

The term millet does not refer to a definite botanical group (species, genus, or tribe) of plants. Originally it applied to certain species of grasses belonging to the genera ('hetochloa (Setaria), Panicum and Echinochloa, which are still spoken of as the "true millets."

Agriculturally speaking, the word "millet" embraces a number of annual cereal and forage grasses which have comparatively small seeds, abundant foliage, and a fibrous root system. They are raised in Europe and the United States for forage vurposes and in a number of Asiatic and African countries for human food as well.

Most of these millets belong to the four genera Chatochloa, Echinochloa, Panicum, and Pennisetum, of the tribe Panicex. Ragi or finger millet (Eleusine coracana) belongs to the tribe Chloridex. It is grown in India to quite an extent as a cereal but has never attained favor in the United States.

Key to P'rincipal Ionomic Types (Species) of Millet and Some Closely Related Common Weed Grasses ${ }^{1}$

Inflorescence paniculate; no involucre below the individual spikelets.

Inflorescence a raceme of short spikes; empty glumes awned or awnpointed, Echinochlou (Barnyard millets and wild barnyard grass). Awns long; spikelets white. E. crusgalli (common barnyard grass).

Awns short; spikelets brown, E. frumenlacea (Japanese barnyard millet).

Inflorescence a drooping panicle; empty glumes not awned, Panicum miliaceum (proso or broom-corn millet).

${ }^{1}$ After Frear. 
Intlorescence spicate; involucre of bristles below each spikelet.

Grain enclosed in lemmat and palet (the hull) at malurity; spilie lomse, Chcelochloa (foxtail millet and foxtail grass).

Panicle usually I centimeter thick or less; bristles commonly green; spikelets about 2 millimeters long, $C$. viridis (green foxtail).

Panicle usually i to 3 centimeters thick; bristles usually purple; spikelets, 2.5 to 3 millimeters long, C. italica (foxtail millets).

Grain globose, forcing open the hull as it matures, and falling free when threshed; spike dense, Pennisetum glaucum (pearl millet).

\section{PENNISETUM GLAUCUM (Pearl Millet)}

Stem.--The plants are erect, and from 3 to 8 feet tall. The culms are cylindrical and pithy; the upper internorles are smooth, the upper nodes either smooth or short-hairy.

Leaf.-The leaf sheaths are open and hairy; the ligule is short and fimbriated; the leaf blade is lanceolate, long-pointed, and long-hairy especially on the upper side.

Inflorescence.- This is a close cylindrical spike (Fig. 79), 6 to 14 inches long and $3{ }_{4}$ to $\mathrm{I}$ inch thick. The main axis is stiff and thick-hairy. The side branches are hairy, 7 to $S$ millimeters long, and bear each one to three (commonly two) spikelets, which are surrounded by a cluster of bristles. These bristles fall with the spikelets at maturity.

Spikelet and Flower-The lower glume is short, broader than long, and truncate; the inner glume is longer. about one-half the length of the spikelet, oval, and three- to fournerved. Each spikelet has two flowers, the lower staminate, the upper perfect. The lemma of the lower staminate flower is oval, and three- to four-nerved; the palet is small, sometimes entirely lacking, the stamens three in number, and lodicules absent. The staminate flower in the spikelet often has both palet and stamens lacking, and in some instances the spikelet has but one flower, the staminate one being entirely lacking. In some few instances, spikelets contain two perfect flowers. The lemma of the fertile flower is oval, 
pointed, and five- to six-nerved; the palet is oval, rounded above, pointed, and thin-membranous; lodicules are absent; there are three stamens; the ovary is obovate, smooth, and with two style branches.

Pollination.-- Pearl millet is regularly cross-pollinated. The flowers near the middle of the inflorescence are the first

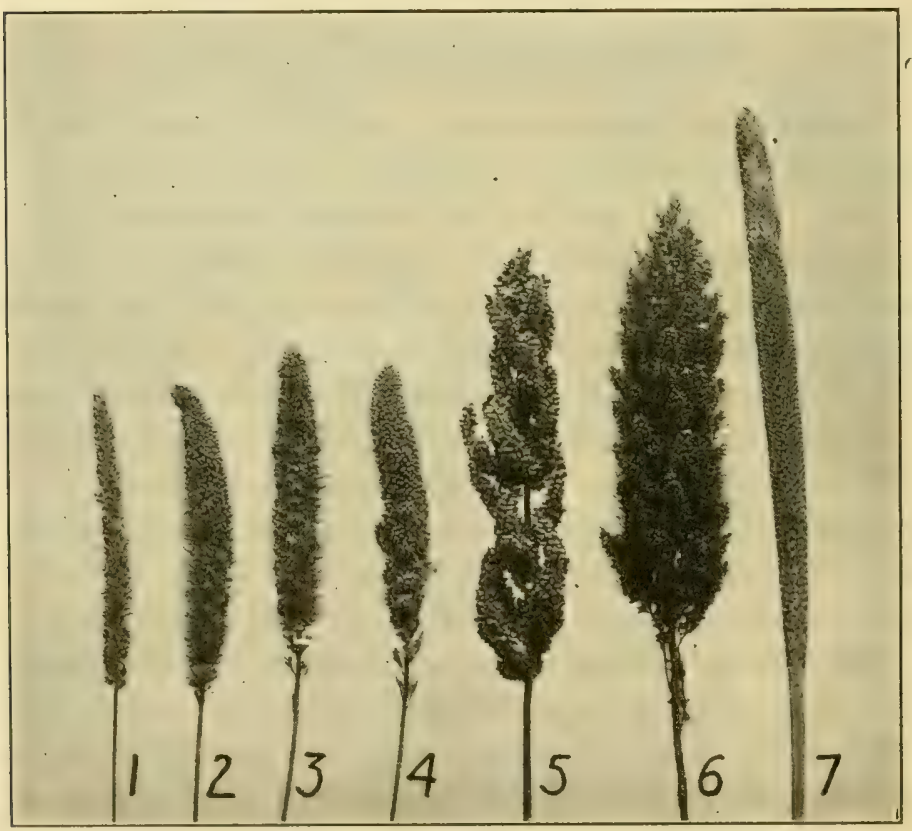

FIG. 79.-Millets. I, Common; 2, Hungarian; 3, Siberian; 4, Golden Wonder; 5, Japanese Barnyard; 6, German; 7, Pearl.

to open. The stigmas of perfect flowers first appear between the closed glumes, then the stamens, which are in turn followed by the appearance of staminate flowers.

Mature Grain.- The kernel is 3 to 4 millimeters long, reaching the length of the glumes, obovate, somewhat flattened on 
the sides, and smooth. One layer of aleurone cells is present. The kernel is easily separated, as a rule, from the lemma and palet.

Varieties.- There is considerable variation in length and thickness of the inflorescence, color of inflorescence, and color of grain. No varietal classification has been made. Pearl millet is sometimes sold under the name of "Pencilaria" (Penicillaria) or Mand's Wonder Forage Plant. There are many common names for Pearl millet, some of which are cattail millet, African millet, Indian millet, Egyptian millet, horse millet, and Japan millet.

Origin.-The wild form from which pearl millet has come is unknown. It is probable that tropical Africa is its native home.

\section{PANICUM MILIACEUM (Proso, Hog or Broom-corn Millet)}

Stem.-The plants are erect, sometimes decumbent at the base, and often reach a height of 3 to $3 \frac{1}{2}$ feet.

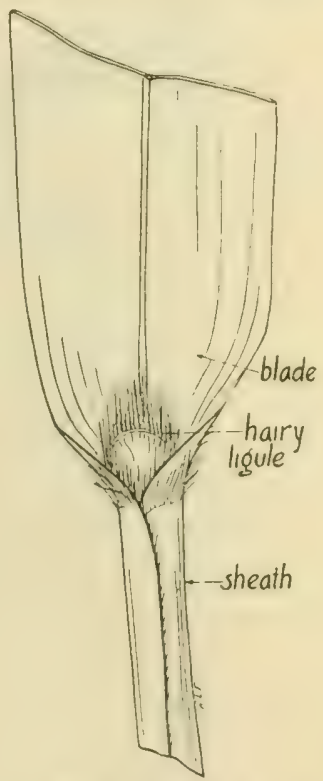

Fic;. So,--Leat of prosin millet (Panicum miliaccum). $\times 2$.

Branches frequently arise from the basal nodes, and they may bear inflorescences. The culms are cylindrical, and rough-hairy or smooth below the nodes.

Leaf (Fig. So).-The leaf sheaths are open. 'They are covered with very small protuberances (papilla) from each of which arises a stiff hair; at the sheath noles the hairs are shorter and not mounted upon papillad. The ligule is short. thick, and fimbriated, and the auricles are lacking. The leat 
blade is linear lanceolate, and hairy, especially upon the upper surface.

Inflorescence.-This is a rather dense panicle (Fig. 8I), 4 to ro inches long; the erect or ascending branches are some-

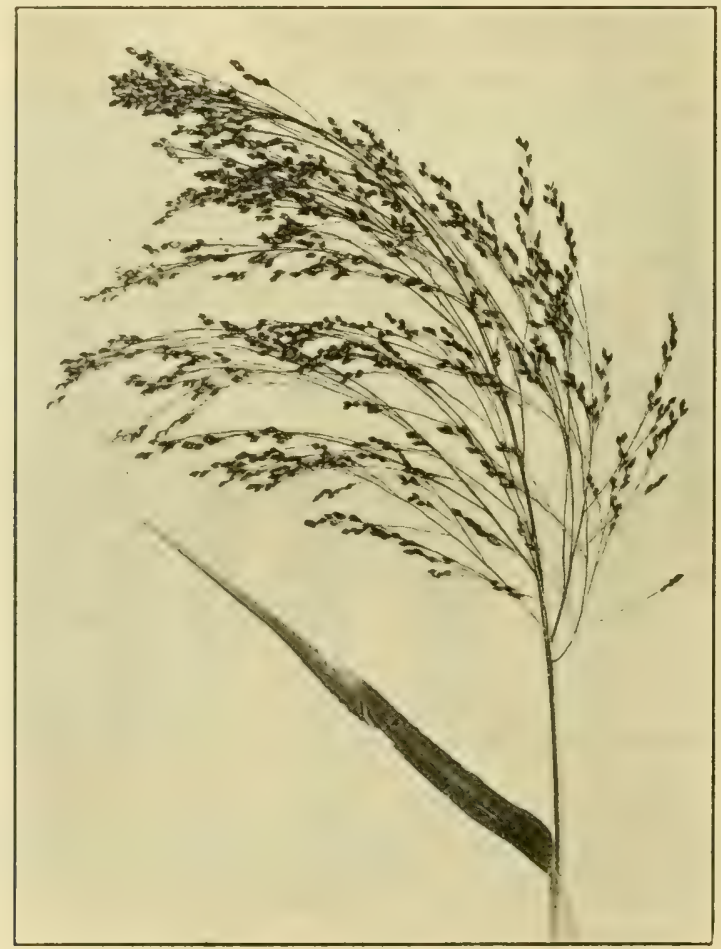

Fig. 8r.-Inflorescence of proso millet (Panicum miliaceum).

what angled and rough with short hairs that point forwards. In some varieties, the branches of the panicle spread to all sides, in others they are more or less compressed and onesided, while in a few varieties, the panicle is much compressed, thick, and erect. 
Spikelet and Flower.- The spikelets are oval in shape and $4^{1,2}$ to $5 \mathrm{~mm}$. long. The lowermost glume is broad, pointed, five- to seven-nerved, and about one-half the length of the spikelet; the second glume is the length of the spikelet and bears 13 nerves. Within the second (longer) glume is the lemma of a sterile flower; this lemma is slightly shorter than the glume surrounding it, and encloses a very small palet. Above this sterile flower, is a perfect one. The lemma of this is parchment-like, broad, and seven-nerved; it encloses the three-nerved palet. The two lodicules are fleshy, smooth, and somewhat broader than long. Stamens are three in number. There are two plumose style branches.

Pollination.-This millet is quite regularly cross-pollinated; however, self-pollination is not excluded.

Mature Grain.-The kernel is firmly surrounded by the indurated, shining lemma and palet. The whole grain measures about 3 millimeters in length and 2 millimeters in width. The kernel itself is broadly oval, smooth, white. and does not possess a groove or furrow as does wheat. The position of the embryo is indicated by a shallow broad marking about one-half the length of the kernel. The wall of the kernel is thin. There is one row of small, flat aleurone cells surrounding the starchy endosperm.

Varieties. -Koernicke recognizes three main types of broom-corn millet. These are as follows:

I. Panicum miliaceum effusum.-Panicle broad, the branches spreading to all sides.

2. Panicum miliaceum contractum.-Panicle less spreading than preceding, one-sided.

3. Panicum miliaceum compachum.-Panicle compact, thick, and erect.

Origin.-The native home of Panicum miliaceum is not 
known. The plant has been cultivated in Europe and Asia from the earliest times.

\section{CH AETOCHLOA ITALICA (Foxtail Millets)}

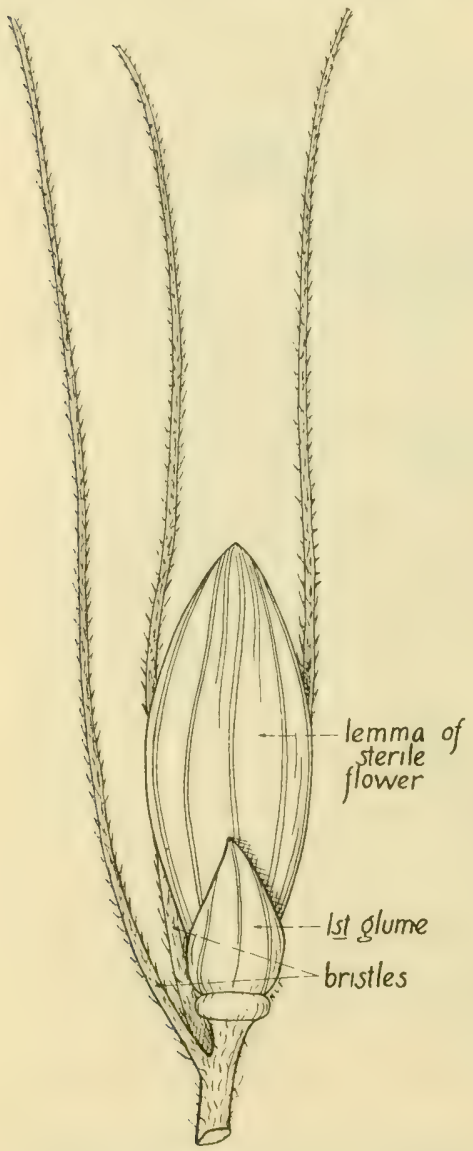

FIG. 82.-Spikelet of foxtail millet (Chrtochloa italica). X I5.

Stem.-The plants are erect and from 2 to 5 feet tall. The culms are cylindrical; they may branch near the base, but such branches seldom produce flowers and fruit.

Leaf.- The leaf sheaths are open, and smooth or hairy. The ligule is short, thick, and fimbriated; auricles are absent. The leaf blades are long, broad, and taper to a sharp point.

In flore scence.-The spikes (Fig. 79) are 4 to 9 inches long, and $1 / 2$ to 2 inches thick. The chief axis of the inflorescence and the short side branches are hairy. On the short lateral branches, there occur bristles (Fig. 82) subtending the spikelets. These bristles bear short hairs that point forward. There is evidence that they are abortive branches. It has been noted that varieties apparently without bristles, occasionally bear spikelets with bristles. 
Spikelets and Flower.- The spikelets are elliptical, and usually shorter than the bristles, which subtend them. Each spikelet (Fig. 83) has two flowers, the lower sterile, the upper with both stamens and pistil. The lowermost glume is oval, pointed, three-nerved, and about onethird the length of the spikelet. The second glume is five-nerved, and slightly shorter than the spikelet; it surrounds the lemma of the sterile flower. The lemma of the fertile flower is broad-oval, and five-nerved; the palet is about the sime length as its lemma. Both lemma and
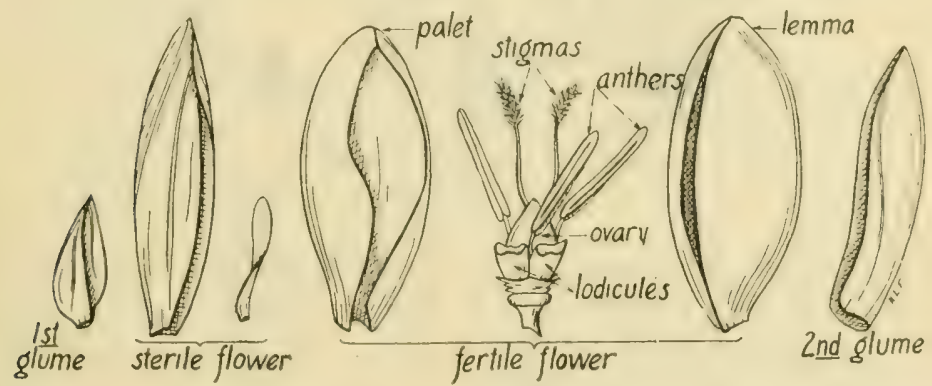

FIG. 83,-Dissected spikelet of common millet (Chatochloa italica). X Io

palet of the fertile flower are smooth, shining, hardened structures. The lodicules are fleshy. There are three stamens. The ovary is long-oval and smooth; its style has two long branches, with the rudiment of a third.

Pollination.-Cross-pollination is the rule; self-pollination occasionally occurs.

Mature Grain (Fig. S $_{+}$). - The lemma and palet enclose the mature kernel. The grain is oval, shining, 2 to 21.2 millimeters long and $I^{1}+$ to $I_{2} y_{2}$ millimeters wide. The kernel is broad-oval, smooth, and white; it does not have a groove or furrow. The position of the embryo is indicated by a mark 
which is about one-half the length of the kernel. The pericarp is thin. There is a single row of small, flat cells in the aleurone layer.

Types and Varieties of Foxtail Millet.-Koernicke recognizes two main groups of cultivated millets belonging to the species Chatochloa italica:
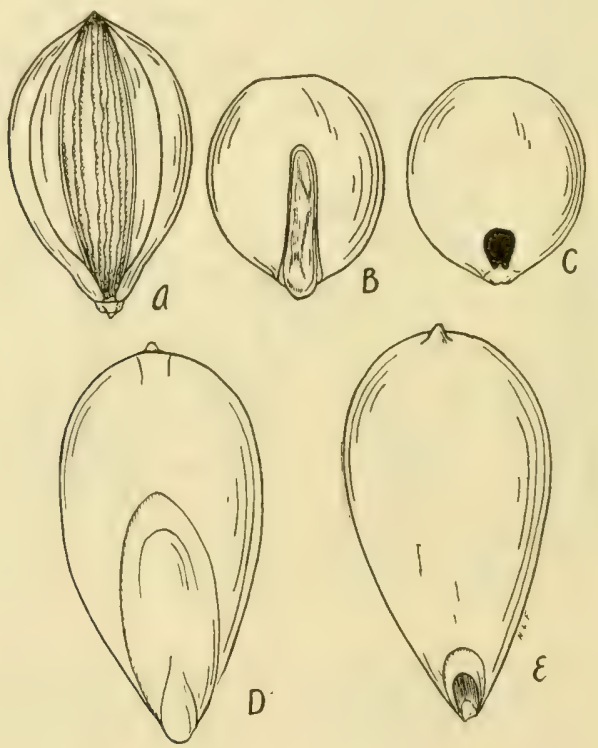

FIG. 84.-A, grain of foxtail millet (Chrtochloa italica) with lemma and palet attached; $B$, grain of same, embryo side with "hull" removed; $C$, grain of same, side opposite the embryo; $D$ and $E$, grains of pearl millet (Pennisetum spicatum). X 10.

I. Chatochloa italica maximum.-Heads long, open, and drooping. This group has two subdivisions: (I) varieties with short bristles, and (2) varieties with long bristles. Here would be included Aino millet, German millet, Golden Wonder millet, and Siberian millet. 
2. Chatochloa italica moharimm.-Heads short, thick. erect, or drooping but very slightly. This group also has two subdivisions: short-bristle and long-bristle varieties. Here belongs Hungarian millet.

Key to Principal Types of Foxtail Millets (Chatochloa italica)'

Heads small, uniform, compact, seeds yellowish to black with usually a large percentage very dark; beards brown or purple, Munswiun lillet. Heads large, more or less open; seeds more or less bunched.

Heads long, slender, very open, lax, drooping; seed groups very distinct, Aino Millet.

Ifeads shorter and plumper, bushy; erect or slightly. drooping; seerl groupls indistinct.

Seeds yellow.

Profusely bearded; medium large heads.

Heads large, seeds small, seed groups more distinct, German Millel.

Heads small, seeds large, seed groups less distinct, Common Millet.

Sparingly bearded; heads very large, Golden Wonder Millet.

Seeds red or pink, Siberian Millet.

Origin of Foxtail Millet.-The stem form of the foxtail millets is Chatochlou iridis, the green foxtail. It differs from the cultivated forms in that its fruit falls from the inflorescence when mature. Chelochloa airidis is a native of the Old World. It is now found in waste places in North America from Texas to Quebec.

ECHINOCHLOA CRUS-GALLI (Barnyard Grass or Barnyard Millet)

Habit, Stems, Leaves. - This grass is an annual, 2 to 4 fect tall; the culms often branch at the base. The leaves are 1,2 to 2 feet long, 14 to I inch wide, and have smooth. gliabrous sheaths and smooth or scabrous blades.

Inflorescence, Spikelet, Flowers, and Fruit.-- The inflorescence is a panicle marle up of from five to fifteen sessile, erect or ascending branches; the lower branches may be spreading ${ }^{1}$ After Frear. 
or reflexed. The spikelets are ovate, green or purple, and densely crowded in two to four rows on one side of the rachis. Each spikelet has two flowers: a lower staminate, and an upper perfect. Within the two empty glumes is the lemma of the staminate flower; then follow the lemma and palet of the perfect flower, both of which are hard and parchment-like in texture. The lemma of the staminate flower is awned, that of the perfect flower abruptly pointed. There are three stamens, and two plumose stigmas. The kernel is firmly surrounded by the hardened lemma and palet.

Distribution.--Barnyard grass is a native of Europe. It is now widely distributed as a weed in cultivated soil and in waste places.

\section{ECHINOCHLOA FRUMENTACEA (Japanese Barnyard Millet)}

In general characters, Japanese barnyard millet corresponds very closely to common barnyard millet, except that in the main, it has a more nearly erect habit, more turgid seeds, is awnless, or has very short awns, and is brown or purplish in color. It is known as Sanwa millet in India, and "billiondollar grass" in the United States. It probably originated from common barnyard millet (E. crusgalli).

Environmental Relations.- The millets require environmental conditions similar to those favoring sorghums. They are sensitive to cold, and hence must be planted after all danger from frost is over. The water requirement of millets, as a group, is less than that of sorghums. Hence they are among our most drought-resistant crops, and on this account, have been cultivated extensively on the Great Plains, from Kansas to Dakota.

Uses of Millets.- The millets are grown as a hay crop, for pasturage purposes, and for the seeds, which are most commonly fed to poultry. Nillet is a quick-growing crop, 
and is reaty to cut for hay in from six to ten weeks after scerling. The foxtail millets are more valuable for hay than the proso group). The latter is most frequently grown for the grain.

\section{References}

B.ale, ('irtatun R.: Pearl millet (P'ennisetum spicatum). UT. S. I)ept. Agr. Farmers' Bull. I68: I-I6, I903. 


\section{CHAPTER XVIII \\ PHLEUM PRATENSE (Timothy)}

Description.-Common timothy is a perennial grass, from $I^{1} \frac{1}{2}$ to 5 feet high. Corms or bulbs form in the lower leaf axils, a single seedling sometimes having from eight to twenty. These bulbs develop in the fall of the year, live through the winter, and send up new shoots the following season. Thus we see that the plant reproduces vegetatively as well as by seeds. In cultivation the plant shows marked variation in stem, leaf, and inflorescence characters, in earliness, duration of bloom, longevity, vigor, stooling power, disease resistance and yield of hay and seed. The leaves are flat, and three to eight per stem; the upper sheaths are long, usually exceeding the internodes, and slightly inflated; the ligule is rounded. The inflorescence is cylindrical and spicate; although it is often called a spike, it is in reality a contracted panicle. The spikelets are one-flowered. Each spikelet is subtended by two membranous, compressed glumes which are ciliate on the margins (Fig. 85), truncate at the tip and awned; the lemma is much shorter and broader than the glumes, thin, truncate, and finely toothed at the apex; the palet is narrow and thin. Stamens are three in number. There are two distinct styles with plumose stigmas. The whole process of blooming and dehiscence of anthers takes place in about one and one-half hours. Clark observed that the average number of days the individual heads remain in bloom varies from seven to ten. The upper third of the head blooms first. The time of blooming is just before daybreak. The egg-shaped grain is enclosed 
by the lemma and palet. Self-fertilization usually occurs in timothy, although cross-fertilization may also take place.

It is customary to cut timothy while it is in bloom or just past bloom, for at this time the yield of dry matter is greater than at any other stage of maturity. This is due to the loss of leaves and the movement of food materials to the roots which follow the blooming period.
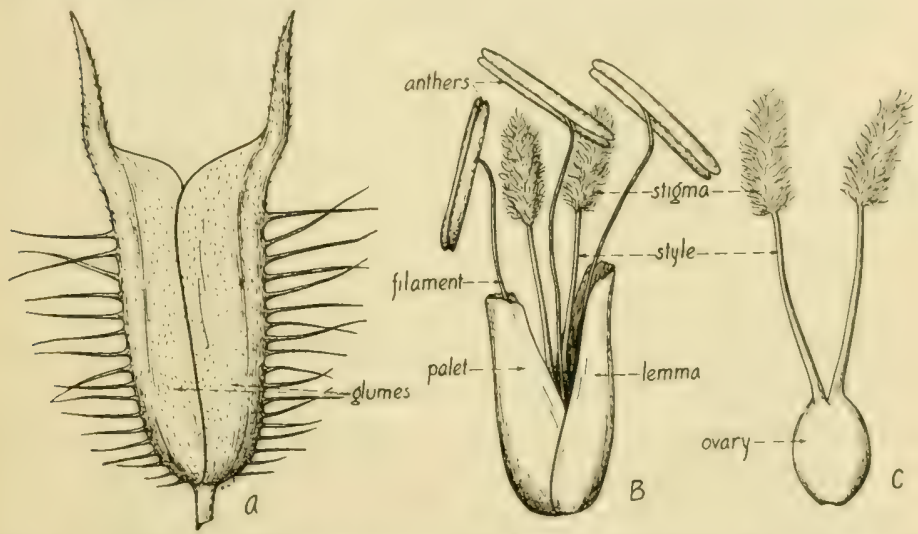

FIG. 85.-Timothy (Phleum pratense). A, single spikelet; $B$, spikelet with glumes removed; $C$, pistil.

Environmental Relations.- Timothy thrives best in a moist and cool climate; it is not grown south of the $36^{\circ}$ latitude, except at high elevations. It is unable to endure hot, dry summers, such as exist in the Great Plains and intermountain areas. It is an important crop at high altitudes in the Rocky Mountains, where it is usually mixed with Alsike clover.

It will grow on both clay and loam soils, and does best when lime is present.

Closely Related Species.-Mountain timothy (Phlcum alpinum) is common in meadows from Labrador to Alaska, in the mountains of both the East and the West, also Europe, Asia, and temperate South America. The inflores- 
cences are much shorter than those of common timothy, the awn is about onehalf the length of the outer glume, and the upper leaf sheath is inflated.

\section{References}

Clark, Charles F.: Variation and Correlation in Timothy. Cornell Agr. Exp. Sta. Bull. 279: I-350, I9I0.

Observations on the Blooming of Timothy. Plant World, I4: I3I-136, Igir.

Webber, H. J.: The Production of New and Improved Varieties of Timothy. U. S. Dept. Agr. Bur. Plant Ind. Bull. 3г 3: 339-38 г, I9r2. 


\section{CHAPTER XIX}

\section{SACCHARUM OFFICINARUM (Sugar Cane)}

Habit, Roots.- Sugar cane is a tall, perennial plant, resembling corn and the sorghums in general habit. The root system is fibrous and rather shallow.

Stems.-The stem is of the usual grass type-divided into a number of joints. The cylindrical, solid culm is 8 to ${ }_{5}$ feet high, and $I$ to 2 inches in diameter. There are sometimes as many as 60 to 80 nodes. The jointed stem is prolonged into the ground, and the roots arise from the lowermost nodes. This stem arises from the rootstock of the previous year, or, under artificial conditions, from the planted portion of a cane. The buds are found, as usual, in the leaf axils. They are better developed in the lower leaf axils than in the upper. Around the culm, at the bud, are several rows of dots; roots arise from these dots when the cane is planted, or when in any way it is brought into contact with the soil. Sugar cane "suckers" readily. The plant is propagated entirely from stems. The whole stalk may be used or only the lower parts of the stools, the so-called "rattoons."

Leaves.-There is a single, broad, clasping leaf at each node.

Inflorescence, Flowers, Fruit.- The inflorescence is a loose panicle, I foot or more in length, with numerous branches. The spikelets are arranged in a racemose fashion on slender branches. They occur in pairs, one of which is pedicellate, the other sessile. There are two glumes at the base of the 
spikelet. Each spikelet is two-flowered; the lower one is sterile and consists of a palet; the upper is fertile and has a lemma and palet, two minute lodicules, one to three stamens, and a single ovary with two stigmas. There is a tuft of long, silky hairs at the base of each spikelet. The grain

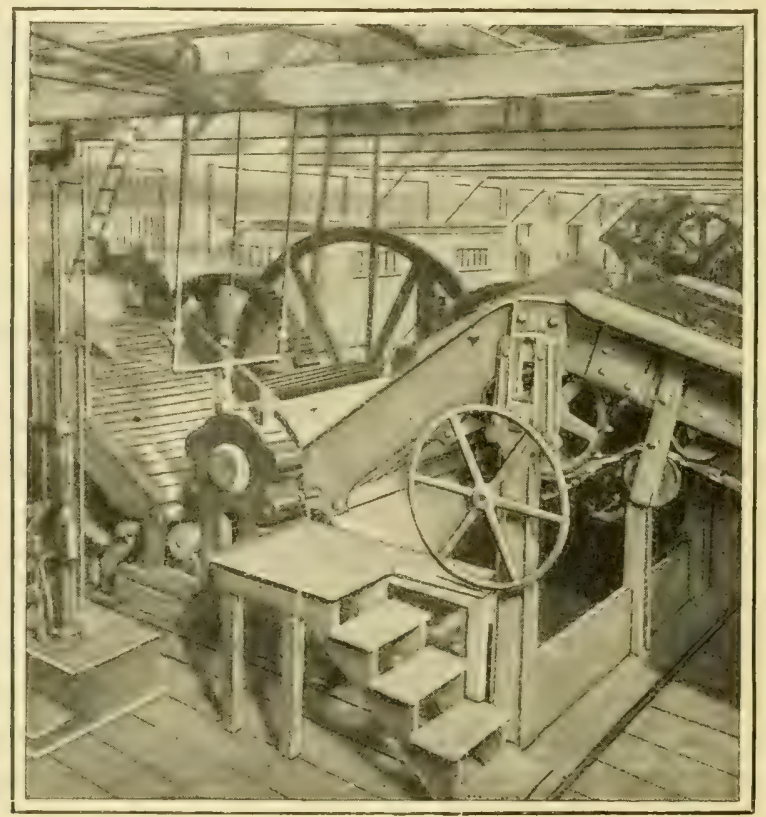

Fig. 86.-Mill where sugar cane is crushed. (From Essentials of Geography, Second Book. Copyright, I9I6, by Albert Perry Brigham and Charles T. McFarlane. American Book Company, Publishers.)

is small, silky, and of low vitality. Mature grains are seldom produced in cultivated plants and pollen is often infertile.

Geographical.- Saccharum officinarum is a native of the tropics. It is now grown as a crop throughout our Southern States and in many other warm regions. It is not a success 
north of the latiturle of $33^{\circ}$. The roots are unable to stamel a temperature much lower than $15^{\circ} \mathrm{F}$.

Sugar from Sugar Cane.- The canes, stripped of their leaves, are first shredded by revolving spiked cylinders, and then passed between three different sets of rollers, which crush out the juice. About 75 per cent. of the juice is pressed out by the first set of rollers. Between the first and second set of rollers, the canes are sprayed with the heated juice from the third set. About Io per cent. of the total amount of juice is removed by the second set of rollers. Before reaching the last set of rollers, the crushed material is sprayed with hot water; in this process about 5 per cent. of the total juice is removed. The crushed canes, known as "bagasse," are utilized as a fuel to run the mill.

The juice that flows from the rollers is turbid, due to the impurities which it contains. It is strained, and then milk of lime is added. The limed juice is heated with steam. The impurities unite with the lime, and appear as scum on top or as a sediment at the bottom of the purified juice. The clear juice is run into vacuum evaporators, where it is concentrated to the desired point. The concentrated juice is then pumped into tanks, where crystallization is brought about.

The grain of the sugar is under the control of the one who has the crystallizing pans in charge. A high temperature in the vacuum pans favors the formation of hardgrained sugar; while a low temperature and high vacuum produce a "soft sugar." The mixture of molasses and sugar crystals is termed "massecuite." They are separated by centrifugal action. The sugar crystals are then dried, and packed for shipment.

By-products of Manufacture. Cane molasses from the manufacture of white and high-grade yellow sugars is used for 
baking purposes and as a table syrup. Poorer grades are employed in rum and alcohol manufacture, and in stock feeding.

Mention has been made of the fact that the stalks from which the juice has been removed are used as a fuel to run the mill. The refuse that accumulates in the purification process is used as a fertilizer. It is rich in phosphorus and potash.

Production of Cane Sugar.-The world's production of cane sugar during the I9I3-I9I4 campaign was II,225,000 short tons (excluding Central America). During the same period, the world production of beet sugar was $9,430,145$ short tons. Sugar-cane production in the United States is confined almost exclusively to southern Louisiana, and to Texas, immediately adjoining.

Leading Countries in the Production of Cane Sugar, igr3-19i4

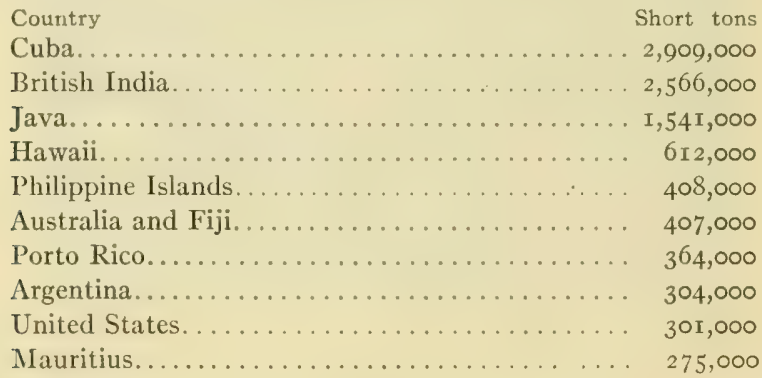




\section{CHAPTER XX}

\section{LILIACE $\notin$ (Lily Family)}

Representatives of the lily family are found all over the world, although the family is best developed in drier parts of the temperate zone. The family is by no means of as great economic importance as the grass family. A number of representatives are cultivated as vegetables, the principal ones being onions and asparagus. Yucca, lily (Lilium), hyacinth and tulip are chief among those cultivated as ornamentals.

Habit, Roots.--Most members of the family are fleshy herbs from bulbs or rhizomes. Some species of Aloe and Dracana, however, are shrubs or small trees. In herbaceous forms, the roots are mostly fibrous and shallow, sometimes fleshy and extending to considerable depths in the soil.

Stems.-Both underground and aerial stems are borne. Underground stems in the family are either rhizomes or bulbs. The character of rhizomes has been described (page 29). Bulbs are fleshy stems with a very short, usually conical stem upon which are many fleshy, overlapping leaves (Fig. I4). Bulbs, like rootstocks or rhizomes, are storage organs. They are made use of in vegetative propagation. The acrial stems may be leafy or free of leaves for a long distance. In Yucca - the soapweed or Spanish bayonet-of the semi-arid sections of the country, the base of the acrial stem is persistent from year to year.

Leaves.-The leaves are mostly linear, seldom divided or toothed, and not divided in to petiole and blade. 
Inflorescence and Flowers.- There are a number of different types of inflorescences in the family. The flowers are often single or solitary, as in the lilies; or racemose, as in the soapweed and hyacinths; or umbellate, as in onion. The umbellate or umbel-like type of inflorescence consists of many flower stalks of about equal length arising near together on

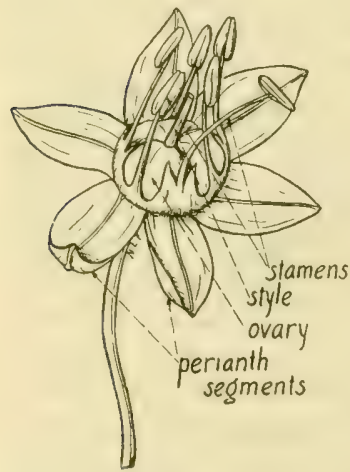

FIG. 87.-Flower of onion (Allium cepa). the stem; the outside flowers open first, the inside last, that is, the order of opening is centripetal. This is the order of opening in all racemose types of inflorescences. The perianth consists of six separate segments, in two whorls of three each, which are very similar in size, shape and color (Figs. $3 I$ and 87 ). The stamens are attached to the receptacle or to the perianth. The anthers are usually large and conspicuous. The superior ovary is three-celled, has one style and a three-lobed stigma.

Fruit and Seeds.- The fruit is a capsule or berry. The capsule is a dry, splitting (dehiscent) fruit with several united carpels. When the carpels split down the middle line as they do in lilies, the dehiscence is said to be loculicidal. It is distinguished from septicidal dehiscence of capsules, in which the carpels open along the line of their union, as in rhododendron, and from poricidal dehiscence in which the carpels open by pores, as in the poppy. The berry is a fleshy fruit possessing several to many seeds which are more or less imbedded in the fleshy ovary wall (pericarp).

The seeds always possess abundant endosperm. which encloses the embryo. Considerable quantities of oil occur in the endosperm. 


\section{ALLIUM}

To this genus belong chives, garlic, leek, onion, shallot and Welsh onion. They are all herbs with a characteristic

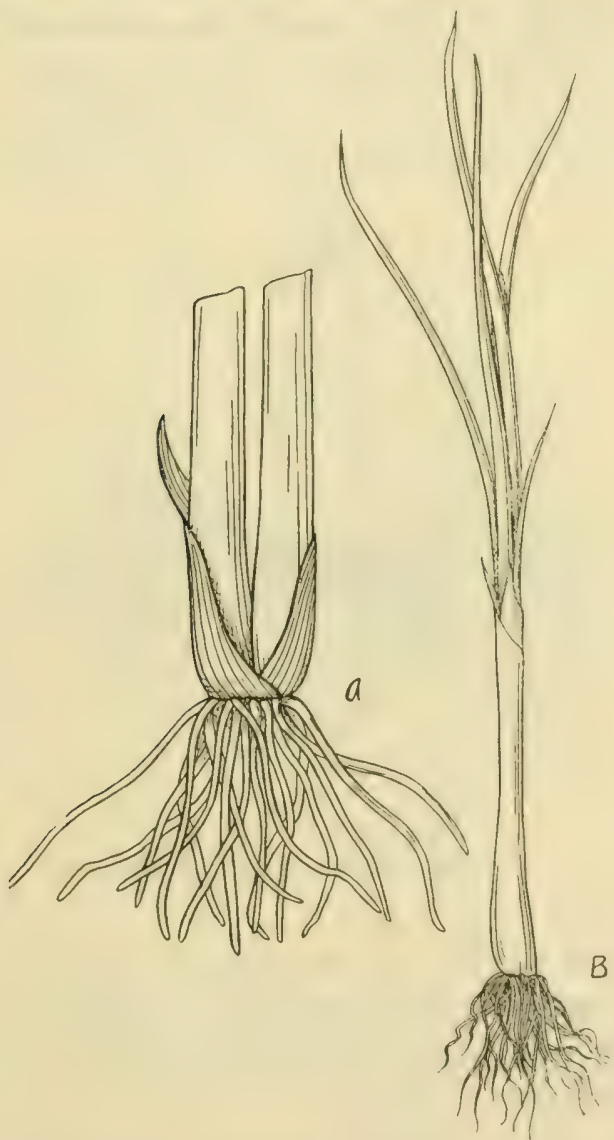

FIG. 88.-A, Welsh onion (Allium ascolonicum); $B$, cive (Allium schœnoprasum).

alliaceous oclor, which is due to the presence of ally! sulphide. 
Roots.-The root system is fibrous and very shallow (Fig. 88). The roots arise from the reduced stem, forming a fibrous tuft.

Stems.-With but few exceptions, species of the genus Allium bear bulbs. In chives (Allium schanoprasum), the bulbs are very small (Fig. 88), and in Welsh onion (Allium fistulosum) and leek (Allium porrum), they are nearly always

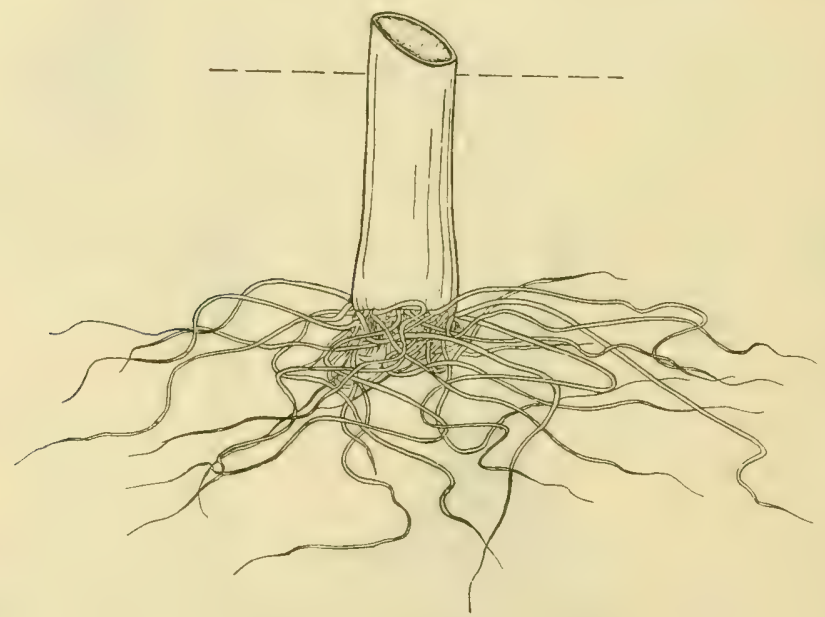

FiG: 89,-Leek (Allium porrum).

absent (Figs. 88 and 89). In the common onion (Allium cepa), they are large and well developed. Examination of the mature bulb of the common onion shows it to be made up of the much thickened bases of leaves, attached to a comparatively small, conical stem (Fig. 14). This is best seen in a median, Jongitudinal section. From a terminal bud on this small, underground stem, there is sent up a long hollow or solid, leafless stem (Fig. 90) (scape) bearing an inflorescence at the top, which in this case is an umbel. Lateral buds are 
sometimes borne in the axils of the leaves, and these may also develop into flower shoots.

Leaf.- The first foliage leaf emerges from a slit in the cotyledon. All leaves are very thick and fleshy, and overlapping. There is no petiole. The oldest leaves are on the

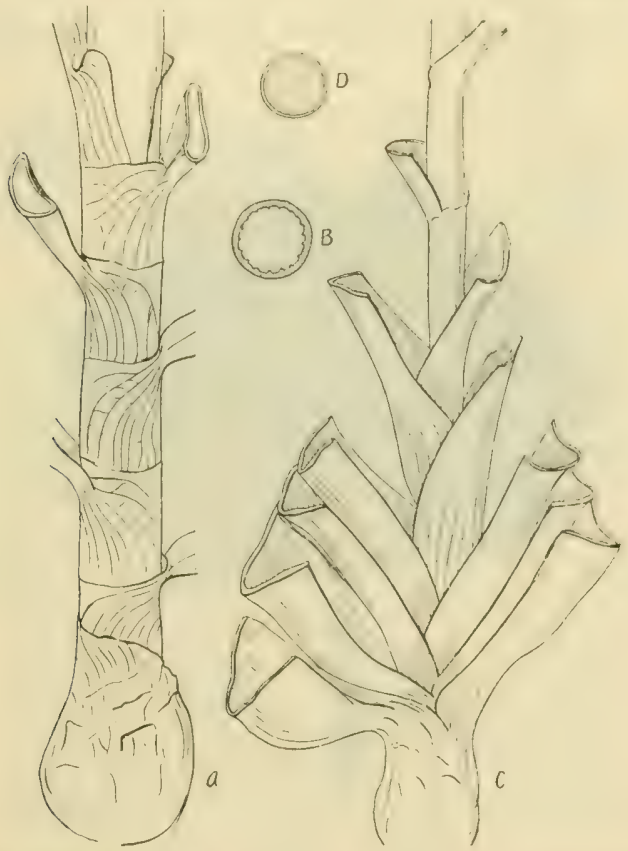

FIG. 90.- $A$, base of stem of common onion (Allium cepa) showing hollow: leaves cut across; $B$, cross-section of hollow stem of same: $C$, base of stem of leck (Allium porrum) showing flattened solid leaves; $D$, crosis-section of solicl stem of same.

outside of the bulb, while the younger appear toward the inside. In a longitudinal section of the bulb, it will be noted that these younger leaves, coming from within, are higher on the compressed stem than the older (Fig. If). 'The edible portion of the common onion, and of some other 
species, is the fleshy bases of leaves. In some species, as leek and shallot, the leaves are used as a seasoning in food. The leaves may be either flat or cylindrical (terete), and are sometimes hollow. Onions have been known to bear buds (epiphyllous buds) on their leaves.

Inflorescence (Fig. 91),- The numerous flowers are in simple, terminal umbels. The umbel is subtended by a

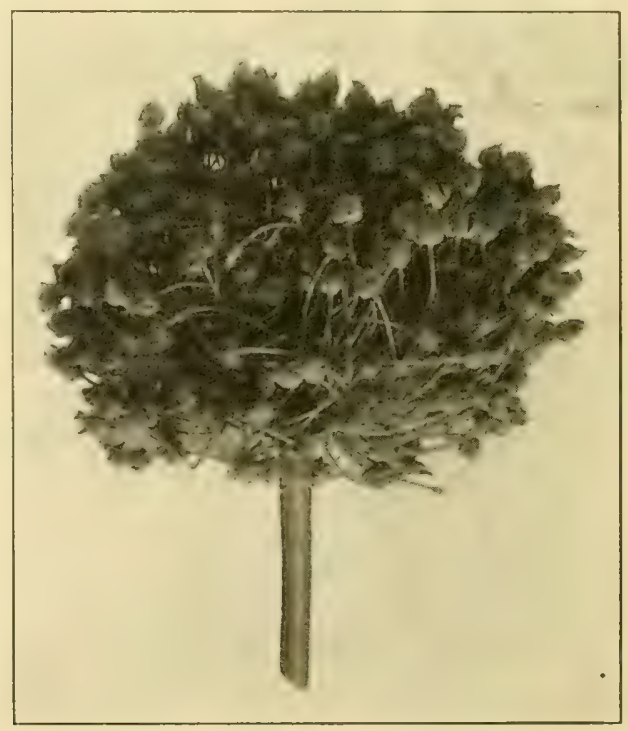

FIG. 9r.-Umbel of onion (Allium cepa).

spathe, consisting of two (rarely three) papery bracts. The spathe encloses the entire umbel in the bud. The pedicels are long and slender.

Flower.--The flowers (Fig. 87 ) are regular and periect. The perianth consists of six distinct segments which are very similar as to size, shape and color. The six stamens are inserted on the bases of the perianth segments. Alternate 
filaments are usually dilated at the base, and the anthers are oblong, and opening inward (dehiscing inward). The single, superior ovary is imperfectly three-loculed and bears a

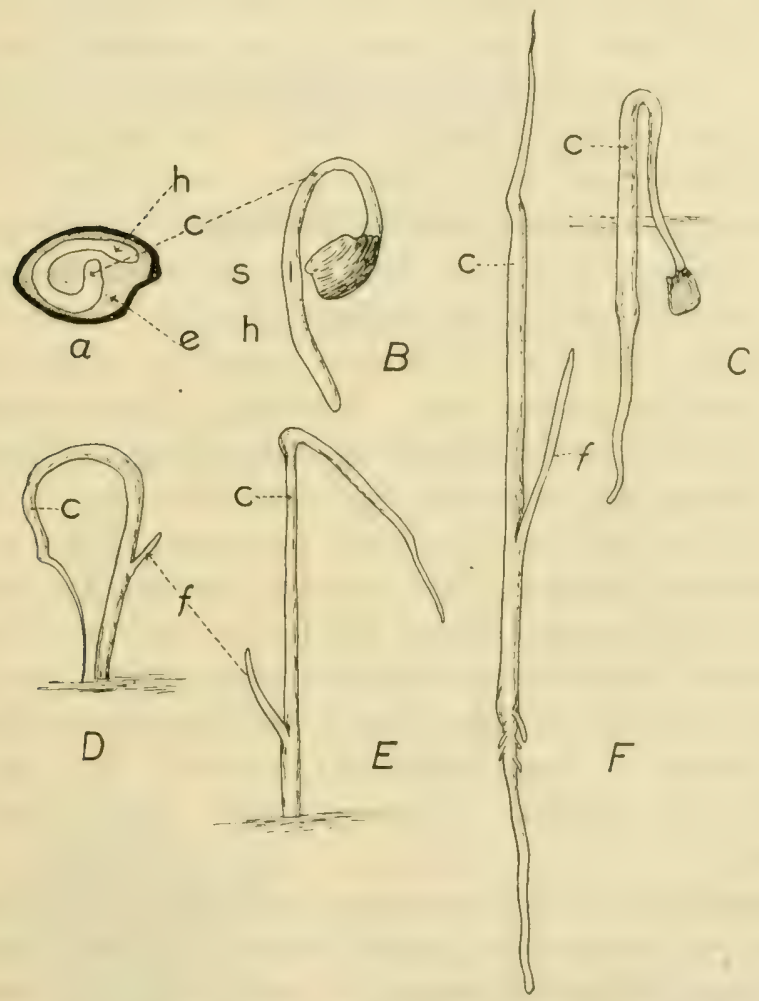

Fig. 92.- Seed and seedling of onion (Allium cepa). A, seed; $B$, to $F$, successive stages in the development of the seedling; $c$, cotyledon; $\ell$, endosperm; $f$, first true leaf; $h$, hypocotyl; s; slit from which the first true leaf emerges. $A$ considerably magnified. (After Bergen and Caldwell.)

single filiform style, which may be more or less indistinctly three-cleft at the apex.

Pollination. Species of fllimm are insect pollinated. The anthers of the flower usually mature before the stigma, at- 
though the reverse is sometimes the case. The inner circle of stamens is the first to shed pollen.

Fruit.-This is a three-celled, membranaceous capsule with loculicidal dehiscence. Two seeds, black in color, are usually borne in each locule of the capsule. The seeds (Fig. 92) are convex on one side and almost flat on the other, and possess a large quantity of oil. The embryo is cylindrical and curved.

Germination of Seed, and the Seedling.-At the beginning of germination, the primary root is forced out by the growth of the curved end of the embryo (Fig. 92). The curved end of the embryo, the cotyledon, comes out of the ground in the form of a closed loop. The tip of the cotyledon remains attacked to the endosperm and seed coat. When the soil is loose, the endosperm and seed coat may be pulled from the ground, but in case it is compact, they remain beneath the ground. The cotyledon absorbs nourishment from the endosperm. When this is used up, the cotyledon tip withers and becomes detached from the seed coat. At the base of the cotyledon, where it joins the hypocotyl, there carly appears a longitudinal slit; through this, the first foliage leaf emerges. The cotyledon later disappears entirely.

Geographical.--There are about 250 species of the genus Allium, the majority of which occur in boreal America, Mexico and northern Europe. A number are also found in Abyssinia and extratropical Asia. The cultivated onions require cool, moist weather during the early stages of their development, but ripen better if the weather is drier.

Key to Principal Cultivated Species of Genus Allium Leaves flat and solid (Fig. 90).

Leaves keeled, very narrow, Allium salivum (garlic).

Leaves keeled, very broad, Allium porrum (leek). 
Leaves cylindrical and hollow (Fig. 90).

Plants forming a dense clump with very small bulbs, Allium schonoprasum (cive or chives).

Plants not forming dense clumps; bulbs of considerable size.

Leaves short, awl-shaped; bulbs in clusters (Fig. 88), Allium ascalonicum (shallot).

Leaves long, rather broad; bulbs not in clusters.

Bulbs very distinct, generally large (Fig. r4), Allium cepa (common onion).

Bulbs not distinct, usually a mere swelling at base of plant (Fig. SS.). Allium fistulosum, (Welsh onion, ciboule).

\section{ALLIUM SATIVUM (Garlic)}

Garlic is a perennial herb. The bulbs are composed of several small, elongated, egg-shaped bulbils, called "cloves,"

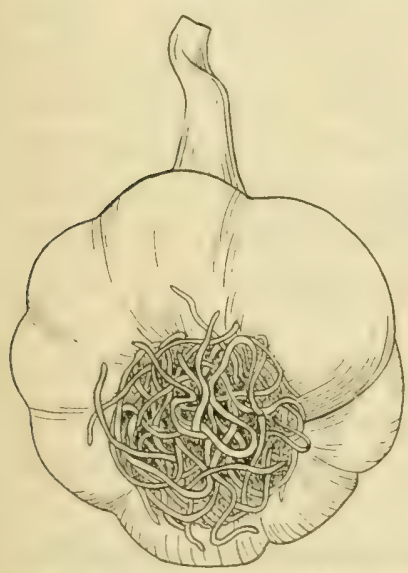

Fisi. 9.3.-Bulls of garlic (Allium sativum). $\times 3 / 2$. all of which are enclosed by a whitish skin (Fig. 93). There are often as many as ten bulbils in a single bulb. The scape is from I to 2 feet high, round, and possesses alternate, broadlinear, solid, flat leaves. The spherical umbels bear many bulblets among the small, longstemmed flowers. Seeds and bulblets are borne in the same head. In propagation, the bulblets in the flower head and the cloves are used more commonly than seeds.

Garlic is a native of southern Europe. Both the cloves and leares are used in seasoning salads and soups, and the stems are also of ten an ingredient of sausage and other ground meats. 


\section{ALLIUM PORRUM (Leek)}

Leek is a very robust biennial plant. The bulbs are small. The tall scape is solid and bears broad, solid, keeled leaves (Fig. 90).

Leek is a native of the Mediterranean region.

The edible portions of the plant are the bases of stems and leaves. The stems are blanched and eaten the same as asparagus or as common onions. The leaves are used to season soups, salads and stews.

Important varieties are Large American Flag, Musselburgh, Large Rouen and Monstrous Caratan.

\section{ALLIUM SCHCENOPRASUM (Chives or Cives)}

Chives (Fig. 88) are hardy perennials bearing small, white, narrowly ovoid, clustered bulbs with membranous coats. The scape is stout and up to 2 feet high. The leaves are linear, terete, and hollow, 7 or 8 inches in length and borne in dense tufts. The rose-colored flowers are in dense, globular umbels. Although the plant flowers profusely, it seldom produces seeds. It is propagated by division of the tufts of bulbs.

Chives are natives of Europe, Asia and North America. In this country, they grow wild from New Brunswick to Alaska, south to Maine, northern New York, Michigan, Wyoming and Washington.

The young leaves are used in the seasoning of soups, onielets, and stews. The plants are also used, ornamentally, in garden borders.

\section{ALLIUM ASCALONICUM (Shallot)}

This is a perennial herb with small, oblong-pointed bulbs about $I$ inch in diameter and 2 inches long (Fig. 94). The 
bulbs are borne in clusters, but unlike garlic, are not surrounded by a thin membrane. The leaves are short, cylindrical and hollow. The compact umbels bear lilice or reddish flowers.

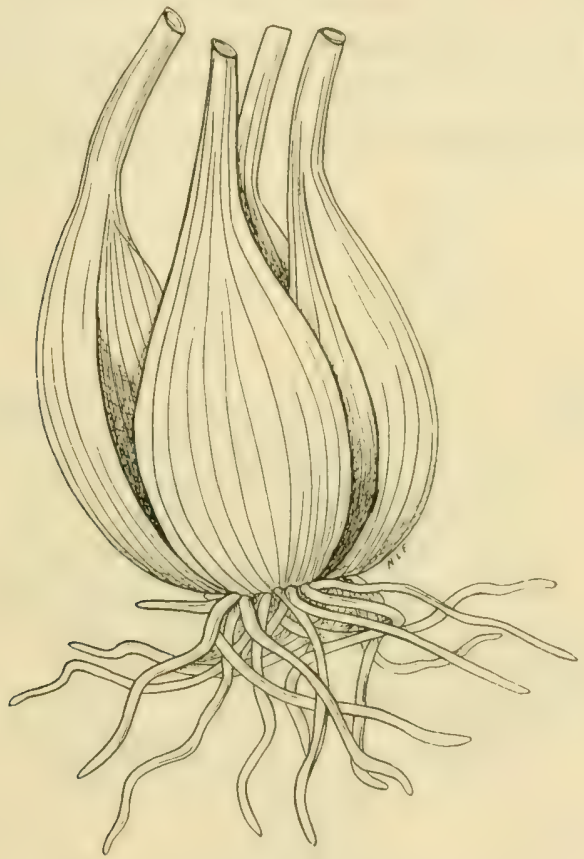

FrG. 94.-Shallot (Allium ascolonicum).

\section{ALLIUM FISTULOSUM (Welsh Onion or Ciboule)}

This is an annual or biennial with long, fibrous roots. No bulbs are produced, mere swellings occurring at the base of the plant (Fig. 88). The leares are long, rather broad and hollow. It seeds well.

The plant has been found wild about the Mltai Mountains and Lake Baical in Siberia. It is not known how the plant got its name "Welsh Onion." 
The leaves are used as a seasoning in stews, soups and salads.

\section{ALLIUM CEPA (Onion)}

Description.-The common onion is a biennial with large bulbs, that are usually single. The scape is 2 to 3 feet tall, smooth, and somewhat enlarged near the middle. The leaves are long, broad, cylindrical and hollow (Fig. 90).

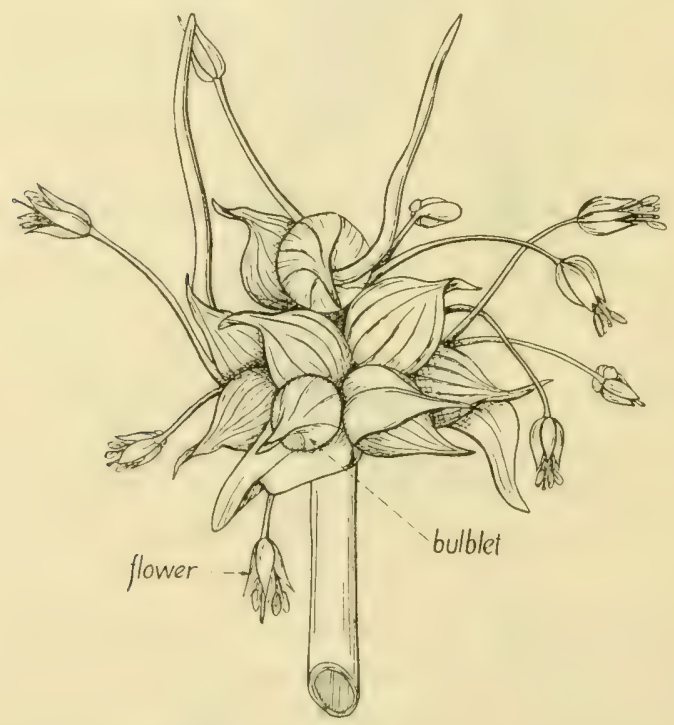

FIG. 95.-Top onions.

History.- The common onion is at present not found in a wild state. Its cultivation dates back to the earliest times in the history of India, Egypt, and China. It was used by Egyptians as a sacrificial offering. By I390, the onion was quite extensively used in Europe. The earliest colonists brought the onion with them to America. 
Types of Onions. The varieties of commen onions difier quite widely as to manner of propagation, quality, shape, color and size of bulbs, and time of maturity. L. H. Bailey proposes a classification as follows:

I. Propagated by division (Allium cepa var. mulliplicans).

Potato onions.

Multipliers.

2. Propagated by inflorescence bulblets or "lops" (Figr. 95$)$ (.1/lium cep"l var, bulbellifera).

Top onions.

Tree onions.

Egyptian onions.
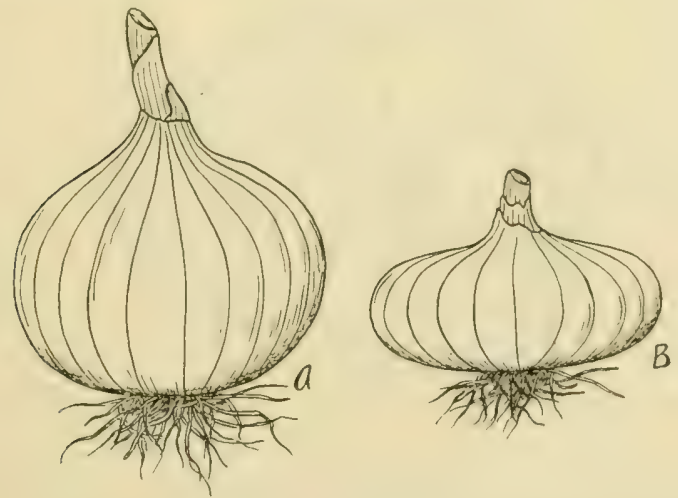

Fig. 96.-Two common types of onions based upon shape of bulb. A, globe type; $B$, flat type.

3. Propagated by seeds (Allium cepa). (These are also propagated by "sets," which are small bulbs grown from seed and arrested in their develop. ment.)

Skin of mature bulb silvery white.

I. Globe onions (Southport White Globe) (Fig. 96).

2. Flat onions (Fig. 96).

(a) Bulbs large (White Italian Tripoli, Silver Skin, White Bermudla, White Portugal).

(b) Bulbs small (Queen). 
Skin of mature bulb colored.

1. (jlole onions (Southport, Yellow Gilobe, Southport Red Gilobe, Ciiant Rocco, Golden Ball, Yellow Danvers).

2. Flat Onions.

(a) Bulbs deep and distinctly red (Red Wethersfield, Red Globe, Red Bermuda).

(b) Bulbs indifferent in color, reddish or yellowish (Yellow Danvers, Prizetaker, Strasburg).

The "multiplier" onions have compound bulbs (Fig. 97), copper-yellow in color, with rather thick skin and mild flavor. When large bulbs are planted, they segregate into a number of bulbs, and each produces six to twelve stalks. The potato

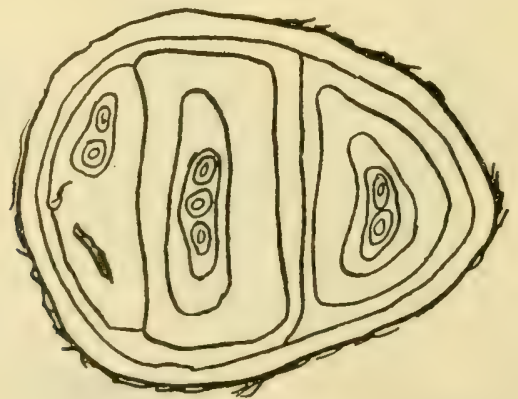

FIG. 97-Cross-section of a multiplier onion bulb. (After Bailey.)

onion is a hardy "multiplier," sometimes called English multiplier. The principal use of the "multiplier" group is in the production of "bunchers" for the early market. There are both white and yellow "multipliers."

In "lop," "tree," and "Egyptian" onions, clusters of bulblets are produced at the top of the scape. Some primordia develop into flowers and others in to bulblets. In some cases, all the primordia may develop into bulblets, and again, almost all may develop into flowers, some of which may produce fertile seed. Bulblets may be produced in separate clusters one above the other on the same stalk. They may 
grerminate while still attacher to the inflorescence. It is not clearly known what is the cause of bulblet formation in the inflorescence. Ligyptian onions are often called "perennial tree onions." They are valued for fall planting in the North to produce early spring "bunchers." They are a hardy" type.

The types of onions grown from seed are also classified by Gofi and by Gross. In these classifications, the primary divisions are made on the basis of bulb shape, the secondary ones, on size and color.

Foreign and Domestic Onions.- There is a rather sharp) distinction between "foreign" and "domestic" types of onions. The foreign types include Bermuda, Spanish and Italian onions. As compared with American types, they are larger, less hardy, the flesh is more tender and mild, but they do not keep as well. On account of their tenderness, the foreign types of onions do best in Florida, Texas, and southern California. Seed of the Bermuda onion is produced successfully only in Teneriffe, one of the Canary Islands, off the west coast of Africa. Attempts to grow seed in the United States have given comparatively poor results. The Prizetaker is our best example of a Spanish onion. Important varieties of Italian onions are the Barletta, White Italian Tripoli, White Rocco, and Giant Gibraltar. There are numerous varieties of American onions, well-known ones being as follows: Red Wethersfield, Southport (ilobe (white, yellow and red), Danvers, American Prizetaker. White Portugal, Silverskin and Strasburg.

Composition of Onions.- I)ifferent varieties of onions vary as to flavor and composition. 'The foreign types are milder than American types. The flaror is usually more pronounced in bulbs than in leaves or other parts of the plant. The flavor and odor of onions is due to an oil-like 
organic compound of sulphur, allyl sulphide. The compound is volatile to a high degree, and is broken down by heat; consequently the onion is milder when cooked than when raw. As a rule, white varieties are milder than yellow and red kinds, although there are exceptions to this.

Uses of Onions.-Onions are most commonly used as a vegetable, but in many instances for flavoring purposes. The small varieties such as Queen, Barletta, and American Silverskin are used for pickling. The Egyptian (perennial tree onion) and multipliers are valued for the production of bunchers. It is considered that the allyl sulphide in onions stimulates the flow of digestive juices and hence they are often recommended for those having a tendency to constipation. Again, on account of the small amount of starch and sugar they contain, onions are made a part of the diet of invalids who are not allowed starchy foods.

\section{ASPARAGUS}

Generic Description.-Nembers of the genus Asparagus are all perennial plants with rather fleshy roots and short rootstocks. From the latter, arise branching acrial stems, which are sometimes annual, as in the common edible asparagus (A. officinalis), or perennial as in A. laricinus, one of the ornamental asparagi. The stems are erect or climbing, in some instances (A. falcatus) reaching a distance of 25 feet or more. The small leaf-like structures along the stem, the so-called "leaves," are in reality modified stems (cladophylls) (Fig. 98). They may be slender, as in common asparagus, or broad, as in Smilax. They are arranged in clusters or whorls in the axils of the true leaves. The true leaves (Fig. 98) are scales or spines, usually very small. They subtend the branches. The flowers are solitary, in small umbels or racemes and arise in the axils of the scales 
or fascicles of cladophylls. Fach flower is mounted on a very slender jointed pedicel. The perianlle consists of six similar segments which are separate or slightly united at the base. They are persistent in the fruit. Stamens are
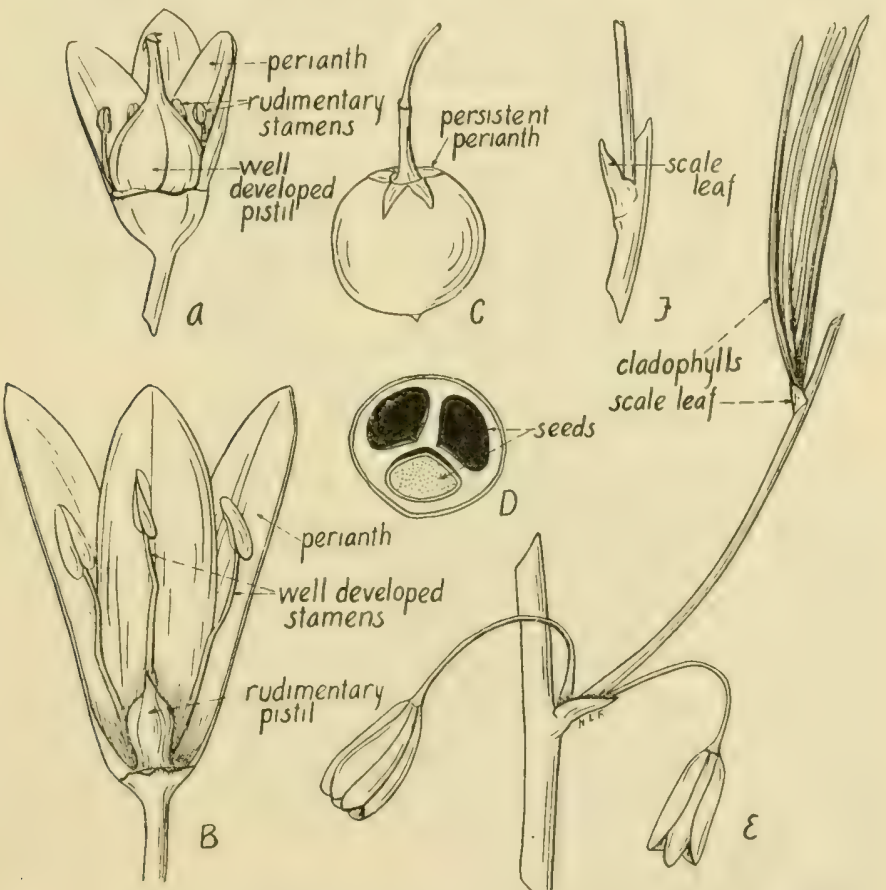
is a globose berry with two seeds (sometimes more), in each of the three locules. The seeds are subglobose, often dark in color. The embryo is cylindrical.

Economic Importance of Genus.-The genus Asparagus contains about I50 species distributed throughout temperate and tropical parts of the old World. There are numerous ornamental species, the most common being Asparagus medeoloides (smilax), A. plumosus (the plumy asparagus), a climbing plant used for decorative purposes and often called "asparagus fern," and A. sprengeri, another "asparagus fern," much used for planting in hanging baskets. The only edible species of any consequence is Asparagus officinalis, the common garden asparagus.

\section{ASPARAGUS OFFICINALIS (Asparagus)}

The common garden asparagus is a much-branched perennial herb reaching a height of 3 to 7 feet.

Roots.-The roots (Fig. 99) are numerous and fleshy, extending horizontally in the soil to some distance, but being confined to the surface layers. They arise both from the sides and bottom of the thickened rootstock. Each year new roots are produced and the older ones die and become hollow, without becoming separated from the stem. New roots appear above the older; which accounts for the so-called "lifting" of the plants.

Stems.-Asparagus bears both subterranean and aerial stems. The underground stems are rootstocks. They are much thickened, branched, rather woody, and about as long as broad. The rootstock or "crown" makes an annual growth of $\mathrm{I}$ to 3 inches. Its extension is horizontal, taking place at one or both ends. The older portions of the rootstock gradually die. The rootstocks send up aerial shoots (Fig. 99). These at first are thick and fleshy ("spears") and form the 
edible portion of the plant. The scales borne on these fleshy shoots are true leaves. At lenthg, the stems become much branched. The filiform cladophylls (Fig. 98) are mostly clustered in the axils of the minute seales. They perform the function of leaves, as is evidenced by their green color.

From the time of seeding, it is usually four years before the rootstock is vigorous enough to allow cuttings to be made.

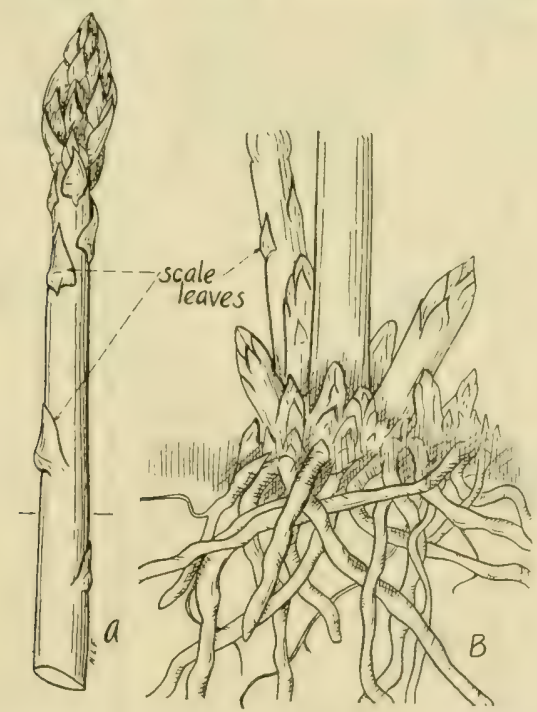

Fig. 99.-Garden asparagus (Asparagus officinalis). A, young shoot or "spear"; $B$, thick, fibrous roots and young shoots arising from "crown."

However, good crops have been produced two years after seeding. The plant may be propagated by divison of the rootstocks, but the common method is by seeding.

Leaf.- The true leaves (Fig. 98) are minute scales sul)tending the whorls of cladophylls. They do not perform leat functions.

Flower.-The flowers are small, drooping, greenish-yellow and usually solitary, but sometimes in twos or more at the 
nodes. Each flower is borne on a short, slender jointed - pedicel (Fig. Ico). The perianth is campanulate (bellshaped), about 6 millimeters long, the segments being linear

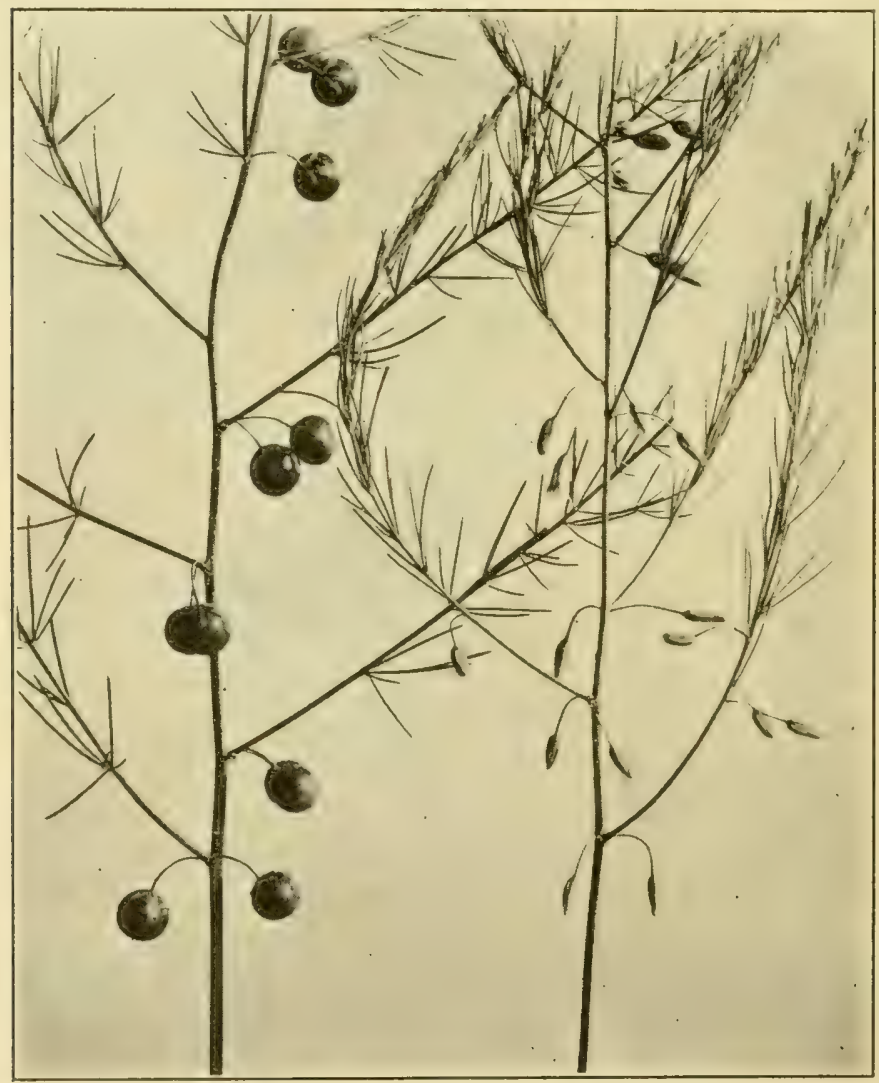

FIG. I00.-Garden asparagus (Asparagus officinalis). Portion of pistillate plant in fruit, on left; and of staminate plant in flower, on right.

and obtuse. The stamens are shorter than the perianth lobes. The single ovary has a short style, a three-lobed stigma and three locules. Common asparagus is diocious- 
staminate and pistillate flowers are borne on different plants. Hermaphroditic flowers sometimes occur, however. The staminate flowers (Fig. 98) are slightly larger than pistillate ones. Staminate flowers bear six well-developed stamens and a very short, rudimentary pistil. Pistillate flowers (Fig. 98) have six rudimentary stamens and a single welldeveloped pistil. Such flowers are practically unisexual.

It has been shown that staminate plants are more productive than pistillate ones. Green, in determining the relative productivness of pistillate and staminate plants, obtained the following results:

Product from Fifty Plants Each, Staminate and Pistillate

\begin{tabular}{|c|c|c|}
\hline & $\begin{array}{l}\text { Fifty staminate } \\
\text { plants, ounces }\end{array}$ & $\begin{array}{l}\text { Fifty pistillate } \\
\text { plants, ounces }\end{array}$ \\
\hline First period, ten days. . . . . . . . . . . ! & 37 & $2 \mathrm{I}$ \\
\hline Second period, ten days........... & 104 & 68 \\
\hline Third period, ten days............. & 266 & I64 \\
\hline Fourth period, ten days. . . . . . . . . & 203 & I 54 \\
\hline Total for season............. & 6 го & 407 \\
\hline
\end{tabular}

This shows a gain of the staminate plants over the pistillate plants of about 50 per cent. for the whole season, the greatest difference being in the first period. Hence, it seems to show that staminate plants are earlier and more productive than pistillate ones. Fruit production makes a greater demand for food than does the formation of stamens. It is for this reason that staminate plants are able to produce a greater growth of "spears" than pistillate ones.

Pollination.-Common asparagus is insect-pollinated. The nectaries are small and concealed at the base of the perianth. Staminate flowers are first to open. 
Fruit.-This is a red, spherical berry (Fig. 98) with three cells, each of which usually contains two seeds. The perianth is persistent in the fruit. The dark, somewhat triangular seeds run about fifty to a gram. They preserve their germinating power for four or five years, and may even retain their vitality when soaked in water for a year. When two years old, the plant begins to produce seed, but the best seed is not produced until the plant is three or four years old. It is held that the best seed comes from the lower branches of the plant.

Geographical.-Common asparagus grows wild in Europe and Asia and has escaped from cultivation in this country, often occurring as a weed in fields and along roadsides. The plant has been under cultivation for over 2,000 years. It is cultivated under a wide range of temperature conditions. Although able to withstand drought, it will not endure an extremely wet soil.

Types and Varieties.- Two sorts of asparagus are sold on the market, blanched asparagus and green asparagus. Green asparagus has a more delicate flavor and is quite generally considered the more desirable. Blanched asparagus has a much thicker stalk than the green sort. It must be understood that these two market types of asparagus are simply the result of cultural methods, and may be produced from the same variety. To produce etiolated or blanched asparagus, the plants are banked or ridged up with soil just as they appear above ground, so that they must make an additional growth of 4 to 10 inches before they come to light. The shoots that develop in the soil are, of course, whitish for the reason that the green coloring matter (chlorophyll) does not form in the absence of light.

The number of American varieties of asparagus is small. The most common of these are Conover's Colossal, Palmetto, Barr's Mammoth, Eclipse and Columbian Mammoth White. 
The Palmetto is grown most in the south, and is well-known on account of its resistance to asparagus rust (Pucciniu asparagi).

Uses. The common asparagus is used as a regretable. Is a rule the tender shoots are eaten fresh, but large quantities are also canned each year. The principal canning factories are located in California and on Long Island. New York. For canning, Conover's Colossal and Palmetto have given the best satisfaction. A method has been devised by which the soft pulp of the asparagus plant is separated from the fiber and canned in the form of a thick paste. In European countries, particularly, asparagus is dried. In this form it keeps indefinitely.

\section{References}

B.MLry, L. H.: Preliminary Synopsis of Onions and Some of Their Mllies. Rep. of Prof. of Hort. and Landsc. Gard., 26th Ann. Rept. State Bd. Agr. Mich., 94-98, r887.

Gorf, E. S.: Onion. 6th Ann. Rept. N. Y. State Agr. Exp. Sta., rgo-2 r4, 1887.

Green, W. J.: Asparagus. Ohio Agr. Exp. Sta. Bull. 9 rol. 3 (second series), 24I: 244, I 890.

Gross, A. R : American Onions. Proc. Soc. Prom. Agr. Sci., iI $5^{-1} 32$, r9or. 


\section{CHAPTER XXI \\ MORACE $\notin$ (Mulberry Family)}

The mulberry family has about 925 species in 55 genera, occurring in tropical and temperate regions of both hemispheres. It possesses a number of plants of considerable economic importance. Several Asiatic species of the genus Ficus yield a sap from which rubber is made. Ficus carica is our cultivated fig. The India rubber plant of greenhouses and in homes is Ficus elastica. Artocarpus communis is the well-known bread-fruit of the tropics. Toxylon pomifertm is the osage orange, a tree whose wood is valuable for wheels, posts and other small articles; it is also planted for ornament. The paper mulberry (Papyrus papyrifera). is a native of Asia. Its bark is of value in paper-making. Other genera of importance are Morus (mulberry), Humulus (hop), and Cannabis (hemp).

Description.- Members of this family are trees, shrubs, or herbs with a milky sap. The buds may be naked or scaly. The leaves are petioled (stalked), stipule-bearing, and borne oppositely or alternately on the stem. The flowers are in ament-like spikes or heads on stalks which arise in the axils of leaves. An ament is a spike-like inflorescence each flower of which is subtended by a conspicuous bract. The flowers may be monocious or diøcious. In the slaminate flower. the calyx is three- to six-lobed or parted, the petals are absent, and the stamens are one to four, inserted at the base of the calyx. The filaments are thread-like, and erect or inflexed in the bud. In the pistillate flower, the calyx consists 
of three to five partly united sepals. The single superior oiary is one- to two-celled and bears one to two styles. The fruil is drupe-like in mulberries, an achene in hops and hemp, and a synconium in figs.

\section{Key to Principal Genera}

Trees or shrubs.

Flowers not in a receptacle; buds scaly, Morus (mulberry).

Flowers inside of a hollow receptacle; buds naked, Ficus (fig).

Herbs.

Erect herbs, Cannabis (hemp).

Twining herbs, Humulus (hop).

\section{MORUS (Mulberry)}

Habit, Stems.-Mulberries are trees or shrubs with milky sap and scaly bark. The branches are slender and cylindrical. The winter buds are scaly.

Leaves.- The leaves are conduplicate (Fig. Ior) in the bud, alternate, serrate, three-nerved, often deeply lobed, and deciduous. The stipules fall soon after development. The

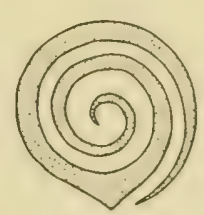

convolute

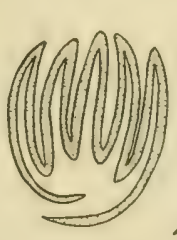

plicate conduplicate

FIG. Ior.-Three principal types of vernation.

leaves on one shoot may be relatively entire, while those on another may be moderately or deeply and irregularly lobed.

Inflorescences.- The flowers appear rather early in the season in the axils of the lower leaves. The staminate and pistillate inflorescences may be on different branches of the same tree (monœcious) or on different trees (dicecious). 
The staminate inflorescences are long, cylindrical catkins. They soon fall. The calyx of the staminate flowers is deeply divided into four rounded lobes. The three or four stamens are inserted at the base of the calyx, beneath the rudimentary pistil. The filaments are thread-like, inflexed in the bud and uncoil like a spring at the moment of anther dehiscence. The two-celled anthers open lengthwise and shed their pollen toward the inside of the flower (introrse dehiscence).

The pistillate inflorescences are short, dense catkins. The flowers in these have a deeply four-lobed calyx, the two outer lobes being the broader. All the calyx lobes are persistent, become fleshy, and enclose the ovary in the fruit. The sessile ovary possesses one cell, and a single style divided almost to the base into two very slender, hairy stigmas.

Fruit.-Each ovary develops into a nutlet bearing remnants of the styles at the tip and enclosed by the thickened, juicy calyx lobes. There is a single seed within each fruit. However, the mulberry "fruit" as commonly understood, is not a single drupe-like structure, as given above, but an aggregate of these, i.e., an entire pistillate flower cluster. The single fruits are very much crowded together, making up a collection, which commonly goes by the name "mulberry."

Other "Mulberries."-The so-called paper mulberry (Papyrus papyrifera), a native of eastern Asia and now planted for ornament in many parts of eastern and southern United States, may be easily distinguished from the true mulberries (Morus) by its non-edible globular fruit and the occurrence of its pistillate flowers in heads. In some sections of the country, the "flowering raspberry" (Rubus odoratus) is confused with and often called a "mulberry." It is true that the fruit of this has some resemblance to a mulberry "fruit," but instead of bearing its single drupe-like fruits along an axis, the true drupes of the raspberry are borne on a receptacle. 
The "fruit" of the mulberry is a collection of one-seceled fruits developed from a number of separate flowers in a dense inflorescence, while the raspberry "fruit" represents the matured ovaries of a number of pistils belonging to a single flower.

Geographical.--The genus Morus is a native of eatstern North Imerica, higher altitudes in Mexico, Central America, Western South America, Asia, Japan, and the Indian Archipelago.

\section{Key to Principal Species of Genus Morus}

Leaves smooth beneath, sometimes slightly hairy on the veins.

Fruit white or pinkish; leaves becoming light green above, Horus alba (white mulberry).

Fruit black; leaves becoming dark green and shining above, Morus nigra (black mulberry).

Leaves hairy beneath; fruit red or purplish, IJorus rubra (red mulberry).

\section{MORUS ALBA (White Mulberry)}

Description.-This is a low-branched tree, sometimes reaching a diameter of 2 feet. The slender, round twigs are at first hairy, later becoming light grayish brown. 'The leares are light green, with prominent whitish veins, and variously lobed or divided. The staminate inflorescences are I to 2 centimeters long, slender and drooping. The pistillate ones are from ${ }_{2}^{3}$ to I centimeter long. The fruil is white or pinkish in color, I to 2 centimeters long, and poor in quality.

Geographical.-The white mulberry is a native of Asia, probal,ly of (hinat. It has spread throughout Eurone and has also become naturalized in eastern United States.

Types and Varieties.-Economic Importance.-- There are a number of types and varieties of the white mulberry. According to L. H. Bailey, the following are forms or offshoots of Morus alba: Morus alba var. tarlarica (Russian mulberry) and Morus alba var. venosa. The Russian mulberry 
is a very hardy, low, bushy tree with small fruit which va ies in color from white to red and almost black. It is an important wind-break and shelter-belt tree in the Great Plains. Teas' weeping mulberry is an ornamental variety of the Russian. Morus alba var. venosa (M. nervosa) is an ornamental curiosity bearing jagged leaves with white, prominent veins.

Morus multicaulis ( $M$. alba var. multicaulis) was introduced into America in $\mathbf{1} 826$ and, for a while, gave a great impetus to the attempts to grow silkworms. It is a small tree with rough, long-pointed leaves.

The chief horticultural varieties of the white mulberry are: New American, Trowbridge. Thorburn and Downing. The Downing is supposed to be a variety of $M$. multicaulis. However, the so-called Downing of most nurserymen is the New American.

Early Attempts in the United States to Grow Silk.-The white mulberry has been cultivated from the earliest times, chiefly for feeding the silkworm. In I62 I, mulberries were introduced into Virginia by the London Company with a view of establishing the silk industry in the New World. Early attempts to grow silk were made not only in Virginia but in Carolina, Georgia and Connecticut. After the Revolution, early in the roth century, silk culture was again agitated. There existed what has been called "The Morus multicaulis mania." This species was introduced into America in I826, and since it was thought to be the source of the renowned Chinese silk, soon gained wide fame here. The "craze" died down in about ${ }_{1} 836$, and since that time, there has been little effort to grow silk in North America upon a commercial scale.

Uses.-As has been said, the white mulberry is the one upon which silkworms are raised. In the Old World the 
wood of the white mulberry is used for various purposes. The roots furnish a yellow dyestufi. In western Asia the fruit is ground into a meal for food.

\section{MORUS NIGRA (Black Mulberry)}

Description.- The black mulberry often attains a height of 40 to 60 feet and a diameter of I to 2 feet. The numerous branches are slender, slightly hairy at first, but later become smooth and brownish gray. The leaves are dark, dull green, large, pointed at the apex, rounded or heart-shaped at the base, and the teeth rather small and close together. The staminate inflorescences are i to 2 centimeters long. The pistillate inflorescences are from 5 to 8 millimeters long. The fruit is black, I to 2 centimeters long and has a deep red juice.

Geographical.--Morus nigra is a native of Asia, probably of Persia. It has become naturalized in various parts of Europe and in the United States. In this country, it occurs in the Southern States and on the Pacific Coast.

Varieties.-The black mulberry has always been the principal fruit-bearing mulberry in Europe and, in an early day, in America, but it is less tender than our native red mulberry (Morus mbra), and hence has been replaced by the latter, especially in the north. The Black Persian variety of the Southern States and California belongs to this species.

Uses.-Over central and eastern Asia the black mulberry is a common and rather valuable fruit, and large quantities are dried. The wood is used like that of the white mulberry. The juice of the ripe fruit has medicinal value. The fruit of all mulberries is relished by hogs and poultry, and it is the practice in some localities to plant mulberry trees along fences enclosing pastures or poultry yards. 


\section{MORUS RUBRA (Red Mulberry)}

Description.-This is the largest of the mulberry trees, reaching a height of 60 feet and a diameter of 5 to 7 feet. The twigs are slender, dark green, with a reddish tinge, but finally become dark brown. The leaves are large, those on young shoots deeply lobed, and with oblique and rounded sinuses, in the bases of which there are no teeth; they are rounded or heart-shaped at the base, singly or doubly toothed or three-lobed, and with a rough upper surface and a soft lower surface. The staminate inflorescences are slender and cylindric. The pistillate inflorescences are much shorter than the staminate ones. The fruit is bright red, becoming nearly black, sweet and juicy, and about r centimeter long.

Geographical.-The red mulberry is a native of North America. It grows from Massachusetts to southern Ontario, Michigan, and southeastern Nebraska, eastern Kansas and southward to Florida and Texas. It is most abundant and reaches its largest size in the Central States.

Varieties and Uses.-There are a number of varieties of the red mulberry, all of which are more hardy than those of the black mulberry. The principal horticultural varieties are Hicks, Johnson and Stubbs. The wood is used for posts and fencing, but finds its greatest usefulness in the making of shoe lasts, churns and cooperage material.

\section{HUMULUS (Hop)}

\section{HUMULUS LUPULUS (Common Hop)}

Root.-The root system of the common hop plant is large as compared with above ground parts. This holds true in both young and old plants. The roots extend to considerable depths in the soil and also spread horizontally in the surface layers. They give rise to a fine network of small rootlets. Older roots become covered with a reddish-brown bark. 
Stems. - The common hop is a perennial, herbaccous, climbing plant from an underground stem, a rootstock. These rootstocks may become quite woody. They are commonly used for propagation. Cuttings from them readily form numerous adventitious roots. Hop plants send out, near the ground line, "runners" which extend several feet. These are cut into pieces, possessing two or more buds, and used for propagation. They are known in hop culture as "roots." However, they are stems and not true roots.

The aerial stems, commonly known as "bines," die back to the ground in the fall. The lower portion of each stalk ("bine"), below ground, does not die, but forms an addition to the rootstock. The above ground stems are herbaceous, hollow and angular, and vary in color from pale green to purplish red or green streaked with purple. They have a twining habit, always winding about the support clockwise (Fig. I02). The angle of the support determines, to a degree, the manner

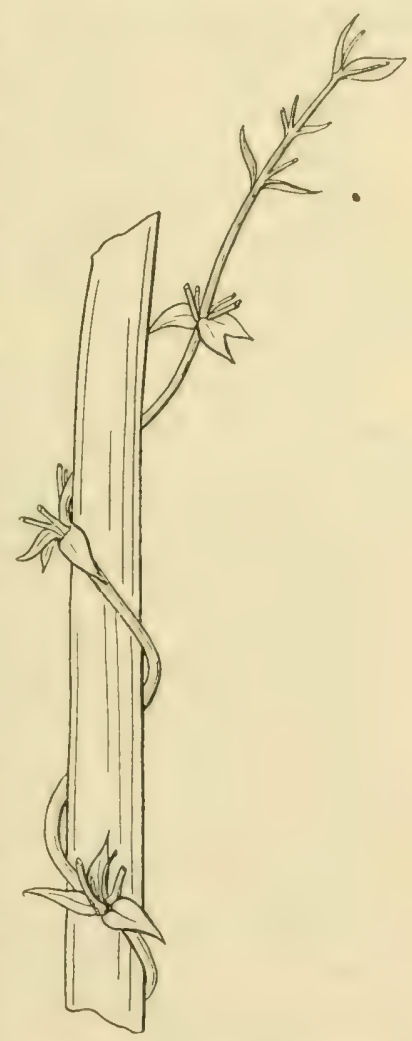

FIG. I02.-Dextrorse twining of hop stem. and rate of growth. The most rapid and uniform growth is made, and the longest internodes produced, when the supports are vertical. The "bines" are assisted in their climb)ing and clinging to supports by the presence of hooked, re- 
trorse hairs on each of the six edges of the stems, and on the petioles and leaf veins. The main stems bear opposite lateral branches. These reach their greatest length near the middle of the main stem. They bear the pistillate inflorescences (hops), and hence it is important that they be formed in abundance.

Leaves.-The hop leaves are opposite, broad, palmately veined, and three- to five-toothed (Fig. I03). In palmately veined leaves there are several main veins which radiate from the leaf base. The stipules are broad, those of opposite leaves being united.

Inflorescences.-Hops are commonly dicecious, rarely monocious. Hermaphroditism in hops has been noted. Some have held that injury is the cause of this abnormality. This theory has been refuted by Stockberger as a result of a number of experiments in which the plants were cut back, or pruned, or the tap root removed or portions of the crown removed. All of them failed to develop the abnormality (hermaphroditism). Hop plants of this type arise independently of injury. They transmit the abnormality to their progeny when propagated vegetatively. It is held that perfect flowers appear only in pistillate inflorescences.

Staminate inflorescences (Fig. Io3, B) are paniculate, and grow from the axils of the main shoot or from the axils of lateral ones. Pistillate inflorescences (Fig. I03, A) are spikelike in appearance. They are the "hops" of commerce and are often spoken of as "burrs" or "strobiles." These are mostly borne on lateral branches from the main stem; they arise in the axils of the leaves.

The pistillate inflorescence has a central, hairy axis (Fig. I03, C) upon which are arranged a number of very short lateral branches or axes. At the base of each short lateral branch, or axis, is a pair of bract-like structures. These are in 


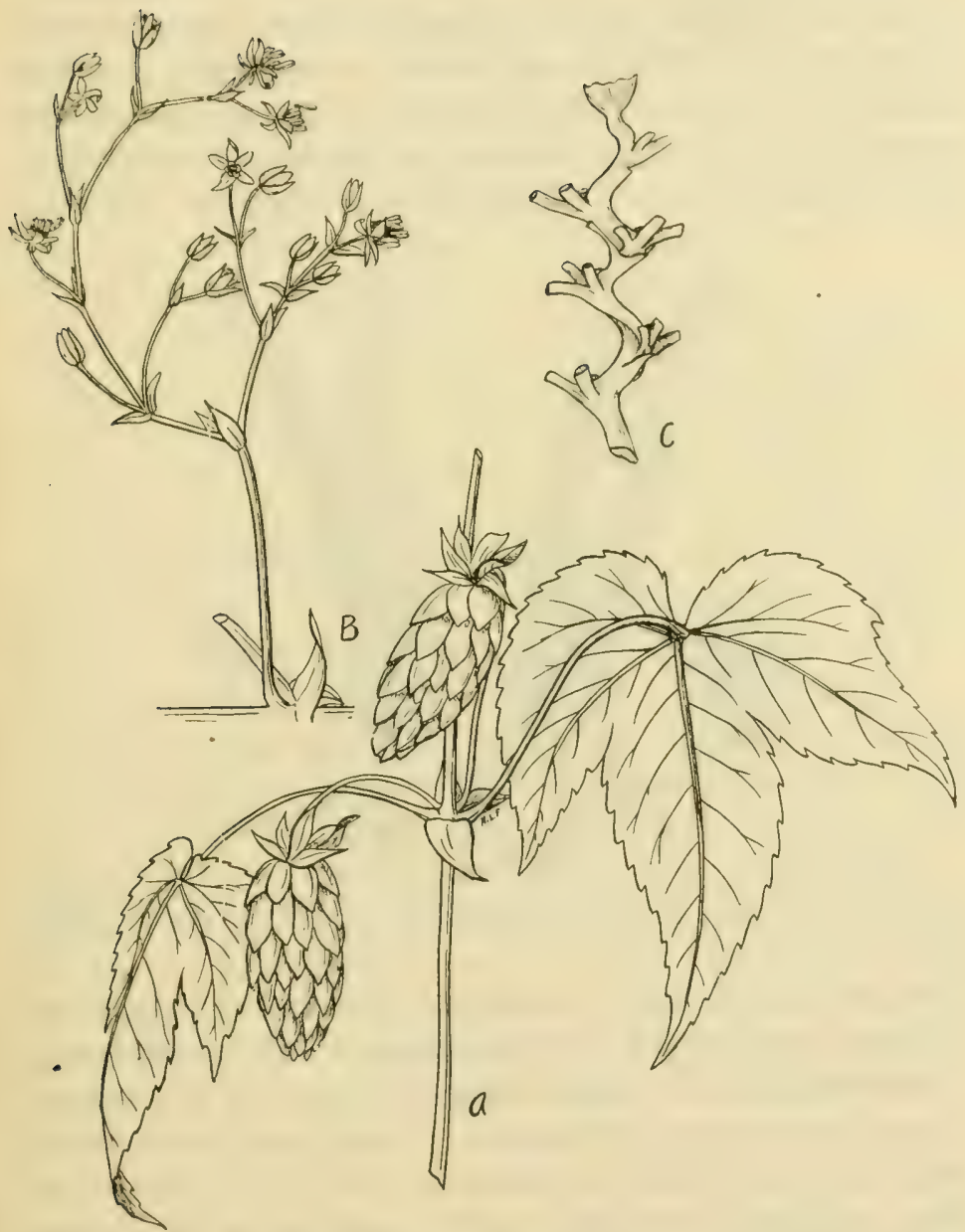

Fig. I03-- Hop (Humulus lupulus). A, portion of plant showing pistillate inflorescences; $B$, staminate inflorescence; $C$, rachis of pistillate infloresence ("hop"). 
reality stipules belonging to leaves which, normally, do not develop. Each of the lateral branches bears four pistillate flowers. Below each flower is a single bracteole (small bract). Hence, examination of a single lateral axis or branch shows it to be made up of the following parts, from below upwards: (I) two bract-like stipules; (2) brac-

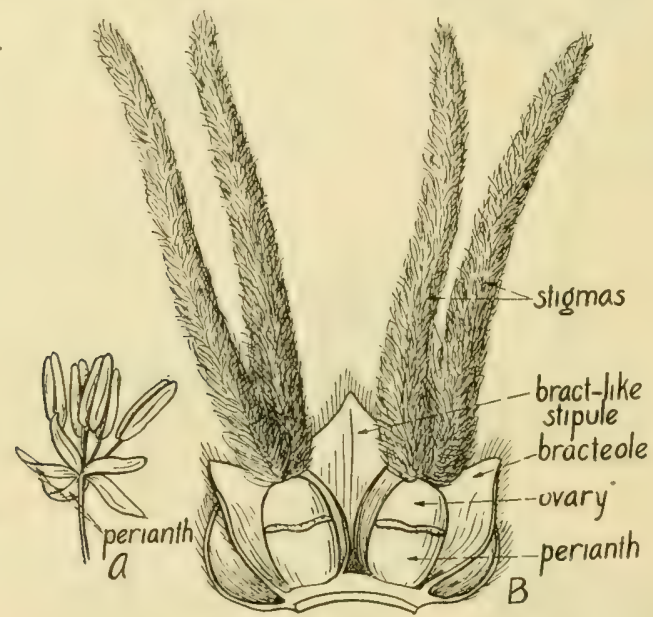

FIG. I04--Hop (Humulus lupulus). $A$, single staminate flower; $B$, two pistillate flowers with bracteoles and bract-like stipule. ( $B$ after Wossidlo.)

teole and first flower; (3) bracteole and second flower; (4) bracteole and third flower; (5) bracteole and fourth flower.

Flowers.- The staminate flowers (Fig. I04, A) measure about 6 millimeters in diameter. They have a five-parted calyx, no corolla, and five stamens opposite the calyx lobes. Each pistillate flower (Fig. I04, B) is subtended by a single bracteole (Fig. I05, A) that partially encloses it at maturity. It has a single ovary surrounded by a cup-shaped perianth. There is one style with two long stigmas, which are covered their full length with papillæ. 
Pollination, Fertilization, and Development of the "Hops."-The long, brush-like stigmas adapt the plant to wind pollination. When the pistillate inflorescences are young, the stigmas protrude from between the small "bracts" and become very conspicuous. Only the basal bracts of the inflorescence are to be seen. As soon as fertilization has taken place the stigmas ("brush") drop off and the "bracts" rapidly increase in size.

The necessity for fertilization to secure the best development of the "hop" has been determined by a number of observers. The hops will only develop properly when a certain number of bracteoles bear seeds. If the young pistillate inflorescences ("burrs") are enclosed in paper bags to prevent fertilization, no seeds result, and the hops are poorly developed. It is true that the bracteoles develop to some extent without fertilization of the ovules, but the bracteoles connected with normal seeds are much larger and a brighter yellow than those bearing rudimentary seeds. Furthermore, hops, not fertilized, remain in blossom longer than those fertilized. Howard has shown that hops artificially pollinated start to grow out at once, while those not pollinated at all begin their growth seven to ten days later. He shows that fertilization stimulates growth, hastens ripening, improves the color and increases the mold-resisting power of the plant. Salmon and Amos have shown that, in England at least, seeded hops bearing an average of 9.5 seeds per hop, contained 15 per cent. resin and produced I 47 pounds of resin per acre, while seedless hops contained I 7.2 per cent. of resin and produced 92 pounds of resin per acre. It is true that there are certain disadvantages connected with growing seeded hops. Extra space is needed for growing staminate plants, and there is also a possi- 
bility that the soil is more quickly exhausted by seeded hops than by seedless ones.

The Mature Fruit.- The fruit (Fig. I05) is a small achene surrounded by the persistent cup-shaped perianth. The

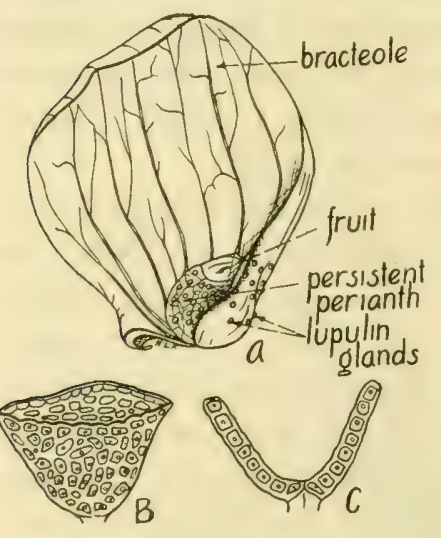
single seed within has a curved embryo about which is a small amount of endosperm.

Lupulin Glands. - In the mature hop, the outer surface of the bracteoles, the perianth, and, to a less extent, the bases of the bract-like stipules are covered with yellow pollen-like grains, the so-called "hop-meal" or "lupulin" (Fig. 105).

Each yellow grain is a cup-

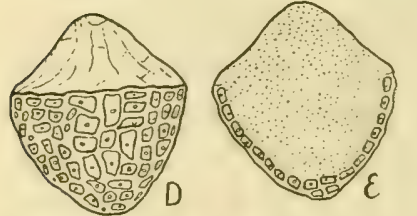

Fig. I05.-Hop (Humulus lupulus). $A$, bracteole; $B$, immature lupulin gland; $C$, same in section; $D$, mature lupulin gland; $E$, same in section. (B-E after Percizal.) shaped, multicellular, glandular hair filled with a resinous secretion. It is an outgrowth of an epidermal cell and consists of a short stalk and a cup of one layer of cells. Each cell has a rather thick cuticle. The secretion of the cells collects just beneath the cuticle, raising the latter up until finally the cup-shaped depression is filled with the secretion which remains covered by the cuticle itself. In immature hops, the lupulin glands are bright yellow and transparent. In mature hops, they are a paler yellow and somewhat opaque. The commercial value of hops depends entirely upon the amount and quality of the "hop-meal." It constitutes from I 5 to 32 per cent. by weight of the hop. Geographical.-- The hop grows wild in England, the 
northern part of the continent of Europe and in Asia ats far as eastern Siberia and south to Persia; it also grows wild in North America, across the continent westward to New Mexico and British America. It requires a moist, cool climate to attain its best development. Oregon, California, New York, and Washington are the leading States in the commercial production of hops.

Closely Related Species.-Humulus japonicus, the Japanese hop, is grown as an ornamental plant. It is an annual; its pistillate inflorescence does not enlarge into a "hop." Along streams from Wyoming to Utah, New Mexico and Arizona, there is a hop (Humulus lupulus neomexicanus) which is distinguished from the Linnæan species by its more deeply divided leaves and more sharply acuminate bracts.

Varieties.-There are a number of varieties of hops, based upon length and color of vines, size, shape and color of hop, shape of bracteoles and stipular bracts, aroma, lupulin content and time of ripening. In California the chief variety is Large Gray American. Common New York varieties are English Cluster, Pompey, Humphrey Seedling and Canada.

Composition.-The composition of the strobiles or hops is of great importance, for they possess the valuable constituents of the plant, most of which reside in the lupulin glands. There are four principal active ingredients in the "lupulin," as follows:

I. Essential oil.

2. Non-resinous bitter principle.

3. Resins.

4. Tannin.

Hop oil is volatile and gives the hop its characteristic aroma. The amount of essential oil in hops varies from 0.2 to o.8 per cent. The non-resinous bitter principle of the hop) 
hop is probably the alkaloid, lupuline. Of the resins in the lupulin glands, two principal ones have been identified, a hard and a soft resin. The hard resin has a slight bitter taste and little or no antiseptic power in the beer wort. The soft resins are much more bitter, imparting this taste to the beer wort; they also prevent the growth of bacteria in the wort and thus have a preservative effect. The total resin content of hops varies from io to I 8 per cent. Hop tannin makes up about 4 to 5 per cent. of the hop. It is thought by some that it serves to precipitate the albuminous material from beer wort.

Uses of Hops.-In some European localities, young hop sprouts are used as an early spring vegetable. The most tender sprouts are those which have been covered with soil during the winter.

Before the days of yeast cakes, yeast for bread-making was made by cultivating wild yeast in a decoction of hops and water. Some of the material obtained was mixed with the dough. The various constituents extracted from the hops add flavor to the bread, and also have antiseptic properties.

The most important use of hops, however, is in the brewing process. Preparatory to their use in the breweries, the hops are taken through a curing process in which they are kilndried, and then subjected to the fumes of burning sulphur. "Sulphuring" bleaches the hops, and acts as a preservative. After the sweet beer wort is made in the brewing process, it is boiled with hops. In this process, among other effects, the flavor of the wort is improved by the extraction of the active ingredients in the hops. The essential oil of the lupulin glands imparts an aroma to the beer, the non-resinous bitter principle and the resins give to the hopped wort a slightly bitter taste, and the tannin probably serves to precipitate albuminous substances. Moreover, the malic and citric 
acids in the hops tend to increase the acidity of the wort, and the ash adds to its mineral composition.

\section{FICUS (Fig)}

Habit, Roots, Stems.-Members of this genus are trees, shrubs or woody climbers (lianas). A number of species are parasitic on other trees. A parasite is an organism which secures its food material from another living organism. A complete parasite has no power of making its own food as do those plants which possess chlorophyll. The Golden Fig (Ficus aurea) begins life as an epiphyte; the seed germinates in the crevices of other trees; the aerial roots that are first produced take root when they strike the soil, and hence become trunk-like. Aerial roots may be sent down from branches, take root and also form trunks. The banyan tree (Ficus benghalensis) also starts its life on the bough of a tree, receiving all its nutriment from substances available on the bark. Hence in its early life the banyan is an epiphyte. When once rooted in the soil, the plant becomes independent. In the East Indies, the banyan is "universally known as an immense living columned hall, consisting of a flat expanded canopy of leaves and numerous stem-like prop roots growing down from the boughs" (Schimper's Plant Geography).

Leaves.-The leaves are alternate, sometimes opposite. thick, leathery and deciduous or persistent. In the Buddhists' sacred Peepul tree (Ficus religiosa), a plant of tropical rain forests, the leaves have a long "dripping point," by means of which rain water is soon drained off. The stipules are interpetiolar and early deciduous.

Inflorescence.-The flowers occur within an enlarged, fleshy, hollow receptacle (Fig. I06) which is commonly borne in the axils of leaves. Staminate and pistillate flowers may be borne in the same receptacle or in different receptacles. 
Some tropical figs are cauliflorus, that is, the receptacle with its numerous small flowers is borne on main stems or branches. This is a rather unusual condition; in our common woody plants, the flowers and fruit are borne on young twigs only.

Staminate flowers have a two- to six-parted perianth (sometimes none), and one to three stamens with united filaments. In the staminate flowers, there is no indication of an ovary.
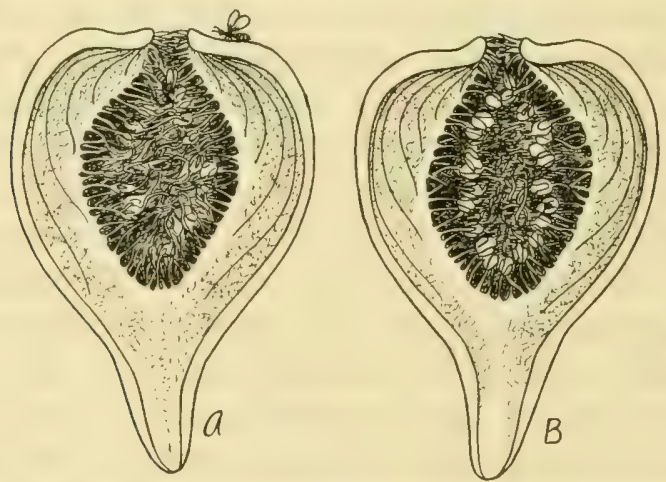

FIG. I06.-Pollination of the fig (Ficus carica). $A$, medium lengthwise section of a synconium containing fertile pistillate flowers; note the female fig wasp near the orifice, also another one which is inside. $B$, similar section of synconium showing gall flowers. (After Kerner.)

Pistillate flowers have a two- to six-parted perianth (sometimes none), a single one-celled ovary and single style. The small nutlets are enclosed in the thick, succulent receptacle, forming a fruit known as a synconium ("fig").

Geographical Distribution, and Economic Importance.There are about 600 species of the genus Ficus very widely distributed throughout the American tropics, southern Asia and the islands of the Pacific. Two species, $F$, aurea and $F$. brevifolia, are native to peninsular Florida and the Keys, while $F$. carica has been introduced into southern California 
and a number of the Gulf States. As compared with other genera in the family Moracea, Ficus is by far of the greatest economic importance. The most important species is ficus carica, the common fig of commerce.

\section{FICUS CARICA (Common Fig)}

Habit of Plant, and Stem.- The common fig is a shrub or small tree, seldom reaching a height of more than 25 feet. The main trunk of the tree is short. It branches rather irregularly, forming a round head. The gray or reddish bark is smooth and fits closely to the wood. The twigs are stout and thick, at first somewhat hairy but later becoming smooth and grayish-green in color. The fig is propagated mainly from stem cuttings.

Leaves.- These are thick and leathery and from 5 to $\mathrm{I}_{5}$ centimeters long. The general outline of the leaf is usually oval, sometimes about circular. The leaf base is truncate or slightly heart-shaped. There are five to seven deep lobes, which are coarsely toothed or slightly lobed again; each lobe is blunt at the tip. The leaves are light green, rough and hairy on the upper side, paler and hairy on the under side; leaf venation is prominent.

Inflorescence, and Flowers.-The numerous small flowers line the inner wall of a hollow receptacle (Fig. I06), except near the small opening ("eye") at the apex where there are scales or small leaves.

Among the various types of Ficus carica, there are four distinct kinds of flowers, staminate, pistillate, gall and mule.

Staminale Flowers (Fig. I07, E).-These rarely occur in cultivated figs, being found for the most part in the wild fig (Caprifig). They occur just below the scales in the receptacle. Each staminate flower usually has a four-lobed 
perianth which is shorter than the stamens. The stamens vary from one to five; four is the ordinary number.
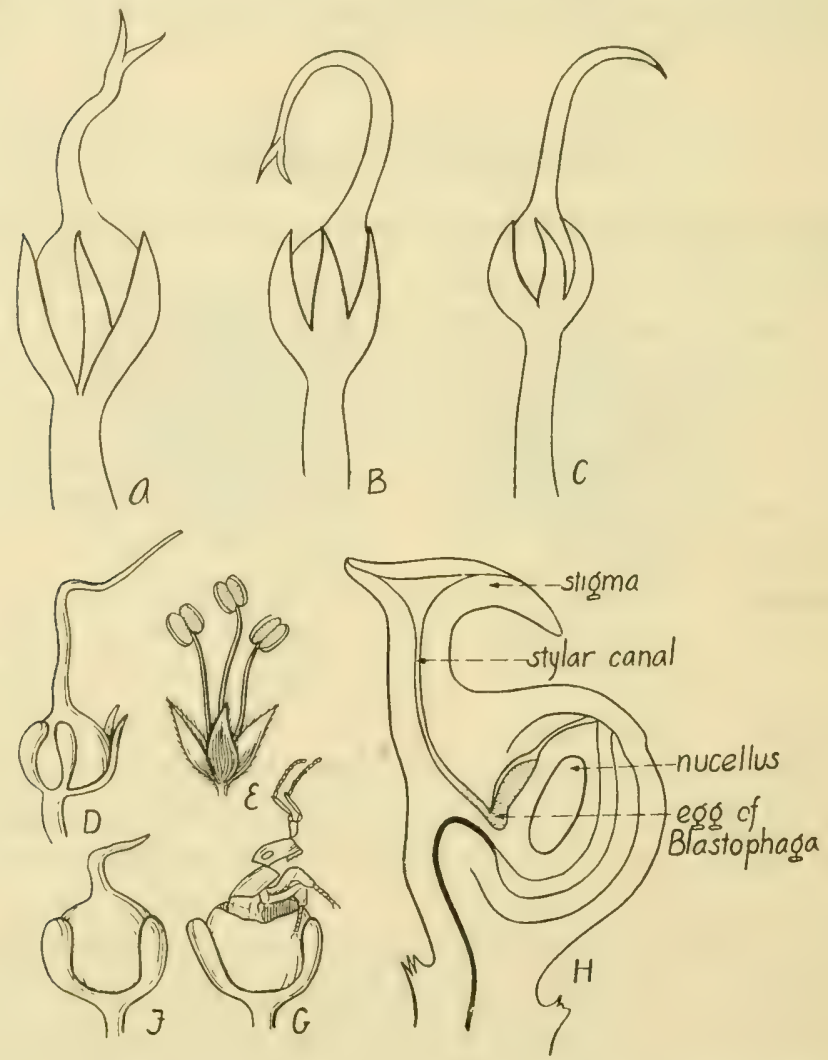

FIG. I07.-Flowers of fig (Ficus carica). $A, B$ and $C$, mule flowers; $D$, long-styled pistillate flower; $E$, staminate flower; $F$, gall produced from a short-styled gall flower; $G$, fig wasp escaping from a gall; $H$, gall flower. ( $A$, $B$, and $C$ after Eisen; $D$ to $G$ after Kerner; $H$ after Solms-Laubach.)

Pistillate Flowers (Fig. 107, D).-Pistillate flowers are sometimes found in the Common Mission figs; they are the only sort in Smyrna figs; they also occur in the second crop of San 
Pedro figs, the first crope of Arlriatic figs, the second (rop) of Erinocyce figs and the second crop (mammoni) of ('appriligs. In the receptacle of the latter, they come below the staminate flowers. The pistillate flowers have a three- to five-lobed perianth, which is rather fleshy. The single, superior ovary bears a bent style several times longer than the ovary, and often divided into two unequal stigmatic lobes.

Gull Filowers (Fig. 107, H).--These are found only in Caprifigs and Erinocyce figs. They are degenerate or transformed pistillate flowers, not producing seed; the ovary harbors the eggs and larve of the fig wasp (Blastophagal). It must not be thought that gall flowers are true pistillate flowers modified by the fig wasp; they exist independent of the wasp) the wasps select them for the deposit of their eggs. (iall flowers occur at the base of the receptacle. Their perianth is smaller than that in true pistillate flowers; the style is very short or entirely wanting; the embryo is imperfect and the stigmas do not possess receptive papillæ.

II ule Flowers (Fig. 107, A, B, C, ). -With the exception of an occasional pistillate flower, mule flowers are the only kind found in the common edible fig. They are also the only sort present in the first crop of San Pedro figs, and second crop of Adriatic figs. They are not present in Caprifigs. They are imperfect pistillate flowers neither capable of maturing seed nor serving as a breeding place for the fig wasp. The style is intermediate in length between that of gall and of true pistillate flowers; the stigmas are non-receptive; the embryo is imperfect, and hence no seed is produced.

Pollination.-The common edible fig comes to maturity without pollination, artificial or otherwise. In other types of figs all or at least one of the crops require the visitation of the fig wasp) (Blastophaga grossorum) in order that the fruit form properly. The close dependence of certain figs upon this 
insect has been a topic of great interest to students of botany. Pollination in the Caprifig will be considered first.

Crops of Fruit in Caprifigs.- In the wild fig (Caprifig) there are three crops of fruit in a year. These are as follows:

First Crop (Profichi).- The figs of this crop form in the autumn, rest over the winter and mature the following June or July. They bear staminate and gall flowers but no pistillate flowers. When the figs are about one-fourth grown, female wasps enter and deposit their eggs in the gall flowers. In about two months, the eggs hatch out, the perfect wasps emerge and the females, covered with pollen, come from the fig and seek other figs in which to deposit their eggs. By this time (June and July) the second crop of figs is about one-fourth grown.

Second Crop (Mammoni).- The fruits of this crop possess staminate, pistillate and gall flowers. The wasps which emerge from the figs of the first crop enter the narrow orifice at the apex of the receptacle (second crop), crawl down along the inner side, first over the staminate flowers, then over the pistillate flowers, finally reaching the gall flowers at the base of the receptacle, in which they deposit the eggs. The pollen on their bodies is rubbed off on the receptive stigmas, which are elevated on the long, curved styles, and thus pollination is secured. As a result, a few fully developed seeds are found in the second crop of Caprifigs. In August or September the eggs, deposited in the gall flowers of the second crop, hatch out. The mature female wasps emerge from the receptacle, in search of other figs in which to lay their eggs. By this time the third crop of Caprifigs is about onefourth grown.

Third Crop (Mamme).-The figs of this crop possess staminate and gall, but no female flowers. When they are about one-fourth grown, in August or September, 
wasps from the second crop) come to them, depositing exgs: in the gall flowers. These figs, together with the egress of the wasp, hibernate until March or April, when the perfect insects hatch out, seeking the profichi stage.

Caprification.- It will be recalled that the common edible fig matures its fruit without fertilization. Such is not the case with some other types, particularly; Smyrna figs. The latter have only pistillate flowers and, unless these are fertilized, the receptacle does not come to full maturity. Hence, it has been found necessary, in order to grow Smyrna figs, to resort to artificial fertilization.

The artificial process of fertilization as applied to figs is termerl saprification. In this horticultural process, a number of first-crop figs (profichi) of the Caprifig are suspended on the branches of the Smyrna tree. The female Blastophagas which hatch from the eggs in the gall flowers of the profichi become covered with pollen as they emerge from the figs. In search of a place to lay their eggs, they go to the partly mature figs of Smyrna. They enter the orifice of the fig and scatter pollen on the stigmas, and fertilization of the orules ensues. The pistillate flowers of the Smyrna fig, unlike the gall flowers, have styles of such a length that the wasps are unable to lay their eggs in the proper place. Consequently, the wasps perish in the fruit and their bodies are absorbed by the growing cells. Gall flowers are the only ones in which eggs may be laid properly, and hatch.

In California, caprification of Smyrna figs is done in June or July. The second crop of San Pedro figs and the first crop, but not the second, of Adriatic figs, require caprification.

Effects of Fertilization (caprificalion). In caprifigs, as has been noted. there are two general types of receptacles: those 
possessing pistillate flowers (mammoni) and those without pistillate flowers (profichi and mamme). The effects of fertilization may be observed in comparing the behavior of caprificated figs of the mammoni with the non-caprificated ones of the profichi and mamme, or the non-caprificated ones of the mammoni.

Prior to fertilization, the figs of the two types are about the same size. Caprificated figs become larger than those not fertilized; they cling to the tree more tightly, the ribs are more pronounced and the branches that bear them grow more vigorously.

As has been indicated, Smyrna figs must be caprificated to bring about the development of the ovaries and seeds and the proper ripening of the receptacle. The superiority of Smyrna figs is due to the aromatic flavor of the seeds.

The Mature Fruit.-The "fruit" of fig (Fig. Io6) is termed a synconium. This is a pear-shaped receptacle on a very short stalk; the nutlets (true fruits), when present, are imbedded on the inside of the fleshy receptacle walls. At the apex of the fig, is the "eye" or orifice of the receptacle. The "neck" and "cheeks" (sides) of the fruit are marked by a number of rings. The fruits vary widely as to size, form, neck, stalk, ribs, eye, color of skin, color of pulp, seeds, quality and growth.

Geographical.-Ficus carica is considered to be a native of southern Arabia. Some one or more of its different types are now grown in most of the tropical and subtropical countries. The first figs brought into the United States were a common edible type and were introduced into California by the Franciscan order of Mission Fathers. From California, they have spread and are now being cultivated in many of the Southern States. Fig culture in the cooler sections of the United States is very limited, and special care needs to be 
taken there to prevent the trees from winter-killing; this object is attained by growing the plant in a bush form and covering it with several inches of soil during the winter.

Closely Related Species in the United Stutes. In Filorida. there are two native figs ( $F$. aurea and $F$. breifolia) which are distinguished from the common figs by their entire. smooth leaves, and small, inedible fruit.

Types of Figs. - Eisen describes the following types of figs:

I. Common Figs or Mission Figs.- These produce two crops of fruit without caprification or fertilization. Mule and a few pistillate flowers are present, but there are no gall or staminate flowers, except in a very few cases. The figs of the first crop occur on old wood. First crop figs are called "Brebas." Second-crop fruit is borne in the axils of current leaf growth, on new wood. Second-crop figs are called "Summer figs." Brebas are large figs, not very rich in sugar, and are desirable for eating fresh. Summer figs are smaller and sweeter, and hence are suitable for drying.

2. Smyrna Figs (known in California as "Bulletin Smyrnas" or "Lobfigs"). - These bear only pistillate flowers and produce fruit only when caprificated or hand-pollinated. The seeds produced are perfect, and it is the aromatic qualities in them to which the superiority of Smyrna figs is due. Smyrna figs are now grown with success in California.

3. San Pedro Figs.-These produce but one crop, the Brebas. The second crop possesses only pistillate flowers, and the fruit drops before reaching maturity. First-crop) figs bear mule flowers only.

4. Adrialic Figs.- This is a type of figs in which the Brebas require caprification, while the second crop does not.

5. Erinocyce Figs.- This is a rare type in which the first crop is inedible, producing staminate and gall flowers. while the second crop has both pistillate and gall flowers. 
6. Cordelia Figs.-These are also rare. They are an edible fig possessing only staminate flowers.

7. Caprifigs.-This is considered to be the original type of fig from which all the above have come. They grow wild in southern Europe, northern Africa and western Asia. There are three crops of Caprifigs: First crop (profichi). which bear staminate and gall flowers, but not pistillate. The receptacles form in the autumn, maturing the following June or July. Second crop (mammoni); staminate, pistillate and gall flowers occur in the figs of this crop. The fruit matures in August or September. Third crop (mamme); the figs of this crop have only staminate and gall flowers. They hibernate over the winter, reaching maturity in March or April.

Uses of Figs.-Figs are grown chiefly for the fruit. This is sometimes eaten fresh, but is more commonly dried for transportation. Brebas are juicier than Summer figs, and hence are more desirable for eating raw. Summer figs and Smyrnas, however, are richer in sugar, and for this reason are better for drying. A limited area of land near Smyrna produces the largest percentage of dried figs. However, the industry of drying figs is growing in California. Here, the figs are washed in salt water, dried, and rewashed in salt water, graded, and packed. Fig syrup is a medicinal product of the fruit. The fig tree is sometimes planted for ornament and shade, and the soft, light, but elastic wood finds considerable use.

\section{CANNABIS SATIVA (Hemp)}

Description.- The common hemp is a stout, erect, branching annual, 5 to ${ }_{5}$ feet high. The main stem is hollow and produces a few branches near the top. The leaves are alternate above and opposite below. They are compound, 
digitate, with five to cleven linear-lanceolate, pointed and serrate leaflets. Hemp is dicecious. 'The slaminate inflorescences (Fig. Io8, A) are in axillary, narrow and loose panicles, the pistillate in erect, leafy spikes, also axillary. The staminate flower is borne on a slender pedicel subtended by a bracteole; it has five distinct sepals and five short stamens. Each pistillate flower (Fig. I08, B) is subtended by a leafy bract, and possesses a single, thin, entire calyx segment, wrapped about the ovary. The ovary has two threadlike feathery stigmas. Hemp is wind-pollinated. The ovary matures into an ovoid, hard achene. The curved embryo is imbedded in a fleshy endosperm. The fruits of hemp are much larger and heavier when grown in a moist habitat than when grown in a dry one.

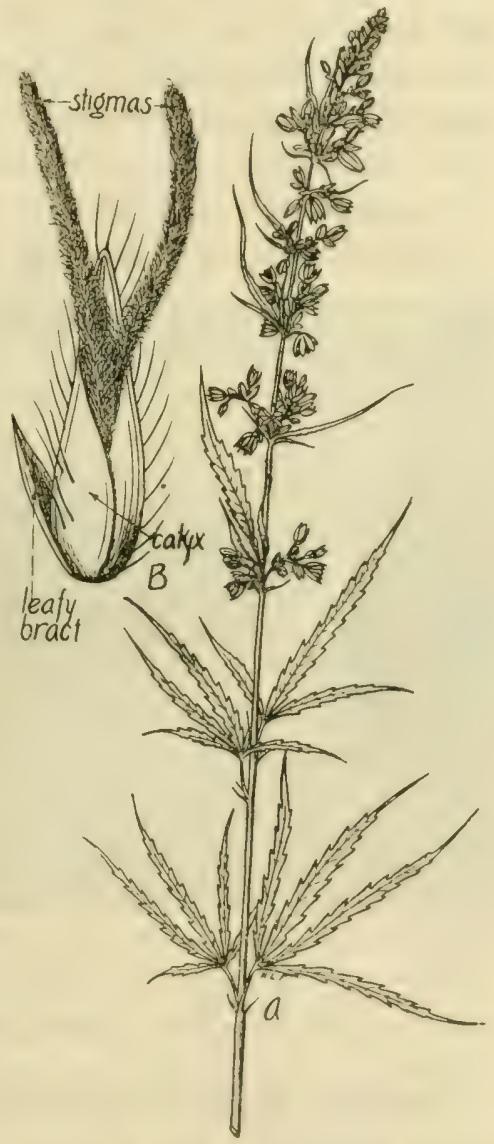

Frg. I08.-Hemp (Cannabis sativa). $A$, branch of staminate plant; $B$, single pistillate flower. ( $B$ after Wossidlo.)

Geographical.- The native home of common hemp is central and western Asia. It has spreat, ats a result of cultivation, throughout Europe, Isia and Amprica. In many places, it has escaped from cultivation and become a rather troublesome weed. 
Varieties.-Nearly all hemp grown in this country is of Chinese origin. The Japanese hemp is identical, or very similar, to Chinese hemp. European varieties (Piedmont, Neapolitan, Hungarian, and Russian), often termed Smyrna types, differ from the Chinese and Japanese ones in that the plants are shorter, the growth is more compact, the seeds are in denser clusters and earlier in maturing. The best quality of hemp fiber comes from Italy.

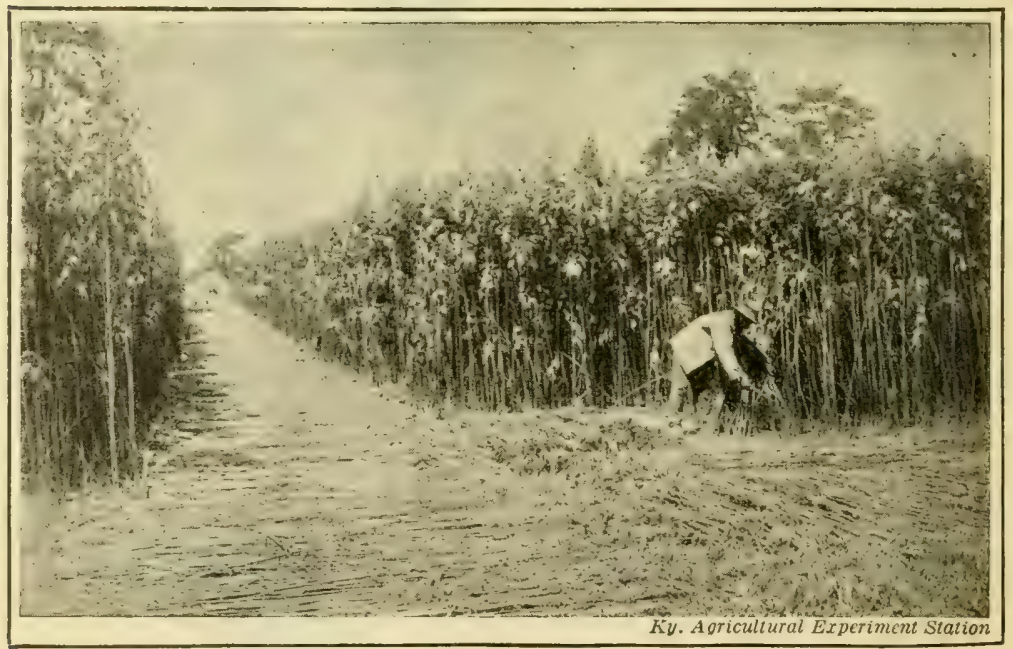

FIG. I09.-Cutting hemp, Kentucky. (From Essentials of Geography, Second Book. Copyright, I9I6, by Albert Perry Brigham and Charles T. McFarlane. American Book Company, Publishers.)

The Hemp Industry in the United States.--Since about the year I 906, there has been a slight decline in the domestic production of hemp. This falling off has been due to the difficulty of obtaining laborers to do the work of retting, breaking, and preparing the fiber for the market; to the lack of development of labor-saving machinery; to the fact that greater profits are derived from raising other crops in hernp- 
growing regions; and to the greater use of other fibers in the manufacture of products formerly made of hemp.

Kentucky began to raise hemp in $\mathrm{I} 775$, and that State now leads in hemp production. Kentucky now furnishes the seed for nearly all of the hemp grown for fiber in the United States; the hemp from this State is mostly of Chinese origin. The chief hemp-growing States are Kentucky, California, Nebraska, Indiana, New York, and Wisconsin.

Preparation of Hemp for Market.-Harvesting Hemp.In some places, hemp is still harvested by hand with a reaping knife or hemp hook. However, in most hemp-growing districts, sweep-rake reapers, mowing machines, or self-rake reapers are used.

The hemp stalks, usually 8 to 14 feet long, are bound into bundles about ro inches in diameter, and shocked. They are allowed to stand in the shocks for ten to fifteen days, or until they are dry enough to be stacked.

There is an advantage in stacking hemp, in that it rets more quickly and more uniformly than hemp that is taken directly from the shock. Furthermore, the stacking of hemp improves the quality and yield of the fiber.

Relting.- This is a process in which the substances surrounding the bast fibers are partially dissolved, thus allowing the fibers to be separated from the wood ("hurd") and thin outer bark, and from each other. This separation is due to the decomposing action of bacteria, in fact the retting organism has been isolated and grown in pure cultures. There are two commercial methods of retting: dew-retting and waterretting. The former is the common method in this country. The hemp stalks are spread out in thin, even rows on the ground, where they are exposed to alternate freezing and thawing, or to cool, moist weather. The process of retting is complete when the bark separates easily from the woody 
portion ("hurd") of the stem. Water-retting is practised in European and Asiatic countries. The stalks are immersed in streams, ponds, or artificial tanks.

Breaking.- In the breaking process, the inner cylinder of wood is broken in pieces, which permits it to be removed, leaving behind the long bast or hemp fibers. The removal of the broken pieces of woody tissue is known as scutching. In this country, both hand breaks and machine breaks are in use. The stems must be dry before breaking, so as not to injure the fibers.

Hackling.- The long, straight hemp, known as rough hemp, is sorted and hackled by hand. In the process of hackling, the rough fiber is combed out by drawing it over coarse hackles; the product is known as "single-dressed hemp." This may be combed out by drawing it over finer hackles, thus preparing a fiber known as "double-dressed hemp." Double-dressed hemp brings the better price on the market. Hemp tow is from broken or tangled stalks, and is inferior in quality to the long, straight hemp.

Uses of Hemp.--Hemp is grown primarily for its fiber. The fibers are in the bast and average about 20 millimeters in length. They are of the best quality if the plants are cut when staminate plants are in full bloom. If cut too early, the fibers lack strength, and if harvested too late they are coarse and brittle.

Hemp fiber is put to a variety of uses. It is used in the manufacture of sail cloth, yacht cordage, binder twine, tying twine, carpet yarns, carpet thread, sacking, bagging, rope, upholstery webbing, and belt webbing. The ravelings of hemp rope, termed "oakum," are used for calking seams of wooden boats and joints of iron pipe, in pumps, engines, and other machinery. The seed of hemp is often fed to poultry and cage-birds. Moreover, the seed contains 20 to 
25 per cent. of an oil, which is sometimes extracted and used as a substitute for linseed oil. The drug Cannabis indica is derived from the stems and leaves of common hemp, which under the hot climatic conditions of India, chiefly, develop) a volatile oil and a strong narcotic resin (camnabin). These substances are secreted by the glandular hairs on stems and leaves. They are not produced to any extent in cold climates. Hemp-seed oil is used for making soft soaps, as a paint oil. and low grades are utilized for certain varnishes. Recent tests show that a fair quality of paper can be made from hemp "hurds."

The chief fiber competing with hemp is jute. Jute is produced in India from two species of plants, Corchorus capsularis and Corchorus olitorius. It is used extensively for the manufacture of sugar sacks, gunny sacks, burlaps, grain sacks, and wool sacking. It is about two-thirds as strong as hemp fiber of the same weight, and is not as durable. Although hemp has been used to some extent in the manufacture of binder twine, most of the binder twine now is made from the fibers of sisal and abacá.

Sisal Hemp.-The main center of production for Agave fibers is Yucatan in Mexico. On the low limestone plains of this country, Agava sisalana thrives. It belongs to a different family (Amaryllidacex) than that to which common hemp belongs. This plant yields the well-known "sisal hemp" or "hennequin." The plant is cultivated. This country now imports large quantities of sisal hemp, all of which is from Yucatan. It is used mainly in the manufacture of binder twine. About 200,000,000 pounds of binder twine are required annually to harvest the grain, corn, and flax crops of the United States. Practically all of the fiber from which this twine is made comes from the Agave plant of Yucatan. 


\section{References}

Bailey, L. H.: Mulberries. Cornell Agr. Exp. Sta. Bull. 4I: 223-243, I892. Sketch of the Evolution of Our Native Fruits. The Macmillan Co., I 898 . Bri.int, L.Awrence, and Meacham, C. S.: Hops. The Influence of Climate, Ripeness, Soil, Drying, and General Manipulation on the Value of Hops. Jour. Fed. Ins. Brewing, 2: 423, I 896.

Chapman, A. C.: The Essential Oil of Hops. Proc. Chem. Soc. (London), 9: 177, I893; 10: 227-229, 1894. Jour. Chem. Soc. (London) Trans., 67: 54-63, 1895a. Jour. Fed. Inst. Brewing, 4: 224-233, I898. Jour. Chem. Soc. (London) Trans., 83: 505-513, I903.

The Hop and its Constituents. A Monograph on the Hop Plant. London, I905. Published by Brewing Trade Review.

Chedsey, MI: The Influence of Pollination upon the Development of the Hop (Humulus lupulus). Plant World, 8: 281-283, I905.

Соок, O. F.: Sexual Inequality in Hemp. Jour. Hered., 5: 203-206, I9г4. Eisen, Gustav: Edible Figs, their Culture and Curing. U. S. Dept. Agr. Div. Pom. Bull. 5: I-33, I897.

The Fig: Its History, Culture, and Curing. U. S. Dept. Agr. Div. Pom. Bull. 9: I-3I 7, I90I.

Biological Studies on Figs, Caprifigs, and Caprification. Proc. Cal. Acad. Sci., ser. 2, vol. 5: 897-1003, I896.

Gross, E.: Hops in Their Botanical, Agricultural, and Technical Aspects and as an Article of Commerce. Scott, Greenwood \& Co., London, 1900. Transl. from German by C. Salter.

Howakd, A. Hop Experiments in rgo4. Councils Kent and Surrey. Southeastern Agr. Col., Wye, Bull. I: I-29, I904-5.

The Influence of Pollination on the Development of the Hop. Jour. Agr. Sci., I: $49-58,1905$.

Howard, L. O.: The Present Status of the Caprifig Experiments in California. U. S. Dept. Agr. Div. Ent. Bull. 20 (new ser.): 28-35, 1899.

Smyrna Fig Culture in the United States. U. S. Dept. Agr. Yearb., 1900: 76-106, г901.

M.ıtruews, J. M.: The Textile Fibers: Their Physical, Microscopical, and Chemical Properties. John Wiley \& Sons, I9I I.

MYrick, H.: The Hop: Its Culture and Curing, Marketing, Manufacture. Orange Judd Co., I899.

Power, F. B., Tutin, F., and Rogerson, H.: The Constituents of Hops. Jour. Chem. Soc. (London), I03: 1267-I292, 1913.

RAB.Ak, F.: Aroma of Hops: A Study of the Volatile Oil with Relation to the Geographical Sources of the Hops. U. S. Dept. Agr. Jour. Agr. Research, 2: II5-I59, I9I4. 
S.umox, E. S., and Amos, A.: On the Value of the Male Inep. Jour. Sontheist. Agr. Col., Wye, 17: 365-39r, I908.

S.ILMon, E. S.: The Pollination and Fertilization of IIops and the (haracteritics of "Seeded" and "Seedless" Hops. Jour. Agr., 2I: 22-3I, I23-133, I9I4.

The Pollination and Fertilization of Hops and the (haracteristics of "Seeded" and "Scedless" Hops. Jour. Bd. Agr. (London), 2: $123-$ I33; 3: 23-220; 20: 953-966;2 I: 22-3I, 1914.

Scimidr, J.: Investigations on Hops, V. On the Aroma of Hops. Compt. Rend. Lab. Carlsberg, II: I49-163, I9I5.

Stockberger, W. W.: Change of Sex in Humulus Lupulus not I)ue to Traumatism. Abs. in Sci., n.s. 31: 632, I910.

Torrsors, J.: Sexual Studies of the Hop Plant. Inn. Aci. Nat. Bot., () ser., I9: 49-I9I, I9I4.

IIinge, O.: The Pollination and Fertilization Processes in Humulus Lupulus L. and H. Japonicus Sieb. et Zucc. Comp. Rend. Lab. Carlsberg, II: $\mathrm{I}^{-46}$, I9I4. 


\section{CHĄTER XXII \\ POLYGONACEÆ (Buckwheat Family)}

Herbaceous representatives of this family are largely found

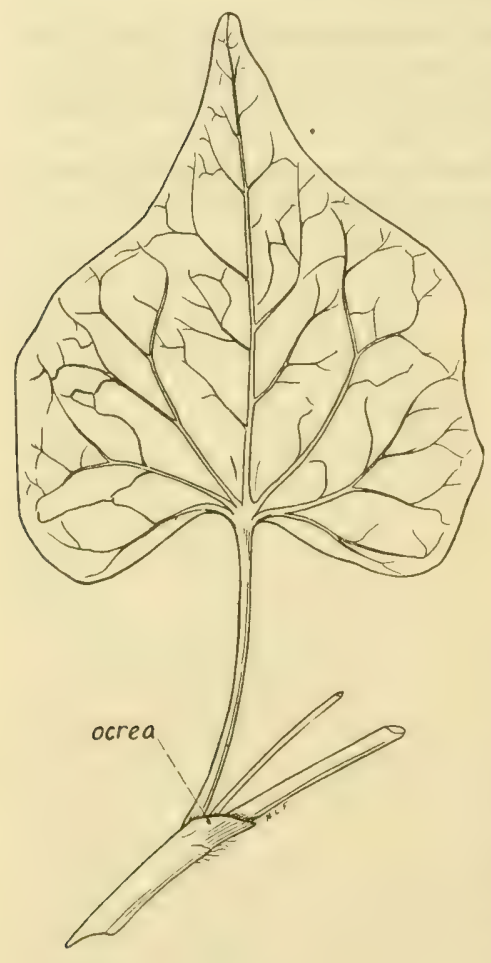

FIG. I $10 .-$ Leaf of common buckwheat (Fagopyrum vulgare). $\times \mathbf{I}$. in temperate regions, treelike species in American tropics, while shrubby ones are limited to western Asia. There are about 30 genera and 800 species. Rhubarb and buckwheat are the principal cultivated members, while a number of species of Rumex (dock), and of Polygomum (knotweed, bind-weed, etc.) are bad weeds.

Stems.-The stems are conspicuously jointed and usually swollen at the joints. The leaves are alternate (Fagopyrum), opposite (Macounastrum), or whorled (mountain sorrel, Oxyria digyna). They are mostly entire, rarely lobed or divided. The stipules, with a few exceptions, are membranous, sheathing, and united to form a very characteristic structure, the ocrea (plu. ocrea) (Fig. I IO). 
Inflorescences.- The inflorescences vary a great deal within the family; in buckwheat they are panicled racemes. in Polygonum sple. terminal or axillary spike-like racemes. in Eriogonum spp). cymes, umbels or hearls. The cyme is a determinate type of inflorescence. In this type, the terminal flower is the oldest and subsequent ones open in order from the inside to the outside of the inflorescence (centrifugal opening of the inflorescence). In the head type of inflorescence, so well exemplified by the dandelion or sunflower, the flowers are crowded on the receptacle; the stalk of each flower is very short or entirely absent; it is an indeterminate type.

Flowers.-The flowers are small, mostly perfect, rarely. diocious or monocious, and radially symmetrical. In the genus Eriogonum, the flowers are subtended by a five- to eight-toothed involucre. The calyx consists of two to six segments which are below the ovary and free from it; the segments are in one or two series, often imbricated (overlapping), and the inner or both series are petaloid (resembling petals). There are no petals. The stamens vary from two to nine; in perfect flowers, they are attached near the base of the calyx, while in staminate ones, they may be crowded on a central disk; the filaments are filiform. mostly distinct but sometimes united in a ring at the base, and commonly dilated at the base; the anthers possess two cells, and are longitudinally dehiscent. The pistil is solitary. The superior ovary is one-celled, three-angled or compressed, rarely four-angled, and usually sessile; the styles are most frequently three in number, rarely two or four, and attached to the apex of the ovary; the stigmas are capitate (head-shaped) or tufted, and sometimes two-cleft. Within each ovary there is a single ovule.

Fruit.-The fruit is a three-angled (rarely four-angled) achene, about which is frequently the persistent calyx; the 
pericarp is hard or leathery. The single seed in each fruit assumes the shape of the pericarp; the seed coat (testa) is membranaceous, the endosperm is abundant and mealy, and the embryo is straight or curved.

\section{Key to Principal Genera}

Flowers subtended by involucres; ocreæ wanting, Eriogonum.

Flowers not subtended by involucres; ocrex present.

Calyx six-parted (rarely four).

Stamens nine (very rarely six), Rheum (rhubarb).

Stamens six, Rumex (dock).

Calyx five-parted (rarely four).

Achene much surpassing the calyx, Fagopyrum (buckwheat).

Achene enclosed by the calyx, Polygonum (bistort, persicaria, knot weed, bindweed, etc.).

\section{RHEUM RHAPONTICUM (Rhubarb, Pie Plant)}

Roots, Stems, Leaves, Flowers.- This plant is a perennial from large, quite woody rhizomes which have a fibrous and

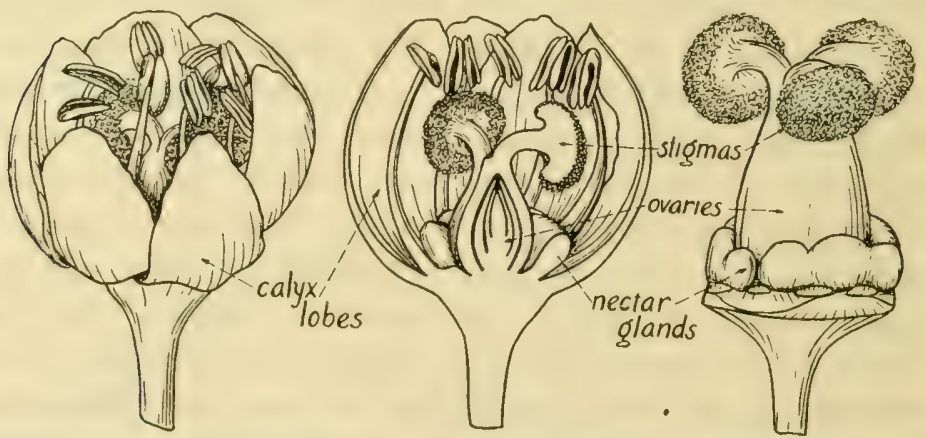

FIG. III.-Rhubarb (Rheum) flower, external view, median lengthwise section, and with perianth and stamens removed. (After Lïrssen.)

well-developed root system. The rhizome is used in the propagation of the plant. In the spring, a number of large leaves are sent up from the underground stem, and, later in 
the scason, there arise flower shoots, bearing clongated leafy inflorescences, crowded with small whitish flowers. Unless seed is desired, flower shoots should be promptly removed.

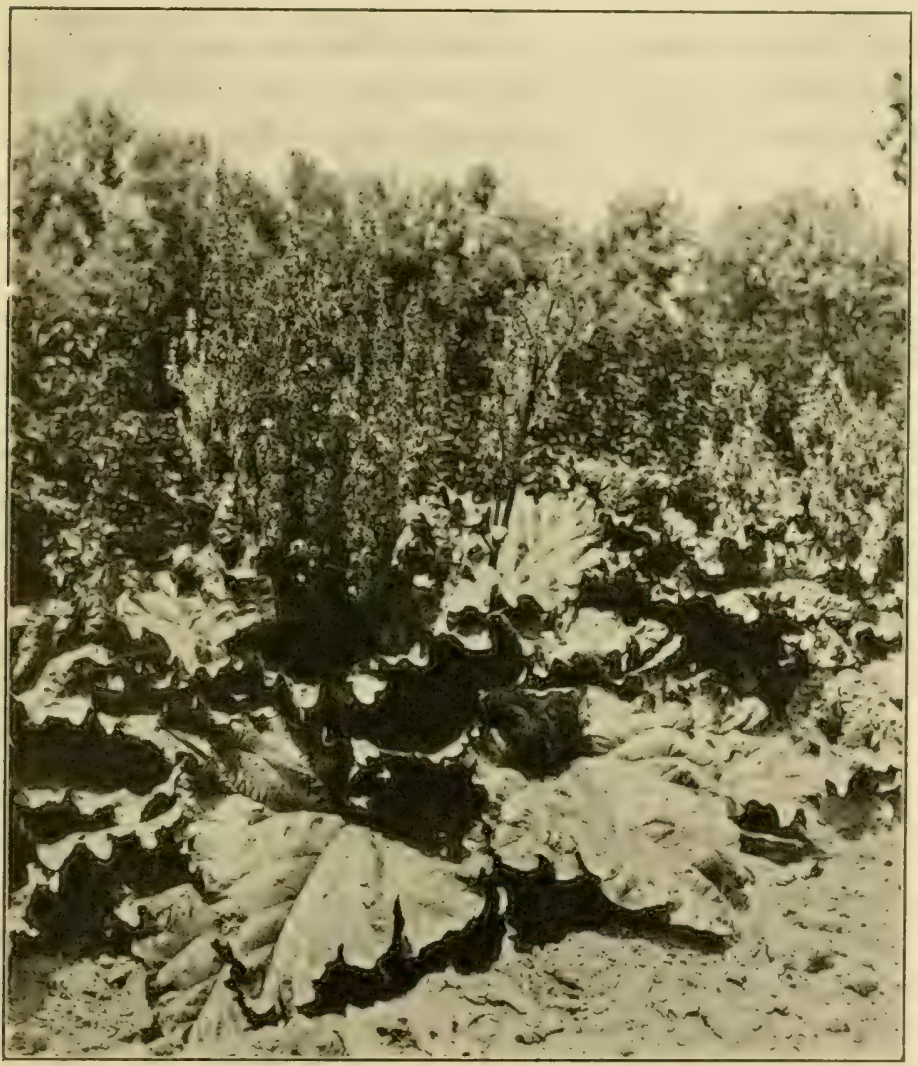

FIG. I I2.-Rhubarb (Rheum rhaponticum) plant in fruit.

as they require considerable food supply which should go) to the support of the roots. The leaves are large, circular in outline, cordate at the base, and with sinuate reins beneath; leaf petioles are semi-cylindrical and bear membran- 
ous ocrex. The flowers are on short, jointed pedicels and occur in fascicles, each of which is a raceme; the entire inflorescence is paniculate. The flowers (Fig. III) are small, greenish white and perfect; the calyx is six-parted, persistent, and becomes enlarged somewhat in the fruit (Fig. II3); there are nine stamens; the ovary is three-angled and bears three short, recurved styles, with large stigmas.

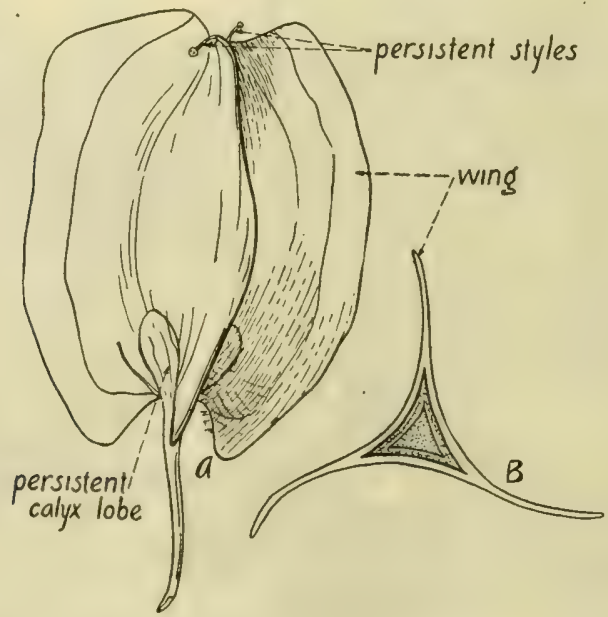

FIG. II3.-Fruit of rhubarb (Rheum rhaponticum). $A$, external view; $B$, cross-section. $\times 5$.

Self-pollination is prevented to a large degree by the maturation of anthers before the stigmas. Stigmas of flowers below on the inflorescence receive pollen from the anthers of younger flowers borne above them. Pollen is disseminated by wind, insects, and gravity.

Fruit.-Rhubarb fruit (Fig. II3) is an achene surrounded at the base with the persistent remains of the perianth; it has three broad, thin wings which are traversed by a longitudinal nerve running near the margin; it is tipped by a small per- 
sistent style. The seeds are three-angled, conforming in shape to the fruit; the testa is thin and red; the hilum and micropyle are basal; the endosperm is abundant and surrounds the large, straight embryo. Good-sized plants can be raised from seed in one season if it is planted early. 'The seedlings of rhubarb show interesting variation.

Geographical, and Varieties.- The common rhubarb is a native of Asia. It has become introduced into many countries of the temperate climates. It is a cool season crop that will withstand summer heat, and the roots winter freezing. It is claimed that a number of the varieties now grown are hybrids between $R$. rhaponticum, $R$. undulatum and $R$. palmatum. The principal varieties grown are Linnæus, Victoria and Monarch. There are a number or ornamental species of Rheum, most of which are distinguished from common rhubarb by their more or less lobed leaves, the margins of which may be coarsely or finely toothed.

Uses.-Rhubarb or pie plant is a vegetable used for its large, acid leaf stalks, which are of the best quality early in the season. The leaf stalks are usually made into pies or sauce, and occasionally wine is made from the juice.

\section{FAGOPYRUM VULGARE (Common Buckwheat)}

Roots.-Common buckwheat is an annual, from 2 to 4 feet tall. It has a small root system. There is a single primary root which may reach down to a distance of 3 or 4 feet; side roots are given off along the primary, but they do not extend far into the soil. Buckwheat differs from the true cereals, in the possession of a single primary root, and a much less extensive root system.

Stems.- The stems are quite succulent, smooth, except at the nodes, and strongly grooved. Each seed gives rise to but one stem which may branch freely, but, unlike grasses, no 
"suckers" or "tillers" are produced. The amount of branching depends upon the thickness of seeding; the plants branch freely when not crowded and feebly when crowded. The young stems vary from green to red, and turn brown with age.

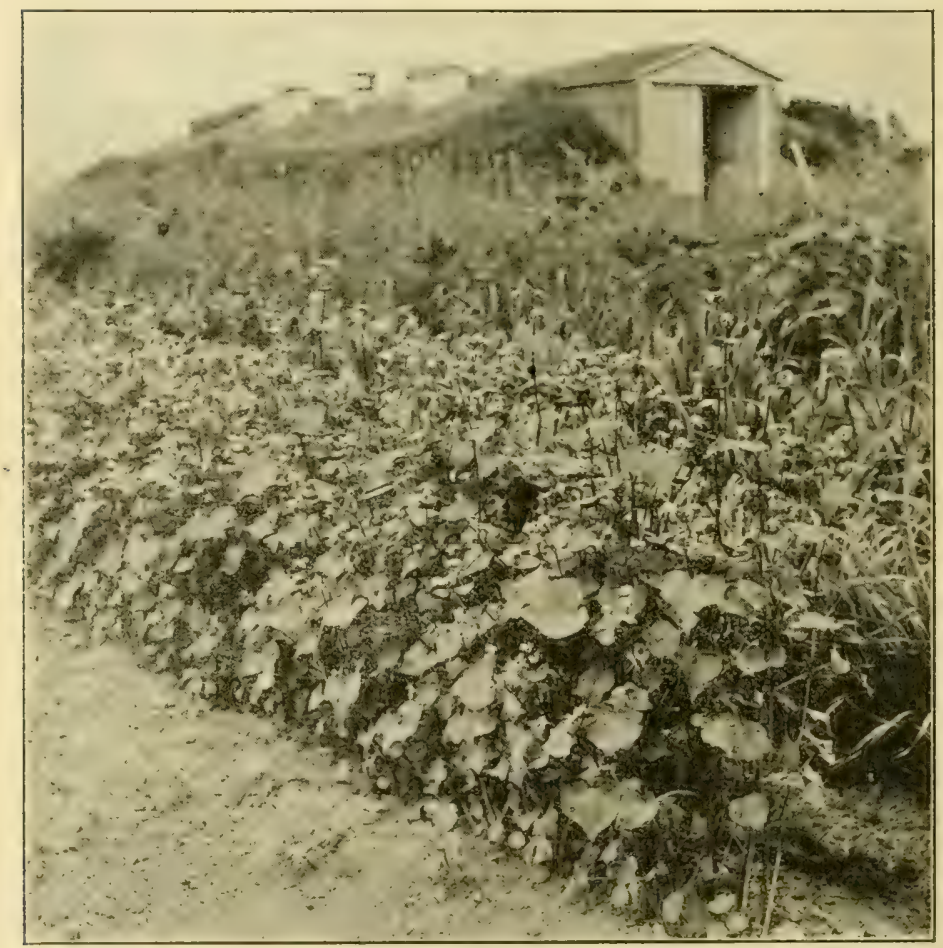

FIG. I 4 4.-Buckwheat (Fagopyrum vulgare).

Leaves.- The leaves are alternately arranged on the stem and characteristically hastate (halberd-shaped) (Fig. I Io), or triangular heart-shaped; they may be sessile or shortpetioled, and bear an ocrea (Fig. I Io), which soon falls off. 
Inflorescence.- 'The inflorescence is a raceme which may be either paniculate or corymbose (a corymb is a flat-topped raceme type of inflorescence); it is terminal and axillary, many-flowered, and erect or slightly drooping.

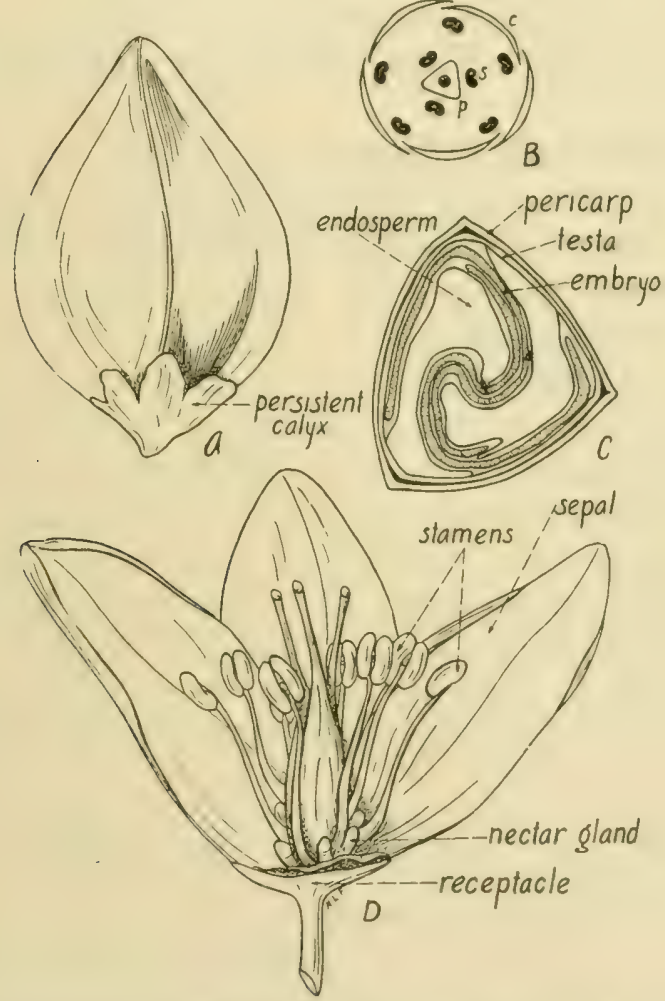

Fig. II5-Common buckwheat (Fagopyrum vulgare). $A$, achene; $B$, floral diagram; (', cross-section of fruit; $D$ ), flower. (B after Hossidlo; ( after Stevens.)

Flowers.- The flowers (Fig. I I 5, D) are white, tinged with pink. There are no petals (hence is apetalous), but there is at five-parted corolla-like calyx which remains attached to the 
base of the fruit. 'There are eight stamens with glabrous filiform filaments and oblong anthers. Three of the stamens closely surround the styles and dehisce outward, while the five others are inserted outside of these three, and dehisce inward. The single ovary is one-celled and one-ovuled and bears three style branches, which are bent back in fruit.

The plant begins to bloom when quite young and continues until frost.

Dimorphism and Pollination.-- Common buckwheat has dimorphous flowers, i.e., there are two forms. One of these forms has short styles and long stamens, and the other, long styles and short stamens. This condition is known as heterostyly. The pollen grains of short-styled flowers are larger than those of long-styled flowers. Usually, all the flowers on one plant are of one form or the oti er. Occasionally, however, both long-styled and short-styled plants may bear a very few flowers with styles and stamens of the same length. These "equal-styled" flowers are not fertile. The seeds from either form of flower will produce buckwheat plants, some of which produce one form and some the other.

Buckwheat is regularly visited by numerous insects. Heterostyly is a condition which tends to prevent self-pollination.

Fruit.- - The mature fruit (Fig. I I 5, A) is a triangular (sometimes two- or four-angled) crustaceous achene, brown, streaked with black, or entirely black; the point of the "grain" is the stigmatic end, while the opposite end shows a fragment of the flower stalk (pedicel), and small, persistent, withered calyx lobes which have become adherent to the pericarp. The "hull" is the pericarp and attached portions.

Seed.--The single seed conforms in shape to the pericarp. There is an abundance of white, dry, floury endosperm in which is imbedded the embryo. Buckwheat endosperm is 
more starchy than that of wheat, oats, barley, rye and corn, and the fat content is lower. Consequently. buckwheat flour is low in pereentage of protein and fat. The embryo ("germ"), however, has an abundance of fat and protein, and for this reason "middlings," which contain the embryo, are a valued stock food. In a cross-section of the fruit (Fig. I $5, \mathrm{C})$, the embryo has the form of the letter $\mathrm{S}$, and reaches from one of the three angles of the seed to another.

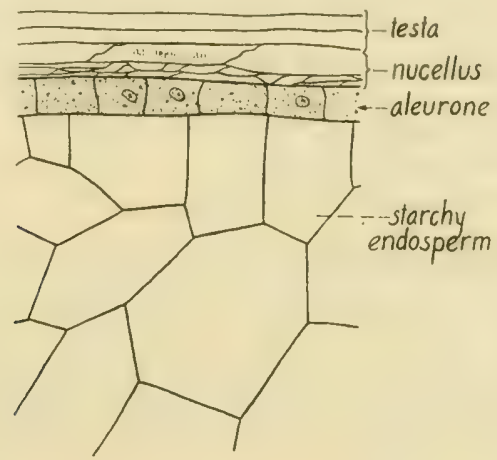

FIG. II6.-Common buckwheat (Fagopyrum vulgare). Section of mature seed. (After Stevens.)

Geographical.- Common buckwheat has been cultivated in China for 1,000 years. It was introduced into Europe during the middle ages. It was brought into this country by the early settlers. It has escaped from cultivation in North America, and is now common throughout northern United States and Canada.

Other Species.- There are two other species of Fagopl'rum. one of which, $F$. lataricum, at least, has been cultivated to a slight extent in this country, and is also an occasional escape from cultivation. Tatary buckwheat is distinguished from the common form by the simple racemes, its rough hull, and the wavy fruit angles. It is cultivated where a hardy sort is 
needed. The notch-seeded buckwheat (F. cmarginatum), a form cultivated in northeastern India and China, is distinguished from the preceding by having the angles of the smooth hull prolonged into wide, rounded wings.

Varieties.-Three varieties of common buckwheat are grown in the United States: Japanese, silver hull, and common gray. They may be distinguished by the following key:

\section{Key to Varieties of Common Buckwheat}

Faces of grain slightly concave; angles extended into very short wings, Common gray.

Faces of grain flat; angles not extended into wings.

Grain small and plump, Silver hull.

Grain large and not so plump, Japanese.

Environmental Relations.-Buckwheat is a temperateclimate plant, finding the best conditions for growth where the summers are cool and moderately moist. Dry, hot weather is inimical to the proper setting of the fruit. According to the work of Briggs and Shantz, buckwheat has a water requirement intermediate between that of barley and oats, the actual amount being 578. Buckwheat is known to do well on poor soils, even those in which the drainage is such as to make it impossible to grow the small cereals profitably.

Uses.-The principal use of buckwheat is in the manufacture of pancake flour. As a food for stock, it is used in various forms. The whole grain is sometimes fed to poultry, hogs and cattle. Usually, however, the hulls are removed from the grain, and the seeds ground, before feeding to hogs. The middlings (hulls mixed with bran) are prized as a stock feed. Buckwheat straw is used both as a feed and a bedding for stock. Honey from buckwheat flowers has always possessed a high reputation for flavor. Buck- 
wheat will grow well on poor soil-a soil that will not support true cereals. Therefore, it may be used ats a green-manure crop.

\section{References}

Morse, J. F.: The New Rhubarb Culture. Orange Judd Co., ror 2.

STLYens, N. E.: The Morphology of the Seed of Buckwheat. Bot. (iatz, 53: 59-66, I9 2 .

Observations on Heterostylous Plants. Bot. Gaz., 53: 277-308, I9 I2.

Tsutsum, Ochmera: Studies on the Buckwheat. Bot. Mag. (Tokyo). 8: 288-29I; 4I 7-42 I, I 894.

Wrilinus, F. N.: Primary Characters in the Species of Rheum, 20: $202-205$, I89x. 


\section{CHAP'TER XXIII}

\section{CHENOPODIACE $\nRightarrow$ (Goosefoot Family)}

This family is widely distributed geographically. They are, for the most part, saline plants found near the ocean or in deserts and steppes. They are characteristic plants of the alkaline swamps and meadows of the western United States. Plants that are able to grow in soils very rich in salts are designated halophytes. Of course the salinity of the soil solution retards the rate of water intake by the roots, and, consequently, halophytic plants are found with structural adaptations which prevent a rapid loss of water from the leaves. Our most typical halophytic plants are found within the goosefoot family.

From an economic standpoint, the family is of considerable importance. The principal cultivated forms are the beet and spinach. A large number are weeds, chief of which are goosefoot, pigweed, lamb's quarters, strawberry blite, and Russian thistle.

Habit, Stems and Leaves.-Members of the family are annual or perennial herbs, or shrubs (Atriplex, saltbush). The stems are cylindrical or angled, erect or decumbent. The leaves are usually alternate, rarely opposite, without stipules, simple, and entire, toothed or lobed.

Inflorescence and Flowers.-The flowers may occur in panicled spikes (beet), or in globular, axillary, sessile heads (Blitum capitatum, strawberry blite) or sometimes they are solitary in the axils (Salsola, Russian thistle). The flowers 
are usually small, erreenish, and bractless (Sarobalus, greasewood), or bracteolate (Beta). They are perfect (Beta), pistillate (Kochia), polygamous (Kochia), monoecious (Sarcobalus), or dicecious (Atriplex spp.) They are usually regular. There are no petals. The calyn is three- to five-lobed or parted, rarely of one sepal (Monolepis), or is entirely wanting in the pistillate flowers of some genera (Atriplex). The calyx is persistent in the fruit. There are usually as many stamens as lobes of the perianth, rarely fewer (Chenopodium spp.); the filaments are commonly slender and bear longitudinally dehiscent, two-celled anthers. The ovary is superior, free from the calyx and one-celled; the styles are terminal, short or elongated, one to three in number, and bear capitate stigmas. It has a single, erect ovule.

Fruit.-The mature fruit is a utricle (oneseeded fruit with a loose pericarp) with membranous, leathery, or thin pericarp. The seeds may possess an abundance of endo-

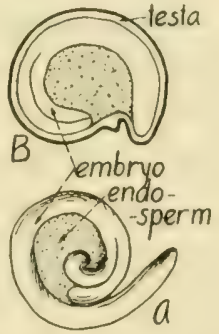

FIG. 1 I $7,-A$. spiral embryo of Sarcobatus; $B$. annular embryo of Beta. sperm (Beta, Eurotia, etc.), or none (Sarcobatus, Salsola); the embryo is spirally coiled (Fig. I I 7) (Salsola), annular (Beta), or conduplicate (Salicormia).

\section{Key to Principal Genera}

Embryo spirally coiled (Fig. II 7); endosperm little or none.

Shrubs, Sarcobalus (greasewood).

Herbs, Salsola (Russian thistle).

Embryo not spirally coiled, partly or completely annular (Fig. I I 7 ); endosperm abundant.

Flowers perfect (polygamous in Kochia).

Calyx with five lobes, about the base of which is developed a wing, Kor hict. Calyx wingless, persistent.

Lobes of calyx becoming fleshy and bright red, Blitum (strawberry blite). 
Lobes of the calyx not becoming fleshy, and never red in color.

Developing large fleshy tap roots, Beta (beet).

Tap roots not fleshy, Chenopodium (goosefoot, lamb's quarters, pig-weed).

Flowers monœecious or diœcious.

Bractlets silky-hairy, Eurotia (winter sage).

Bractlets not silky-hairy.

Pistillate flowers without a calyx, Atriplex (orache).

Pistillate flowers with a calyx, Spinacia (spinach).

\section{SPINACIA OLERACEA (Spinach)}

Description.--Spinach is an erect, smooth, annual herb. Early in the season, it throws out a number of large leaves, crowded near the ground surface. Somewhat later, a flower stalk is sent up to a distance of 2 or 3 feet. The leaves are

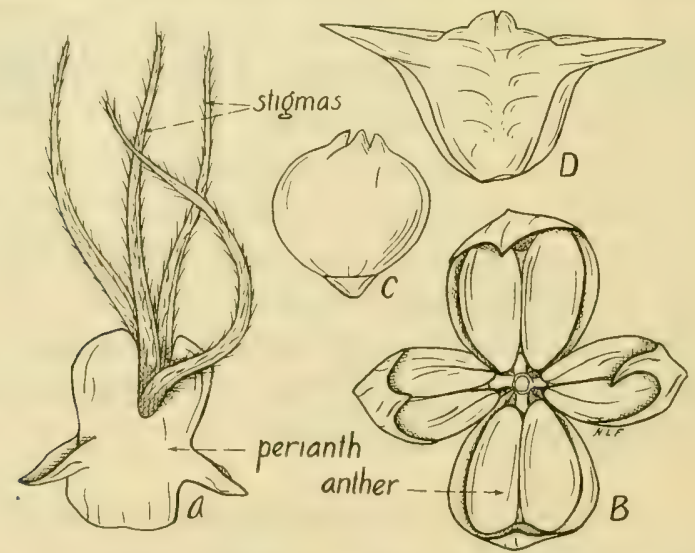

FIG. II8.-Spinach (Spinacea oleracea). $A$, pistillate flower of pricklyseeded spinach; $B$, staminate flower of same; $C$, fruit of smooth-seeded spinach; $D$, fruit of prickly-seeded spinach.

large, alternate, petioled, and triangular-ovate or arrowshaped in outline. The flowers occur in axillary clusters. They are diøcious. The staminate flowers (Fig. II8, B) have a four- to five-parted calyx and four to five stamens inserted at the base of the perianth. Pistillate flowers 
(Fig. II 8, 1) have a two-to four-divided perianth which encloses the fruit. The single overy bears four to five stigmas, united at the batse. The mature fruit (Fig. Irs, (, 1$)$ ) is a utricle consisting of a compressed seed surrounded by the cartilaginous calyx lobes, which are either smooth or spiny, and by a membranous pericarp. The seed is compressed, about the size of beet seed, and has an annular cmbryo surrounding the floury endosperm.

Spinach is a native of southwestern Asia. It has become widely spread in cultivation. It is a cool-season crop requiring an abundance of water. It runs to seed in warm weather.

Other Plants Named "Spinach."-There are two types of "spinach" which do not belong to the genus Spinacia: New Zealand Spinach (Tetragonia cxpansal) and Mountain spinach, or orache (Atriplex hortensis). New Zealand spinach or New Zealand ice plant, is a member of the family Mesembryacer, and a native of New Zealand. It is grown as summer "greens." The plant is low, but profusely" branching and spreading; the numerous, upright lateral branches are beset with tender leaves; the tips of these branches are the edible portion of the plant. The alternate triangular leaves are rather fleshy; the flowers are axillary, small, yellowish green, and without petals; the fruit is nut-like, and has one to nine locules, each of which is oneseeded. Mountain spinach or orache is more dosely related to the common species, belonging in fact, to the same tribe. It is a plant 4 to 6 feet tall. branching, and bears an abundance of fruit. It not only differs from common spinach in its more erect habit but in its floral and fruit characters. The pistillate flowers do not have a perianth, but in fruit the seed is enclosed by a pair of compressed bracts which become enlarged and wing-like. 
Groups of True Spinach.-Kinney places the varieties of true spinach (Sfinacia) into four types or groups, which may be distinguished by the following key:

\section{Key to Groups of Spinach}

"Secds" prickly, Prickly-seeded group.

"Seeds" smooth.

Ends and lobes of leaves rounded; plants compact in habit, Round-lcaved group.

Ends and lobes of leaves more or less pointed.

Plants large, leaves long, and spreading on the ground, Thick-leavcd group.

Plants not so spreading, more vase-form and erect, on account of the stronger leaf stalks, Norfolt or Bloomsdale group.

It was formerly thought that prickly-seeded spinach was more hardy than the smooth-seeded varieties, but a number of the latter have proven quite as hardy as pricklyseeded ones. Norfolk, Bloomsdale, Curled Savoy, and American Curled are important varieties in the Norfolk group; Victoria and Long Standing in the round-leaved group; Broad-leaved Flanders, Viroplay and Long Season in the thick-leaved group.

Spinach is one of the foremost plants for "greens," or for use as a pot herb.

\section{BETA VULGARIS (Beet)}

Botanical Groups.-The above is the only species of the genus Beta of any economic importance. It is a complex species, however, separated into a number of rather distinct groups as follows:

I. Sugar beet.

2. Mangel-wurzels or mangels.

3. Common garden beet. 
4. Leaf beets.

(a) Chard or Swiss chard.

(b) Ornamental or foliage beets.

The Wild Beet.--Along the coast of southern Europe, there grows a perennial sea beet (Beta maritima) with a tough, slender root. It is considered by some that the cultivated groups of beets have been derived from some form of this wild beet.

\section{SUGAR BEET}

Habit.-The sugar beet is a biennial, storing up food the first year in the crown (fleshy stem) and tap root from which aerial shoots are produced the second year.

Root.-The "beet" itself is, for the most part, an enlarged tap root. The "crown" of the beet is developed from hypocotyl. The root part of the beet may be distinguished from the hypocotyl portion (stem) by the two opposite, longitudinal rows of secondary roots (Fig. 4). The tap root extends almost straight downward, and the lower portion becomes small and thread-like and commonly reaches a depth of 4 feet and often 6 or 7 feet. The lateral roots and rootlets are very abundant. The first 6 to 8 inches of the root, however, are almost free of side roots. The upper laterals are the largest of the branch roots and extend farthest in the soil, spreading almost horizontally 2 to 3 feet. The lower laterals are more vertical, and those near the very tip almost parallel with the tap root.

Stems.-The upper part (crown) of the sugar beet is hypocotyl, i.e., stem. This is a very much shortened fleshy stem with the leaves crowded at the apex. The second year, it sends up, from terminal and axillary buds, stout, angular, branching stems to a height of 3 or 4 feet; these stems give rise to flowering branches (Fig. Irg). 
Shape and Structure of Beet (Tap Root and Hypocotyl) - Bect Shape and Size, and Sugar Content.-There is great variation in the shape and size of sugar beets. Some importance has been attached to the correlation between sugar content and beet shape and size. This relation, however, is

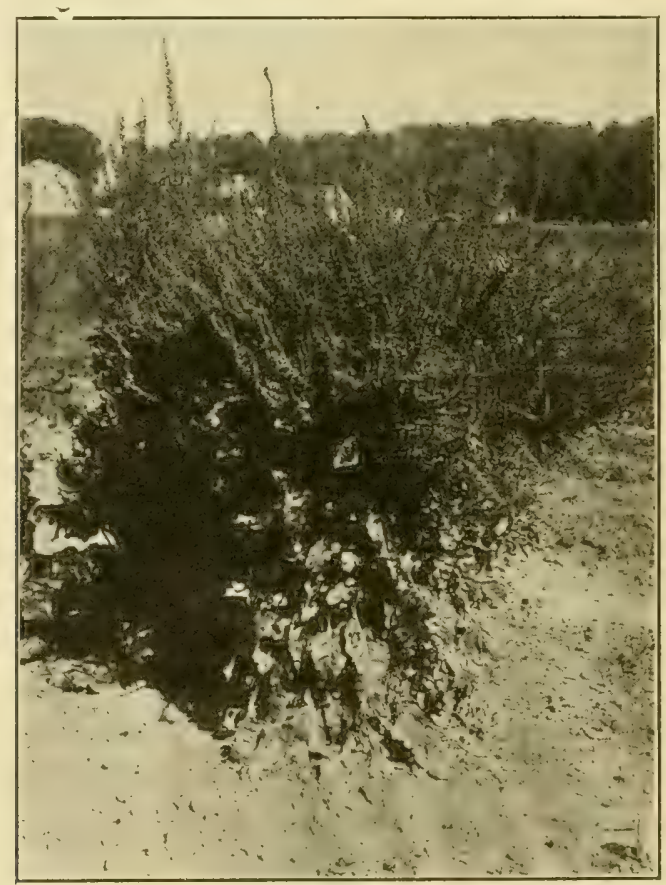

FIG. II9.- Sugar beet plant in full fruit.

of little significance. Pritchard has recently shown that differences in the size and sugar content of individual beet roots are fluctuations, and show no evidence of inheritance. It is true that uniformity of type is desirable, but any attempt to judge of the sugar content of an individual beet by the 
shape and size is useless. Beets with a large crown are undesirable.

Anatomical Structure and Sugar Content.-The researches of a number of European investigators have shown that the anatomical structure of the sugar beet is correlated with sugar content. In general, beets with a high percentage of sugar have a finer structure than those with a low percentage. A cross or lengthwise section of a beet shows it to be made up. for the most part, of a ground tissue penetrated by groups of vessels. In cross-section (Fig. I 20), these groups of vessels

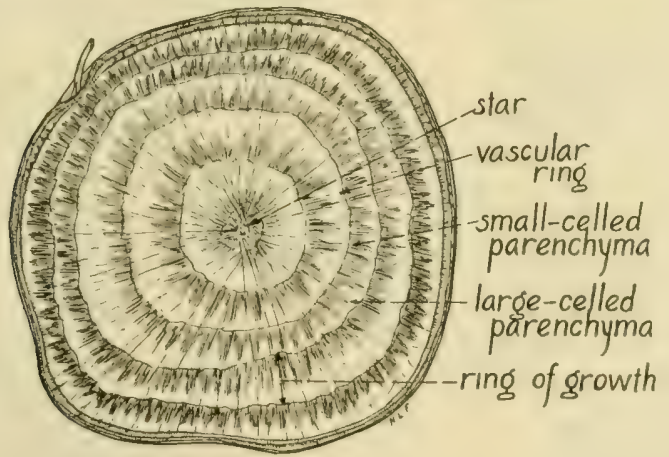

FiG. I20.-Diagrammatic cross-section of sugar beet root.

take a circular form, being separated from each other by parenchyma tissue. At the center of the beet, the bundles are close tcgether, forming the so-called "star." The tissue that separates vessels is composed of two kinds of parenchyma cells: small cells surrounding the vessels, and large ones farther removed. The smaller parenchyma cells are rich in sugar, while the larger ones are principally water storage cells. poor in sugar. Hence, beets with a predominance of smallcelled parenchyma are richer in sugar than those in which large water storage cells predominate. It must not be as- 
sumed from this that it would be possible to find conspicuous differences in the anatomical structure of beets varying $\mathrm{I}$ or 2 per cent. in sugar. Furthermore, a certain microscopical appearance is not to be associated with a given sugar content.

Distribution of Sugar in the Beet.- Fig. I I shows that the beet root is divided into various zones differing as to their

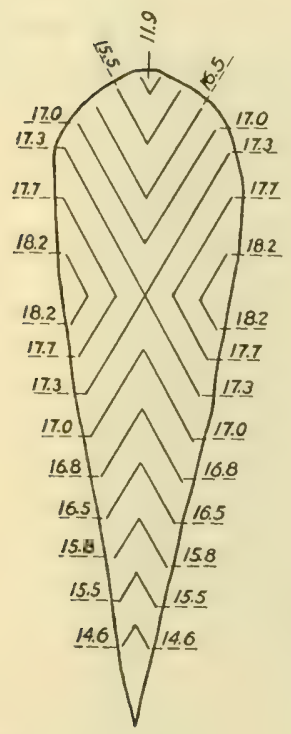

FIG. I 21.-Diagram showing distribution of sugar in an average sugar beet. (After Molinari.)

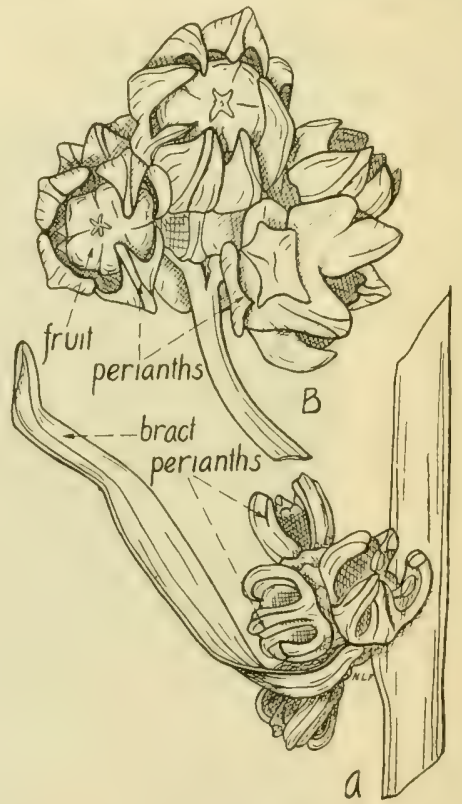

FIG. I22.- Sugar beet (Beta vulgaris). $A$, flowers grouped in the axil of a bract; $B$, cluster of flowers which fuse to form a multiple germ beet "seed."

sugar content. The sugar content decreases from a point below the broadest portion of the root to the crown and tip.

Crossing of Vascular Bundles in Croun.-In a longitudinal section of a beet, it will be seen that there is a crossing of the vascular bundles in the stem. The oldest part of the beet is 
the center; new rings of growth are placed upon these, while the new leaves come from the center of the crown. Hence, there is a crossing of the older and younger bundles that lead into the leaves.

Rings of Growth. - The rings of growth vary in number, depending upon the length of the growing season. Ordinarily, six to ten rings complete their growth. The cambium rings arise in the pericycle, each remaining active but for a short period of several weeks.

Leaves.-A cluster of large leaves is developed from the crown of the beet during the first season. The oldest leaves

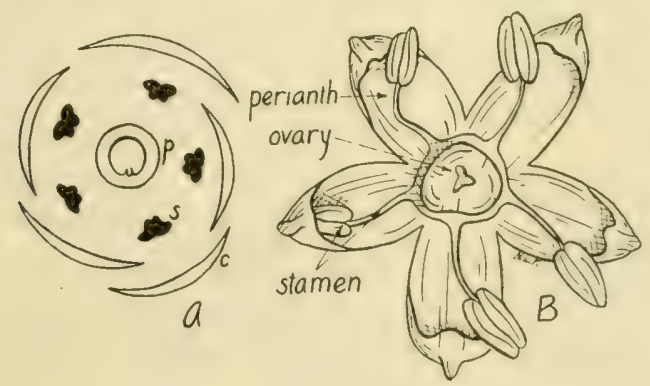

FIG. I23.-Beet (Beta vulgaris). A, floral diagram; $B$, flower, face view. (A after Bessey.)

are on the outside, the youngest toward the center. Each leaf has a long petiole which broadens out at the base; the blade is large and roughly triangular in shaipe at the base, and longer than broad; the veins are prominent.

Inflorescence.- The inflorescences are loosely spicate and terminal. The flowers are arranged along an axis, singly or in dense, sessile clusters, each of which is subtended by a small bract. Fig. I22, A shows a characteristic cluster of beet flowers in the axis of a bract.

Flowers.- Beet flowers are perfect. The perianth consists 
of live parts united below to the base of the ovary (Figs. I 23 and I 24). There are five stamens opposite to and partially attached to the perianth ring. The ovary is half-inferior, that is, partially imbedded in the flesh of the receptacle, onecelled and one- to three-seeded. There are two to three short, awl-shaped stigmas, united at the base.

Pollination and Fertilization.-The beet flower is protandrous. Shaw has shown that "self-fertilization" (autogamy)

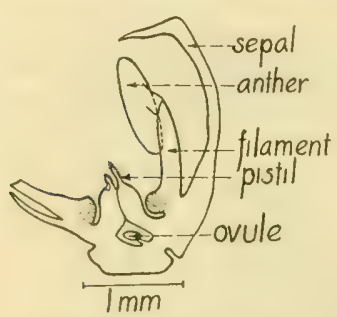

Fic. 124 -Diagram of leet fluwer, showing onehalf of flower cut lengthwise. (Afer Townsend and Rittue, U. S. Dept. Agri.) does not take place, and that "close fertilization" (geitonogamy) is usually ineffective. He has also demonstrated that thrips voluntarily travel from plant to plant, and positively assist in pollination of beet flowers. Bees are of little consequence in this process. Wind is the chief factor in beet pollen dissemination.

Fruit and Seed.-The ripened ovary of each flower is imbedded in the receptacle and the base of the perianth. The fruit is hard and nut-like, and contains a single, dark, smooth seed. The beet seed of the market is frequently called the "seed ball." The "seed ball" usually contains a number of germs; however, in some cases a single germ is produced. The multiple-germ beet seed arises when the flowers are in clusters; in this case, the parts of the several flowers stick together forming a several-seeded mass, the "seed ball." If the flower stands by itself on the stem, a single-germ beet seed is produced. The single flowers are usually located at points on the stem where a branch arises. According to this, a highly branched inflorescence will produce a greater proportion of single flowers.

Tests of the comparative yields of beets from single-germ 
seeds and multiple-germ seeds have not been made. ()if course, the advantage of single-germ seed is in the eliminattion, to a large extent, of "thinning." Townsend and Rittue say that there is some inclication that plants grown from single-germ seeds produce a greater number of single flowers than plants from multiple-germ seeds. It must be borne in mind that the so-called "beet seed" is in reality a fruit, that a multiple-germ seed consists of several oneseeded fruits, and a single-germ seed of one one-seeded fruit.

The true seed is kidney-shaped and about the size of a turnip seed. The testa is thin, dark and smooth. The hilum and micropyle are basal. The white and floury endosperm lies in the middle of the seed, surrounded peripherally by the annular embryo (Fig. II 7).

Seed Production.-The beet industry in the United States has been dependent almost wholly upon Germany for its supply of beet seed. However, in the last year or so, considerable activity has been manifested in the growing of beet seed at home, and as a result, we are now growing successfully large quantities of seed. Since the beet is a biennial, it is necessary to store the roots of the first year, and set them out the following season, in order to obtain seed. The "mother beets" may be tested for their sugar content before planting, and only those which show the desired percentage of sugar set out for seed production. The testing and selection of mother plants for seed has resulted in the striking improvement of beets.

Germination, and the Seedling.- The primary root is the first to appear. Soon, the cotyledons follow, pushing their way above ground. The seedling consists of a very short hypocotyl which scarcely appears above ground, two rather fleshy, glabrous, short-petioled, one-nerved cotyledons, and 
a tapering primary root which gives off a few red, fibrous laterals.

Types of Sugar Beets.--There are two well-known and common types of sugar beets: Kleinwanzlebener and Vilmorin. The Vilmorin beet is of French origin, and as compared with the Kleinwanzlebener, a German beet, is more circular in cross-section, smaller, has a lighter skin, and a much smaller top of leaves. The secondary root lines are straight in Vilmorin beets, and spiral in Kleinwanzlebener beets. The percentages of sugar in the two types are about the same. The tonnage of the Vilmorin is smaller.

Composition of Sugar Beets.-The following analyses of sugar beets were made by Headden. ${ }^{1}$

\begin{tabular}{|c|c|c|c|c|}
\hline & $\begin{array}{l}\text { German } \\
\text { beet, } \\
\text { grams }\end{array}$ & $\begin{array}{l}\text { Michigan } \\
\text { beet, } \\
\text { grams }\end{array}$ & $\begin{array}{c}\text { Colorado } \\
\text { beet, } \\
\text { grams }\end{array}$ & $\begin{array}{c}\text { Montana } \\
\text { beet, } \\
\text { grams }\end{array}$ \\
\hline Average weight trimmed........ & $\ldots \ldots$ & $8 I_{3} .000$ & 673.000 & $479 \cdot 300$ \\
\hline Water.................. & $74 \cdot 550$ & 78.000 & 75.800 & 74.603 \\
\hline Dry substance.............. & $25 \cdot 450$ & 22.000 & 24.200 & $25 \cdot 370$ \\
\hline Sugar............. & 16.600 & $15 \cdot 300$ & I 8.300 & I 8.240 \\
\hline Total ash.... & 0.800 & $0.70 \mathrm{r}$ & 0.820 & 2.680 \\
\hline Protein................... & 0.706 & 0.769 & 0.543 & 0.436 \\
\hline
\end{tabular}

Except in extreme cases, there seems to be little support for the statement that the greater the weight the less the sugar content of the beet. The composition of the beet is affected by age, disease, fertilizers, insufficient food supply, light, time of topping, rainfall, etc. The average sugar content of American grown beets is about 15 per cent. Frequently, the yields are more than 20 tons, and the sugar content 17 to 20 per cent.

Manufacture of Sugar.--The chief use of sugar beets is in the manufacture of sugar. The beet sugar industry has made very rapid development in this country. In the making of beet sugar, the topped beets are first washed, and then cut by

1 Colorado Agri. Exp. Sta. Bull. r83. 
machinery into narrow strips ("cossettes"). These strips are placed in diffusion vessels, treated with water at a temperature of about so $t 0 S_{4}{ }^{\circ} \mathrm{C}$., and the sugar extracted by diffusion. The juice is then run in to large tanks, where milk of lime is added to it. The liming is followed by the intro duction of carbonic acid, which precipitates the lime as a carbonate and salts of the acids of the juice. The precipitate carries down most of the impurities in the juice. When the first "carbonatation" process is about completed, the juice is heated nearly to the boiling point, filter-pressed, and the filtrate lead into a second carbonatation tank. This may be followed by a third carbonatation. The purified juice is concentrated by boiling, and crystallization brought about in vacuum evaporators. The material that comes from the vacuum evaporators is a mixture of crystals and molasses. This mixture ("masscuite") is placed in centrigufal machines lined with fine sieves; here the molasses is driven out and the sugar retained. The sugar is next fed into the granulator, where the crystals are separated from each other during the drying process. The molasses from the first boiling is again boiled, and further crystallization brought about.

By-products of Manufacture.--After the sugar has been removed from the sliced beets, there is left a substance known as "beet pulp." This is a valued stock food. However, it cannot be made the sole ration of an animal, as it is deficient in nitrogenous food materials. Beet pulp is sometimes dried, mixed with molasses, and fed to dairy cows. Molasses from the second boiling is also valued as a stock food. 'The refuse that accumulates in the purification process is sometimes employed as a fertilizer. It has been demonstrated that it is possible to manufacture fusel oil, alcohol, rum, and vinegar from the refuse molasses. There are many other ways of utilizing sugar-beet molasses. 


\section{COMMON GARDEN BEET}

The botanical characters of the garden beet are very similar to those of sugar beet. As is well known, however, they are not so rich in sugar and differ from them in color, shape, and edible qualities.

Types.-As to color, there are two main groups of garden beets: (1) Flesh red (Early Blood Turnip, Eclipse, Egyptian, Detroit, Dark Red); and, (2) Flesh yellow (Early Yellow

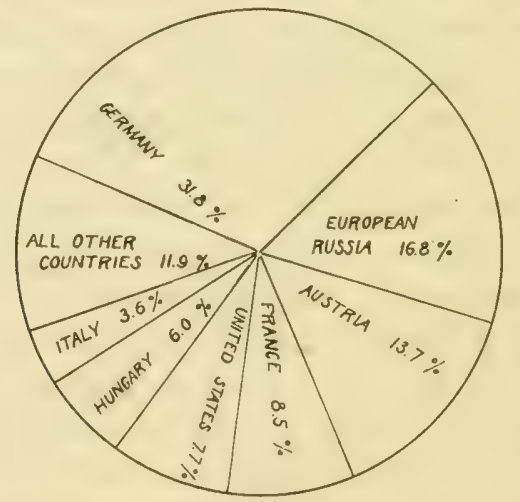

FIG. I25.-Percentage of the world's supply of beet sugar (raw) produced in the different countries, campaign of $1913^{-14}$.

Turnip, Golden Globe). Goff divides garden beets into four types as to shape:

I. Root oblate or top-shaped (Early Blood Turnip, Eclipse, Egyptian, etc.).

2. Root half long (Victoria).

3. Root oval (Strasbourg Pear-shaped, Dell's Black-leafed).

4. Root long-conical (Long Blood, Long Yellow).

Uses.-Garden beets are mostly for table use. The flavor of early varieties is more delicate than that in later maturing ones. The roots are boiled, pickled, or mixed in salads. Considerable quantitites are canned, and in some cases the common garden sorts are used for stock food. 


\section{CHARD}

The edible "leaf beets" go under various names: Spinach beet, sea-kale beet, Swiss chard, silver beet, chard, and Beta cycla. The flowers and fruit are like those of the

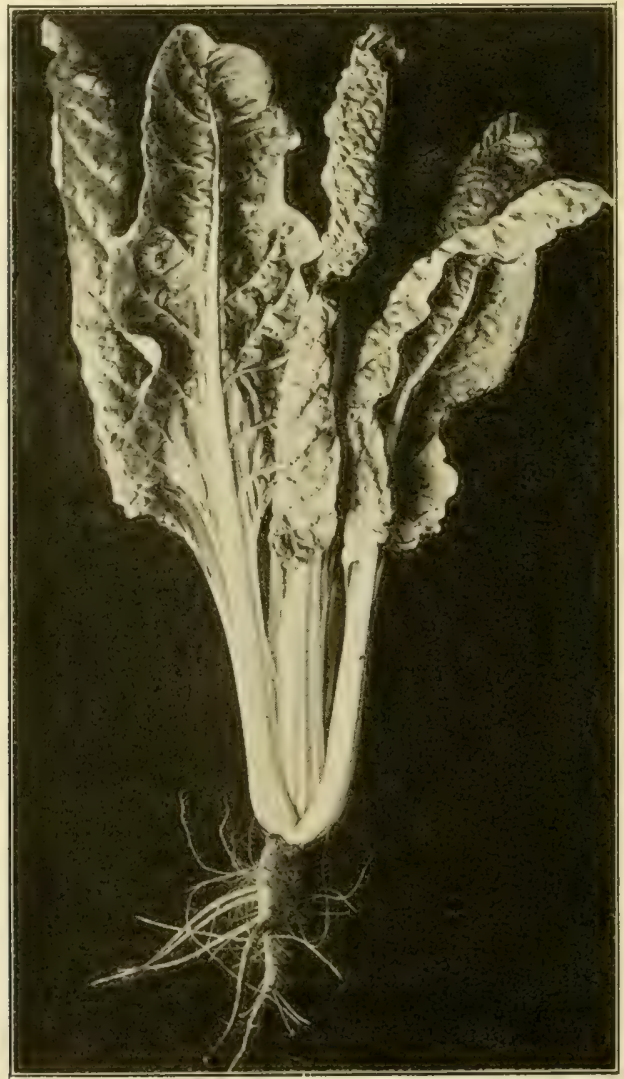

FiG. 127.-Chard or leaf beet (Beta vulgaris).

common beet. Cultivation has changed its habit of growth, however, such that leaves, instead of roots have become developed. 
The plant is a biennial with a somewhat branched and thickened, but not fleshy, root system. The leaves are clustered at the surface of the ground (Fig. 127); they bear large, thick leaf stalks and large blarles. The leaf stalks are often ats much ats 2 feet long and i to 3 inches thick.

The chief variety grown in this country is Lucullus, one in which the leaves are heavily crumpled or "savoyed." Swiss chard is a variety with dark, green leaves. There are forms of chard with white, red or pink leaf stalks.

Chard is grown for its tender leaves and petioles. The leaves are boiled like spinach, and the petioles are served like asparagus.

\section{MANGEL-WURZELS OR MANGELS}

To this group belong the stock-feeding varieties of Bela iulgaris. The botanical characters are very similar to those given for the sugar beet.

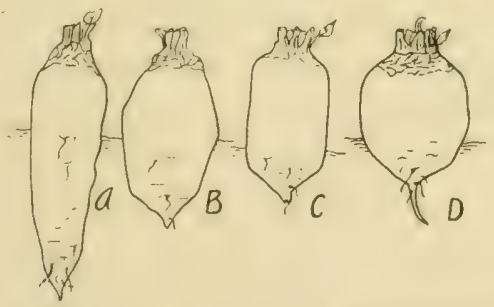

FIG. I28.-Types of mangels. A, long; $B$, intermediate; $C$, tankard; $D$. globe. (After Percival.)

Types.- As to shape. there are four well-recognized types of mangels (Fig. I 28 ):

I. Globe.-In these varieties, the roots are globular, and project above ground for more than half their length (Yellow Globe, Orange Globe).

2. Tankurd.-- Varieties of this type have roots which are 
almost cylindrical, and narrow abruptly at both ends. The roots are comparatively small (Golden Tankard).

3. Oval or "Intermediate."-The roots in these are oval, and intermediate in shape between globe and long varieties. They vary in color (Giant Intermediate).

4. Long.- Roots of this type are several times longer than broad and project above the soil for a considerable proportion of their length. They are heavy yielders. Both red and yellow-skinned varieties (Long Red, Long Yellow) occur. The ox-horn varieties have long twisted and horn-like roots.

Composition and Uses.-T'he mangels vary in sugar content from 3 to 8 per cent., the Golden Tankard and Globes having the highest percentage. Long varieties are relatively low in sugar content but produce a greater tonnage per acre. The water content varies from 85 to 92 per cent. Mangels are being extensively grown for stock food. They are one of the most important root crops. The root crops include all plants whose underground vegetative parts, such as rootstocks or roots, are utilized. Bulbs and tubers, however, are usually excluded. Examples of root crops are beets, mangels, turnips, carrots, rutabagas, sweet potatoes, and artichokes. Root crops are used for human food and also for forage. It must be kept in mind that all "root crops" are not wholly roots, morphologically, but that in some, such as the carrot, turnip, rutabaga, mangel and beet, the lower two-thirds or more of the underground part is root, the remainder stem ("crown"). Practically all root crops are best adapted to localities with a cool growing season.

\section{References}

Goff, E. S.: Vegetables: Garden Beet. 6th Ann. Rept. N. Y. Agr. Exp. Sta., I 20-132, I 887 .

Kinney, L. F.: Spinach. R. I. Agr. Exp. Sta. Bull. 4I : 99-I3I, r896. 
Pritenard, F. J.: Some Recent Investigations in Sugar-beet Breeding. Bot. Gaz., $62: 425-465$, I9I6.

R̈̈gginberg, II.: Beitrage zur Inatomie der Zuckerrübe. Mitt. Kaiser WilheIms Inst. f. Landw. Bromberg, 4: 399-4I5, I9I2.

Sraw, G. H.: Thrips as Pollinators of Beet Flowers. U. S. Dept. Agr. Bull. I04: I-I2, I9I4.

Tow xsend, C. O., and RitTte, L. C.: The Development of Single germ Beet Seed. U. S. Dept. Agr. Bur. Plant Ind. Bull. 73: I-23, I 905.

Towrsend, C. O.: Single-germ Beet Seed. Jour. Hered., 0: $3.51 \cdots 354$, 1015. 


\section{CHAP'TER XYIY}

\section{GROSSULARIACE $\notin$ (Gooseberry Family)}

There is but one genus-Ribes-in this family. It includes the gooseberries and currants.

Stems.-Gooseberries and currants are erect or procumbent shrubs. The stems of gooseberries are armed with spines and prickles, while currants have neither of these present on the stems. The spines and prickles of gooseberries are stem emergences, thus differing from those of certain plums and thornapples, which are reduced branches. Some cultivated varieties of gooseberries are almost thornless. In gooseberries the fruit is borne on one-year-old wood and from spurs (short branches) on older wood. As a rule, these spurs only bear well for the first two or three years. Black currants produce the most fruit on wood that is one year old, while red and white currants produce fruit most abundantly on spurs that arise from wood two or more years old. When the canes ("stems") reach an age of four or five years their vield decreases, and hence it is the practice to prune out old canes, and keep a supply of new ones coming on. The cutting back of old canes not only induces the formation of fruit spurs, but new canes as well. Propagation of both gooseberries and currants may be made by stem cuttings; gooseberries are also propagated by layering, and occasionally from root cuttings. In layering, the branches are bent over and covered with earth; after the buried stems take root, the newly rooted part is severed from the parent plant. 
Leaves.- The leaves are alternate, palmately lobed, often resinous-glandular or viscid. Stipules are wanting or present. In all gooseberries and most currants, the leaves are plicate (Fig. ror) in the bud. In a few cases, as the golden currant (Ribes aureum), they are convolute (Fig. Ior).

Inflorescence and Flowers.-Currants and gooseberries usually have a typical racemose type of inflorescence; rarely the flowers are solitary. Wach pedicel is subtended by a

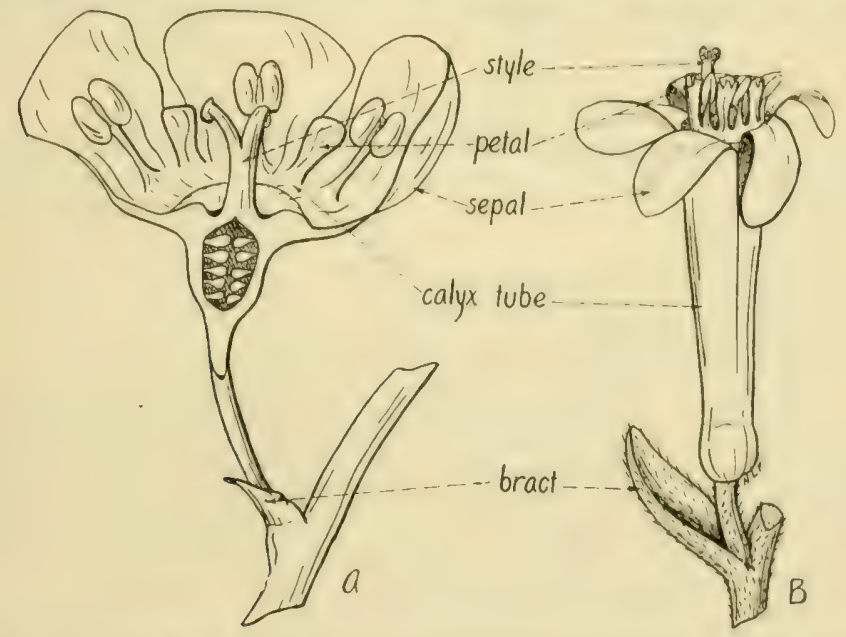

FIG. I29- - A, flower of red currant (Ribes rubrum) in lengthwise section; $B$, flower of golden currant (Ribes aureum). The portion designated calyxtube is in reality toral tube. ( $A$ afler Surgent.)

bract and usually also bears two bractlets at about the middle. The flowers are perfect, regular, with calyx and corolla both present and well differentiated (Fig. r 20 ). The receptacle (torus) is cup-shaped and surrounds the carpels (Fig. 130). The calyx is divided into four or live lobes. often colored. There are four or five very small petals, scale-like and alternating with the calyx lobes; the petals are free, and inserted on the throat of the calyx tube. The 
stamens are of the same number as petals, and are usually included, and attached to the perianth. The inferior ovary is one-celled with two parietal placenta, each bearing numerous ovules; two more or less united styles are present.

Pollination.--Gooseberries and currants are cross-pollinated, for the most part. Insects are the chief agents in pollination.

The Mature Fruit.- The fruit of the currant and gooseberry has been regarded as a berry; that is, a true fruit

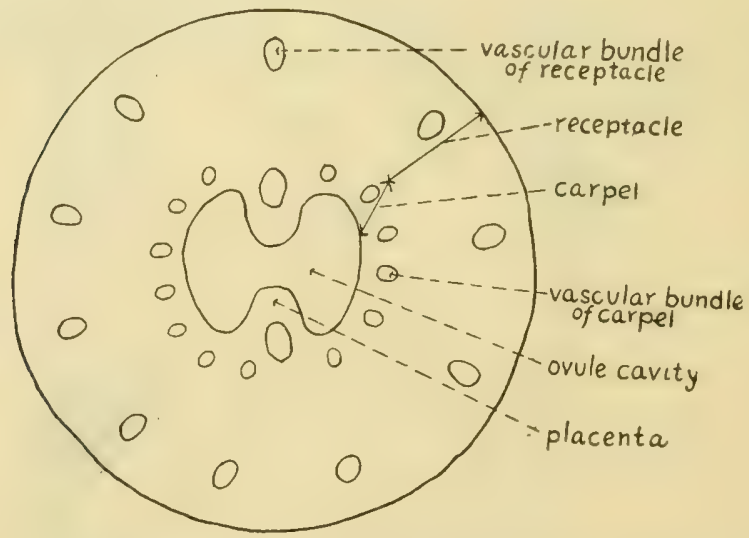

FIG. I30.-Diagrammatic cross-section of Ribes flower prior to fertilization. Note that carpel tissue is surrounded by receptacle tissue, as is evidenced by the two distinct sets of vascular bundles. The fleshy part of the Ribes fruit is thus seen to be composed of receptacle tissue for the most part; hence the fruit is not a berry, morphologically, but rather pome-like. (Diagram from microscopic section and data furnished by E. J. Kraus.)

possessing numerous seeds more or less imbedded in a fleshy endocarp and mesocarp. Recent, unpublished work of Kraus establishes the fact that the fruit is in reality pomelike in its structure. A cross-section through the base of the flower or through the fruit shows two distinct sets of vascular bundles (Fig. I30), the outer belonging to the re- 
ceptacle and leading to the sepals, petals and stamens, the inner to the carpels. Thus it is seen that a large portion of the flesh of the Ribes fruit is toral and not carpellary. Toral or receptacle tissue and carpellary tissue imperceptibly grade into each other.

Seeds. - The seeds are small, and slightly flattened on one side. The outer layer of the seed coat is comparatively thick and gelatinous and the inner layer is thin. There is an abundance of endosperm. A minute embryo occurs at the base of the seed.

Geographical.- There are about roo species of the genus Ribes. These are, for the most part, natives of temperate Europe, Asia, North America and the Andes of South America.

\section{Key to Important Species of Genus Ribes}

Stems with one to three thorns below the clusters of leaves, often with numerous scattered prickles on the branches, sometimes upon the fruit also. Leaves plaited in the bud (Fig. Ior) (Gooseberries).

Fruit unarmed and smooth; spines on the branches generally solitary (sometimes triple) and slender. R. oxyacunthoides (common gooseberry). Fruit armed with prickles, or rough and glandular-hairy; spines on the branches usually three together, stout. $R$. grossularia (European gooseberry).

Thornless and prickleless; leaves plaited in bud (Fig. IOI); racemes few- to many-flowered (Currants).

Torus dilated immediately above the ovary.

Leaves without resinous dots beneath; fruit red or light. $R$. rubrum (garden currant).

Leaves with resinous dots beneath; fruit black. R. nigrum (European black currant).

Torus prolonged above the ovary into a campanulate, cylindrical tube. $R$. americanum (American black currant).

Thornless and prickleless; leaves convolute in the bud (Fig. Ior); racemes several flowered; torus above much elongated, bright yellow. $R$. aureum (Missouri, flowering, golden, or Buffalo currant). 


\section{CURRANTS}

Species.-There are four principal species of currants in American currant culture.

(I) Ribes rubrum ( $R$. vulgare) includes all our red and white varieties, and is the most important species commercially. The leaves are hairy at first, but become smooth with age. The small, greenish-yellow or purplish flowers are in drooping racemes. The fruit varies in color; it may be bright red, yellowish, white, or striped. This species is found growing wild from New England to Minnesota and northward; also in Europe and Asia. Commercially, its culture is restricted to northern latitudes. Important varieties are Victoria, Red Dutch, Cherry, Versaillaise, Fay, Prince Albert, and White Grape.

(2) Ribes nigrum, the European black currant, is but little cultivated in America. It differs from the preceding in several respects: the lower surfaces of leaves are covered with yellow, resinous dots, and the fruit is black. The greenishwhite flowers are in drooping racemes, and the fruit and toral tube are both hairy and resinous-dotted. This currant is a native of middle and northeast Europe, through northern Asia to Manchuria and northern China.

(3) Ribes americanum, the native wild black currant of America, is not cultivated to any extent. The plant has a spreading habit. As in the European black currant, the lower surfaces of leaves are resinous-dotted, and the fruit is black in color, but it differs from the European species in that the toral tube and fruit are not resinous. It is distributed from Nova Scotia and New England south to Virginia and westward to Colorado and Manitoba.

(4) Ribes aureum is the chief American flowering currant. It is cultivated principally ats an ornamental shrub, but also 
for its fruit. The wedge-shaped leaves are three-lobed, smooth, and resinous when young. The short inflorescence is very leafy. The most characteristic feature of the plant is its flowers (Fig. I 29, B) which have a long, tubular, yellow toral tube, and small reddish petals. The fruit is dark brown or black. The species is native to the Mississippi Villey, and westward to the Rocky Mountains. Important varieties are Crandall, Deseret and Jelly.

Uses.-Currants are made use of for jelly, pies, sauce, and wine.

\section{GOOSEBERRIES}

Species.-The cultivated gooseberries belong to two species: Ribes grossularia, of Europe, and Ribes oryacanthoides ( $R$. hirtellum), of America. European gooseberries. as compared with American sorts, are less productive, less hardy, not so easily propagated by cuttings, have a thicker skin, a poorer quality of fruit and are less resistant to the common gooseberry mildew (Spharotheca mors-ui'e).

Ribes grossularia.- This is a robust plant, bearing large thorns, usually in threes. The leaves are shining and pubescent. The flowers have a pubescent toral tube and fruit. The large berry is rough, hairy or prickly, red, greenish, or yellowish in color. The species is a native of Europe, northern Africa and western Asia.

Ribes oxyacanthoides.- The American gooseberry is not as robust as the preceding. The thorns, sometimes in threes, sometimes single, are much more slender, and in some varieties may be entirely wanting. The leaves are shining and finely hairy. The greenish or purplish flowers have a smooth or hairy toral tube and a smooth fruit. The small berry is perfectly smooth, and reddish in color. Riles oxyacunthoides grows from Newfoundland to New Jersey 
and westward to the Rocky Mountains. Important varieties are Downing, Pale Red, Red Jacket, Champion and Pearl. There are hybrids between the American and European species.

Uses.-Gooseberries are used either green or ripe. They are made into pies, jelly, wine, and stewed or canned. 


\section{CHAPTER XXV \\ CRUCIFERE (Mustard Family)}

This family is of world-wide distribution. There are in the neighborhood of 2,000 species in 180 genera. The largest number of genera and species is found in southern Europe and Asia Minor. They are found from low to high latitudes and from low to high altitudes.

Many of the genera yield crop plants, such as cabbage, turnip, rutabaga, rape, black mustard, white mustard, radish, water cress and horse radish, while a number of genera include pernicious weeds, such as penny cress, wild mustard or charlock, shepherds purse, false flax, and tansy mustard.

Stems, Leaves.-Most mustards are herbaceous; a few are woody. The sap is usually watery and acrid. The leaves are alternate, simple, and variously lobed or dissected. The stipules are wanting.

Inflorescence and Flowers.--The predominant type of inflorescence is a terminal raceme; rarely the flowers are solitary at the end of a scape. The mustard flower is char- 
acteristic (Fig. $13 \mathrm{~T}$ ). It is perfect and regular with four sepals, four petals, six stamens (two short and four long), and a two-celled ovary. The four sepals are entirely dis-

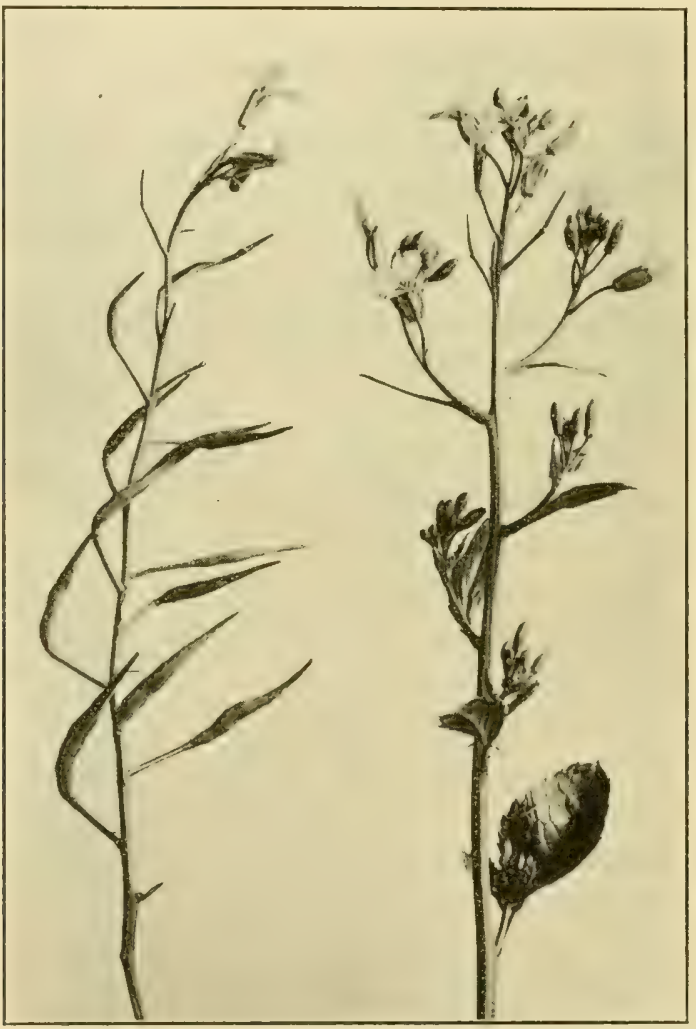

FIG. I32.-Common garden radish (Raphanus sativus). In flower, on right; and in fruit, on left. Note the characteristic racemose inflorescence with flowers at the apex and fruit at the base.

tinct, but often overlapping; the two outer are narrow, and the two inner may be narrow also, but often are distinguished from the outer by being concave or saccate at the base; they 
are in two distinct whorls. The four pelals are so arranged that when one looks at the face of the flower, it hats the appearance of a Greek cross, hence the name (ruciferie (Latin, crux, cross, + fera, to bear). The petals, ats at rule. are clawed, that is, have a narrow or stalklike base at the tip of which is a broader blade; they are similar as to size and shape. Nectar glands are frequently found at the base of petals. The six stamens are in two whorls, the outer two opposite each other and opposite the two sepals of the inner whorl, and with short filaments, the inner four stamens opposite the petals and with long filaments; the anthers are two-loculed (rarely one), and longitudinally dehiscent. The single pistil is superior, usually sessile, compound, and has a single style with a more or less two-lobed or disk-shaped stigma; the ovules are attached to two parietal placentas, which are connected by a "false" partition, an outgrowth of the placentas themselves.

Fruit.- The ovary develops into a pod-like fruit (Fig. I33), which is termed a silique (Brassica) when long and slender, and a silicle (Bursa) when short and broad. 'The sides (valves) of the fruit separate at dehiscence, leaving the two placentas and false

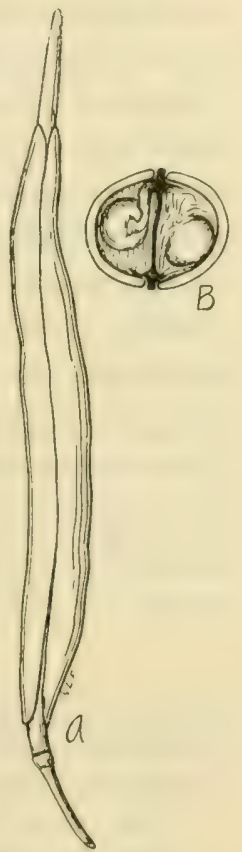

FIG. I33.-Fruit of cabbage (Brassica oleracea capilata). 1. external; B3. cross-scetion. partition. In a few genera (Raphanus, radish), the fruit is indehiscent.

Seeds.-The sceds are usually many, atlached to both sides of the partition, and have a mucilaginous testa; the endosperm is lacking; cotyledons are incumbent (with their 
back against the hypocotyl), accumbent (margins folded against the hypocotyl), or conduplicate (folded upon themselves lengthwise).

The seeds of mustards, like those of grasses and composites, are short-lived, as compared with those of the mallow family, potato family and pea family. Longevity of seeds is due to a number of factors, chief of which is impermeability of the seed coats to water and oxygen. Seeds with permeable coats are more sensitive to moisture and temperature changes than are those with impermeable ones. When moisture is absorbed by the seed its rate of respiration is increased, and hence its vitality reduced. This may be an important factor in shortening the life of the seed.

Closely Related Families.-Members of the mustard family may be mistaken for those of the poppy family (Papaveracea) or caper family (Capparidace(e), both of which are closely related. The poppies have perfect flowers usually with two early deciduous sepals, while capers are distinguished from mustards by the six approximately equal stamens and by the one-celled capsule.

\section{Key to Principal Genera}

Pod indehiscent, Raphanus (radish).

Pod dehiscent into two valves.

Pod a silique, at least twice as long as wide.

Leaves dissected, Sophia (tansy mustard).

Leaves broadly-lobed.

Silique beaked by a persistent style); seeds in one row, Brassica (cabbage, turnip, rutabaga, rape, black mustard and white mustard).

Silique beakless; seeds in two rows, Radicula (water cress and horse radish).

Pod rarely more than twice as long as broad.

Silique not flattened, nearly circular in cross-section, Camelina (false flax).

Silique flattened.

Silique elliptic or oval, Lepidium (penny cress).

Silique triangular-obovate or obcordate.

Basal (radical) leaves pinnatifid, Capsella (shepherd's purse).

Basal leaves entire or merely toothed, Thlaspi (penny cress). 


\section{BRASSICA}

Generic Description.-This genus inclucles ammual (b) lack mustard), biennial (turnip), or perennial (cabbages under their natural conditions) herbs. The root system may be fleshy (turnip), or rather woody and solid (cabbages). The basal (radical) leaves are frequently pinnatifid, while those of the stem (cauline) are entire, dentate, or broadly loberl. The large, yellow flowers are in elongated racemes. The sepals, petals, and stamens are as described for the family. The silique (Fig. I33) is elongated, sessile, terete or foursided, and tipped with an indehiscent, conic, usually oncseeded beak; the ralves are convex, one- to three-nerved, the lateral ones often flexuous; the septum (partition) is membranous or spongy; at the tip of the silique is a short or elongated style tipped by a truncate or two-lobed stigma. The seeds are in one row in each cell.

Pollination.- Representatives of the genus are for the most part insect pollinated. It appears that both self- and crosspollination takes place.

Seedling.--At germination of the seed, the cotyledons are brought above ground. In all representatives of the genus. the cotyledons are emarginate (notched at apex), unequal in size, and three-nerved at the base.

Geographical.-There are about 80 species in the genus Brassica, chiefly occurring about the Mediterranean region; some are now cultivated, however. in boreal and subtropical regions of Europe, $A$ sia, Africa, and North and Simuth America. None of the Brassicas are native of America or Australia.

\section{Key to Principal Species of Genus Brassica}

Leaves of flowering stem not clasping; annuals; sepals spreading.

Seeds small, reddish-brown; valves of silique one-nerved, $B$. nigra (b)ack mustard).

Seeds large, pale yellow; valves of silique three-nerved, B. albu (white mustard). 
Leaves of flowering stem somewhat clasping; biennials; sepals erect.

Roots swollen and fleshy.

Young leaves glaucous; a distinct short stem on upper part of root, $B$. campestris (rutabaga or Swede turnip).

Young leaves grass-green; no distinct short stem on upper part of root, $B$. rapa (turnip).

Roots not fleshy.

Young foliage covered with a few hairs, B. napus (rape).

Young foliage smooth, B. oleracea (cabbages, etc.).

\section{BRASSICA OLERACEA (Cabbages, etc.)}

Wild Cabbage.-This is the parent of the various forms of cultivated cabbage. It grows wild along the coasts of

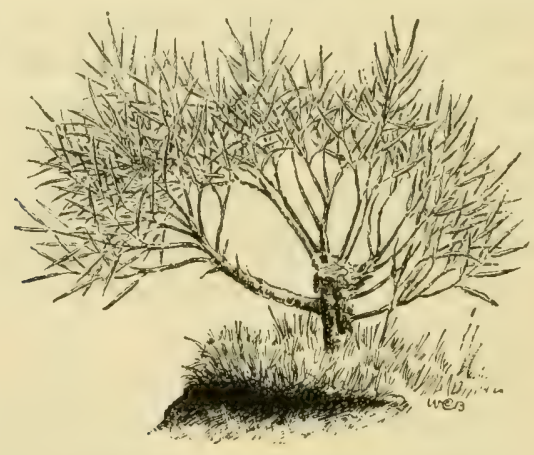

FIG. 134.-Wild cabbage. (After Bailey.)

England and Wales, Channel Island, and western and southern Europe. It is a stout perennial or biennial from a tough and woody root. The stem is branching and attains a height of I to 2 feet (Fig. I34). The lower leaves are stalked, lyrate or pinnatifid, entire, and broad, while the upper ones are sessile and much smaller. There is no tendency to form heads in the wild form. The flowers are in elongated racemes and are rather large, about ${ }^{3} 4$ to $\mathrm{I}$ inch in diameter, and of a pale yellow color. The fruit is a smooth silique often 3 or 4 inches long. 
Cultivated Types of Cabbages. I number of types have arisen, probably as mutants, from the native wild cabbage. The modifications concern the stem ats in kohlralsi, the folliage as in kale, head cabbage, and Brussels sprouts, and inflerescence, as in broceoli and cauliflower. The characteristic differences between these are shown in the following key:

\section{Key to Cultivated Types of Cabiages}

Stem of first year elongated.

Stem branched and leafy; plant much resembling wild cabbage ( Iigr. 1,35.

B. oleracea var. viridis (kales and collard).

Stem unbranched, the axillary buds developing inte small heads (lite. 1,3(1), B. olcracea var. gemmifera (Brussels sprouts).

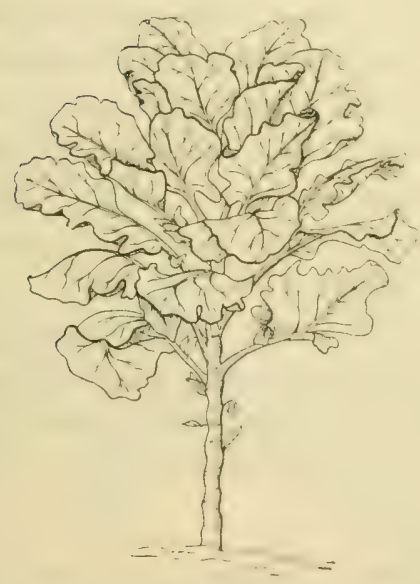

Fig. 135.-Kale (Brassica oleracea viridis). (After Vilmorin.)

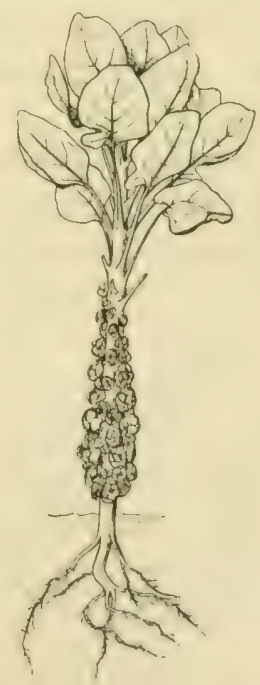

FIG. I36.-Brussels sprouts (Brassica oleracea gemmifera).

Stem of first year short.

First-year stem forming a "head" (Fig. I37), B. oleracea var. capitall (common cabbage).

First-year stem not forming a "head." 
Turnip-like stem which stands mostly above ground. (Fig. i 38 ), $B$. oleracea var. caulo-rapa (kohlrabi).

Stem not turnip-like, leafy below, inflorescence partially developing first season (Fig. I39), B. olcracca z'ar. bolrytis (cauliflower, broccoli).

\section{BRASSICA OLERACEA VAR. VIRIDIS (Fig. 135)}

The members of this group resemble very much the wild form of cabbage. The terminal and lateral buds elongate during the first season, giving the plant a branching habit. Forms of this variety are known as kale, borecole, marrow cabbage, or collard. Collards are grown in the South particularly. This southern form is known as the Georgia collard. Marrow cabbage or marrow kale is a broad-leaved form. There are a number of kales with finely dissected leaves; among such are the well-known Scotch kales, rather common market sorts. The tree kales have straight, stiff and strong stems often 3 or 4 feet tall; the dwarf kales are lower and close to the ground. Dwarf Green Scotch Kale is the most common sort grown in the Norfolk truck-gardening area. Thousand-headed kale is a very large, highly branching form. The large-leaved kales, such as marrow kale and thousand-headed kale, are used as stock food. The finer-leaved varieties are used as a boiled green vegetable.

Unlike their close relatives, Brussels sprouts, head cabbage, kohlrabi and cauliflower, kale and collard will endure the heat and drought of summer, and kale, at least, will stand considerable freezing.

BRASSICA OLERACEA VAR. GEMMIFERA (Brussels sprouts) (Fig. 136)

Here belong those cabbages in which the axillary buds develop into small heads or "sprouts." These are formed in the axils of leaves. The main stem is elongated and unbranched. The first "sprouts" to appear are those at the base of the stem, subsequent ones appearing in order from 
below upwards, almost to the top of the stem. Brussels sprouts resemble the kales except that the axillary buds, instead of developing into side branches, do not elongate but develop into "heads," which are in reality specialized buds, usually I to 2 inches in diameter.

Types.-There are two general types of this plant: tall Brussels sprouts and (lwarf Brussels sprouts. The former type grows to a height of 2 to 3 feet, is rather slender, and the leaves and "sprouts" are comparatively far apart. It is not grown to any extent in this country; dwarf varieties are preferred here. These latter seldom exceed 2 feet in height; they have a stout stem upon which the leaves and "sprouts" are crowded. As a rule, the leaves of the dwarf type are more crimped than those of the tall type. All the types are cool season plants.

Uses.-Brussels sprouts are much more tender than common head cabbage. The smaller "sprouts" are the most desirable. They are cooked in a manner similar to cabbage.
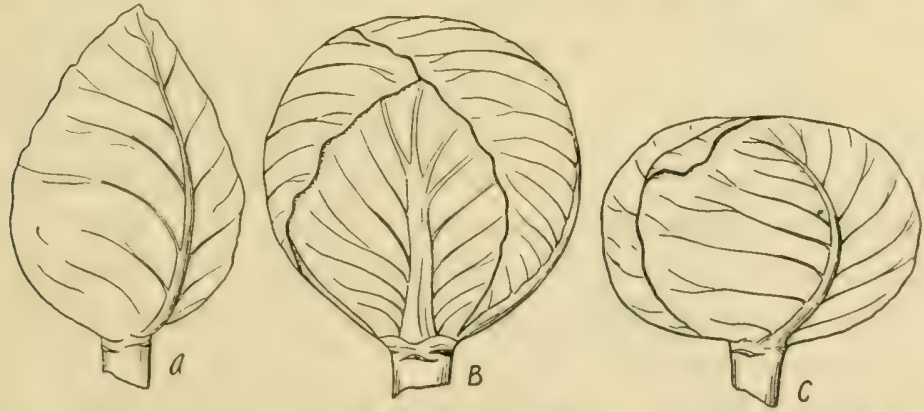

Fic. 137.-Common head cabbage (Brassica oleracea capitata). Three common types of heads: $A$, pointed or oblong; $B$, ballhead; $C$, drumhead.

\section{BRASSICA OLERACEA VAR. CAPITATA (Common Head Cabbage)}

(Fig. 137)

The common head cabbage produces, the first year, a short stem upon which are found numerous, thick, overlapping, 
smooth leaves, the whole forming the "head." A longitudinal section of a cabbage head shows the terminal bud, and, in some instances, rather well-developed axillary ones.

Types.- There are numerous varieties of cabbages. 'They' have been grouped into a number of different types. These types vary as to color, size, and shape of head and leaves, texture of leaves, length of stalk, earliness, etc. As grouped here, the types may be distinguished as follows:

\section{Key to Types of Common Head Cabbage}

Leaves smooth, not crimped or curled.

Leaves dark purple or red, Red cabbagcs.

Leaves glaucous-green.

Heads cone-shaped, longer than broad (Fig. I37, A), Winningstadt and W akefield cabbages.

Heads spherical (Fig. 137, B), Danish Ball Head cabbages.

Heads flat, broader than long (Fig. 137, C), Flat Dutch or Drumhead. cabbages.

Leaves crimped or curled, Savoy cabbages.

The red varieties of cabbage are valued for pickling and slaw. The Wakefields are the ones most extensively grown in trucking districts. There are two main types of Wakefields: True Jersey Wakefield which has small heads pointed at the tip, and Charleston Wakefield, with a head broader, flatter and more obtuse-pointed. Danish Ball Head cabbages are most used for storage purposes. The Savoy cabbages, especially when slightly frosted, are known for their very excellent flavor.

Uses.--Cabbage is grown as a market-garden, truck and farm crop, and is best adapted to a cool climate. As a human food, it is most generally boiled or used as slaw. Saucrkraut is cabbage cut up into very fine pieces and allowed to ferment in a brine made of its own juice with salt. The sour taste is due to the presence of lactic acid, formed by the action of 
latetic-acid species of bacteriat on the sugrat in the cabbatge juice. (Ordinarily there is a maximum of about I per cent. of lactic acid, the presence of which prevents putrefaction of the sauerkraut. Among other organisms, yeast is universally present in the fermenting cabbage. Cabbages are also used quite extensively for pickling, and as a food for stock and chickens.

\section{BRASSICA OLERACEA VAR. CAULO-RAPA}

(Kohlrabi or Turnip-rooted Cabbage) (Fig. 138)

The stem is short, much thickened, fleshy, and stands out of the ground. The fleshy part comes from the stem above the cotyledons, hence is not root. The swelling begins at the ground line; there is formed a large, spherical body upon which are very prominent, broad leaf scars.

As to color there are two principal types: Those with white "balls" or stems (White Vienna Erfurt); and those with purple "balls" (Purple Vienna).

Kohlrabi is not grown extensively in the United States. It is used particularly by our foreign population, being stewed and eaten like turnips or rutabagas. It is also a valuable stock food; both the stems and leaves are used for this purpose.

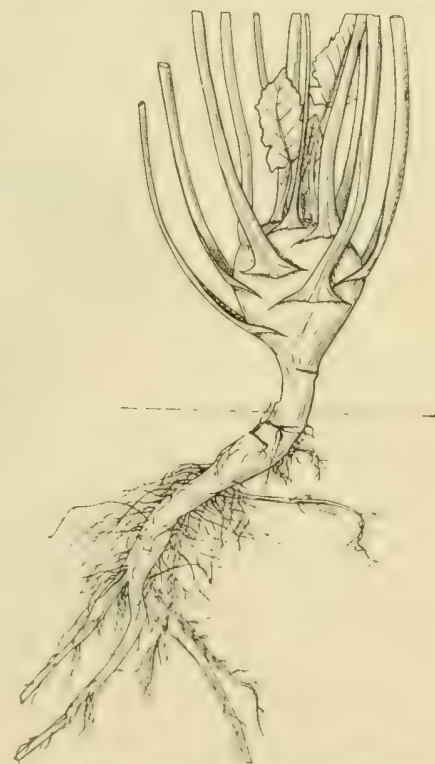

Fri. I.38.-Kunlrabi (Brassiua oleracea caulo-rapa). Kohlrabi is chiefly grown as an early spring crop), less frequently as a fall crop. It does not endure the heat of summer. 


\section{BRASSICA OLERACEA VAR. BOTRYTIS}

(Cauliflower, Broccoli) (Fig. 139)

Cauliflower and broccoli are types of cabbage in which there is a large "head," composed of abortive flowers upon very much modified, thickened flower stems (Fig. I39). The

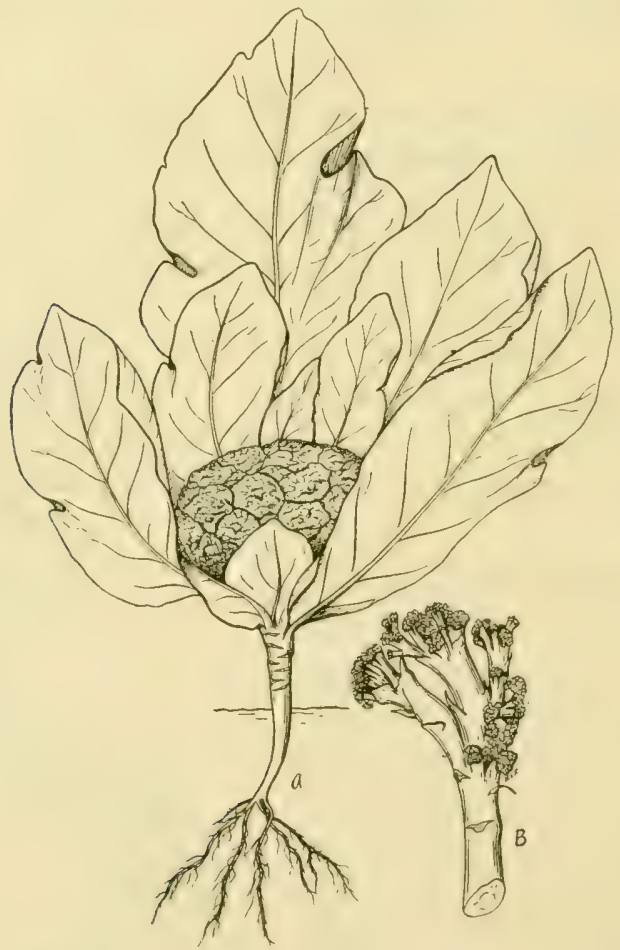

Fig. 139.-Cauliflower (Brassica oleracea botrytis). $A$, entire plant; $B$, portion of "head."

metamorphosed inflorescence develops the first season, its numerous short, fleshy, and closely crowded flower stalks forming the head, as indicated above. Subtending the head are a number of cabbage-like leaves. In growing the vege- 
table, these basal leaves are lied up about the fleshy, white head to prevent its browning by the sun.

A distinction is made between cauliflower and broccoli. The latter requires a longer time to mature than cauliflower; furthermore, the heads are smaller and the leaves broader, narrower, stiffer and more numerous.

Cauliflower and broccoli are both cool-season crops.

\section{BRASSICA RAPA (Turnip)}

Description.- The common turnip is a biennial. The first year a swollen and fleshy tap root is formed. However, the "turnip" is combined primary root and hypocotyl. The upper portion to which the leaves are attached is stem, while the lower portion to which secondary roots are attached is root.

The leaves that arise from the "turnip" the first season are in the form of a rosette. They are oblong to oval, sometimes entire, serrate, or the later ones pinnate or pinnatifid. First-year leaves are grass-green and rough-hairy. The second season, a stem I to 3 feet tall is sent up from the terminal bud in the center of the rosette of leaves, which bears alternate, clasping, lanceolate or oblong, entire or dentate, smooth leaves. The flower stem is branching. The inflorescence is a raceme. The flowers are bright yellow, about 1,2 inch in diameter and of the characteristic mustard type. The fruit is $1 \frac{1}{2}$ to 2 inches long, cylindrical, and tipped by a short beak. The seeds are reddish brown in color, spherical, and number 15 to 25 in each silique.

Geographical.-The turnip seems to have originated in Europe or Western Asia. By cultivation, it has spread into all temperate regions. The cultivated sorts are grown as cool-season crops.

Types of Turnips. - There are numerous varieties of turnips, varying chiefly as to shape and color of "root" (Fig. I40). 
The principal varieties grown in the United States may also be classified as follows (in each division but one or two examples are given):

Flesh white.

Root entirely white.

Flat (Early White Flat Dutch Strap-leaved, Extra Early White Milan).

Spherical (Snowball, White Globe Strap-leaved).

Qval (White Egg).

Carrot-shaped (Cow-horn).

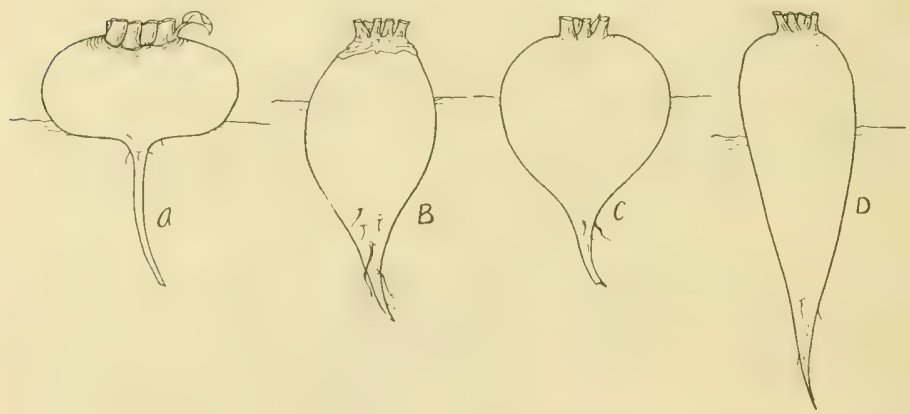

F1G. I 40.-Types of turnips (Brassica rapa). A, flat; $B$, tankard or spindle; $C$, globe; $D$, long. (Afler Percival.)

Root purple or red at top, white below.

Flat (Purple 'Top Strap-leaved, Extra Early Purple-topped Milan).

Spherical (Purple Top White Globe).

Root entirely red (Scarlet Kashmyr).

Flesh yellow.

Root entirely yellow (Golden Ball).

Root green at top, yellow below (Amber Globe).

Root red at top, yellow below (Early Red Top Globe).

Structure and Uses.- It will be recalled that the greater portion of a turnip is tap root. In cross-section, it shows the following layers (Fig. I4I):

I. Outer layer or cortex (bark).

2. Cambium.

3. Main flesh of turnip (wood and pith). 
In the fleshy root of the turnip, the walls of the cells which make up the wood are not lignified, and hence the tissue is soft, unlike ordinary wood tissue. The medullary rays are very indistinct. Some turnips are coarse in texture and such are used for stock food. The turnips of finer texture

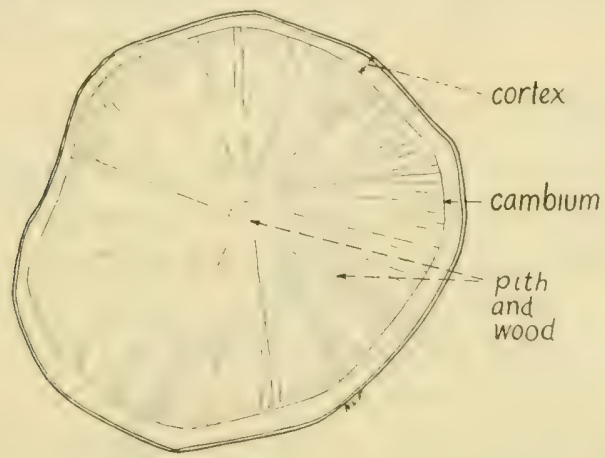

FIG. I 4I.-Root of turnip (Brassica rapa) in cross-section. Diagrammatic.

are used as food by man. In the South the variety Seven Top is grown as a green forage and green manure.

\section{BRASSICA CAMPESTRIS (Rutabaga or Swede Turnip) (Fig. I42)}

Description.-This species resembles very closely $B$. rapa, the common turnip. Rutabagas or "Swedes," have a short stem or "neck" at the upper part of the regetable. It is this character which easily distinguishes the rutabaga vegetable from that of turnip. The flesh is solid and yellow or orange in color. The first leaves are bluish white, and all leaves have thick, fleshy petioles. The yellow flowers are larger than those of the turnip, and the claws are longer.

Uses.-Rutabagas or "Swedes" have less water than common turnips. They are commonly grown as a food for stock, but are also eaten in large quantities by man. They 
develop the sweetness and flavors for which they are so well known only in the Northern States where the nights are cool.

\section{BRASSICA NAPUS (Rape)}

Description.--Rape is a biennial plant, growing to a height of 2 to 3 feet. It thrives best in those regions with cool summers. The stem is branched to a considerable

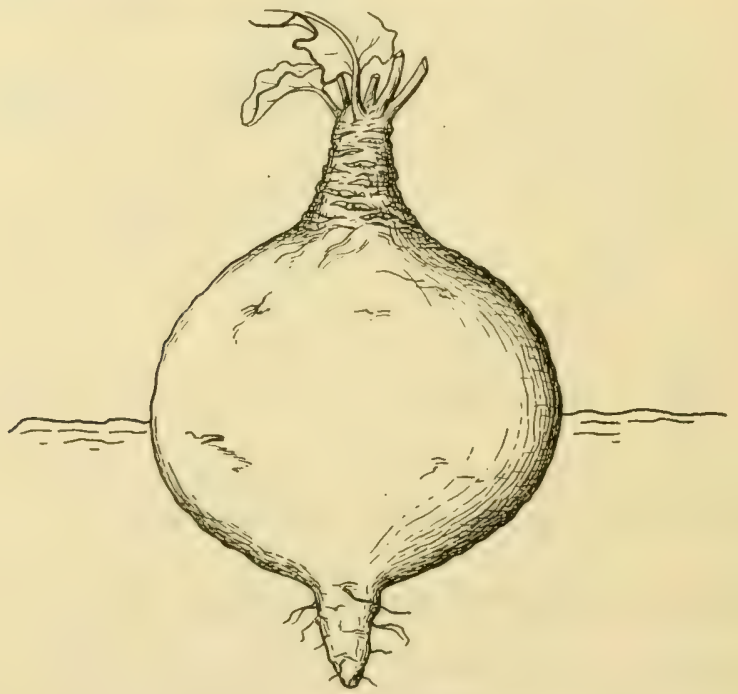

FIG. I42;-Rutabaga (Brassica campestris).

extent. There is no swollen root. The lower leaves are lyrate, the upper ones oval to lanceolate and clasping the stem. The inflorescence is of the typical racemose type. The flowers are bright yellow. The seeds are black or dark purple. The seedlings and young plants resemble those of B. campestris (rutabaga).

Varieties and Uses.-The principal variety of rape in the United States is Dwarf Essex or English rape. This is a 
variety used for its green foliage, and hence is treated ats an annual. This type of rape is used as a fall pasture for sheep, pigs or cows, as a green manure, and as a soiling crop, catch crop, or cleaning crop. "Rape cake," made from the seeds by expressing the oil, is used as a stock food, and the oil itself is of some value. About 42 per cent. of the seed is composed of rape oil.

\section{BRASSICA NIGRA (Black or Brown Mustard)}

Description.-The black mustard is an annual herb 2 to 7 feet tall, and freely branching. The lower leaves are hairy and deeply pinnatifid, with one large, terminal lobe and two to four smaller, lateral ones; the lobes are coarsely toothed. The upper leaves have much shorter petioles than the lower, or they are entirely sessile, and the blades are entire and oblong or lanceolate. The flowers are bright yellow. The pods are slender, four-sided, oppressed against the stem, and measure about $1 / 2$ inch or more in length. The seeds are dark brown.

Black mustard is a native of Europe and Asia. It has become naturalized in this country and has escaped from cultivation, becoming frequently a troublesome weed.

Black mustard resembles charlock (Brassica arvensis), one of the worst pests in grain fields of the Middle West. Charlock has long, knotted porls with stout beaks, while the pods of black mustard are short, four-angled, and with short beaks. The pods of white mustard are somewhat bristly. Charlock, black mustard and white mustard are propagated by seeds. In their eradication, no attention needs to be directed toward the starving out of rootstocks, which are so typical of perennial weeds. Every effort is made to prevent them from going to seed. Much success has attended the use of chemical herbicides, chiefly iron sulfate, in eradicating 
the mustards from grain fields. All grasses are resistant to injury from this spray, but the young mustards, and many other weeds, are quite easily killed by it. This is due to the fact that the spray does not adhere so readily to the smooth grass leaves as to the mustard leaves; moreover, although the tips of grass leaves are injured, the growing tissue at the leaf base may not be touched by the spray, and hence the recovery is rapid.

Related Species.-It is closely related to the white mustard which is described hereinafter, and to Chinese or Indian mustard (Brassica juncea). The latter is adventive from Asia in this country, often a bad weed, and sometimes its leaves are used for "greens." In the Indian mustard, the pods are I to 2 inches long, and some of the forms have leares twice the size of those in the ordinary black or white mustards. The Japanese or pot-herb mustard (Brassica japonica) is introduced into the United States. It has thin, soft leaves which are valued as "greens."

Uses.-The plant is used mainly for garnishing, also in salads and in the preparation of meat dressings and sauces. Occasionally it is boiled like spinach. Table mustard is the ground seeds of black mustard. The aroma and pungency of mixed mustard (table mustard) does not exist in the seed itself, but is given rise to when the ground seed is mixed with water. This pungent, volatile oil is an allylthiocyanate and is formed by the action of a specific enzyme, myrosin, upon potassium myronate - a glucoside present in the seed.

\section{BRASSICA ALBA (White Mustard)}

This species has characteristics very similar to those of black mustard. It is distinguished from the latter chiefly by its lighter colored bristly pols, and its lighter colored and larger seeds.

The plant is a native of Europe, Asia and northern Africa. It is used similarly to the black mustard, and in addition is 
sometimes used as a green manure. The mixed mustard from this species is less pungent than that from B. nigra.

\section{RAPHANUS SATIVUS (Garden Radish)}

Habit.- The common garden radish is an annual or biennial herb. It may produce fruit the same year, when planted early in the season, while, if planted late, it produces a fleshy tap root the first year, which may be kept over the winter until the next year, when it produces fruit.

Root.- The radish vegetable is mainly a tap root, varying in size, shape, and color. At the top is a short hypocotyl (stem). The laterals from the tap root are few in number and very slender.

Stem.-From the hypocotyl or crown of the radish, there first appears a rosette of leaves, and later an erect, freely branching stem, I to 21,2 feet tall. This stem may be sparsely pubescent with stiff hairs, especially below, or rarely glabrous throughout.

Leaves. - The basal and lower leates are deeply lyrate-pinnatifid, 4 to 8 inches long; the upper leaves are few, small. and oblong.

Inflorescence and Flowers.-- The inflorescence is an elongated raceme (Fig. 132). The flowers are of the typical mustard type; the sepals are erect and sac-like at the base; the petals rose-lilac or white.

Fruit. - The pods are I to $I^{1}$ inches long, two- to threeseeded, fleshy, or corky with a spongy tissue separating the seeds; the pods are not longitudinally grooved or prominently constricted; they are capped by a long conic beak which may equal or exceed the pod itself.

Seeds and Seedling.- The seeds are small and of a yellowish color; on one side, when viewed with a hand lens, may be seen a small spot, in reality double, made up of the hilum and 
micropyle. Endosperm is absent. The cotyledon leaves are persistent until the root becomes of considerable size and may be seen at the crown of the radish, lying flat against the root. Each cotyledon leaf is oblong in outline and broadly notched at the tip.

\section{Geographical Distribution and Origin.-The common} radish is found growing wild in the temperate regions of the Old World. It was introduced into this country by the earlier settlers and here, as wherever it is planted, has escaped from gardens, becoming in many instances a rather common wayside plant. Radishes that run wild in this manner produce a root that is slender and woody, possibly reverting to the type from which it came. E. A. Carriere held the opinion that our common garden radish has sprung from Raphanus raphanistrum, the wild radish or white charlock, and a common weed throughout Europe, and also adventive in the United States. He bases his opinion on his own experiments which in brief were as follows: The seeds of Raphanus raphanistrum, which has very woody and slender roots, were planted and after five years of care there was developed a type of root which was fleshy, large, and varying in form and color. The roots developed had the flavor of our garden radishes and were edible.. In spite of the experiments of Carriere, many botanists believe that white charlock is not the projenitor of the radish. For example, it is known that the garden radish long ago was a common plant in India, China, and Japan. But Raphames raphanistrum is not found in these countries, and furthermore, the main movement of cultivated plants has not been from Europe to Asia, but from the orient to the occident. The true history of the radish seems to be unknown.

Closely Related Species.-Raphanus raphanistrum, white charlock, mentioned above, may be quite easily mistaken for the common radish, especially 
when the latter has run wild. White charlock, however, has yellowish flowers turning white or purplish, and a siligue which is much more conspicu ously jointed and longitudinally grooved than that of common radish.

Raphanus satious caudalus, the rat-tailed radish, an annual herb native (n) South Asia, has a slender, twisted pod, \& to ro inches long, which thus difier: from the short, thick ones of common radish. These pods form the edilole portion of the plant.

Types of Radishes.-As to seasonal development, there are three groups of radishes, as follows:

r. Early or Forcing Radishes.-A forcing crop is one grown out of season, and out of its natural environment. Hot beds, cold frames and greenhouses are the forcing structures in use. The chief crops forced besides radishes are lettuce. tomatoes, cucumbers, cauliflowers and beans. Early or forcing radishes reach an edible size very soon, often in from twenty to thirty days. In this group, belong such varieties as French Breakfast, Early Scarlet Turnip, Scarlet (ilobe. Long Scarlet Short Top, and White "Icicle."

2. Summer Radishes.-The roots of this group are slower in maturing, requiring from six to eight weeks to reach a marketable size, and are larger than those of the first group. Here belong such varieties as Long White Vienna, Chartier: White Strasburg, Stuttgart.

3. Winter Radishes.--These have a compact and firm flesh and keep well through the winter. The roots require several months to reach maturity, often attaining a large size. Common winter varieties are Black Spanish, Sakurajima or Japanese radish, and White Chinese.

As to shape, radishes may be classiffed as follows (Fig. I43):

I. Round or turnip-shaped (Early Scarlet Turnip, Scarlet Globe, Scarlet Gem).

2. Olive or oval-shaped (intermediates) (French Breakfast, Early Scarlet Olive-shaped, Black Spanish).

3. Half-long (Scarlet Half-long, French, Half-long I)eep Scarlet).

4. Long (Vienna, Chartier, Long Scarlet, White "Icicle"). 
Radishes vary in color: some varieties are white, others pink, red, purple, mottled, or black, or red, tipped with white, etc.

\section{RADICULA (Water Cress and Horse-radish)}

Members of this genus are branching herbs with simple or pinmate lobed, dissected, or rarely, entire leaves. Flowers are
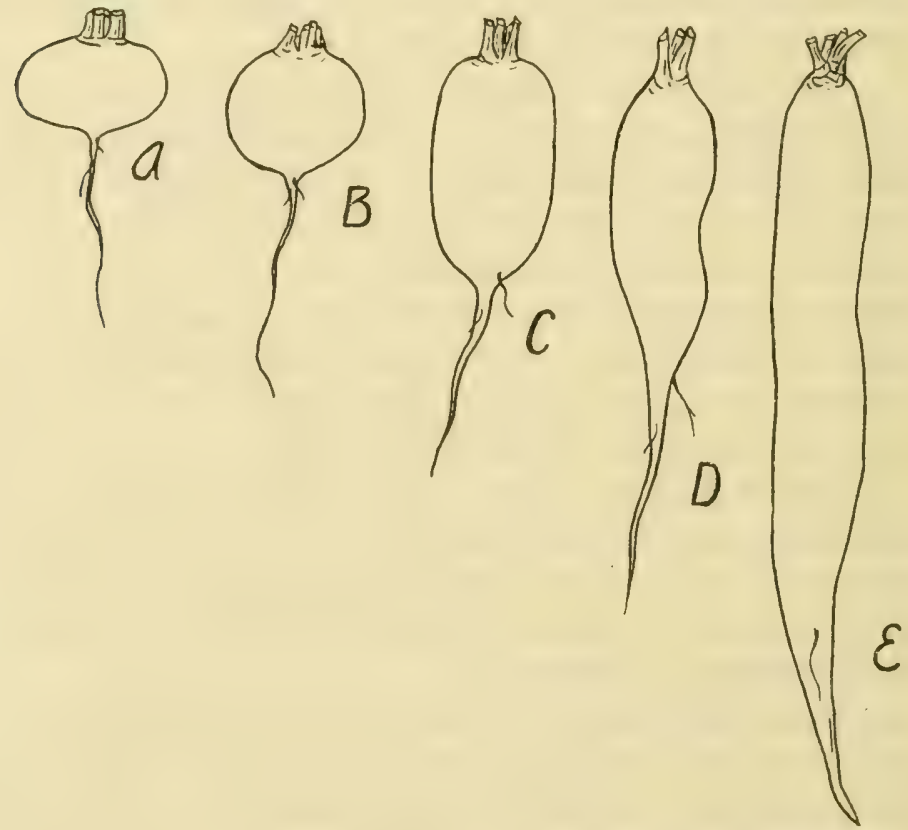

FIG. I43.-Types of radishes (Raphanus sativus). $A$, turnip-shaped; $B$, globular; $C$, olive-shaped; $D$, half-long; $E$, long. (After Corbett.)

in elongated racemes; they have spreading sepals, yellow or white petals, and one to six stamens. The siliques are short or elongated, pencil-shaped, without a stalk or stipe, with onenerved valves; there are numerous turgid seeds in two rows in each cell, or very rarely one row in each cell. 
The genus is one of wide distribution; it is most abundant in the north temperate zone.

There is a rather large number of species, some of which are amphibious, others atpuatic. The two principal economic species are Radicula armoracia (horse-ralish) and Radicula nasturiaum-aqualicum (water cress). The former is terrestrial. the latter aquatic.

\section{RADICULA ARMORACIA (Horse-radish) (Fig. 144)}

Description.-Horse-radish is a hardy perennial from at white, fleshy, cylindrical root which branches at the lower end. The fibrous roots may penetrate to a depth of 6 or 7 feet. In propagating the plint, the slender side roots usually are used; pieces of the main root are also used for this purpose. The plants are 2 to 3 feet tall, branching, with long-petioled. oblong, basal leates, 6 to 2 inches long, that have crenate, sinuate or pinnatifid margins. The upper leaves are smaller, sessile, oblong, or lanceolate. The racemes are terminal or axillary, and bear white flowers. The pods are oblong or nearly globose and bear a short persistent style. In cultivation, the plant seldom produces seed, but is propagated by root cuttings.

Geographical.- Horse-radish is a native of Europe. It is a common home garden plant in the United States, and in some instances hats escaped from cultivation and become a troublesome weed.

Uses.-The root is grated or scraped, sometimes mixed with vinegar, and used as a condiment.

\section{RADICULA NASTURTIUM-AQUATICUM (Water Cress)}

Description. This is a perennial, aquatic plant with long floating or creeping stems which readily take root at the 
nodes. The leaves are compound and odd-pinnate (Fig. I45); the terminal segment is larger than the laterals, all of

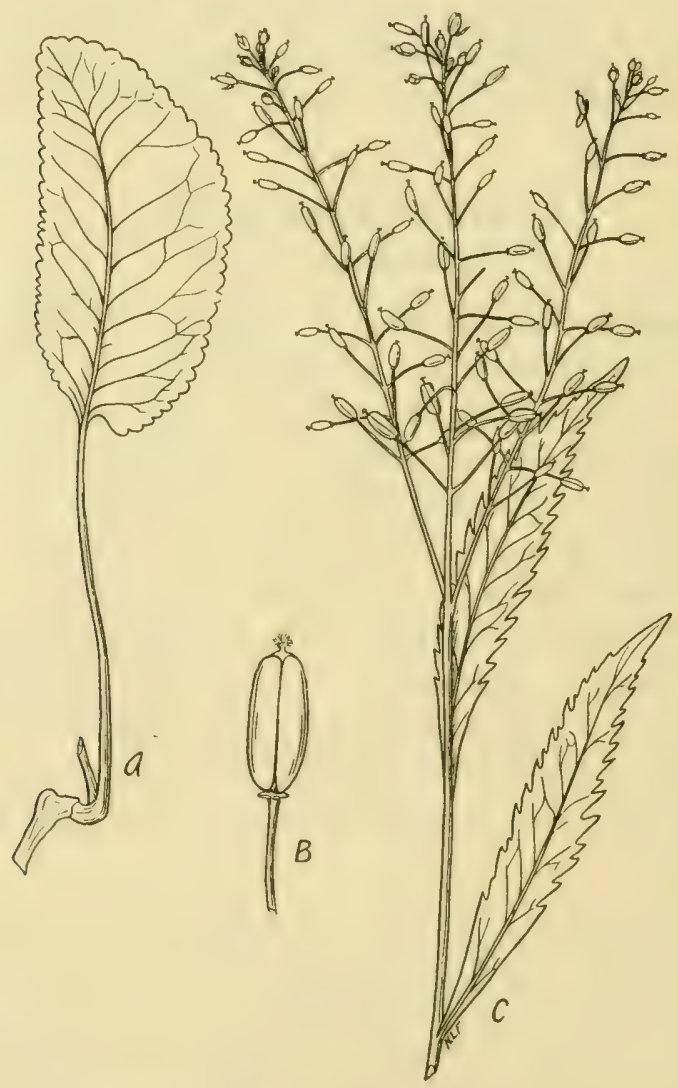

FIG. I44.-Horse-radish (Radicula armoracia). $A$, basal leaf; $B$, fruit; $C$, cauline leaves and inflorescence.

which are slightly wavy on the margin and of a dark green color. The white flowers are in terminal racemes; the petals are twice as long as the sepals. The siliques (Fig. I45) are 
slightly curved, on pedicels of equal length, and bear a few seeds in two rows.

Geographical.-Water cress is a native of Europe and Northern Asia, but has become naturalized in both North and South America. It is widespread in North America.

\section{References}

CArriere, E. A.: Une nouvelle plante fourragere et economique. Journ. d'Agric. Prat. Annee, 33, tome II : $845^{-847}$, I 869 .

Goff, E. S.: Vegetables: Turnip. 6th Ann. Rept. N. Y. Agr. Exp. Sta., I68-190, 1887.

Henslow, G.: The History of the Cabbage Tribe. Jour. Roy. Hort. Soc. (London), 34: 15-23, 1908-1909.

Shaw, T.: The Rape Plant: Its History, Culture, and Uses. U. S. Dept. Agr. Farmers' Bull. II: I-20, I893.

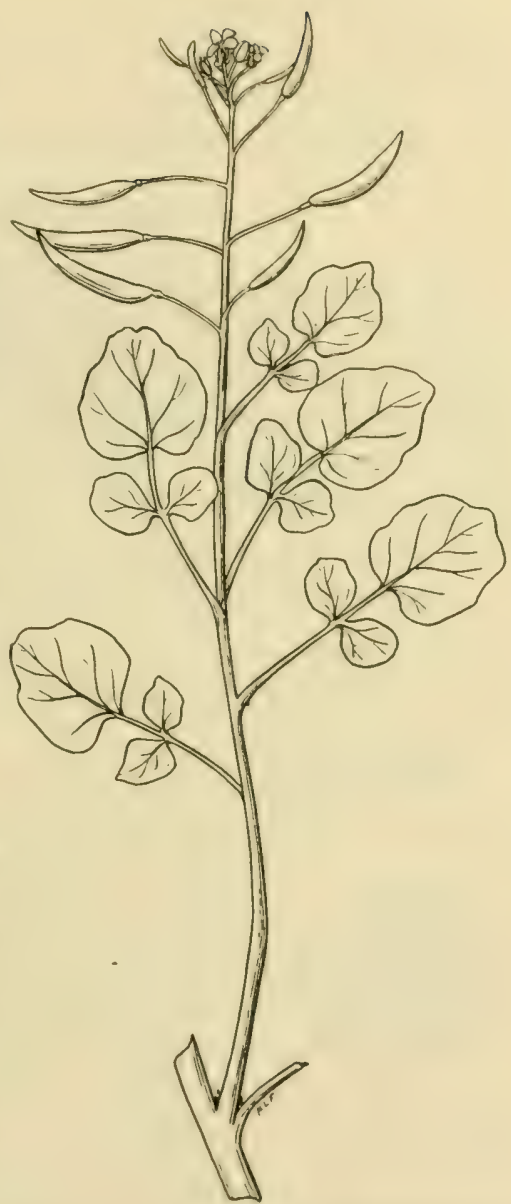

FIG. 145.-Water cress (Radicula nasturtium-aquaticum). 


\section{CHAPTER XXVI

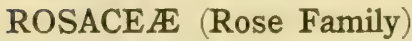

The Rosacex are well represented in North Temperate climates. There are about 1,200 species within 65 genera. The most important genera from the crop standpoint are Rubus (raspberry, blackberry and dewberry), and Fragaria (strawberry). Other genera of importance or of interest are Sfirca, an ornamental shrub, Potentilla (five-finger or cinquefoil), Cercocarpus (mountain mahogany), and Rosa (rose).

Leaves.-The leaves are alternate, either simple (as in some Rubus species), or compound (strawberry, rose). There are two rather prominent stipules, free from or adherent to the petiole.

Inflorescence.- There are several different kinds of flower clusters in the family. It is a terminal corymb (flat-topped

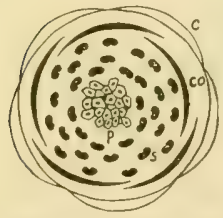

FIG. I 46.--Floral diagram of Rubus. (After Wossidlo.)

raceme) in Opulaster, either racemose, cymose, corymbose or paniculate in Spirca, terminal or axillary and solitary, racemose or paniculate in Rubus, and corymbose or racemose in the strawberry. It is interesting to note the great number of different sorts of inflorescences in this one family, and contrast it with the mustard family, in which the raceme is the one prevailing type, or with the carrot family in which the umbel is, with the exception of one genus, the only type, or with the sunflower family, all members of which have a head inflorescence.

Flowers.--The flowers (Fig. I 46) are regular, and usually perfect. In some cultivated strawberries imperfect flowers 
are bornce. 'The alder is iree from or grown to the ovary, fire-loberl, and sometimes subtended by a set of brates (epicalyx, as in strawberry). The pelals are distinct, ats many as the lobes of the calyx and inserted on the margin of

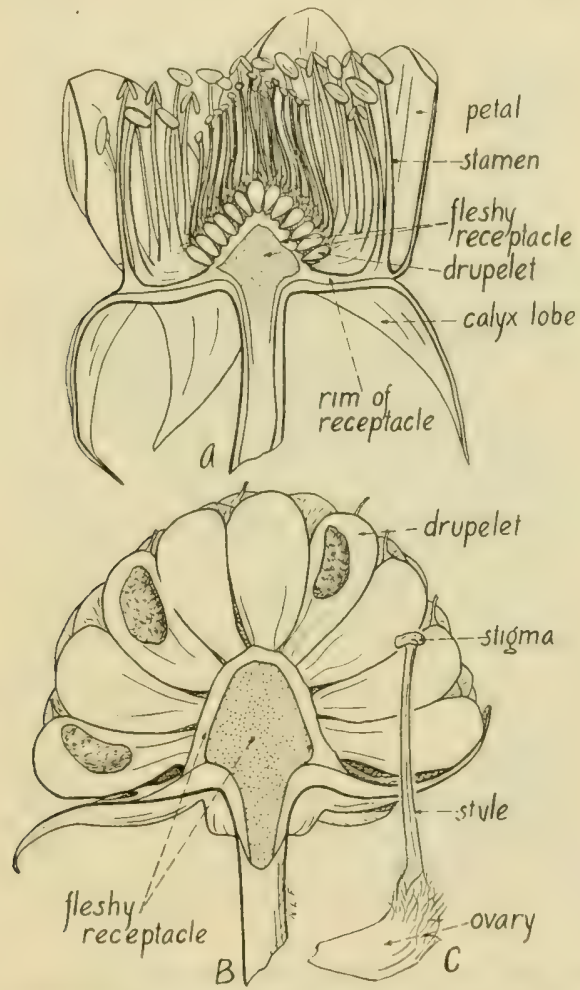

Fig. I 77.-American red raspberry (Rubus st rigosus). A. median lengthwist section of flower, $\times 4 ; B$, same of fruit, $\times 4 ; C$, single immature pistil, $\times 5$.

the disk (Fig. $1+7$ ). This disk is an outgrowth of the recep)tacle and forms a fiat rim about the calyx bate. In cultivated roses there are numerous petals which have developed from primordia that normally become stamens. 'This bears out the 
belief that stamens are leaves, morphologically. The production of supernumerary petals is known as "doubling." The stamens are numerous, distinct, and attached to the margin of the toral disk (Fig. I47). The anthers are small and two-celled. The carpels are usually numerous and distinct, or rarely attached to the calyx. The ovary is one-celled (rarely imperfectly two-celled) with a terminal or lateral style, and with from one to many ovules.

Fruit.-The fruit is a follicle in Spirca, an aggregate of drupelets in raspberry, blackberry and dewberry, or an aggregate of achenes in strawberry and rose. The follicle is a pod-like fruit, with one carpel, which opens along one side only and usually bears numerous seeds. The true pod, characteristic of the pea family, is a one-carpelled fruit, which splits along two sides. It will be remembered that the capsule has several carpels. A drupelet is a small drupe-a one-seeded fruit with a fleshy mesocarp and stony endocarp.

\section{Key to Important Genera of Rosacem}

Fruit not inclosed in a hollow receptacle, i.e., the calyx not constricted over the fruit.

Carpels becoming follicles, Spiraa.

Carpels become small drupelets crowded on a fleshy receptacle, Rubus (raspberry, blackberry, dewberry).

Carpels becoming dry achenes.

Style becoming long and plumose, Cercocarpus (mountain mahogany).

Style short.

Receptacle fleshy in fruit, Fragaria (strawberry).

Receptacle not fleshy in fruit, Potentilla (five-finger or cinque-foil).

Fruit inclosed in a hollow receptacle, i.e., the calyx constricted over the fruit, Rosa (rose).

\section{RUBUS (Raspberry, Blackberry, Dewberry)}

Stems.-The plants of this genus are usually shrubs, rarely herbs (Rubus Chamamorus, cloudberry, knotberry or 
mountain bramble). 'The'y atre usually designated ats "brambles." The stems are, as a rule, prickly, erect, decumbent, or creeping. The stems ("canes") commonly die after one or two years, new ones being sent up from the roots. The main growth of the stem is made during the first year, in

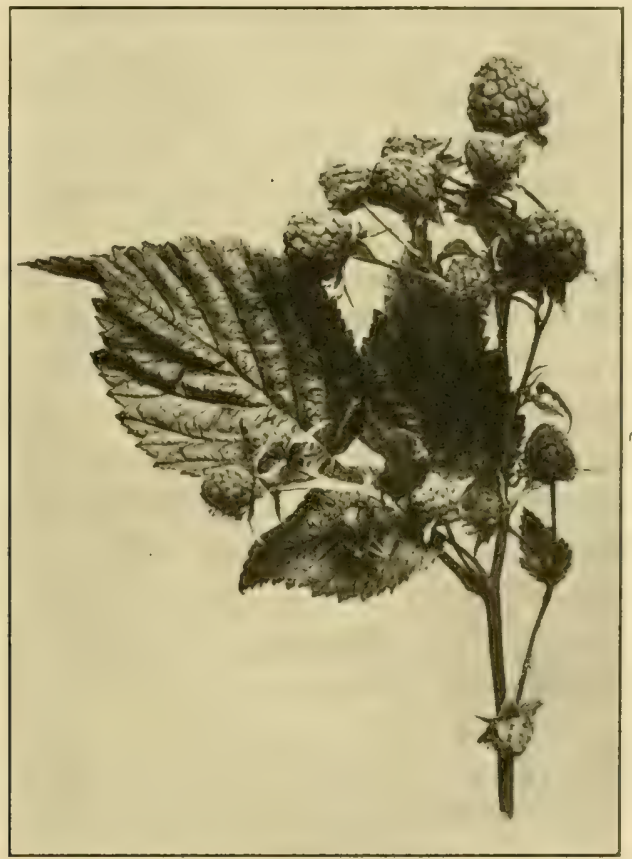

Fig. I 48.-Fruiting branch of American red rasplberry (Rubus strigusus).

most Rubi; side branches are produced the second year; the flowers and fruit are developed on these side branches. The entire cane usually becomes weak and dies after fruiting. This suggests the advisability of removing canes once they have bornę fruit.

Propagation.- Red raspberries, blackberries and dewberries (rarely) "sucker" readily. This natural tendency to 
send up) sprouts from the roots is taken advantage of by the fruit-raiser. All plants which reproduce naturally from suckers are easily propagated from root cuttings. Blackcap raspberries and dewberries produce stolons. A shoot bends over by its own weight and takes root at the tip. When once the tip has rooted well, the shoot may be cut loose from the parent stem and such rooted tips used as "sets."

Leaves.--These are alternate, simple, palmately lobed or compound three- to seven-foliate, and bear persistent stipules. In Rubus trivialis, southern dewberry, the leaves are evergreen.

Inflorescence.- The flowers are terminal or axillary, solitary, in panicles or racemes. The flowers and fruit in all representatives of the genus $R u b u s$ are borne on shoots which arise from the growth of the year before. For example, in I9I3, a shoot (cane) is sent up from the root. This bears leaf buds entirely. In I gI4, these lateral buds elongate, and some of the resulting shoots bear inflorescences. The shoots, developed in I913, once having borne fruit in I9I4, are no longer useful. The cutting out of these useless shoots will induce the development of new ones from the roots.

Flowers.- The flowers (Fig. I47, A) are rather large, regular, and usually perfect. In Rubus aitifolius, the Pacific Coast dewberry, however, there are both hermaphroditic and pistillate plants. Rubus Chamcmorus is diocious. The receptacle is flat or convex. The five-parted calyx is persistent in the fruit. There are five petals, which are usually white, and deciduous. The stamens are numerous, and attached at the base of the disk. The numerous pistils are separate and crowded on the receptacle; each pistil bears a single thread-like style. The styles are hairy and somewhat broadened at the base in the raspberry; while they are narrow and free from hair at the base in the blackberry. 
Pollination. Is a rule, the anthers and stigmats mature simultaneously: There is abundant nectar secreted by a fleshy ring on the margin of the receptacte inside of the stamens. Insects fatcilitate pollination. Better yiclds are secured, in the case of some dewberries, if they are planted adjacent to another variety so that cross-fertilization will result.

Fruit.--The fruit (Iig. $1+7$ ) of the genus is an aggregate. The numerous pistils ripen into drupelets which cling together to a greater or less degree. In the dewberries and blackberries, the drupelets are firmly attached to the receptacle while in raspberries the drupelets readily separate from the receptacle when the fruit is being picked, clinging together in the form of a cup. The exposed surface and the angles between the faces of each drupelet are pubescent in the rasp)berry, and the faces themselves are glabrous. The sticking together of the drupelets is due to the interlocking of thesc crooked hairs. The blackberry and dewberry drupelets are glabrous throughout.

Geographical.-The Rubi are of wide geographic distribution; the greater number of species, however, occurs in North Temperate regions.

Classification. The numerous members of the genus fall into three groups which may be distinguished as follows:

\section{KFy to Groups of GeNus RUBUS}

I rupelets firmly attached to receptacle, not separating form the latter when fruit is being picked.

Stems upright; plant propagating by suckers; lower, outer flowers open first, Blackberries.

Stems trailing; plant propagating by tips; center flowers open first. $D_{1}$ i. berries.

Drupelets readily separating from the receptacle when fruit is being picked, clinging together in form of cup, Raspberrics. 


\section{BLACKBERRIES}

Only those species are considered in the following keys which have yielded us our important fruit-bearing varieties. The key considers the groups of blackberries as given by L. H. Bailey in "The Evolution of Our Native Fruits."

\section{Key to Species of BLACKBERries}

Inflorescences conspicuously loose, the few flowers scattered on long pedicels, Rubus nigrobuccus $\times R$. villosus (loose-cluster blackberries or blackberry-dewberry).

Inflorescences more compact, the flowers not so scattered along the main axis.

Inflorescences leafy, i.e., pedicels subtended by leaves, Rubus argutus (leafy-cluster blackberries).

Inflorescences entirely or almost leafless.

Clusters long.

Berries black, R. nigrobaccus (common long-cluster or high-bush blackberry).

Berries cream-colored or pink, R. nigrobaccus var. albinus (white blackberry).

Clusters short.

Lower surfaces of leaves white-pubescent; plants I to 3 feet tall, very thorny, R. cuneifolius (sand blackberry).

Lower surfaces of leaves pubescent but not whitish; plants I to 8 feet tall, thorny, $R$. nigrobaccus var. sativus (short-cluster blackberries).

Rubus nigrobaccus.- The tall stems are furnished with strong, hooked prickles. The long-stalked leaves have ovate and distinctly pointed leaflets. Inflorescences are long, glandular-hairy racemes with large, showy flowers on pedicels that stand out almost at right angles. The fruit is firm, oblong, sweet, and aromatic.

The plant is found throughout eastern United States and northward into Canada. The variety Taylor is the best known. Snyder and Kittatinny are common varieties of the short-cluster blackberries. The white blackberry has grcenish-yrellow stems and cream-white fruits, and occasionally grows wild.

Rubus nigrobaccus $\times$ R. villosus. - The loose-cluster blackberries are considered to be hybrids between the high-bush or long-cluster blackberry and the northern dewberry. The plants are rather low and spreading and have characteristic, broad, jagged leaflets. 
The fruits are small and grobular or grobulat whlong, and gres: in = math clusters. Wilson and Rathbun are typical varieties.

Rubus argutus. - The plants are crect, stiff, prickly, and with stems strongly angled, almost grooved. The small leaflets are firm and rather rigid, and coarsely toothed. Inflorescences are short and leafy. The iruit is small, globular, and black. The species is found growing wild from New England to Florida and Arkansas. Common varieties are Dorchester, barly IIarvel, and Brunton Early.

Rubus cuneifolius.-The sand blackberry is a stiff, thorny plant aloout 3 feet tall. The leaflets are thick, obovate, and white-pubescent beneath. Inflorescences are short and bear but a few (two to eight) flowers. The fruit is of medium size, sweet, and desirable. This species grows wild from south. ern New York and Pennsylvania to Florida, Louisiana and Missuturi. Topty is the common cultivated variety; it often does not have the pubescence of the species.

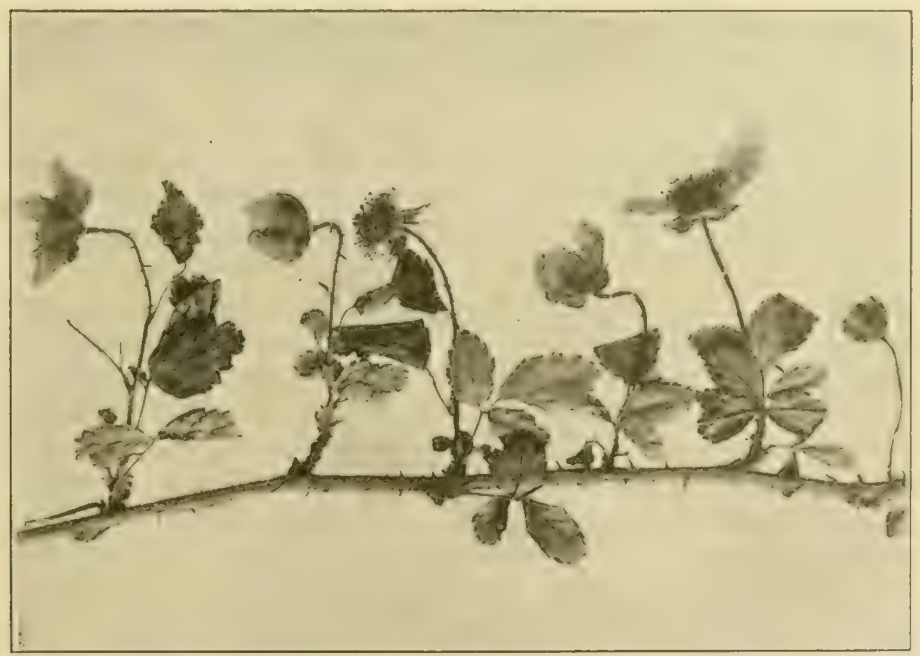

FIG. I 49.-Northern dewberry (Rubus villosus).

\section{DEWBERRIES}

These differ from blackberries - in their trailing habit, cymose inflorescences, and propagation by tips. They have received the name "trailing blackberry." There are 
four principal groups of dewberries, which are distinguished in the following key:

\section{Key to Principal Species of Dewberies}

Leaves evergreen, $R$. trivialis (southern dewberry).

Leaves deciduous.

Buds tipped by the united ends of the sepals, forming a spine; flower clusters forking into two or three parts, $R$. invisus (northern dewberry). Buds not tipped by the united ends of the sepals to form a spine.

Both hermaphrodite and pistillate plants; leaflets coarsely toothed, $R$. vitifolius (western dewberry).

Plants all perfect; leaflets finely toothed, $R$. villosus (northern dewberry).

Rubus trivialis.-These are trailing shrubs, with stout, hooked prickles and bristles on the stems, and with upright branches 3 to 9 inches tall. The leaves are trifoliate, petioled, and with oval, leathery, serrate, evergreen leaflets. The inflorescences are one- to five-flowered. The flowers are large, white, and have petals that are much longer than the sepals. The fruit is black, and up to $r$ inch long. The species occurs from Virginia to Florida and westward to Texas and Missouri. The best-known horticultural variety is Manatee.

Rubus invisus.-The stems are moderately prickly. The leaflets are large and coarsely and simply dentate. The erect peduncles are elongated. The large flowers are on long pedicels; flower buds are tipped by the united ends of the sepals. The species is reported by Bailey as growing wild from New York to Alabama and east to Kansas and Missouri. The chicf varieties are Bartel and Mammoth.

Rubus vitifolius.--This species occurs in California, Oregon, Washington and Idaho. Skagit Chief is the principal form in cultivation.

Rubus villosus.-The plants are robust, with smooth stems and large, thick leaves, which have three to seven oval or ovate, long-pointed and sharply double-toothed leaflets. The inflorescences are one to three-flowered, leafy, and cymose. The fruit is globular, and has a few, shining-black, and swect drupelets. This is the common dewberry of the Northern States; it is found growing wild from Newfoundland to Virgina and westward to Minnesota and Kansas. Windom, Geer and Lucretia's Sister are varieties. The Lucretia dewherry (auricly roribacsus) is a more robust form with large wedge-obovate, jagged leaflets, and large flowers on long pedicels. 


\section{RASPBERRIES}

There are four well-known groups of cultivated rasp)berries: black-cap, purple-cane, American red, and European red.

\section{Kry to Principal Species of Raspibreries}

Fruit purple-black, rarely yellow; propagating by tips, $R$. acridinalis (black-cap).

Fruit purple, dark red, light red, or sometimes yellow; propagating by tips or suckers.

Stems stiff and erect; fruit produced more or less continuously throughout the season, $R$. idøus (European red).

Stems more slender and drooping; fruit produced less continuously through out the season.

Stems bristly, not glaucous; fruit light red; inflorescence racemose, $R$. strigosus (American red).

Stems prickly, slightly glaucous; fruit dark red; inflorescence racemessecymose, $R$. strigosus $\times R$. occidentalis (purple-cane).

Rubus occidentalis:- The slender stems are often ro to i 2 feet long, rooting at the tip, sparingly supplied with small hooked prickles, and sometimes glandular-bristly above. The leaves are trifoliate, stipulate, with oval or acuminate, toothed leaflets, that are white-hairy on the under side. The inflor escences are dense, and corymbose. The flowers are on short pedicels; the petals are shorter than the sepals. The black-cap raspberries are the most important in this country. The species is found throughout eastern United States, northward into Quebec and Ontario, and westward to Oregon and British Columbia.

Some of the western forms have been given distinct specific names i $R$. lencodermis, $R$. glaucifoline, $R$. bernardinus.

Rubus idæus.-The stems are stiff and erect, and furnished with prickles; glandular bristles are never present except in some cultivated forms which may be considered as hybrids between $R$. ideus and $R$. strigosus; pubercence occurs on peduncles, pedicels, petioles are nearly always llattened and slightly curved. The thick leaves are white-downy beneath. The fruit is purple of yellow and is produced throughout the season. The European raspherry is not cultivated to any extent in this country at the present time. It is a mative of Europe and Asia.

Rubus strigosus. - The stems are slender and hear stiff, stratight or henkent prickles; glandular bristles oceur on perlundes, pedicels. petioles, and calyx. The leaves are three- to five-foliate, with owate or oblong oxate. sharply serrate 
or lobed leatlets, which are whitish-pubescent beneath. The inflorescences are terminal or axillary, and racemose; the flowers are white. The fruit is light red, rarely yellow, and is not produced continuously throughout the season. Rubus strigosus is the native, common red raspberry. It is distributed from North Carolina to New Mexico, northward in the Rocky Mountains to NIanitoba and British Columbia and eastward to Newfoundland and Labrador. Cuthbert is one of the principal varieties.

Rubus strigosus $\times \mathbf{R}$. occidentalis (R. neglectus). - The stems are long and often rooting at the tip, glaucous, prickly, and bristly. The inflorescence is racemose-cymose and has short, erect or ascending peduncles. The fruit varies in color from purple-black to bright purple, and sometimes yellow. Shaffer and Columbian are the chief varieties.

The Loganberry. - This is a rather notorious fruit that has resulted from crossing a blackberry and a raspberry. It is supposed that the blackberry was the variety Aughinbaugh and the raspberry, Red Antwerp. Aughinbaugh is a pistillate variety of $R$. vilifolius. Evidence ${ }^{1}$ has recently been presented tending to show that the loganberry has behaved as a true species, and is not a hybrid. The loganberries are large, often $x$ to $I^{1} 4$ inches long, and of a rich, dark red color, but unfortunately not of very superior flavor.

Mayberry.-This is supposed to be a cross between a Japanese species, Rubus microphyllus and Cuthbert, a variety of Rubus strigosus.

\section{FRAGARIA (Strawberry)}

Roots and Stems.- Strawberries are low, perennial plants with very short, thick stems set close to the surface of the ground. Such very short-stemmed plants are usually termed "acaulescent." The branches that arise from the axils of the closely set leaves are called "rumners." Runners are slender stems, growing along the ground surface; they have long internodes, and produce leaves and flowers and roots at the nodes. Runners are used as a means of propagating the plant. They are attached to the old plant for but one season. In the Virginian group of strawberries, the runners start to form as early as new lcaves are produced and may attain a considerable length before the fruit is mature. In the Chilean group, the runners are usually formed after

${ }^{1}$ Journal of Heredity, 7: 504-507, $19 \mathrm{x} 6$. 
the fruit is matured. Runners may branch. New branches: from the main perennial stem appear, of course, above the old ones, hence there is a tendency for the short stem to become more and more exposed above the ground surface. Roots do not extend over a depth of 2 feet in the soil, and horizontally, scarcely beyond the area covered by the leaves. Practically all roots are within the first foot of soil.

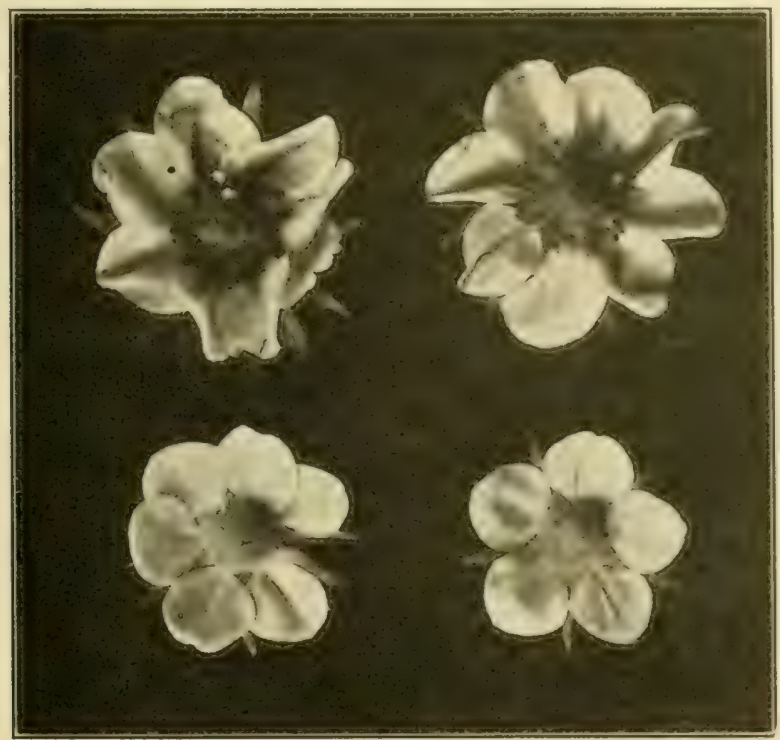

FIG. I50.-Flowers of strawherry (Fragaria chiloensis). Above, two perfect flowers; below two pistillate flowers.

Leaves.-The leaves are alternate and arise in a tuft; the: petioles are usually much longer than the leaf blitles. which are divided into three leaflets (trifoliate); sheathing, membranous, adnate stipules which increase in size ats the leaf grows, occur at the base of the petiole.

Inflorescence and Flowers.- The white flowers are in small racemes or corymbs on long, erect, leafless scapes 
which spring from the crown of the plant. The flowers are usually perfect; however, there are some varieties (Bisel, Princess, Warfield, etc.) which have only pistillate flowers (Fig. I50); there are no commercial varieties that have only staminate flowers. In planting varieties with pistillate flowers only; it is necessary to have rows near-by planted to pollen-bearing individuals. Some perfect-flowered varieties

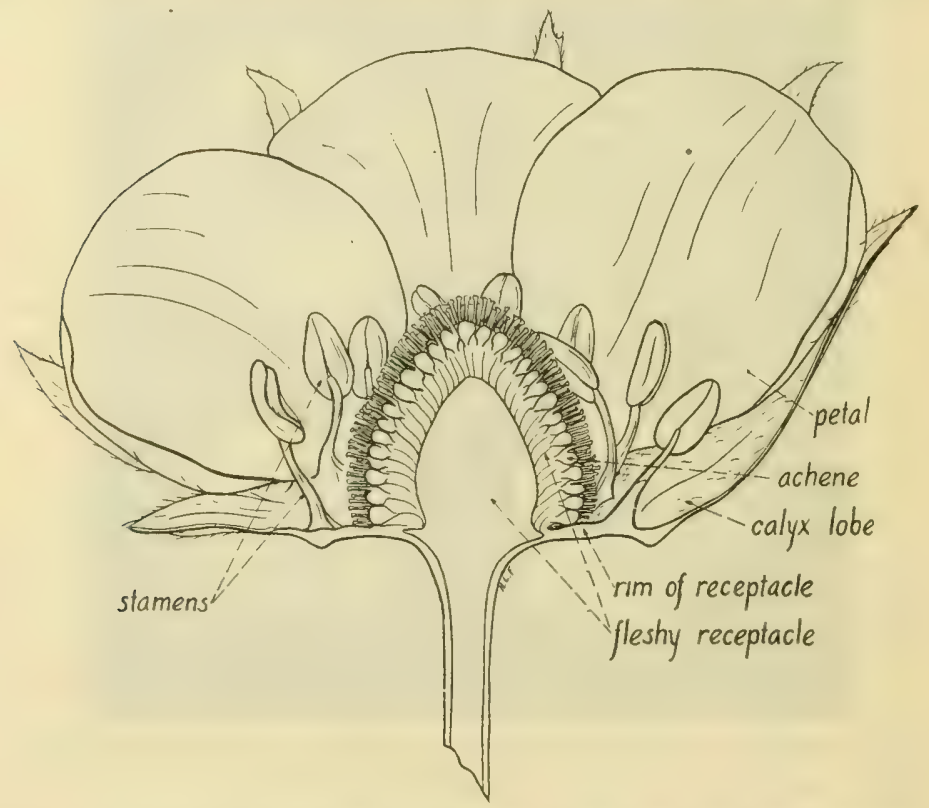

FIG, I5 1. - Strawberry (Fragaria chiloensis). Median lengthwise section of flower. $\times 4$.

(Glen Mary and Crescent) bear very few stamens, and hence are practically self-sterile. The receptacle is convex or conical (Fig. I5I). The calyx is five-parted, with five bracteoles (epicalyx) below, that are persistent in the fruit. There are five obovate, short-clawed petals, attached to the rim of 
the receptacle. There are numerous stamens, als a rule. sometimes a few or none; they are attached to the rim of the receptacle, persistent in the fruit, and possess slender filitments and small anthers. P'istils are numerous on the smooth, convex, or conical receptacle which becomes modified in the fruit (Iig. 152, 1). Each carpel bears a style laterally placed (Fig. 152, B), and a single orule.

Fertilization, and Development of the Fruit.- Strawherries are protogynous, that is, the pistils of a flower mature before its stamens. Hence cross-fertilization is secured; and this usually by insects. Non-fertilization or incomplete fertilization is usually indicated by berries with hard, greenish. undeveloped apices, so-called "nubbins." The true fruits of a strawberry are the achenes (so-called "seeds") scattered over the fleshy receptacle. Unless the ovules are fertilized, the receptacle does not mature properly. This behavior is the rule in most plants. When a sperm nucleus of the pollen tube unites with the egg nucleus of the orule, resulting in fertilization, there is set into action a train of changes which not only involve the orule itself, but which extend to the ovary wall, and, as in the strawberry, to the receptacle. Undoubtedly, the stimuli are chemical in nature, but just what they are and how they act is not known.

The Mature Fruit.- The strawberry "fruit" (popularly speaking) is an aggregate of true fruits. The fleshy part of the "fruit" is receptacle, while the true fruits (botanically speaking are achence partially imberded in the surface of the receptacle. In a lengthwise section (Fig. I 52, A) of the ripened fruit. the receptacle is seen to be composed of a fleshy pith and cortex with hibro-vasculatr bundles hetween them. It is in reality stem structure. These bumelles send ofi side branches inte the cortex, and some of them extend to the achenes. The persistent calyx and epicalyx, and 
withered stamens are at the base of the fruit. These constitute the "hull" of the fruit. The achenes are attached to the receptacle a short distance above their base and the styles arise from the ventral side, a little above the point of

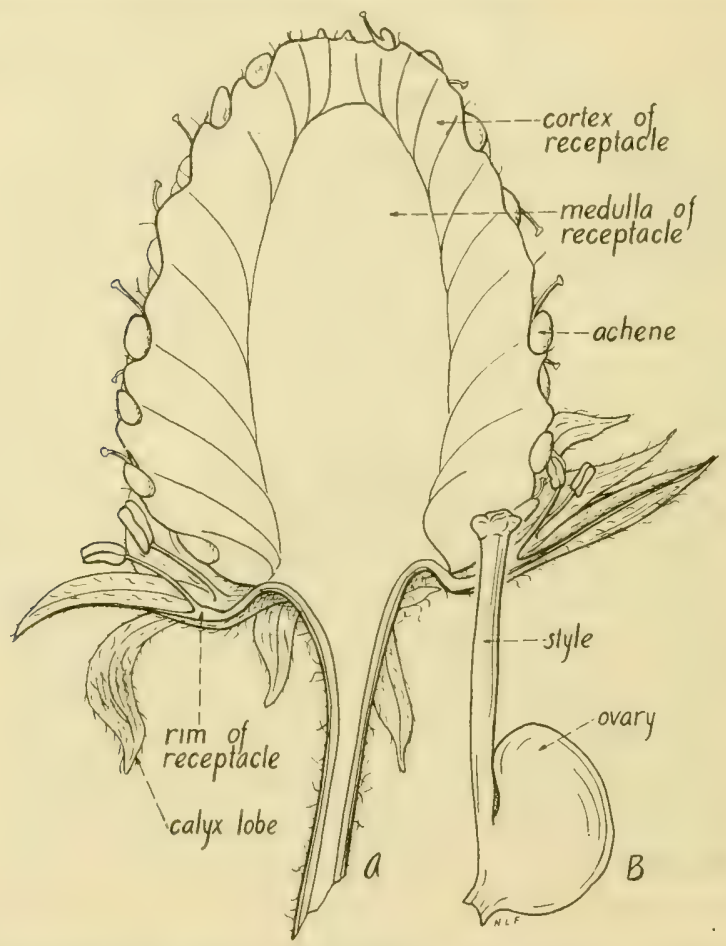

FIG. I 52.- Strawberry (Fragaria chiloenisis). A, "fruit" in median lengthwise section, $\times 215 ; B$, single achene, $\times 20$.

attachment of fruit to receptacle. The achenes are commonly termed "seeds."

Geographical.-The genus Fragariat possesses about eighteen species most of which are natives of the north temperate zone; a number are found in the Andes of South America. Strawberries are cultivated in all parts of the United States. 
Principal Fruit-bearing Species.-The erolution of the strawberry has been given to us by Bailey. Most of our cultivated varieties of strawberries belong to the species Fragaria chiloensis. This plant is a native of western Chile, from which country it was brought to Europe at the beginning of the eighteenth century. The Chilean strawberry is also a native of the western coast region of North America, as well as of South America. However, some botanists would refer the forms as found in this continent to the species Fragaria californica and $F$. glanica.

The early settlers in the Eastern States cultivated the common wild strawberry (Fragaria sirginiana) which they found growing in their fields. But few cultivated varicties belong to it. Varieties of the wild strawberry of Europe (Fragaria resca) have also been cultivated in America, but only to a slight extent. These varieties are the Everbearing or Perpetual strawberries.

Hence, the varieties of strawberries in America fall into three groups, as follows:

I. Chilean group from Fragaria chiloensis.

2. Scarlet or Virginian group from Fragaria írginiana.

3. Perpetual or European group from Fragaria iesca.

These three species may be distinguished by the following key:

\section{Key to Principal Spectes of Fragaria}

Leaves usually projecting above the flowers and fruit; achenes sunken in the flesh.

Runncrs appearing after the fruit; berry dark; calyx large; leaves shining above, bluish-white beneath, $F$. chiloensis (Chilean strawberry).

Runners appearing with the fruit; berry scarlet; calyx medium; leaves light green on both surfaces, $F$, wirginiand (scarlet or Virginian strawberry). Leaves usually not projecting above the flowers and fruit; achenes not sunken in the flesh, $F$. zesca (perpetual or European strawherry).

Fragaria virginiana (Tirginia or Scarlet Stmotbery).-.'This is a stout, darli 
wreen, tufted herb with soft-hairy leaves. The petioles are from 2 to 6 inches long, the leaflets oval or obovate, obtuse, dentate, the lateral not symmetrical at the base. The scape is usually shorter than the leaves, at least not exceeding them, hence the fruits are borne below the leaves. The calyx lobes are erect at maturity. The fruit is red, ovoid, and with achenes imbedded in the flesh.

The species extends from New Brunswick to South 1)akota, south to Florida, Louisiana and Arizona.

Fragaria vesca (European II nod or Everlasting Strancherry).--This is a stout, dark green, tufted plant with hairy leaves. The leaflets are ovate or broadly oval, obtuse, dentate, the lateral not symmetrical at the base. The scape is longer than the leaves, hence the fruits are borne above the leaves. The calyx lobes are spreading or reflexed. The fruit is red, hemispheric or conic, with achenes not imbedded in the flesh.

This strawherry is a native of Europe, but naturalized in the Eastern and Middle States. It has given us our Perpetual and Ever bearing varieties.

Fragaria chiloensis (Chilean Struaberry).-The Chilean strawberry is a low form with thick leaves, shining above and bluish-white beneath; the runners appear after the fruit is gone. The fruit is large, firm, dark, with a large "hull," and with achenes sunken in the flesh.

It is a native of the western coasts of South America and North America. Most of the common varieties of strawberries belong to the Chilean species.

Varieties.-- The number of varieties of strawberries is great . They are commonly divided into three groups as to time of maturing: first, carly (Warfield, Excelsior, Bederwood); second, medium (Ridgeway, Dunlap, Marshall, Jucunda); and third, late (Aroma, Gandy, Chesapeake, Splendid). Growers distinguish between commercial varieties and those for home consumption. A good commercial variety should be hardy, very productive, of good color. firm, and of good size and form. Among good commercial varieties, may be mentioned Bederwood, Excelsior, Jucunda, Dunlap, Captian Jack, Splendid, and Parson's Beauty. Such varieties as Warfield, Ridgeway, Marshall, Aroma, and Chesapeake are grown for home use.

Origin of New Varieties.- Strawberries seldom come true to seed; hence it is possible to secure new varieties by plant- 


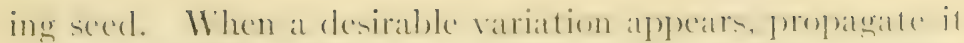
and keep) it "true" by meatms of rumers. This methent of regetative propatgation insures permanency in the chatrateres of the variety selected.

Uses. Strawberries are used chiefly in the fresh state. There is an increasing demand for such strawberry proclucts as crushed fruit, preserves, marmalades, and jellies. Itarege (quantities are put up) fresh for use at soldat fountains and in the manufacture of ice cream.

\section{References}

Bailey, L. H.: Survival of the Unlike. Essay 25, Strawberrics, The MacMillan Co., I896.

Blanchard, W. H.: Rubus of Eastern N. A. Bull. Torrey Bot. Club, 38 : $425-439$, I9r.

Bunyard, E. A.: The History and Development of the Strawberry. Jour. Hort. Soc., 39: 54I-552, I9I4.

Corbett, L. C.: Strawberries. U. S. Dept. Agr. Farmers' Bull. I98: I-2.4, 1904. 


\section{CHAPTER XXVII \\ POMACE $Æ$ (Apple Family)}

Habit, Leaves.-Members of the apple family are either trees or shrubs. The alternate simple or compound leaves are petioled, and have small deciduous stipules.

Inflorescence.-The inflorescences are racemose (Amelanchier, service-berry), cymose (Malus, apple, Sorbus, mountain ash) or simple (Cotoncaster, evergreen or fire thorn).

Flowers:- The flowers (Fig. I57) are regular, perfect, and usually with a concave or cup-shaped receptacle or torus to which is attached a five-lobed or five-toothed calyx, five separate petals, numerous distinct stamens and a one- to fivecelled ovary. The ovary is ordinarily five-celled, and the carpels are wholly or partly united. The carpels vary in texture from parchment-like (Malus, etc.) to bony (Cratcegus and Cotoneaster). The number of styles varies in the different genera: generally three in Sorbus, two to five in Malus (usually five), mostly five in Pyrus (pear), two to five in Amelanchicr, one to five in Cratagus (thorn apples), two to five in Cotoneaster. They may be distinct, as in Sorbus, or partly united as in Malus. The ovules are commonly two (Malus) in each cell, sometimes one (Amelanchier), or rarely several (Cydonia, quince).

Fruit.-The fruit is a pome. Representatives of the family are commonly spoken of as "pomaceous." The pome is a false or spurious fruit in which the receptacle or torus becomes fleshy, to form the greater portion of the fruit, and encloses five bony, leathery or papery carpels (Fig. I 58 ). 
Geographical.- The family is of wide geographical distribution, there being close to 225 species within about 20 generat. Most of the species occur in north temperate or boreal regions.

\section{Key to Important Genera of Poiracex}

Ripe carpels bony, Cralcegus (thorn-apple, haw, hawthorn).

Ripe carpels papery or leathery.

Leaves compound, Sorbus (mountain ash).

Leaves simple.

Ovules one in each cavity, Amelanchier (service-berry, June-berry).

Ovules (usually) two in each cavity.

Flesh of the pome with grit-cells, Pyrus (pear).

Flesh of the pome without grit-cells, IT ulus (apples and crab-apples). Ovules many in each carpel, Cydonia (quince).

\section{MALUS (Apples)}

Stems.-Malus species are either trees or shrubs. In the apple, all rapid-growing shoots develop only leaf buds. Flower buds, which in the apple are "mixed" buds, are almost always borne on the ends of "spurs" or short twigs. When a "spur" terminates in a flower bud, lateral buds lower down continue the growth of the shoot, hence the crooked appearance of such spurs (Fig. I53). These lateral buds may grow for a year or so, bearing leaf buds at the terminus, and then be stopped in their growth in that direction by the formation of a terminal flower bud. As a rule, a shoot that has once started to bear flowers continues to do so, making but a very short growth of wood each year. Such a shoot is marked by the closely crowded leaf scars, terminal-bud scars, and flower and fruit scars. The position of a fruit is usually. marked by a large circular scar surrounded by a number of smaller ones of the same shape. The smaller ones represent scars made by flowers or fruit that failed to develop. It has been recorded generally, particularly for Eastern orchards, that the fruit buds in apples are always terminal, and further- 
more that the fruit spur must be two or more years old before it will bear fruit. Padklock and Whipple ("Fruit Growing in

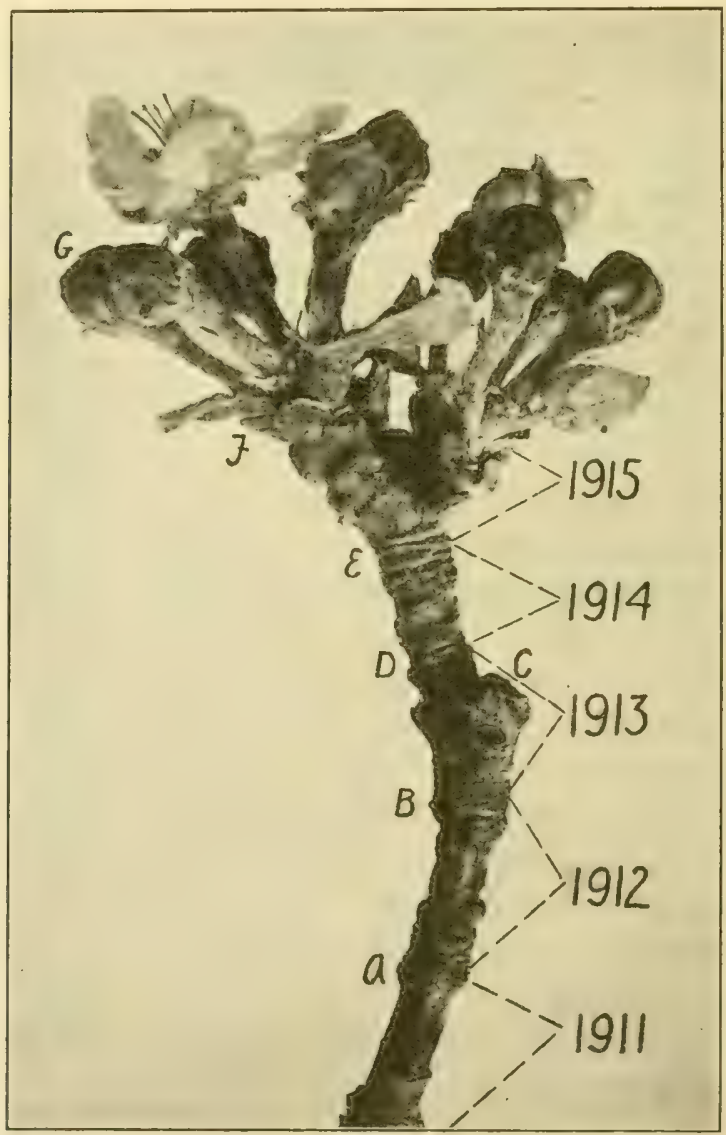

Fig. I53.- Spur of Yellow Transparent apple.

Arid Regions") have noted that in certain districts of Colorado many varieties produce flower buds in the axils of leaves on the growth of the current scason and that one-year-old spurs 
may in many instances bear fruit ( Figr. 15.5), w that fruit maty be borne at the end of last year's teminal growths, not spurs. Hyslop, Mann, Missouri P'ippin, Strawherry, Striped, Transcendent and Winesap are among those varieties producing fruit in the axils of leaves. Astrachan, Ben Davis, Grimes, Hyslop, Jonathan, McIntosh, Missouri P'ippin, Newton, Northern Spy are a few varieties found to be bearing fruit on one-year-old spurs. A few varieties such as Grimes, Hyslop, Transcendent, Willow Twig, and Yellow Transparent produce fruit on the end of last year's terminal growths, not spurs.

Gourley has observed axillary fruit buds throughout the Eastern States on both old and young trees, and in many varieties. Different forms of fruit branches occur; furthermore the same variety, or even tree, may bear more than one sort of fruit branch. Frequently, it has been noted that spurs bear annually, instead of biennially, as is the rule. In such a case, fruit buds are developing on a spur at the same time that an apple is maturing.

It is not always an easy matter to distinguish between the fruit and leaf buds of apple. Generally, fruit buds are rather thick and rounded, while leaf buds are smaller and more pointed.

It has been shown that fruit buds are differentiated very early, and may be distinguished

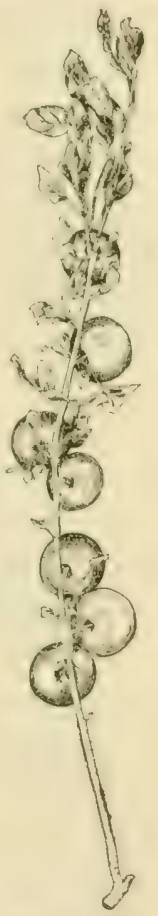

Fisi. I 54 . Mature Jonathan apples from axillary flower buds. (After Paddock and Whipple.) by microscopic study, from leaf buds, as early as the last week in June of the year preceding the opening of the flower. The above has been reported by Drinkard, and Kraus hats observed that in the Yellow Newton apple, under Oregon 
conditions, the fruit and leaf buds are differentiated in early July, and in early varieties, even by the latter part of May.

The form of the tree, nature of twigs, branches, bark and leaves vary a great deal in the many varieties of apples.

Leaves.-These are simple, alternate, and toothed or lobed; the stipules are free from the petiole.

Inflorescence.- It will be recalled that the buds containing flowers are mixed buds. Hence, when each opens there is developed a very short axis bearing closely crowded leaves and flowers. On this axis, the flowers are apical, the leaves basal. The flowers may be so crowded that the cyme is umbel-like in appearance. In most cases, the inflorescence is terminal, but, as has been indicated above, it is axillary in some varieties. The number of flowers in a single mixed bud may vary from two or three to eight or ten. As a rule, but one flower matures its fruit, thus illustrating the struggle for existence among the different individual flowers.

The determinate inflorescence, cyme, of apple is not always definitely so. It will be remembered that in the cyme type of inflorescence the flowers open in order from the inside outward. Sometimes the central flower is tardy in its development, and often the central and some of the laterals may open simultaneously.

Flowers and Their Development.-The development of the apple flower (Yellow Newton) has been worked out by Kraus. A longitudinal section (Fig. I 55) of a growing axis shows a number of bracts and bud scales surrounding it; on the sides of the axis, appear the primordia of flower buds and leaves. The primordia of sepals are the first to appear. The torus develops especially toward the outer edge by a growth of the cells beneath the developing calyx, and finally takes on a concave shape. The torus continues to uprise during the development of petals and stamens, both of which 
are seen to arise from the concave sides of the torus. Following the appearance of sepal primordia, appear petal primordia, then those of stamens, and lastly those of the carpels. The succession of floral cycles is acropetal, i.c., in orcler from without to the inside.
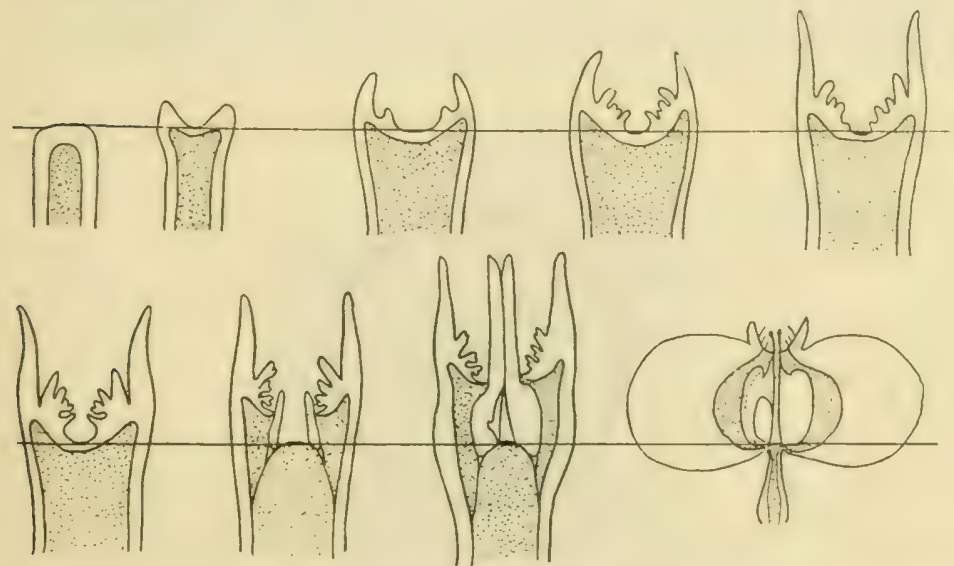

Fic. I 55.-Diagram showing the development of apple. Dutted area represents pith. Not drawn to scale. (After Kraus, Oregon Agr. Exp. Sta.)

The primordia of stamens appear in three cycles, those of the outer usually being laid down first (Fig. I 56). The carpel primordia appear within the central portion of the cup-shaped torus. There are five of these surrounding a small central cavity, which is formed by a lack of growth at the center of the torus. Hence there is no common placenta, but each carpel has its two separate placentas, which in "open-cored" pomes may become closely connected. These facts will be considered again in the account of fruit development.

It is thus shown by the studies of Kraus that calyx lobes, petals, stamens, and carpels are all outgrowths of the urnshaped receptacle. 
Pollination and Fertilization.-The literature on this subject is extensive. Cross-pollination is the rule and self-pollination the exception in the apple and pear. Experiments have shown that the wind aids but little in crosspollination, and that insects, chiefly the honey bee, are relatively more important. The bee is attracted to the flowers by the nectar which is produced rather abundantly.

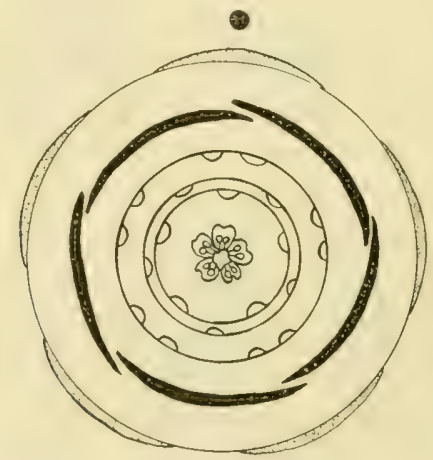

FIG. I 56.-Floral diagram of apple (Malus sylvestris). Note that the stamens are in three distinct whorls. (Afler Kraus.)

Self-sterility and Self-fertility.-Many apples and pears are self-sterile, that is, will not fertilize their own pistils. In such cases, pollen from another variety will usually result in fertilization. Self-sterility and self-fertility probably vary with different climatic conditions. In Oregon, Lewis and Vincent found that the Spitzenburg is self-sterile but capable of being fertilized with pollen from a number of other varieties, such as Yellow Newton, Arkansas Black, Jonathan, and Baldwin. Evidently, the mutual affinities of apple varieties must be considered in setting out an orchard. It would not be well to plant solid blocks of Spitzenburg, for example. It should be alternated with rows of some one of 
the other varieties the pollen of which is capalble of fertilizing it. It is no doubt true that the failure of many varieties $(0)$ set fruit is due, in part, to self-sterility.

Effects of Strange Pollen.-The secondary effects of foreign pollen on the mature fruit have received considerable attention. It is claimed by many that the pollen from one vatriety when placed on the stigma of another, immediately

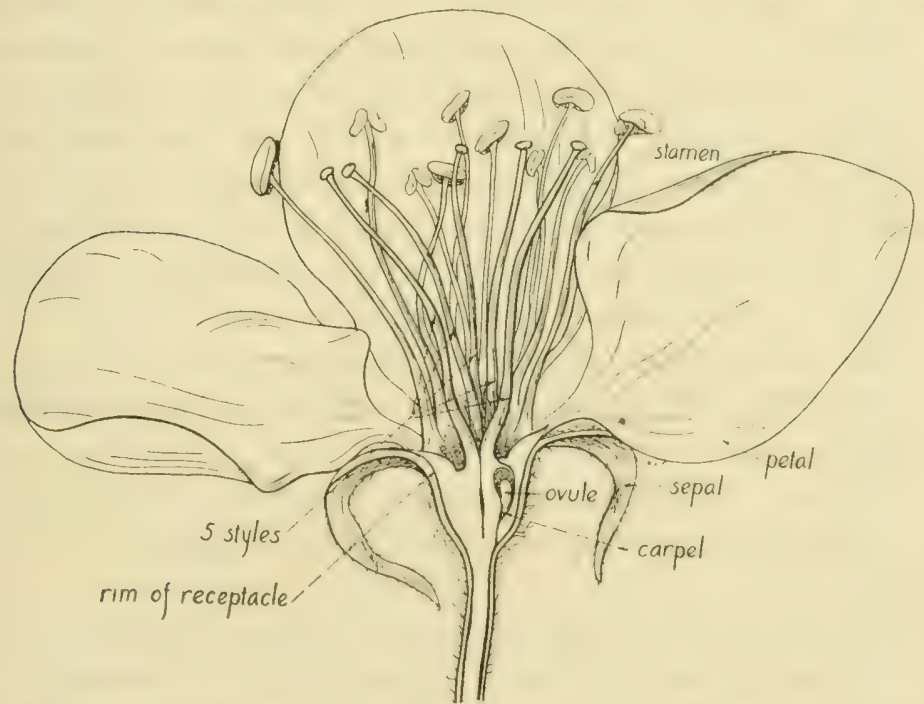

FIG. I57.-Apple (Malus sylvestris). Median longitudinal section of flower.

impresses its characteristics upon the fruit. It is difficult to understand how foreign pollen could have any considerable effect of this kind. The flesh of the apple is receptacle for the most part. The sperm nuclei of the pollen, of course, do not come in to contact with the nuclei of the receptacle cells. It is altogether possible, howerer, that uniformity of crop, percentage of set, and size of fruit are immediately affected by strange pollen. 
Parthenocarpy.-As a general rule, lack of fertilization of the ovules in the ovary is followed by the shedding of the blossoms; the ovary fails to develop completely if a good number of its ovules are not fertilized. However, development of the ovary does sometimes occur although fertilization fails. Such an unusual development of carpels is called parthcnocarpy. This phenomenon is not unknown in the apple. With certain sorts of both apples and pears, fruits weighing Ioo grams have been developed without fertilization. Of course, parthenocarpic fruit is seedless. There are among cultivated plants many which bear seedless fruit. We noted that in the common Mission figs the fruit matures normally without fertilization of the ovules. Seedless tomatoes, egg plants, English forcing cucumbers, oranges, grapes, and bananas are quite common.

The Fruit and Its Development.-Morphology.-There are two common opinions as to the nature of pomaceous fruits:

I. Flesh is thickened calyx tube.

2. Flesh is receptacle or torus closely connected with the carpels.

The recent work of Kraus appears to establish the latter. In following through the development of the flower (Fig. I 55), it is seen that the receptacle, by more rapid growth at the sides than toward the center, becomes urn-shaped and bears on the rim and inside face, calyx lobes, petals, and stamens. In the development of the fruit, there is a continuation of the enlargement of the receptacle; the throat of the receptacle becomes narrow, and through it the styles protrude; and the connection between receptacle and carpel tissues becomes a very close one; hence receptacle makes up the greater portion of the flesh of the apple.

Ripening Process.-Important chemical changes take place 
in the ripening process. The content of sucrose (canc sugar) increases steadily in the ripening process up to a maximum and then suddenly decreases. 'There is a rapid decrease of starch throughout the entire period. Invert sugar (a mixture of glucose and fructose) increases throughout the ripening period while the total sugar increases up to the date when starch entircly disappears, after which time it fluctuates slightly. Malic acid, which gives the fruit its sourness. gradually becomes less and less. Ripening takes place in two stages. The first stage involves that portion of the fruit within the core line (Fig. I 58). Here there is at lirst a decrease in the starch content just between the locules, at the tips of the carpels. This loss extends outward from these points to the core line. The second stage of the ripening process involves the region outside the core lime. At first, streaks free of starch appear in the midst of this area. Soon the middle portion of the area becomes free of starch. 'There is a gradual increase of this starch-free area, the last regions to ripen being $V$-shaped areas radiating from the vascular bundles as seen in cross-section. Furthermore, anatomical changes take place in ripening. The middle lamella of the cells soften, resulting in a slight separation of the cclls, an increase in the regularity of the cell outline, in the size of intercellular spaces, and amount of intercellular air.

"Mealiness." - This results from a softening of the midclle lamellæ; those varieties that are comparatively very mealy have correspondingly weak lamellax. When a coll divides into two, the common primary wall between them becomes the middle lamella of the thicker wall formed by the depesition of material from both protoplasts. Hence in the mature cell wall, the primary or first-formed wall appears as a definite layer between the added layers. Separation of two adjacent cells naturally takes place along this midrlle line. 


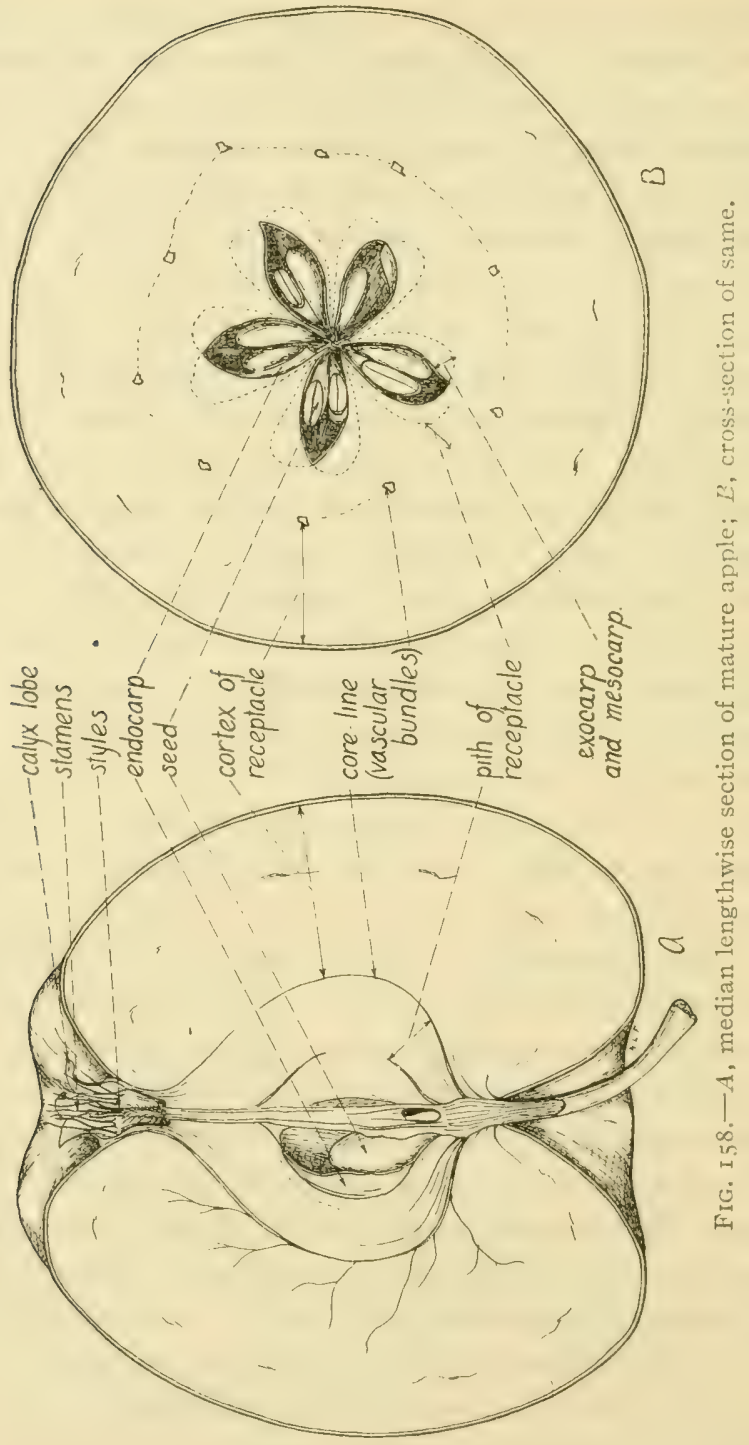


Cross-section of Fruil.- In a median crosisection of the apple fruit ( Fig. 158 ), the relation of carpels and receptacle is well marle out. 'The live carpels radiate from the center. Each carpel is composed of a parchment-like endocarp, fleshy mesocarp) and fleshy exocarp). The pith of the receptacle, which is in reality stem. surrounds and unites with the carpels; the pith is without vascular bundles. As a rule, there are ten primary vascular bundles seen in the median cross-section. They mark the limits of the pith, all tissue outside of them being cortex of the receptacle.

The tissues of the carpels and pith are very similar. Howcrer, the tissue of the carpels bears a network of very fine vascular bundles, while that of pith is without such a network. Many observers have wongly considered all tissue from parchment-like tissue, surrounding the seed carities, out to vascular ring, inclusive, as carpellary, whereas others have considered only the parchment-like tissue as carpellary.

The ten primary vascular bundles are related in their development with the carpels, as is shown by the fact that when six carpels occur there are twelre bundles instead of ten, and when there are four carpels, eight bundles.

Longindinal Section of Fruit.-In longitudinal section (Fig. 158$)$, the flesh is seen to be separated into two parts by a distinct line, the "core line." The core line marks the junction of pith and cortex of the receptacle. The primary vascular bundles of the torus follow the core line, and branches from them spread out into the cortex of the fruit. Kraus has demonstrated that apple varieties show marked variation in their internal structure, and that this structure is distinctive for any given variety.

Ealemal characteristics.- These are very important in technical descriptions of the atpple. Form is of consielerable conseguence. Inyjudging form, the apple is helel so as to 
be seen in a line at right angles to an axis from stem end to calyx end. Form terminology includes such terms as round, ol)late, conical, ovate, oblong, elliptical, etc. The flower stem persists in the fruit. The depression about the stem is termed the cavity. It varies in shape and depth in the different varieties. At the opposite end from the cavity is the basin. This also varies in character and is of taxonomic value in the classification of fruits. The remains of the calyx are persistent within the basin of the common apple. In the pure Siberian Crabs, the calyx is deciduous, while in hybrid forms of Siberian Crabs and in the common apple it is partly deciduous. The dried stamens and styles may be seen within the calyx lobes.

The stamens may be basal, situated near the base of the calyx tube; median, near the middle; or marginal, near the outer edge. The calyx tube itself varies in shape from conical to funnel-shaped. The calyx segments, five in number, vary in their arrangement in the mature fruit. They may be divergent, that is, reflexed, erect convergent, when their margins touch. flat convergent, when they are flat and close the tube, and connivent, when they are overlapping. In a median transverse section, the "cells" in different varieties vary in shape and relation to the axis of the apple. They may be "open" or "closed," axile or abaxile. When the walls extend to the axis, the cells are axile, and when they are distant from the axis, and unsymmetrical, they are abaxile. When the core line meets inside the calyx tube, the core is said to be meeting; if near the calyx tube, it is clasping. The core outline varies in shape. There are usually two seeds in each cell cavity; however, there may be more than two or fewer or sometimes none at all. They vary in size and color. 


\section{Key to l'Rinctpat Species of MTtuts}

Calyx deciduous from the apex of fruit.

Leaves conduplicate in the bud (Fig. sor); petioles thick, usually abrut , inch long; flowers rose-colored, Mulus floribunda (fowering crat)).

Leaves convolute in the burl (Figr. IOI); petiole's slender, usually about 2 to 3 inches long; flowers white or very light rose-colored, Malus baccala (Siberian crab).

Calyx persistent on the fruit.

Leaves glabrous, at least when mature.

Leaves prominently lobed, thin, Malus coronaria (American crabapple).

Leaves toothed, but not lobed, thick, Malus anguslifolia (narrowleaved crab-apple).

Leaves persistently pubescent or tomentose beneath.

Leaves narrowed at base; pomes small, I to $1 \frac{1}{2}$ inches in diameter.

Pedicels slender, I to $\mathrm{I} \frac{1}{2}$ inches long, Walus iocnsis (Western cral)apple).

Pedicels stout, $\frac{1}{2}$ to I inch long, Malus soulardii (Soulard crabapple).

Leaves rounded or subcordate at base; pomes large, 2 to 4 inches in diameter Malus sylvestris (common apple).

Malus floribunda, Flowcring Crab.-This is a shrub or small tree, often thorny. The leaves are conduplicate in the bud, the flowers abundant, showy, and rose-red, the fruit red, about the size of a pea, and on slender stalks. It is highly ornamental, and flowers in carly spring. It is a native of Japan.

M. baccata, Sibcrian Crab.-This crab is a small, spreading tree with leaves that are convolute in the bud, abundant flowers, usually white and showy, and fruit that is $\frac{1}{2}$ to $3 / 4$ inch in diameter, yellow or red, firm and translucent. The species occurs in many forms. The orchard fruits known as " cral". apples," are believed to be hybrids between this and the common apple, $M$. sylvestris. The Siberian crab grows wild from Siberia to Manchuria and the Himalaya region.

M. angustifolia, Narrou-leaed (rab-apple.-It is a low tree with small. narrow, lanceolate leaves, few-flowered cymes, fragrant pink flowers, and fruit about $I$ inch in diameter. It is distributed from Pennsylvania to Tennessee and Florida.

M. coronaria, American Crab-apple.-This is a small, bushy tree with thorny, crooked branches, ovate or triangular-orate, sometimes three-lobed, leaves, large flowers, with a persistent calyx, and fruit that is 1 to $I \frac{1}{2}$ inches in diameter, somewhat flattened endwise, greenish-ycllow; waxy, fragrant, and 


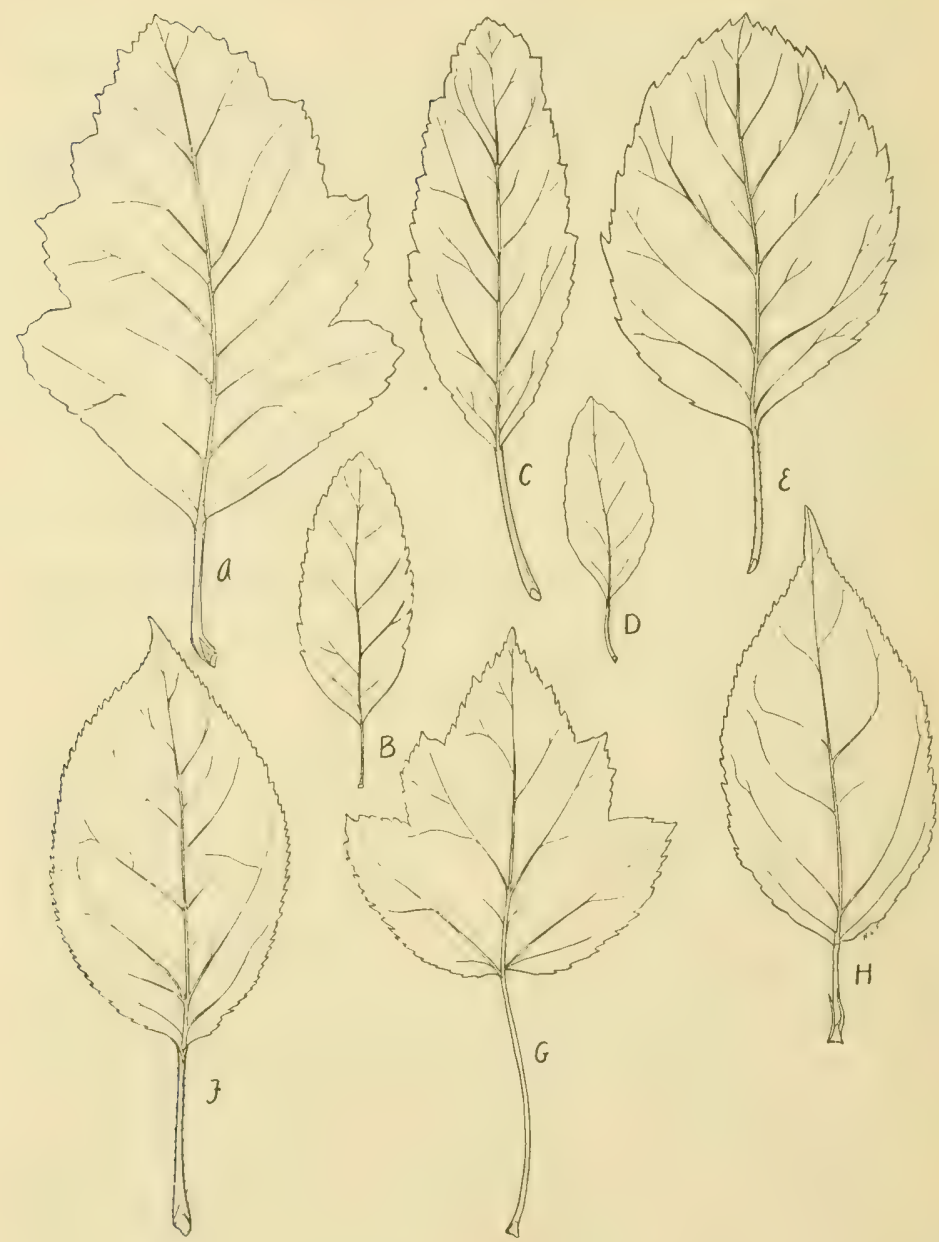

FIG, I 59,-Leaves of Malus species. $A$ and $B$, western crab (M. ioensis); $C$, flowering crab (M. floribunda); $D$, narrow-leaf crab (M. angustifolia); $E$, Soulard crab (M. soulardi); $F$, common apple (Wealthy) (M. sylvestris); $G$, American crab (M. coronaria); $H$, Siberian crab (M. baccata). $\times 1 / 2$. 
rich in malic acid. It grows wild in Ontario and North Atlantic States, west to Kansas and Missouri.

M. ioensis, Western or Prairie States Crab-apple. It is a small tree with large leaves, firm in texture and of various shapes, large flowers, and wren fruit with light-colored spots. It is native of Minnesotat, IViseonsin, Illi nois, Iowa, Missouri, and Kansas.

Bechtel's Double-tlowering Crab is probably a double-thwered form of Malus ioensis.

M. soulardii, Soulard Crab.--This is a natural hybrid between the common apple (1/. sylastris) and the Western crab-apple (1/. iunsis). It is a small, stout tree, with leares similar to those of $M$. ioensis, in close chusters on short, densely woolly pedicels; the fruit is larger and of better flator than that of $\mathrm{K}$. iansis. It grows wild in the Mississippi Valley.

M. sylvestris, Common Apple.-The common apple is a large tree with twigs and under surface of leaves gray-woolly; the flowers are in close clusters, and on short pedicels; the fruit is very variable. There are numerous varieties differing as to form, size, color, and taste of fruit. In order to keep) the vitrieties true to type, propagation is vegetative rather than sexual.

The common apple is considered to be a native of western . Isia and southeastern Europe. In eastern Lnited States, it occasionally escapes from cultivation. It is grown commercially in all parts of the United States except in Florida, the regions bordering the (iulf of Mexico, and warmer portions of the Southwest. The leading apple-growing section of this country is from Nova Scotia south and west to Illinois and Missouri.

The Classification of Apples (Malus syliestris).- There have been a number of systems of classifying cultivated varieties of apples. A brief sketch of the most important of these is given in the American Horticultural Manual Part II, Systematic Pomology. The principal classifications mentioned in the above work are those of Johann Jonston, (iermany i668, Manger, Germany i780, Dr. Diel, Germany I792, Diel-Cochnahl, Germany i 855. Diel-Lucas. Germany 1856 , John A. Warder, America 1867 , John J. Thomats. America I 849 , Robert Hogg, England i 876 .

The system of Dr. Diel of Germany, wats the first to be widely adopted in toto or with modifications. He divided the varieties into seren classes, and these into orders. These classes are as follows: Ribbed apples, Rose apples, Ram- 
bours, Reinettes, Stripelings, Pointlings, and Flat apples. Beach gives the following groups of varieties: Fall Pippin, Rhode Island Greening, Winesap, Fameuse, Alexander or Aport, Wealthy, Duchess of Oldenburg, Northern Spy, Blue Pearmain, and Ralls-Genet.

Composition.-According to the determinations of $\mathrm{Al}$ wood and Davidson, the average amount of juice recovered from summer apples by grinding and pressing is 53.2 per cent.; from winter fruit 53.92 per cent. Crab-apples show an average juice content of $57.3 \mathrm{I}$ per cent. The average water content of the whole apple varies from 80 to 86 per cent. of its total weight. It is not possible, of course, to remove all the juice from apples by ordinary pressing, and furthermore, the amount of juice recovered depends upon the grinding and pressing methods. The above workers chemically analyzed the juice and pomace of many varieties. The percentage composition of the juice is shown in the following table:

\begin{tabular}{l|l|l|ll|l|l|l|l}
\hline & $\begin{array}{l}\text { Specific } \\
\text { gravity }\end{array}$ & $\begin{array}{l}\text { Total } \\
\text { solids }\end{array}$ & $\begin{array}{l}\text { Total } \\
\text { sugar }\end{array}$ & $\begin{array}{c}\text { Invert } \\
\text { sugar }\end{array}$ & $\begin{array}{l}\text { Cane } \\
\text { sugar }\end{array}$ & $\begin{array}{c}\text { Acidsas } \\
\mathrm{H}_{2} \mathrm{SO}\end{array}$ & Tannin \\
\hline & & & & & & & \\
\hline
\end{tabular}

For vinegar-making, a high sugar content is desirable. A commion notion is that acid or "tartar" apples are better for vinegar-making than those low in acid. The amount of acetic acid in a vinegar, which is the important test of its quality, is dependent upon the amount of sugar in the juice (cider) and not upon the acid. The sour taste of apples is due to the malic acid present. So-called "sweet apples" do not neces- 
sarily contain more sugar than "sour apples," but they do contain less acid, hence their "sweetness."

Cider and Vinegar.- Cider is the juice or wine of apples. In the transformation of cider to vinegar, two fermentation processes take place, in the following order: (I) alcoholic fermentation, and (2) acetic acid fermentation. When cider "begins to work," it is an indication that the first fermentation process is going on. The sugar of the apple juice is being converted into alcohol and carbon dioxide. The escaping of this gas from the fermenting cirler causes a "frothing." The process of alcoholic fermentation is produced by a microscopic organism, the yeast plant. When the evolution of carbon dioxide gas has ceased and the alcohol is at its maximum, the cider is spoken of as hard cider. The second step in vinegar-making is the conversion of the alcohol of the hard cider into acetic acid. This change is brought about by a bacterium, the acetic acid germ. The characteristic properties of vinegar are due to acetic acid.

Dried Apples.-The output of dried apples in the United States in I 909 was $44,000,000$ pounds. Many housewives dry their apples in the sun. When apples are dried on a large scale, they are peeled, cored, and sometimes sliced by machinery. The fruit is then dipped for a few minutes in a weak salt solution, which tends to prevent discoloration. It is then placed in trays and taken to the drying machine. It is the practice in some manufacturing plants to subject the apples, before drying, to sulphur fumes for a short time. These fumes bleach the apples slightly, and also kill any organisms that may be present. The most common drying method is to pass hot air under high pressure over the fruit. After removal from the drying machine, the apples are allowed to sweat for several day's either in the open air or in well-ventilated chambers. They are then ready for packing. 
Production of Apples in the United States.- In 19 I 5 there were produced $230.010,000$ bushels of apples in this country, at an average farm price per bushel of 74.6 cents. The ten leading States in the order of their production were New York, Missouri, Ohio, Pennsylyania. Illinois, Virginia, Kentucky, Indiana, Iowa and Michigan.

\section{PYRUS (Pear)}

The characters of this genus are very similar to those of Malus. The pears are trees or shrubs with simple leaves, and large flowers in terminal cymes, resembling those of the

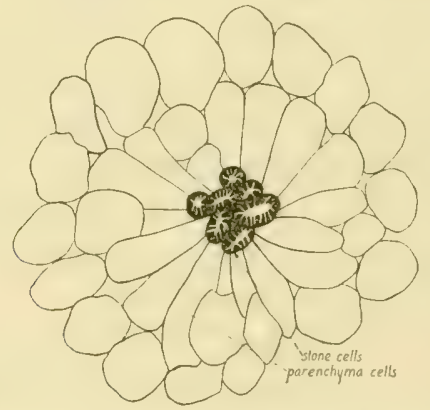

FIG. I60.-A group of stone cells and surrounding parenchyma cells from the flesh of pear (Pyrus communis). Highly magnified.

apple; the styles are usually free to the base. The fruit is a pome, varying in shape, with five carpels, two seeds in each cavity, and an abundance of grit cells in the flesh (Fig. 160).

The two most common species of Pyrus are Pyrus communis, the common pear, and Pyrus serolina culta, sand, Japanese, or Chinese pear.

In the common pear, the teeth on the leares are obtuse, the flowers appear with the leaves, and the calyx is persistent, while in the Japanese or Chinese pear, the teeth on the leaves are sharp-pointed or bristle-like, the flowers appear before the leaves, and the calyx is deciduous. 


\section{PYRUS COMMUNIS (Common Pear)}

Stem.- The common pear is a tree of upright-growing habit. The flower buds are mixed and terminal, as in most apples. Paddock and Whipple have shown that, in Colorado at least, the Anjou pear may produce blossom buds on oneyear-old spurs; that Bartletts may form bloom on the end of the last year's growth; that Anjou, Bartlett, Duchess, and Kieffer varieties produce bloom in axillary buds on the last year's growth, and that a number of varieties, as Anjou, Bartlett. Duchess and Sheldon, are annual bearers. There are usually from six to nine flowers in a bud. The "spurs" are similar in appearance and development to those of the apple.

Leaves and Flowers.-The leaves are ovate, elliptic, and finely toothed. The flowers are in simple terminal cymes; the pedicels are 2 to 3 inches long, and appear with the leaves; the petals are five in number, rounded, short-clawed, and usually white; the sepuls are persistent; the styles are distinct to the base.

Fruit.-The fruit varies in shape, usually tapering to the base; the flesh is with grit cells (Fig. I60) (groups of stone cells imbedded in parenchyma).

Geographical.-The common pear is probably a native of southern Europe and Asia. In many localities, it has escaped from cultivation. There are numerous cultivated rarieties. The pear thrives best in the northern half of the United States.

\section{PYRUS SEROTINA CULTA (Sand, Japanese, or Chinese Pear)}

This is a strong-growing tree with broad-ovate, longpointed leaves that are very sharply toothed. The large flowers appear before the leaves. The fruit is hard and russet-like, keeps well, and has a deciduous calyx.

The tree is a native of China. Chinese Sand, Madame von 
Siebold, Mrikado, and Japanese Sand are a few of the varieties grown in the United States. It is also often used to hybridize with our common pear, the Kieffer variety being the best-known one resulting from such a cross.

- Self-sterility in Pears.--The work of Fletcher has pointed out the reasons for the barrenness of many pear orchards. Nuch of this is due to self-sterility, that is, the inability of the pollen of a variety to fertilize the ovules in the pistils of that variety. It has been frequently observed in many portions of the country that when a certain variety of pear, as well as other fruits, was planted thickly, there was often pronounced self-sterility. This is particularly true, it seems, of Bartlett and Kieffer pears. Fletcher obtained the following average results, under Virginia conditions, in self-fertilizing Bartlett, and in crossing with a number of varieties (in the table, the last mentioned variety of a cross furnished the pollen):

\begin{tabular}{|c|c|c|}
\hline Pollinations & $\begin{array}{c}\text { Av. number of } \\
\text { blossoms set }\end{array}$ & $\begin{array}{l}\text { Av. weight of } \\
\text { mature fruit, } \\
\text { ounces }\end{array}$ \\
\hline Bartlett $\times$ Bartlett....... & $I$ in 513 & 2.00 \\
\hline Bartlett $\times$ Kieffer. . . . & $I$ in 10 & 3.00 \\
\hline Bartlett $\times$ Anjou ........ & $I$ in 7 & $3 \cdot 75$ \\
\hline Bartlett $\times$ Lawrence ..... . & $x$ in & $3 \cdot 50$ \\
\hline Bartlett $\times$ Duchess ...... & $I$ in $I 0$ & $3 \cdot 50$ \\
\hline
\end{tabular}

The following table shows similar relations in the case of Kieffer pears:

Pollinations

Kieffer $\times$ Kieffer

Kieffer $\times$ Bartlett.

Kieffer $\times$ Le Conte

Kieffer $\times$ Lawrence

Kieffer $\times$ Duchess

Kieffer $\times$ Anjou. .

Kieffer $\times$ Clairgeau

Kieffer $\times$ (iarber.
Av. number of
blossoms set

I in 253

I in 5

$x$ in 7

$I$ in 6

$I$ in 5

I in 4

$I$ in 3

I in 7 
From these experiments, Fletcher recommends imbler Virginia conditions, at least) that Anjou, Lawrence, I uchess and Kieffer are desirable varieties to plant with Bartlett. and that Bartlett, Le Conte, Garber, Latwence, Duchers. Anjou, and Clairgeau are desirable varieties to plant with the Kieffer.

It is not probable that the same degree of self-sterility. for a given variety will prevail under different climatic and soil conditions. Furthermore, it must be held in mind that no immediate effect of strange pollen need be expected in the resulting fruit.

Dwarf Pears.--The pear is the most common tree grown in a dwarf form in the United States. The usual method of dwarfing pears is to graft them on quince roots, which are very slow-growing.

In a graft, the two plants retain their individuality to a large degree. However, there are numerous instances cited of the influence of the stock upon the scion, or scion upon the stock. ${ }^{1}$ When pears are grafted on the more slowly growing roots of the quince, the stock in this case retards the growth of the pear, and dwarfing results. The common quince used in Angers and the varieties ordinarily dwarfed are Angouleme, Bartlett, Anjou, and Louise Bonne. I) warting appears to improve the quality of the fruit.

${ }^{1}$ If the common apple is grafted on the wild crab, the fruit of the sionn growth is more sour than usual. Late varieties of apple may mature carlier when grafted on early stock. The influence of the scion upon the stock is well shown in the case of grafting the morning glory, an annual, upon the sweet potato, a perennial. In this case, the tuberous roots develop much earlier than usual. I most interesting illustration is the development, in Abutilon, of leaves with white spots (albescent leaves) on a green-leared scinu when grown as a graft upon an albescent stock. 


\section{CYDONIA (Quince)}

The genus has much the same characters as Malus and Pyrus, except that each of the five carpels has several seeds, covered with a mucilaginous pulp, and the large flowers are in small clusters or sometimes single at the tips of branches.

There are several species of Cydonia, the most common being $C$. oblonga (edible quince).

\section{CYDONIA OBLONGA (Common Quince)}

Stem.-The common quince is a small tree seldom over I $_{5}$ feet high, or a shrub, with rather crooked, slender branches. The shoots that come from axillary buds and those that come from terminal buds may give rise to flower-bearing shoots, but it is usually the case that the largest fruit comes on branches arising from axillary buds on the last half of the annual growth. The flowers are not from fruit buds formed in the autumn; after a woody shoot has grown several inches, a flower is produced which terminates the season's growth of that shoot.

Leaves.-The leaves are alternate, with blades 2 to 3 inches long, oval, somewhat heart-shaped or rounded at the base, acute at the apex, green above and soft-hairy beneath, and with petioles about $1 / 2$ inch long.

Flowers.-As a rule, the flowers are solitary; the fetals are white or light pink; the slamens are numerous; there are five carpels with several ovules in each cavity.

Fruit.-The fruit may be apple- or pear-shaped, hard, woolly when young, becoming smooth with age; the flesh is free of grit cells; the skin is yellow at maturity; each of the five cells of the ovary contains several seeds which have a mucilaginous coating.

Varieties.-Bailey gives five varieties of the species, 
C'yonia inlgaris: Lusilunica, mulijormis, pyrijormis marmorata, and pyramidalis.

Uses.- Quinces are not usually caten raw but made into marmalarles, or canned. The juice is sometimes employed to flavor manufactured fruit products.

\section{References}

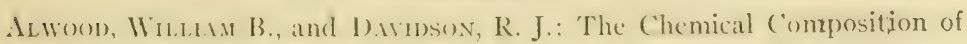
Apples and Cider. U. S. Dept. $\Lambda$ gr. Bur. Chem. Bull. 88: 7-18, I904. Brach, S. A. Bonth, N. ()., and T.uYLor, (). M.: The Apples of New York. 22 d Ann. Rept. N. Y. Agr. Exp. Sta., vol. I: I-409; vol. 2: I-360, I903. Broitow, II. I)., Gore, H. C., and Howard, B. J.: Studies on Apples. U. S. Dept. Agr. Bur. Chem. Bull. 94: I-100, 1905.

Bhack, Caroline 1.: The Nature of the Inflorescence and Fruit of I'yrus malus. Mem. N. Y. Bot. Gardens, 6:519-547, 1916.

13R.IDFord, F. C.: The Pollination of the Pomaceous Fruits. II. Fruit-burl Development of the Apple. Ore. Agr. Exp. Sta. Bull. I29: I-I6, I9I5. Brooks, Cirds: The Fruit Spot of Apples. Bull. Torrey Bot. Club, 35: $+3^{2-}$ 456,1908 (includes notes on structure of fruit).

BUDd, J. L., and II.NSEX, N. E.: Imerican Horticultural Manual. P'art II, Systematic Pomology. John Wiley \& Sons, I9I I.

BtTler, O.: On the Cause of Alternate Bearing in the Apple. Bull. Torrey Bot. Club, 44: 85-95, 1917 .

(intrexdex, F. J.: Pollination in ()rchards. III. Self-fruitfulness and Selfsterility in Apples. Jour. Hort. Soc., 39: 615-628, r914.

Decissin, Joserin: Memoire sur la famille des Pomacees. Nouvelles Archives du Museum, X, pp. II 3 -I92 (Paris), I875.

Le jardin fruitier du museum, un iconographie de touts les especes et varietes d'arbres fruitiers cultives dans cet etablissement. Firmin Didot Freres.

Drivkard, . 1. W.: Fruit-bud Formation and Development. Rept. Vir. Igr. Exp. Sta., I909-1910: 159-205, I9II.

Ewert, K.: Dic Parthenokarpie der Obstbaume. Ber. Deut. Bot. Ciesell., 24: 4I4-4I6, I906.

Die Parthenocarpie der Obstbaume. Ber. Bot. Ges., 26: 4I-4r6, I906.

ILetcher, S. W: Pollination of Bartlett and Kieffer Pears. Reprint from Ann. Rept. Va. Agr. Exp. Sta., 1909:212-232.

Pollination of Bartlett and Kieffer pears. Inn. Rept. Va. Agr. Exp. Sta.. I909 and I910: 213-224, I9II.

(infF, L. S.: The (Origin and Early I)evelopment of the Flowers in the ('herry, Plum, Apple and Pear. 16th Amn. Rept. Wis. Agr. Exp. Sta., 200-303, r800. 
Investigations of Flower Buds. I7th Ann. Rept. Wis. Agr. Exp. Sta., 266285, I900.

Investigation of Flower Buds. I8th Ann. Rept. Wis. Agr. Exp. Sta. 3043I6, I90r.

Origin and Development of the Apple Blossom. Am. Gard., 22: 330 and 346-347, I90I.

Gardner, V. R., Wagness, J. R., and Yeager, A. F.: Pruning Investigations. Oregon Agri. Exp. Sta. Bull. I39: I-88, I9I6.

Gotrley, J. H.: Studies in Fruit Bud Formation. N. H Agr. Exp. Sta., Tech. Bull. 9: I-79, I9I5.

HARdy, J. A., and A. F.: Traité de la taille des arbres fruitiers, ed. I2, I23, Paris.

Hedrick, V. P.: Dwarf Apples. N. Y. Agr. Exp. Sta. Bull. 406: 34I-368, I9I 5 .

Krates, E. J.: The Pollination of the Pomaceous Fruits. I. Gross Morphology of the Apple. Ore: Agr. Exp. Sta. Res. Bull. I, pt. I: I-I 2, I9I3.

The Study of Fruit Buds in Oregon. Ore. Agr. Exp. Sta. Bull. 130: I2-2I, I9I5.

Variation of Internal Structure of Apple Varieties. Ore. Agr. Exp. Sta. Bull. I35: 3-42, I9I6.

Kraus, E. J., and Ralston, G. S.: The Pollination of the Pomaceous Fruits. III. Gross Vascular Anatomy of the Apple. Ore. Agr. Exp. Sta. Bull. I3 8: 4-I2, I9I6.

Lewis, C. I., and Vincent, C. C.: Pollination of the Apple. Ore. Agr. Exp. Sta. Bull. I04: I-40, I909.

McAlpine, D.: The Fibro-vascular System of the Apple and its Function. Proc. Linn. Soc., N. S. Wales, $36: 613-625$, I9Ir.

The Fibro-vascular System of the Quince Fruit Compared with that of the Apple and Pear. Proc. Linn. N. S. Wales, 37:689-697, I9r2.

Paddock, W. and Whipple, O. B.: Fruit Growing in Arid Regions. MacMillan Co., rgro.

Pickett, B. S.: Factors Influencing the Formation of Fruit Buds in Apple

Trees. Trans. Mass. Hort. Soc., pt. I: $57-72$, 1913.

SAndsten, E. P.: Some Conditions Which Influence the Germination and Fertility of Pollen. Wis. Agr. Exp. Sta. Research Bull. 4: I49-I72, Ig09.

Sнuw, J. K.: The Technical Description of Apples. Mass. Agr. Exp. Sta. Bull. I 59: 73-90, I9r4.

Warte, W. B.: The Pollination of Pear Flowers. U. S. Dept. Agr. Div. Veg. Path, and Phys. Bull. 5: I-IIO, 1894 .

West, G. H.: The Pollination of Apples and Pears. Trans. Kans. State Hort. Soc., 32: 38-50, 1912. 


\section{CHAPTER XXVIII \\ DRUPACE E (Plum Family)}

Habit, Stems.- Representatives of the plum family are trees or shrubs. The bark exudes a gum, and the leaves, bark, and seeds are bitter, and contain prussic acid. Many cases of poisoning have been recorded from eating the seeds of peach and bitter almond, and it is also known that stock is poisoned from eating the leaves of wild cherries. The glucoside, amygdalin, acted on by emulsin, an enzyme, in the presence of water is changed to prussic acid, grape sugar, and benzaldehyde. Prussic acid is deadly poisonous even in small amounts.

Leaves.-The leaves are alternate, petioled and commonly finely toothed. The teeth and petiole are often glandular (Fig. I6r); the stipules are early deciduous.

Flowers.-The perfect, regular flowers (Fig. I62) are
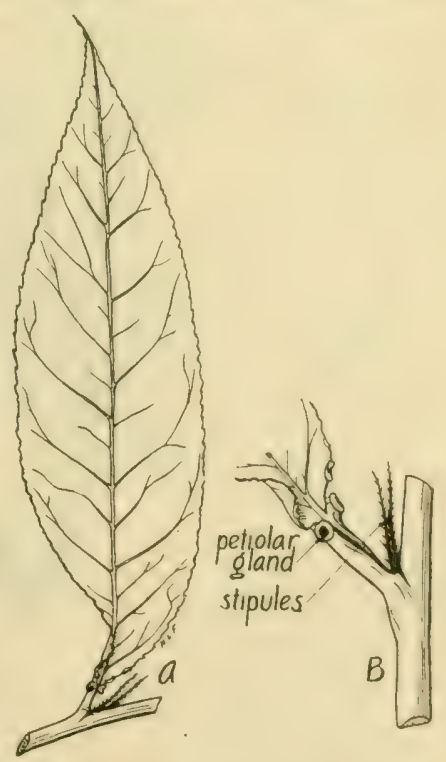

FIG. I61.-Leaf of peach (Amygdalus persica). The base of the leaf considerably enlarged. in $B$. solitary (apricot), or in racemes (wild black cherry, etc.), umbels (sweet cherry, etc.), or corymbs (perfumed cherry). The calyx is free from the ovary, five-lobed, bell-shaped or 
tubular and with its lobes imbricated in the bud; the corolla has five distinct petals; there are numerous stamens. In a

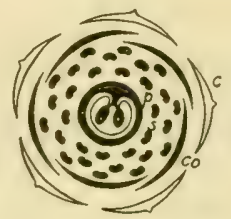

FIG. I62.-Floral diagram of Prunus.

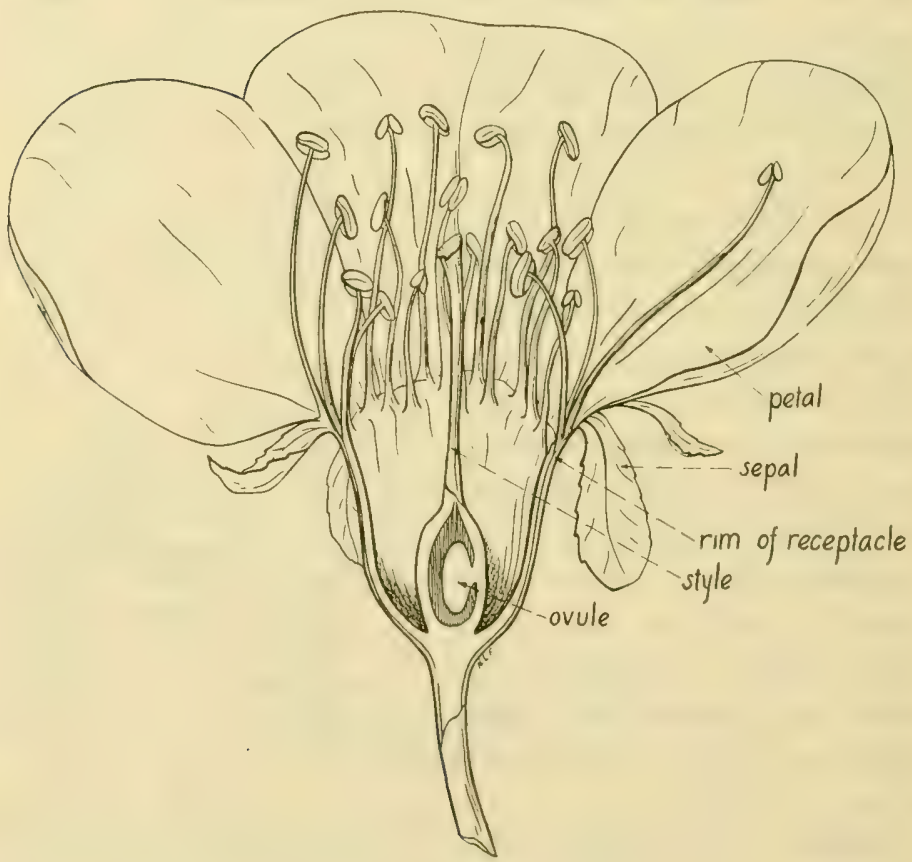

FIG. I63.- Sour cherry (Prunus cerasus). Median lengthwise section of flower.

longitudinal section (Fig. I63) of the drupaceous flower, it is seen that the ovary is placed down within a cup commonly 
called the "calyx tube." If it is a calyx tube, then petals and stamens are inserted upon it. It is very probable that this tube is receptacle and that calyx, corolla and stamens are mounted thereupon. There is one pistil, situated at the bottom of the hollow receptacle; the ovary is one-celled and two-ovuled; the style is single and terminal and bears a small, head-shaped stigma.

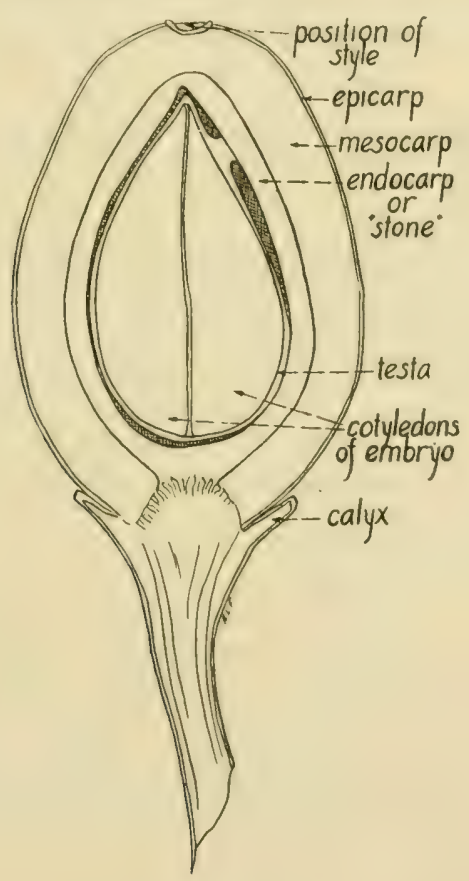

FIG. I64.-Median lengthwise section of young cherry fruit (drupe).

Fruit.-The fruit is a drupe (Fig. I64), that is, one with a single seed surrounded by a stony endocarp, fleshy mesocarp, and an outer skin or exocarp (epicarp). However, if one examines the young ovary of a Prumus flower he will find 
two ovules; one of them aborts, the other develops into a seed. The endosperm is absent, or present only in a small amount. The cotyledons are fleshy.

The only genus of any importance is Prumus. It has the characteristics of the family.

\section{PRUNUS}

This genus includes the plum, cherry, almond, peach and apricot. These main groups may be distinguished by the following key:

\section{Key to Main Groups of Genus Prunus}

Stone smooth.

Flowers clustered; fruit glabrous.

Fruit large, usually grooved, covered with a bloom; stalk short; stone usually compressed, longer than broad; leaves convolute in the bud (Fig. Ior), Plums.

Fruit small, usually not grooved, not covered with a bloom; stalk long; stone usually globular; leaves conduplicate in the bud (Fig. ror), Cherries.

Flowers solitary or in two's; fruit velvety at first, A pricots.

Stone pitted or furrowed.

Flesh soft, thick, juicy, Peaches.

Flesh hard, thin, dry, Almonds.

The genus has about 90 species, nearly all of which occur north of the equator; they are widely distributed in both eastern and western hemispheres. Most species are confined to the temperate zone. The evergreen cherries include a group found in the tropics and subtropics.

\section{PLUMS}

Stems.-The plums are shrubs or small trees. The different species vary considerably in bark and twig characters. The bark of southern forms is lighter in color than that of those growing in the north. Plums have a tendency 
to produce spurs (Fig. 165). Flower buds are, as a rule, on these spurs, one spur bearing from 2 to 20 burls. The spur may terminate in a leaf bud. However, in most plums, true terminal buds are seldom formed. In such cases, if the last lateral bud is a branch bud, this continues the growth of the branch in a straight line. The line between the two seasons' growths is not as sharp, in this case, as when a terminal bud develops. If the last lateral bud is a flower bud, the twig usually dies back to the lateral branch developed from the last branch bud. In all plums, the flower buds are lateral. Flower buds usually stand out at an angle of about $30^{\circ}$, while leaf buds are more appressed to the stem.

Leaves.-The leaves of plums vary a great deal in size, form, color, surface, thickness, and margin. In some species, the serrations are tipped by glandular prickles. Stipules are present. The leaves are convolute in the bud (Fig. IOI).

Inflorescence.- The flower buds of the plum, unlike those of the apple and pear, bear only flowers. They may break open before, simultaneously with, or after the leaf buds. The flowers are in fascicled umbels. The number of

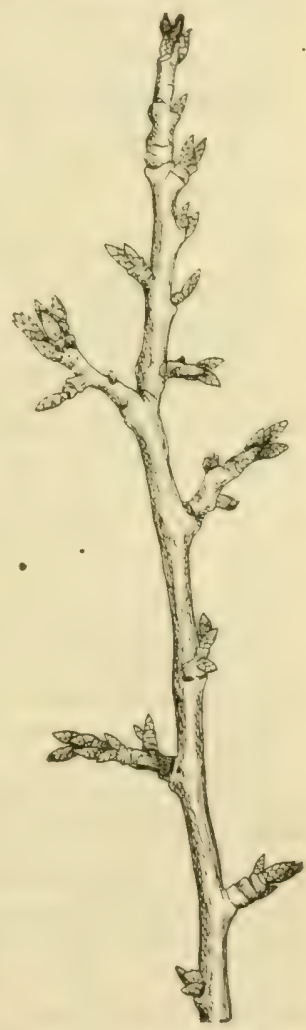

FIG. I65.- Twig aI Domestica plum (Prumus domestica). (After I'uddock and Whipple.) flowers in the bud varies from one to five, two and three being the most common numbers.

Flowers.-The receptacle forms a hollow cup (Fig. 10,3). 
On its edge, are arranged five sepals, five petals, and fifteen to twenty stamens. There is a single pistil bearing one style and one stigma. The pistil is at the bottom of the receptacle. There are two ovules in the young ovary; one of them aborts during maturation of the fruit.

Fertilization.-Many of the plums are practically selfsterile. The native plums exhibit the greatest self-sterility; this is due to the impotency of the pollen when used on the stigma of the same flower. Japanese and domestic plums are less self-sterile than native species. In some cases, not only are pistils developed that are so weak as to fail even if pollinated, but some flowers do not form pistils. Again, pistils and stamens of the same flower often mature at different times. Usually, the pistils mature first. Rarely, the opposite is the case. Hence it is seen that cross-fertilization is very necessary in plum orshards, but not only cross-fertilization between different trees of the same variety but between different varieties. It is reported by Hendrickson that French and sugar prunes in California set a very light crop unless a large number of bees are present in the orchard at the time of blooming. They appear to be self-sterile to some extent. Imperial prune trees that were enclosed in a tent from which all insects were excluded set no fruit. It seems that, with the Imperial prune, fruit is not set unless pollen is brought from other trees. It is distinctly self-sterile. All Prunus species are insect-pollinated for the most part.

Fruit.-After fertilization, the receptacle, with its attached sepals, petals, and stamens, is cut off by a circular abscission layer near its base (Fig. I64). The ovary wall increases in thickness to form the following fruit parts (Fig. I64): (I) skin, exocarp; (2) flesh, mesocarp; and (3) hard stony layer about the seed, cndocarp. The style and stigma do not persist in the fruit. 'The seed is within the endocarp. Hence 
the stone ("pit") of the plum consists of hardened endecarp. seed coat, and embryo. The stone is compressed.

Classification of Plums.- For a complete deseription of the species of plums in American plum culture, see "The Plums of New York" ; Hedrick, Report of the X. Y. Agr. Exp. Sta., vol. 3, pt. II, rg I; and Wight, W. F.. "Native American Species of Prunus," Bull. I79, B. P. I., I9 5 .

\section{Key to Principal Species of Plums*}

Flowers in clusters of one or two (three in P. triflord), OLD WorLin Plums.

Shoots and pedicels pubescent.

Fruits large, more than I inch in diameter, variable in shape, often compressed; tree large; stamens about 30, $P$. domestica.

Fruits small, less than I inch in diameter, uniformly oval or ovoid; tree small, compact; stamens about $25, P$. insititia.

Shoots glabrous or soon becoming so, pedicels glabrous.

Flowers mostly single, $P$. cerasifera.

Flowers in threes, $P$. triflora.

Flowers in clusters of three or more, rarely two, AMERICAN PLUMS.

Leaf serrations glandless, acute; calyx lobes cntire, glabrous on the outer, pubescent on the inner surface, not glandular, $P$. americana.

Leaf serrations g)andular (at least when they first unfold), rounded or ob) tuse; calyx lobes glandular (except in $P$. angiustifolia).

Leaves broad, mostly oblong-ovate or obovate, the margin often doubly serrate; flowers 2 to 2.5 centimeters broad; calyx with a reddish tinge, at least when old, the lobes glandular serrate, $P$. nigra.

L.eaves narrow, ovate, ovate-lanceolate, the margin rarely doubly serrate; flowers 8 to 5 millimeters broad; calyx ratrely reddish, the lobes entire, either glandular or glandless.

l.eaves thick, slightly lustrous on upper surface; reins comspicunus helow; margin coarsely and irregularly serrate, $P$. horlulana.

Leaves usually thin, lustrous on upper surface, reins not conspicuous below, margin finely and evenly serrate.

Leaves usually 6 to ro centimeters long; calyx lobes glandular, $P$. munsoniana.

Leaves 2 to 6 centimeters long; calyx lobes glandless, $P$. angustifolia.

* Adapted from The Plums of New York by Hedrick. 


\section{DISCUSSION OF SPECIES}

Prunus domestica.-This is a vigorous-growing tree which may reach a height of 30 or 40 feet. The leaves are ovate or obovate, elliptical or oblong-elliptical; the upper surface is smooth, the lower often finely hairy, the margins coarsely toothed, and the teeth often glandular. The flowers usually appear after the leaves, sometimes with them. The fruit is generally globular, the skin varies in color, the flesh is yellowish, and the stone free or clinging.

This is the best known and most widely distributed species of plums. It has been cultivated for 2,000 years, originally coming from about the Caucasus Mountains. The first colonists brought varieties of this species to North America. There are now over 950 varieties of Domestic plums grown in this country. These have been divided into a number of groups, largely based upon fruit characteristics. These groups are as follows:

I. Green Gages (Reine Claude).-These are low trees with dark bark which cracks deeply, with leaves doubly toothed, fruit relatively small, round, mostly green or golden, and of excellent quality. The stone is either free or clinging. Important varieties are Reine Claude, Bavay, Spaulding, Yellow Gage, Washington, etc.

2. Prunes.-A prune is any plum that can be cured without removing the pit. All plums with a large percentage of sugar make good prunes. The fruit is large, oval, usually compressed, blue or purple, and with a firm, greenish, yellow, or golden flesh, and free stone. Prunes are raised on the Pacific Coast. The industry there has become a large one. Important varieties are Italian, German, Agen, Tragedy, Tennant, Sugar, Giant, Pacific, and Ungarish.

Preparation of Prunes.-In the preparation of prunes, the 
plums are first cleaned, and their skins ruptured to permit of more rapid drying. Usually, they are dipped into boiling water or hot lye, which not only cleans but also cracks the skin. They are then dried in the open sun, or in drying sheds where artificial heat may be utilized. After drying. the prunes are allowed to "sweat" for two or three weeks. They are then graded and "glossed" or finished by heating in steam or immersing in salted boiling water, glycerine or fruit juice. This gives the surface of the prunes a shiny appearance, and also sterilizes the exterior.

3. Peridrigon Plums.- This is a prune plum grown only in France.

4. Iellow Egg Plums.- The fruit of these is large, in fact the largest of plums, long-oval, and has a yellow or purple skin, and yellow flesh. Well-known varieties are Yellow Egg, Red Magnum Bonum, Golden Drop, and Monroe.

5. Imperatrice Plums.--These are medium-sized, dark blue plums, with thick skin, firm flesh, and clinging stones. Such varieties as Ickworth, Arch Duke, Monarch, Shipper, Arctic, etc., belong to this group.

6. Lombard Plums.-This group includes the reddish or mottled varieties of Domestic plums. Lombard, Bradshaw. Victoria, Pond, and Duane are well-known varieties.

Prunus insititia.-This is a small tree not over 2.5 feet high with small ovate or obovate, finely toothed leaves which are usually glandular; both surfaces of the leaves are slightly hairy. The flowers are usually in lateral, umbellate clusters. The fruit is globular or oval, small, usually bluish black or golden yellow, and has yellow flesh, and a clinging or free stone.

Varieties of this species are hardy and thrify. 'The species has been in cultivation over 2,000 years, but in all that time has shown but little variation. Insititia plums rank second 
to Domesticas. The species grows wild from the Mediterranean northward into Norway, Sweden and Russia. Insititia plums fall into four groups as follows:

I. Damsons.-These are spicy plums, mostly sour, and much desired for preserving.

2. Bullaces.-This group contains a few varieties differing but little from the preceding group, except as to fruit shape. The Bullaces are spherical.

3. Mirabelles.-These are round, yellowish or golden plums with a free stone and resemble much the green gages as to quality.

4. St. Juliens.-This is a name applied to a group of plums resembling the Damsons. They were formerly used in this country as stocks.

Prunus cerasifera.-These are the cherry or Myrobalan plums. They are hardy, thrifty varieties, free from disease, readily adaptable and most suitable for hybridizing. The trees are small, bloom profusely, and bear a small, round, cherry-like plum from $1 / 2$ to I inch in diameter. They are adapted to ornamental usage. They are also used as stocks upon which to bud other plums.

Prunus triflora.-These are the Japanese plums; they are not cultivated in many parts of the world. They are native of China. It is a highly adaptable group, vigorous, productive, early-bearing, and disease-free. Varieties are, for the most part, cling stones.

Prunus americana.-This is our most important native plum. It grows wild from New Mexico to Manitoba, and eastward to the Atlantic Coast. Not being able to raise European plums in the Mississippi Valley, Americans domesticated the native American plum. Varieties of this species are hardy. The American plum tree is usually small, with rough, shaggy bark. The fruit is reddish or yellowish. Altogether, there are about 260 varieties of the americana. Waugh finds that they often bear defective pistils or stamens, or that they are often protandrous or protogynous. From his observations, he recommends some provisions for cross-fertilization when planting americanas.

Prunus hortulana.-This species includes a number of plums well suited for jelly, preserves, and spicing. They are very free of suckers. Important varieties are American, Golden, Juicy, Ruby, Waugh, and Gonzales. The Hortulanas are adapted to the Southern States. 
Prunus nigra.--This is the most northern of American plums. It is well adapted to the States along the Canadian border.

Prunus munsoniana.- This is the plum most grown in the South. The varieties are mostly cling stones. Of all plums, these are most in need of cross-pollination. A few of the chief rarieties are Robinson, Newman, Wild Goose, Arkansas, and Downing.

Prunus angustifolia.--The Chickasaw plum is a small tree, 6 to 10 feet high, sometimes shrubby. The fruit is small, almost globular, flesh yellow, and of good quality. It ranges from Delaware to Louisiana and westward to Arkansas and Texas. Its varieties do well in the Southern States.

The two subspecies, watsoni and rarians, have varieties of some horticultural value, such as Purple Panhandle, African, Clark, Emerson, etc.

\section{CHERRIES}

Description.- The cherries resemble plums in many respects. The bark of the cherry separates in rings. The flower buds are usually found on short spurs (Fig. I66). In some sour cherries, however, axillary flower buds occur on long, strong shoots. These buds produce fruit the following spring. Since the lateral buds in such shoots are flower-bearing, no lateral branches are produced, and the result is a long, naked branch. On the spurs, the flower buds are axillary and a branch bud terminates the short shoot.

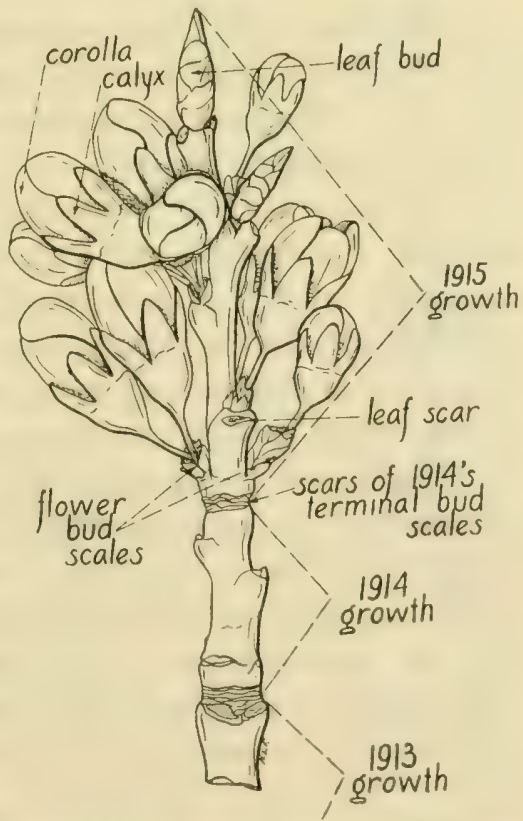

Fic. 166.-Spur of sour cherry (Prunus cerasus).

The flower buds bear only flowers and no leaves (except very rudimentary ones which persist but for a short time). There 
are from two to live blossoms, usually two, in each bud. 'The flowers are in umbels, as a rule. The flowers and fruit of cherries are, morphologically, similar to those of plums.

The leading commercial varieties of cherries grown in California have been shown to be self-sterile. It is altogether possible that sterility in cherries is widely spread.

Groups of Cherries.-According to Bailey the principal cultivated cherries are from two species, Prunus avium, the sweet cherries, and Prumus cerasus, the sour cherries.

\section{PRUNUS AVIUM (Sweet Cherry)}

Description.-The sweet cherry is a tall tree, strong-growing, long-lived, and frequently attains a diameter of $\mathrm{I}$ foot or more. The bark is gray-brown, the outer layer often being roughened; lenticels are inconspicuous. The leaves are thick, oval, ovate or obovate, 4 to i 2 centimeters long, abruptly short-acuminate, irregularly. and coarsely toothed, or doubly so, green and smooth above, lighter beneath, slightly hairy on the veins, more or less drooping, and with long slender petioles. Flowers appear with the leaves, in lateral, sessile umbels; the flower pedicels are 3 to 6 centimeters long; the petals are white, and the stamens 35 or 36 . Self-sterility has been reported in the sweet cherry orchards of the Northwest. The fruit is variously colored, spherical to heart-shaped, with flesh soft or hard, usually sweet, and with the skin adherent to the flesh.

Geographical.-The species is a native of Europe. It has been cultivated in this country for many years, and in some places has escaped from cultivation.

Groups of Sweet Cherries.-The sweet cherries include four general groups:

I. Mazsards. - The fruit is small, and varies in shape and color. Mahaleb and mazzard stocks are the two common 
sorts upon which sweet cherries are grafted, the results leing somewhat better when grown on mazzard stock. Sour cherries are also propagated on mazzard stock.

2. Hearts (Geans).-The fruit is heartshaped and has a soft flesh. Tartarian, Black Eagle, etc., are varieties in this group.

3. Bigarreaus.-The fruit is heart-shaped, light or dark in color, and with hard flesh. Common black varieties are Windsor and Schmidt, common light ones, Yellow Spanish and Napoleon.

4. Dukes.-Dukes resemble the Hearts in shape and color, but have a juice somewhat acid. Dukes are often classed with the sour cherries, but Bailey would class them with the sweet cherries on account of the habit of growth of the trees, and the flower and leaf characters. Hedrick considers Duke cherries as hybrids between Prumus avium and $P$. cerasus. They resemble sweets more than sour. Dukes commonly produce sterile seed. There are both dark- and light-colored sorts. Reine Hortense and May Duke belong here.

\section{PRUNUS CERASUS (Sour Cherry)}

Description.--Sour cherry trees are smaller than those of sweet cherries. They "sucker" readily from the root. The bark is graybrown and quite smooth; lenticels are conspicuous. The leaves are thick, ovate or

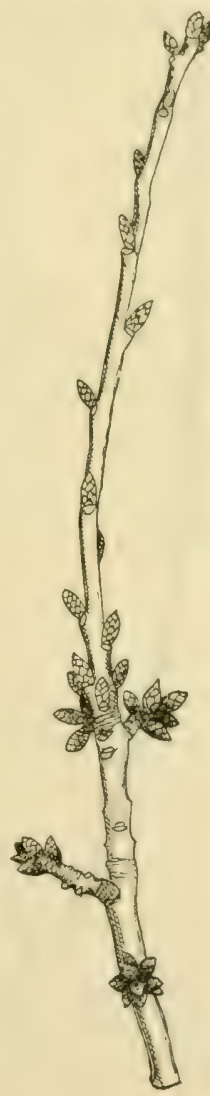

FIG. I67.-Twig of sweet cherry (Prunus avium). (After Paddock and Whipple.) ovate-lanceolate, abruptly acute or acuminate at the tip), variously toothed, becoming smooth on both surfaces, usually erect, and with short, strong petioles. Flowers appear before 
or with the leaves in small umbels from lateral buds; the pedicels are about 24 centimeters long; and the stamens are about 30 in number. The fruit is globular, always red, with

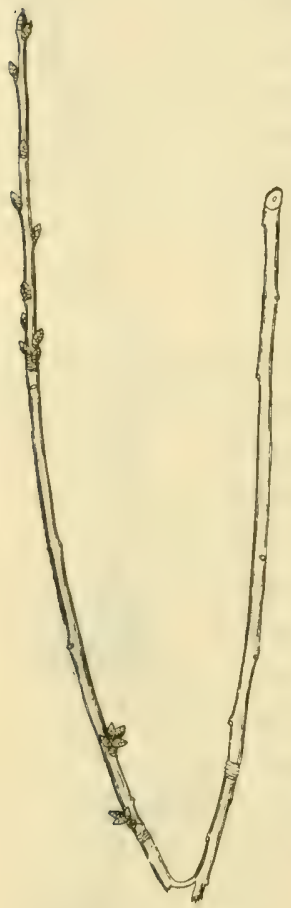

FIG, I68.-Twig of sour cherry (Prunus cerasus). (After Paddock and Whipple.) soft flesh and skin that usually separates readily from pulp.

Geographical.-The species is a native of Europe and an occasional escape from cultivation in this country.

\section{Groups of Sour Cherries.-The sour} cherries include two general groups:

r. Amarelles.-These cherries are pale red in color, have colorless juice, and are generally somewhat flattened on the ends. They have less acid than darkcolored cherries. Montmorency and Early Richmond are the most common Amarelles.

2. Morellos or Griottes.-These are cherries with dark red fruit and dark juice, and they vary from spherical to heart-shape. Common varieties are Ostheim, Olivet, Louis Philippe, and the Morello.

Other Species of Cherries.-The species of cherries native to America are of little horticultural importance. Chief of these are $P$. pennsylvanica, $P$. cmarginata, $P$. pumila, $P$. cuneata, and $P$. besseyi. $P$. pennsylvanica is sometimes used as a stock on which to bud the sour cherry.

Prunus mahaleb, a native of Europe and Asia, is very extensively used in this country as a stock for all sweet and sour cherries. It is an excellent dwarfing stock.

Uses.- Both sour and sweet cherries are used as a dessert fruit, and in the making of pies. The bulk of the cherries 
grown for canning purposes are sour red sorts, and are produced in New York, Michigan. Wisconsin, and California. Maraschinos are sweet cherries. most of which are imported from Italy and Spain. A californian variety, Napoleon, is also used to some extent for this purpose. Recent investigattions point to the conclusion that a number of commercial products may be obtained from cherry pits and cherry juice. two by-products of the cherry industry. The fixed oil expressed from the fresh kernels is much like almond oil, and can be utilized in similar ways. Also, the volatile oil is quite similar to bitter-almond oil, and can be used in the same way. The pressed cake, that which remains after the oils are removed, may be ground into a meal and used as a feeding stuff. The waste cherry juice can be changed into syrup. jelly and alcohol.

\section{APRICOTS}

Stems.-The common apricot varieties belong to the species Prunus armeniaca. The trees are small, roundtopped, and resemble the peach tree. As in the plums, true terminal buds are seldom formed. Lateral branch buds and flower buds are found together in the axils of leaves (Fig. r69). Except for a few rudimentary leaves, the fruit buds bear only flowers. Normally, there is but one flower (sometimes two) in a bud; they appear before the leaves. The flower buds, which are lateral, occur singly at nodes; often three buds are developed in the axil of a leaf, the central one being a branch bud, while the two laterals are flower buds. However, not all branch buds on a twig are accompanied by flower buds. The vigor of the tree and twigs, and pruning methods will determine the position of the latter, to some extent. In strong-growing twigs, the flower buds are raver near the tip of a year's growth; on twigs of moderate 
growth, they will be found along the central portion of the twig; while on feeble-growing branches, they usually occur singly, and are quite evenly distributed along the entire

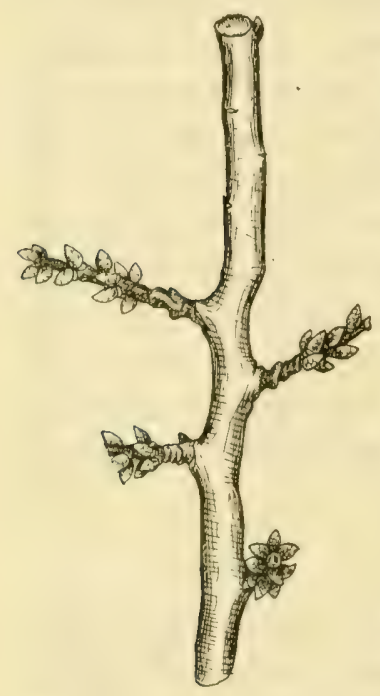

length. However, not all the flower buds are formed on the long shoots. Many are developed on extremely short spurs, but always axillary; usually the flower buds are single in such short growths.

Leaves.- These are usually ovate, often somewhat heart-shaped at the base, abruptly short-acuminate, smooth above, slightly hairy beneath, finely toothed, on glandular petioles, and convolute in vernation.

Inflorescence and Flowers.-The flowers are solitary or in pairs, pinkish, sessile or nearly so. Morphologically, the flowers are similar to those of plum, cherry and other

FIG. I69.--Twigs of apricot (Prunus armeniaca). Whipple.)
(Afier Paddock and
Prumus spp.

Fruit.-This is much like a peach in color and shape; the skin is velvety at first, but becomes smooth at maturity; the flesh is always yellow. The stone (endocarp and seed) is flat, smooth, and grooved on one edge. In the maturing of the fruit, the 
parts of the flower are cut off by a basal ring of growth, ats described in the plums.

Distribution.-The species is considered to be a native of southern Asia. It is now cultivated in most temperate climates. In the United States, the practice is to graft apricots on to the roots of plum or peach.

Other Species.-There are several other species of apricots besides $P$. armeniaca, but none of them bear fruit of marketable size. They are generally planted as ornamentals. Among such are $P$. sibirica, the Siberian apricot, $P$.dasycarpa, the purple or black apricot, and $P$. mume, the Japanese apricot.

Uses.-Apricots are prized as a table fruit, both in the fresh and the dried condition. They are usually pitted before they are dried, but may be dried with the skins off or on. "Sulphuring" may precede the drying process proper. Almond oil is derived from the seeds.

\section{- PEACHES}

The common varieties of peaches come from one species-Prumus persica. Some writers place the peach in a separate genus, Amygdahus persica. The latter is the name given to the peach by Linnaeus.

Stems.-The tree is low, seldom over 25 feet in height, broad-topped, and with a scaly, dark brown bark. Young twigs are glossy green. The flower buds of the

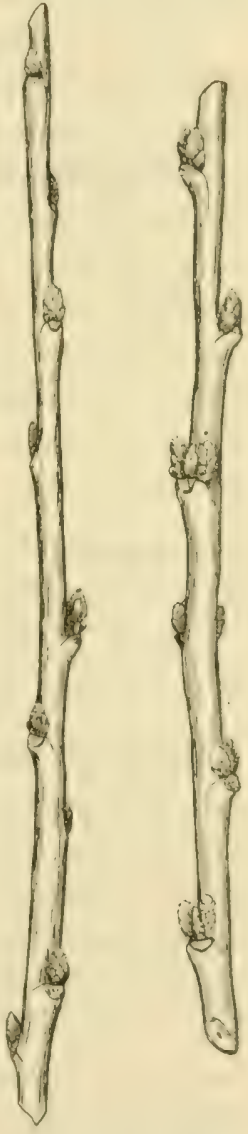

Fig. I70.-Twigs of peach (Prunus persica). (Afler Paddock and Whipple.) peach are simple, containing only flowers, or flowers and a few rudimentary leaves; each burl has one, sometimes two, flowers. The flower buds are borne singly or in pairs with 
a branch bud (Fig. I 70). In this respect, they are similar to the apricot.

Leaves.-These are conduplicate (Fig. IOI) in the bud, clliptic to lanceolate or oblong, and taper toward either end; they are finely and sharply toothed, and on stout petioles.

Inflorescence and Flowers.- The flowers are normally solitary in the axils of leaves and appear before the leaves; they are large, pink, fragrant, and showy.

Fruit.-The fruit is subglobular, grooved slightly on one side, has velvety skin, and hard flesh which may be free (freestones) or adherent (clingstones) to the stone. The stone is compressed, pointed, and pitted. The seed is of the shape of an almond, aromatic, and slightly bitter.

Geographical.- The peach is a native of Asia, probably China. It was introduced into Europe at a very early date, coming by way of Persia. This fact accounts for the specific name, persica, and common name, peach. The tree is now cultivated in temperate regions. Occasionally it is escaped from cultivation, especially throughout our Northern and Middle States.

Types of Peaches.-The first system of classification of peaches was worked out by Onderdonk, of Texas. $\mathrm{He}$ divides the varieties of peaches into five classes or races, based primarily upon the country in which they originated, hence upon their range of adaptability.

I. Peen-to Race.-The stone is almost spherical (Fig. I 7 I , C, D). somewhat compressed at the end, and with small and round corrugations; the fruit (of original peen-to) is much flattened; the skin is white, blotched with red, and flesh white; the stone is free or cling. It is adapted to subtropical regions. Varieties: Angel, Clara, Hall, Waldo.

2. South China Race ("Honey" Group).-The stone is oval (Fig. I 7 I, B), and its corrugations slight; the fruit is slightly flattened, with a peculiar long, conical apex more or less recurved, small, oval, and has a very deep suture at 
the stem end; the flesh is juicy, firm, gemerally white; the stone is free or cling. It is adapted to subtropical conditions. Varieties: Climax, Imperial, Pallas, Taber.

3. Spanish. Race.-The stone is large, oval, nearly flat (Fig. I7I, A), its apex prominent, and corrugations small: the fruit is large, yellow, or yellow streaked with red. It is adapted to southern conditions. Varieties: Cabler. Druid, Onderdonk, Texas.

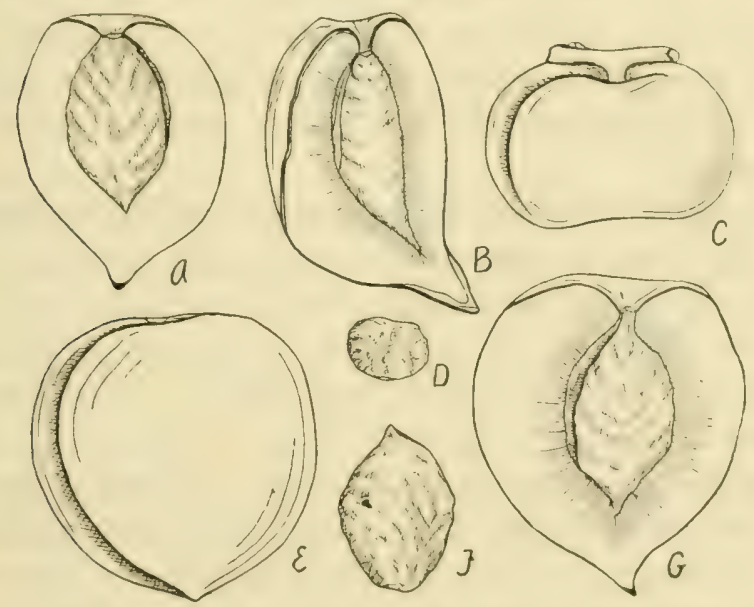

FIG. I71.-Fruit of the races of peaches. A, Spanish Race; $B$, South Chinese Race; $C$, Peen-to Race; $D$, stone of Peen-to Race; $E$, Persian Race; $F$, stone of Persian Race; G, North Chinese Race. (After Price, Texas Agr. Exp. Sta.)

4. Torth China Race ("Chinese Clings").- - The stone (Fig. I 7 I, G) is globular, thick, its corrugations not at all prominent, cling, semi-cling or free; the fruit is large, almost globular, and its flesh is fine-grained and juicy. It has a wide range of adaptability. Varieties: Belle, Lee Ray, Superb. Elberta and several other varieties are considered crosses between the North China and Persian races. 
5. Persian Race.-The seed is globular, with corrugations prominent toward the apex (Fig. I 7 I, E, F); the fruit is much like the preceding. The common varieties of peaches grown in northern orchards belong to this race. Varieties: Crothers, Foster, Late Crawford, Reeves, Salway, Walker.

In addition to the above, the Nectarine should be added as a variety of peach. It differs from the common peach in that its fruit is smaller, the skin is smoother, and the leaves are commonly more prominently toothed. There are both freestone and clingstone nectarines. It is known that nectarines appear on peach trees and peaches on nectarine trees. Such fruits that thus appear are evidently "bud variants."

Uses, and Production of Peaches in the United States.The fruit is used largely as a dessert, both fresh, dried and canned. Peaches are usually pitted before they are dried. The seeds of the peach, as well as those of almond, apricot and plums, contain both fixed and volatile oils, which are of commercial value.

There are peach interests of commercial importance in a large proportion of the States. The total output of peaches for the country in I9I 5 was $64,218,000$ bushels, which were sold at an average farm price of 8 I. I cents. California led in production, with 9,768 ,000 bushels. The other nine leading States, in the order of their output, were Arkansas, Georgia, Texas, Missouri, Alabama, Kansas, Tennessee, Oklahoma and Ohio.

\section{ALMONDS}

Description.-The common almond is Prunus amygdalus (Amygdalus communis). The tree is much like the peach in shape and size. The flower buds are axillary along with branch buds, as in the peach and apricot. The leaves are 
lanceolate, firm, shining, and finely toothed. The flowers are normally solitary and appear before the leaves. They are large, pink, and showy. Many varieties are sterile without cross-fertilization. The drupe is much compresserl. The mesocarp (portion corresponding to the flesh of peach or plum) is leathery and tough and separates readily at maturity. from the stone (endocarp and seed). The "unshelled" almond of commerce consists of the thin, pitted, light-colored endocarp, within which is the seed or "kernel."

The common almond is a native of Asia.

Types of Almonds.-The two general types or races of common almonds are the bilter and the sweet. The difference is in the composition and taste of the kernel. The sweet or edible almonds consist of two groups: Hard-shell and softshell. The latter are of the greater economic importance.

In addition to the common almonds, Prunus amygdalus, there are a number of dwarf forms which are grown mostly as ornamentals.

Uses.-Almonds are grown for the nuts which are used directly as a food. Almond oil finds use in the manufacture of flavoring extracts. The seeds are also a source of prussic acid.

Almond Oil.-Most of the so-called oil of almonds is derived from the seeds of the apricot; almond and peach seeds also furnish a considerable quantity. The oils from these three sources are very nearly the same. In the process of extracting almond oil, the seeds are ground, subjected to great hydraulic pressure to remove the undesirable fatty oil, and the residue ground again. fermented, and distilled with steam. The distillate is almond oil and hydrocyanic acid. This latter, deadly poisonous substance is removed by treating the mixture with lime and copperas. 


\section{References}

Bailey, L. II: Fourth Report on Japanese Plums. Cornell Exp. Sta. Bull. I75: I 3I-I60, I899.

Bailex, I. H., and Poweld, G. H.: Cherries. Cornell Agr. Exp. Sta. Bull. 98: $47 \mathrm{I}-500,1895$.

Earle, F. S.: Japanese Plums. Ala. Agr. Exp. Sta. Bull. 85: 423-448, I897.

Gardner, V. R.: A Preliminary Report on the Pollination of the Sweet Cherry. Ore. Agr. Exp. Sta. Bull. ir6: I-40, I9I3.

Goethe, R.: Über die Klassification der Pfirsichsorten. Gartenflora, 55: I69-182, I907.

Gould, H. P.: Growing Peaches: Varieties and Classification. U. S. Dept. Agr. Farmers' Bull. 633: I-18, I914.

Hedrick, V. P.: The Cherries of New York. 22d Ann. Rept. N. Y. Agr. Exp. Sta., vol. 2, part 2: I-37I, I9r5.

The Plums of New York. I8th Ann. Rept. N. Y. Agr. Exp. Sta., vol. 3, part 2: I-6I6, I9II.

The Blooming Season of Hardy Fruits. N. Y. Agr. Exp. Sta. Bull. 407: 367-39I, I9r5.

Hendrickson, A. H.: The Common Honey Bee as an Agent in Prune Pollination. Calif. Agr. Exp. Sta. Bull. I74: 127-132, г9r6.

Hume, Harold H.: The Peen-to Peach Group. Fla. Agr. Exp. Sta. Bull. 62 : 505-519, 1902.

Onderdonk, Gilbert: Report of the Commissioner of Agr., i887, pp. 648650. Containing the Original Classification of the American Varieties of Peaches.

Powell, G. Harold: The'Chinese Cling Group of Peaches. Del. Agr. Exp. Sta. Bull. 54: I-32, I902.

Price, R. H.: The Peach. 'Tex. Agr. Exp. Sta. Bull. 39: 803-848, I896.

Quaintance, A. L.: The Development of the Fruit Buds of the Peach. Ga. Exp. Sta. Rept. 13: 349-35 I, 1900.

Rabak, Frank: Peach, Apricot, and Prune Kernels as By-products of the Fruit Industry of the United States. U. S. Dept., Bur. Plant Indus. Bull. 133: 1-34, 1908.

The Utilization of Cherry By-products. U. S. Dept., Bur. Plant Indus. Bull. 350: I-24, I9I6.

Remer, F. C.: The Honey Peach Group. Fla. Agr. Exp. Sta. Bull. 73: 135153,1004 .

Wignt, W. F.: Systematic Botany of the Plum as Related to the Breeding of New Varieties. Ann. Rept. Am. Breeders' Assn., 8: 488-497, IgI 2. The Varieties of Plums Derived from Native American species. U. S. Dept. Agr. Bull. I72: I-44, I9I5.

Native American Species of Prunus. U. S. Dept. Agr. Bull. I 79: I-75, I915. 


\section{CHAP'TER XXIX \\ LEGUMINOS E (Pea Family)}

The pea family is one of wide geographical distribution, occurring both in temperate and warm climates. According to Piper there are about 487 genera and 10,782 species in the family. () these, 3.846 species in 10.3 genera are American.

"Legume" is a popular name applied to members of the Leguminosa. Probably no family is of greater agricultural importance than this one, unless it is the Gramineax. Leguminous plants are comparatively rich in protein; this applies to all portions of the plant. and not to seeds alone. For this reason they help to balance the food ration of man and of domestic animals, which is quite largely made up of starchy foods, such as are furnished by the cereal crops. Furthermore. the fact that legumes are rich in nitrogenous substances makes them of value as fertilizer crops. MIoreover, they leave a considerable quantity of vegetation behind them when harvested, and thus add humus to the soil, which improves both the chemical and physical properties of the soil.

Root Tubercles.--The roots of the legumes support the growth of a bacterium (Pscudomonas radicicola) which forms upon them abnormal growths called nodules or tubercles. The tubercles are root colonies of the above organism, which stimulates rapid growth of certain root cells and hence the formation of swollen, gall-like structures. These organisms have the power of fixing free nitrogen of the air. That is, free nitrogen gats from the soil air is taken by the organism 
and, together with other chemical elements, made a part of its protein. It is probable that the legume bacteria, while active in the nodule, are throwing off continuously nitrogenous substances which are absorbed directly by the plant upon which they are growing. Moreover, when the nodules decompose, their protein contents are ammonified, and nitrified, and finally there is left in the soil, nitrates which are available as a source of nitrogen for green plants. Legumes are regularly employed as rotation crops with cereals, and root crops. Since they are heavy soil feeders, they make excellent crops to plow under.

Habit.-Leguminosæ are either annual, biennial or perennial; and are either herbs (peas, beans, alfalfa, etc.), shrubs (Genista, dye-weed or green-weed), or trees (Robinia and Gleditsia, locusts), and a very few are vines (Vicia spp., vetches).

Leaves.- These are alternate on the stems, stipulate, and mostly compound. They are generally odd-pinnate, that is, a leaflet terminates the rachis of the leaf, as in Robinia (locust), Astragalus (vetches) and Aragallus (loco); sometimes they are even-pinnate, that is, terminated by a tendril or bristle, as in Vicia (vetch) and Lathyrus (wild and sweet peas); or they may be trifoliate, as in clovers, or digitate, as in Thermopsis (buckbean).

Inflorescence.- The flowers are nearly always arranged in racemes (pea), sometimes in a head (clovers), or spike-like raceme (alfalfa), or spike (Glycyrrhiza, licorice).

Flowers.-These are irregular (Fig. I72); they have a butterfly-like shape, and for this reason, flowers of the pea type are often spoken of as "papilionaceous." The calyx: is normally four- to five-toothed or cleft, the teeth or lobes being equal or unequal. The petals are usually five in number, a broad upper one (standard, banner or vexillum), 
two lateral ones (aings or ale), and two lower ones more or less united along their rentral edges (forming the ked or carina) (Fig. I 72); this keel encloses the stamens and pistils. In the bud, the keel is enclosed by the wings, and the wings by the standard. Slamens are mostly ten in number, and either all the filaments are united (monadelphous), as in Lupinus, or nine are united and one is free (Fig. I SS) (diadelphous), as in clovers and alfalfa, or rarely all stamens are separate (polydelphous), as in Sophora and Thermopsis.

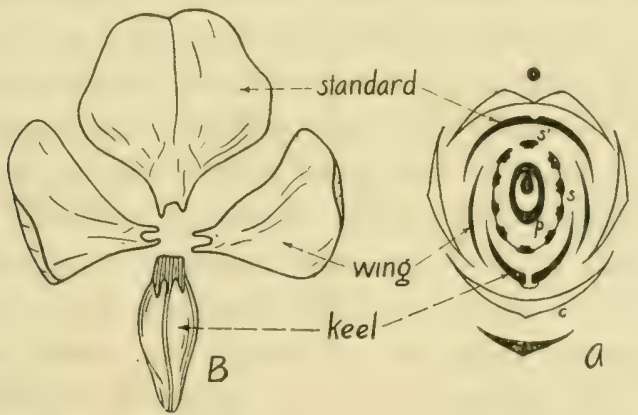

FIG. 172.-Flower of Leguminosæ. A, floral diagram of Vicia faba; $B$, stweet pea flower, dissected, diagrammatic. (A after Eichler, $B$ after Bergen and Caldwell.)

The united stamens form a tube enclosing the pistil in monadelphous and diadelphous forms. There is a single superior pistil; the ovary is usually one-celled, sometimes two-celled by the intrusion of the sutures, as in some $A$ stragalus spp., or occasionally several-celled by cross-partitions; there is one style, and one to many ovules.

Fruit.--In nearly all members of the family, the fruit is a legume or pod, that is, a fruit of one carpel which opens along two, both the ventral and dorsal, sutures. The ventral suture of the bean or pea pod, for example, is the one along which the seeds are attached. In one-tribe (Hedysarea), 
the fruit is a loment, that is, a jointed indehiscent legume, constricted between the seeds. The style, calyx, and withered stamens are often partly persistent in the fruit.

Seeds.-The seeds are usually without endosperm; the cotyledons are thick and full of food.

The seeds of legumes are noted for their great longevity. Some have been known to retain their viability for 150 to 250 years. This is correlated with their very hard, impermeable seed coats. So-called "hard seeds" are very common in the pea family. Such seeds are tardy in their germination, either under laboratory or field conditions. As a rule, only a portion of a crop of seeds is hard, although in some cases the whole crop may be hard. It is claimed that a larger percentage of hard seeds is produced in dry climates or when ripening takes place under dry seasonal conditions than in moist climates or moist seasons. The permeability of leguminous seeds can be increased by "scarifying," that is, passing them through a machine that abrases the surfaces. The ordinary alfalfa huller is effective as an abraser, as is shown by the experiments of Harrington who found that alfalfa seed, grown under a variety of soil and climatic conditions, had about 90 per cent. of hard seeds if hulled by hand and only about 20 per cent. if hulled by machine.

\section{Key to Principal Genera of Leguminos e}

Plants with tendril-bearing leaves (Fig. I9).

Calyx lobes leafy; stipules large, rounded (Fig. I9), Pisum (pea).

Calyx lobes not leafy; stipules mostly small, pointed.

Style slender, bearded at the tip (Fig. I73, A), Vicia (vetch).

Style flattened, bearded along the inner side (Fig. I73, B), Lathyrus (vetchling).

Plants without tendril-bearing leaves.

Leaves palmately three-foliate (Fig. I83), Trifolium (clover).

Leaves pinnately three-foliate, rarely five- to seven-foliate (Fig. I 82). 
Flowers small, many in a cluster.

Flowers in slender, spike-like racemes, Mclilotus (sweet clover).

Flowers in heads or short spikes, IVedicago (alfalfa and other medicks). Flowers medium to large, few in a cluster.

Pods smooth, mostly large.

Keel of corolla spirally coiled (Fig. 1 76, A), Phaseolus (bean).

Keel of corolla merely incurved, Vigna (cowpea).

Pods hairy, small, Soja (soy bean).

Leaves pinnate, with two pairs of leaflets, Arachis (peanut).

\section{PISUM (Pea)}

Description.--The plants are herbaceous trailers or climbers with hollow stems. The leaves are pinnately compound, with one to three pairs of leaflets, the terminal one, and in some cases the upper lateral ones, modified as tendrils, which are sensitive and prehensile; the stipules are large and leaf-like (Fig. 19). The inflorescence is a fewflowered axillary raceme. The flowers are either white or purplish, diadelphous, and bear a single pistil with the style bearded on the inner side (Fig. I73, A). The pea is capable of self-fertilization although it may sometimes be cross-fertilized. The mature fruit is a typical legume with a number

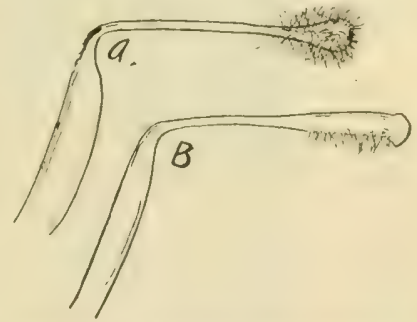

FIs. I 73,-1. style and stigma of Vicia; $B$, same of Lathryus.

of smooth or wrinkled, usually green or yellow seeds ("peas"). Gregory studied the histology of round and wrinkled peas. In round peas, including the indented sugar peas, the central tissue in the cotyledon leaves is filled with very large starch grains. In wrinkled peas, on the other hand, this region of the cotyledons has starch grains which are usually compound, the component parts being about one-half the size of the grains in smooth peas. The seed coat is 
thin; endosperm is wanting; the stored food is within the two cotyledons. The cotyledons remain underground during germination (hypogean germination), as in all cereals. This type of germination is different from that in the bean and squash, for example, in which the two cotyledons are raised above ground, and for a time are food-making organs. This sort of germination is called epigean.

Types of Peas.- There are but two well-recognized types of Pisum: Garden peas and ficld peas. These are briefly distinguished as follows:

llowers white; seeds globular, uniformly yellowish, white or bluish green; leaf axils green, unpigmented; comparatively tender Pisum sativum (garden pea).

Flowers colored, usually purplish, red or lavender; seeds angular, graybrown, gray-green, gray-yellow or gray speckled with fine spots of various colors; leaf axils pigmented; comparatively hardy Pisum satizum (field pea).

Gurden Peas.-The common garden pea can be divided into two groups: Shelling peas, and edible-podded or sugar poas. In the former, the pod is lined on the inside by a thin, hard membrane (endocarp) which at maturity causes it to split open. In the edible-podded or sugar peas, this membrane does not become dry and twisted at maturity, and the pods remain soft and tender.

Shelling Peas.-Vilmorin classifies the varieties of common shelling peas into two groups: Round or smooth-seeded, and irinkled-secded. Each of these is divided into (r) tall climbing. (2) half-dwarf, and (3) dwarf varieties, and each of the latter three groups into white-seeded and green-sceded sorts. The sugar peas occur in both tall, half-dwarf, and dwarf forms.

Period of Muturing.-As a general rule, the earliest sorts of peas have smooth, round seeds, while the late sorts have 
wrinkled seeds. Simooth-seeded varieties are hardier than wrinkled-seed varieties. This is not invariably the case, however. Furthermore, dwarf and medium-sized forms are early, while tall varietics are late. Green garden peas

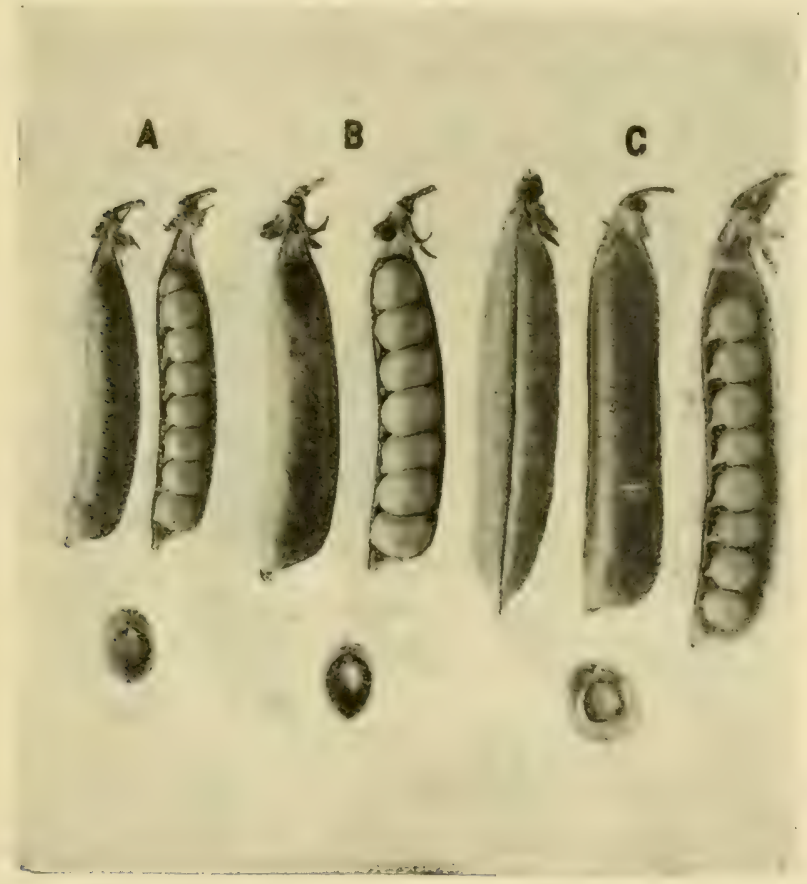

FIG. I74--Pea pods showing types and range of variation. $A$, extra early dwarf wrinkled pea, American Wonder; $B$, medium carly wrinkled pea, Nott's Excelsior; C, main crop smooth pea, Marrowfat. (After Corbelt.)

are sometimes classified as to their time of maturing into carly, medium, and late or main crop. First of all, Alaska. and American Wonder are examples of early sorts, McLeans, Advancer, and Pride of Market of medium sorts, while among late-maturing crops are such varieties as Telephone, Telegraph and White Marrow Fat. 
Ficld or Canadian Field Peas.-- These have smonth, hard, rather angular seeds. They are gray-green, gray-yellowish, or gray dotted with purple. blue, rust red or brownish spots. Garden peas are sometimes used as a field crop.

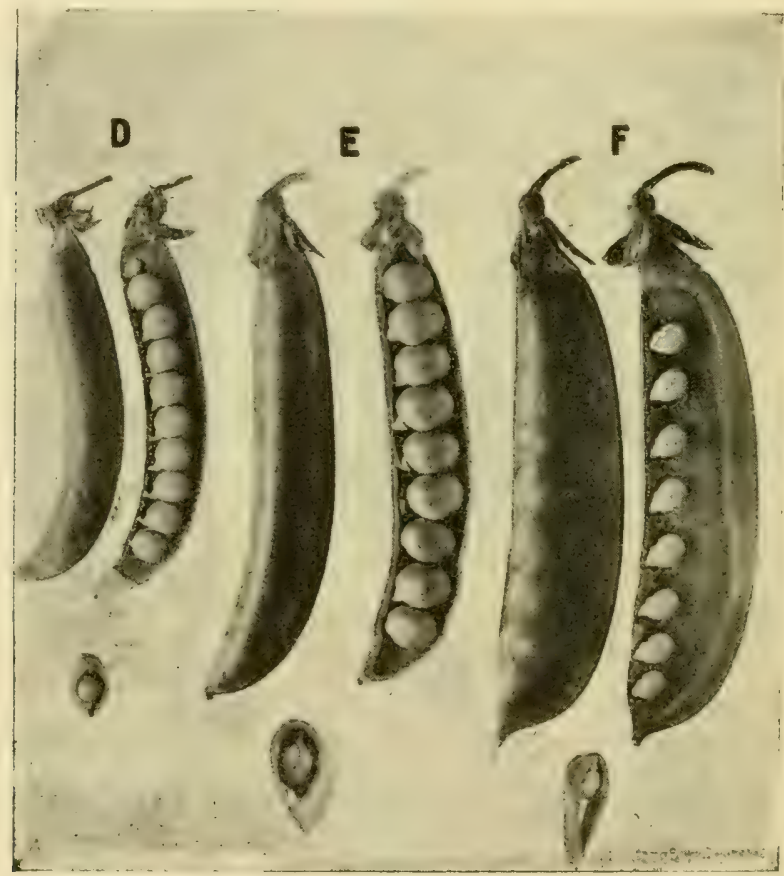

FIG. 175.-Pea pods showing types and range of variation. $D$, French canning type smooth pea, French Canner; $E$, large podded wrinkled pea, Pride of Market; $F$, fleshy or edible podded pea, Melting Sugar. (After Corbett.)

Field peas are successfully grown only in those regions with a cool growing season, in fact, they will withstand quite heavy frosts. High temperatures accompanied by high relative humidity are decidedly injurious. Excellent crops are grown at 7,000 to 8,000 feet in the San Luis Valley of Colorado. They do well on most types of soil. 
Peas and Mendelism. - (iregor Mendel's famous experiments in plant hybridization were carried on with the common garden pea. He discovered certain laws in the behavior of his hybrids, and these are now famed as Mendrl's Luas. He selected a number of differentiating (paired) characters and observed their behavior when crossed with each other. In the brief summary, here of his work, a number of characters of the genus Pisum are brought out:

1. Round or roundish form of seed is dominant over angular or wrinkled seed. That is, when a plant bearing roundish seeds is crossed with one bearing angular or wrinkled seeds, the hybrid offspring bears seeds all of which are roundish.

2. Yellow color of cotyledons is dominant over green color of cotyledons.

3. Gray seed coats are dominant over white seed coats.

4. Inflated seed pods are dominant over pods constricted between the seeds.

5. Green color of unripe pods is dominant over yellow color of unripe pods.

6. Distribution of flowers in leaf axils is dominant over their distribution on the ends of stems.

7. Tall stem is dominant over short stem.

Uses.-Peas in the green state are one of the most common regetables. They are also canned in large quantities. Field peas are being grown as a companion crop, soiling crop, green manure, and as a food for hogs, sheep, horses and cattle. It is the practice in many places to pasture live stock, particularly hogs and sheep, on field peas.

\section{PHASEOLUS (Bean)}

Description.- Representatives of this genus are annual or perennial herbs or vines with pinnately three-foliate, rarely one-foliate, leaves. The flowers occur in axillary racemes; they vary in color: white, yellow, red, or purple. The calyx is five-toothed or five-lobed, the two upper teeth or lobes being either united or free. The standard of the corolla is often recurved or somewhat contorted; the wings equal or exceed the standard, while the keel is characteristically' spirally' coiled (Fig. I76, A). The slamens are diatelphous (nine and one). The ovary has a style longitudinally bearded, and 
numerous ovules. Members of the genus are quite regularly visited by insects. The pod is linear, straight or curved, subterete or compressed, two-valved, and tipped with a

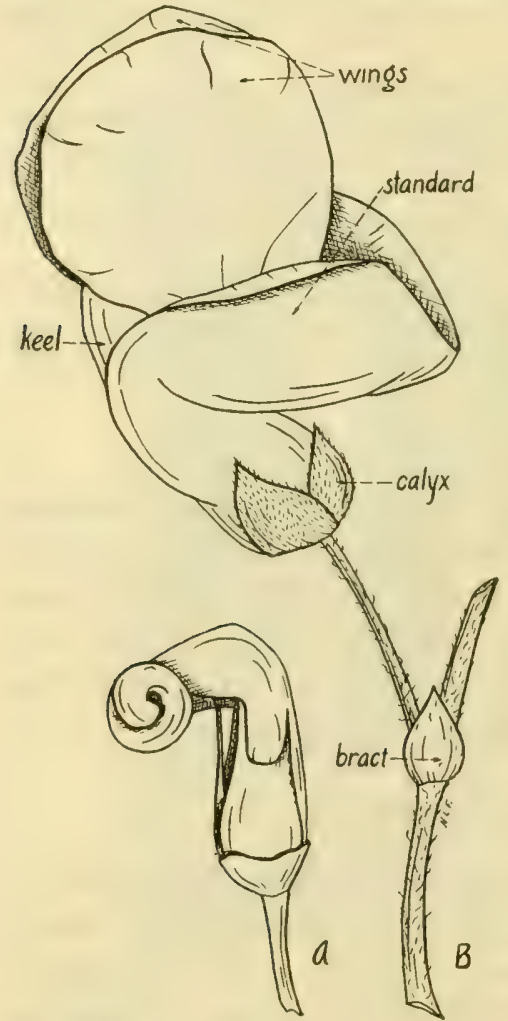

Fig. I76.-Common kidney bean (Phaseolus vulgaris). $A$, spiral keel; $B$. entire flower. $\times 215$. persistent style. The seeds ("beans") are large and have a prominent, approximately central hilum, on one side of which is the micropyle, on the other, the raphe. The embryo is large and occupies the whole of the seed, i.e., endosperm is wanting. The hypocotyl and plumule are prominent; the two large cotyledons are slightly concave on their inner faces. The germination of the bean, and the bean seedling, are common objects of study in general botanical courses.

Geographical and Species.Members of the genus Phaseolus are tropical and warm-country plants. According to Britton and Brown, there are close to 180 species.

A number of "beans" do not fall within the genus Phascolus, for example, broad bean (Vicia faba), soy bean (Soja max), velvet bean (Mucuna utilis), asparagus or dolichos bean (Vigna sesquipedalis), cowpea or bean (Vigna sinensis), Jack bean (Canavalia ensiformis), locust bean (Ccratonia siligna) and hyacinth bean, bonavist or lablab (Dolichos lablab). 
The adjuki bean (Phaseolus angularis) and mung bean (Phascolus aurcus) are now grown to some extent in this country.

\section{Key to Principal. Species of Phasrorus}

Roots tuberous or much thickened, P. multiflerus (scarlet rumner bean). Roots fibrous.

Seeds flat or flat-oval in cross-section, P. lunulus (Sieva and Lima beans).

Seeds mostly circular, but sometimes flat in cross-section, $P$. iulstri (kidney bean).

\section{PHASEOLUS MULTIFLORUS (Scarlet Runner Bean, Dutch Case- knife Bean, Flowering Bean, or Painted Lady)}

These are perennials which usually have tall, climbing stems and pinnately trifoliate leaves. The large and showy' flowers are scarlet (scarlet runner), or white (Dutch case-

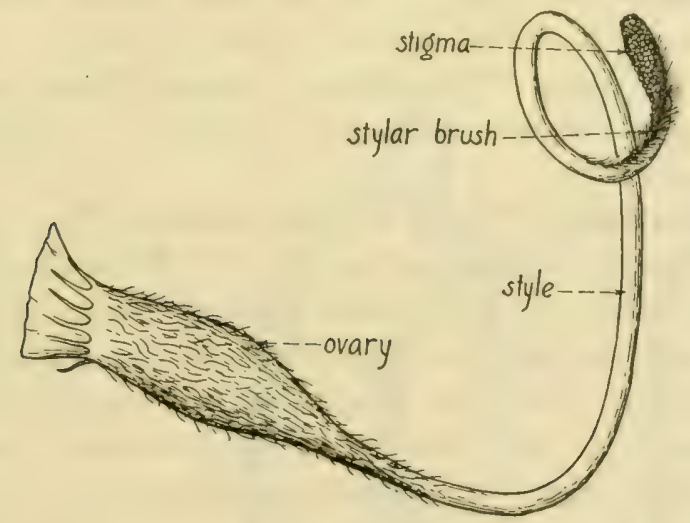

FIG. I77.-Pistil of flower of common bean (Phaseolus vulgaris). (After Knuth.)

knife), and form racemes. Pods are 3 to 6 inches long, and curved; the seeds are large and plump, flattened or cylindric. and vary in color.

The scarlet runner form is also known ats the flowering bean or painted lady, and is much used as an ormamental vine. The Dutch case-knife form of this species - one with white 
flowers - is grown for the edible beans. The Aroostook bush Lima bean is considered by Tracy to be a bush form of Phaseolus multiflorus. The species is raised to some extent by the Mexicans, and it is very probable that some at least of the so-called "Mexican beans" are varieties of this species.

Phaseolus multiflorus is a native of South America and Mexico.

\section{PHASEOLUS LUNATUS (Sieva and Lima Beans)}

These vary in form from low and bushy to tall and climbing. The leaves are pinnately trifoliate, the leaflets varying from narrowly lanceolate to ovate. The flowers are small, and in axillary racemes. The pods are usually broad and flat, and have flattened, variously colored beans.

The native home of these beans is tropical South America. They require higher temperatures than the varieties of Phaseolus vulgaris.

Classifications of Types of Lima Beans.- There are two general types of Limas, as follows: (I) Phaseolus lunatus, including the Sieva or Carolina type of Lima, and (2) $P$. lunatus var. macrocarpus, including the true Limas. The latter have a taller and much more robust growth, and thicker leaflets than the Sievas or Carolinas. In both groups above, there are pole and bush forms.

\section{Table Showing Relationship of Types of Lma Beans}

Phaseolus lunatus (Sieva, Civet, or Carolina beans).

Plants bush (Henderson's Bush Lima).

Plants pole (Small White Lima, Florida Butter).

Phaseolus lunatus var. macrocarpus (true Limas).

Seeds very flat and veiny; pods broad and flat, with tip not prominent leaflets broad, not ovate, Flat-secded Limas.

Plants bush (Burpee's Dwarf Lima).

Plants pole (King of the Garden). 

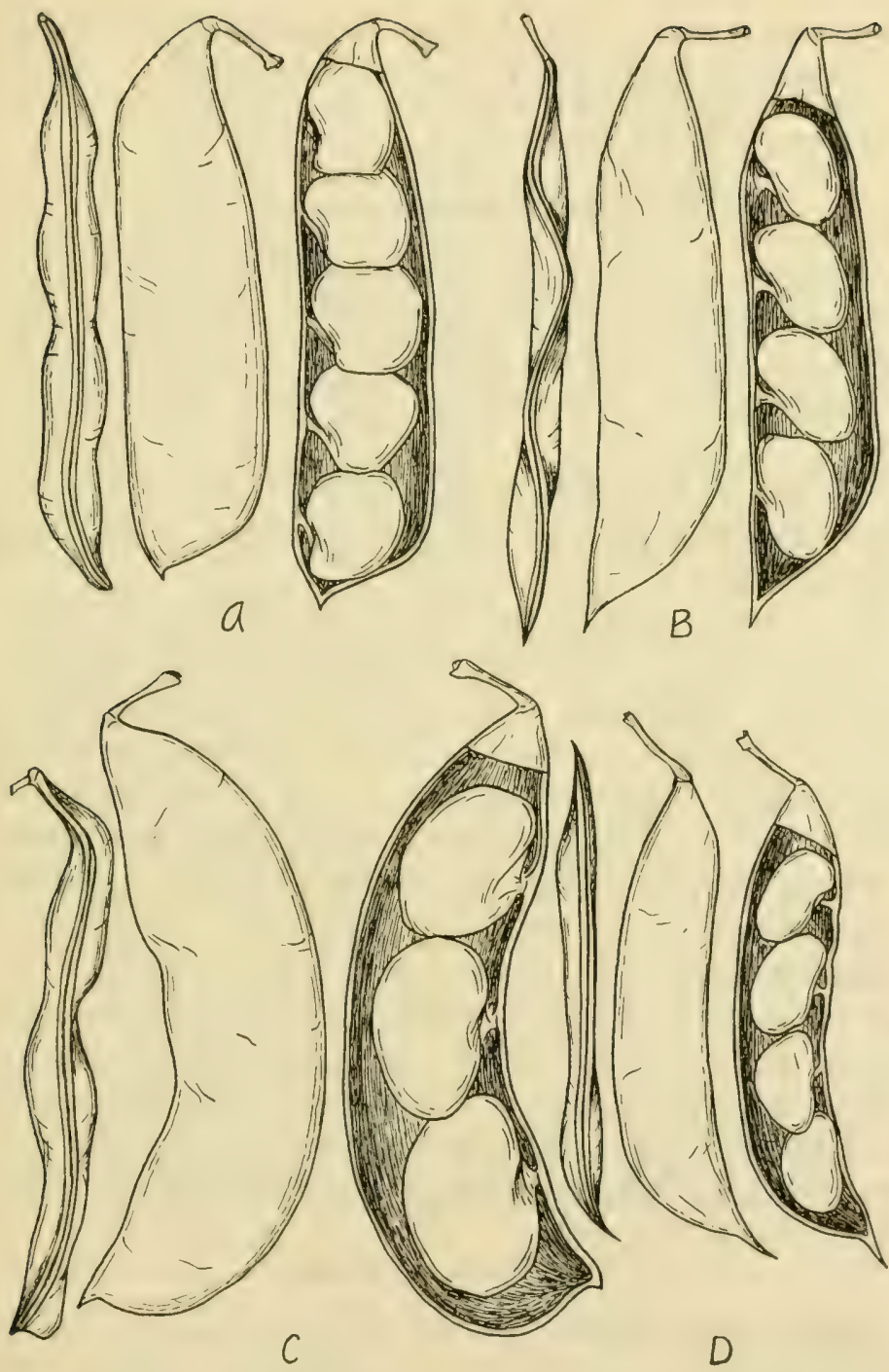

FIG. I 79.- Types of Lima beans. 1 , Potato Lima, pole; $B$, Sicva type, pole; $C$, large, flat Lima, dwarf; $D$, Sieva type, dwarf. (Modified after Corbell.) 
Seeds smaller; pods short and thick, with prominent tip; leaflets tapering, long ovate, Potato Limas. .

Plants bush (Dreer's Dwarf Lima).

Plants pole (Dreer's Improved).

\section{PHASEOLUS VULGARIS (Kidney Bean)}

These are annual plants, with pinnately trifoliate leaves and ovate leaflets. The flowers are small, not over $5 / 8$ inch across the wing, and are white, yellowish, or blue-purple. The slender pods vary in shape, and have kidney-shaped seeds.

This species is thought to be a native of tropical America. The cultivated varieties thrive best where the growing season is warm.

There are, according to Tracy, I45 varieties of kidney beans in America. These are usually divided into two large subdivisions, pole and bush. These in turn each possess green-podded and wax-podded sorts. The bush beans are often grouped together under the variety $P$. vulgaris nanus. Most of our common garden sorts are dwarf or bush beans. ${ }^{1}$

The stringiness of bean pods is due to strips of inedible, tough fibers at the sutures.

Uses of Beans.-Beans are used in large quantities dried, and in the pod as "green beans." Lima beans are often canned with corn in succotash. Great quantities of common kidney beans are put up in the form of "pork and beans." The Mexicans and southwestern Indians raise beans in large amounts; beans constitute one of their chief articles of diet.

\section{VICIA (Vetch, Broad Bean)}

Generic Description.--The Vicias are climbing or trailing herbaceous vines. The leaves are pinnate, tendril-bearing,

${ }^{1}$ For a detailed classification of American varieties of beans see Bull. Iog, Bureau of Plant Industry, by W. W. Tracy. 
and with half-sagittate or entire stipules. The flowers are blue, violet, yellowish, or white, and in axillary racemes. 'The calyx tube is oblique, and its teeth or lobes are about equal, or the two upper ones somewhat longer. The standard is notched at the tip, and the wings are attached to the curved keel. The stamens are diadelphous (nine and one), or monadelphous below, and have filiform filaments. The sessile or stipitate ovary has numerous ovules and a slender style with a tuft or ring of hairs at its summit (Fig. 173, A). The pod is flat.

Geographical.-There are more than I0o species of Vicia, of wide geographical distribution. There are about 20 wild species in the United States.

Key to Important Species of Vicia

Plants erect, smooth, or only slightly hairy, seldom tendril-bearing; flowers whitish with dark blue spots on each wing, $V$. $f a b a$ (broad or Windsor bean). . Plants weak, usually hairy, tendrilbearing; flowers purplish.

Leaves rounded at tip; flowers many, in long one-sided racemes (Fig. I 82 ), $V$. villosa (hairy vetch).

Leaves truncate at tip; flowers few, usually two in each leaf axil, $V$. sativa (vetch).

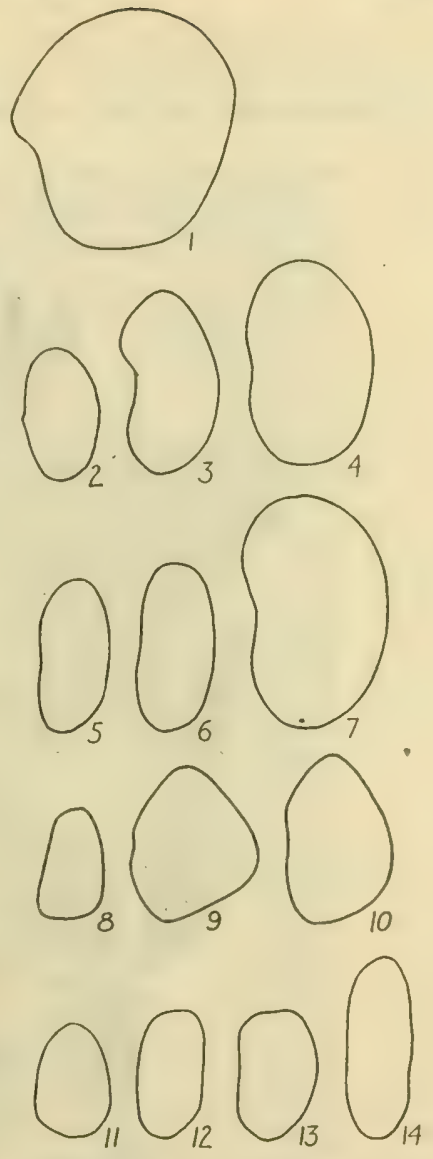

FIG. I 80.-Types of bean seeds. I, Broad Windsor; 2, White Narrow Field; 3, Dutch Case Knife Pole; 4, White Dutch Runner Pole; 5, Grenells Stringless Green Pod; 6, Long Yellow Six Weeks; 7, Long White Pole Lima; 8, Powell's Prolific Pole; 9; Dreer's Pole Lima; ro, Florida Butter Pole Lima; II, Yellow Cranberry Bush; I2, Horticultural Wax; 13. Red Mexican; 4 $_{4}$ French Kidney. (Modified after Tracy, U. S. Dept. Agri.) 
Less Common Species. - There are a number of other Vicia spp. that are cultivated to some extent, as follows: Narrozi-leuved vetch (Vicia anguslifolia) is a native of the eastern United States, and is grown somewhat in Georgia

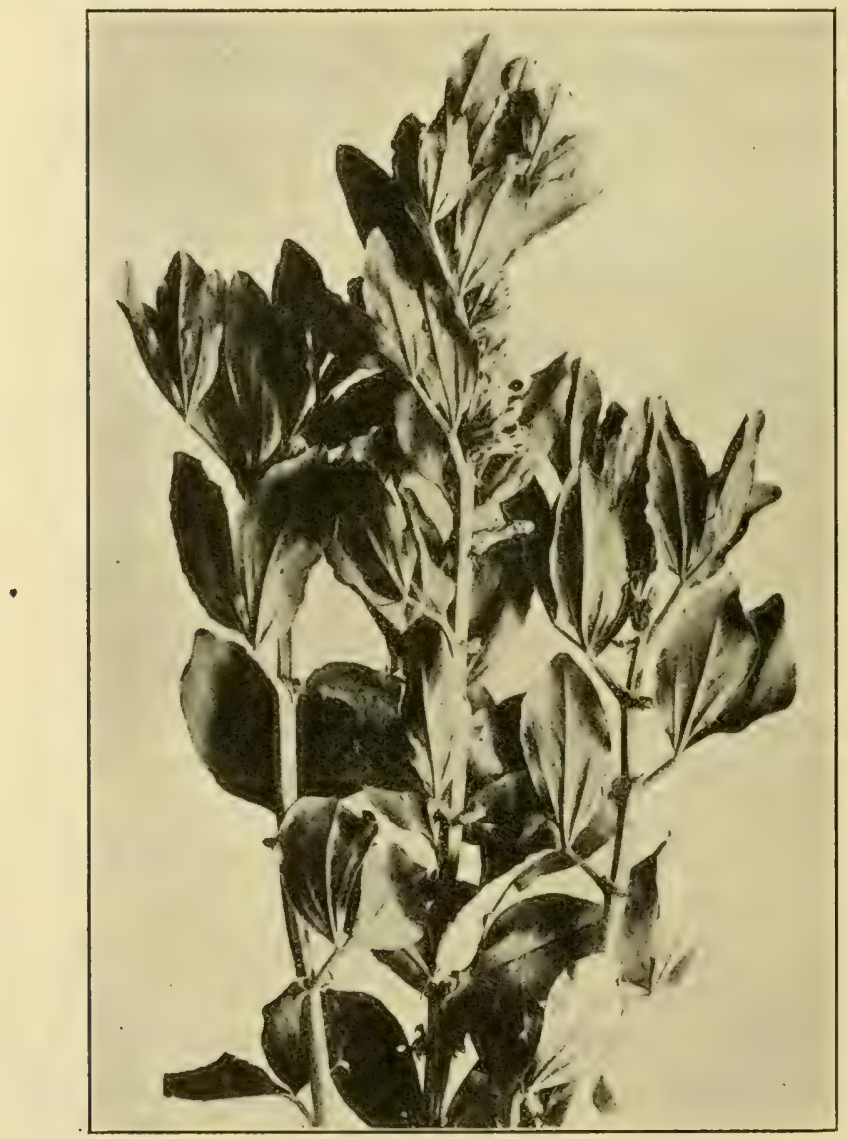

FIG. I8I.-Broad or Windsor bean (Vicia faba).

as a hay crop. Black bitter velch (Vicia crvilia) is an Asiatic species, cultivated somewhat as a winter green-manure crop in California. Purplevelch (Vicia atropur purea) resembles hairy vetch from which it differs, however, in being smooth. It is cultivated on the Pacific Coast and in the South. Scarlel 


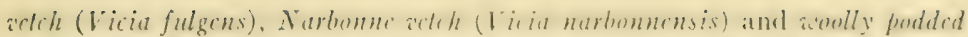
welch (licid dasycarpa) are rather rare species, cultivated to at slight degree on the Pacific Coast.

The term "vetch" is given to a number of plants, not belonging to the genus Vicia, for example: (rown retch (Coronilla sp.), kichey retch ( 1 nh/hyllis vulneraria), Dakota vetch (IIosackia americana) and Lathyrus spp.

\section{VICIA FABA (Broad Bean, Windsor Bean)}

This is a strong, erect annual, 2 to 4 feet high with a welldeveloped primary root (Fig. I8I). The leaves are pinnately' compound, and become blackish on drying. The inflorescence is an axillary raceme of two to six flowers. The flower is white, its wings marked by a large black spot. The pods are large and thick, and vary considerably in length, each bearing a number of large, black seeds. The smaller-seeded sorts, sometimes known as pigeon bean. field bean and tick bean, are used as an animal food, while the large-seeded varieties are used as human food.

The home of the wild plant from which the cultivated varieties are derived is Algeria. Broad bean is cultivated chiefly in Canada. It thrives best where the summers are long and cool.

\section{VICIA SATIVA (Common Vetch or Tares)}

This is an annual climbing plant which branches freely. The leaves are pinnately compound with about seven pairs of leaflets, and a terminal tendril. Flowers occur singly or in twos in the leaf axils; they are short peduncled, and reddish purple (rarely white) in color. The flowers are cross-fertilized. The hairy pods have four or five smooth, globular, gray or marbled seeds. The Willamette Valley, Oregon, produces a large proportion of the common vetch seed in the United States. Vetch seed loses its viability very rapidly after about the third year. The plant is a native of Europe. 
It has become naturalized in many parts of the United States, occurring in fields and waste places. Common retch is sown either as a winter or spring annual. If the winters are severe it is planted in the spring. This is the practice in the Northern States. However, in the south, where the winters are mild, it is planted in the fall. It is adapted to a light soil. It is intolerant of a poorly drained soil. The poorer soils of the East, deficient in lime, will support a fair crop. There are numerous varieties of the common vetch. Spring and winter varieties are recognized. The white or pearl vetch has white flowers and seeds.

Uses.-Common vetch is grown in the old country, and to an increasing extent in United States, as a hay crop. When grown for this purpose it should be cut when in bloom. The seeds are sometimes made into a flour. The species is also being recommended as a cover crop for orchards, and as a green manure.

\section{VICIA VILLOSA (Hairy, Hungarian, Russian, Siberian, or Villous Vetch)}

Hairy vetch (Fig. I82) is an annual or biennial, hairy plant naturally suited to cool temperate regions. The plants may grow to a length of $\mathrm{I} 2$ feet or more, but seldom to any considerable height on account of the weak stems. There is an extensive and deep root system which in the early stages of growth, particularly, constitutes a large proportion of the total weight of the plant. There are five to eight pairs of leaflets, and many (about thirty) violet-blue, rarely white, flowers in one-sided racemes. Cross-fertilization is necessary for the normal production of seeds. Bees are chief agents in the dissemination of pollen. The pods are smooth, pale in color, and contain two to eight small, globular black seeds. The cotyledons remain underground at germination, as is the case in the common garden and field pea. Hairy vetch is a 
native of Europe and Asia. It is much hardier than $\mathrm{common}$ vetch, and consequently can be grown at higher latitudes. Moreover, it is more drought-resistant and tolerant of alkali.

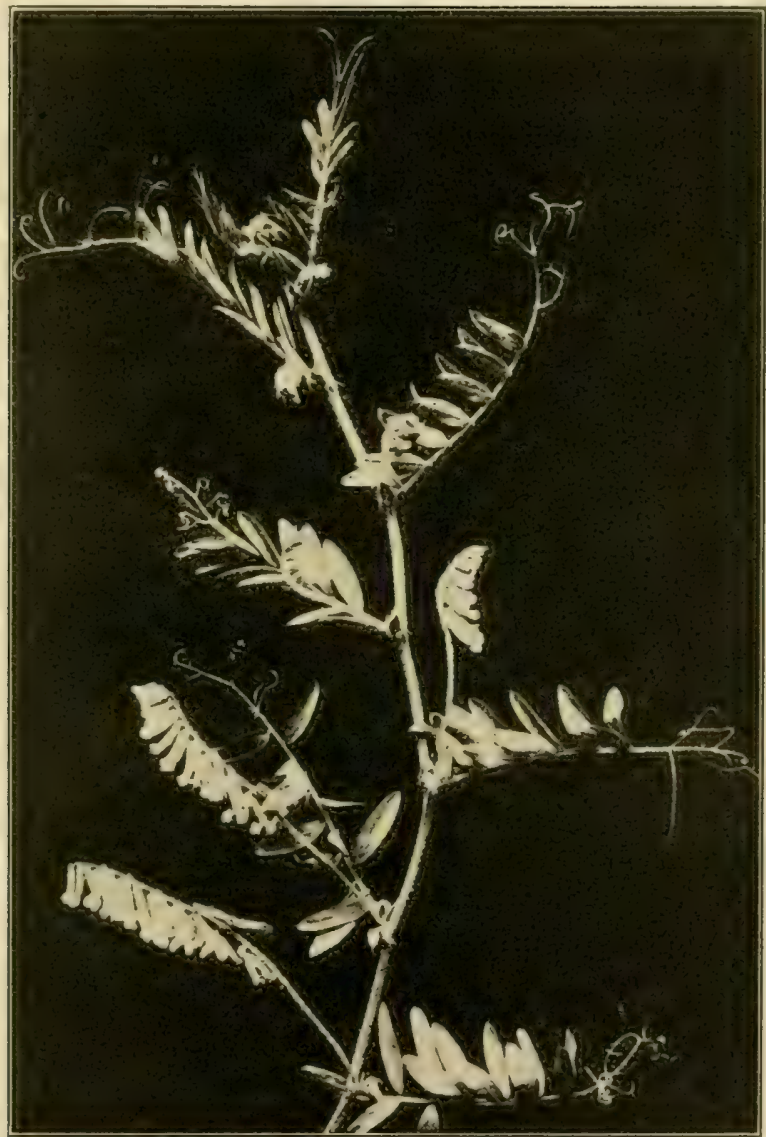

FIG. I82.- Hairy vetch (Vicia villosa).

Hot summer weather is very harmful to its growth. It is frequently planted on light, sandy soils, where it may be plowed under as a green manure. 
The plant has a variety of uses: hay, pasturage, cover crop, silage, and green manure. It is usually cut for hay about the time the first pods are full grown. The quality of the hay decreases after this period.

\section{LATHYRUS (Vetching, Wild Pea)}

This genus resembles Vicia. The leaflets are broader, as a rule, however, the flowers are larger, and the stigma is hairy along the inner side (Fig. I73, B).

There are over roo species of Latbyrus, natives of the Northern Hemisphere and of South America. There are numerous wild sorts in the United States. The two most common species are Lathyrus odoratus, the common sweet pea, and Lathyrus latifolius, the everlasting or perennial pea. Lathyrus odoratus is an annual, bearing two to four flowers on a peduncle, and pods 4 to 5 inches long. The following Lathyrus species are of forage value and are now planted to some extent in this country: L. tingitamus (Tangier pea), L. cicera (flat-podded pea) and L.ochrus (ochrus).

\section{TRIFOLIUM (Clover)}

Generic Description.-Representatives of this group are annual (crimson clover) or perennial (white clover) herbs with palmately trifoliate (hence the name, Trifolium) leaves (Fig. I83), the stipules of which are adnate to the petiole. The inflorescence is a dense spike or head. The flowers. vary in color. The calyx is persistent, its teeth nearly equal, and usually bristle-form. The corolla is also persistent, sometimes grown fast to the tube of filaments. The stamens are diadelphous (nine and one). The ovary is sessile or stipitate, and few-ovuled. The pods are small, membranaceous, mostly one-seeded (rarely more), indehiscent or opening circularly. The seeds are small and kidney-shaped. 
Geographical. - There are (luse 11 , 300 species of Trifolium, most of which occur in the north temperate regions; a few, however, also occur in South America and South Africa. They are distributed from low to high altitudes. Besides those given in the following key, two others, T. subveolens (Shaftal or Persian clover) and T. alcxandrinum (Berseem) are grown to some extent in the United States.

\section{Key to Principal Seecies of Trifolium}

Flowers in spike-like heads, much longer than thick, T. incarnatum (crimson or scarlet clover).

Flowers in globular or ovoid heads.

Corolla white or yellowish-white, sometimes touched with pink; stems creeping, T. repens (white clover).

Corolla red, red-purple, or rose-colored; stems erect or nearly so.

Flowers pedicelled; stipules acuminate (Fig. $18_{3}, 1$ ), T. hybridum (Alsike or Swedish clover).

Flowers sessile; stipules abruptly acute (Fig $18_{3}, \mathrm{D}$ ).

Blade of leaflet marked with large spot; heads sessile, $T$. pratense (red clover).

Blade of leaflet without spot; heads stalked, T. medium (mammoth or zigzag clover).

\section{TRIFOLIUM REPENS (White or Dutch clover)}

Description.- This is a low, smooth, perennial herb arising from a straight tap root. The root system is shallow. The plant possesses creeping stems which develop adventitious roots at the nodes. The long-petioled, trifoliate leaves have inversely heart-shaped or notched leaflets and narrow, membranous stipules. The inflorescence is a head and is borne on a long flower stalk which arises in the leaf axils. The flowers are small, fragrant, and white or pinkish. They are erect at first, but become deflexed when mature. The visitation of insects is necessary for the production of a good crop of seed. The small pods are usually four-seeded. The seeds vary a great deal in their longevity. Germination of so-called "hard seeds" may be delayed several years in the soil. Such seeds usually show up in germination tests. 
Geographical, and Uses.-White clover has become distributed throughout the greater part of temperate North America, Europe, and Asia. It is common in lawns, pastures, and meadows, and is an important ingredient of lawn grass mixtures. The only distinct agricultural variety is Ladino clover (Trifolium repens latum). It is larger than ordinary white clover, and less resistant to cold.

Environmental Relations.-White clover will withstand greater temperature extremes than either red clover or alsike clover. It is naturally suited to cool, moist regions. It is more tolerant of shade than red and alsike clovers.

\section{TRIFOLIUM HYBRIDUM (Alsike, Alsatian, or Swedish clover)}

Description.--Alsike is an erect, branching, rather stout, almost glabrous perennial, $x$ to 3 feet tall. Its life period is from four to six years. There are many secondary roots which soon become as large as the main tap root. The leaves are long and have greenish veins, long taper-pointed stipules (Fig. I83, A), and obovate leaflets. The plant is more leafy than red clover. The plant is usually cut for hay when in full bloom. The flowering heads are on long peduncles which arise from leaf axils. The flowers are pedicelled, and white or pinkish. The pods are two- to four-seeded. The seeds lose their viability rapidly after the second year.

Geographical, and Uses.-Alsike clover is a native of Europe. It has been introduced into this country for agricultural purposes and has escaped from cultivation, often being found in fields and waste places. It is not a hybrid between white clover and red clover, as formerly thought. The plant is grown in the same manner and for the same purposes as red clover. The plant is very hardy, more so than red clover, and is quite frequently mixed with timothy 
for planting at high altitudes and latitudes. It is prized as a honey plant.

\section{TRIFOLIUM INCARNATUM (Crimson, Scarlet, or Italian Clover)}

Description.--This is an erect, soft-hairy annual, 6 to 36 inches high. The leares are long petioled; the stipules are broad and with dark purple margins; the leaflets are
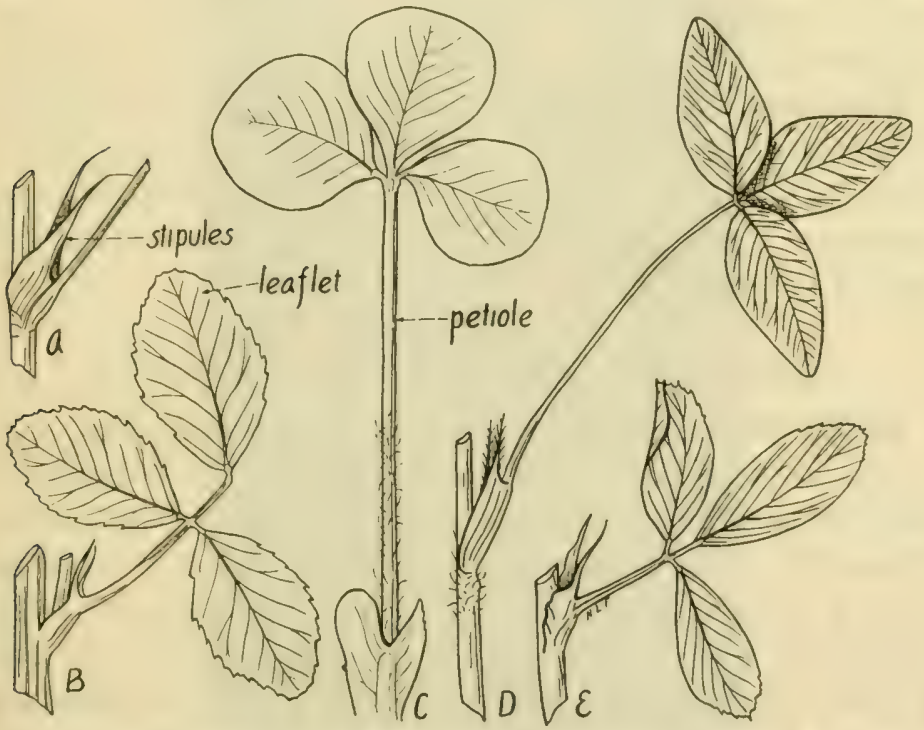

FIG. I83.-A, stipules of alsike clover (Trifolium hybridum); $B$, leaf of yellow sweet clover (Melilotus alba); $C$, leaf of crimson clover ( $T$. incarnatum); $D$, leaf of common red clover ( $T$. pratense); $E$, leaf of alfalfa (Medicagu) sativa).

almost sessile, and obovate or obcordate. The inflorescence is a terminal, dense, elongated, spike-like head (Fig. I84). The flowers are bright crimson (rarely white, yellow, rose or variegated) and showy. The seed is shiny when fresh and pinkish in color. 
Geographical, and Uses. (rimson clover is a native of Europe. It has become naturalized in the eastern portions of the United States, where it occurs quite commonly in waste places. The plant is grown in this country mainly as a crop for hay, forage, or silage. It also has some value as a soiling crop and as a cover crop. The hay sometimes proves dangerous to horses, due to the tendency of the hairy calyces to form indigestible masses in the stomach of the animal, especially if the plants are too ripe when cut. These hair balls seldom form in the stomachs of cattle and sheep.

Environmental Relations.--Crimson clover is less resistant to low temperatures than any of the other common clovers. It is grown with success in orchards, because of its shade tolerance. Although it prefers sandy soil, it will do well in soils of heavier type.

\section{TRIFOLIUM PRATENSE (Common Red or Purple Clover)}

Habit, Stems and Roots.-This is a perennial plant, more or less hairy, branching, decumbent or erect, 6 to 24 inches tall, rising from the crown. The life period is a varietal character. The average is about three years. It develops from a strong tap root which possesses an extensive system of laterals. The tap root reaches a depth of 3 or 6 feet. It draws moisture and mineral nutrients from the lower soil layers. In general there is about $\mathrm{I}$ pound of root to 2 pounds of plant above ground. This means that the clover crop leaves considerable organic matter in the soil.

Leaves.-The leaves are of the clover type, with hairymargined leaflets and large conspicuously purple-veined stipules. The leaflets often bear a pale spot in the center.

Inflorescence and Flowers.-The terminal inflorescences are ovate (Fig. I 84 ). Each inflorescence has from 35 to I 50 purple-rose flowers. The second crop usually has more flowers 
per head than the lirst crop). The flowers are of the ordinary pea type, except that the petals are united at their bases and to the staminal tube to form a corolla-tube about 1,2 inch long.

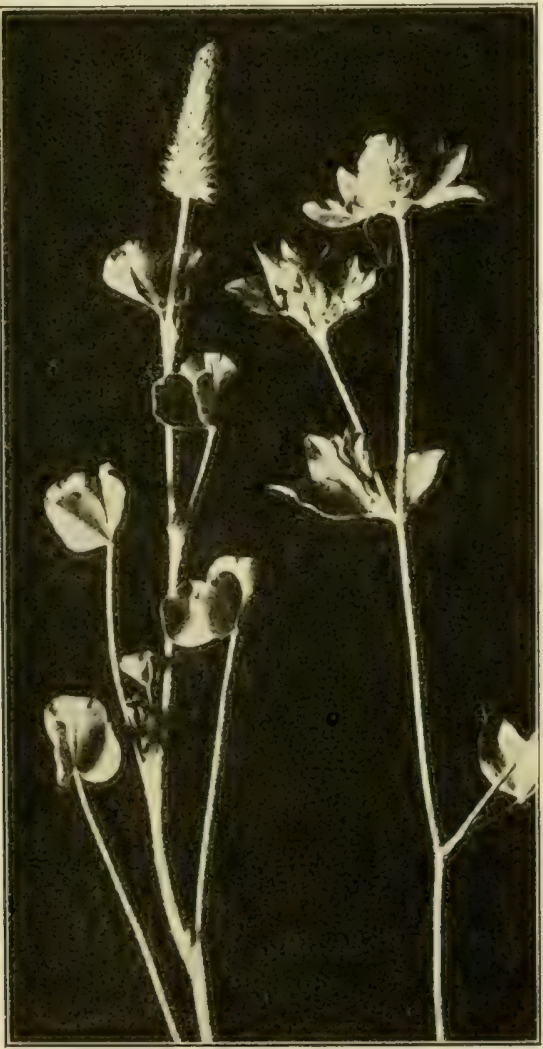

FIG. I84-Crimson clover (Trifolium incarnatum), on left; common red clover ( $\mathrm{T}$. pratense), on right.

Fruit.-The ofary develops into a capsule, bearing one seed. There are two ovules in each ovary, but only one, as a sule, matures into a seed. Infertile ovules are quite com- 
mon in red clover, the larger percentage usually being in the first crop. This is probably one of the chief reasons why the second crop of clover is more commonly used for seed. An additional advantage in harvesting the second crop for seed rather than the first is that the farmer is able to get two crops in a season, for if the first crop is allowed to seed, there is insufficient food supply, and in some instances a season too short, for the development of a vigorous second growth. In

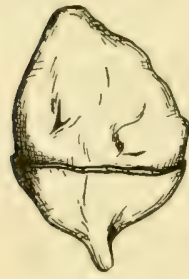

FIG. I $85 .-$ Fruit of red clover (Trifolium pratense), much enlarged. addition to the reason given above for the relatively light yield of seed in the first crop, it is claimed that pollinating insects are not abundant enough, and that the plant is occupied with the production of new shoots rather than reproductive activity. In general, a rank-growing plant is not a good seed producer.

When the capsule is mature, the stylar end separates from the basal part by an irregular transverse line. The upper part of the capsule, together with the style, comes off as a lid (Fig. I85), and the single seed escapes. The seeds are kidney-shaped, and yellow, or mixed yellow and violet in color.

Pollination.--Red clover flowers are protandrous. The work of Westgate and Coe establishes the fact that "red clover flowers must be cross-pollinated in order to set seed on a commercial basis." The pollen must come from a separate plant, for even when taken from flowers of the same plant, the percentage of seed set is very small. The bumblebee (Bombus) is the most important insect visitor of the red clover. It is capable of pollinating 30 to 35 flowers a minute. Honey bees are also efficient pollinators. When the bumblebee lights on the clover head and inserts its proboscis into the staminal tube, its weight presses down on the keel and 
wings of the flower, from which nectar is being taken, thus forcing out the stigma and anthers up against the bee's head. The stigma becomes dusted with pollen from another flower and the anthers open, leaving pollen on the under side of the bee's head. The flower parts return to their original position when the bee leaves the flower. Nectar sought by the bee is secreted at the bases of the stamens, and collects in the staminal tube.

Geographical.- The species is a native of Eurasia. It has become naturalized in the United States, occurring commonly in the fields and meadows throughout most of our area.

Environmental Relations.-Red clover attains its best growth in humid sections of the country, and where the summer and winter temperatures are not extreme. Unlike alfalfa, dry atmospheric conditions are detrimental to red clover; but like alfalfa it requires lime in the soil. Moreover, it is intolerant of a poorly drained soil and of much shade.

Mammoth Clover.- This clover, sometimes known as perennial clover, sapling clover, pea-vine clover, and bull clover, is a form of the ordinary Trifolium pratense; as compared with the latter, mammoth clover matures later. has a more highly branching tap root, longer pedicels, and solid stems. It is known as Trifolium pratense perenne.

Uses.-Common red clover is one of our most prized forage and hay crops; it is also raised to some extent as a green-manure and cover crop. Its importance as a crop in the United States may be judged from the fact that the total acreage is about five times that of alfalfa. It is adapted to the humid sections of the country. The highest percentage of digestible substances occurs in the plant just before full bloom. The plant soon becomes tough and fibrous after the blooming period. 


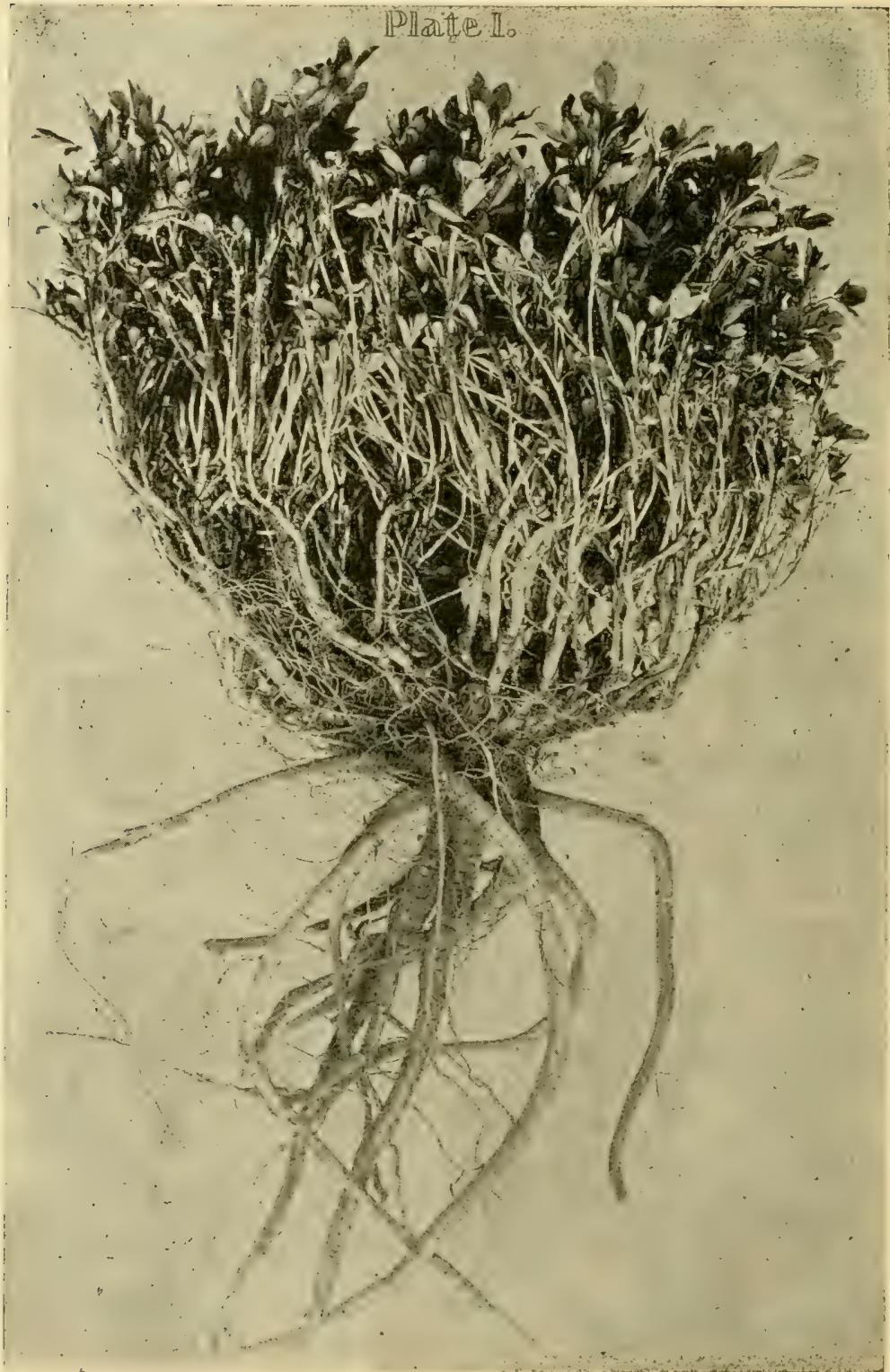

FIG. I 86.-A vigorous alfalfa plant showing the "crown" from which arise the numerous shoots. (After Headden, Colo. Agr. Exp. Sta.) 
TRIFOLIUM MEDIUM (Zigzag, Medium Red, White, Mammoth or Meadow Clover)

This is a peremial clover resembling red clover (T. pra(ense), described above. 'The plant is larger, however, its stems are more spreading and bent more zigzag at the nodes; the leaflets are longer and narrower, and the stipules longer and more pointed. The leaflets are lanceolate or oblong and not spotted as in the red clover. The flowers are bright purple.

This species is a native of Siberia and possibly Europe. It has gained entrance into this country and occurs here and there in the eastern United States as a ruderal.

The plant is being grown in the same manner and for the same purpose as common red clover.

\section{MEDICAGO (Medics)}

Generic Description.-The medicagos are mostly herbs, sometimes woody at the base, as in common alfalfa, and very rarely shrubby (one species in southern Europe). The leaves (Fig. I83, E) are pinnately three-foliate, the stipules adnate to the petiole, and the leaflets commonly dentate, pinnately veined,

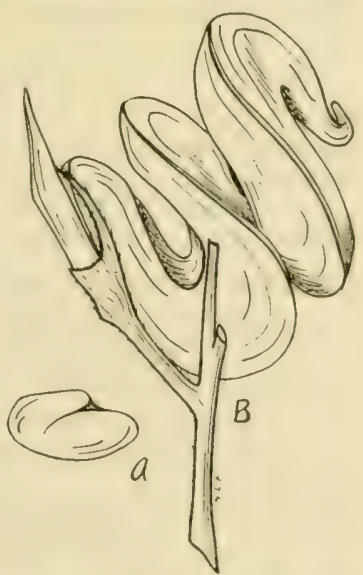

Fin. I87.-Seed and pesel of alfalfa (Nedicago sativa). $\times 5$. with the veins terminating in the teeth. The flowers are small, yellow or violet, in axillary heads or racemes. The calyx teeth are short, and about equal in length. The pelals are free from the staminal tube; the standard is obovate or oblong, the wings oblong, and the keel short and obtuse. The stamens are diarlelphous (nine and one). The 
ovary is sessile or short-stipitate, and several- or rarely oneovuled; it has a subulate (awl-shaped), and smooth style. The pods (Fig. I87) are curved or spirally twisted, veiny or spiny, and indehiscent.

Geographical.-There are a number of species of $M c d i$ cago, all of which are native to the eastern hemisphere. They naturally range from Eastern Asia to Southern Africa. There are seven perennial species of Medicago, and about 37 annual species, one of which, yellow trefoil (Mcdicago lupulina), has a biennial or possibly perennial form. The nonperennial species are commonly known as "bur clovers." They will grow naturally as winter annuals.

\section{Key to Principal Species of Medicago}

Perennial, erect-growing plants; flowers violet, Medicago sativa (alfalfa). Annual, low-growing plants; flowers yellow.

Pods kidney-shaped, without spines, Medicago lupulina (hop clover). Pods cylindrical, with spines.

Stems pubescent; pods $3 \frac{1}{2}$ to 5 millimeters diameter; purple spot in center of each leaflet; two to eight seeds in each pod, Mcdicago arabica (spotted bur clover).

Stems glabrous, pods 7 to ro millimeters diameter; no purple spot in center of each leaflet; three to five seeds in each pod, Medicago lispida (toothed bur clover).

\section{MEDICAGO SATIVA (Alfalfa, Lucerne)}

Roots.-Alfalfa is a deep feeder. The young plant usually sends down a single tap root. As a rule, this takes a straight downward course. Comparatively few side roots are given off. Usually, these are below the depth of 4 feet. Headden found in a plant only nine months old, that the young roots had extended to a depth of over 9 feet. Ordinarily the weight of roots exceeds weight of top.

Stems.-Alfalfa is an ascending or erect perennial. Its life period is dependent upon environmental conditions, and 
the variety. The average life is from five to seven years. Fields 20 to 25 years old are found in the semi-arid sections. At or near the ground level, is a short, compact stem (crown) from which the numerous (20 to 50) branches arise (Fig. 186). Blinn has shown that there is a well-defined relationship between the nature of the crown and hardiness. Non-hardy types of alfalfa have an upright-growing crown with but few buds and shoots developed below the soil surface. The crown of hardy types is more spreading and the numerous buds and shoots come from below the soil surface. Hence in the latter case, the buds and young shoots are protected by the soil from winter freezing. These hardy types are Grimm and Baltic strains. The stems of alfalfa are rather slender and freely branching. Common alfalfa has no rootstocks. Some forms of Medicago falcata possess them, however, and they also occasionally appear in some variegated types.

"Cuttings" of Alfalfa.-The number of "cuttings" of alfalfa depends upon the length of the growing season, and the water supply. Three cuttings are usually marle throughout most of the alfalfa-growing regions of the United States. In the Imperial Valley, California, ordinary alfalfa has yielded as many as nine cuttings in a year. This practice indicates that alfalfa has the capacity of sending up numerous shoots from the crown. The shoots of a second or third crop begin to appear about the time the plant is coming into bloom, and it is the usual practice to cut the crop at this time, so that the food supply that would normally go into developing fruit and seed, is diverted to the young growing shoots of the succeeding crop. Furthermore, the leaves are richest in nutritive substances when the plant is in bloom. The leaves contain about so per cent. of the protein in the plant, hence methods of harvesting should look toward the prevention of their loss. The different cuttings of alfalfa 
vary somewhat in quality and chemical composition. How. ever, more data are needed to determine the relative feeding value of the different cuttings.

The alfalfa plant is a heavy feeder. According to Ames and Boltz, a 3 -ton yield of alfalfa hay contains ${ }^{6} 6_{3}$ pounds of nitrogen, I7 pounds of phosphorus, 99 pounds of potassium, and 90 pounds of calcium.

Leaves.-The alternately arranged leaves are trifoliate (Fig. I $83, \mathrm{E}$ ). They are oblong in general outline and sharply toothed along the margin; the tip is terminated by a projecting midrib. The stipules are prominent.

Inflorescense.- This is a dense raceme springing from the axils of the branches.

Flowers. The ordinary color of the flower is purple or violet, but in variegated types, may be blue, green, or yellow. The calyx teeth are longer than the tube of the calyx. The standard is somewhat longer than the wings, which in turn surpass the keel. The staminal tube is held in a state of tension by two opposite lateral projections on the inside of the keel (Fig. I88).

Pollination (Fig. 188).--Alfalfa possesses a mechanism for the explosive dispersal of its pollen. When the edges of the keel are spread apart, the staminal tube is released, and both the pistil and stamens snap up against the standard. The pollen is scattered in this process. The process is called "Iripping." Alfalfa flowers are usually tripped by visiting insects, chiefly bumblebees and leaf-cutting bees (Megachile). The weight of an insect may be sufficient to cause a separation of the keel edges, and consequently "tripping." Usually, however, the separation is brought about by the protrusion of the insect's proboscis between the edges of the keel. It has been observed that alfalfa flowers may be tripped without the visitation of insects. This is termed 
"atutomatic" tripping. Humiclity and temperature conditions are probable causative factors in automatic tripping. Both self- and cross-pollination are effective in alfalfa.

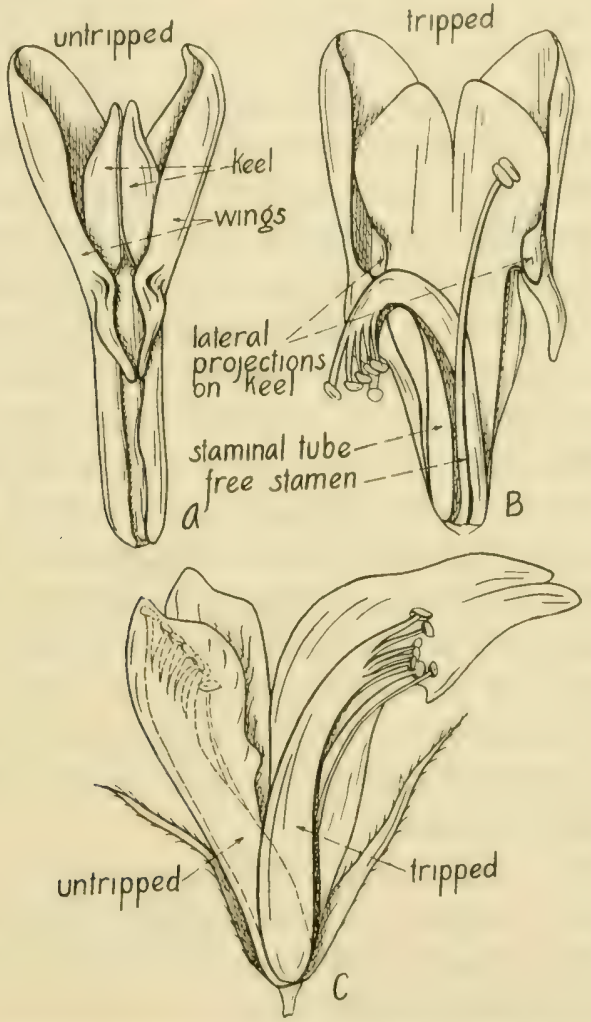

Fic. I 88.-Pollination of alfalfa. A, flower untripped with calyx and standard removed; $B$, same tripped; $C$, position of staminal tube untripped and tripped. (After U. S. Dept. Agri.)

Self-pollination usually results from automatic tripping. It is known that good seed crops are produced in regions where tripping insects are scarce. However, the number 
of pods set and the number of seeds per pod are increased if cross-pollination (xenogamy) is accomplished.

Factors Affecting Seed Production.-As has been indicated, cross-pollination results in a greater crop of seed than self-pollination. An abundance of tripping insects may increase considerably the seed output; however, good seed crops occur in regions where tripping insects are scarce. Seed production is usually light in humid sections of the country. Moreover, too much irrigation water applied during the flowering period is detrimental to seed production. The heaviest yields of alfalfa seed occur in the arid sections of Kansas, Colorado, Utah and Idaho. Isolated plants invariably produce a greater crop of seed than those in a thick stand. The sun's heat favors automatic tripping.

Martin finds that the setting of seed pods in alfalfa is largely dependent upon the proper functioning of the pollen. The pollen grains require a certain amount of water to germinate. When a pollen grain comes to the stigma, the amount of water it finds there depends upon the moisture delivery of the stigma and the moisture of the air. The supply of water for germination of the pollen grains may be changed by increasing the water in the soil, or the atmospheric humidity about the plant.

Fruit.-This is an indehiscent legume, coiled two or three times (Fig. I87). There are one to eight seeds in each pod; they are kidney-shaped, and about 1/8 inch long. The seeds retain their viability for many years.

Germination and Seedling.- The young seedling consists of two short cotyledons, a hypocotyl, and a tap root. The first foliage leaf is simple, while the second, third, and all others are trifoliate. There is soon formed an erect stem with but few branches; hence the first growth looks thin. However, there spring up later numerous branches from 
the lowermost nodes and from the axils of the cotyledons. The result is a well-developed "crown."

Geographical.- Common alfalfa is a native of temperate western Asia. The original home is probably from northern India to the Mediterranean region. It is now being cultivated in many parts of the world, and wherever so cultivated, frequently escapes and becomes a ruderal.

Types of Alfalfa.-Medicago sativa is now quite generally considered to be an heterogeneous species, made up of many strains, varieties, and even subspecies. Westgate holds that some of our hardy strains of alfalfa (Grimm, for example) owe their hardiness to the possession of a small percentage of the "blood" of the hardy yellow-flowered or sickle alfalfa (IIedicago falcata). Numerous forms of alfalfa arise where ordinary alfalfa ( $M$. sativa) and yellow-flowered alfalfa $(M I$. falcat $($ ) grow together. These hybrid forms are, of course, unstable. They have been recrossed several times with ordinary alfalfa and also among themselves. Such forms have been termed "variegated alfalfas." Sand lucerne (Medicago media) is considered by some botanists to be a natural hybrid between $M$. sativa and $M$. falcata; others consider it to be a distinct species. Sand lucerne has flowers ranging from bluish and purple to yellow, with numerous intermediate shades. The seeds are not as heavy as those of common alfalfa. The plant is a hardy type. Grimm alfalfa, as has been indicated, is quite certainly a form with hybrid characteristics, the parents being common alfalfa and yellow-flowered alfalfa. Other well-known types of alfalfa are: Turkestan, German, American, Arabian, and Peruvian.

Turkestan was secured from Russian Turkestan in 1898 . The water requirement of the plant is low, and it also possesses an ability to withstand extremes of temperature. The plant is ordinarily a little smaller, and the leaves are narrower and more hairy, than other common sorts. German 
alfalfa resembles Turkestan. It is less harly, however, and is a poorer yielder than the American type. The latter is the most common western alfalfa. Arabian alfalfas are not resistant to cold, hence they are restricted to the warmer States, particularly Arizona, New Mexico, Texas, and California. Peruvian alfalfa is a productive sort adapted to growth under irrigation in the southwest, where the winters are mild. Brand proposes to place Peruvian alfalfa as a distinct variety (Medicago sativa var. polia). It is taller, less branched, and more rapid in its growth and recovery after planting than common cultivated alfalfas. Furthermore the flowers are slightly longer, and the floral bract is longer than either calyx teeth or calyx tube.

Environmental Relations.-Alfalfa is able to withstand high temperatures if the air is dry, but high temperatures accompanied by a humid air are decidedly injurious. For this reason, it is particulary well adapted to the semi-arid sections of the United States, where it is grown both on irrigated and non-irrigated land. Its resistance to low temperatures is a varietal characteristic, and also somewhat dependent upon cultural operations. Grimm and Baltic types are less liable to suffer from winter killing than the so-called common alfalfas.

The following data shows the water requirement of alfalfas, in comparison with other crops (from Briggs and Shantz).

\begin{tabular}{|c|c|}
\hline Crop & $\begin{array}{c}\text { Water } \\
\text { Requirement }\end{array}$ \\
\hline Millets............... & 3 Iо \\
\hline 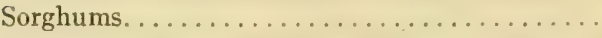 & 322 \\
\hline 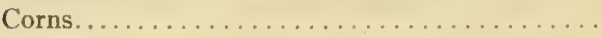 & 368 \\
\hline Wheats. . . . . . . . . . . . . . . . . & $5 \times 3$ \\
\hline 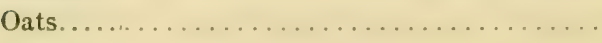 & 597 \\
\hline 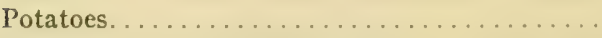 & 636 \\
\hline Alfalfa, Peruvian S. P. I., $(30,203) \ldots \ldots \ldots \ldots$ & $65 \mathrm{I}$ \\
\hline Alfalfa, Grimm S. P. I. $(25,695) \ldots \ldots \ldots \ldots$ & 963 \\
\hline
\end{tabular}


In spite of its relatively high water requirement, alfalfa is able to withstand drought. This is due to its deep root system which draws upon the water in the lower strata of soil.

Alfalfa cannot withstand alkali, and suffers if soil drainage is not good. The plant requires lime in the soil. The soil type has considerable influence upon the form of the root system. A hard compact soil causes a more or less branching root system, while in a loose soil the tap root system is typically developed.

Uses and Production.-Alfalfa is the most important hay crop in the Western States. The total number of acres in alfalfa in the United States, I909, was 4,707,146; of this number, the Western States furnished $4,523,513$ acres. The five leading States, I909, named in the order of their alfalfa production were Kansas, Nebraska, Colorado, Cal. fornia and Idaho.

\section{MEDICAGO LUPULINA (Hop Clover, Black Medic, Yellow Trefoil)}

This plant is usually annual, sometimes perennial. The stems are four-angled, pubescent, and branched at the base, the branches being decumbent and spreading. The petioled leaves have small obovate, oval or orbicular, denticulate or crenulate leaflets. The flowers are small, yellow, in dense. oblong or cylindrical heads. The pods are black, curved, strongly veined, and one-seeded.

The plant is a native of Eurasia. It is now found throughout the greater part of the United States and other temperate regions where it occurs in fields and waste places. It is sometimes planted on poor soil, and has some promise as a green manure.

\section{MEDICAGO ARABICA (Spotted Bur Clover)}

This is a smooth annual plant with procumbent stems. The leaflets have a dark purple spot in the center. The pods 

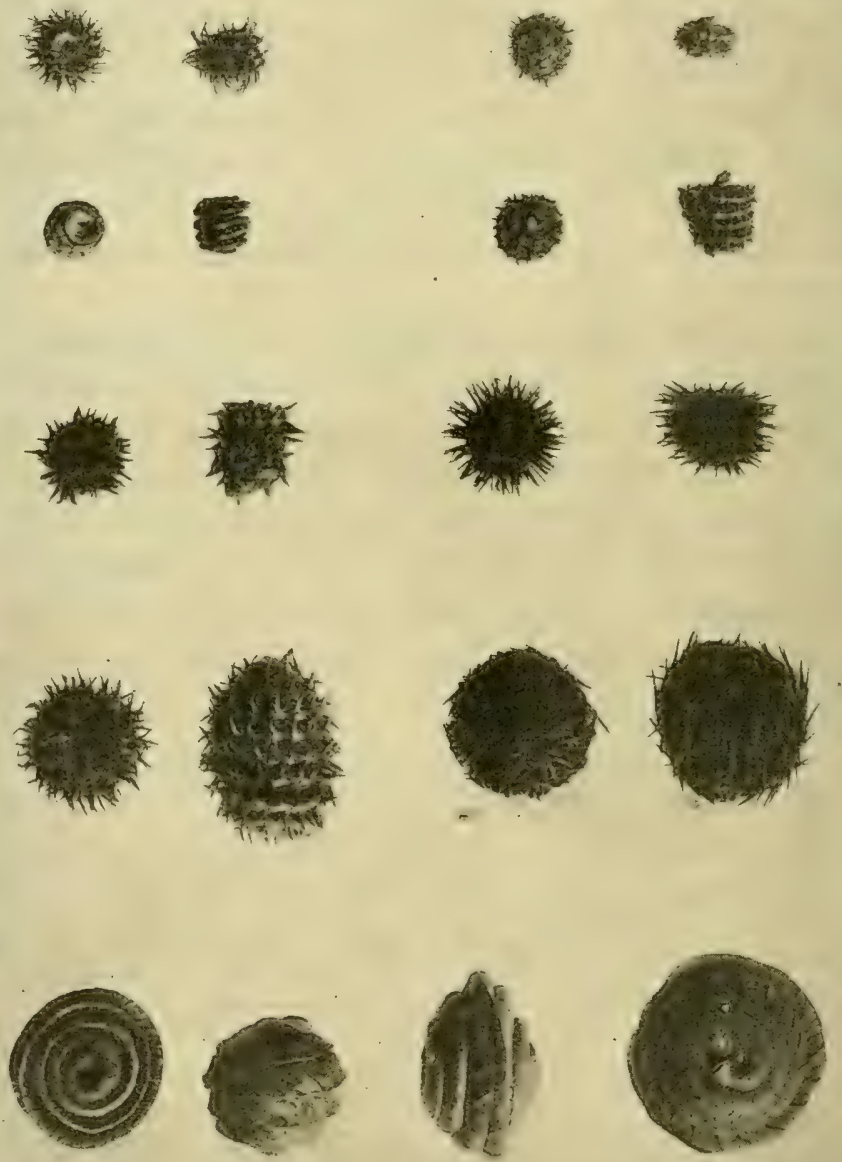

FIG. I89.-Pods of Io species of Medicago. Top row, M. arabica and M. hispida denticulata; second row, M. hispida confinis and M. hispida terebellum; third row, M. muricata and M. hispida nigra; fourth row, M. ciliaris and M. echinus; bottom row, M. scutellata and M. orbicularis. (After McKee and Ricker, U. S. Dept. of Agr.) 
(Fig. I 80 ) are in long clusters, twisted inte three to fire spirals, and the edges bear numerous grooverl spines which interlock. The sceds are kidney-shaped, and about 21 millimeters long. Medicagoarabica inermis is a spineless-podrled form.

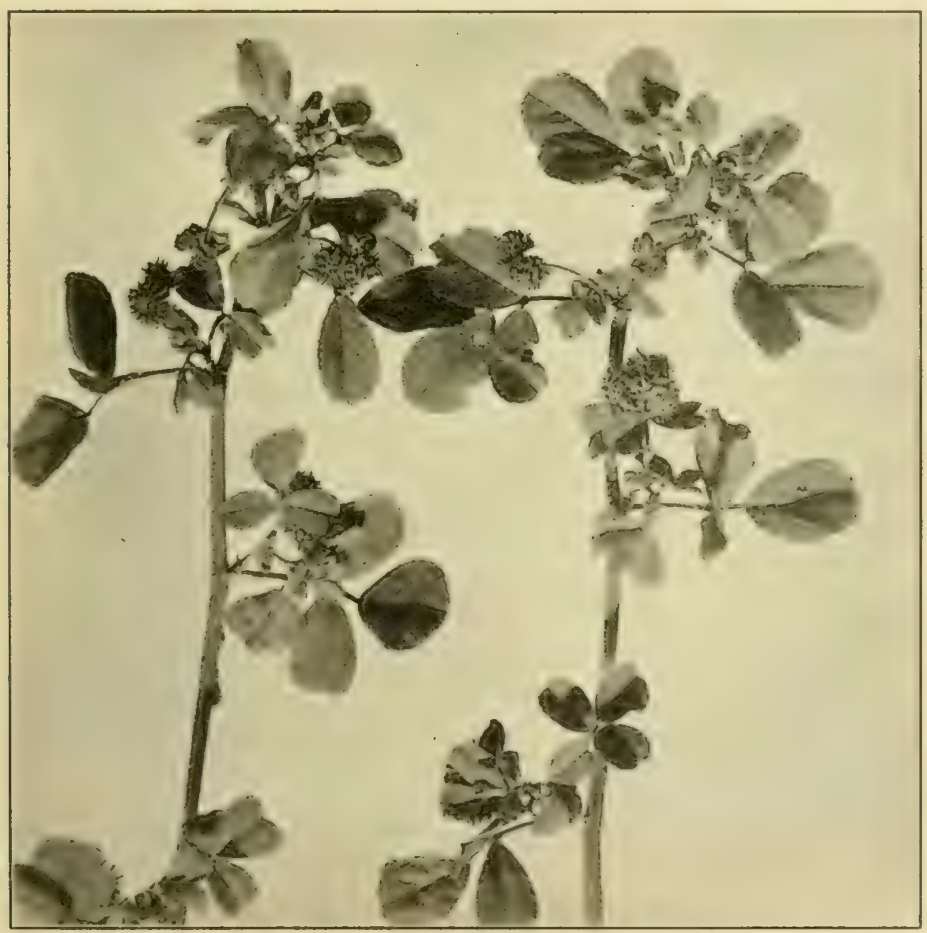

FIG. I90.-Toothed bur clover (Medicago hispida).

Spotted bur closer is a native of Europe and II estern Asia. It is introduced into the United States and occurs on the Atlantic, Gulf, and California coasts. It is being used as a pasturage crop. 


\section{MEDICAGO HISPIDA (Toothed Bur Clover)}

Toothed bur clover (Fig. I90) is a smooth, annual plant with decumbent leaves. The leaflets often have small whitish and dark red spots scattered over the surface, which disappear with age. The flowers are yellow. The pods are nettedveined, twisted spirally, and spiny. The seeds are light- to brownish-yellow, kidney-shaped, and about 3 millimeters long. Medicago hispida reticulata and $M$. hispida confunis are forms with spineless pods. Toothed bur clover, Medicago hispida denticulata, is native to the northern Mediterranean region. It is the most common bur clover grown in California. It finds some use as a pasture, hay, cover and green-manure crop.

In addition to the two species of bur clover given above, there are about 35 species that are not cultivated to any extent. They are all native to the Mediterranean region. All are warm-climate crops.

\section{MELILOTUS (Sweet Clover)}

Generic Description.-Sweet clovers are tall, erect, annual or biennial herbs, with a fragrant odor, especially when bruised. The leaves (Fig. I 83, B) are pinnately three-foliate, petioled, and possess large stipules and dentate leaflets, the veins of which end in the teeth. The flowers are long, slender, and in one-sided, axillary racemes. They are small, and white or yellow. The calyx teeth are short and about equal. The standard is obovate or oblong, the wings oblong, and the keel short and obtuse. The stamens are diadelphous (nine and one). The sessile or stalked ovary bears a single thread-like style. The pods are ovoid or globose, small, indehiscent or finally 2-valved, and usually one-seeded. Ordinarily, all the seeds of one year's production do not 
germinate the first season. "This results from the profluction of some "hard seeds."

There are 15 to 20 species of sweet clover, natives of Europe, Africa, and Asia. They are known by different names, such as wild alfalfa, melilot, giant clover, Bokhara, and sweet clover.

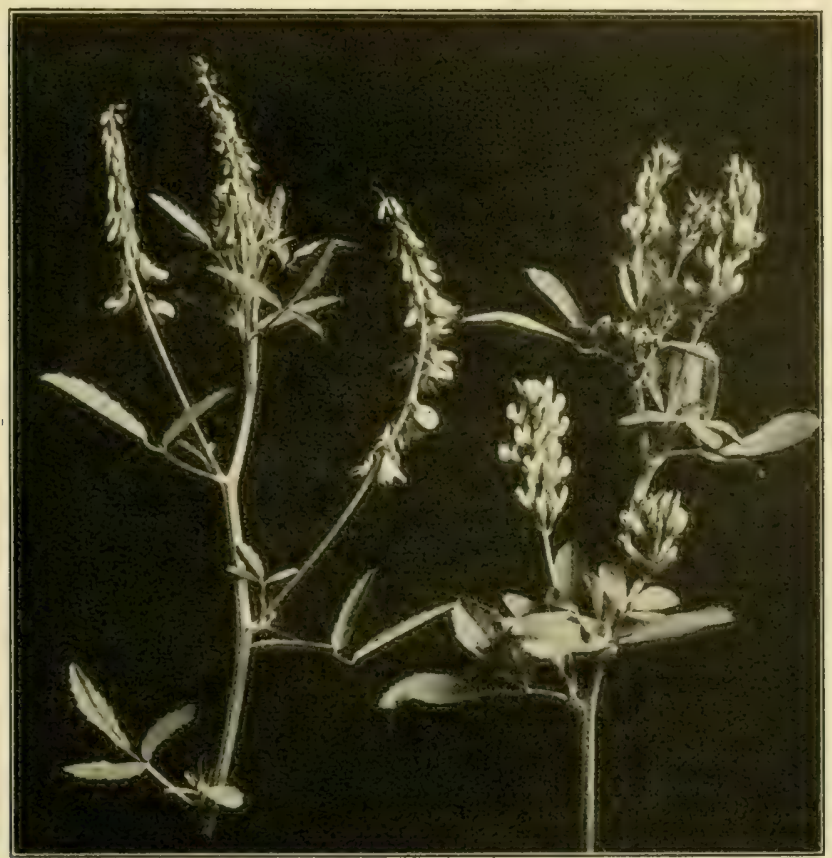

FIG. I9I.-Leaves and inflorescence of white sweet clover (Melilotus alba) on left, and alfalfa (Medicago sativa) on right.

The young plants resemble alfalfa, from which they can be distinguished by the bitter taste of the foliage and the thicker leaflets.

Species of Melilotus.--There are two common species of Mclilotus: $M$. alba. white sweet clover, and $M$. officinalis, 
ycllow sweet clover. Several other species of Mclilotus have been used agriculturally to some extent; among such are $M$. indica ("sour clover"), M. altissima, $M$. gracilis, and $M$. speciosa.

The characters of the two most important species are arranged in parallel rows for purposes of comparison.

M. alba

Commonly biennial.

Flowers white.

Standard slightly longer than wings.

Pods ovoid, glabrous.

\section{M. officinalis}

Commonly annual, sometimes biennial.

Flowers yellow.

Standard about equal the wings.

Pods ovoid, often slightly pubescent.

\section{MELILOTUS ALBA (White Sweet Clover)}

Description.-This is an erect and smooth-stemed biennial. It may reach a height of 3 or 4 feet the first season, from seed; the second season's growth is much more vigorous, and will yield two crops in the Northern, and three in the Southern States. New sprouts arise from above ground near the base of the plant after each cutting, and for this reason the plants must not be cut too close to the ground line. The leaves have thick, oblong, finely toothed leaflets which are narrowed at the base, and truncate, notched or rounded at the apex. The racemes are numerous, slender, and often one-sided. The flowers are white and have a standard which is somewhat longer than the wings. The pods are ovoid. slightly reticulated (netted), and smooth.

The species is a native of Eurasia. It is a common roadside and waste-place weed throughout this country.

\section{MELILOTUS OFFICINALIS (Yellow Sweet Clover)}

Description.--This plant is much like the preceding. It does not grow so tall, however, is less common, and has 
yellow flowers. It blooms somewhat earlier than the white sweet clover and is more commonly annual in its habit than biennial. It is a native of Eurasia and, like the preceding species, has become naturalized in this country, being widely distributed as a ruderal throughout both the Northern and Southern States.

Environmental Relations.-The sweet clovers thrive in both semi-arid and humid climates, and upon all types of soils-heavy and light, rich and poor, well-drained and illydrained. They are also drought-resistant. It is being introduced where, for any reason, alfalfa and clover have failed.

Uses of Sweet Clovers.-Like other legumes, sweet clover supports nodules of bacteria on its roots. In fact, it is nearly as valuable as alfalfa to plow under as a green manure to renew the soil. It makes good hay when properly handled, and for pasturage purposes it has considerable value. As a forage crop, it can be utilized where alfalfa or red clover cannot be grown successfully. The plant becomes coarse and unpalatable soon after blooming, and hence it must be cut before this stage. The plants possess a bitter principle, cumarin, which may cause an animal to reject them as food at first, but usually the animal becomes accustomed to them.

White sweet clover is much larger and more vigorous than yellow, and consequently is the one recommended for cultivation.

\section{SOJA (Soy Bean)}

Generic Description.-The soy beans are prostrate or erect herbs with pinnately three-, rarely five- or seven-, foliate leaves. The flowers are in short axillary racemes, and are purple or whitish. The pods are linear or falcate, and twovalved. The seeds are globular and pea-like. 
There are between 15 and 20 species of Soja, natives of tropical Asia, Africa, and Australia. There is only one species of any economic importance. This is Soja max.

\section{SOJA MAX (Soy Bean, Soja Bean, Coffee Bean)}

Description.-This is an erect, bushy appearing, hairy annual, varying from I $1 \frac{2}{2}$ to 6 feet in height (Fig. I92). Unlike the cowpea, it has a definite growth, that is, reaches a certain size and matures its seed. All the pods of the soy bean

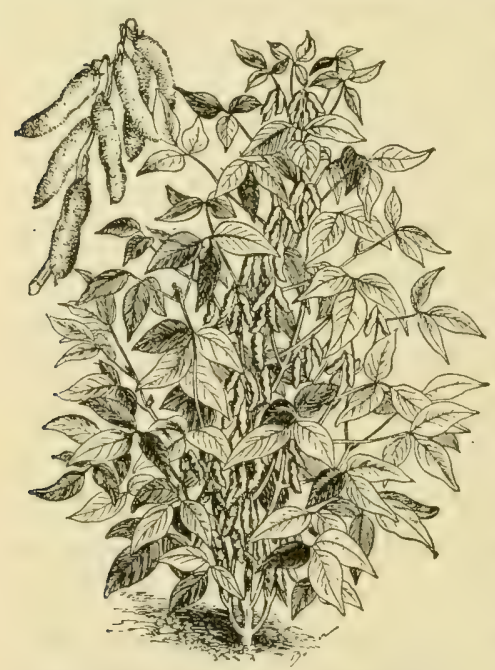

FIG. I92.-- Soy bean (Soja max). (After Piper.) mature at one time. In the cowpea, new pods are formed as long as the plant lives. The tap root is short and strong. The leaves are trifoliate. Usually they have withered and fallen by the time the pods are mature, but in some varieties remain green and stay on the plant for sometime after the pods mature. The flowers are borne in axillary clusters; they are small, and either white or purple in color. The flowers are self-pollinated as a rule, and are completely self-fertile. Occasional cross-fertilization occurs in the field when varieties are planted very close together. The pods are from I to $2 \frac{1}{2}$ inches long, yellowish or brown, and covered with short bristly hairs. As many as 300 to 400 pods have been found on one plant, and each pod usually contains two or three seeds. In fact, the soy bean is the greatest seed producer of any legume grown in temperate 
climates. The seeds vary greatly in color; there are shades of cream, white, yellow, green, brown, and black; they also vary in shape from globose to elliptical. Under the most farorable conditions, soy bean seeds do not retain their viability for more than five or six years.

Soja max is a native of China and Japan. The cultivated varieties are adapted to the warmer sections of the United States; they are intolerant of cool nights. However, there are several very early maturing varieties which may be grown in the northern tier of States. The soy bean will grow in moist climates, and also manifests drought-resistant propensities. The plant is grown on a variety of soil types, and will even produce a fair crop on poor soils of a sandy nature.

Uses.-The soy bean is the most important legume in Asiatic countries, and is becoming of increasing value in the United States. The chief product of the bean is the oil which is expressed from the seeds. It is used in the manufacture of soaps, lubricants, water-proof goods, linoleum, rubber substitutes and printing ink; also in the preparation of varnishes and paints, as a substitute for linseed oil. After the oil is expressed from the seed, the "cake," either unground or ground into a meal, is used as stock feed or as a fertilizer. Soy-bean meal is of considerable value as human food. Soy-bean flour is an important constituent in many food specialties such as diabetic breads, crackers and biscuits. Soy-bean flour is very low in carbohydrates, that made from soy-bean cake having a carbohydrate content of 33.85 per cent., ${ }^{1}$ as compared with 75.35 per cent. in wheat flour. The protein content of flour made from soybean cake is given as 47.3 per cent., whereas that of wheat flour is but I per cent. Soy beans are also utilized to make a so-called soy-bean milk, which is valued for cooking ${ }^{1}$ Data from the U. S. Dept. of Agri. Bureau of Chemistry. 
purposes by bakers, confectioners and chocolate manufacturers. The seeds of soy beans are sometimes used as a substitute for coffee. Soy-bean hay has a comparatively high feeding value. It is recommended as a pasture for hogs. The plant is recognized as a valuable soiling and ensilage crop. Nitrogen-fixing bacterial nodules occur on the roots of the soy bean.

\section{VIGNA (Cowpea and Related Species)}

Description.-The "Vignas" are usually climbing or trailing herbs, sometimes erect, that are much like the common bean. They differ from the common bean (Phaseolus inlgaris), however, mainly in that the keel of the corolla is short and merely incurved rather than spirally coiled. 'The leaves are pinnately trifoliate. The flowers are yellowish or purplish, in head-shaped or racemose inflorescences at the ends of long peduncles; these arise in the axils of leaves. The calyx is five-toothed. The stamens are diadelphous (nine and one). The ovary is sessile, many-ovuled, and bears a style that is bearded along the inner side. The pods are linear, straight or slightly curved, and two-valved. The seeds are much like the common kidney bean in shape (Fig. I93).

All the Vigna spp. ("Vignas") are natives of warm and tropical regions, and consequently they have been most successfully cultivated in the Southern States.

Species.-There are but three cultivated species of "Vignas": Vigna sesquipedalis (asparagus bean), Vigna catjang (catjang), and Vigna sinensis (cowpea). The asparagus bean has pendant pods I to 3 feet long, and kidney-

FIG. I93.-Seeds of 16 varieties of Vigna showing range in variation of shape, size and color. The top three rows are catjangs (Vigna catjang), the bottrom two rows are asparagus beans (Vigna sesquipedalis), and the others are cowpeas (Vigna sinensis). (After Piper, U.S. Dept. of Agri.) 


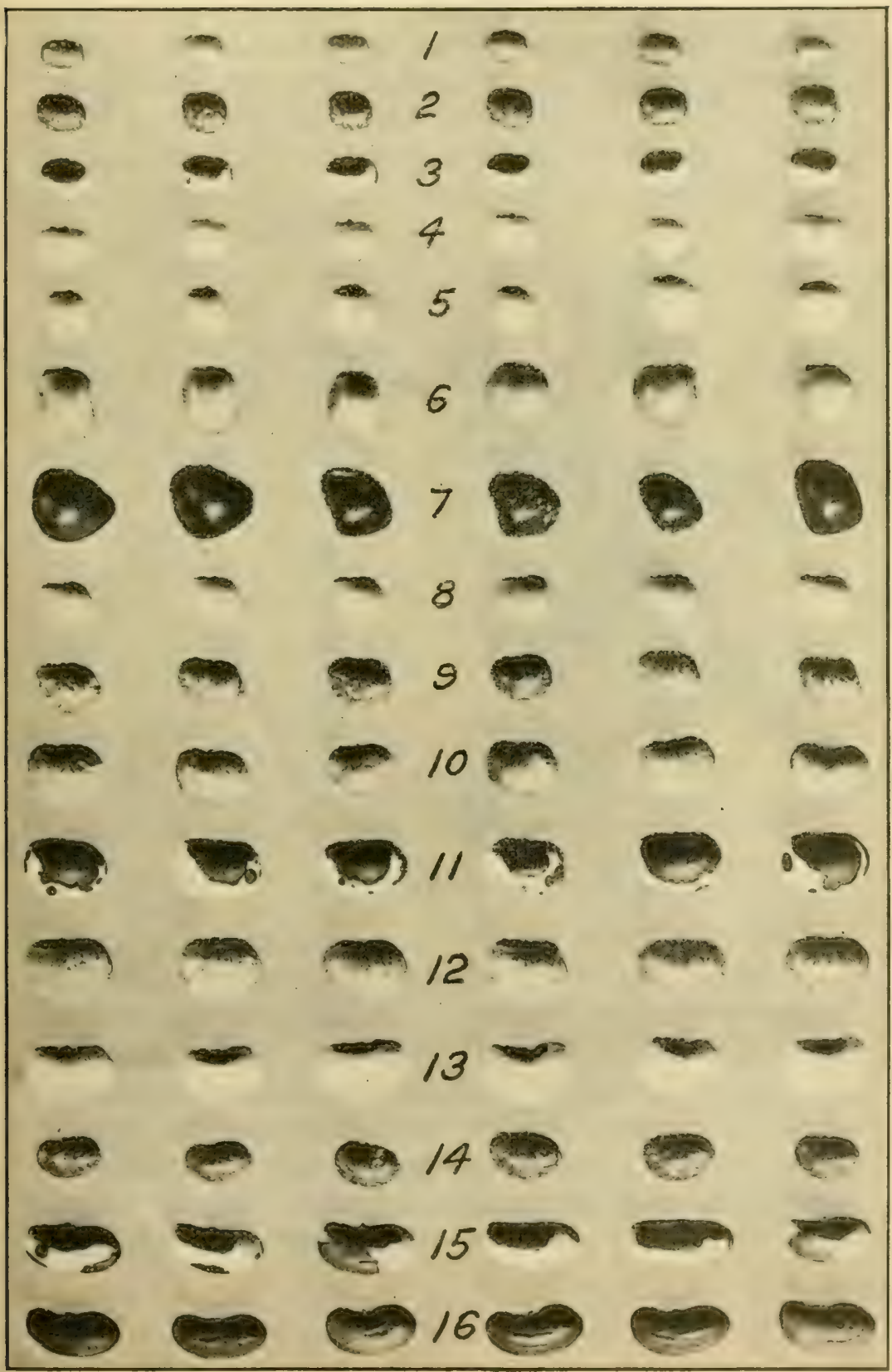

FIG. $\pi 03$. 
shaped seeds 8 to I 2 millimeters long. In catjang, the pods are small, 3 to 5 inches long, and usually erect or ascending (Fig. I94). In the cowpea, the pods are 8 to I 2 inches long, and become pendant with age. The cowpea is by far the most important, economically.

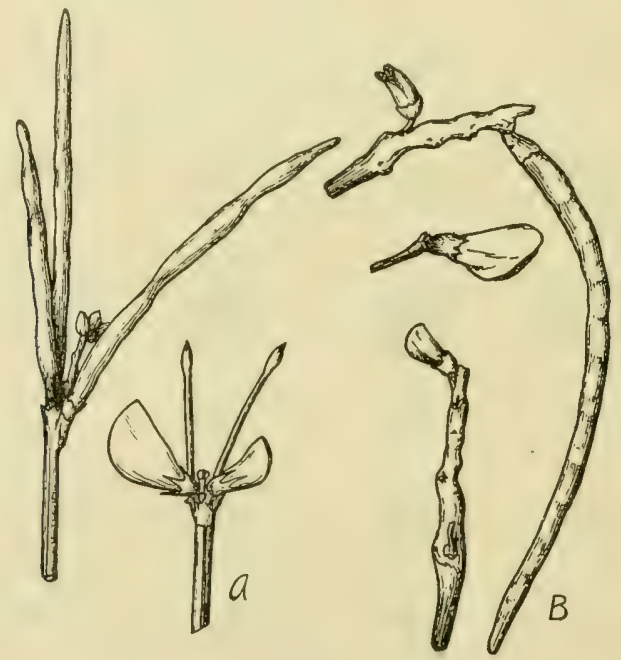

Fig. I94.- $A$, flowers and fruit of catjang (Vigna catjang); $B$, flowers and fruit of cowpea (Vigna sinensis). (After U.S. Dept. of Agri.)

\section{VIGNA SINENSIS (Cowpea)}

Description.-The cowpea is a vigorous annual herb with a strong tap root which sends out large side roots almost horizontally for I or 2 feet (Fig. 'I95). The greater part of the root system lies in the first $\mathrm{I} / 2$ feet of soil. The varieties vary in habit from prostrate trailing herbs to tall and half-bushy forms. The cowpea has an indeterminate growth, that is, it continues to grow indefinitely, providing environmental conditions are favorable. As in the majority of plants vegetative growth is favored by an abundance of water and 
heat, and seed production is stimulated by adverse conditions. The first pods may come to maturity within seventy to ninety days in the so-called early varieties; on the other hand, some varieties do not even come into bloom under conditions prevailing in the states along the Gulf of Mexico.

The flowers are white or pale violet with three bracts at the base of each pedicel. The cowpea flower is capable of selffertilization, and this is probably the most common occurrence although the flowers are often visited by honey bees or bumblebees. They are attracted chiefly by the extra-floral nectaries. The long pods (Fig. 194) are cylindrical, somewhat curved, and usually constricted between the seeds. The seeds are numerous, usually bean-shaped, spotted, marbled, speckled, or marbled and speckled, and have a dark circle around the white hilum. Great

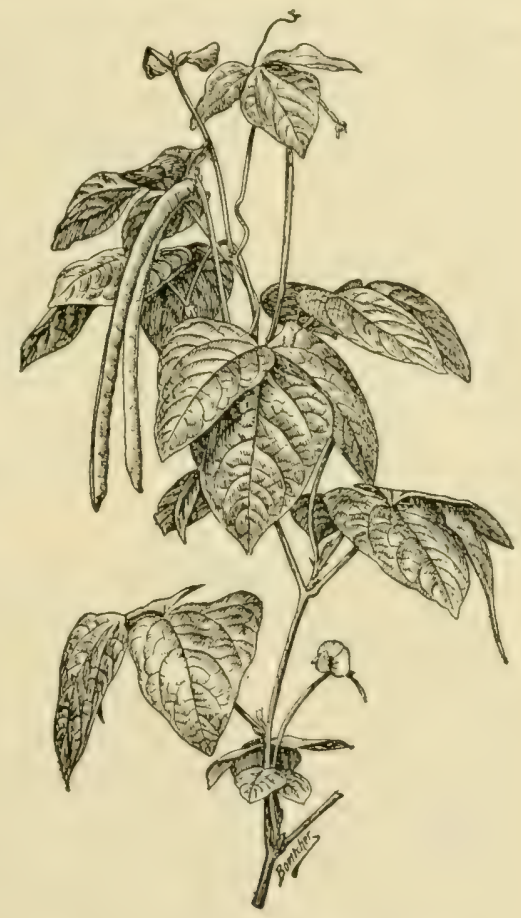

FIG. I95.-Cowpea (Vigna sinensis). (After Piper.)

variation occurs in pods and seeds. There are two groups of cowpeas based upon pod and seed characteristics; kidney and crowder. The former have compressed pods with kidneyshaped seeds; the latter have thick-walled, cylindrical pods with globular seeds. 
Environmental Relations.--The cowpea is of tropical origin, and, hence, is adapted to those sections of the country with warm summers; in fact, it requires more heat than corm, and like corn, does not thrive where the nights are cool. It is seldom grown north of the Ohio River. It will grow on many different soil types, and will withstand shading.

Uses.- The cowpea is of very great economic importance. It is the chief forage plant in the South Central and South Atlantic States. The acreage of the crop is increasing each year. Cowpea hay is prized as food for stock. The plant may also be pastured with hogs or sheep when mature, or with cattle before the peas mature. The plant is being introduced into many localities as a catch crop or as a green manure, and is adapted to rotation in a cropping system. The seeds are fed to poultry, and are also recommended as a food for man. The roasted seeds are a substitute for coffee.

\section{ARACHIS HYPOGEA (Peanut, Goober)}

Habit, Stem.- The peanut is an annual plant with a tap root (Fig. I 96). The plant may be low and prostrate, as in the "running types," or upright and bushy, as in the "bush types." The stems are thick, angular, branching, and hairy.

Leaves.- The leaves are pinnately compound, usually with two pairs of subsessile, entire leaflets, and no tendrils; the elongated stipules are adnate to the petiole base.

Flowers (Fig. 197).-The flowers are axillary, sessile, and orange-yellow in color. There are two sorts of flowers on the plant, sterile and fertile. Sterile flowers are most numerous in the upper axils, on long, slender pedicels; they have monadelphous stamens (nine united, one abortive) and a minute abortive ovary. The calyx tube is long and slender, and bears on its rim the calyx lobes, corolla, and 
stamens; the four superior lobes of the calys are uniterl, while the inferior one is free. The standard is suborbicular, the wings oblong and free, and the keel incurved. The oidry, at the base of the long, narrow calyx tube, has one to several ovules, and bears a long thread-like style, terminated by a very small stigma.

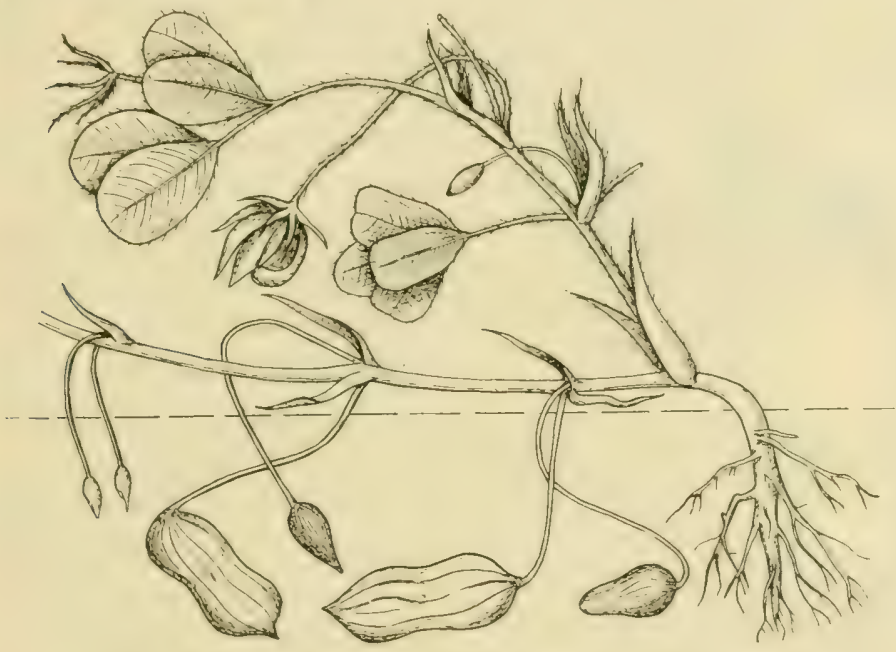

FIG. I96.-Peanut_(Arachis hypogæa). (Afler Jones.)

Development of Fruit (Fig. I06).-After the orules are fertilized, the stamens and corolla fall off; then the flower stalk elongates, bends downward, and carries the developing ovary several inches into the ground. (Once buried, the ovary ripens. If the ovary is not brought underground, it withers, and fails to mature.

Fruit.-The fruit is a large, oblong, reticulated, indehiscent legume, with one to several oroid seeds. The "shell" of the "peanut" is the pericarp; the thin skin that surrounds each seed or pea ("nut") is the testa. The cotyledons are large, and rich in stored food. 
Types.-The American varieties may be divided into two large groups: (I) large-podded and (2) small-podded. Each of these is further subdivided into "bush" or "bunch," and "running" types. Well-known varieties in this country

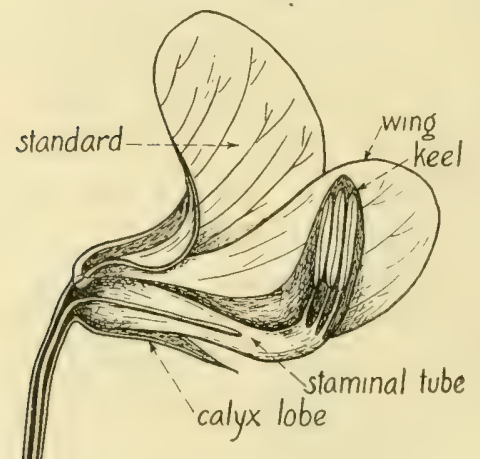

long style

within calyx tube

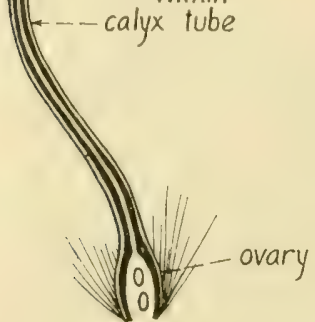

FIG. I97.-Flower of peanut (Arachis hypogæa). (After Tanbert.) are Virginia Bunch, Virginia Runner, Carolina, Spanish, and Tennessee Red. The last-named variety has redskinned seeds. The nuts in the Spanish variety are smaller than those of the other types. Large-podded varieties are sometimes termed "Jumbos."

Environmental Relations. - The peanut is a tropical plant. Consequently, it is raised where the growing season is long, and warm. It succeeds best south of the $36^{\circ}$ latitude.

The plant is favored by ample sunshine and moderate rainfall. It is grown successfully on both sandy and clay soils, although the former are preferred, especially. when the pods are grown for the market and a bright, clean appearance is desired.

Uses.-Peanuts are largely used in the roasted state as a human food. Peanut butter has become a very popular food article. One bushel of first-class nuts will yield about I 2 pounds of butter. Oil, salted peanuts and peanut candies 
are other products. The nuts ("goobers") are fed to hogs, or the animals are turned in to pasture on both the vines and nuts. Peamut oil, pressed from the seeds, is a nearly colorless product, which is employed as a salad oil, to a limited extent in the manufacture of soap, and in the making of oleomargarines and similar compounds. Analyses show that Spanish and Valencia peanuts are richer in oil than Virginia and other common types. The percentage of oil in shelled nuts varies from about 45 to 50 per cent. Peanut meal, the product left after pressing the oil from the seeds, is a high-grade stock feed. Nearly all peanut oil used in this country is made in Europe. The United States imported I,332, I08 gallons of the oil during I9I4.

\section{LESS IMPORTANT LEGUMES}

The following list includes several of the less important members, agriculturally, of the Pea Family.

Lupinus (Lupines).-Annual or perennial herbs with palmately seven- to fifteen- foliate leaves, and spikes of white, yellow, or blue, showy flowers. They can grow on poor sandy soil, but are little used in this country except to plow under as a green manure. The species used for this purpose are annuals.

Lespedeza striata (Japan Clover).-A branched, spreading annual with three-foliate leaves, short petioles, and small flowers in the axils of the leaves. It was introduced from Japan or China to the South Atlantic States, where it is quite largely grown for pasture and hay. It is adapted to clay soils and does well on thin uplands.

Onobrychis viciæfolia (Sainfoin).-A deep-rooted perennial with erect stems, odd-pinnate leaves, six to twelve leaflets, and erect, dense racemes of rose-colored flowers. The one-seeded, brown, lens-shaped pods are indehiscent. The seed loses its viability rapidly, and is slow to germinate.

The plant was early introduced into America from Asia, but it is little grown here. It is adapted to dry barren lands that are not suited to clovers and alfalfas. It has been grown with success on calcareous soils.

Ornithopus sativus (Serradella).-A low, branched annual, with pinnately" compound leaves, and rose-colored or purplish flowers in umbels. The pods 
break into joints. The plant makes good hay and thrives on fairly thin soils, if not dry. It grows best in cool weather, and is not very hardy.

Lotus corniculatus (Birds-foot Trefoil).-An annual plant similar to clover. The low-spreading stems are from a long tap root; bright yellow or

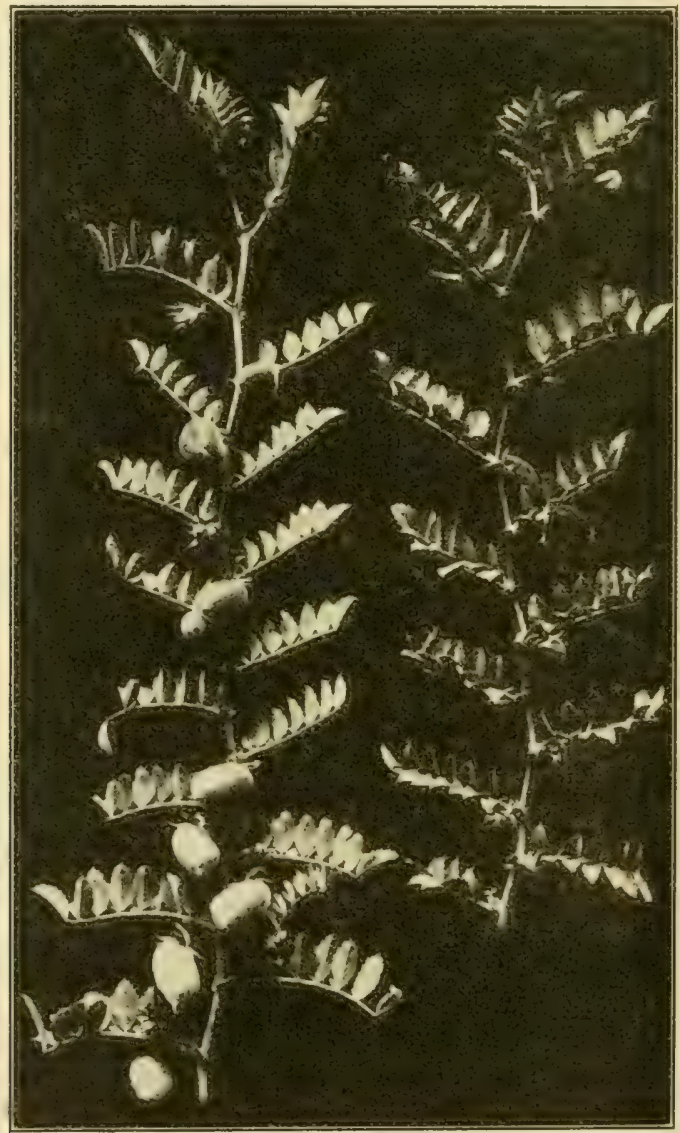

FIG. 198.-Chick pea (Cicer arietinum).

red flowers occur in small clusters at the ends of the stems; pods are narrow and pendant. It is an Old World plant, but is naturalized in the South where it is sown in mixtures for dry pastures. 
Cicer arietinum (Chick-pea). I bushy, hairy annulil, i to 2 fert high, with odd-pinnate leaves and small, white or pink, solitary flowers, follewed by short, thin pords. The seeds are peal-like, with a beak-like projection near the hilum. The plant is grown in Lurope, Asia, and Mexico for its secels which are used for both stock and human food. The herbage is unlit for stock because of a poisonous principle. The seeds have been used ats a coffee substitute.

Trigonella fœnum-grœeum (Fenugreek).--In crect plant with cloverlike leaves, and long, pointed pods. It is grown principally for its seeds, which have medicinal properties, and also as an orchard green manure. The seeds are made into a "condition powder" for horses.

\section{References}

Barthitr, G.: The Native and Cultivated Viciere and Phaseolece of Ohio. Ohio Nat., 15: 393-404, 1914.

Bral, A. C.: Livolution and Pollination of the Sweet Peal. Florist's lixill., 32: I40-I4I, I9II.

Belttie, Wr. R.: Peanuts. U. S. T)ept. Agr. Farmers' Bull. $35^{(1)}$ : 1 - fo, I()o().

The Peanut. U. S. Dept. Agr. Farmers' Bull. 43I: I-39, xgII.

Buinn, Phulo.: Alfalfa-the Relation of Type to Hardiness. Colo. Airr. Fixp. Sta. Bull. I8r: I-r6, I9r r.

Frexch, G. T.: Observations on Medicago lupulina L. Science, 11. s., 2. 28: 127, I908.

Fucsho, Mnhaly: Über die biologischen und entwickelungsgeschichtlichen Verhaltnisse des Pericarps der Papilionaten. Ung. Bot. Bi., S: $26,426,5$. I909.

Anatomie, Entwickelung und Biologie der Fruchtwand der Papilionatit. Bot. Közlem, 8: 154-212, I909.

Gregory, R. P.: The Seed Characters of Pisum sativum. New Phytol., 2: 226-228, 1903.

H.ixdr, R. B.: Peanuts: Culture and Uses. U. S. Dept. Igr. Farmers' Bull. 25: I-23, I 896 .

Headden, Wur. P.: Alfalfa. Colo. Agr. Exp. Sta. Bull. 35: I-92, I896.

Jones, B. W.: The Peanut Plant. Orange Judd Co., 1885.

Kircirner, Oskar: Über die Wirkung der Selbstbestiubung bei den Papilionaceen. Naturw. Ztschr. Land-u. Forstw. Jahrg., 3, Heft I: I-16, I905.

Martin, J. N.: Relation of Moisture to Seed Production in difalfil. Iowa Agr. Exp. Sta. Research Bull. 23: 303-324, I9r 5.

Mckee, Roland, and Ricker, P. L.: Non-perennial Medicagos: the Igronomic Value and Botanical Relationship of the Species. U.S. Tept. Agr. Bur. Plant Ind. Bull. 267 : I-36, I9I3.

Oaklex, R. A., and Garver, Samuel: Medico falcalta, a Fellow-flowered Alfafa. U. S., Dept. Agr. Bull. 428: I-70, I9I7. 
Pammer, Eidna C., and Ciark, Cearissa: Studies in Variation of Red Clover. Proc. Ia. Acad. Sci., 18: 47-53, 19r1.

Pammer, L. II., and Kisc, (hardotre .11.: Pollination of Clover. Proc. Ia. Acad. Sci., I8: $35^{-4}-45$, 9 II

Pollination of (Cover. ('ontrib. Bot. I)ept. Ia. State College, 47: I-45, 19r r. Pejeningier, Urs.: Untersuchung der Fruchte von Phaseolus vulgaris $\mathrm{L}$. in verschicdenen Entwickelungstadien. Ber. Deut. Bot. Ges., 27:227-234, rgog.

PIPER, C. V., and Morse, W. J.: The Soybean; History, Varieties, and Field

Studies. U. S. Dept. Agr. Bur. Plant Ind. Bull. I97: I-84, I910.

Five Oriental Species of Beans. U. S. Dept. Agr. Bull. II9: I-32, I9I4.

The Bonavist, Lablab, or Hyacinth Bean. U.S. Dept. Agr. Bull. 318 : I-I5, 1915 .

The Soy Bean, with Special Reference to Its Utilization for Oil, Cake and

Other Products. U. S. Dept. $\Lambda$ gr. Bull. 439: I-20, IgI6.

P'IP:R, C. V.: Agricultural Varieties of the Cowpea and Immediately Related

Species. U. S. Dept. Agr. Bur. Plant Ind. Bull. 229: I-I60, I9I2.

Soja Max. Jour. Am. Soc. Agron., 6: 75-84, I9I4.

Jiper, C. V., Evans, Morgan W., McKhe, Romand, and Morse, W. J.:

Mfalfa Seed Production; Pollination Studies. U. S. Dept. Agr. Bull. 75' I-32, I9I4.

PIPER, ( $\therefore$ V., and ACKLE, RoJAnd: Vetches. U. S. Iept. Agr. Farmers' Bull. 515: $x-28$, I9I 2 .

Scomblo, (CARL S.: The Botanical IIistory and Classification of Mlfalfa

U. S. Dept. Agr. Bur. Plant Ind. Bull. 13 I: II-19, 1908.

Sirnw, Tmosns: Canadian Field Peas. U. S. Dept. Agr. Farmers' Bull. 224 : I-I6, 1905 .

'Tracy, W. W.: American Varieties of Garden Beans. U. S. Dept. Agr. Bur. Plant Ind. Bull. I09: $x-173, x 907$.

Wristgite, J. M.: Variegated Alfalfa. U.S. Dept. Agr. Bur. Plant Ind. Bull. I69: I-63, г910.

Westgate, J. M., and Hillman, F. H.: Red Clover. U. S. Dept. Agr. Farmers' Bull. 455: I-48, 19 II.

Westgate, J. M., and Vinall, H. N.: Sweet Clover. U. S. Dept. Agr. Farmers' Bull. 485: 7-39, I912.

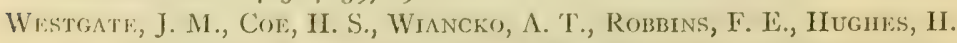

J)., Pammin, L. II., and Miartin, J. N.: Red-clover Seed Production:

Pollination Studies. U. S. Dept. Agr. Bull. 289: I-3I, I9I5.

Wrgir, W. I:: The IIstory of the Cowpea (Vigna unguiculata) and Its Introduction into America. U. S. Dept. Agr. Bur. Plant Ind. Bull. Io2: $43-59,1907$.

Wiston, Kite, B.: Comparative IIistology of Alfalfa and Clovers. Bot. Gaz., 57: 53-63, r914. 


\section{CHAPTER XXX}

\section{LINACE $\not E$ (Flax Family)}

Habit, Stem, Leaf.- The species of this family are annual or perennial herbs, or shrubs. The plants are tap-rooted. and each tap root bears a number of slender, lateral branche's. The stems are single. The leares are simple, narrow, nearly sessile, and usually alternate, although sometimes opposite (L. catharlicum). They are linear, linear-lanceolate, or oblong, and sharply awn-pointed, blunt, or rounded at the apex.

Infiorescence and Flowers.--The inflorescence may be a few-flowered corymb or cyme, or the flowers may be more or less scattered on the branches. The flowers (Fin. $2 \mathrm{I})$ are perfect, regular, and five-parted in all respects. The sepals are imbricated and persistent. The petuls are wedge-shaped, and may be as long or longer than the sepals. They may be some sharle of yellow or blue, orange with rosetinted base, red, or white. The five slemens have their filaments united at the base. The outer whorl of stamens is wanting or staminodial. The pistil consists of at fivecelled ovary, each cell of which bears two ovules. The five styles may be free, united to the stigmas, or united part way from the base.

Fruit.- The flax fruit is a five-celled calpsule with two seerls in each cell; each cell is partially or completely divided into two by a false partition between the two seeds, thus making the capsule apparently ten-celled (Fig. 2T). 
The Names Derived from "Linum."- This family contains but one important genus, Linum. The name Linum is the latin for flax. The word "linen" means made from flax or of flax. It is from these and other similar foreign names that we get our common words linen, lint, linseed, and line:

Geographical, and Environmental Relations.--The family has about 135 species, which are widely distributed over the world. The important commercial species is L. usitatissimum. All cultivated flax varieties in this country are treated as belonging to this one species.

Flax is raised under a wide variety of climatic conditions and soils. In regions with low rainfall, the crop is of little value for fiber, and hence is grown chiefly for its seed. A fair quality of fiber flax is produced in certain sections of the United States where the rainfall is 25 to 30 inches. The water requiremen of flax is higher than that of any of the cereals, being about three times that of millet and sorghum.

\section{LINUM USITATISSIMUM (Common Flax)}

Habit, Root.-Common flax is an upright herb which under cultivation grows to a height of from I to 4 feet (Fig. I99).

It is a dainty surface feeder with a small root system; this consists of a slender tap root sparingly supplied with slender branches in the first 12 to 18 inches of soil. The tap root runs downward vertically to a depth of 3 to 4 feet in some cases. No network of roots is formed near the surface of the soil. Long-stemmed flax as compared with other varieties appears to have a weaker root system and less root penetration. Deep planting is adverse to root development of flax.

Stem.- The stem is simple, erect, and branching in the upper part, rarely at the base. As it matures, it becomes 
rigid, at the same time retaining considerable elasticity due to the bast fibers.

Flax Fibers.--Three tissue areas are recognizable in the stem: pith, wood, and bark. The flax bark contains the bast or flax fiber cells. These bast fibers give flax straw

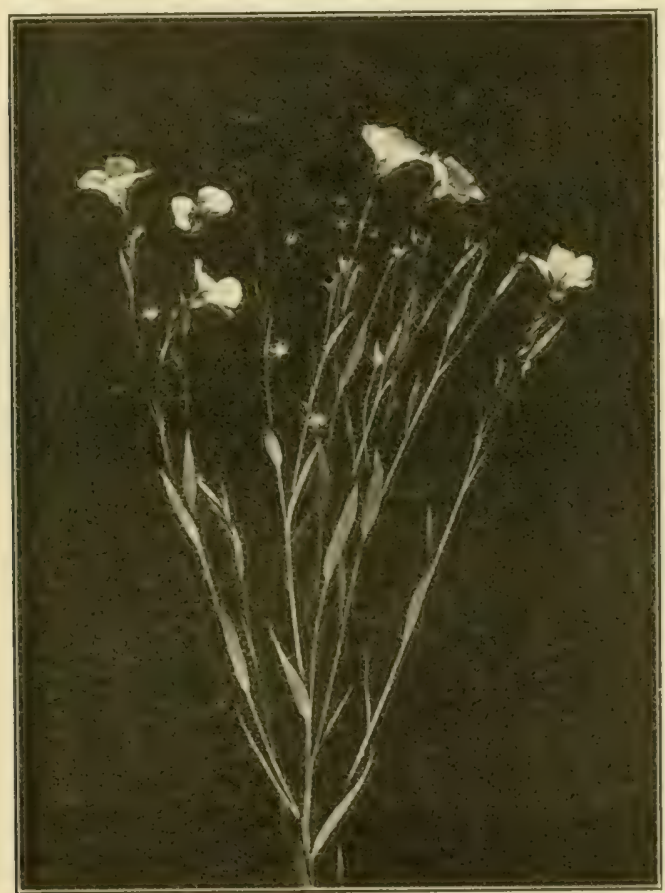

FIg. I09,-Common flax (Linum usitatissimam).

its great financial value since they make up the part from which linen is marle. Each bast fiber is a single cell, 25 to 30 millimeters long, and cylindrical in shatpe.

Leaves, Inflorescence and Flowers.-The leaves are narrow, entire, and blunt at the apex. The inflorescence 
is loosely cymose. 'The flowers vary in color from white to leep blue. The same plant always bears flowers of the same color. Yellow-flowered varieties are not found in this species. The petals are large, conspicuous, wedgeshaped, and about twice as long as the sepals.

Pollination.--Studies of flax varieties indicate that there is close-pollination. Individual flowers produce seed freely, whether associated with other flowers or not. Examination of flax flowers at the proper time shows anthers in close proximity to the stigmas, and the latter covered with pollen.

Mature Fruit.-The flax fruit (Fig. 2I) is a round capsule known commercially as the "seed ball." The seed ball is composed of five fused carpels. The balls are divided into five true cavities or locules by means of five true partitions (septi) extending from the wall (pericarp) to the axis. Each locule contains two seeds and is divided more or less incompletely into two loculi by means of false septi. The seed balls are ${ }_{1}^{1}$ inch or more in diameter. When fully ripe, they are easily separated into parts at the points where the carpels are joined.

Seeds. - The seeds vary in length from $1 / 7$ to $1_{5}$ inch. They are lenticular, compressed, and slightly longer than wide. They have a very smooth, polished surface and vary in color from yellow to dark brown. Light brown is the standard color. A mucilaginous material which quickly becomes sticky (viscid) in hot water is found filling the epidermal cells of the seed. It is this substance which gives flax its medicinal value. The embryo is surrounded by a thin layer of endosperm which, in the mature seed, contains starch.

Geographical.-Common flax is a native of Europe. It is now widely distributed over the world, being grown commercially in many countries. India is a heavy producer of seed, and in Argentina it is grown extensively for oil. 
Types and Varieties.-- There are large-seeded and smallseeded varieties. The large-seeded types are sometimes known as Sicilian flax, and are grown almost entirely for their seed, rather than fiber; there are both blue- and whiteflowered sorts. The small-seeded types are grown both for fiber and seed; there are both blue- and white-flowered varieties. The fiber flaxes have more slender stems, fewer basal branches, and a more compact panicle than the seed flaxes.

Uses.-Linseed Oil.- The manufacture of linseed oil is carried on in manufacturing plants having investments of millions of dollars. The seeds are crushed, heated to about $165^{\circ} \mathrm{F}$., placed in tanks or cylinders, and while hot, treated with naphtha to extrect the oil. From 30 to 39 per cent. of the seed is oil. Linseed oil is used in the manufacture of paints, patent leather and varnishes. Linoleum is a preparation of linseed oil which is hardened by treating with sulphur chloride or by exposure to heated air. It is sometimes used as a substitute for india-rubber. Oil cloth and other sorts of floor cloth, are made by mixing ground cork with the hardened linseed oil (linoleum), and pressing upon canvas.

Oil Cake and Oil Meal.--The residue from the crushed flax seeds is known as oil cake. It is sold either as oil cake or ground into a meal, and used as a stock food. Belgium and Holland are our chief customers for linseed-oil cake.

Flax Fiber.-Linen is made from flax fiber. Our finest linens are from foreign grown flax, the best of which is grown in Belgium in a region through which flows the River Lip. The creamy Flemish flax from which the finest linen fabrics are made is grown in this section. Flax fiber is also utilized for making thread, carpet yarns, fishing lines, seine twines, etc. It is also employed to some extent for upholstering, for insulating cold-storage plants, refrigerator cars and ice 


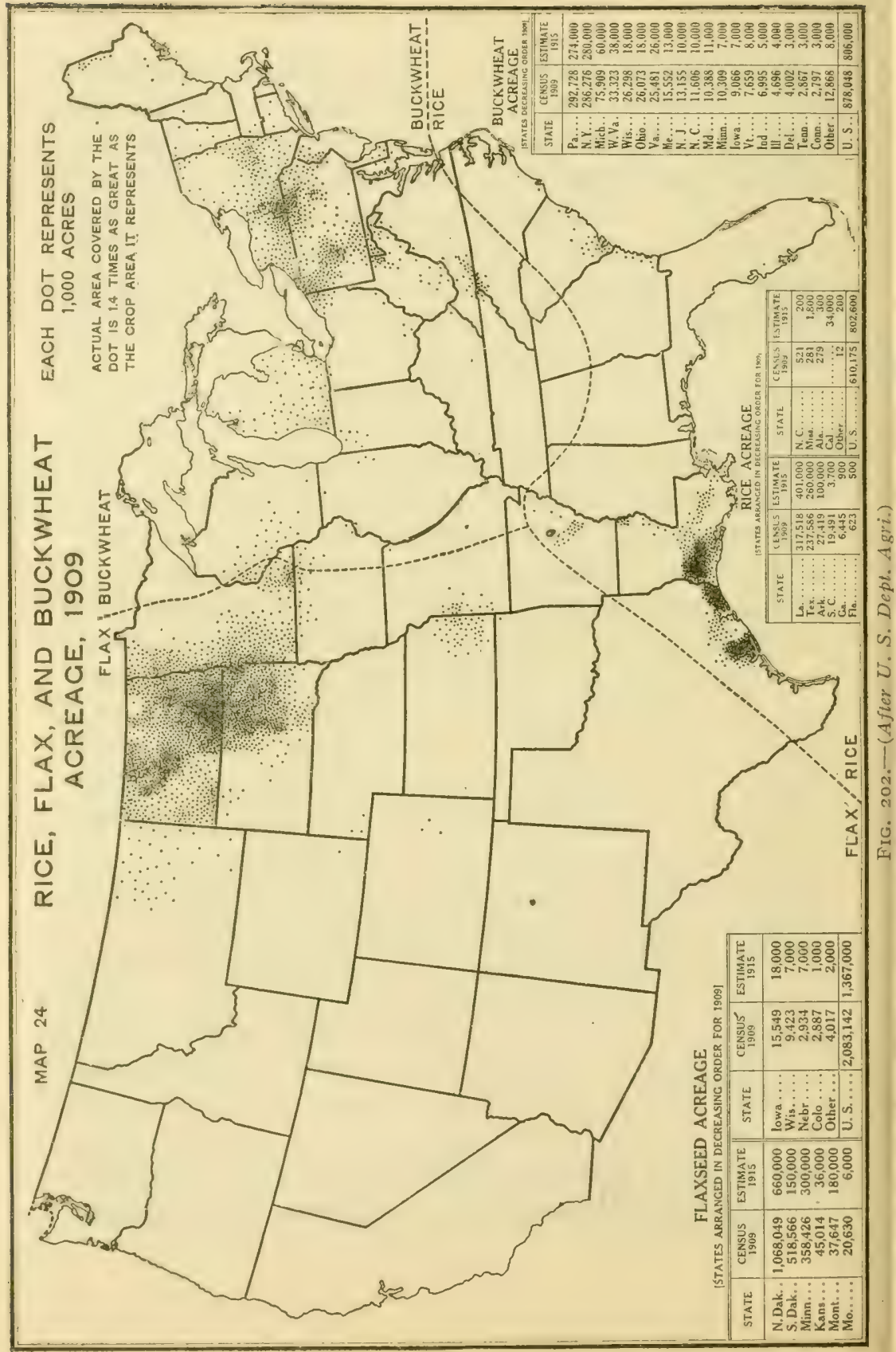


boxes. A line grade of paper (linen paper) is made from linen rags. Linen paper treated with sulphuric alde gries at parchment which takes the plate of "shere skin."

Preparation of Flax Fiber.- Flax plants for liber are [ulled by hand and tied into small bundles. 'The bundles are shocked and permitted to cure. After the seed is thrasherl from the plants, they are spread out thinly on the groumel and exposed to the weather for several weeks. 'The exposure brings about a partial separation of the batk and woxel. This process is known as retting. It is essentially a fermentaltion process. Retting is also carried on in stagnant water and fresh rumning water. Most French and Belgium tlax is retted in running streams, while most Irish flax is retted in stagnant water. The bundles of straw are then pounderl by hand or bent by machinery, until the fiber is almost entirely freed of other stem parts. The next treatment. known as "scutching," consists in beating the libers until any" fragments of bark or wood or course fibers, not removed in the breaking process, are eliminated. Pabldles, operated by hand or by machinery, are used in the scutehing process. The fibers are sorted and baled, and kept in this form until ready to be spun.

Production of Flax.--Most of the flax for liber is grown in the European countries. The United States is one of the largest seed-producing countries but raises at very small amount of fiber. In I9I4, Argentina produced i9. 71.000 bushels of flax seerl, British India I $5+40.000$ bushels, and United States 1 3,7+9,000 bushels. The large flax seed-poroducing States in 10 rt were North Dakotal. Minnesotat. Montana, South Dakota, and Kansas. 


\section{CHAPTER XXXI}

\section{RUTACE $\nRightarrow$ (Rue Family)}

Description.-This family is represented by trees, shrubs, and herbs. The leaves are alternate or opposite, simple or compound, exstipulate, and glandular-dotted. The glands, which appear as translucent dots, are internal. They vary somewhat in size and shape. The flowers (Figs. 200 and 20I) are solitary or in small axillary or terminal cymes. The sepals are four to five in number, but sometimes absent. There are as many petals as sepals, and they are either hypogynous or perigynous. The separate or united stamens are attached to the receptacle, and vary considerably in number; the anthers are two-celled, usually versatile, and introrsely dehiscent. The two to five carpels may be distinct, or united to form

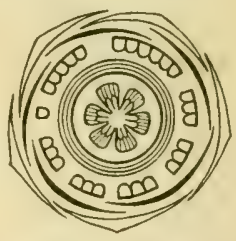

FIG. 200.-Floral diagram of Citrus. (Afler Eichler.) a compound pistil. The receptacle is frequently modified to form an annular disk (Fig. 20I, B). The fruit is a capsule, berry, drupe, or samara. The seeds are oblong or kidneyshaped, and have a straight or curved embryo, a fleshy endosperm, and fleshy cotyledons. The seeds of lemon may germinate in the fruit.

Geographical.- The family is well represented in the tropical countries. There are, according to Britton and Brown, about I Io genera and 880 species. A few members of the Rue Family are native to the United States; chief of these are the prickly ash (Xanthoxylum), hop-tree (Ptelea), and torch-wood (Amyris). None of the Citrus species are native of America. 


\section{Key to Important Generd of Rutace ${ }^{1}$}

Leaves trifoliate, Poncirus (trifoliate orange).

Leaves unifoliate.

Ovary three- to seven-celled; ovules two in each cell; stigma cavernous, Forlunella (kumquat).

Ovary eight- to fifteen-celled; usually more than two ovules in each cell; stigma solid, Citrus (orange, lemon, grapefruit, lime, etc.).

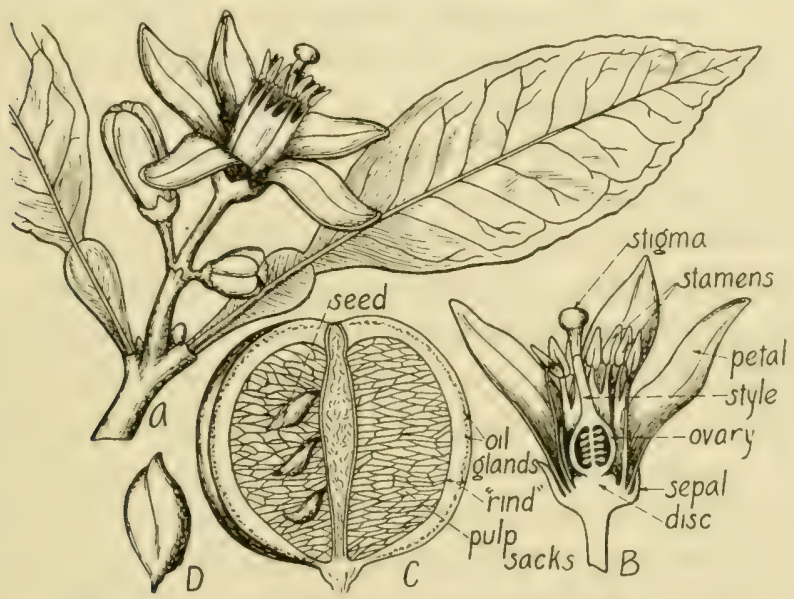

FIG. 20I.-Sour orange (Citrus aurantium). $A$, flowering branch; $B$, lengthwise section of flower; $C$, lengthwise section of fruit; $D$, seed. (Afler Wossidlo.)

\section{CITRUS (Citron, Lemon, Orange, etc.)}

Habit, Roots.-Citrus species are aromatic, mostly thorny shrubs or small trees with the spines disposed singly in the leaf axils. The sweet orange tree is a surface feeder; almost its entire root system is in the first 18 inches of soil. The sour orange root system penetrates to a much greater depth. The citrus plant is different from most plants in the total absence of root hairs. Absorption is carried on by the fibrous roots which are abundant and capable of rapid growth.

Leaves.-The leaves are glandular-dotted, winged-petio-

${ }^{1}$ Iume has been followed largely in the discussion of this group. 
late, glatuesus, leathery, evergreen, and unifoliate (with the exception of (itrus trifoliale); the leaf stalk is usually articulated to the blade and also to the twig. The life of the leaf depends upon the kind of wood upon which it is borne. On the fruiting branches, orange leaves, for example, remain on the tree about fifteen months, while on twigs with vigorous vegetative growth they may remain on the tree for three or four years. The leaves of trifoliate oranges fall in the autumn. 'The aromatic odor of freshly crushed leaves of citrus plints is clue to the numerous glands which are scattered over its surface.

Flowers.- The white or purplish-pink flowers are solitary. or in small axillary or terminal cymes or panicles. The flowers are hermaphroditic; the caly $x$ is three-to six-toothed; the corolla has four to eight separate thick segments (petals); and there are 20 to 60 stamens, united at their bases to form groups; the oidry possesses 8 to 75 cells and is subtended by a cushion-shaped disk (receptacle).

Pollination and Fertilization.-Some varieties of citrus plants require fertilization in order to set fruit, while others mature parthenocarpic ("seedless") fruits. Some rarieties of oranges require cross-fertilization, and moreover, will not set fruit unless pollen is derived from certain congenial varieties. Pollination may occur without the visitation of insects. The time for complete fertilization after pollination varies from thirty hours in Satsuma oranges to four weeks in trifoliate oranges. Parthenocarpic varieties seldom bear viable pollen. In navel oranges there is no pollen in the anthers at flowering time:

Fruit.-The fruit is a modified berry (hesperidium); it is spherical or spheroidal and is made up of a thick, leathery "rind" with numerous lysigenous oil glands, and a juicy pulp composed of numerous stalked "juice sacks." 
Bomatia considers the rind of citrus fruts to emsist of a whorl of modited leares that has grown up about the carpels. The number of carpels ("sections") varies in the same variety.

Seeds.--There are from one to eight light-colored seeds in each cell of the fruit. The seed coat is either leathery. or membranous; endosperm is lacking; each seed has two or more embryos with fleshy, hypogean cotylerlons. The polyembryonic condition of citrus fruits is characteristic. As many as thirteen seedlings from one seed have leen noterl. Strasburger has shown that embryos of citrus seerls may be derived from nucellar cells, as well as from fertilized ova. He has (lesignated such embryos as "adventitious." Hence. in the polyembryonic seed, there are two sorts of embryos: (r) those formed by the union of egg nucleus and sperm nucleus, true sexual embryos; and (2) "adrentitious" embryos formed by vegetative growth. Obviously, the secdlings from adventitious embryos may be used for propogation with confidence that they will come true to the plant which bore them. Early disintegration of embryo sacs appears to be prevalent in citrus fruit. This may be one cause, along with infertile pollen, of seedless fruits in this group.

Geographical.-Citrus species are mostly natives of the Mality . Irehipelikgo. and adjacent Asiatic territory: Citrus fruits are grown only in these parts of the United States where there is an almost continuous growing seaton, and where freezes seldom occur.

\section{Key to Principal. Species of Citrus}

Petals white inside, purplish or reddish outside.

Stamens 30 to to; fruit 6 to 9 inches long, its skin thick, C. medict (citron.

Stamens 20 to 30 ; fruit about 3 inches long, its skin medium thick, C. limionia (lemon). 
Petals white both on the inside and outside.

Leaves wingless or narrowly winged.

Fruit small, $1 \frac{1}{4}$ to $2 \frac{1}{2}$ inches in diameter, its skin thin, C. aurantifolia (lime).

Fruit large, its skin thick.

Tree small, I 2 to 20 feet tall; skin of fruit easily removed, C. nobilis (king orange).

Tree large, 20 to 40 feet high; skin of fruit not easily removed, $C$. sinensis (common sweet orange).

Leaves broadly winged.

Fruit large, pale lemon-yellow when ripe, C. grandis (grapefruit, pomelo, shaddock).

Fruit medium-sized, orange-colored or reddish when ripe, $C$. aurantium (sour or Seville orange).

\section{CITRUS MEDICA (Citron)}

Description - This is a shrub or small tree with short, stout thorns; the leaves are large, crenate or serrate, and its petioles are wingless; the large flowers are usually in clusters of 3 to ro; their petals are white above, and reddish purple below; the stamens are as many as 30 or 40 ; the ovary usually has from 9 to ro locules; the fruit is large, 6 to 9 inches long, rough or warty, lemon-yellow when ripe, its skin thick, the pulp scarce and very acid, and the juice sacks small and slender. In the "fingered citron," the fruit segments are separated into a number of finger-like projections.

Geographical.- This species is probably a native of India. It is cultivated most extensively in the Mediterranean region, and to some extent in this country.

"Citron."-The commercial "citron" is the dried fruit of Citrus medica. Before the fruit is candied, it is placed in brine to extract the undesirable oil in the skin. The fruit is then boiled for an hour or so in a sugar solution to which has been added some glucose. The glucose prevents the product from becoming too brittle. It is then allowed to 
stand in the syrup for about a month, and subsequently boiled in a pure sugar syrup.

\section{CITRUS LIMONIA (Lemon)}

Description.--The lemon tree is small, from ro to 20 feet in height, with short, stout thorns; the leaves are 2 to 3 inches long, long-ovate, sharp-pointed, serrate, and its petioles wingless; the large flowers are axillary, usually solitary,

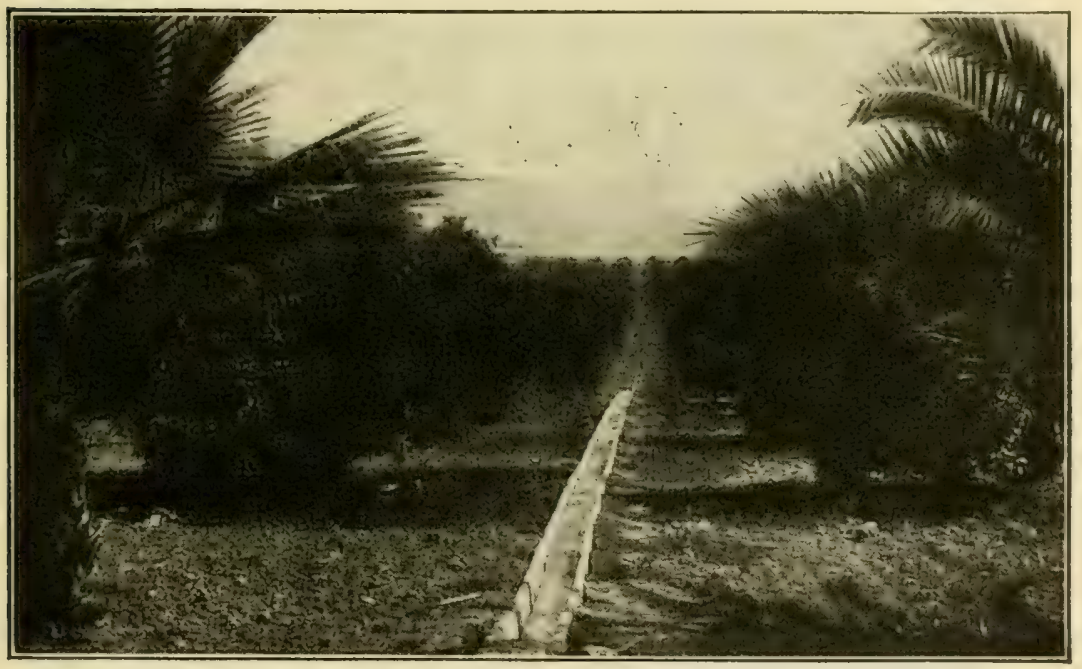

FIG. 203.-A citrus orchard in Southern California (From Calif. Agr. Exp. Sta.)

sometimes in small clusters; their petals are white inside, and purplish above; the stamens are usually between 20 and $3 c$ in number; the ovary has 7 to Io locules. There are three sorts of flowers in the lemon: (I) perfect flowers, (2) flowers with rudimentary pistils and normal stamens, and (3) flowers that fail to develop beyond the bud stage. The first class is the only one to set fruit. The fruit is about 3 
inches long, light yellow when mature, its skin mediumthick, the pulp abundant and acid, and the juice sacks long and pointed. 'The fruit requires about nine months to reach maturity.

Geographical.-The lemon is probably a native of India. It is cultivated extensively in the Mediterranean region, and to a considerable extent in California and Florida.

Colpr of Lemon Fruit.-Lemons are picked when they reach a size demanded by the market, regardless of the degree of maturity. Hence many of the lemons, when picked, are dark green, and not the lemon-yellow of those we buy in the market. The fruit is colored and ripened before shipment. If they are not to be shipped for several months, they are placed in storage houses where coloring and ripening goes on gradually. However, if they are to be shipped soon after picking, the coloring process is hastened. This is done by putting them in "sweat rooms" that are kept at a temperature between $90^{\circ}$ and $95^{\circ} \mathrm{F}$. The proper color is obtained by this treatment within four to six days.

Uses.-Lemons are used in the home for lemonade, as an ingredient in a number of prepared foods, as a stain-remover, and as a bleaching agent. One of the chief uses of lemons is in the manufacture of lemon extract.

I.cmon Extract.-This ranks second to vanilla extract in the quantity consumed. Sicily now produces the world's supply of lemon oil. Cull lemons are utilized for the production of the oil. Lemon extract is made by dissolving 5 parts of lemon oil in 95 parts of strong alcohol. Lemon oil is secreted by special cells in the outer surface of the rind. About 95 per cent. of the lemon oil produced is obtained from the lemons by the sponge method, the remainder by the machine method. There are two sponge methods, known as the two-piece, and three-piece sponge methods. In the former 
method the lemons are cut by hand into two pieces, and the pulp removed; the rinds are then thoroughly soaked in water, and after standing for several hours, passed on to the spongers. The apparatus of the sponger consists of a round stick about I inch in diameter, placed across the top of an earthenware bowl about 8 inches tall and the same in diameter, and three sponges. A flat sponge is hung across the stick, upon this another thicker sponge, and finally a third above this. The third or upper sponge is cup-shaped; into this depression, the lemon rind is inserted. By main strength the operator presses upon the sponge, repeating this pressure, after turning the rind over several times. Only $\mathrm{x}$ pound of oil is secured from 1,600 to 2,200 lemon halves. The threepiece method differs but slightly from the preceding.

\section{CITRUS AURANTIFOLIA (Lime)}

Description.-This is a small straggling tree or shrub, with numerous, small, very sharp thorns; the small leaves are elliptic-oval, crenate, glossy-green, and its petioles are narrowly, but distinctly, winged; the flowers are small, and usually produced in clusters of 3 to Io; the petals are white both above and below; the stamens range from 20 to 25 ; the ovary commonly has about io locules; the fruit is small. from $I \frac{1}{4}$ to $2 \frac{1}{2}$ inches in diameter, oblong, or roundedoblong in outline, light yellow when ripe, its skin thin, the pulp abundant, greenish and very acid, and the juice sacks small, oval, and pointed.

Geographical.-The lime is a native of India and southeastern $A$ sia. It is cultivated in many tropical countries, and to some extent in Florida and the Keys. The fruit is used in the making of "limeade."

"Limequat."-The "limequat" is a hybrid between at kumquat and the Mexican lime. 


\section{CITRUS SINENSIS (Common or Sweet Orange)}

Description.--The sweet orange tree is 25 to 40 feet high, round-topped, and usually bears slender, flexible, blunt spines; the leaves are oval or ovate-oblong, and the petioles are narrowly winged, articulated both with the blade and the twig; the flowers occur singly or in small cluster; the petals are white above and below; there are from 20 to 25 stamens; the ovary has Io to 14 locules; the fruit is subglobular, light orange to reddish, smooth, the pulp abundant and sweet, and the juice sacks spindle-shaped.

Geographical.-The sweet orange is the most widely cultivated of all citrus fruits; it is probably a native of southeastern Asia.

Types.-There are a number of groups or types of sweet oranges; the four principal ones are Spanish oranges, Mediterranean oranges, blood oranges, and navel oranges. Spanish oranges have large, coarse-grained fruit. Mediterranean oranges are of good quality and fine-grained. Blood oranges have red pulp or white pulp streaked with red; the fruit is of good quality. Navel oranges are so named on account of the umbilical mark at the apex of the fruit. This mark is due to the protrusion of additional carpels developed within the fruit.

Uses.-Whereas oranges were once regarded as luxuries, they are now produced in such quantities and sold at such prices as to be within the reach of the majority of people. Oranges are used mainly as a fresh dessert. Orange extract is made by dissolving orange oil in strong alcohol. Up to the year I9II, almost the entire world's supply of orange oil came from Sicily, Italy and adjacent parts of southern Europe. Since then the West Indies have developed the industry.

The oil is used in the manufacture of perfumes, soaps, and flavoring extracts, and to a slight extent as a drug. 
Hood and Russell have recently pointed out that the extraction of sweet orange oil is a commercial possibility in this country, and that waste oranges may be utilized.

\section{CITRUS NOBHIS (King Orange)}

Description.-The King orange tree is I 2 to 20 feet tall, with slender, drooping branches, and thornless, or with small sharp spines; the leaves are small, lanceolate to oval, and the petioles are wingless or very narrowly winged; the flowers occur singly or in small clusters; the petals are white above and below, fleshy and recurved; there are from $\mathrm{I} 8$ to 24 stamens; the ovary has 9 to 15 locules; the fruit is oblate, orange to reddish in color, its peel loose and easily removed, the pulp sweet or sub-acid, and the juice sacks broad and blunt.

Varieties.-Citrus nobilis var. deliciosa is the mandarin orange. In this variety are included the tangerine varieties, which have an easily removable skin and segments that come apart readily, also the tangelo which is a hybrid between the tangerine and the Bowen grapefruit. Citrus nobilis var. unshiu is the Satsuma or Unshiu orange. It is a small, spineless, dwarf tree, and very hardy.

\section{CITRUS GRANDIS (Grapefruit, Pomelo, Shaddock)}

Description.- This species is a large tree, 20 to 40 feet in height, with slender, flexible spines, if present; the leaves are large, ovate, crenate, broadly rounded at the base, and the petioles are broadly winged and articulated; the flowers are borne singly or in clusters of 2 to 20 ; the petals are white both above and below; there are from 20 to 25 stamens, with large linear anthers; the ovary has from I I to i 4 locules; the fruit is very large, 4 to 6 inches in diameter, globose, oblate or pear-shaped, pale lemon-yellow when ripe, its skin smooth, 
the pulp peculiarly acid or sub-acid, and the juice sacks large and spindle-shaped.

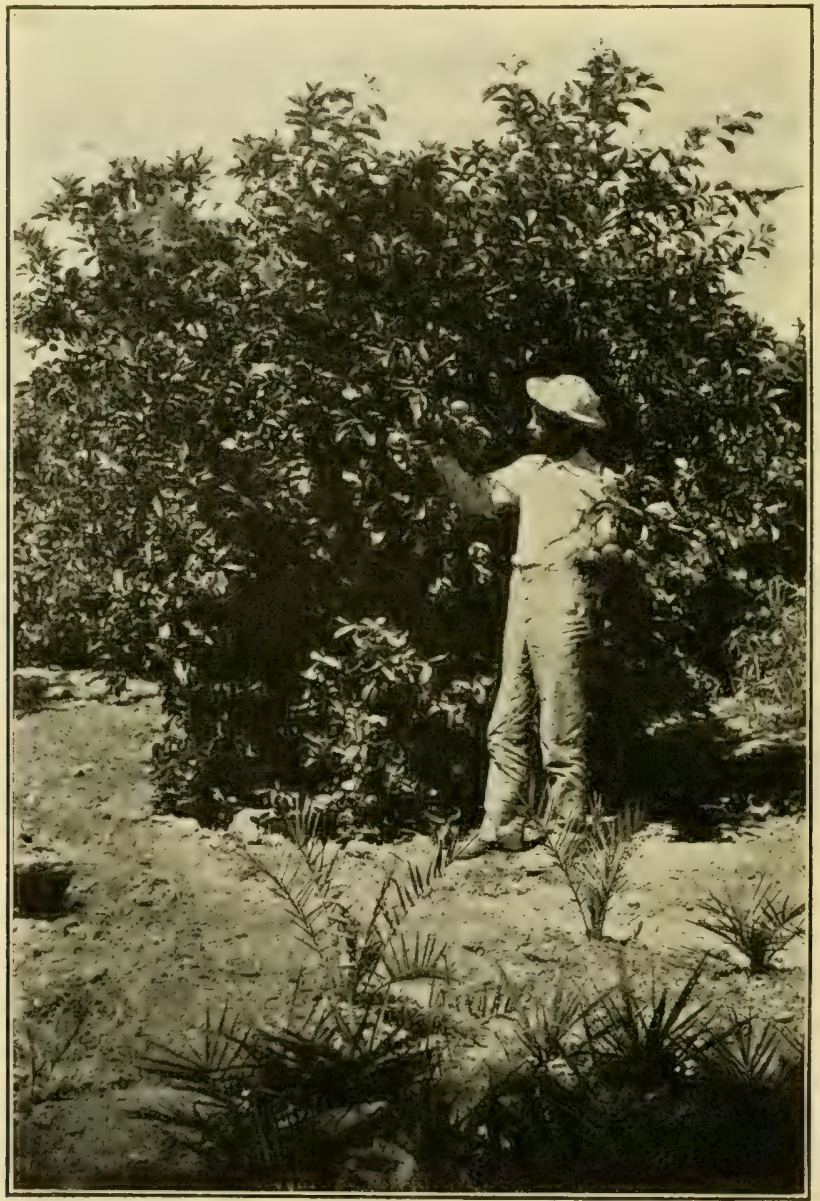

FIG. 204.-Pomelo (Citrus grandis), in the fourth summer. (From Calif. Agr. Exp. Sta.)

Geographical.-The species is a native of Polynesia and the Malay Archipelago. It is now grown in the United States. 
Variety and Name.- The name grapefruil is the one that this species is known by commercially. Shaddock is a horticultural variety, the fruit of which is much larger than the common grapefruit. It is a coarse, thick-skinned fruit, with thick, leathery septa between the locules, and is of no commercial importance. The name pomelo is now recognized by most horticulturists. Grapefruit is a well-known breakfast fruit.

\section{CITRUS AURANTIUM (Sour or Seville Orange)}

Description.-The sour orange tree is 20 to 30 feet high. and bears long, flexible, blunt spines; the laves are 3 to 4 inches long, wedge-shaped at the base, pointed at the tip, and the petioles are broadly winged; the flowers are borne singly or in small axillary cymes; the fragrant glandulardotted petals are white above and below; there are from 20 to 24 stamens; the ovary has 6 to I4 locules; the fruit is globose, orange-colored or reddish, rough, the pulp acid, and the juice sacks small and spindle-shaped.

Geographical.- The sour orange is probably a native of southeastern . Isia. It is cultivated in the United States, being used as a stock on which to burl other citrus fruits.

Other Species of Citrus.-Other Citrus species of less commercial importance in the United States are C. mitis, the Calamondin orange, C. ichangensis, Ichang lemon, and C. bergamia, bergamot.

\section{FORTUNELLA (Citrus) (Kumquat or Kinkan)}

Description.--The kumquats are evergreen shrubs with simple, glandular leaves; the scented white flowers are single or in clusters of three or four, and axillary; the early flower: in the spring are usually without pistils; there are four times as many stamens as petals; the ovary has three to seven cells. 
and each cell contains two ovules; a characteristic feature of the flower is the cavernous stigma; the fruit is small, I to $\mathrm{I} / \frac{1}{4}$ inches in diameter, its rind usually thick, fleshy, spicy,

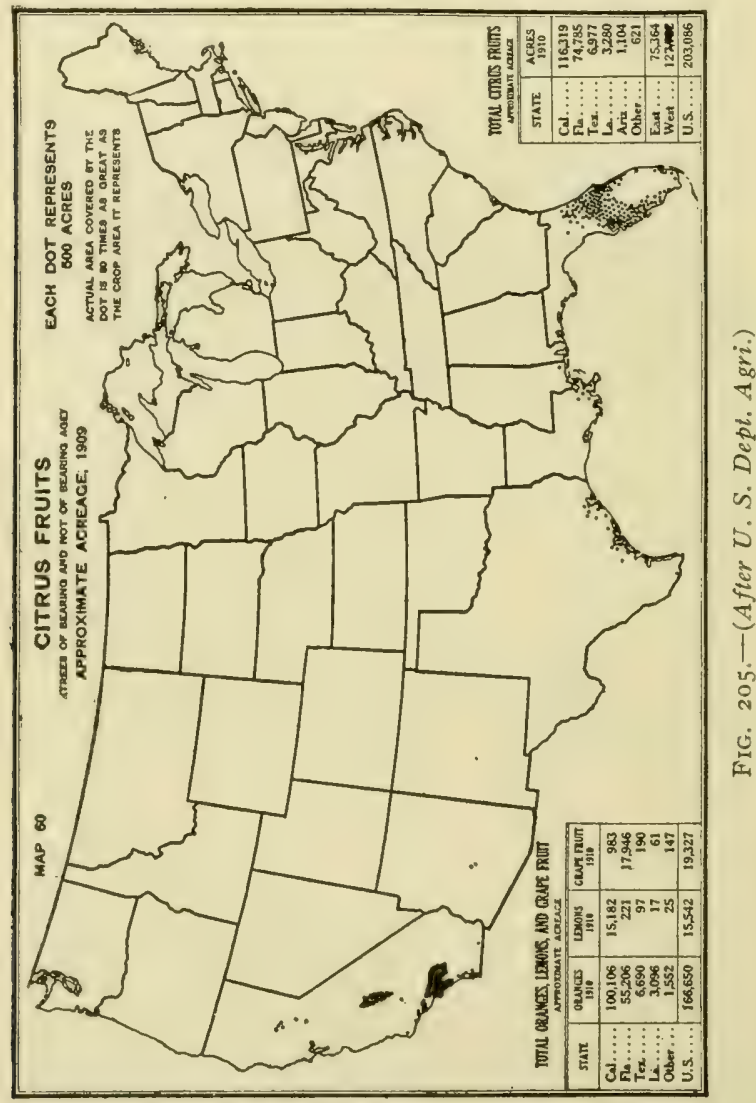

and aromatic, its juice acid, and its seeds small and pointed; there may be one or two crops of bloom and fruit in a growing season.

Species.-The two most common species of Fortunella are $F$. margarita, the Oval or Nagami kumquat, and $F$. 
japonica, the Round or Marumi kumquat. The former is athornless shrub or small tree with oval fruit, the latter a thorny shrub with globose fruit. $F$. crassifolia is the Meiwa kumquat, and $F$. hindsii, the Hongkong wild kumquat. The latter is considered by Swingle to be the wild stem form of our Citrus species.

Uses.- The kumquats are shrubs grown as ornamentals, and also for their fruit, which is eaten raw and entire.

\section{PONCIRUS, (Trifoliate Orange)}

Description.- The trifoliate orange is a low tree, seldom over I 5 feet high; the older branches are thorny, the thorns being $\mathrm{I}$ to $\mathrm{I}_{2}$ inches long, and flattened at the base; the characteristic deciduous trifoliate leaves are composed of thin, elliptical, crenate or dentate leaflets; the flowers usually appear before the leaves, singly or in pairs in the leaf axils; the five sepals are greenish yellow in color, and pointed at the tip; the corolla is white; the fruit has a light orange color, is rough, and covered with short hairs; it is of no commercial value; the numerous seeds differ from those of other allies in being oval, rounded at one end and blunt-pointed at the other. The pulp is acid, bitter, and gummy.

A Hardy Orange.- The trifoliate orange is a native of China and Japan. It is the hardiest of our citrus species, and for that reason has been used in crosses with less hardy, but more desirable species, in the hope that hybrid forms would be secured which would combine hardiness and desirable fruit characters. Hybrids of trifoliate and sweet oranges are known as citranges. Varieties of citranges are Colman, Morton, Rusk, Rustic, and Savage.

\section{References}

Biermann, M.: On the Structure and Development of the Fruit of Citrus Vulgaris. Arch. Pharm., 235: I9-28, I897. 
Bonavia, E.: Oranges and Lemons of India, vol. i.

Cort, J. E.: A Study of the Factors Influencing Seed Formation in Citrus Fruits. Calif. Agr. Exp. Sta. Rpt., Io5-Io6, r9r4.

Citrus Fruits. The MacMillan Co., I9 5 .

Hood, S. C., and Russell, G. A.: The Production of Sweet-orange Oil and a New Machine for Peeling Citrus Fruits. U. S. Dept. Agr. Bull. 399: I-I9, I9I6.

Hume, H. Harold: Pomelos. Fla. Agr. Exp. Sta. Bull. 58: 385-42 I, Igor. The Kumquats. Fla. Agr. Exp. Sta. Bull. 65: 555-566, I902.

The Mandarin Orange Group. Fla. Agr. Exp. Sta. Bull. 66: 571-594, 1903. Citrus Fruits and Their Culture. Orange Judd Co., I9r3.

Ineda, Tomochika: On the Parthenocarpy of Citrus fruits. Jour. Sci. Agr. Soc. Tokyo, 63, I904.

Osawa, I.: Cytological and Experimental Studies in Citrus. Jour. Col. Agr. Imp. Univ. Tokyo, 4: 83-II6, I9I2.

Strasburger, E.: Über Polyembryonie. Jenaisch. Zeitsch. Naturwiss., I 2: $647-670$, I 878 .

Webber, H. J.: Complications in Citrus Hybridization Caused by Polyembryony. Science, n. S., II: 308, I900. 


\section{CHAPTER XXXII \\ VITACEÆ (Grape Family)}

Family Description.-Members of the grape family are either climbers or erect shrubs with nodose joints. There is an abundance of watery sap. The leaves are alternate and petioled, either simple (Vitis) or compound (Parthenocissus) (Fig. 206). The inflorescence is commonly a panicle (Vitis) or a cyme (Parthenocissus). The flowers (Fig. 2 Io) are small, greenish, perfect or polygamo-diœecious (perfect flowers on one individual and imperfect on another). The calyx is entire or four- to five-toothed. The four to five petals are either separate or united and fall away very soon after development. Stamens are four to five in number and

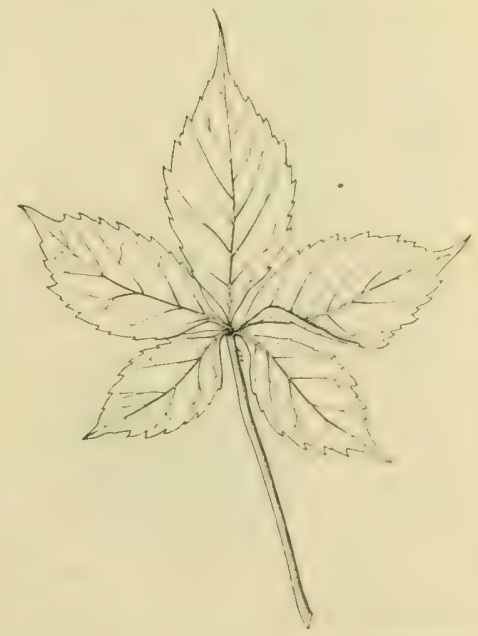

FIG. 206.-Compound digitate leaf of Virginia creeper (Parthenocissus quinquefolia). opposite the petals. The single ovary has two to six cells with one to two orules in each locule. The fruit is commonly a two-celled berry.

Geographical.--There are about ro genera and 450 species in this family, many of which are natives to tropical countries. 


\section{Key to Important Genera}

The three most important genera are Vitis (grape), Cissus (pepper vine) and Parthenocissus (Virginia Creeper and American Ivy). These may be distinguished as follows (as far as our species are concerned):

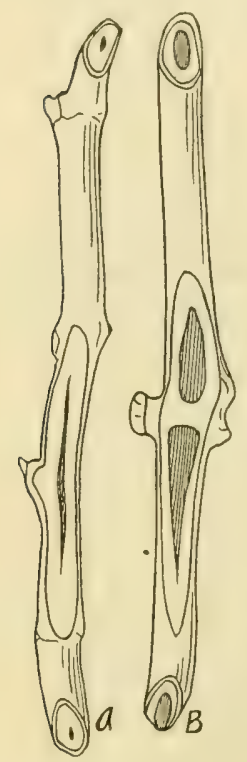

FIG. 207.-Two types of grape stems cut in median lengthwise section. $A$, southern fox grape (Vitis rotundifolia) with pith continuous at the nodes; $B$, old world grape (V. vinifera) with pith interrupted at the nodes. (After Hedrick.)

Leaves simple or pinnately compound.

Petals united into a cap, falling away without separating (Fig. 210), Vitis (grape).

Petals separate, spreading, Cissus (pepper vine). Leaves digitately compound, Parthenocissus (Virginia creeper, American ivy).

\section{VITIS (Grape)}

Stems.-Grapes are climbing or woody vines with tendrils. The stem is jointed. The internodes have a large pith. In many species there is a woody tissue (diaphragm) at the nodes separating the pith; in others this woody tissue is absent (Fig. 207). In pruning the vines, the practice is to make the cut through the nodes rather than through the internodes; by cutting through an internode, the pith shrinks, leaving a hollow in which water may collect and rotting set in. Grapes have a tendency to produce suckers and water sprouts. The former arise from below or near the surface of the ground and should be removed. Water sprouts arise from dormant buds above ground. They do not produce fruit. If dormant buds develop, producing these sterile shoots, it indicates that there is not a sufficient number of fruit buds to take care of all the sap coming to aerial parts. Water sprouts should be removed during winter pruning.

Tendrils, morphologically, are modified stems. This is 
shown by the fact that they sometimes bear small leaves or flowers. In the Fox grape (Fig. $2 \mathrm{c} 8$ ), there is either a tendril or an inflorescence opposite each leaf. This continuity

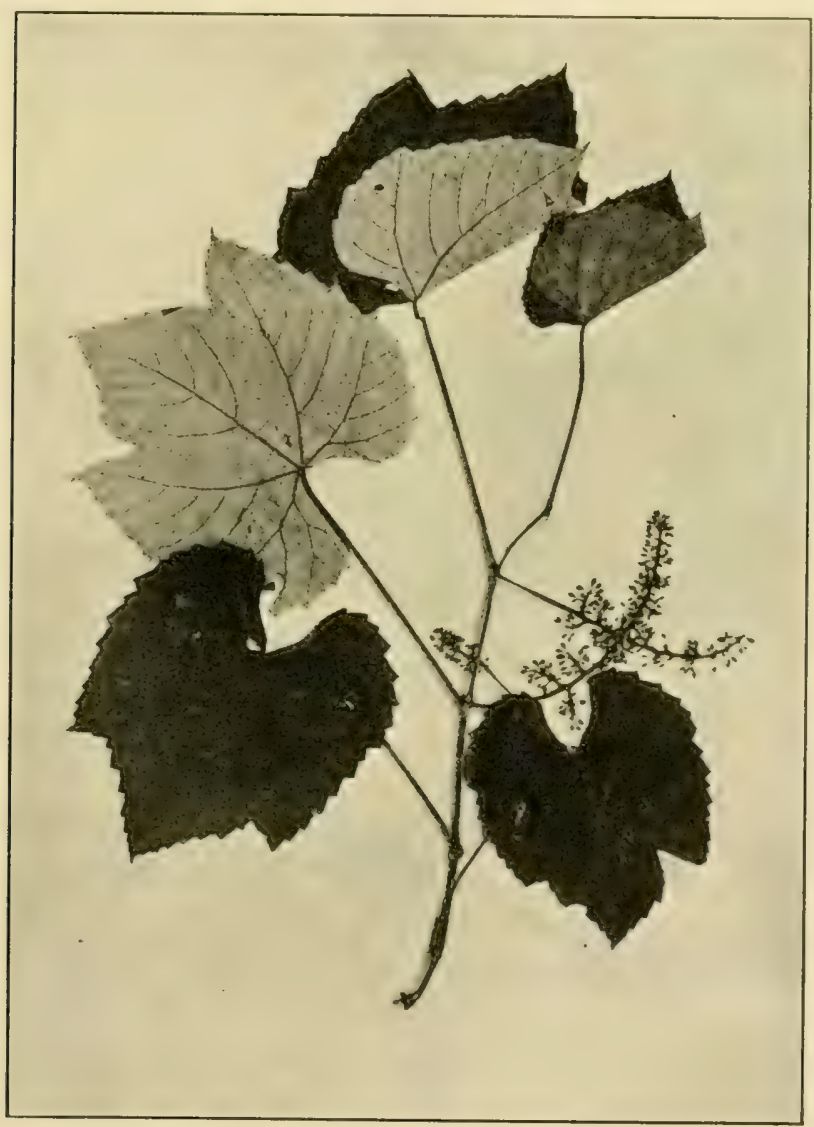

FIG. 208.-Northern fox grape (Vitis labrusca).

is somewhat variable, however. In all other species, there are two successive leaves with a tendril or inflorescence oppo- 

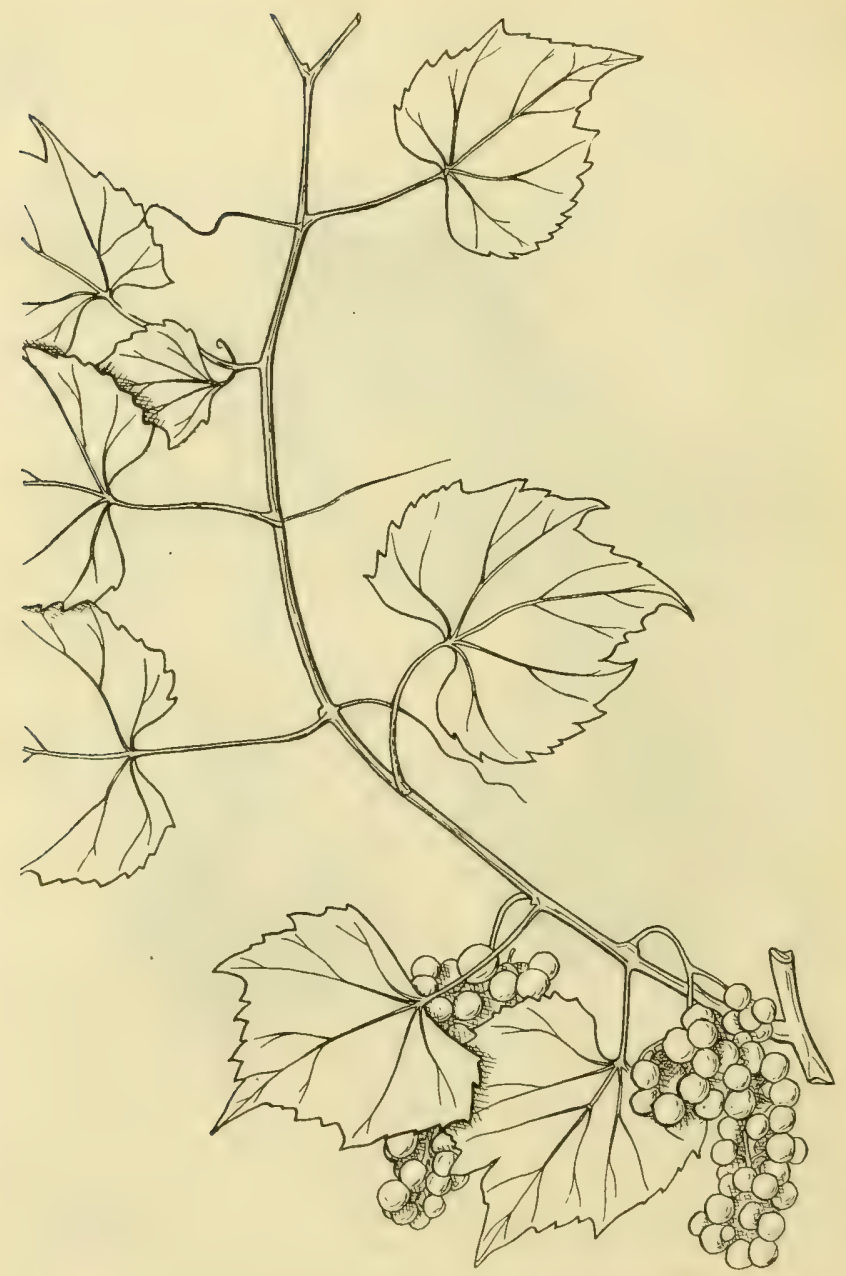

FIG. 209.-Fruit-bearing shoot of river-bank grape (Vitis riparia). (After Hedrick.) 
site each, while the third leaf is without at tendril, and so on. there being no tendril or cluster for each third leaf (Fig. 209). A tendril or inflorescence terminates the stem growth.

Flower clusters are borne on growing shoots. In the spring, a bud sends out a growth; flower clusters appear early near the base of this growth, while the shoot continues to grow until the end of the season. I'itis labrusca averages three to six clusters to a cane; all other species average two to a cane. This shoot bears a number of buds, each of which may, the following season, produce another shoot, in turn bearing fruit clusters. If all these buds are allowed to develop, the fruit developed on the shoots will be very small. Hence in practice it is found necessary, each year, to prune back the current season's growth, leaving only a few buds to develop the succeeding year.

Grapes are commonly propagated from stem cuttings. The European grape has been grown vegetatively for over 5,000 years.

Leaves.-The grape leaf is simple, palmately lobed or dentate, alternate, with grooved petiole and small stipules. The leaves of the different species vary as to size, shape, number of lobes, nature of petiolar groove, and surface.

Inflorescence and Flowers.-The grape inflorescence is a compact panicle. As has been indicated, the clusters are borne at the basal nodes of the current season's growth, opposite a leaf or a tendril. In Vitis labrusca, there are from three to six inflorescences to a cane, while in all other species the average is two inflorescences per cane.

In the wild state, grape vines are of two types: some vines bear self-sterile perfect flowers and other vines bear only staminate flowers. In cultivated forms, there are two types of perfect flowers; those in which the stamens are upright and those in which the stamens are reflexed. In the first 
case, the pistil is fully developed and the pollen potent, while in those flowers with reflexed stamens, the pollen is more or less impotent. Flowers without stamens do not occur. Among cultivated European varieties, only perfect flowers are common. This has resulted from selection.

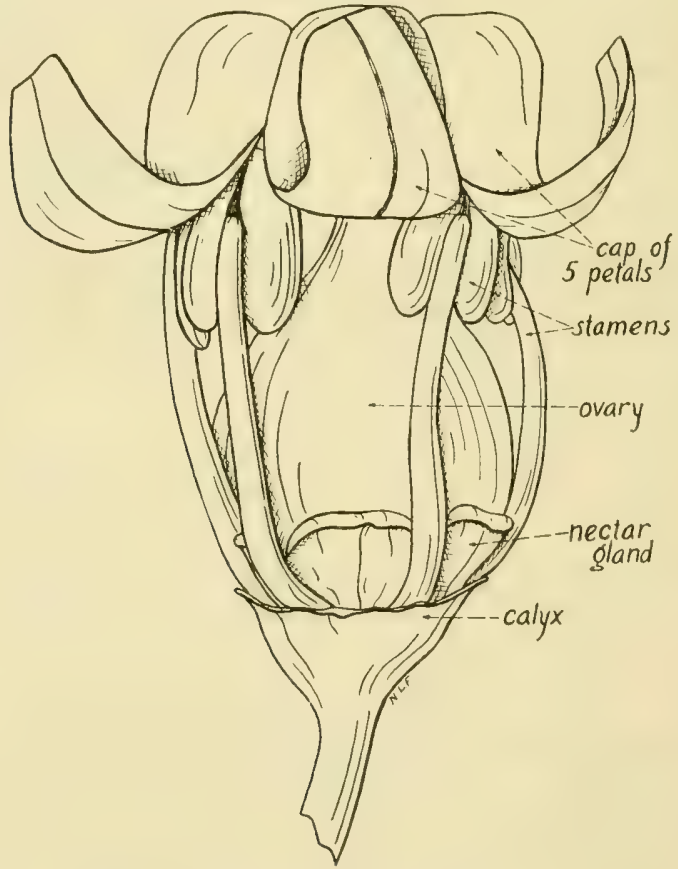

FIG. 210.-Grape flower, opening. $\times 20$.

The flowers (Fig. 2 Io) are hypogynous and regular. The calyx consists of a narrow rim at the base of the flower. The corolla has five united, greenish petals; in the bud, they form a cap (Fig. 2 I0) over the stamens and pistils. When the flower opens, the petals become loosened at the base but remain united by the tips. Stamens are five in number and 
there is an equal number of nectar glands between. The one pistil is two-celled and two-ovuled. The fruit is a berry.

Dorsey has cited marked variations in the flowers of the genus Vitis: stamens may vary from three to nine; petals, nectariferous glands, and carpels have a corresponding numerical variation.

\section{Opening of Flower and Pollination.-Flower Opening.-} The opening of the grape flower is indicated by the breaking away of the petals at the base (Fig. 2 Io). In some instances, all the petals break away at about the same time; at other times, one petal may initiate the process, and be followed by the others. The cap of five petals, adhering at their apices, finally falls off. The rate of flower opening varies from a few minutes to several hours. The anthers seldom open until the cap falls off. Most grapes are insect pollinated.

Self-sterility.-Many cultivated varieties of grapes are self-sterile; this is due, for the most part, to impotent pollen. Some cultivated varieties are perfectly self-fertile, others partially self-fertile, and still others entirely self-sterile. As has been indicated, perfect flowers bearing reflexed stamens usually have impotent pollen. However, in some cases, perfect flowers with erect stamens also bear impotent pollen. As a rule, the self-fertile varieties, those that can develop marketable clusters when self-fertilized, have long stamens. Self-sterile varieties, those that cannot produce marketable clusters of fruit when self-fertilized, usually possess short stamens. However, long stamens and short stamens are not absolute criteria of self-fertility and selfsterility respectively. With but few exceptions, the strongly self-sterile varieties are hybrids. Booth suggests that the grape is "now in a state of evolution from an assumed older hermaphrodite form to forms which are essentially staminate 
and pistillate." He finds all gradations between "pseudostaminate" and "pseudo-pistillate" forms among wild species.

Grape Pollen.- In a study of grape pollen, Booth found that self-sterile pollen differs from self-fertile pollen. In the self-fertile form, the grain is surrounded by a mucilaginous substance which causes them to stick together; the grain is oblong in shape, symmetrical, and blunt at the ends. Selfsterile pollen has no mucilaginous substance about it; it is irregular in shape and more pointed at the ends. Selffertile and self-fertile pollen may be mixed in the same variety. The degree of self-sterility or self-fertility seems to vary with environmental conditions.

"Couloure" of Muscat Grape.-This valuable raisin grape has a tendency to drop its blossoms without setting fruit. This trouble is known as "couloure." It results from a lack of fertilization. This is due to the fact that in this variety stamens are shorter than the pistil, that the pollen has a tendency to stick together in masses which makes its distribution less certain, and to the rather frequent development of imperfect pollen grains. The difficulty is largely overcome by planting, in the Muscat vineyard, varieties that produce an abundance of viable pollen, and that blossom at the same time as the Muscat. These varieties will furnish pollen for fertilization of Muscat flowers.

Flowers in Wild Grapes.--Grapes in the native condition differ from those in cultivation. The wild forms seldom bear self-fertile perfect flowers. In these, there are just two sorts of vines: (I) staminate, and (2) self-sterile hermaphrodite. There are no self-fertile hermaphrodites. The staminate flowers have abortive pistils, and the so-called pistillate forms retain their stamens, but they are abortive. 
Key to Most Important Species of Vitis ${ }^{1}$

Skin of mature berry not separating frecly from the pulp, lilis sinifere (Old World grape).

Skin of mature berry separating readily from the pulp.

Nodes without diaphragms (Fïr. 207,1 ); tendrils forked, Vitis rolundifolit (Southern fox grape).

Nodes with diaphragms (Fig. 207, B); tendrils forked.

Leaves and shoots glabrous at maturity and without bloom.

Leaves broader than long; petiolar sinus usually wide and shallow, V. rupestris (sand grape).

Leaves ovate in outline; petiolar sinus usually medium to narrow, $V$. riparia (river bark grape).

Leaves rusty or white tomentose or glaucous blue below.

Leaves not covered with a thick, dense felt-like tomentum when fully grown, $V$. astivalis (summer grape).

Leâves covered with a dense, thick, felt-like tomentum when fully grown, $V$. labrusca (Northern fox grape).

\section{Vitis vinifera (Old-World Grape, Wine Grape, Raisin} Grape). The Old-IForld grape is not as large a plant as most American species. The leuves are thin, smooth, and three- to seven-lobed; they may be smooth or woolly-hairy when young; the lobes are rounded or pointed, and their margins coarsely toothed. The oval, oblong, or globular berries are in long and broad clusters.

The varieties of this species have a high sugar content. On this account, they make better wine and raisins than American varieties. American varieties are table grapes; European varieties are wine and raisin grapes. The latter are now grown in California, where the wine and raisin industries have developed to considerable importance. I'. vinifer is not resistant to the attacks of Phylloxera, a scale attacking the leaves and roots. American varieties are comparatively more resistant to these insects and on this account are used as stocks upon which European varieties are grafted.

${ }^{1}$ The key is adapted from "The Grapes of New York," by Hedricl. 
Vitis vinifera is probably a native of western and southern Asia.

Vitis rotundifolia (Southern Fox Grape).-This is usually a very vigorous, high-climbing grape, with hard wood and smooth bark. The leaves are broadly heart-shaped, with coarse, blunt teeth, light green in color, smooth above and below or sometimes slightly hairy on the veins below. The large, spherical, black or greenish-yellow berries are in small loose clusters. It grows wild from southern Delaware to Missouri, Texas, and the Gulf States.

The varieties of this species are known as Muscadine grapes. One of the chief varieties is the Scuppernong.

Vitis rupestris (Sand Grape).-This is a low shrub with small, broadly beart-shaped, slightly lobed leaves with coarsely toothed margins. The small, black or purple-black berries are in small clusters.

This species is southern in its distribution, reaching southern Pennsylvania as its northernmost limit. It is very resistant to rot and mildew of the foliage.

Vitis riparia (River-bank Grape).-The river-bank grape is a rather vigorous climbing plant with smooth and slender twigs. The leaves have large stipules; the margin has sharp teeth that vary in size. The berries are small, black, coated with a bloom, and occur in rather compact, but small clusters.

This is the most widely distributed and the hardiest of American grapes. It is common on stream banks in the United States east of the Rocky Mountains.

Vitis aestivalis (Summer Grape).-This is a strong-growing species with leaves that are short-stipulate, thick, three- to five-lobed, shallowly dentate, dark green above and rusty pubescent beneath. The berries are astringent, of average size, and usually in long clusters.

This species is native to southeastern United States. Its varieties are wine grapes.

Vitis labrusca (Northern Fox Grape).--This is a stocky plant with large, heart-shaped leaves which are either entire or three-lobed, dark green above, and densely pubescent below. The clusters of thick-skinned berries are medium to large. 
By far the greatest number of cultivated grapes are varieties of this species, or hybrids from it and other species, chiefly Vilis vinifera, the Old-World grape.

Varieties of Table Grapes.--There are four very common varieties of table grapes:

I. Catawba, hybrid of V. labrusca and V. vinifera.

2. Delaware, hybrid of V. labrusca and V. bourguiniana.

3. Niagara, hybrid of $V$. labrusca and $V$. vinifera.

4. Concord, variety of V. labrusca.

Color of Grapes.-Varieties of grapes may be grouped as to color as follows:

I. Berries Purplish-black to Black.-America, August Giant, Bacchus, Black Hamburg, Canada, Champion, Concord, Ives, Mills, Muscat, Hamburg, Norton.

2. Berries Purplish-red.-Agawam, Brighton, Catawba, Delaware, Diana, Iona, Jefferson, Lutie, Massasoit, Red Eagle, Rochester, Vergennes.

3. Berries Light Green.-Colerain, Croton, Diamond, Duchess, Elvira, Grein Golden, Lady, Niagara, Triumph.

Wine and Raisin Grapes.-As has been indicated, the European grape is a wine and raisin grape. Some varieties such as Petite Sirah, Beclan, Mondeuse, Verdot, Lagrain, Refosco, etc., are adapted to the manufacture of dry, white wines; Grenache, Mission, Palomino, and Boal, are a few varieties from which sweet wine is made; while some common raisin grapes are White Muscat of Alexandria, Malaga, and Sultanina.

Uses.-Dried Grapes.--These are known under the names "raisins," "Sultanas," and "English," "Corinth" or "Zanta currants." Thin-skinned varieties, such as Vinifera grapes, whose seeds do not adhere to the pulp, are preferable for ralsins. "Sultanas" are small light-colored raisins made 
from a small, seedless grape. "English, "Corinth" or "Zanta currants" are small dried grapes, grown chiefly in the south of Greece. Table raisins are made from the most select grapes, and usually dried in the sun, without preliminary dipping. The lower grades of grapes that are made into raisins for cooking purposes are nearly always dipped in weak lye before thy are dried. California produces almost all the raisins of the United States. According to the census of rgro the production of raisins and dried grapes in the United States amounted to $\mathrm{I} 69,245,100$ pounds, of which California furnished $169,210,675$ pounds.

Wines.-There are two well-known sorts of wines: (I) dry wines, and (2) sweet wines. Dry wines are those in which the grape sugar has been converted into alcohol through fermentation. Sweet wines are those in which the grape sugar has not been converted into alcohol, but the process of fermentation has been prevented by adding alcohol. There are two groups of dry wines: (I) red wines (clarets, Burgundies, etc.); and (2) white wines (Hocks, Rieslings, etc.). Red wines are made from colored grapes, the skins usually furnishing the coloring matter for the fermenting juice. In the making of red wines, the skins and pulp are crushed and placed in fermenting vats. The unfermented grape juice is termed "must." Fermentation is brought about by the activity of yeast plants, and in this process, the conversion of sugar to alcohol takes place. After the completion of fermentation, the wine is drained from the pomace (skins and other solid material of the grape) and stored in various sorts of receptacles. A slow fermentation goes on in storage, and during this period, settlings accumulate, which are finally removed, leaving the clear wine product.

White wines are made from white grapes, or from those 
colored grapes with a colorless juice. The coloring matter in the skin is not permitted to get into the juice, as the skins are removerl by pressing, and the juice allowerl to ferment alone.

The two chicf sweet wines in this country are the ports and angelicas. Port wines are made from colored grapes. The fruit is crushed and allowed to ferment; however, the process of fermentation is not allowed to proceed far, but. is stopped by the addition of alcohol. This adding of alcohol to stop the fermentation process is called "fortifying." In the making of angelica wines, the grapes are crushed, pressed immediately to remove the pomace, and the juice permitted to ferment until the desired degree of sweetness is attained, and then the process of fermentation stopped by "fortifying."

Brandy.-Brandies are made both from white wines and red wines. Pure "cognac" is obtained from the distillation of French white wine. The inferior grades of brandy come from the distillation of inferior sorts of wine.

Vinegar. - Grape vinegar is made from white and red wines. giving white and red vinegars respectively. Many grapes unsuited for drying, shipping, or wine-making can be turned into excellent vinegars.

Other Uses.- Grapes are a common fresh clessert. 'The' unfermented juice is sold in large quantities in bottles. I good table syrup can be made from some varieties. 'The' wood is sometimes used in the manufacture of baskets. furniture, and rustic work. The plants are ornamental and are frequently turned into arbors. 'There are a number of by-products from the grape plant. Brandy, feed, fertilizers, and acetic acid are made from the pomace. 'Tartaric acid is manufactured from the stems, shells and the "lees" of wine. The seeds are used as a food for stock and as a suurce 
of tannin and grape oil. A brandy has been made by fermenting the sugary substance that sticks to the seeds, and this material may also be made into a syrup.

\section{References}

Beacri, S. A.: Notes on Self-pollination of the Grape, N. Y. State Agr. Exp. Sta. Ann. Rept. Ir: 597-606, I892.

Self-fertility of the Grape. N. Y. State Agr. Exp. Sta. Bull, 157:397-44I, I 898 .

Fertilizing Self-sterile Grapes. N. Y. State Agr. Exp. Sta. Bull. I69: 33I-37I, I899.

Bоотн, N. O.: A Study of Grape Pollen. N. I. Agr. Exp. Sta. Bull. 224: 29I-302, I902.

Dorsey, M. J.: Variation Studies of the Venation Angles and Leaf Dimensions in Vitis. Am. Breeders' Assn., 7:227-250, I9II.

Variation in the Floral Structure of Vitis. Bul. Torrey Bot. Club, 39:3752, I9I2.

Pollen Development in Vitis with Special Reference to Sterility. Minn. Agr. Exp. Sta. Bull. I44: I-60, I9I4.

Pollen Sterility in Grapes. Jour. Hered., 6: 243-249, I9 5 .

Hedrick, V. P.: The Grapes of New York. 15th Ann. Rept. N. Y. Agr. Exp. Sta., vol. 3, part 2: I-564, Igo8.

Husmann, George C., and Dearing, Charles: The Muscadine Grapes.

U. S. Dept. Agr. Bur. Plant Ind. Bull. 273: 1-64, 1913.

Munson, T. V.: Investigation and Improvement of American Grapes. Texas Agr. Exp. Sta. Bull. 56:217-285, I899.

Rabak, Frank: The Utilization of Waste Raisin Seeds. U. S. Dept. Agr., Bur. Plant Indus. Bull, 276: I-36, I9г3.

Reimer, F. C., and Detjen, L. R.: Self-sterility of the Scuppernong and Other Muscadine Grapes. N. C. Agr. Exp. Sta. Bull. 209: I-23, I910. 


\section{CHAPTER XXXIII}

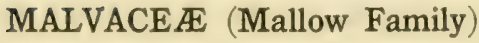

Habit-Members of the family are herbs, shrubs, or trees. Tree species are tropical. The mallows are usually rich in mucilage.

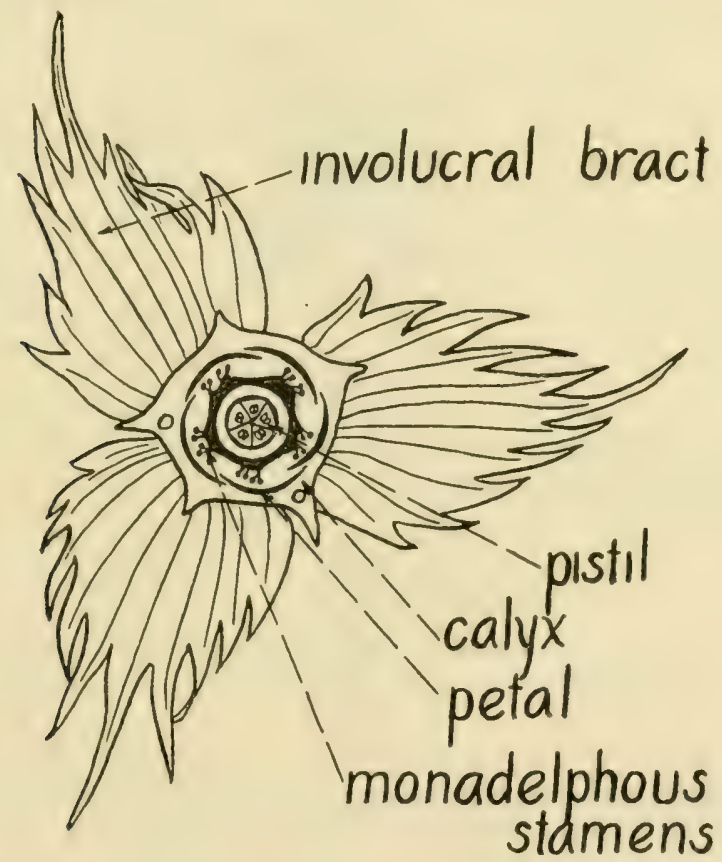

FIG. 2II.-Diagram showing arrangement of parts in the cotton flower. (After Cook, U.S. Depl. Agri.)

Leaves.-The leaves are alternate, and mostly palmately veined and palmately lobed. The stipules are small, narrow, and deciduous. 
Flowers.- The flowers are either single or in clusters, and are terminal or axillary. Some are subtended by an involtucel which resembles the epicalyx of strawberries. This involucre (Fig. 2 I I) consists of three or more bractlets, which may be separate or united. In the marsh mallow (Althœa), the involucre consists of six to nine bractlets united at the

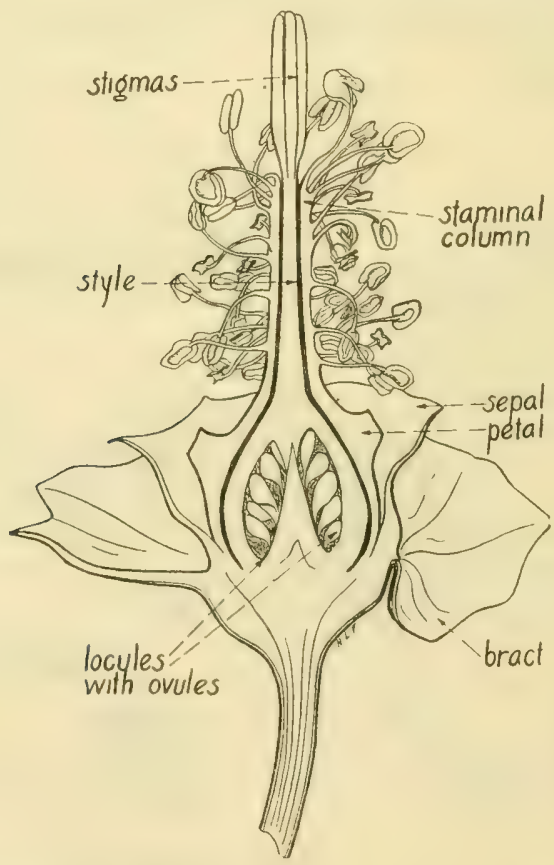

FIG. 2I2.-Upland cotton (Gossypium hirsutum). Median lengthwise section of flower. $\times 2$.

base; in Abutilon, there is none; in Hibiscus, it is of numerous narrow bractlets; and in cotton (Gossyfium), there are three large heart-shaped bractlets (Fig. 2II). The flowers are regular (Fig. 2I2), perfect, often large, rarely diœcious or polygamous. There are live sepals (rarely three or four), 
more or less united, the lobes valvate or rarely imbricate. There are five petals, slightly united at the base, convolute in the bud, and often contorted. 'The slamens are characteristic features of the family. They are numerous, and united to form a long tube enclosing the styles; the staminal tube is united with the bases of the petals (Fig. 2 I2). There are five more or less distinct projections at the top of the tube of stamens; this seems to indicate that there are in reality but five stamens, united by their filaments, and branched above into numerous stalks bearing pollen sacs. This is further evidenced by the fact that each stalk bears a single pollen sac, a structure equivalent to one-half of a typical anther. The stamen tube may be anther-bearing at the summit, as in Malia, Abutilon, etc., or anther-bearing below the summit, as in Hibiscus and Gossypium. The orary is several-celled. Usually, there are as many styles as cells of the ovary; the styles are united below, and distinct above, and generally project beyond the stamen column.

Fruit and Seeds.-The fruit is a several-celled capsule (rarely a berry). The seeds are kidney-shaped, globose or obovoid, and have large cotyledons and either little or abundant endosperm.

Geographical. - Members of the family are widely distributed in tropical and temperate regions. There are about 40 genera and soo species.

Economic Importance.-The mallow family possesses onc of our most valuable economic plants-cotton (Gossypium). Cotton is the chief fiber plant of the world. It is grown throughout tropical and subtropical regions. Another (rop) plant is okra or gumbo (IIt)iscus esculenlus). Altheet officinalis is the marsh mallow, the roots of which are used principally for mucilage and for medicinal purposes. (Ornamental representatives are hollyhock (1llheel rosea), mallow 
(Malva spp.), poppy mallow (Callirhoë spp.), Abutilon and Hibiscus. The Rose of Sharon is Hibiscus syriacus.

\section{Key to Important Genera of Malvace.e}

Stamen column anther-bearing at the summit.

Carpels one-seeded.

Involucre of six to nine bractlets, Althaa (marsh mallow and hollyhock).

Involucre of one to three bractlets, or none.

Petals notched at the apex, Malva (mallow).

Petals erose at the apex, Callirhoë (poppy mallow).

Carpels two- to several-seeded, Abutilon.

Stamen column anther-bearing below the summit (Fig. 2I 2).

Bractlets of involucre, numerous, Hibiscus.

Bractlets of involucre, three, Gossypium (cotton).

\section{GOSSYPIUM (Cotton)}

Habit of Plants, and Roots.-There are more than 40 species of Gossypium, all of which are perennial in their native home. There are herbaceous, shrubby, and treelike species. In cultivation, the plants are annual or biennial, and herbaceous.

There is a long, branching, and deeply penetrating tap root. This extends to a depth of 2 feet or more in sandy soil. There are four rows of lateral roots from four shallow grooves that run lengthwise on the main root. The lateral roots are only a few inches below the soil surface.

Stems.- The main stems are erect and branching. The usual height of Upland cotton plants is $2 \frac{1}{2}$ to 4 feet. The branches may be slender or stocky and are usually spreading.

Kinds of Branches.- There are two sorts of branches in the cotton plant: (I) Vegetative branches or "limbs," and (2) fruiting branches. There are two buds at the base of each leaf. One of these is a truc axillary bud, the other one, extra-axillary. Vegetative branches or limbs may arise 
from either axillary or extra-axillary buds. Normal fruiting branches arise only from extra-axillary buds. It frequently happens that both a fruiting and a vegetative branch arise at one node, that is, both the extra-axillary and true axillary buds develop. Ordinarily, however, only one bud at a node develops. The axillary buds usually develop into

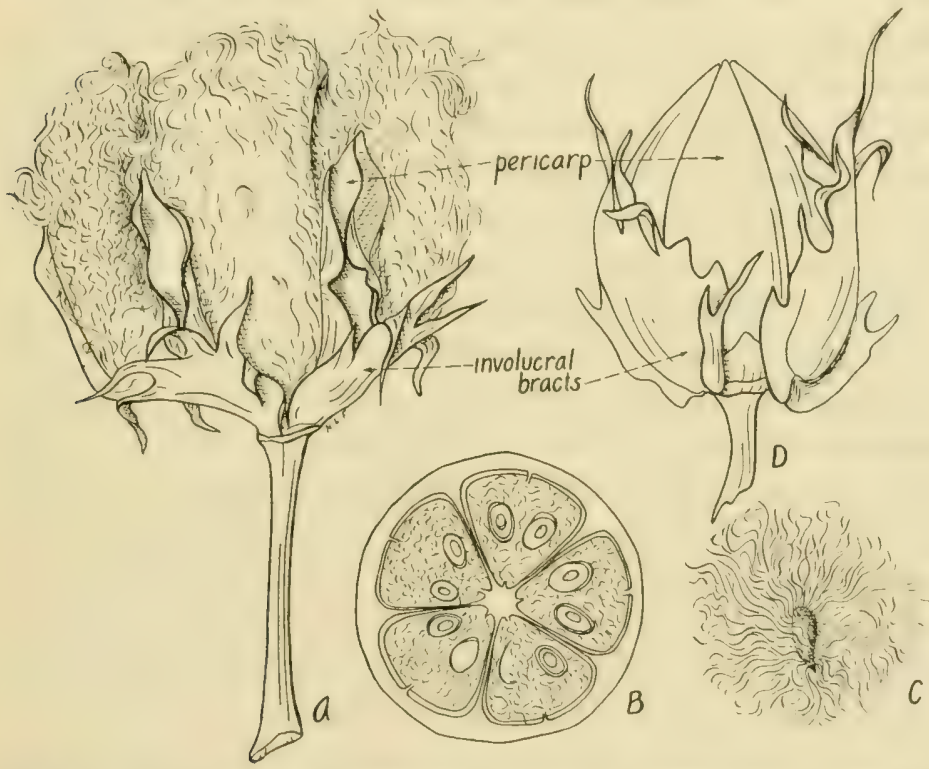

FIG. 21 3.-U pland cotton (Gossypium hirsutum). A, mature boll opened out; $B$, cross-section of young boll; $C$, single seed with fibers; $D$, young boll.

branches at only a few nodes on the lower part of the main stem. The accompanying extra-laterals remain dormant. On the other hand, the upper true axillary buds normally fail to develop, while each of their accompanying extralaterals forms a fruiting branch. Hence, in most cultivated cotton varieties, no fruiting branches occur on the lower part of the main stem. 
In Upland varieties the fourth or lifth node is the first at which fruiting branches are produced; in Egyptian cotton, the first fruiting branches are produced from the eighth to the fourteenth nodes.

Vegetative and fruiting branches differ from each other in other ways than origin. The former make a small angle with the stem from which they arise, while fruiting branches are more horizontal. Vegetative branches produce no flower buds, while fruiting branches bear a flower bud opposite each leaf. Vegetative branches are frequently as long as the main axis, while fruiting branches are much shorter. The basal internode of fruiting branches is usually longer than the others. The difference in length is much more pronounced in Egyptian cotton than in Upland cotton. The internodes of vegetative branches are about equal in length. Vegetative branches may form both fruiting and secondary vegetative branches, but fruiting branches seldom bear secondary fruiting branches or vegetative branches. Cottons with short-jointed fruiting branches are more productive and usually earlier than those with fewer and longer internodes.

Form of Plant.- The general form of the cotton plant is determined to a large extent by the length and number of vegetative branches, as well as by the angle they make with the main axis. The plant may consist of a single stalk with a number of fruiting branches but no vegetative branches. An excessive development of lower regetative branches makes a bushy plant.

Branch Zones.-The cotton plant frequently has three branch zones. This condition, described by McLachlan, is pronounced in Egyptian cotton. The zone of vegetative branches extends from the third to the tenth node; this is followed by a "transition zone" or "zone of rudimentary branches," of two or three nodes "at which the buds remain 
dormant, or the branches are extremely short or abortive." The "zone of fruiting branches follows from about the thirteenth node to the tip of the plant."

L'nderground Stems. - The cotton plant may produce underground stems. These arise from the same grooves from which lateral roots come. At first, these subterranean shoots are gall-like. Later, they attain various sizes.

Leaves.--The leaves have a regular spiral arrangement. The most common phyllotaxy in the cotton plant is threeeighths. This is the normal arrangement in all pure strains of Upland and Sea Island species and other natives of tropical America that are related. It is pointed out that with "the advance of acclimatization, the leaf arrangements are varied by frequent examples of one-third and two-fifths spirals"

Egyptian-Upland hybrid plants may have a one-third, two-fifths, or five-thirteenths arrangement. The phyllotaxy is one-third in Asiatic cottons. 'However, when Asiatic species are crossed, the hybrid plants may show a two-fifths or three-eighths arrangement. Leaf arrangement is similar on main stem and vegetative branches, but on fruiting branches the leaves are in two alternate rows; this latter condition is brought about by a twisting of the joints, each internode being twisted in the opposite direction from the adjacent.

The leaves are petioled, stipulate, cordate as a rule, and three- to seven-lobed, sometimes nine-lobed. Glands may be present or absent on the leaves. When present, they occur on the under side of the main ribs, about one-third of the distance from the bases.

The leaves on fruiting branches are often irregular in outline and may have one or two glands. The leaves on vegetative branches and on the main stem are regular in outline, and have nectaries on the midrib and occasionally on the principal 
veins on the underside. Three to six inches is the common length of Upland cotton leaves.

Flowers.-Flower buds arise on fruiting branches. They do not arise in the very axil of a leaf, but are distant from it. There is a flower opposite a leaf at each node. There is one flower in each bud. The flowers of Asiatic species are often pendant. Upland cotton flowers are 3 to 4 inches across, white when they first open but turning pink on the second day. Sea Island cotton flowers are usually yellow, with a purple-red spot at the base of each petal.

Involucre.- Each flower is subtended by an involucre (Fig. 2 I I) composed of three bracts (sometimes four in cultivation) united at the base. They are frequently large, dentate or laciniate, sometimes entire. One of the bracts is often somewhat smaller than the other two which are equal in size. In some cases bractlets may occur inside the involucre. They alternate with the bracts. When two are present they stand on either side of the smaller bract. This is the case in Upland varieties in the United States. In certain Central American varieties, they are sometimes six bractlets, a pair alternating with each of the three bracts.

Nectaries.-At the base of the outer surface of the bracts are nectaries, in American sorts, but they are absent in all cultivated Asiatic cottons. There are also inner involucral glands in both American and Asiatic varieties. In the former, these inner involucral glands are naked, with exception of Guatemalan cotton, while in Asiatic cottons they are protected by a velvety covering of hairs.

Calyx.-This is a very short, cup-shaped structure at the base of the corolla. The rim of the cup is usually five-lobed, the lobes being short and broad, or sometimes rather long and pointed. In Egyptian cotton and some Asiatic species, the rim of the calyx is frequently very even, 
scarcely lobed. 'The calyx lobes often vary in size. 'There: may be two large lobes, two small ones, and one intermediate in size. Floral nectaries appear at the base of the calyx on the inner side.

"Intracalicary Organs."-These sometimes occur in the cotton flower. They are a series of small greenish organs: between the calyx and corolla. There are five of these structures, but often some of them are so small as to be visible only by use of the hand lens. They are attached to the calyx, and alternate with its lobes. Cook and Meade regard them as "supernumerary calyx lobes or as representing free stipular elements of the calyx lobes."

Corolla.-This is hypogynous. There are five petals, often united at the base, and attached to the lower part of the stamen tube. They are usually yellow or red in color. In $G$. barbadense the petals are yellow or sulphur-colored, with a purple spot on the claw. The petals are convolute in the bud.

Stamens.-These are monodelphous in cotton. There are often as many as 80 or 90 stamens, all inserted on a tubular staminal column, which encloses the pistil. The column is dilated at the base and narrowed above. There are five vertical ridges on the staminal column, each of which gives rise to a number of filaments. The column is regarded as being made up of the united filaments of the stamens. The filaments are thread-like and exserted. The anthers are onecelled, and each is dehiscent into two halves, by a semicircular opening.

Ovary (Fig. 213).-This has three to five cells or "locks." As a rule, the style is long, thus bringing the stigmas above the stamens. In Upland varieties, however, the style is usually shorter than the stamens. There are as many stigmas as there are cells in the ovary. 


\section{Pollination, Fertilization, and Development of Fruit.-} Both cross- and self-fertilization may occur in cotton. Bees may be necessary in those varieties in which the style is long and brings the stigmas above the anthers. Floral nectaries, at the base of the calyx on the inner side, are reached from within the corolla by long-tongued bees and butterflies. This is enabled by the failure of the petals to overlap at the base, thus leaving gaps through which the insect may protrude its tongue.

In Mississippi the period required for maturity of bolls is from forty-four to forty-six days.

The seeds retain their attachment to the placenta until lint begins to develop, when their connection is broken through the absorption of the seed stalk, and the mechanical pressure of growing lint. Hence, the seeds come to occupy a position in the center of the cavity. Fiber begins to develop first at the apex of the seed.

Fruit.-The cotton fruit (Fig. 2I3) is a leathery capsule loculicidally dehiscent by three to five valves. The mature capsule is called a "boll." It varies in shape: subglobose, oval, or ovate-acuminate. The number of cells or "locks" is three or four in Sea Island and Egyptian varieties, and four or five in Upland sorts.

Seeds.--There are numerous seeds in each "boll." Seeds vary in shape: subglobose, ovate, or subovate.

Fiber.-The cotton fiber or hair is a simple extension of an epidermal cell of the seed coat. As a rule, there are two kinds of hairs on the seed: (I) long hairs-lint or commercial fiber ("staple") and (2) short hairs or fuzz. The fuzz may be white, green, or brown in color. Some varieties produce no fuzz; hence when the seed is "ginned," it is left naked. Fuzzy-seeded varieties usually possess an abundance of long fibers. A high percentage of lint usually indicates small 
seed. In some varieties, the lint may form it per cent. or more of the seed.

Distribution of Seed IIairs.- Lint and fuzz are mixed together over the entire seed surface in Upland cottons. In Egyptian sorts, fuzz is limited to the ends of the seeds, with long fibers between the two patches. The lint at the tip of the seed in some Upland cottons is longer than that at the base.

Fiber Differences.- The fibers of Upland cotton are I to 2 centimeters long, and abundant; those of Sea Island are 2.5 to 4 centimeters long, but the yield is not as great as in the preceding species.

The following table is taken from Monie:

\begin{tabular}{|c|c|c|}
\hline & $\begin{array}{l}\text { Average length of } \\
\text { staple in inches }\end{array}$ & $\begin{array}{l}\text { Average diameter } \\
\text { of staple in inches }\end{array}$ \\
\hline Sea Island ........... & I. $6 \mathrm{I}$ & 0.000640 \\
\hline New Orleans......... & I. 02 & 0.000775 \\
\hline Texas.............. & $1 . \infty 0$ & $0.00076_{3}$ \\
\hline Upland . . . . . . . . . . . & 0.93 & 0.000763 \\
\hline Egyptian........... & I.4I & 0.000655 \\
\hline
\end{tabular}

Form and Structure of Fiber.-Young cotton fibers are circular in cross-section. As they increase in length, the walls become thinner, and the fiber takes on a flattened ribbon-like appearance. The thickness of the walls becomes greater when the boll opens, due to the rapid consolidation of the liquid cell contents, which become deposited on the inner walls. The deposition is irregular, hence the twisting of the fiber. This twisting is a characteristic of the cotton fiber. The twist is not necessarily in one direction throughout its length; there may be a reversal here and there.

The fiber is uniform in diameter for about three-fourths of its length, and then tapers gradually to a point. At the point, it may be perfectly cylindrical and solid. The hair cavity or lumen takes up about two-thirds of the entire 
breadth. Inmature fibers or unripe fibers may show no evidence of internal structure, but are smooth, straight, and flat. "Kempy" fibers or "dead cotton" are such that are normal in structure a portion of their length, and have the appearance of immature and overripe fibers for another portion. 'The quality of fiber depends largely upon the number and regularity of twists, and upon its length and fineness. The mature cotton fiber is almost pure cellulose.

Cotton Fibers Distinguished from Other Common Textile Fibers. - There are two chief ways of distinguishing textile fibers, by microscopical examination and by chemical reactions. The cotton fiber is a flat, ribbon-like band twisted in a characteristic manner. The flax fiber is a straight, untwisted, cylindrical fiber, with peculiar transierse markings at intervals along its length. Hemp fibers resemble those of flax, but they may be distinguished from the latter by the peculiar forked ends which are nearly always exhibited, whereas flax fibers never show this character. All wool fibers possess characteristic overlapping scales. The silk fiber is smooth, structureless, transparent and quite regular in diameter.

There are many ways of distinguishing the fibers by observing their reactions to various chemicals. The following short key will illustrate a few of their characteristic reactions.

Dissolves in caustic potash.

An alkali solution of the fiber treated with lead acetate colors fiber black, Wool.

The above treatment does not color the fiber, Silk.

Does not dissolve in caustic potash.

With iodine and sulphuric acid the fiber swells and becomes green, Hemp.

With iodine and sulphuric acid the fiber swells and becomes blue.

Immerse fiber in concentrated sulphuric acid for two minutes, wash in water, treat with dilute ammonia, dry-fiber forms a gelatinous mass soluble in water, Collon.

With above treatment, fiber is not altered, Linen.

Species. - Watt, in his great work, describes 42 distinct species and varieties of Gossypium. $\Lambda$ number of them are known only in the wild state. Gossypium, as a genus, is indigenous to tropical regions. It is now grown under cultivation to the $40^{\circ}$ latitude on either side of the equator.

Watt divides the wild and cultivated cotton plants of the world into five "sections," as follows: 
Section I. Species wilh at luz but no Floss.-. "Wild species (never recorded as met with under cultivation), distributed from the western coast tracts and islands of America to Australia." Ilere are included G. slurtii, davidsonii, klotschianum, robinsoni, darwinii, tomentosum, drynarioides, harknessii, and stocksii. The bracteoles are free, extralloral nectaries absent, the fruit small. and the rather large seeds have a fuzz but no lint.

Section II. Fuzy-scided Cotlons with United Bracleoles.-"One or perhaps two members of this section have been recorded as met with in a wild condition, the others are undoubted cultivated plants derived very possibly from four specitic types-G. arborcum, G. nanking, G. oblusifolium, and $G$. herbuceum." Most of these are Asiatic and African cottons. The bracteoles are united below, the claws of the petals are purple, and the seeds are covered with both fuzz and lint. Watt is strongly of the opinion that G. arboreum i'ar. neglccla, was at an early date introduced into the United States, the form being known as "Okra." Its cultivation was abandoned, however.

G. nanking is the "Chinese cotton" of commerce, also known as "Siam cotton " or "Nankin cotton." It is "cultivated in China, Japan, the Malaya, Siam, Burma, India, the northwest Himalaya, Persia, Central Asia, to the Celebes; less abundantly in Madagascar, Arabia, and Africa."

G. obtusifolium is an oriental species that occurs both wild and cultivated in India and Ifrica. Trar. wightiana is the most valuable Indian cotton.

$G$. herbaceum is not known to occur as a wild species anywere, although Watt is of the opinion that it is indigenous to North Arabia and Asia Minor. In 1621, it was brought to the United States, and for a time cultivated, but was finally replaced by the more desirable West Indian cottons. G. herbaceum is considered to be the first cotton cultivated in Europe. Watt believes that it still survives as an Upland cotton of the United States, though "mostly in a state of hybridization with G. hirsutum." Cook regards our Upland cottons as belonging to $G$. hirsulum.

Section III. Fuzzy-sceded Cottons with Free Bracteoles.-These are American and, in one case, African species. Here belong G. mustelinum, punctutum, hirsulum, palmerii, fruliculosum, schollii, lanceolatum, microcarpum, peruit anum, and mexicumum. G. mustelinum is a native of Brazil and Colombia. $G$. punctutum is native to southern United States, West Indies, and northern Africa. It exists in a state of cultivation in rarious sections. Watt considers $G$. hirsutum as "only a cultivated state of G. punctatum" . . In this country, however, the Upland cottons are all considered as offsprings of hirsutum (Fig. 21.t). (r. pulmerii, fruliculosum and lanceolulum are Mexican species. G. sthullii is from Yucatan, and is known as the "split-leared" cotton. G. microcurpum. known as . Ishmouni cotton and Red Peruvian cotton, grows in Mexicn, northern South America, Mfrica, and Malaya. It is cultivated. G. permitumum is the Peruvian or Andes cotton. Watt regards many of the Figyptian cottons as races or hybrids of this species. G. mexicanum 
probably originally came from Mexico. Watt says: "I am convinced that the best Upland cottons would be more correctly described as cultivated states of this plant (G. mexicanum), rather than as forms of G. liirsutum." He considers many of our Upland or short staple cottons as hybrids of $G$. mexicanum and G. hirsutum, sometimes with the characters of the one predominating, sometimes with those of the other. The long staple Upland series, chief

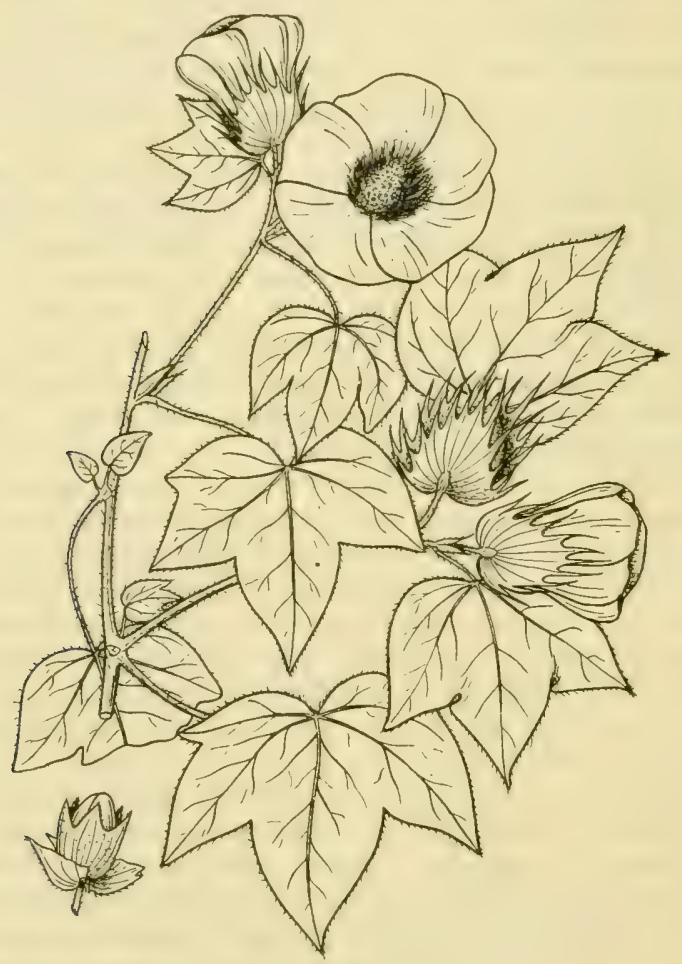

FIG. 2I4.-American upland cotton (Gossypium hirsutum). (Afler Wall.).

representatives of which are Allen, Peeler, Simms and Sunflower, are also hybrids, with hirsutum characters dominant.

Section IV. Naked-sceded Cottons with the Bracteoles Free or Nearly so and Glands Conspicuous.-This section includes both Old- and New-World forms. The seeds are naked or nearly so, and the lint is easily removed. There is always some fuzz on the seed at the apex, hence they are not absolutely 
"naked." To this section belong G. taitense, purpuruscens, vilifolium, barbadense, and brasiliense.

G. taitense is the wild cotton of Polynesia. It is not cultivated. G. purpurascons is known as Bourbon, Porto Rico, and Siam cotton. It is an important cultivated species. G. itifolium, the vine-leaved cotton, has fur-

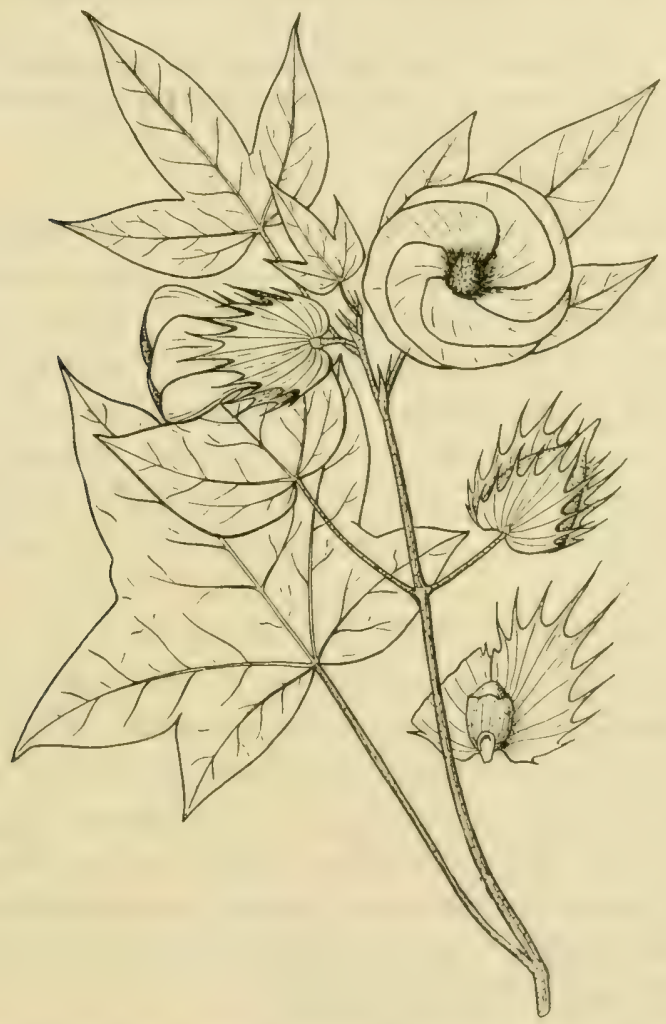

Fig. 2I5.-Sea Island cotton (Gossypium barbadense). (Afler Wall.)

nished a number of valuable cultivated types in Egypt, Antilles, etc. It is closely related to $G$. barbadense. G. barbadense (Fig. 215) includes the Sea Island cottons of America and Egypt. Watt belieres that Sea Island cotton is a modern development, not indigenous to Barbados or any of the Hest Indian Islands, but probably from somewhere in South Imerica. He salys 
that "it is highly probable the modern stock is a hybrid." The Sea Island cottons proper which have been grown with the greatest success on the islands off the coast of Carolina and Georgia are referred to $G$. barbadense var. murilima. G. brasiliense is indigenous to South America. It is cultivated extensively and is known as "Chain, Kidney, Stone, Brazilian, Guiana, Essequilo, Berbiche, Bahia, Pernambuco, and Coton-pierre cottons." This group is no longer of great commercial importance.

Scction Ir. Tuked-seeded Cotton with Bracteoles quite Free and Floral Glands Absent.-Only one species, G. kirkii, belongs to this. It is from East and Central Ifrica, and is not cultivated. The lint is easily removed from the seed.

Wild Cottons.- Wild cottons all have a red-colored, hairy coating on the testa. As is seen above, there may be fuzz only, or both fuzz and lint, or lint alone. Cultivated cottons have a long white lint, in both fuzzy-seeded and naked-seeded forms. Sea Island cottons have the least fuzz of all cultivated forms. White lint may be regarded as brought about by cultivation. The appearance of rust-colored fuzz or lint may be regarded as a tendency to revert to the ancestral type.

The reddish tint of wild cottons is due to an aggregation of colored particles in the central core of the fiber.

American Cottons.-American authorities place the cottons of the United States into two species: G. hirsutum, American Upland cotton, and G. barbadense, Sea Island, cotton. It has been noted above, however, that Watt claims that our ${ }^{-}$Upland cottons are hybrids between G. hirsutum and G. mexicanum. Ninety-nine per cent. of the cotton crop in the United States is Upland.

The most important distinction between these two species is in staple length. The fibers of Upland cotton are from I to 2 centimeters long, those of Sea Island 2.5 to 4 centimeters long. The yield of the former is greater but the quality not so fine. The flowers are white, turning red on the second day of blooming in Upland cotton, but yellow with a purple-red 
spot at the base of each petal in Sea Island cotton. 'The' latter is limited to a small area along the coast of south Carolina, Georgia, and Florida.

Types and Varieties.- Upland is the chief Imerican cotton. It has been divided by Duggar into a number of "groups" as follows:

x. Big Boll Group.-Plants vigorous and stocky; limbs strong, usually two in number; fruiting branches strong, varying from short to long; bolls large, 45 to 68 of them yielding a pound of cotton; four to five locules; seeds large, very fuzzy, white to brownish gray or greenish in color; lint 20 to 30 millimeters long. Examples: Russell, Truitt, Truimple, Texas Storm-pronf, and Jones Improved.

2. Long Staplc Group.-Plants slender; limbs two or three, sometimes absent, slender; fruiting branches also slender; bolls small to medium, long. slender, tapering to a point, three-, four-, or five-loculed; seeds medium to large, sometimes partly naked, but usually densely covered with a brownishgray fuzz; lint 30 to 45 millimeters long, percentage low. Examples: Allen, Grifin, and Cook.

3. Cluster Group.--Plants slender, often tall, limbs heavy, one to several; fruiting branches very short-jointed, causing the bolls and leaves to be in clusters, apparently two or three from each node; bolls small to medium, four- to five-loculed; seeds small to medium, fuzzy, gray to brownish- or greenish gray; lint short, soft, and of good strength. Examples: Jackson, Dickson.

4. Semi-cluster Group.-This group resembles closely the preceding. The bolls are borne singly but close together. It is probably a hybrid group with strong cluster tendencies. Examples: Pecrless, Defiance, Bernett, Berryhill, Hawkins.

5. Rio Grande or Peterkin Group.--Plants slender; limbs one to several; fruiting branches slender, long-jointed; bolls very small to medium, three-, four-, or five-loculed; seeds very small to medium, nearly smooth, darkcolored, sometimes covered with a short fuzz; lint medium in length, percentage large. Examples: Peterkin, Texas Wood, Rio Grande.

6. King or Early Group.-Plants small and slender; limbs one to three or more; fruiting branches medium to short-jointed, but long in proportion to plant height; bolls small, three-, four-, or five-locked; seeds small to medium, fuzzy, greenish or brownish gray; lint short to medium, 33 to 35 per cent. of seed. Earliest American cottons. Examples: King, Dozier, Hodge, Mascot.

7. Long-limbed Group.-Plants large; limbs long with lnng joints; bolls and seeds medium to large; lint percentage low; fuzz of various shades. Examples: Petit Gulf, Peeler, Hagaman. This group is of little importance.

S. Intermediate Group. - This group inclucles a number of varieties with 
characters so badly mixed up as to make it impossible to refer them to any particular group. It is well known that our American cottons hybridize quite readily under field conditions. Examples: Breeden, Boyd, Roby, Tucker.

Environmental Relations.-Cotton is a tropical plant. The upper latitudinal limit of cotton growing in this country is about coextensive with the summer (June, July and August) isotherm $77^{\circ} \mathrm{F}$. The plant is extremely sensitive to low temperatures, and even a light frost in the fall stops its development. It seldom matures in less than 180 days. The plant not only requires a high temperature, but also one not subject to fluctuations, as such conditions cause premature ripening. After the plant has attained its vegetative growth, the ripening of fruits and seeds is favored by cooler nights than prevailed up to that period.

Light, frequent showers which permit of an abundance of sunshine favor the development of the plant. Too much rain is liable to stimulate an excessive development of vegetative growth at the expense of fruit formation.

Upland cottons are adapted to a variety of soils, while the Sea Island varieties are best suited to soils with low waterretaining capacity, and of medium fertility.

Picking and Ginning of Cotton.-Cotton is picked by hand, and loaded into wagons. This labor is performed almost exclusively by negroes. The seed cotton is removed from the wagon by means of a suction fan, and carried over a single gin or battery of gins. It passes into chutes over the feeders, and is then fed evenly to the gin saws, where the lint and seed are separated. The seeds are carried by a screw conveyor to the seed house or seed bin. The lint cotton is led from the gin saws through a flue to the condenser. Here it is cleaned, smoothed out into sheets or bats, wrapped and tied into bales. The usual size of a cotton bale is 27 by 54 inches and the weight about 500 pounds. Sea Island cotton is ginned 
in a type known as the roller gin, as the fiber is injured by the saw gin type.

When seed cotton comes to the gin, it contains boll hulls and trash. This is usually removed by passing the seed cotton through a cleaner, before it reaches the gin saws. The boll hulls are frequently used for fuel.

Bleaching of Cotton.-The object of this process is to remove the waxy coating of the fiber, in order that it may absorb the dyestuffs easily, and also remove all the impurities adhering to the fiber. Cotton may be bleached in any stage of its manufacture, in the loose state, as yarn, or as cloth. The process of bleaching is the most thorough and is carried further in the making of print cloth than in the preparation of other grades of cloth, as the cloth must be absolutely white and free of all impurities in order that the printing colors can be applied properly, and the patterns appear distinct and sharp. The cloth is first singed to remove loose fibers and lint, and leave a clear even surface. It is then taken through the boiling out process, in which the cloth is given one or more boilings in caustic soda in order to remove the waxy, fatty and pectic substances from the fiber. After a thorough i'lshing in water, the cloth is treated with a bleaching powder solution. The souring process follows, in which the cloth by treatment with a dilute solution of sulphuric acid is rendered free of the lime compounds and undecomposed chlorine derivatives. Another thorough washing then follows, after which the cloth is given a finish, the nature of which depends upon the use to which it will be put.

Uses of Cotton.- The lint is spun into thread or yarn, and woven into all sorts of fabrics. The finer threads are made from Sea Island cotton, while ordinary threads and yarns are from long staple upland cotton. The short lint or fuzz, 
known as "linters," which is not removed in ginning, is taken from the seeds and made into coarse twine, carpets, and batting.

Cottonseed IIulls.-These are used in the manufacture of paper and fiber board from which are made gear wheels, trunks, etc. The hulls are also utilized as fuel and fertilizer, and as a cattle food.

Cottonseed Oil.-This is one of the most valuable products of the cotton plant. The oil of the seed is in the embryo. After the seed coats are removed, the embryos ("meats"), are cooked for twenty to thirty minutes to melt the oil, and to drive off some of the water. The oil is then extracted under pressure. A ton of seed yields about 40 gallons of crude oil. Various grades of cottonseed oil are secured by different processes of refining and filtering.

Cottonseed oil is now produced in large quantities in this country. The United States exported 35,304,000 gallons of the oil in I913. It is used for edible purposes, appearing on the market usually under some such name as "sweet nut oil," "salad oil," or "table oil." It may be utilized as an adulterant of such oils as peanut and olive oils. However, it is fully as nutritive as olive oil and is actually preferred by many. It is used sometimes in the manufacture of soaps. It is also extensively employed in the manufacture of "oleomargarine," and butter and lard substitutes. "Cottolene" is composed of refined cottonseed oil and beef suet.

Cotlonseed Meal.--Cottonseed meal is the ground cake left after the oil is pressed from cotton seed. It is now used extensively as a feed, although formerly it was considered of little value. United States produces annually about $2,000,000$ tons of cottonseed meal, valued at about $\$ 53,000$,ooo. The death of animals sometimes associated with its use is due to a toxic substance, gossypol. Cottonseed 
kernels are now rendered less toxic by extracting the gossypol with ether, or with ether and alcohol; or by treating the meal with an alcoholic solution of an alkali, thus oxidizing the

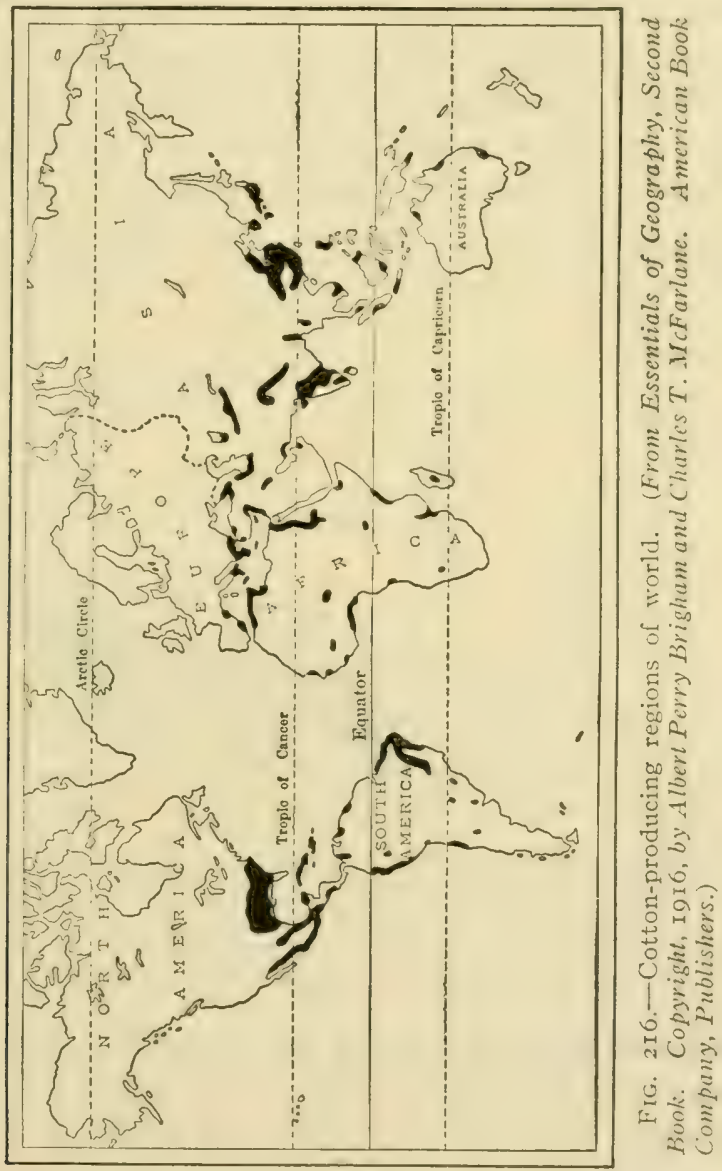

gossypol and rendering it non-toxic. Cottonseed meal is also highly prized as a fertilizer.

Guncotton.-This is a powerful explosive made by treating 
cotton or some other form of cellulose with nitric acid or sulphuric acid. Military guncotton is a mixture of very highly nitrated cellulose nitrates. Less highly nitrated guncotton is soluble in alcohol and ether, and such soluble guncotton is used in the manufacture of collodion, celluloid, etc. Celluloid is made by subjecting a mixture of guncotton, camphor, and other minor substances to great pressure. Collodion is a solution of guncotton in ether and alcohol.

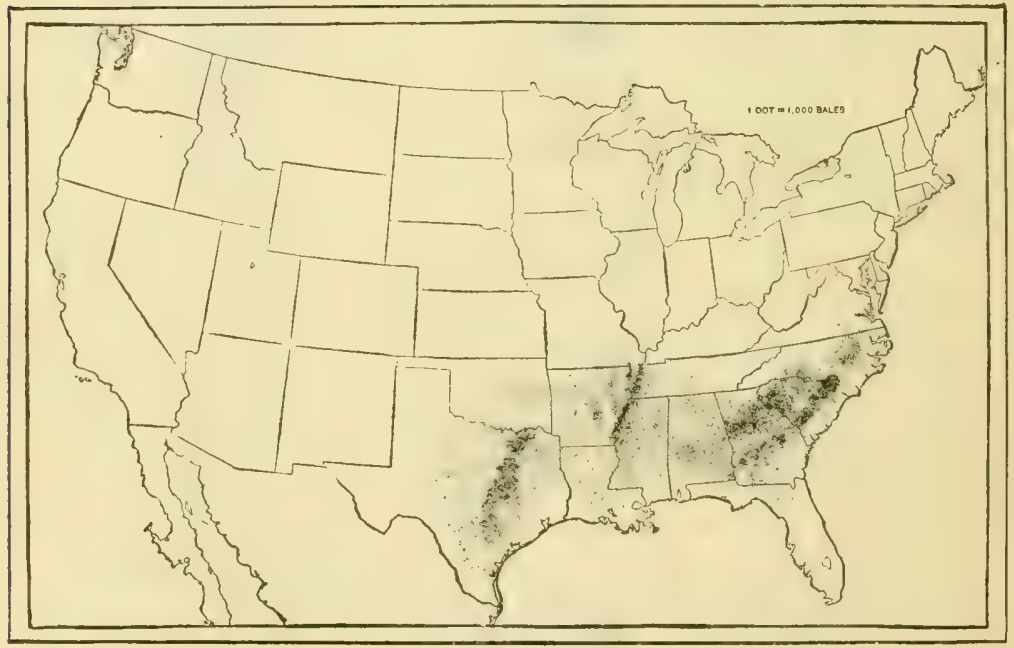

FIG. 2I7.-Cotton-producing regions of the United States. (From Essentials of Geography, Second Book. Copyright, 1916, by Albert Perry Brigham and Charles T. McFarlane. American Book Company, Publishers.)

Importance, and Production of Cotton.-Cotton is the most important fiber plant in the world. The clothing of a great majority of people is cotton. The largest of manufacturing enterprises are concerned with the production of cotton goods. Cotton is the most important article of world trade. The world's crop in 1910 is estimated at $22,433,269$ bales, as compared with $5,893,59 \mathrm{I}$ bales in 1900 . In I9I 4 , the United 
States led in cotton production, with 10,1,3+,9,30 bales. British India ranked second with an output of $4,238.494$ bales. The following table gives the production of cotton by States, I9I 5 .

Production of Lint (Excluding Linters) in 500-pound Gross Weight Bales, by States, igr 5

State

Texas.

Bales

Georgia

3, I 75,000

South Carolina.

I, 900,000

Alabama

I, 160,000

Mississippi.

I, 050,000

940,000

Arkansas

785,000

North Carolina

708,000

Oklahoma........................

Iouisiana.

630,000

360,000

'Tennessee.

396,000

All other States

I08,000

United States

I I , I 6 I, 000

Total value of crop

$\$ 602,393,000$

\section{HIBISCUS ESCULENTUS (Okra, Gumbo)}

Description.--Okra or gumbo is a stout, annual plant. The stems are cylindrical and usually rough-hairy. The leaves are large, heart-shaped, three- to five-lobed, and with very prominent veins; the lobes are coarsely toothed. The solitary, showy flowers arise in the leaf axils; they are subtended by numerous, narrow, involucral bracts; the calyx is five-cleft; there are five large yellow petals; the stamens form a column which is five-toothed at the apex, and is anther-bearing along its entire length; the ocary has five cells, each of which has several ovules; there are five style branches, each tipped by a capitate stigma. Okra is regularly cross-pollinated by insects, chiefly bumblebees. The fruit is a pod with five longitudinal ribs; the seeds are large and kidney-shaped. 
Geographical.- The original home of okra is Africa. It is now introduced into many civilized countries, and grown as a vegetable with particular success in the warmer ones.

Types.-Beattic divides the varieties of okra into three types: (I) Tall green, (2) dwarf green, and (3) lady finger. Each of these is further divided into long-podded and shortpodded sorts. Plants of the "lady-finger" type are much lighter in color than those "of the other two types. Tall green okras are 4 to 8 feet high, dwarf green sorts about $\mathrm{I} 1 / 2$ to $3 \frac{1}{2}$ feet high, and lady-finger varieties close to 3 feet high.

Uses.-Okra is used chiefly in soups. Not infrequently the young seeds are cooked. When the pods are very young and tender, they are cooked and served as a salad. A fiber used in the manufacture of paper is sometimes made from both stems and mature pods. In some countries the pods are dried, and in this form kept for winter use.

\section{References}

Balls, W. L.: The Sexuality of Cotton. Yearbook Khediv. Agr. Soc. Cairo, I905.

Be.rtte, W. R.: Okra: Its Culture and Uses. U. S. Dept. Agr. Farmers' Bull. 232: I-I6, I905.

Bownan, F. H.: Structure of the Cotton Fiber. Manchester, England, 188I. Brooks, E. C.: The Story of Cotton. Chicago, New York, and London, IgI I. Cook, O. F., and Meade, R. M.: Arrangement of Parts in the Cotton Plant. U. S. Dept. Agr. Bur. Plant Ind. Bull. 222: I-26, I9 I I.

Dimorphic Leaves of Cotton and Allied Plants in Relation to Heredity. U. S. Dept. Agr. Bur. Plant Ind. Bull. 22I: I-59, I9 Ir.

Cook, O.F., Mclachlin, Argree, and Meade, R. M.: A Study of Diversity in Egyptian Cotton. U. S. Dept. Agr. Bur. Plant Ind. Bull. I56: I-60, 1909.

Duggar, J. F.: Descriptions and Classification of Varieties of American Upland Cotton. Ala. Agr. Exp. Sta. Bull. I40: I-I04, I907.

Evans, W. H.: Butany of Cotton. U. S. Dept. Agr. Office of Expt. Stats. Bull. 33: 67-80, 1896. Contains a Bibliography of Cotton.

Fintters, A.: The Cotton Plant: Its Development and Structure and the Evolution and Structure of the Cotton Fiber. London and Manchester, I906. 
Ileizmans, II.: Die Baumwolle. Zurich und Leipsic, igr3.

MEADE, R. M.: Methods of Securing Self-pollination in cotton. U. S. I) put. Agr. Bur. Plant Ind. Cir. $121: 29: 30$, I9I3.

MIonie, Hzgr: The Cotton liber, Its Structure, Ete. Manchester and London, I89o.

Oppel, A.: Die Baumwolle. Leipsic: Duncker und Humblot, 1002.

PARLATore, Filippo: Le specie dei cotoni, is66.

REed, E. L.: Leaf nectaries of gossypium. Bot. Gaz., 63:229-2.3 r, I9ri.

Stedckart, C.: Die Baumwolle, ihre Herkunft, ihre Verwendung, ihre (ieschichte, und Bedeutung. Leipsic, I9r4.

Tyter, F. J.: The Nectaries of Cotton. U. S. Dept. Agr. Bur. Plant Ind. Bull. I3 1 : 45-54, I908.

Varieties of American Upland Cotton. U. S. Iept. Agr. Bur. Plant Ind. Bul. I63: I-127, I910.

IWatr, G.: The Wild and Cultivated Cotton Plants of the World. New York and London, 1907. 


\section{CHAPTER XXXIV \\ UMBELLIFER (Carrot Family)}

Stems and Leaves.-All the common representatives of the carrot family are herbs. A very few are shrubs or trees. The stems are usually hollow. The leaves are alternate, sometimes opposite at the base of the stem, and as a rule pinnately or ternately compound. In a few genera (as Bupleurum, II ydrocotyle and Orypolis), they are simple. In Sanicula, they are digitately parted or lobed. In the carrot. fennel, and others, the leaves are decompound. The petioles are frequently swollen and broadened at the base and partly sheathe the stem. There are no stipules, or, if present, are very small.

Inflorescence and Flowers.-The inflorescence is nearly always an umbel, either simple or compound, but occasionally a head (as in Eryngium). The umbel is so characteristic of this group of plants as to suggest the name "Umbelliferæ" (literally meaning umbel-bearing). In a compound umbel, the smaller groups of flowers are designated umbellets. The umbel as a whole is commonly subtended by an involucre, the umbellets by an involucel (little involucre). When the inflorescence has an involucre, it is said to be involucrate; when it has involucels, it is involucellate.

The flowers (Fig. 2I8) are small, mostly regular, perfect or polygamous, and pentamerous. In some instances, the outer flowers of the umbel are irregular, the petals pointing outward being somewhat larger than those pointing inward. The calyx, when present, forms a tube wholly adnate to the 
ovary; the limb of the tube is absent, or divided into five inconspicuous teeth. The corolla consists of live separate petals, attached to the base of the calyx tube; the tips of the petals are usually turned in, and emarginate or two-lobed. There are five stamens, curved inward in the young flower, with filiform filaments and versatile anthers. 'The single,

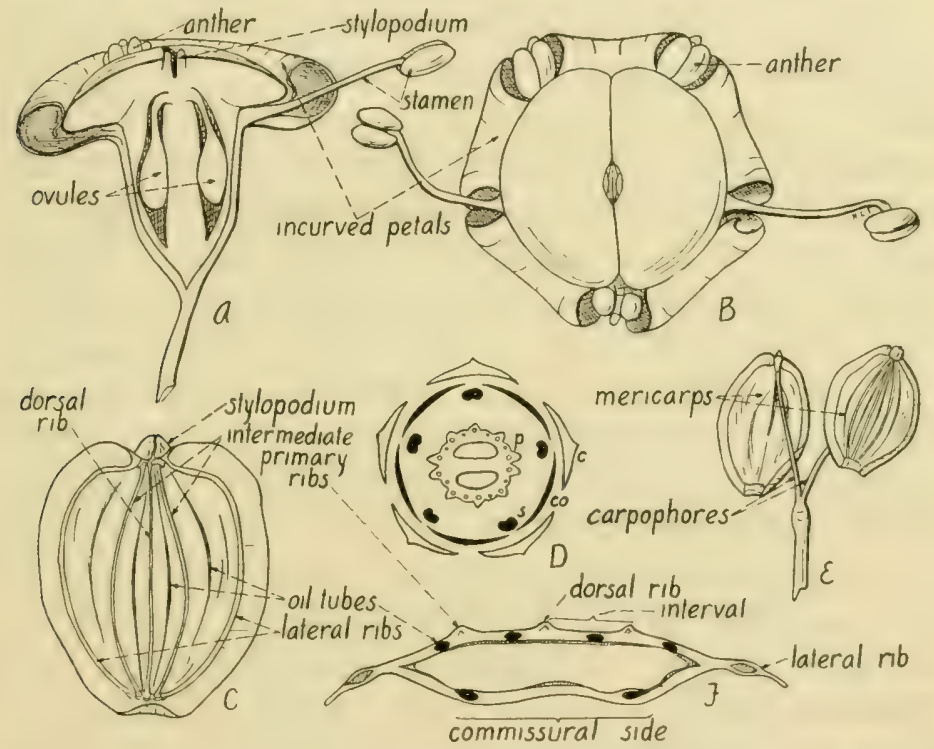

FIG. 218.-Parsnip (Pastinaca sativa). A, median lengthwise section of flower, $X \pm 2 ; B$, face view of same, $\times 12 ; C$, dorsal view of single mericarp, $X$ 21,$2 ; D$, floral diagram; $E$, schizocarp with mericarps separating at maturity, $\times 2 \frac{1}{2} ; F$, cross-section of single mericarp, $\times 10 . \quad(D$ after Strasburger.)

inferior ovary consists of two locules, with a single seed in each, and of two distinct, straight, filiform styles borne on a swollen nectariferous style foot, the stylopodium (Fig. 218). In some genera (as Apium, celery), the stylopodium is inconspicuous or wanting. The umbellifers are usually insect-pollinated. Protandry is common. 
Fruit. 'The umbelliferous fruil (Fig. 2 I 8 ) is very characteristic. It is termed a schizocarp, i.e., a dry fruit of two carpels, these separating at maturity along the midline or commissure into two one-seeded halves the mericarps. Each individual carpel or mericarp is indehiscent. The two mericarps remain attached for a while after splitting by a forked stalk, the carpophore (Fig. 2 I8, E). At the summit of the fruit is a swollen nectary, the stylopodium, giving rise to two short, persistent, usually outwardly curved styles. Each mericarp bears, on the outside, five longitudinal membranous or corky ribs, the primary ribs. These are modifications of the pericarp; each encloses vascular bundles. In some cases, there is one secondary rib in each of the four furrows or grooves between the primary ones, thus making in many instances nine ribs (five primary, four secondary) to each half of the mature fruit. Within the grooves, as is best seen by a cross-section of a mericarp (Fig. 2 I $8, F$ ), are oil tubes (vittx), running lengthwise of the fruit. These tubes contain secretions of balsams, resins, and volatile oils, which impart to the fruit its characteristic odor and taste. The fruit may be bristly (as in carrot) or smooth (as in parsnip, and many others). The bristles may cover the fruit (as in Sanicula), or be confined to the ribs (as in carrot). Oil tubes are sometimes obsolete or obscure (as in Conium, Hydrocotyle, Washingtonia). If distinct, they are solitary (as in parsnip) or several (as in Angelica, Cymopterus). There are usually two or more oil tubes on the commissural side, that is, on the side that is contiguous with the adjoining mericarp.

The fruit is either flattened laterally (at right angles to the commissure), or flattened dorsally (parallel to the commissure), or in some instances not flattened at all (terete or nearly so). The one seed in each carpel completely fills the 
whole cavity and is usually adnate to the pericarp; the inner seerel faces may be concave or flat. There is considerable oily endosperm present in the seed. The small embryo is imbedded in the endosperm near the hilum. The fruit is of greater taxonomic importance than any other portion of the plant. Usually, it is necessary to have the mature fruit before an accurate determination can be made of a species in hand. Keys to the genera and species are largely based upon fruit characters.

Geographical.- The carrot family is one of north temperate regions, not being well represented in the tropics. According to Britton and Brown, there are close to $\mathrm{I}, 600$ species in about $\mathrm{I} 70$ genera.

\section{Key to Genera of Economic Importance}

Fruit bristly, Daucus (carrot).

Fruit not bristly.

Fruit strongly flattened dorsally, with lateral ribs more or less prominently. winged (Fig. 218, F), Pastinaca (parsnip).

Fruit not strongly flattened dorsally, usually more or less laterally flattened (Fig. 222, B).

Stylopodium conical.

Involucre wanting; leaves pinnately compound.

Flowers white, Coriander (coriander).

Flowers yellow, Fœniculum (fennel).

Involucre present; leaves ternately compound, Carum (caraway).

Stylopodium flat or wanting, $A$ pium (celery and parsley).

\section{DAUCUS CAROTA (Carrot)}

Habit, Root and Stems.- The common carrot is usually a biennial, sometimes, however, running to seed the first year. During the first season of growth, there is a storage of food in the enlarged hypocotyl and prominent tap root, both of which become fleshy, forming the so-called "carrot." Four longitudinal rows of secondary roots are given off from the tap root. The roots are much thinner and woodier in the wild form of the carrot than in cultivated forms. 
In a cross-section of the "carrot" the following tissues may be seen, from the outside to inside: ( I) periderm (skin); (2) cortex and phloem; (3) cambium; (4) central region (wood and pith). A good carrot is one with a proportionately large cortex and phloem, because in these most of the

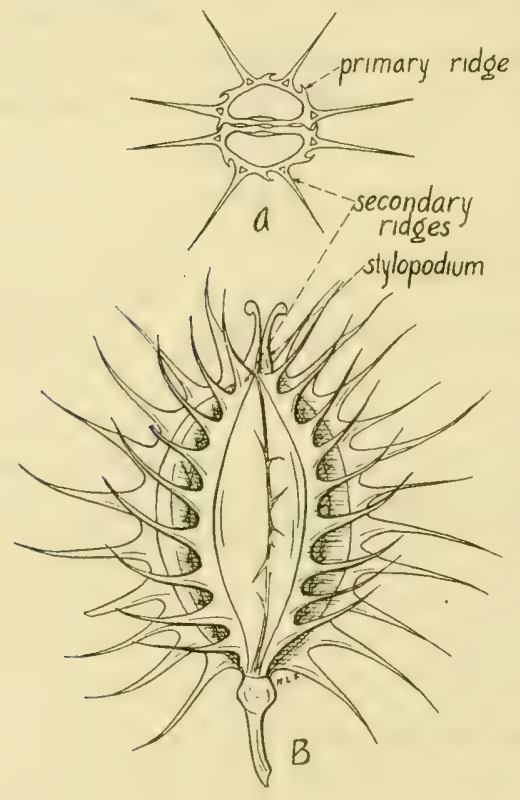

FIG. 219.-Fruit of carrot (Daucus carota). $A$, cross-section; $B$, external view. (A, after Sargent). $B \times \mathbf{I}$. sugar is stored. During the second season of growth, a rough, hispid stem, 2 or 3 feet high, and with spreading branches, is sent up from the "crown" of the carrot.

Leaves.-All the leaves are decompound (doubly compound). The lower ones are two- to threepinnate, the segments linear or lanceolate, dentate, lobed or pinnatifid, the upper ones smaller and less divided.

\section{Inflorescence and} Flowers.-The inflorescence is a compound umbel. At maturity, the outermost pedicels bend inward, the whole forming a structure resembling a bird's nest. The involucral bracts are long, and cleft into a number of narrow lobes. The involucels, at the bases of the umbellets, are made up of entire or toothed lobes. The flowers are small and white, the central one of each umbel often purple, or all the flowers are pinkish. The calyx teeth are lacking. There are five petals, obovate, and with the tips turned in. 
In the outer flowers, the petals are often two-foberl. 'The stylopodium is depressed or wanting, and hats fwo curved stigmas.

Fruit and Seed. 'The fruit (Fig. 219) is oblong and (lorsally flattened. The five primary riclges of each carpel bear long hairs, and each of the four secondary ridges bears about ten long spines, at the ends of which are three or four hooked hairs. The oil lubes (vittx) are solitary in the intervals, that is, under the secondary ribs, and two are on the commissural side of each mericarp. The seed is flattened dorsally, and the face plane or slightly curved.

Geographical.- The wild form of Daucus curold is a native of Europe and Asia. It has become common throughout North America, in many places proving a troublesome weed. All. the cultivated forms of carrot are considered to be derived from this one wild form.

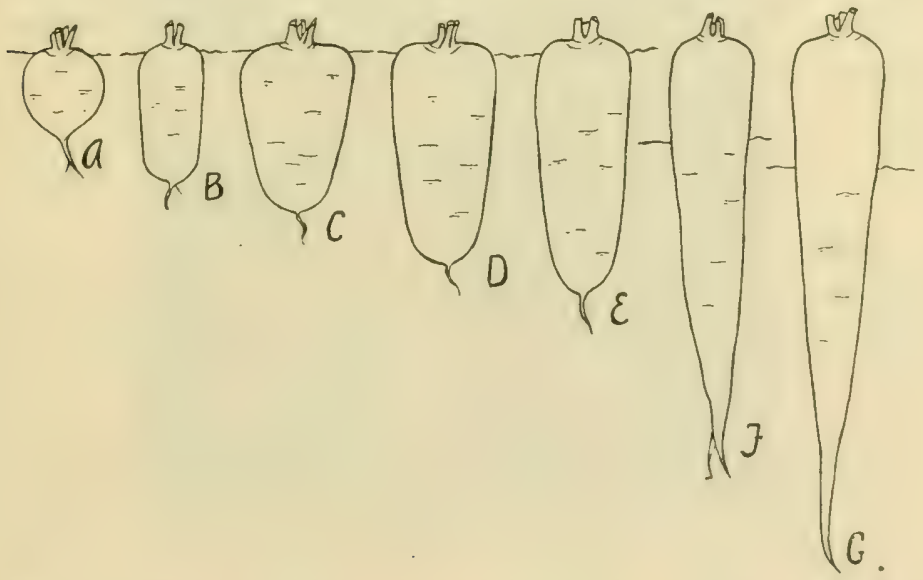

FIG. 220.-Types of carrots (Daucus carota). A, Garden Ball; B, Early . Scarlet; $C$, Oxheart; $D$. Chantenay; $E$, True Danvers; $F$, Saint Vallery; $G$, Long Orange.

Varieties.- There are numerous varieties of carrots varying as to size, shape, color, and quality. Is to shatpe of 
the vegetable, varieties may be divided into two groups (Fig. 220).

I. Roots distinctly pointed, tapering (Long Orange, Saint Vallery).

2. Roots blunt at the tip, not pointed (Early Scarlet Horn, Ox-heart, Chantenay, Stump-rooted Half Long Red).

The roots may be white (Large White, White Vosges, White Belgian), red (Carentan), orange or orange red (Early French Forcing Oxheart, Long Orange), or purple-violet (some Egyptian and Spanish varieties).

Uses.-Medium-size carrots, particularly those with yellow or orange flesh, are used as a table vegetable and for the seasoning of soups and stews. The larger, coarser varieties, such as Large White, Large Yéllow Belgian, Danvers and White Vosges, are grown for feeding stock during the winter season. The yellow coloring matter, carotin, is sometimes extracted from the roots and used for coloring butter.

\section{PASTINACA SATIVA (Parsnip)}

Habit, Roots, and Stems.-The parsnip is of either annual or biennial duration. When grown from seed, a fleshy hypocotyl and tap root are first formed; these constitute the "parsnip" vegetable. In the wild form, the root and hypocotyl are thin, tough, and woody. During the second season, a branching stem is sent up to a height of from 2 to 3 feet. The tall, erect stems are grooved, smooth or somewhat downy pubescent, and become hollow.

Leaves.-The lower and basal leaves are petioled, pinnately compound, the thin segments ovate or oval, lobed, incised or dentate. The upper leaves are sessile, much smaller than the lower, and not so deeply lobed. The terminal leaflet of each leaf is usually three-lobed. 
Inflorescence and Flowers.-The flowers (Fig. 221) are in broad compound umbels usually with 7 to i 5 main "rays,", each terminated by a small umbellet. There are no involucres and involucels in the parsnip, thus differing markedly

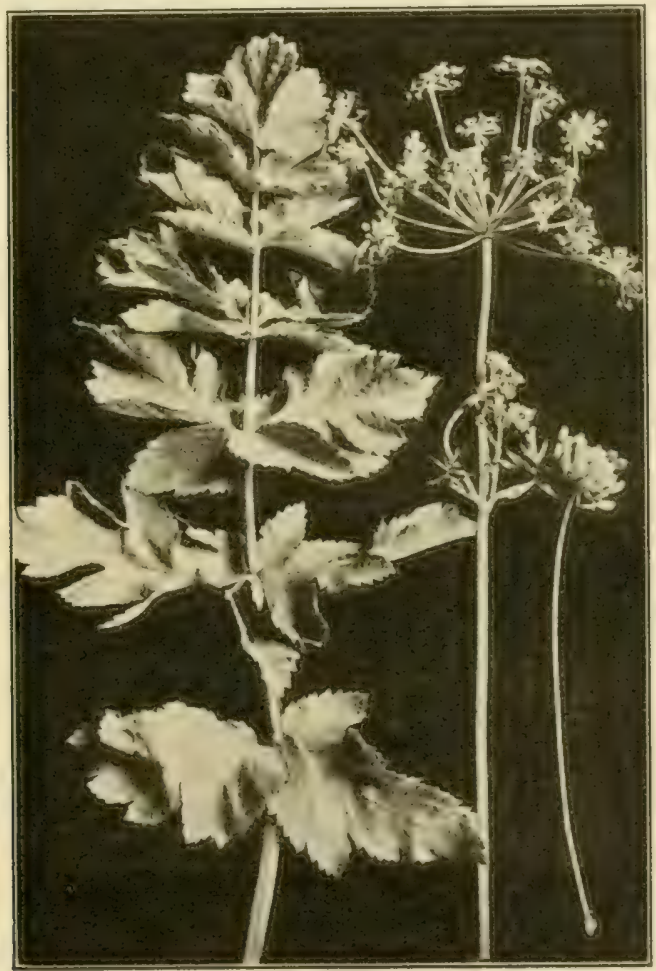

FiG. 22I.-Leaf and inflorescence of parsnip (Pastinaca sativa).

from the carrot. 'The flowers are yellow. The calyx teeth are very small or absent, the petals incurved and small, the stylopodium depressed, and the ovary inferior.

Fruit and Seed. The fruit (Fig. 2IS) is broadly oval and much flattened dorsally. The dorsal and two intermediate 
primary ribsare thread-like, while the lateral ribs are expanded into broad, flat wings, with those of the two mericarps contiguous. The oil tubes are solitary in the intervals; there are four on the dorsal side and two to four on the commissural side. The olive-green seeds are flattened dorsally. The seeds are very short-lived.

Geographical.--The wild parsnip, Pastinaca sativa, from which our cultivated varieties are derived, is a native of Europe. This wild form has become naturalized in many sections of North America, occurring as a weed along roadsides and in waste places.

Varieties.-There are comparatively few parsnip varieties. Probably the most popular sorts are the Guernsey and Hollow Crown. In both of these, the crown is concave.

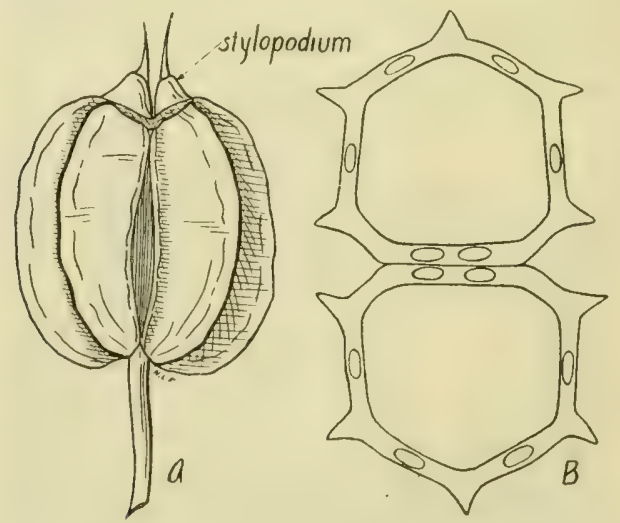

FIG. 222.-Celery (Apium graveolens). A, schizocarp, external, $\times$ I $5 ; B$, diagrammatic cross-section of schizocarp, $\times 20$.

\section{APIUM (Celery and Parsley)}

Generic Description.-Members of this genus are annual or perennial herbs with pinnately divided leaves. The white or greenish flowers are in compound umbels. The involucre and involucels may be present or wanting. The calyx teeth 
are absent. As in many umbellifers, the petals are turner in at the tip). The fruil (Fig. 222) is flattened laterally, broater than lomes. smooth or covered with protuberances. The mericarps have pronounced corky ribs; the oil tubes are solitary in the intervals, with two on the commissural side.

Geographical.- There are about 18 species in this group, distributed chiefly. in the Eastern Hemisphere. There are two well-known cultivated species (parsley and celery) both of which are natives of Europe, and an indigenous species, A pium leptophyllum. These three species are distinguished in the following key.

Key to l'rincipal Species of Apium.

Flowers greenish-yellow, A pium petroselinum (common parsley).

Flowers white.

Leaf segments broad, $A$ pium graveolens (celery and celeriac).

Leaf segments narrow, 1 pium leptophyllum (fine-leaved marsh parsley).

\section{APIUM PETROSELINUM (Parsley)}

Description.-Common garden parsley is a biennial, the first season throwing out a dense whorl of radical leaves that are bipinnate, triangular in outline, and with the segments ovate, and dentate or incised. During the second season, there is sent up an erect, highly branched stem, I to 3 feet high. The upper leaves are also bipinnate, but the segments are linear-oblong and entire.

The inflorescence is a compound umbel with linear involucral bracts and awl-shaped involucellate bractlets. The flowers are greenish-yellow. The fruit is ovate, smooth, and with pronounced ribs.

When large parsley seed is used the plants from them have larger and earlier foliage and are more capable of renewing the tops after being cut back than plants from small seed.

Varieties.-As to leaf characters, there are two types of parsley: 
I. Plain Parsley.-Leaves plain, not curled.

2. Double Curled, Dark Moss-curled, Fern-leaved Parsley.-Leaves curled.

The turnip-rooted or Hamburg parsley is a type bearing a small, fleshy root, which is the edible part of the plant.

\section{APIUM GRAVEOLENS (Celery and Celeriac)}

Description.-This species is either annual or biennial in habit, most commonly the latter. When grown from seed, there is formed, in the cultivated sorts, a clump of leaves with thick, fleshy leaf stalks. The leaf stalks are the edible portions of common celery. If the plants have been stunted or set back in their development, seed stalks may be sent up the first season. Of course, in celery growing, the "seeders" are undesirable and every effort is made to prevent their appearance. Normally, however, seed stalks are sent up from the short rootstock the second season. This stem is erect, glabrous, and I to 3 feet high. The leaves are pinnately compound with three to five oval, coarsely toothed or incised leaf segments. The small white flowers are in umbels. Involucre and involucels are small or wanting. The fruit is oval, flattened laterally, and has corky ribs. The oil tubes are solitary in the intervals and two in number on the commissural side.

Geographical.-1 pium grareolens, the wild form giving rise to our cultivated celery and celeriac, is a native of Lurope. In eastern United States, it has escaped from cultivation, and it is said that in the salt marshes of California it has become naturalized.

Types and Varieties.-There are two types into which the cultivated celery has been modified by breeding and selection: (I) common celery, with enlarged, tender, edible leaf stalks, and (2) celeriac, "German celery" or turnip-rooted celery (A. gravcolens var. rapaceum), with a fleshy, turnip- 
like rootstock, 2 to + inches long. These rootstorkis antstitute the edible portion of the plant (Fig. 22.3).

There are two general types of the common celery: (1) self-blanching varieties-quick-growing, very tender, easilyblanching sorts, especially adapted for fall and early winter use (White Plume, Golden Self-blanching). Blanching (see page $25^{\circ}$ ) is secured by keeping the leaf stalks away from the

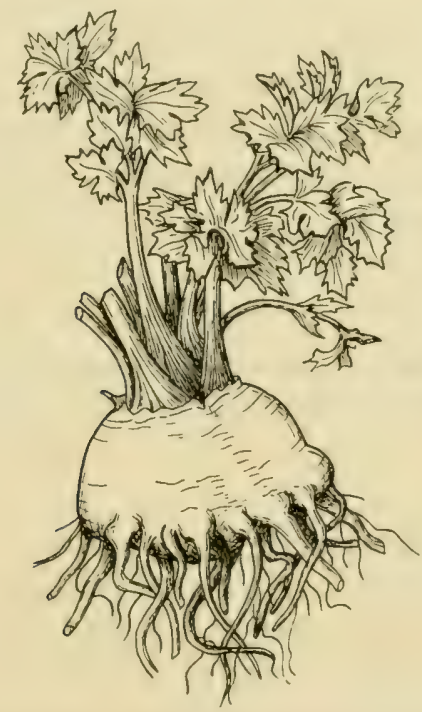

FIG. 223.-Celeriac (Apium graveolens). (After Vilmorin.)

light; the leaf blades, however, are permitted to grow in the light, so that the processes of food-making proceed in a normal manner, and the stalk is not stunted. Chlorophyll is formed only in those parts of the plant exposed to the light directly. Boards, paper or earth are placed about the stalks to exclude the light.

(2) Green or winter varieties-not as quick-growing or easily blanched as those of the preceding type and, further- 
more, with better keeping qualities when stored for the winter (Giant Pascal, Boston Market, Winter Queen, Giant White Solid).

All cultivated varieties of celery require cool weather and plenty of moisture for their best development; they are intolerant of excessive heat. Celery culture is carried on with the greatest success on reclaimed muck soils in regions with a cool climate.

Uses.-Celery is grown principally for the thick, fleshy leaf stalks. The leaves are also used for garnishing and seasoning, and the seeds are used for flavoring salads and soups. The fleshy root of celeriac is used as a flavoring or is stewed separately.

\section{References}

Coulter, J. M., and Rose, J. N.: Monograph of the North American Umbelliferæ. Contr. U. S. Nat. Herb., 7 , No. I : I-256,'r900. 


\section{CHAPTER XXXV \\ VACCINIACE $\mathbb{E}$ (Huckleberry Family)}

This is a widely distributed fạmily occurring in tropical, temperate, and arctic regions. It is closely related to the heath family (Ericacere) which possesses such well-known plants as kinnikinic (Arctostaphylos wa-ursi), the creeping wintergreen (Gaultheria), American Laurel (Kalmia), Labrador tea (Ledum), Azalea, Rhododendron, and trailing arbutus (Epigaa repens). In the heath family, however, the ovary is superior instead of inferior as in the huckleberry family. There are two important genera from an agricultural standpoint, Vaccinium and Gaylussacia. The former genus includes a rather large number of species grown for their fruit; these take in the bilberry, blueberry, cranberry, huckleberry, and whortleberry. Gaylussacia spp. are known as tangleberry, blue huckleberry, and dangleberry. Gaylussacia may be distinguished from Vaccinium by its ten-celled ovary, with one ovule in each cell. In Vaccinium the ovary is four- to five-celled, or sometimes eight- to ten-celled by false partitions.

Habit.-The plants belonging to this group are erect or prostrate shrubs or, in a few instances (e.g., Vaccinium arboreum, the farkleberry) a small tree. Some South American species are epiphytic.

Leaves.-The leaves are simple, alternate, often thick and leathery and sometimes evergreen, and without stipules.

Inflorescence and Flowers.-The flowers are solitary in the leaf axils (as in Chiogenes hispidula, the creeping snow- 
berry, or Tacinimm membranacem, the thin-leaved bilberry), or in racemes (as in $\mathrm{V}$ accinium virgatum, southern

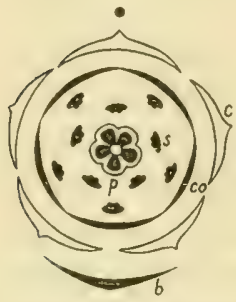

FIG. 22.-Floral diagram of Vaccinium.

black huckleberry, or Vaccinium oxycoccus, the European cranberry). The flower pedicels are usually bracted. The small flowers are perfect, sympetalous, and usually actinomorphic (Fig. 224). The calyx (Fig. 225) forms a tube, grown fast to the ovary, the limb (free portion) four- to five-lobed or four- to five-cleft, and either persistent or deciduous. The sympetalous corolla is divided into four or five lobes or very rarely into nearly separate petals, as in the cranberries. The corolla may be either globe-shaped, bellshaped, urn-shaped, or tubular. There are twice as many

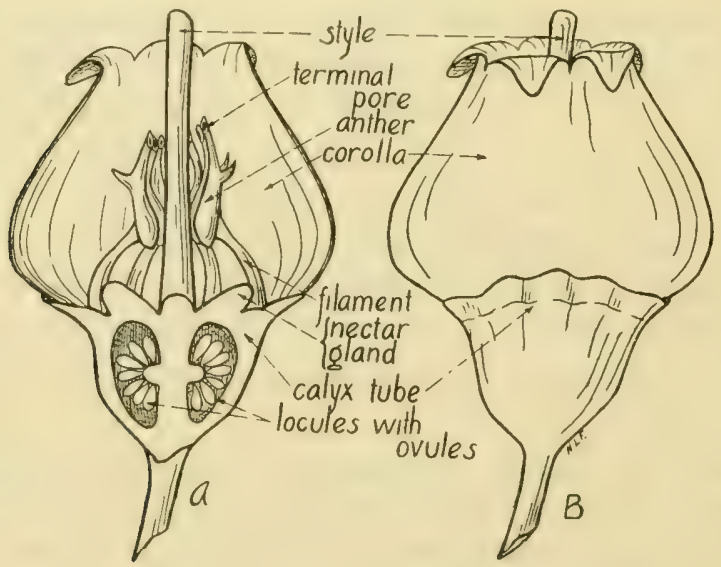

Fig. 225.-Flower of Vaccinium. A, median lengthwise section; $B$, external view.

stamens as corolla lobes, and they are usually inserted at the base of the corolla; the filaments are commonly flattened, short, and either free or united; the two-celled anthers are 
upwardly prolonged into tubes, and open by a terminal pure (Fig. 225). The ocary' is inferior, four- to five-celled or eightto ten-celled by false partitions, and has a filiform style, a small stigma, unmodified at the tip), four - to five-lobed or four-to five-toothed, and one to several ovules in cach locule.

Fruit.-The fruil is globular and either a many-seceled berry (as in Vaccinium) or drupe-like (as in Guylussacia). The seeds are small, compressed, and have a bony seed coat, and a small embryo imbedded in a fleshy endosperm.

\section{VACCINIUM}

The representatives are shrubs or small trees. The leaves are leathery. The flowers are solitary or in short racemes. They have characters as described above under the family.

Pollination.--Coville describes the method of pollination in a blueberry. It is quite probable that this will hold true for most Iaccinium species. The bell-shaped flower is inverted, the ro stamens hang downward and are shorter than the style. The flat filaments form a close circle about the style, being held together by the interlacing marginal hairs. When an insect visits the flower, the only easy way it can get at the nectar, which is situated at the base of the stamens on their inner side, next to the style, is to push its proboscis between the anther tubes. In this process, the mature pollen grains are shaken loose, and some of them stick to the insect's body, to be carried by it to flowers visited subsequently. The anther pores open inward. The stigma is top-shaped and the very apex is the only receptive portion. Hence the rim of the stigma just below the receptive surface, prevents the falling pollen from reaching this surface. In this way self-pollination is to a large extent prevented.

If pollen from the same plant is used in pollination, the fruit that is formed remains small and green, and later drops off. 
This fact serves to emphasize the need, in the propagation of blueberries by cuttings, of making the plantation from cuttings of a number of different bushes.

Fruit.- The fruit is a many-seeded berry. It matures about two months after flowering. The berries are most commonly blue-black in color, although albino forms are known to occur. The calyx is permanently attached to the fruit. Berries may remain on the bushes a month or more after they have reached maturity without losing their flavor or firmness.

Geographical.- The genus is widely distributed in the northern hemisphere, mostly in North America and the Himalayas. It includes about 125 species, about 27 or more of which are native to North America.

Key to Chief Fruit-bearing Species of Vaccinium

Fruit red in color.

Stamens included, $V$. vitis-idea (cowberry, mountain cranberry, foxberry).

Stamens exserted.

Leaves ovate, acute at the apex; stems slender, creeping; berries globular, V. oxycoccus (small cranberry).

Leaves oval or oblong, obtuse or retuse at the apex; stems stout, creeping, with ascending branches; berries egg-shaped or oblong, $V$ macrocar pon (American cranberry).

Fruit blue or black in color.

Plants low, seldom over 2 feet tall.

Leaf surfaces free of hairs.

Berries blue.

Leaves shining above, $V$. capitosum (dwarf bilberry).

Leaves not shining above, $V$. vacillans (low blueberry, blue huckleberry).

Berries black.

Flowers solitary in leaf axils, V. myrtillus (whortleberry, bilberry).

Flowers in groups in leaf axils.

Fruit with bloom, $V$. angustifolium (low blueberry).

Fruit without bloom, V. nigrum (low black blueberry).

Leaf surfaces hairy, V. canadense (Canada blueberry). 
Plants tall, 3 to $x_{2}$ feet, and spreading.

Flowers solitary in leaf axils, I. onulifolium (tall or oval-leaved bilherry). Flowers in groups in leaf axils.

Fruit blue, V. corymbosum (high-bush blucberry, swamp huckleberry). Fruit black, V. atrococcum (black blueberry).

\section{GAYLUSSACIA (Huckleberry, Tangleberry, Dangleberry)}

Description.-Members of this genus are shrubs with alternate and entire or finely toothed leaves. The inflorescence is a raceme. The small white or pink flowers are on two-bracteolate pedicels. The calyx tube is short, five-lobed or five-toothed, and persistent. The stamens are ro in number, and their anthers open by terminal pores. The fruit is described as a berry-like drupe, or ro-celled drupe with ro seed-like nutlets. The "seeds" are each covered with endocarp.

Geographical.-The genus is distributed throughout North and South America. It possesses about 40 species. There are five species of Gilylussacia growing in North America.

\section{Key to North American Species of Gaylussacia}

Leaves evergreen, finely toothed, G. brachycera (box-huckleberry).

Leaves deciduous, entire.

Fruit with a bloom, G. frondosa (blue huckleberry, tangleberry, dangleberry).

Fruit without a bloom.

Leaves 2 to 4 inches long, G. ursina (Carolina huckleberry).

Leaves $I$ to 2 inches long.

Bracts small, deciduous, G. resinosa (black or high-bush huckleberry). Bracts large, persistent, G. dumosu (dwarf or bush huckleberry).

Of the above species, $G$. resinosa is, as a rule, the common black huckleberry on the market. This species is a shrub, I to 3 feet high, with stiff branches, oval. or oblong leaves that are very resinous when young, a few pink or red flowers and sweet, seedy, black fruit. It grows in sandy soil from Newfoundland to Georgia, westward to Kentucky and Manitoba. 


\section{CRANBERRIES}

Some botanists place the cranberries in the genus $O x y c o c$ cus, separate from the blueberries. huckleberries and bilberries, which are included in the genus Vaccinium. In Oxycoccus the corolla is deeply four-cleft or four-divided, while in Vaccinium it is bell-shaped or cylindric and divided only at the very apex. We have placed all the cranberries in the genus Iraccinium. There are two principal species of

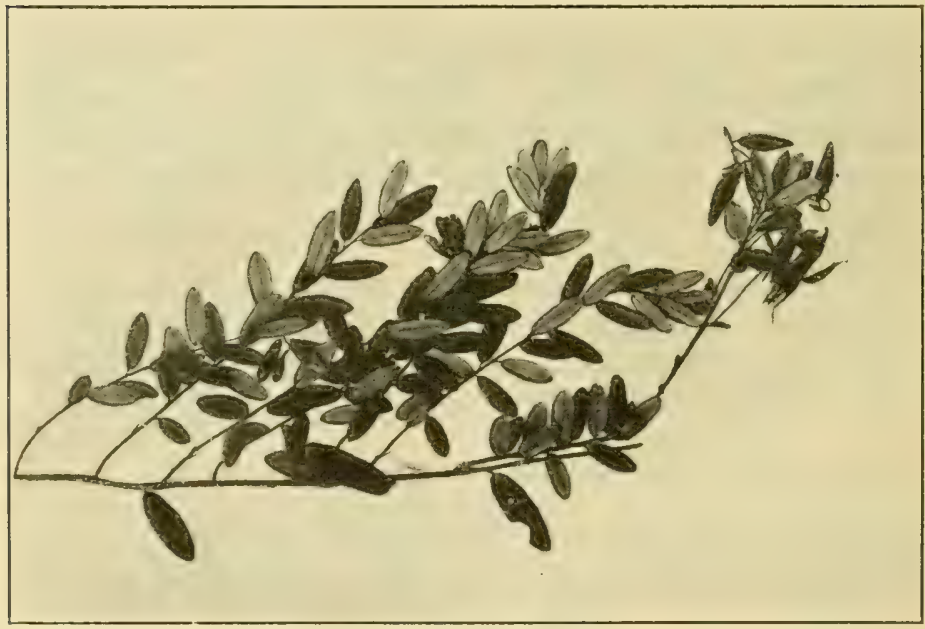

FIG. 226,-American cranberry (Vaccinium macrocarpon).

cranberries grown in America: American cranberry (Vaccinium macrocarpon) and the small cranberry (Vaccinium oxycoccus). These are distinguished in the key above. It seems that the appearance of the flower in the bud has probably suggested the name cranberry or "craneberry." Just before the flower opens, the pedicel, calyx and corolla resemble the neck, head, and bill of a crane.

Vaccinium macrocarpon (Large or American Cranberry).This is a low, slender, creeping plant with oblong or oval 
leaves, whitened beneath, and with rolled margins. 'The flowers are on short upright one-year-old shoots; they occur in very short clusters; the corolla is light pink. The berry is red, ovoid, oblong, or almost globular. At the summit of the fruit, are four persistent, short calyx lobes. bent inward.

This species is found wild in boggy land in the northern part of the United States, adjacent Canada, south along the eastern coast to Virginia and North Carolina. It is also found in South America. It is the cranberry that is cultivated to a large extent in the cranberry centers in this country-Cape Cod, New Jersey, Wisconsin, Michigan and Minnesota. The cultivation of cranberries in the United States is practically confined to cool, moist boggy regions. Cranberries are grown in natural or artificial bogs, which are capable of being drained or flooded at will.

Types.-Corbett divides American cranberries into four groups, based upon fruit shape.

I. Bell.-These are the most popular and include such varieties as Early Black and Centennial.

2. Bugle--Mathews, Howe, Centerville, Dennis.

3. Olive-McFarlin's, Howes, Jumbo.

4. Cherry or Spherical Cranberries.-Early Red, Arpin. Makepeace.

Vaccinium oxycoccus (Small Cranberry).--This is the cranberry of the Old World. It is a slender, creeping plant with thin stems, 4 inches to I foot long, and with ovate, acute or acuminate leaves, dark green above, whitish beneath. The flowers are very similar to those in the preceding species. The berry is red, globular, four-celled, and often spotted when young; it is smaller than that of the American cranberry. although considered by some of superior quality.

The small crabbery is a native of alpine and subarctic 
regions of Asia, Europe, and America. It is not cultivated in America to any great extent.

Vaccinium vitis-idæa (Mountain Cranberry, Windberry, Wolberry, Cowberry, Foxberry).-This is a low evergreen shrub with creeping stems and thick, leathery leaves. The flowers are in short, terminal, one-sided clusters. The berries are dark red.

This plant grows wild from Massachusetts to Labrador, west to British Columbia and Alaska. Although not cultivated, the natives, particularly of Nova Scotia, gather large quantities of this wild cranberry and ship them to eastern markets.

\section{HUCKLEBERRIES AND BLUEBERRIES}

Both of the above names are applied to the fruit of species of Vaccinium and Gaylussacia. However, it is uncommon to see the name blueberry given to the fruit of Gaylussacia spp. These bear Io seeds in each fruit, and although not as numerous as in the berry of Vaccinium, are more troublesome. There are two general types of blueberries: highbush blueberries ( $V$. corymbosum, and $V$. atrococcum), and low-bush blueberries ( $V$. canadense, $V$. angustifolium, $V$. nigrum, and $V$.vacillans).

The common black huckleberry on the market is Gaylussacia resinosa. Vaccinium angustifolium is a rather common low-bush blueberry, while $V$. corymbosum is the species most desirable for cultivation.

\section{References}

Corille, Frederick V.: Experiments in Blueberry Culture. U. S. Dept. Agr. Bur. Plant Ind. Bull. I93: I-I00, I910.

Davrs, W. T.: High-bush Blueberries. Proc. Staten Island Assn. Arts and Sci., 2: 63-64, I909. 


\section{CHAPTER XXXVI \\ OLEACE $Æ$ (Olive Family)}

Family Description.-This is a family of trecs or shrubs. The leaves are opposite, exstipulate, and simple or pinnately compound. The inflorescence is a panicle, raceme, cyme or fascicle. The flowers are regular, and polygamous or diocious; the small calyx is four-lobed, sometimes entirely absent; the regular corolla is four-parted, or of four distinct petals, or absent. There are two stamens, attached to the corolla or to the receptacle. The single pistil is compound, with a two-celled ovary, in each of which there are a few seeds, a short style, and capitate stigma; sometimes the style is absent. The fruit is either a capsule, samara, berry; or drupe.

Geographical, and Economic Importance.-There are about 2 I genera and 500 species distributed widely in temperate and tropical regions. The most important representative is the olive (Olea curopara). Other well-known members of the family are the lilacs (Syringa), privet (Ligustrum), Jessamine (Jasminum) and ash (Fraxinus).

\section{OLEA EUROPEA (Olive)}

Description.- The common olive is a small tree 20 to 25 feet high. All fruit is borne on two-year-old wood, and the same wood never bears twice. The lanceolate leaves are leathery, evergreen, entire, smooth, scaly, and arranged oppositely on the stem. The flowers occur in axillary racemes as a rule, although terminal inflorescences are more or less frequent. The flowers are usually imperfect. The small calyx is four-toothed, the corolla four-cleft, white or whitish, the stamens two, and the pistil one. The fruil is a purplish drupe. 
The olive is probably a native of the Mediterranean region. Its cultivation in this country is confined almost entirely to

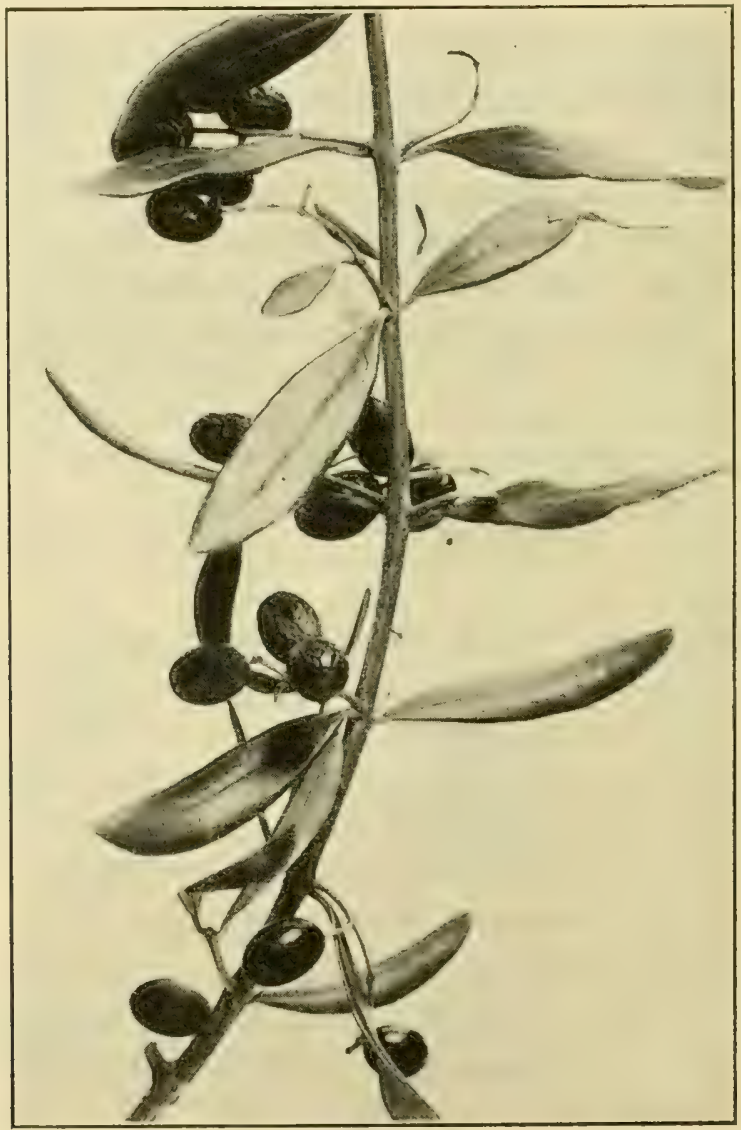

Fig. 227.-Olive (Olea europoea). Branch and fruit. (From Calif. Agr. Exp. Sta.)

the warm, dry portions of California. The olive requires a mean annual temperature of $57^{\circ} \mathrm{F}$., and it is claimed that at no time should the temperature go below $14{ }^{\circ} \mathrm{F}$. 
Seed Germination. - If olive seeds do not receive some treatment before planting, they will not germinate for a year or more. This delay in germination is due to the thick. stony covering, and to the oil present which inhibits water penetration. The delay in germination has been overcome, in part, by various means, such as soaking in warm water. soaking in alkaline or acid solutions, cracking the stones, and clipping the apex of the seed. The last method appears to be the best.

Propagation.-The olive is very easily reproduced vegetatively; in fact, cuttings of any kind will grow. For propagative purposes use may be made of green cuttings with the leaves on, of chips from old trunks, of young or old limbs. and even of knaurs. Knaurs are knots or excrescences formed upon the trunks of old trees. When limbs 2 or 3 inches in diameter are used, they are cut into lengths of $\mathrm{I}$ or 2 feet. each split lengthwise, and planted horizontally with the bark up. Sprouts readily arise from the section of trunk. and such sprouts may be allowed to continue their growth where they are, or be made into green cuttings.

Uses.-Olives are eaten either in the green or ripe state. They are usually "pickled," and left whole, or "stuffed." Olive oil is an important commercial product. The best quality of olive oil, known as "Virgin oil," is made from hand-picked fruit. The fruit is crushed so as not to break the seed. The pulp is treated with water and again pressed. yielding a product which is employed as salad oil. The pressed pulp is again treated with hot water. and subjected to high hydraulic pressure; this process gives an oil known as "olive oil foots." It is employed in the manufacture of soaps, particularly castile soap, and at a lubricant. An oil is also extracted from the seeds. It is much like that from the pulp. 


\section{CHAPTER XXXVII}

\section{CONVOLVULACE (Morning Glory Family)}

The representatives of this family are found chiefly in warm climates. There are close to 900 species in 400 genera. A number are of economic importance, among which may be

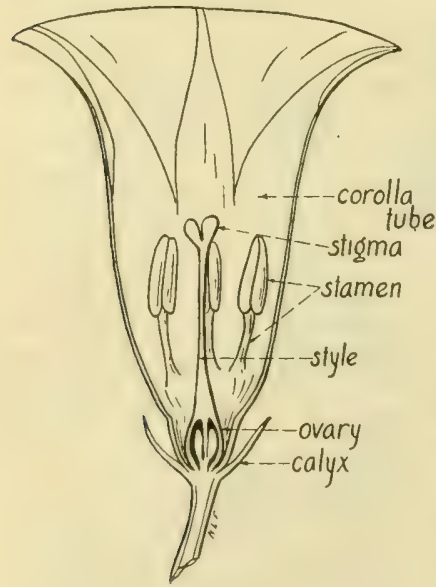

Frg, 228.-Flower of sweet potato (Ipomoea batatas), lengthwise section. (Afler Sargent.) mentioned the sweet potato, man-of-the-earth (I pom xa pandurata), used as food by the Indians, moon-flower (Ipomoa bona-nox), morning glory (I pomæa purpurea), cypress vine (Quamoclit quamoclit) and the bindweeds (Convolvulus spp.).

Habit.-Most of the representatives of this family are twining or trailing herbs; some tropical species are shrubs or trees, often with a milky juice.

Leaves.--The leaves are alternate, exstipulate, entire, dentate, lobed, or dissected.

Inflorescence and Flowers.--The flowers are in an axillary cyme, or sometimes solitary. They are regular, perfect and sympetalous (Fig. 228). The calyx is attached below the ovary, five-parted or five-divided, usually persistent, and imbricated in the bud. The corolla is plaited, convolute, or twisted in the bud, and becomes funnel-form, salver-form, campanulate, or tubular, with a five-angled, or five-lobed, or entire limb (Fig. 228). The five stamens are inserted on the 
tube of the corolla and alternate with its lobes; all are anther-bearing. The filaments are filiform, or dilated at the base, and equal or unequal. The anthers are two-celled, and longitudinally dehiscent. The ovary is superior and usually. has two cells (rarely three cells), each of which bears two ovules. In some instances, the ovary is falsely divided into four to six cells, each with a single ovule.

Fruit.-The fruit is a capsule; its seeds are endospermous.

\section{Key to Important Genera}

Stigmas capitate (knob-like).

Stamens and style exserted, Quamoclit.

Stamens and style included, Ipomoea.

Stigmas two, filiform or oblong, Convolvulus.

\section{IPOMGEA BATATAS (Sweet Potato)}

Roots and Stems.- The sweet potato is a sinistrorse-twining, trailing, perennial herb with very much thickened roots, The "sweet potato" itself is often designated as a "root tuber." The fleshy roots have stored within them large quantities of starch. They should not be confused with the tubers of the Irish potato. Sweet potato "tubers" are roots, while Irish potato "tubers" are stems.

Propagation.- In the propagation of sweet potatoes, these fleshy roots are cut lengthwise, and the cut surface of each piece is laid against moist earth until it produces sprouts. Then the piece is further cut up and each portion replanted. It is necessary to leave a part of the epidermis in order that adventitious buds will develop. Sweet potatoes are frequently propagated by vine cuttings.

Leaves.- These are alternate, heart-shaped, petiolate. dark green, and glossy.

Inflorescence and Flowers.-The large, purple, conspicuous flowers are axillary, solitary or cymose. The 
simpetalous corolla is I to 2 inches wide, funnel-form, and has a five-lobed limb, and plaited tube. The corolla is folded longitudinally and twisted usually to the right in the bud. The stamens are as given under the family description. The two- to four-celled ovary has a thread-like style which bears one or two stigmas. The fruit is a capsule.

In northern latitudes, the sweet potato rarely blossoms. and never matures seeds.

Geographical, and Environmental Relations.-The original home of the sweet potato is the West Indies and Central America. Since the sweet potato is of tropical origin it is largely grown in the Southern States, the five leading ones being North Carolina, Georgia, Alabama, Louisiana and Mississippi. Ample sunshine and high temperatures favor its growth. Although a heary rainfall is desirable during the first part of the growing season, the maturing of the roots proceeds best with rather dry weather. They do best in well-drained, light soils.

Closely Related Species.-The southern, juicy varieties of sweet potatoes are called "yams." They should not be confused, however, with the true yams, or Chinese potatoes of commerce, which belong to the species Dioscorca bululas, in a family. (Dioscoreacex), closely related to lilies. This is a tall climbing plant with simple cordate, shining leaves, small, white flowers, and large tubers.

Types and Varieties.- Sweet potatoes may be divided into two groups upon the basis of the amount of water and sugar present: (I) Dry sucet potatoes are ones in which the flesh is dry. mealy, and yellow; they are the sorts most desired in the Northern States. The Jersey type, which includes spindle-shaped varieties, is probably the best known. "I Ims' are sweet potatoes in which the flesh is watery, rich in sugar, soft and gelatinous when cooked. They are the sorts most in demand in the South. Common southern 
sorts ("Yams") are 'Triumph, Nancy Hall, Dooley Jam, Tineless Iam, Sugar, Southern (gueen. Florida.

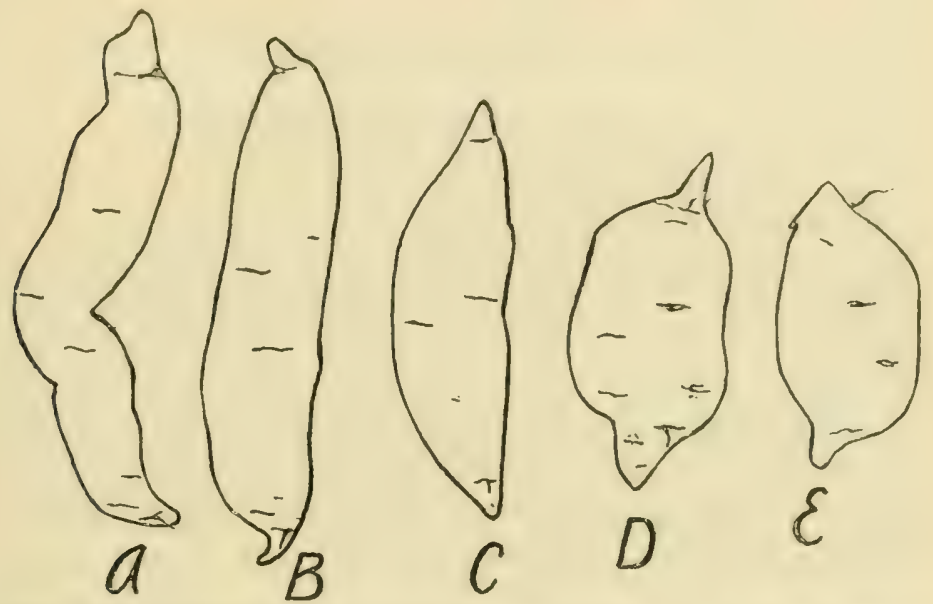

FIri. 220)-Types of sweet potatoes (Ipomoea batatas). 1. Mlack Spanis11; B. Shanghai; C, Big Stem Jersey; I). Reed Bermuda; F, Southern Queen. (Modified afler Corbett.)
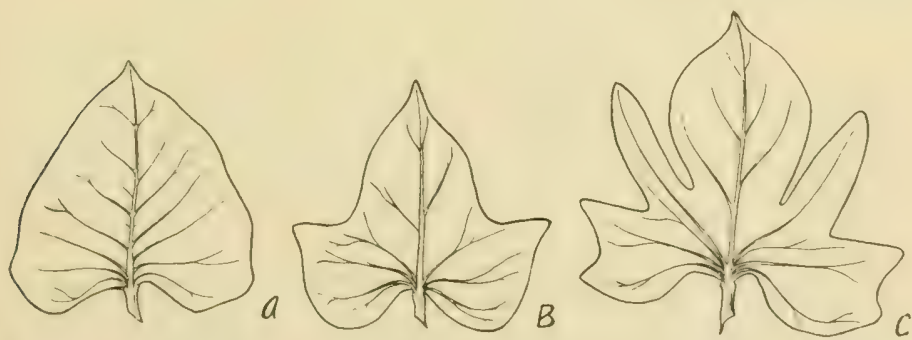

FIG. 230.- Types of sweet potatoes based upon the character of the foliage. $A$, entire or round; $B$, shouldered; $C$, deeply cut or lobed. (After Price, Texas Agr. Exp. Sta.)

Leaf Shape as Basis of Classification.-Price has clasified the varicties of sweet potatoes according to leaf shape. These groups are as follows:

I. Leaves round or entire (Fig 2,30, 1) (Pumpkin, shanghiti, Southern Queen, Big Stem Jersey).

2. Leaves "shouldered," that is shallowly and broadly notched on either 
side near the apex (Fig. 230, B) (Delaware, Early Golden, Yellow Jersey, Red Bermuda).

3. Leaves lobed (Fig. 230, C) (Barbadoes, Sugar, Yellow Yam, Vineless Yam).

Sweet potato varieties may have skin color that is white, straw, red, or purple.

1. Skin white (Vineless Yam, Early Golden, General Grant).

2. Skin straw (Orange, Delaware, New Jersey).

3. Skin red (Pumpkin, Red Bermuda).

4. Skin purple (Black Spanish, Brazilian).

Uses.--Sweet potatoes are used chiefly as a human food. Some of the coarser varieties are grown for hog pasture. The vines have some value as a stock food. Flour, starch, glucose, and alcohol are minor products of the root. Smallsized sweet potatoes, known as "seconds," are canned. Kiln-dried sweet potatoes produce a product very similar to corn meal in its chemical composition.

\section{References}

Groth, B. H. A.: The sweet potato. Contrib. Bot. Lab. Univ, of Pa., 4: I-104, I9II. 


\section{CHAPTER XXXVIII \\ SOLANACE $\notin$ (Potato Family)}

The potato family is a large one, chiefly tropical; it has about $\mathrm{I}, 600$ species in 70 genera. A number of these are important medicinal and food plants. Here are inclucled such economic forms as Red or Cayenne pepper, tobacco, common Irish potato, eggplant, tomatoes, belladonna (Atropa belladonna) which furnishes the atropin of commerce, thorn apple (Datura), petunia, etc.

Habit of Plants.- Representatives of the family are either herbs (potato, tobacco, tomato), shrubs (Lycium spp.), vines (Solanum dulcamara, bittersweet), or trees in some tropical species of Datura.

Leaves-These are alternate, rarely opposite, without stipules, and entire, toothed, lobed or dissected.

Inflorescence and Flowers.-The inflorescence is mostly cymose, sometimes imperfectly racemose, umbellate, or paniculate. The flowers (Fig. 232) are regular, or nearly so, perfect, and vary in color. The calyx is inferior, and usually with five united lobes. The corolla is sympetalous, mostly five-lobed. The corolla varies considerably in shape: rotate (tomato), bell-shaped (Physalis), funnel-form (Lycium s'ulgare), salver-form or tubular (Pelunia spp.) There are as many stamens as corolla lobes, alternate with them, and inserted on the tube; in most genera, the stamens are all equal and bear perfect anthers, but in Pelunia, for example, there are four perfect stamens, the fifth being very much reduced or entirely absent; the anthers are two-celled, dehis- 
cent at the apex or along the sides. The single ovary is usually two-celled (rarely three- to five-celled, as in $L y$ copersicon spp.), the numerous ovules being on axile placentas; the style is slender, simple, and the stigma terminal.

Fruit.- The fruil is either a berry (potato, tomato), or a capsule (tobacco, petunia). In both cases, it bears numerous seeds, which have a fleshy endosperm.

\section{Key to Important Genera}

Fruit a berry (Fig. 233).

Anthers opening by a terminal pore or slit (Fig. 232), Solanum (potato and eggplant).

Anthers opening longitudinally

Flowers white, Capsicum (pepper).

Flowers yellow, Lycopersicon (tomato).

Fruit a capsule (Fig. 244).

Capsule generally prickly, Datura (thorn apple, Jimson-weed).

Capsule not prickly.

Flowers paniculate or racemose; stamens nearly uniform in length, Nicotiana (tobacco).

Flowers solitary; stamens very unequal, Pelunia (petunia).

\section{SOLANUM}

Habit.-The Solanmms are either erect herbs (as $S$. nigmm, the black nightshade, and the common potato, etc.), or climbing herbs (S. dulcamara, bittersweet). In most species, the stems and leaves bear a stellate (star-shaped) pubescence.

Leaves.--The leaves are alternate, exstipulate, and lobed or pinnately dissected.

Inflorescence, and Flowers.-The inflorescence is cymose (bittersweet), umbellate (black nightshade), racemose ( $S$. carolinense, horse nettle), or rarely paniculate. The flowers (Fig. 232) are perfect and regular; in color, they are white (S. tuberosum varieties and $S$. nigrum), blue (S. elaugnifolium, silver-leaved nightshade, and $S$. tubcrosum varieties), 
yellow (S. rostratum, sand hur), or purple (S. dulcamara). The calye is bell-shaped or rotate, generally five-parted or five-cleft. The corolla is rotate or rarely broadly bellshaped, the tube very short, the limb plaited, five-angled or five-lobed. There are five slamens inserted on the throat of the corolla (Fig. 232); the filaments are short, the anthers converge around the style, and are usually dehiscent by a terminal pore, sometimes by a short introrse terminal slit, and sometimes longitudinally. The ovary is superior, usually two-celled; its style is slender and simple, and the stigma terminal.

Fruit.- The fruit is a many-seeded berry; the calyx is persistent at the base, and in some species ( $S$. rostralum) encloses the berry.

Geographical.-There are about 900 species of Solenum, widely distributed, but most abundant in tropical America.

\section{Key to Important Species of Solanum}

Not tuber-bearing.

Plant not prickly or spiny.

Erect herbs or shrubs.

Fruit ovoid or egg-shaped, yellow with purple or violet streaks or splashes, often 4 to 6 inches long, S. muricatum (pepino, melon pear).

Fruit a small, spherical berry, not over I inch in diameter.

Peduncles one- to three-flowered; ripe berries green, S. triflorum (wild tomato, cut-leaved nightshade).

Peduncles bearing small cymes, three- to ten-flowered; ripe berries black, S. nigrum (black or common nightshade).

Climbing vines, S. dulcamara (blue bindweed, bittersweet).

Plant prickly or spiny.

Berry not enclosed by the calyx.

Flowers light blue or white; fruit a small spherical lxerry, S. curolinense (horse-nettle).

Flowers purplish; fruit large, S. melongena (egg plant). 36 
Berry cnclosed by calyx, S. rostratum (sand bur, buffalo bur). Tuber-bearing.*

* Note--Berthault in his monograph on the tuber-bearing Solanums, has a key to 37 species. A portion of this key is here included (modified) to show the relation of common potato to some wild tuber-bearing species.

Corolla rotate.

Points of sepals long and tapering.

Leaves oval, S. tuberosum (common potato).

Leaves elongated, S. immite.

Points of sepals long, not tapering much; leaves oval, S. chiloense.

Points of sepals short.

Anthers straight, smooth, somewhat elongated, S. utile.

Anthers swollen, roughened, S. maglia.

Corolla star-shaped, S. jamesii, S. commersonii, etc.

\section{SOLANUM TUBEROSUM (Potato)}

This species includes all the varieties that are of value for food. They are usually called Irish or common potato, but also white, English, and round potato.

Habit.-The potato is a branched, more or less spreading herb, growing to a height of 2 to 5 feet or more. It has annual aerial stems, but is practically perennial by means of its tubers or underground stems.

Roots.-Upon the whole, the development of the root system is less pronounced than in most other crops. The roots are fibrous and fine. They penetrate the soil to a depth of 2 to 4 feet and frequently extend horizontally 2 feet or more from the plant.

Stems.-Potato stems are of two general kinds as to medium in which they grow: Underground and aerial. The underground stems (Fig. I2) are slender rhizomes, or are swollen to form tubers ("potatoes"). The aerial stems are the ordinary foliage-bearing stems. The discussion of rhizomes and tubers is given on pages 29 and $3 \mathrm{I}$.

Stcm (acrial).--The aerial or foliage stem of the potato is herbaceous and generally erect when young, but usually 
becomes spreading later. It is smooth and generally solisl. It has no ribs at first, but as it revelops, it becomes more or less quadrangular.

Leaves.-- Potato leares are compound pinnate, with more

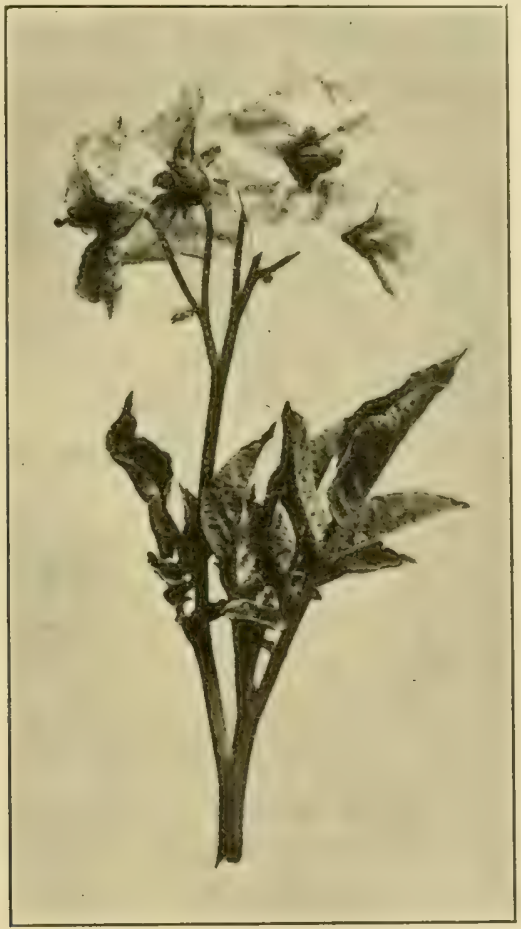

FIG. 23I.-Flowering branch of potato (Solanum tuberosum).

or less petioled leaflets. The petiole bears a number of supplementary leaflets which vary in number and importance with the age of the plant. The rachis is decurrent (Fig. I2) on the stem. The leaflets are oval, acuminate, and the base heart-shape or oblique in shape. The leares as well as the stems are characterized by a narcotic smell. At the begin- 
ning of their development, the leaves are often simple, but they increase in complexity with age. The single terminal leaflet, which frequently appears alone, is soon followed by two lateral leaflets, and these by others, so that the leaf soon becomes distinctly pinnatifid.

Considerable differences have been found to exist in the appearance of the leaves of the different agricultural varieties.

Flower (Fig. 232).-The corolla is tubular, with five lobes.

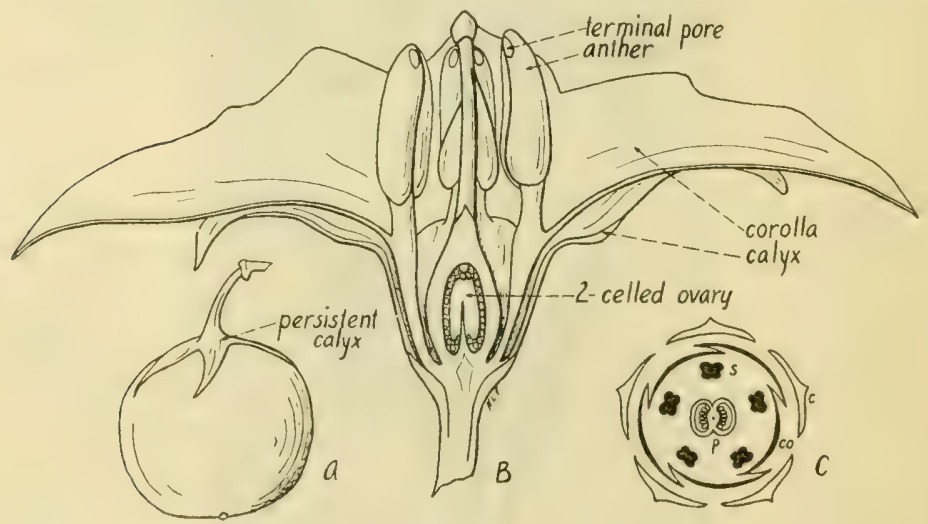

FIG. 232.-Potato (Solanum tuberosum). A, berry; $B$, flower in median lengthwise section; $C$, floral diagram.

It is white, yellow, purple, or blue in color and I to $1 \frac{1}{1} \cdot 2$ inches in diameter. There is a single whorl of five stamens which alternate with the corolla lobes, and are attached to the tube. The stamens are straight, and bear erect, yellow anthers which are longer than the filaments and open only at the top.

Two kinds of pollen grains have been observed. Those of most varieties are variable in size, irregular in shape, roughened, and largely impotent. Those of the other type are smooth, spherical, and potent. The latter kind are found only on varieties which bear fruit. Some varieties produce both kinds of pollen grains, but such plants do not always 
produce fertile flowers. Hence while the presence of round pollen grains seems to be necessary to the production of fruit, their presence by no means assures that the ovary will be formed or fruit produced. The ovary consists of two carpels with numerous ovules in each locule.

Opening of Flower and Pollination.-'The anthers are mature at the same time that the stigmas are receptive. The flowers have been found to open between 5 and 6 o'clock a.m. The pollen is usually shed on the second day of blooming, and at this time, the pistil is most receptive. The anthers open at the top by a pore and, in some cases, split for a short distance. The pollen is carried by the wind. The flowers produce no nectar and are not visited by insects to any extent, although several species of insects have been reported as visiting the flowers. East concludes from observations of his own (and of others) that self-fertilization is natural to the species. The flowers wither about the fourth day, in the profuse-seeding varieties.

Some writers report that fragrance is correlated with pollen yield, but East says he found no noticeable fragrance in American varieties. It is commonly thought that potatoes do not fruit as freely now as formerly, due to the fact that large production of tubers has caused a degeneracy in seeding power. While many of the varieties scldom bloom, and more rarely set seed, some of the best varieties bloom freely and under proper conditions set seed. Fraser says, as a result of working with 300 varieties, many of which were grown for several years, that it is seldom that a variety will not bloom at some time in its life and, furthermore, he found that many of the heaviest yielding varieties bloomed as freely as those of less value.

In many varieties, the flowers do not open. In the Pearl variey, Fitch finds that tuber productiveness "is unirersally 
proportionate to the sexual development of the plant; that the most degenerate tuber is produced on the plant which carries fully developed flowers and virile pollen; while those plants on which only female portions of the flowers appear to be fully developed, produce tubers intermediate in form and yield, and that the best tubers and the largest yield are produced by the type of plant whose flower buds do not even swell." Furthermore, these buds do not show any other color than green and they soon wither and break off.

Fruit.-The fruit (Fig. 233) is a globular or short oval berry with two locules containing numerous seeds attached to the thick axil placenta and embedded in a green acrid pulp. The fruit is called by various names, such as "potato ball," "potato apple," or "apple," but is commonly referred to as the "seed ball." In color the seed balls are brown, purplish green, or green tinged with violet. Single fruits may contain from a few to as high as 200 or 300 seeds, but sometimes no seeds are produced. Fitch found no seeds in $65^{\circ}$ seed balls of Early Rose. One seed ball from a Pearl crossed with a Rural contained no seed, while six seed balls of the reciprocal cross all bore abundant seeds. Removal of the early tubers induces fruit-bearing, while removal of the flowers is said to encourage tuber development.

Seed.-The seeds are small, kidney-shaped, and embedded in the green, very acrid pulp of the fruit.

Germination of Seed.--Potatoes are seldom propagated by seed except for the production of new varieties. As a result, many who are familiar with tuber propagation know little or nothing about seed germination.

Germination of seed begins in about five to seven days after planting, being complete in about eleven to sixteen days.

FIG. 233.--Potato seed balls, showing a cluster, and lateral, sectional and basal views. (After Stuart, U.S. Dept. of Agri.) 


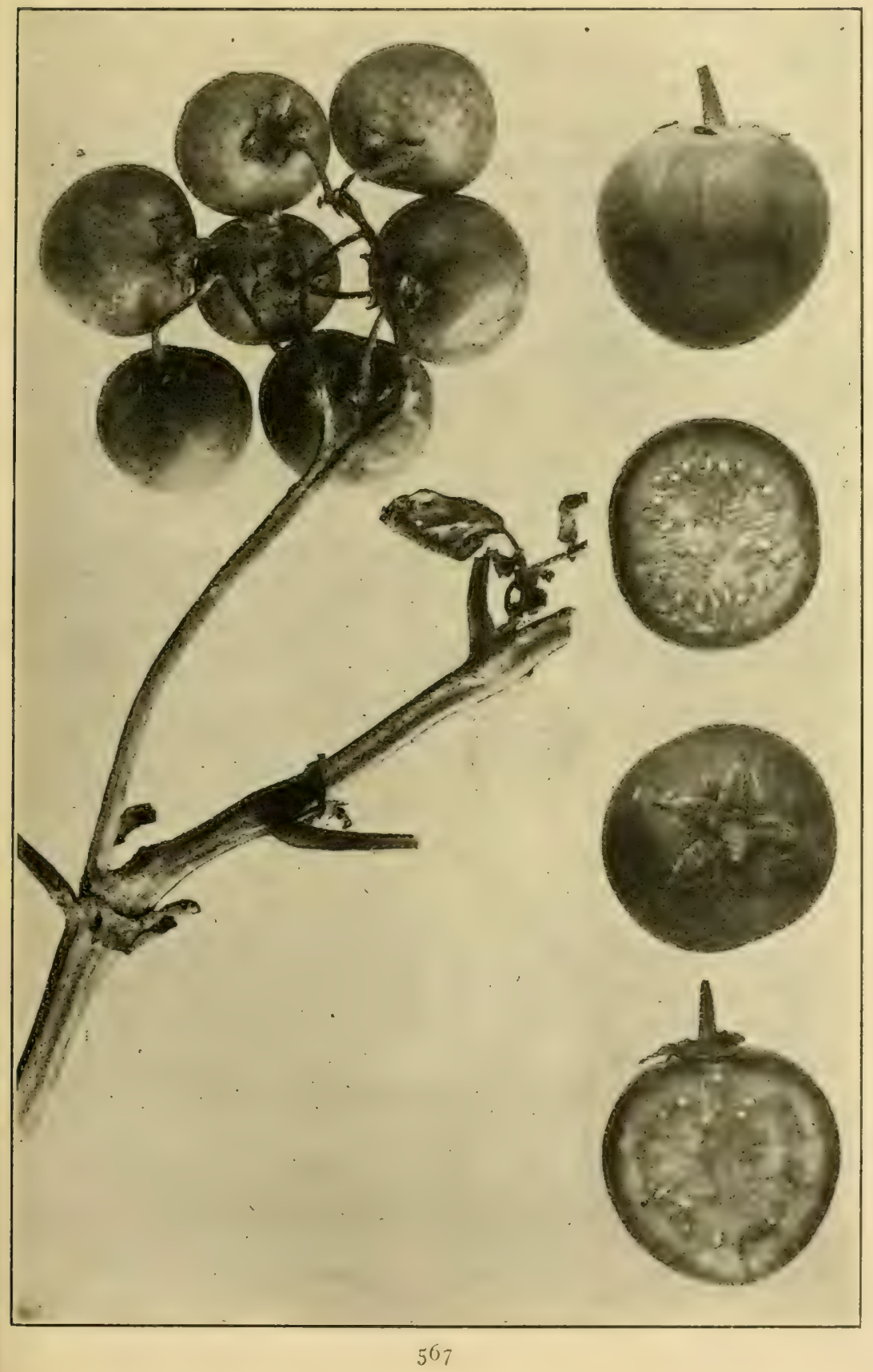


The primary root appears first, soon becomes curved, and is followed by the axis of the hypocotyl. The cotyledon leaves are smooth, oval, and more or less elongated, while the first foliage leaves are provided with unbranched hairs.

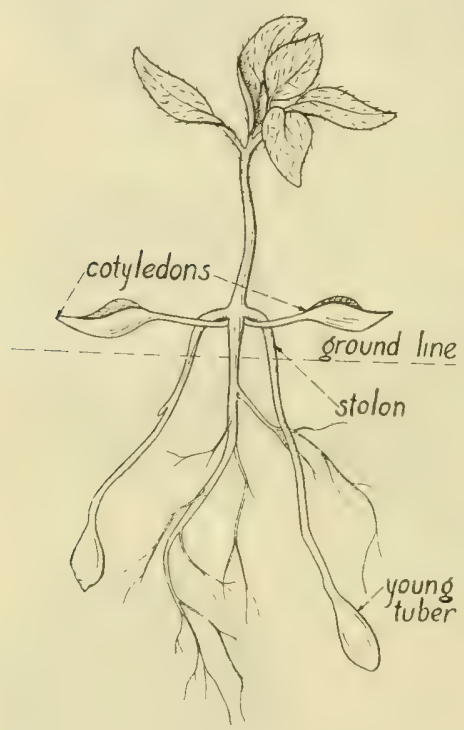

FIG. 234.-Young potato plant grown from seed. (After Percival.)

Development of the Seedling.-From the thirty-seventh to the fifty-sixth day after seeding, the stolons arise (Fig. 234); the first pair comes from the axils of the cotyledon leaves. These slender cylindrical stems possess small rudimentary leaves. They trail along on the ground and finally penetrate the soil. When their tips strike the ground, they begin to swell and form tubers. Hence the first tubers of the plant, grown from seed, are developed at the tips of slender stolons coming from the axils of the cotyledon leaves. Roots soon arise from the stolons. Secondary stolons appear in the axils of the first foliage leaves.

Tubers from Seedlings.--Tubers produced on seedlings are usually small the first year. However, Frazier reports a tuber weighing over 7 ounces that was formed the first year, and says that the Burbank potato was full-sized the first year from seed. It is reported from Svalof (Sweden) that tubers usually attain normal size and type after about the third year from seed.

Tuberization.- It has been noted previously that tubers, 
developed on a plant grown from seed. come at the tips of stolons arising on the stem above ground. However, when the tuber as a cutting is used in propagation, the young tubers form at the ends of long, thin rhizomes (underground stems) which arise underneath the ground from the main axis or stem (Fig. 12). The length of the stolon seems to be constant and a strong variety characteristic. In cultirated varieties, it should not exceed 3 or 4 inches. In $S$. commersonii, it is reported as sometimes reaching a length of ro feet. The tubers or swollen stems bear a number of buds, and these buds send out sprouts when the tuber is planted.

As a rule, the tubers are formed beneath the ground as noted above; but in abnormal cases, or when disturbed by diseases, the above-ground stems may produce tubers. For example, when the fungus, Rhisoctonia, which shuts off the downward movement of elaborated foods from the leaves to the underground tuber-forming stems, is active, normal tuberization under ground is interfered with and the stems above ground will have at tendency to sivell and produce small tubers. This phenomenon is often inclicative of Rhizoctonia.

Fungus Theory of Tuberization.--In general, it is found that darkness and low temperature favor the development of potato tubers. Tuberization is also facilitated somerwat by checking the growth of shoots or fruit.

There is some basis for the theory that the formation of the tubers is associated with the presence of certain fungi. It is certain that tuber production is encouraged in certain orchids when the stem or root is infected with the proper fungus. The fungus appears to check the growth of the terminal bud and cause the development of hypertrophied cells. 
When the potato was first introduced in France, it was found that when tubers were planted a crop was produced, but when seed was sown no tubers were obtained. From this it was inferred that when tubers were planted they infected the new ones, while the seed, free of fungi, did not furnish a supply to infect the stolons, and hence tubers could not form. However, no difficulty is now experienced in securing tubers from seed because the soil has become inoculated with the proper fungi. If this theory is correct, and there seems to be some evidence that it is, the potato tuber is in reality a gall, produced by a foreign organism.

In the potato, tuberization has been induced in concentrated solutions of sucrose or glycerin, etc., independent of fungi. Similar results have occurred in the case of orchids, onions, and rarlishes. From this it seems that the formation of tubers may result when the osmotic pressure in the cultural medium is high. However, this alone does not appear to be the only determiner, since different results follow the use of glucose and glycerine solutions of equal pressure. It certainly seems that plenty of sugar must be present for starch formation, and perhaps also for tubers to form. From this fact, that a more concentrated cell sap is usually present in fungi than in other plants, it does not seem unreasonable to suppose that the rôle of fungi in tuberization consists in raising the concentration of the media which they enter. It has actually been found that cultures of Fusarium in macerated potato tuber preparations increase the concentration. In this connection, it is suggested that low temperatures and dryness of soil may induce tuberization through increasing the concentration of cell sap.

History.-It seems "that the potato was cultivated and utilized by the Chilean and Peruvian people before the arrival of the Spaniards. In I 533, Pizarro found the Chileans 
using the tubers of a plant as their principal foul. There is no evidence that he or his party introduced them into Europe."

Wild plants have been found on the Peruvian coast, on the mountains of Chile, Central America, Mexico, and southwestern United States. However, without a doubt

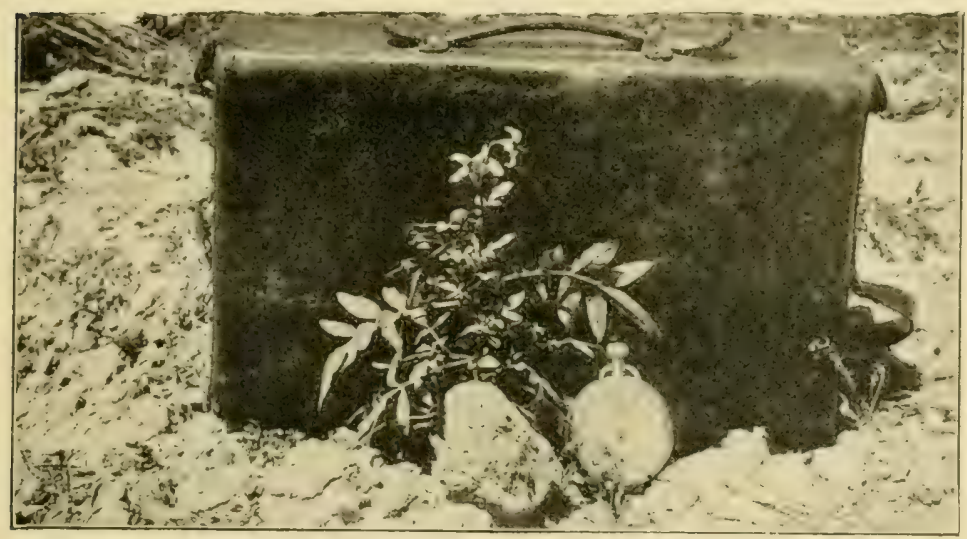

FIG. 235.-The wild potato of southwest United States (Solanum jamesii). (After Fitch, Colo Agr. Exp. Sla.)

those which. were introduced into Europe were from cultivated plants and not from wild tuberous American species. There is little doubt that South America, in the neighborhood of Quito, is the place from which the potato was first introduced into Spain early in the Sixteenth century.

After a careful study of all possible available types and species of Solanmm, and a perusal of the available literature and records, F. Berthault has come to the conclusion that $S$. tuberosum is characterized and differentiated from all other wild tuberous Solanums by its floral characters, notably its rotate corolla, and its calyx which is always mucronate (sharp-pointed). All agricultural varieties of the cultivated 
plant (potato) have been found to correspond to these characters.

Varieties.-- There are at the present time over 500 named varieties of potatoes in the United States. Many of these variety names are found to belong to potatoes which are identical in all respects. Usually, new varieties are the seedlings of established varieties.

The latest attempt at a classification of American potatoes is that of Stuart. In his "proposed system of classification"

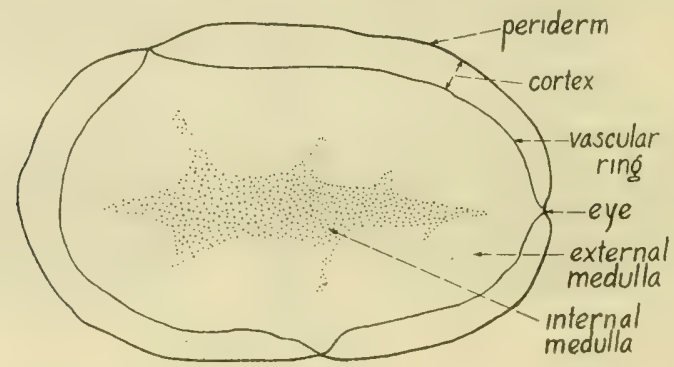

FIG. 236.-Diagrammatic section of potato tuber.

he gives the following "groups": Cobbler, Triumph, Early" Michigan, Rose, Early Ohio, Hebron, Burbank, Green Mountain, Rural, P'earl, and Peachblow. Tuber, sprout and flower characters are made the bases of distinction of the groups. The student is referred to Bull. I76, U. S. Dept. Agr. (Professional Paper) for the descriptions of these groups. Fitch has also proposed a classification using about the same characters.

Tuber Morphology.- The potato tuber is made up of a number of zones or layers which are commonly grouped as follows (Figs. 236 and 237):

I. Periderm or skin.

2. Cortex.

3. Vascular ring. 
4. External medulla.

5. Internal medulla.

According to Coudon and Boussard, these zones (excepting vascular ring) are proportioned (by volume) ats follows:

Per cent.

Skin (average of two varieties) ......... 8.79

Cortex (average of two varieties)......... 36.19

External medulla (average of five varieties)... 34 . I 7

Internal medulla (average of five varieties)... 14.95

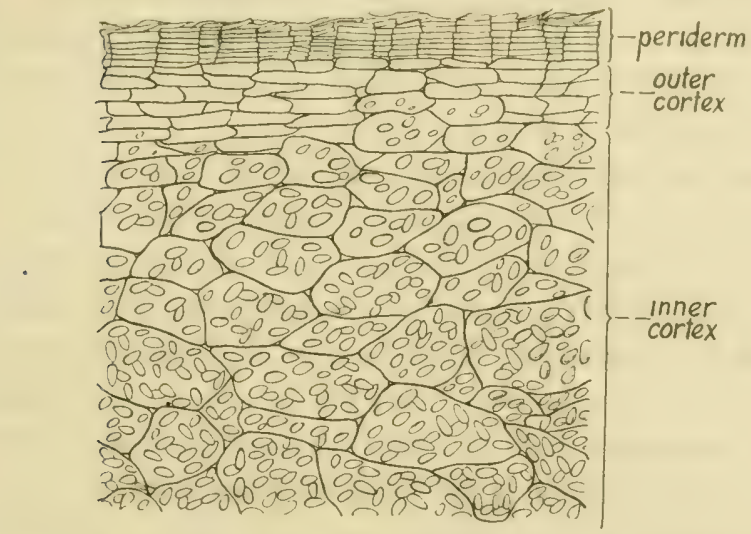

FIG. 237.-Microscopic section through the "skin" and portion of cortex of potato (Solanum tuberosum).

For consideration here, these zones are classified at follows:

I. Periderm or skin.

2. Vascular ring.

3. Parenchyma.

(a) Cortex.

I. External.

2. Internal.

(b) Medulla.

I. External.

2. Internal. 
Periderm or Skin.-- The stolon, which develops into the tuber, possesses the true stem structure. It has a thin epidermis, an outer parenchyma tissue or cortex, fibrovascular bundles, and an internal parenchyma or medulla. As the tuber develops, the cortex becomes relatively reduced, the vascular bundles separate and the medulla becomes larger. The outer layers of cells of the cortex also undergo changes. The cells of these layers become corky and flattened, and so arranged that the vertical walls form straight lines and do not overlap. Their walls become suberized. The original true epidermis gradually dies and disappears entirely. These outer corky layers of cells constitute the periderm or skin of the potato. The outermost layers of periderm split off, giving some varieties a characteristic rough appearance. The cells of the different layers of periderm vary in size and shape in different varieties. The number of layers is usually 7 or 8 , but it varies from 5 to as many as 13 and even 17 . At the eyes, the periderm (skin) becomes thicker. Lenticels are scattered over the tuber.

Some claim is made that thick-skinned varieties are of better quality than thin-skinned ones, but such is not always the case. A netted or rough skin develops on tubers of some varieties as they mature in storage, which suggests, that a rough or netted skin in these cases denotes maturity. Possibly this is sometimes the source of the common idea that a rough-skinned potato is of superior quality. The size and type of netting is found to vary with the variety and the conditions under which grown. Smoother skins are usually found on potatoes grown on sandy soils than on those grown on heavy soils. It has been found that the thicker and rougher-skinned varieties stand up better in shipping, and are preferable for this purpose even though they may have no greater merit in other ways. 
Vascular Ring.- 'The vascular ring consists of a discontinuous circle of vascular bundles. It is located between the cortex and the medulla. At the eyes, the rascular tissue approaches the surface of the tuber. It maintains, however, its proper relationship with the other tissue, i.e., between cortex and medulla. The cortical layer gradually becomes thinner as the vascular bundles approach the eyes. The rascular tissue is poor in starch. The vascular ring is easily recognized as a very narrow darkened ring near the edge of the exposed surface of a cut.

Parenchyma.--Almost the entire mass of tuber tissue inside of the periderm (skin), except the vascular tissue, is parenchyma, and will be referred to as such in this discussion.

The parenchyma is divided into two principal parts: the cortex, and the medulla.

Cortex.-The cortical layer of the parenchyma is just within the periderm. It is separated from the medulla by the vascular ring. The outer cortex is made up of smaller cells than the inner cortex. The cells of the cortex are considerably smaller than those of the medulla, and hence the density of the cortex is greater. The cortex is darker in color than the medulla, which is probably due to its greater density. A thick and dense cortex indicates a potato of good quality. A thinner, more translucent cortex is said to indicate lower quality. The periderm, or skin, and the outer layers of cortex are removed when potatoes are peeled.

Medulla.-The medulla consists of all of the tuber inside of the vascular ring. It is divided into two parts, the external and the internal medulla. When a thin slice of potato is held up to the light, these two areas are easily distinguished; the external medulla appears darker and denser; the lighter color of the internal merlulla is due to its greater percentage of water, and considerably less starch and other solid matter. 
The internal medulla is usually more or less star-shaped. 11 any of the radiating areas of internal medulla penetrate deeply the outer medulla. some of them extending to the eyes. In some tubers, these two zones are more or less intermixed, with no definite zone boundaries. As a rule, in long potatoes, the central area is very much elongated and with lateral radiations, while in many round potatoes it is typically starshaped. The greater the size of the internal medulla and the more its ramifications into the outer area, the poorer the quality of the tuber, since it means a larger area poor in starch and hence less mealy on cooking.

Shape.-The common tuber shapes are round, oblong, and elongated, in outline. One dominant form is found in each variety but never one exclusive form. New varieties based on tuber form are produced by a selection of tubers and are maintained only by continued selection.

In tuber propagation, there appear among the normalshaped tubers a number of aberrant (diverging) forms which are usually in the minority.

Color.- The common tuber colors are yellow, red, violet of different shades, and variegated. Bluish forms are also known. Color variation has been found in a number of cases. In propagation by cuttings, yellow and streaked tubers have appeared from colored ones (red and violet). Yellow tubers have given red and violet ones, a white tuber has given two red and two white tubers, and one with a bluish color has given a series white in color. The Pearl with a brownish-white or a well-russeted skin is from the Blue Victor which has a purple color often streaked with white. When the white streaks cover an eye, the tubers from the eye usually come true (white) in following generations. The People's variety, also from the Blue Victor, is a deeper brown color than the Pearl. At the present time, 
white-fleshed tubers are the only ones accepted in American markets. Vellow flesh is correlated with a strong flavor and a poor quality, at least according to American standards. A number of yellow-fleshed varieties from France are found to be gummy and hard after boiling. They are considered by the French to be of prime quality, however. In this country; these varieties are considered of good quality for the making of salads and for frying.

Eyes (Fig. 236).-The buds of the potato tuber usually occur in groups, each group lying in a more or less depressed area. Such a group of buds is called the "eye." The depression is the axil of a scaly leaf which was in evidence when the tuber was young, but later disappears. The "eye brow" ("eye yoke") is the line above the depression-the line which separates the leaf from the stem. In reality, the eye is a lateral branch with undeveloped internodes, the whole tuber being generally a much-branched stem and not a simple shoot. The central bud in the "eye" is commonly the largest and strongest.

Fitch has noted that the "eye-brow" differs noticeably in vigorous and in degenerate tubers. In the latter, it is stronger and has a tendency to be longer.

Careful study shows that the buds or "eyes" are arranged alternately and at the same time spirally on the tuber. Beginning at one end of a tuber and proceeding toward the other end, at the same time turning the tuber. usually enables one to follow clearly the spiral arrangement.

The so-called "seed end," "rose" end, or "crown" of the tuber is opposite the point of attachment to the stem. The "stem" end is at the "base" or heel of the tuber. The eyes are more numerous and more vigorous at the seerl end. Ordinarily, the terminal bud (at the "seed end") is the strongest and under proper conditions will be 
the only one to devetop. The sprout produced by the terminal eye is spoken of as the "master sprout." The eyes vary in different varieties from very deep to level with the surface; the latter condition results in smooth potatoes. Deep eyes tend to hold moisture; as a result, decay is invited and hastened when the potatoes are stored. Smooth varieties occasionally give rise to deep-eyed tubers, although, as a rule, eye depth is maintained by tuber propagation. It is likely that the deeper-eyed plants give rise also to smooth tubers and that in seed propagation the same results follow as in the case of form and color.

The number of eyes varies considerably within the same variety; in one case, Rural New Yorker, it ranges from 7 to 28 ; and in Early Ohio, from 7 to 22. The number of eyes affects the quality, since the poorer zone of the potato (internal medulla) extends a branch to each eye, thereby increasing the percentage of internal medulla at the expense of the two outermost valuable layers.

Germination or Sprouting of Tuber.-Potatoes undergo some changes in storage. Not only do they lose water and decrease in weight but they increase in sugar. When sprouting commences, the potato becomes sweeter, due to the conversion of starch into sugar by the enzyme diastase. The most vigorous buds are the terminal ones. The tip of the main sprout grows upward. The underground stems bear tubers at their ends. These will not tuber if brought to the light but will develop into ordinary green-leafed shoots.

Physical Composition of Potatoes.--In all varieties the cells of the cortex are much smaller than those of the medulla. In general, potato varieties are characterized by their cellular density and can be grouped accordingly. The groups are not, however, clear-cut. Cellular density is an important factor to consider in the breeding of potatoes for 
table use, of for the industries. For table use, only those tubers should be selected which have small cells (high density), and for starch factories only those with large cells (low density). Even with the same amount of starch in two varieties, it is found that the large-celled one is the more valuable to the starch industry, due to the fact that in the small-celled varieties a larger number of the cells remain intact and do not give up their starch in the starch-removing process, while with the large-celled varieties fewer starch cells escape being broken up. In France, it was found that rich, compact (heavy) soils produced tubers with a low cellular density, while the lighter soils produced tubers with small cells and high density.

Chemical Composition of Potatoes.-- A number of analyses of potatoes have been made in this country and in Europe. Gilmore gives the results of a number of these in the following table:

\begin{tabular}{|c|c|c|c|c|c|}
\hline Source & $\begin{array}{l}\text { No. of } \\
\text { analyses }\end{array}$ & $\mid \begin{array}{c}\text { No. of } \\
\text { varieties }\end{array}$ & Protein & Starch & Quality \\
\hline Cornell................ & 43 & 4 & I. 899 & $17 \cdot 356$ & Very good. \\
\hline Maine.................. & I6 & 4 & 2.170 & 18.037 & Very good. \\
\hline U. S. all sources........... & I 36 & $\ldots \ldots$ & 2.200 & I 8.400 & \\
\hline France: & & & & & \\
\hline Coudon and Boussard..... & 7 & 7 & 2.676 & I I. 798 & Very good. \\
\hline Coudon and Boussard..... & 8 & 8 & $2.4 \mathrm{II}$ & I 3.218 & Good. \\
\hline Coudon and Boussard.... & 7 & 7 & 2.365 & 14.1 I 8 & Passable. \\
\hline Coudon and Boussard..... & I2 & I2 & 2.090 & I6.047 & Poor. \\
\hline
\end{tabular}

Water and nitrogen increase from the outer to the inner zones, while the starch content decreases.

The following table showing composition of the potato is from East: 


\begin{tabular}{|c|c|c|c|c|}
\hline Variety & Zone & $\begin{array}{l}\text { Dry } \\
\text { matter, } \\
\text { per cent. }\end{array}$ & $\begin{array}{l}\text { Total N, } \\
\text { fresh basis, } \\
\text { per cent. }\end{array}$ & $\begin{array}{l}\text { Total } N \text {, } \\
\text { dry basis, } \\
\text { per cent. }\end{array}$ \\
\hline Rural...... & Cortical & 20.95 & 0.46 & 2.20 \\
\hline New Yorker. & Outer Med. & I 8.46 & 0.47 & $2: 56$ \\
\hline No. $2 \ldots \ldots$. & Inner Med. & 14.04 & 0.45 & $3 \cdot 23$ \\
\hline \multirow[t]{3}{*}{ Carman No. 3} & Cortical & 22.20 & 0.49 & 2.23 \\
\hline & Outer Med. & $\mathrm{I} 9.4 \mathrm{I}$ & $0.5 \mathrm{I}$ & 2.63 \\
\hline & Inner Med. & 14.92 & 0.52 & $3 \cdot 49$ \\
\hline
\end{tabular}

This table shows that the dry matter decreases from the outside to the inside of the tuber. The nitrogen content shows an increase, on dry basis, from the outside to the center, although on a fresh basis there seems to be no regularity of percentage, probably due to variability in water content. The inner cells of the cortex contain a much larger amount of starch than those of the external medulla, which in turn contain considerably more than the cells of the internal medulla. The outer cells of the cortex which are removed with the skin (in peeling) are comparatively low in starch.

Starch and Sugar.--Potato starch grains are egg-shaped or nearly spherical with eccentric markings, and with the hilum near the small end. Some varieties of potatoes are abundantly supplied with large starch grains with infrequent small ones, while in other varieties the reverse is the case. No correlation has been found between the size of the starch grains and the size of the tuber or its total starch content. In general, the early varieties contain large starch grains while the late varieties contain a larger proportion of small grains. Starch-grain formation is very slow. At first, many small grains are found, most of which later increase in size. This increase in size begins much sooner in early varieties than in late varieties. 
In addition to starch, potatoes contain noticeable amounts of sugar. The average quantity is not far from 0.35 per cent. This sugar is lost in starch-making, but is utilized in the manufacture of alcohol.

"Mealiness." - In estimating cooking quality of potatoes, mealiness is the most important consideration. Mealiness depends quite largely upon the amount of starch in the cells. When boiled in water, the starch grains expand and coalesce. If there is sufficient starch, as is usually the case in the cortex, this expansion ruptures the cell walls, freeing their contents and producing mealiness. A deficiency of starch, as is usually the case in the cells of the internal medulla, produces swelling insufficient to rupture the cell walls; hence, sogginess results.

As has been shown, the different zones of the potato vary considerably in starch content, the cortex being highest, and the internal medulla lowest. If the internal medulla is large and has branches extending into the external medulla, the tuber is likely to be hard and soggy when boiled. and to contain zones or parts which will not mash uniformly and readily. The external medulla is usually well stocked with starch. When this is the case, and when the starch is distributed uniformly, leaving no "water areas," a high degree of mealiness can be expected in the boiled tubers, a condition necessary for high table quality in America.

Quality of Potatoes.-The standards for table quality in potatoes vary somewhat in different countries. The more noticeable differences seem to be between France and the United States. East notes that most of the potatoes which he examined, imported from France, had a yellow flesh. a strong flavor, and were firm and soggy after boiling. In France, potatoes are commonly cooked by frying in deep fat. For this purpose, a potato yellowish in color which holds its 
form, and is, as a result, more or less soggy after boiling, is preferred. These characteristics are usually found in potatoes which are low in starch and high in protein. In the United States, on the other hand, where probably nine-tenths of the potatoes eaten are boiled, a white, floury, starchy potato which is mealy and dry when cooked is demanded for table use. In Germany, table potato standards are more like those in the United States. In general, it is considered that for table use in this country potatoes must contain about I7 per cent. or more of starch. As a result of experimentation with I5 American varieties, East says: "It is quite evident then that potatoes having as far as possible a homogeneous flesh and containing as large an amount as possible of cortical and outer medullary layers in proportion to inner medullary layer, should be of the finest quality.'

Degree of Maturity and Quality.-Analyses in the United States have shown that the "greater part of the total nitrogen is developed early in the growth of the tuber, while the starch is stored up later." It was also found that "the starch grains of immature tubers are small in size and few in number." Tubers increase in desirability with maturity.

Degeneracy of the Potato. - The "running out" of potatoes is a common observation. New varieties are put on the market, are very productive for a varying number of years, then they usually begin to "run out" or degenerate.

In Colorado, varieties in the mountain districts do not tend to run out, or only very slowly, the tendency apparently being easily overcome by seed selection, while in the Greeley district, on the plains, at an altitude of 4,600 feet, the sexual tendencies and consequent degeneracy seem to overcome other influences, such as selection. At Svalof (Sweden) the opinion is held that in a variety of potatoes "there is no period of old age." On the other hand, degeneracy is be- 
lieved to be the result of "factors which hinder the normal development of the plants and tubers or invite discase." Stewart recently describes forms of degeneration known as leaf-roll, curly-dwarf, mosaic and spindling-sprout. He found that the progeny of plants with normal foliage and high yield may very suddenly degenerate in to dwarfish plants affected with the above-mentioned diseases. The leaf-roll, curly-dwarf and mosaic troubles are passed from generation to generation by means of the tubers. The nature of spindlingsprout is not this well known. The observations are significant in that they show that seed selection may not always insure against "running out." It is claimed by the Svalof investigators that more vigorous seed tubers are produced in cool, moist conditions than in hot, dry regions. This view is also held by Fitch who worked in Colorado. The cause of this increased vigor is another question. It may be due to a well-developed vascular system in the tuber or an abundance of diastase at the sprouting season. Investigators express the view that "where suitable sorts are used, and where suitable tubers of these sorts are utilized for seeding purposes each year, the standard of a varicty maty be maintained indefinitely under all favorable conditions of soil and climate." Hence it seems that the inherent tendency to degenerate is perhaps no stronger in potatoes than in other crops, but that they are more widely and strongly influenced by environmental conditions than are most crops. It is reported that at Svalof the variety Dala, introduced about i 50 years ago in the province of Delarne, is still one of the best sorts grown there.

Environmental Relations.- The potato is a native of the high, cool regions of Mexico and South America. In the United States it thrives best in a cool, moist climate as is evidenced by the fact that the five leading potato States 
touch the Canadian border. It is well adapted to elevation up to 8,000 feet in the Central Rocky Mountains. Smith has shown that the potato makes its best development in those sections of the country where the mean annual temperature is between $40^{\circ}$ and $50^{\circ} \mathrm{F}$, and where the mean for July is not over $70^{\circ} \mathrm{F}$.

The plant is grown on both heavy and light soils, but the latter are preferred; upon these, the plant is less subject to

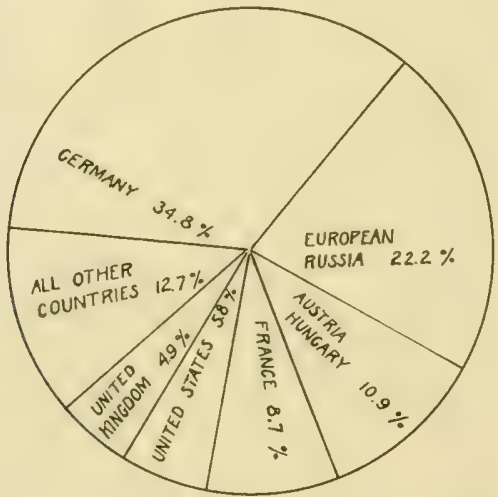

FIG, 238.-Percentage of the world's supply of potatoes produced in the different countries in I9I4.

disease, the tubers are of better quality and smoother, and come to maturity more quickly.

Uses of Potatoes.- Potatoes are put to the four following chief uses: (I) human food; (2) commercial starch; (3) stock food; and (4) alcohol. Potatoes rank second to the cereals in importance as a food of northern peoples. They are fed to all classes of stock, especially hogs. In the dried state, they have been fed, in Germany, to cattle and horses with good results.

Potato Starch.-The potatoes are first soaked for several hours in water, then washed, and finally reduced to a pulp 
by rasping machines. The pulp is passed through sicres. which separate the fiber from the liquor containing starch. The liquor is allowed to stand, and during this time white starch settles in layers at the bottom of the receptacle. The starch is drawn off, purified by allowing it to run over tables. similar to those used in the purification of corn starch (page ${ }_{184}$ ), and finally dried. "(ulls" are profitably employed in starch manufacture.

Alcohol.-In Germany, the potato is used extensively for alcohol manufacture. In this country; it is too expensive for this purpose. The process of converting the starch to alcohol is very similar to that used in the manufacture of alcohol from corn starch.

Production of Potatoes.-The world's output of potatoes in 1912 was $5,872.953 .000$ bushels. Of this amount. (iermany produced I $, 8+4,86_{3}, 000$ bushels, or about 3i per cent. of the total. Russia proper ranked second with a production of $925,775,000$ bushels. France third with 552,074,000 bushels, and the United States fourth with $+20,647.000$ bushels. The five leading potato States in $19 \mathrm{I} 5$ were Minnesota, Wisconsin, New York, Maine and Michigan.

\section{SOLANUM MELONGENA (Eggplant, Guinea Squash)}

Description.-This species is an annual, erect, branching herb, finally becoming subwoody, 2 to 3 feet tall, woolly or scurfy, and spiny. The leaves (Fig. 239) are large, 6 to o inches long, sinuately lobed, ovate or ovate-oblong, thick. becoming almost smooth above but remaining densely hairy beneath. The flowers are solitary or in small clusters in the axils of branches; the calyx is woolly or spiny, the corolla purplish and pubescent (Fig. 239). Parthenocarpy has been observed in this species. Artificial pollination is practiced 
to insure fruit production. The fruit is a berry, 3 to 6 inches in diameter, smooth, and varying in color (Fig. 239). Eggplant is a native of India. All cultivated varieties require high temperatures. They are usually transplanted. They are used exclusively as a table vegetable.

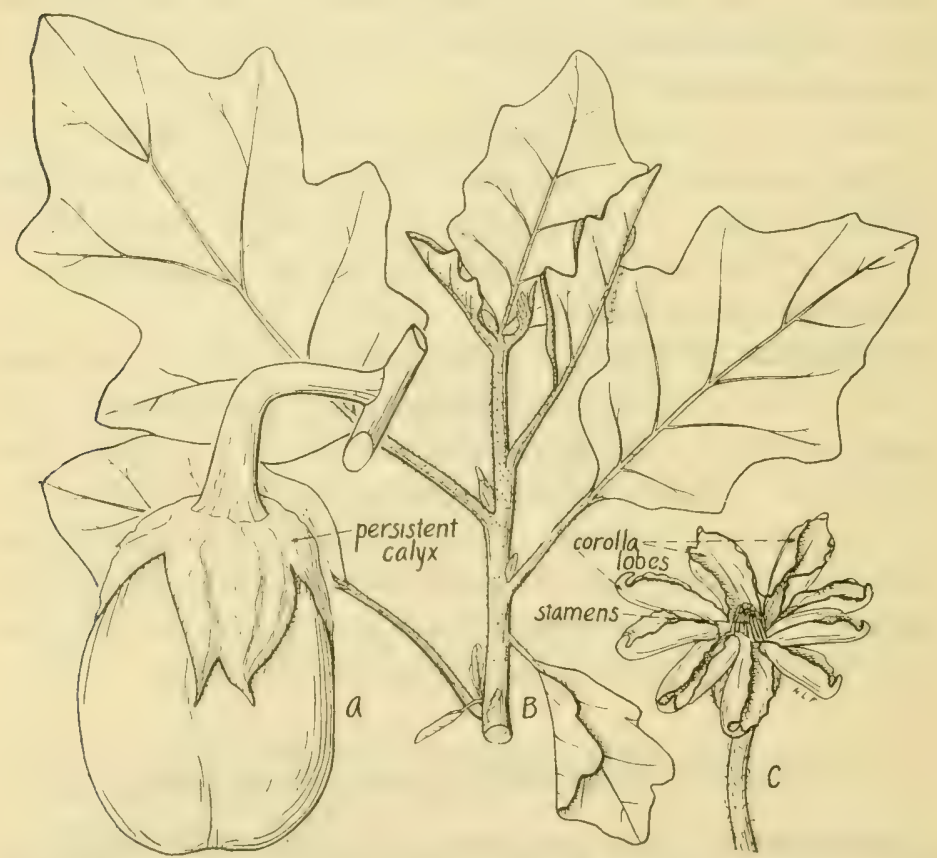

FrG. 239.-Egg plant (Solanum melongena). $A$, mature fruit; $B$, leaves; $C$. single flower.

Types and Varieties.--Bailey has divided the eggplants into three varieties, as follows:

I. S. melongena var. esculentum (Common Eggplant).The plants are tall and stout, the leaves large and thick, and the fruit large and usually spherical or oblong. There are forms in this group) with purple fruit (Black Pekin, New York 
Improved, (iant Round P'urple) and others with white or striped fruit (White (hinese, Long White, White Eggrg).

2. S. melongena var. serpentinum (Snake Eggplant).-The plants are medium to tall, the leaves large, and the fruit long and slender.

3. S. melongena var. depressum (Dwarf Purple Eggplant).The plants are small, weak, and spreading, the leaves small, the flowers small, and the fruit small to medium. pearshaped, and purple (Early Dwarf Purple).

\section{LYCOPERSICUM (Tomato)}

Habit of Growth, and Stems.--The tomatoes are annual or short-lived perennial, coarse, branching or feebly climbing herbs, that vary in size and form with the species; climate, and methods of culture. The upright growing tomatoes (L. csculculum var. ialidum), have a low, stiff, and erect growth form. L. esculcutum var. grandifolium is a tall sort with a few large, entire leaflets. In the currant tomato ( $L$. pimpincllifolium), and cherry tomato ( $L$. cerasiforme), the branches are usually weak and even trailing in habit. The pear tomato (L. pyriforme) has an erect and strong habit of growth.

Roots.-The root system of tomatoes is fibrous and not extensive. It does not penetrate far into the soil and is usually short-lived.

In the transplanting of tomatoes from the seed bed to the garden, it is the practice to allow the seedlings to wilt before they are reset. Under these conditions the fine, tender rootlets, and root hairs are largely destroyed, but the plant promptly throws out a vigorous cluster of new ones. In fact, the new set of ronts possesses greater vigor than those on a seedling that has not been allowed to wilt; in the latter case the roots are not injured beyond recovery, and it ap)- 
pears that their recovery prevents the prompt development of new ones.

Leaves.--The leaves are usually alternate, always compound, odd-pinnate, and petioled. In all tomatoes except L. esculcutum var. grandifolium and possibly L. pimpincllifolium, the leaflet margin is toothed or lobed.

Inflorescence and Flowers.-The flowers are commonly in raceme-like cymes, or in racemes (as in currant tomato). However, even in the currant tomato the racemes are often branched at the tip. The flowers are perfect, regular, and pendant. The calyx is five- to six-parted; the segments are linear or lanceolate, persistent, and increase in size with the derelopment of the fruit. The corolla is rotate or wheelshaped, cleft into usually five, sometimes more, lobes; the tube of the corolla is short. There are five stamens (sometimes more) attached to the corolla tube; the filaments are very short, and the anthers open by a longitudinal slit on the inner side; they are elongated, connate or connivent. There is one pistil bearing a single style and an owary, which is usually two-celled (more than two-celled in cultivated tomatoes) and has a central, fleshy placenta.

\section{Pollination, Fertilization, and Development of the Fruit.-} In the maturing of the flower, the style elongates and pushes the receptive stigma through the tube formed by the anthers. In some instances, this elongation occurs prior to the dehiscing of the anthers, hence eliminating the possibility of selfpollination. Sometimes the anthers shed pollen at the time the stigma is pushed upward, and in the growth of the stigma it rubs against the dehiscing surface of the anthers. Stigmas remain receptive for several days. However, it is known that greenhouse tomatoes do not set fruit well unless artificially pollinated, as is commonly done by jarring the plants at the time of anther dehiscence. Natural cross-pollination seldom occurs. 
Extensive experiments marle by Fletcher and (iregre with greenhouse or forced tomatoes showed that self-fertilized blossoms set fruit as well ats cross-fertilized ones. Furthermore, there was practically no difference in the appearance or weight of the fruit, and no difference in the number of cells.

Parthenocarpy.- This phenomenon is not at all uncommon in tomatoes. By this is meant the ripening of the fruit without the fertilization of the orules. Such fruits, of course, possess no germinative seeds.

Abnormal Tomatoes.-Munson has found, in crossing tomatoes, that the amount of pollen placed on the stigmas affects the size of the fruit. Two stigmas in the same flower cluster were given different amounts of pollen: one abundant pollen, the other ro to 20 grains. With plenty of pollen, normal fruit resulted, while with scanty pollen, small and deformed fruit resulted. In the first case, there was abundant seed, while in the latter, only a few seeels. Onesided tomatoes result when pollen falls upon one side of the stigma only. It is undoubtedly commonly true that small and irregular tomatoes are caused by an insufficient supply of pollen.

The Mature Fruit.-The fruit is a true berry (Fig. 240). The wild form of our common garden tomato (S. esculentum) has a two-celled fruit with a rather dry placenta. The cells are definite in both number and shape. Cultivated forms of the common garden tomato have a number of cells in the fruit; they are indefinite in both number and shape, and the placenta is exceedingly fleshy. The fewest celled fruits are considered nearest the original type. The pear and cherry tomatoes both have two-celled fruit. The calyx is persistent, adhering to the base of the fruit. The fruit varies in shape, color, and smoothness of surface. The seeds are numerous and small. 
Geographical.-All the species in this genus are natives of South America. Dunal, in DeCandolle's Prodromus, gives ro specics of Lycopersicum; this number is reduced, however, by some writers. Tomatoes are warm season "vegetables" that require transplanting in central and northern latitudes.

Important Species and Varieties.-There is a difference of opinion whether to consider certain forms of tomatoes species or only varieties. For example, Bailey recognized

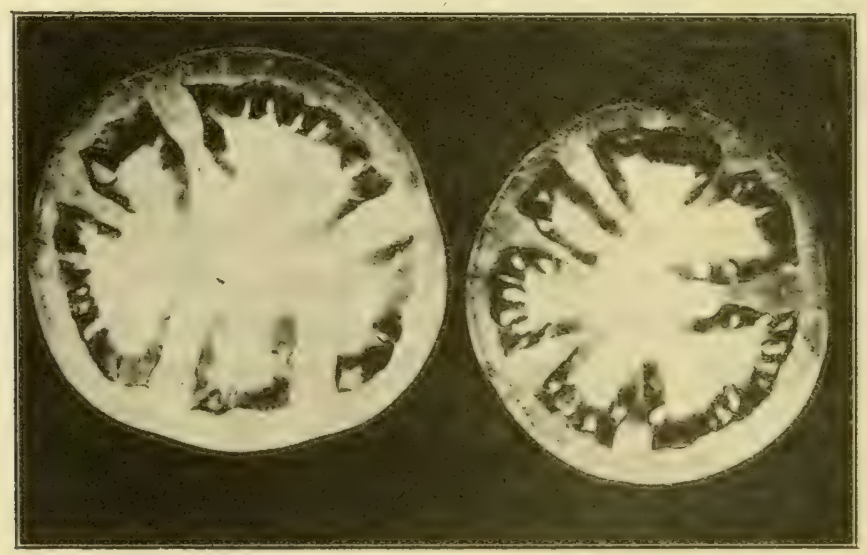

FIG. 240.-Cross-section of mature fruit of cultivated tomato (Lycopersicon esculentum).

but two cultivated species of Lycopersicum: L. esculentum, the common tomato, and L. pimpincllifolium, the currant tomato. L. esculentum is, according to Bailey, divided into the following varieties:

I. L. esculentum var. oulgare, garden tomato.

2. L. esculentum var. cerasiforme, cherry tomato.

3. L. esculentum var. pyriforme, pear or plum tomato.

4. L. esculentum var. validum, upright tomato.

5. L. esculcntum var. grandifolium, large leaf tomato.

L. pimpinellifolium is not subdivided. On the other hand, Tracy regards as distinct species: $L$. pimpinellifolium, $L$. 
cerasiforme, L. pyriforme, and L. esculenlum, inclucling under the last the varieties inlgare, falidum. and grandifolium.

The above types of tomatoes maty be artificially distinguished by the following key; in all instancescultivated forms are understood.

\section{Key to Types of Cultivated 'Tomatoes}

Fruit in long racemes or branched clusters; berries red, currant-like, Currant, German, raisin or grape tomato.

Fruit in short racemes or branched clusters.

Plants low, stiff, and erect, having much the appearance of a potato plant; leaves small, curled, U pright lomato.

Plants taller, the branches weaker and more spreading.

Leaves very large, about two pairs of almost entire-margined leaflets, Large-leaf tomato.

Leaves of medium size, numerous pairs of leaflets the margins of which are toothed or lobed.

Fruit pear-shaped, Pear tomato.

Fruit globular or angular, not pear-shaped.

Fruit globular, smooth, red or yellow, from ${ }^{1} 2$ to ${ }^{3} 4$ inch in diameter, two-celled, Cherry tomato.

Fruit varying somewhat in shape, surface, and color, larger than preceding, many-celled, Common garden tomato.

The common tomato (var. iulgure) has undergone considerable modification as the result of cultivation. As compared with the small two-celled fruit, with thin walls and a dry placenta, and in some instances with distinct grooves on the surface, the cultivated forms are larger, many-celled, the walls and placenta are thick and fleshy, and the fruit surface smooth. There are three general groups of the common tomato: fruit angular, fruit apple-shaped, and fruit oblong.

The cherry tomato (var. cerasiforme) has small globular, red or yellow two-loculed fruit. The pear tomato (var. pyriforme) has small red or yellow, two-loculed pear-shaped fruit. The upright tomato (var. validum) looks much like the potato plant in its growth habit. The large-leaf tomato 
(var. grandifolium), of which the Mikado may be taken as a type, is distinguished from the other varieties by its large leaves with only a few (nomally two) pairs of leaflets.

Closely Related Forms.- The husk tomato (Physalis pubcscens) and the strawberry tomato (Phycalis pubcsens and P.alkekengi) are distinguished from Lycopersicum spp. in that the calyx becomes enlarged, inflated, and entirely covers the small berry. The fruit is esteemed by some for preserving, or making pies, or for eating raw.

The tree tomato ( $C y$ phomandra beluccu), a tropical plant, has a fruit similar in taste, at least, to that of the common tomato. This plant also belongs to the Solanaceæ, but may be distinguished from Lycopersicum by its woody habit of growth.

History.-The tomato is still found in the wild state in South America. The Spanish explorers carried the fruit to southern Europe where it was used as a food long before it was eaten by the people of northern Europe. It was early known in England and America as the "Love Apple." A prejudice against the tomato existed for a long time, no doubt due to its alliance with the nightshades. Now, however, it is it favored article of liet, and from 500,000 to 600,000 acres are devoted to its growth annually in the United States and there are as many as 175 different varieties offered by seedsmen.

Uses.-Tomatoes are commonly used, fresh or canned, as a table vegetable. Large quantities are made into catsup. Such varieties as Red Plum, Yellow Plum, Red Pear-shaped, Red Cherry, and Burbank's Preserving are used quite extensively for pickling.

\section{CAPSICUM ANNUUM (Peppers)}

Description.-This species is either an annual or biennial herb, 2 to 5 feet tall, and sometimes partly woody at the base. In temperate regions, the plant is cultivated as an annual, while in warmer climates it is often biennial. The leaves are 
ovate and entire. The flowers (Fig. 24I) are solitary, or in twos or threes. The calyx is five-lobed, truncate, obconical, cup-shaped or funnelform. The corolla is white, rotate, usually five-lobed, with the lobes valvate. There are five stamens, sometimes six or seven, attached near the base of the corolla; the bluish anthers dehisce longitudinally. The ovary is usually two-celled, rarely three-celled, and bears a thread-like style, and numerous ovules. The fruit (Fig.

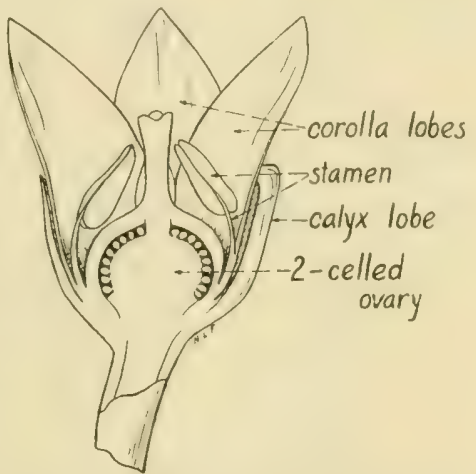

FIG. 241.-Median longitudinal section of pepper flower (Capsicum annutum). $\times 2$. 242 ) is a berry, red or green in color, and short cylindrical or globular in shape. There are many seeds in each fruit.

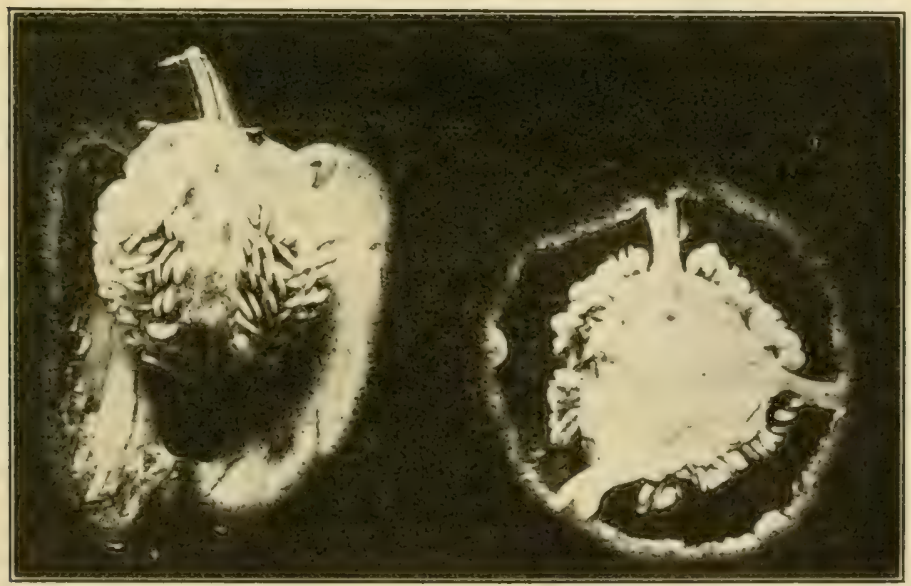

FIG. 242.-Cross and lengthwise sections of the fruit of pepper (Capsicum annuum). 
Geographical.-- Thi- species has never been found wild. But it is quite well established that the entire genus (apsionm had its origin in tropical America.

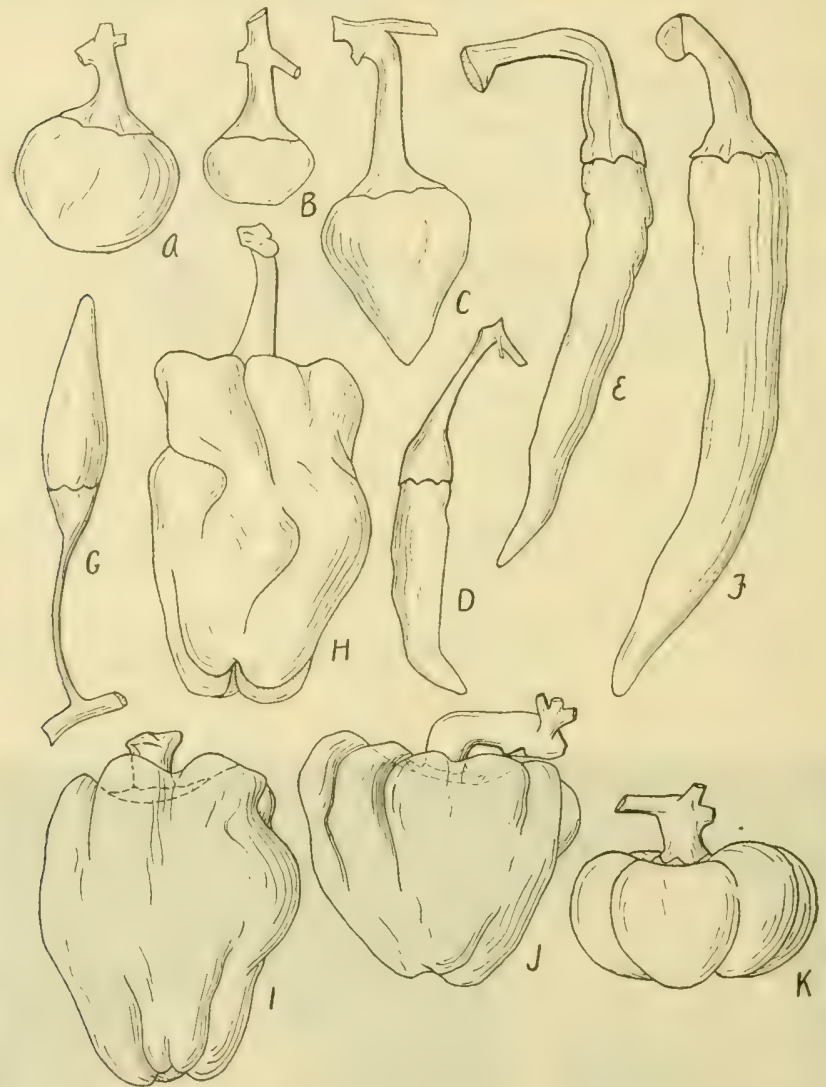

FIG. 243.-Fruits of peppers (Capsicum annuum). A, Oxheart (C. annuum cerasiforme); $B$, Cherry (C. annuum cerasifera); $C$, Celestial (C. annuum abbreviatum); $D$, Chilli (C. annuum acuminatum); $E$, Long Cayenne (C. annuum acuminattum); $F$, Long Yellow (C. annuum longum); $G$, tabasca (C. annuum conoides); $H$, Sweet Spanish (C. annuum grossum); $I$, Ruby King (C. annuum grossum); $J$. Bell (C. annuum grossum); $K$, Squash (C. annuum grossum). (After Irish.)

The temperature requirements of peppers are similar to those of eggplants and tomatoes. Their season of growth is so long that they are unable to 
produce a full crop before frost, except in the Southern States, unless started under glass.

Other Species. The only other species of (itpsicum of any importance is C. frulescens. This is a shrubby perennial o to 10 feet high. Its fruit does not ripen well in northern latitudes. The fruit is reel, small, and is often called "bird pepper."

Types.-Irish, in his excellent monograph of the genus Capsicum, places the numerous commercial varieties into seven types or botanical varieties (Fig. 243). The following key to these types is taken (verbatim) from this work.

\section{Key to Botantcal Varieties of Capsicum Annuum}

Fruit oblong-linear.

Calyx usually embracing base of fruit.

Fruit usually less than $1,1,2$ inches long; peduncles about as long or longer,

C. annum conoides (Coral Gem, Tabasco, Cayenne, Orange-red Cluster).

Fruit usually more than $1 / 2$ inches long; peduncles shorter.

Leaves and fruit fascicled; fruit erect, C. anmum fasciculatum (Red Cluster, Yellow Cluster).

Leaves and fruit not fascicled, C. annuum acuminatum (Chilli, Long Cayenne, Nepal Chili).

Calyx not usually embracing base of fruit, except in the Ivory Tusk variety, C. annuum longum (Black Nubian, Long Red, County Fair, Cardinal, Long Yellow, Ivory Tusk).

Fruit oblate or oblong, truncated, deeply lobed, furrowed and wrinkled; flesh mild, $1 / 12$ to ${ }^{1} 8$ inch thick, C. annuum grossum. (Monstrous, Sweet Spanish, Bell, Sweet Mountain, Golden Dawn, Ruby King, Brazilian Upright, Golden Upright, Squash).

Fruit subconical, ovate or elliptical, slightly longer than broad, ${ }^{3}+$ to 2 inches long; calyx not embracing base, C. annum abhrevialum (C'elestial, Etna, Kaleidoscope, Red Wrinkled, Princess of Wales).

Fruit generally smooth, oval, spherical, cherry or heart-shaped, $3^{3} s^{\prime}$ to $1^{1}, 2$ inches in diameter; calyx seated on the base, $C$. anmunm cerasiforme (Little Gem, Cherry, Oxheart).

Composition.-All varieties of pepper are more or less pungent. The principle which imparts the pungent taste is a crystalline nitrogenous compound called capsaicin. In the smaller peppers (Coral Gem, Tabasco, Chilli, Cayenne 
Cherry) the pungency is in the pericarp as well as in the placenta and seed. In larger varieties (Squash, Bell, Sweet Mountain), the pungent taste is located for the most part about the seeds, while the fleshy pericarp is "mild."

Uses.-Medicinally, the red pepper is used in a great variety of ways. Probably its most important use is as a condiment, Cayenne Pepper being the common form. This is made by grinding up the entire fruit to a fine powder. Pepper sauce is the unground fruit preserved in brine or strong vinegar. Tabasca Pepper and Tabasca Catsup are examples of this. Chilli con carne is a mixture of small, finely ground peppers and meat. Peppers are commonly used in tamalas, also in pickles and salads, while bell-shaped and squash varieties are used as mangoes. Some varieties. such as Little Gem and Prince of Wales, are grown for ornamental purposes.

\section{NICOTIANA (Tobacco)}

Habit.-Most representatives of this genus are tall, stout herbs. Several (as $N$. glauca and $V$. tomentosa) grow to a height of Io feet or more. S. wigandioides is half-shrubby. They are annual or perennial in habit, and for the most part sticky-pubescent; they have a strong odor, and narcotic. poisonous properties.

Leaves.-The leares are simple, alternate, mostly large, entire or wavy along the margin, petioled (in $N . g l u u c a$ ), or sessile and decurrent.

Inflorescence and Flowers.-The inflorescence is a terminal raceme or panicle. The flowers are large and vary in color: white, yellowish, yellowish-white, greenish, purplish, or rose. The calyx is synsepalous, five-cleft, and usually persists in the fruit. The corolla is salverform or funnelform, fivelobed, and the tube is longer than the limb. There are five 
stamens attached to the corolla tube; the filaments are slender, and the anthers split lengthwise. The two-celled ofery' bears a single, slender style, and a capitate stigma.

Fruit.--The frut is a two-celled capsule bearing numerous very small seeds; it splits into two or four valres at maturity.

Geographical Distribution and Economic Importance... 'The genus includes about 50 species. mostly of the American tropics. A number of species are grown for ornamental purposes. Y.tabacum (tobacco) is the only one of great commercial importance.

\section{NICOTIANA TABACUM (Tobacco)}

Habit, Roots, Stems.- The common tobacco is a strong annual plant, 3 to 5 feet tall. The root system is quite extensive and fibrous. 'The American varieties bear large. thick stems which are hairy and sticky. In tobacco culture it is customary to "top" the plants, that is. remore the flower stalks, so that a considerable portion of the food supply which would normally go to flower and fruit production mag be directed to leaf growth. Topping stimulates the production of "suckers" (new shoots). They must be removed before reaching any great size, as the quality of the leaves is damaged by their growth. "The "one-sucker" type of tobacco is one that throws out one or only a few suckers.

Leaves.- There is great variation in the shape, color, texture, and number of leares. In cigar-wrapper tobaccos, the leaves are thin, fine in texture, and small-veined. The leaves of plug and pipe tobaceos are usually coarser, thicker, and tougher. The leaves are sessile, decurrent, and rither narrow or broad, most commonly lanceolate or ovate, and pointed. The number of leares on a plitnt, which is, of course, important commercially, is diferent in the rarious typer and also varies considerably from plant to plant in the 
sime type. In the Sumatra cigar-wrapper tobacco the leaves range from 16 to 30 , in the White Burley plug tobacco from ro to 18 , and in the Zimmer Spanish cigar-filler tobacco from I4 to 20.

Tobacco plants are sometimes grown in the shade of tents, which condition makes a larger and thinner leaf with less vascular tissue. The leaf is thus improved for wrapper purposes. The chief effect of shade is to reduce the rate of transpiration. There is evidence that transpiration rate is the important factor determining the development of vascular tissue.

"Grain" in Tobacco Leaves.- "Grain" of tobacco appears as small pimple-like projections or papilla over the cured leaf. The papilla vary in size from about I millimeter to microscopic dimensions. Each grain body consists of from one to sereral leaf cells filled with crystalline substance. The grain is composed chiefly of calcium, with some potassium and magnesium, in combination with citric and malic acids. Grain of tobacco is developed during the process of curing and fermentation. It is a character that the buyer takes into consideration when he selects tobacco.

Inflorescence and Flowers.- The inflorescence is a terminal panicle. The flowers (Fig. 244) are about 2 inches long, and pink, yellow, purple or white. The tubular or bell-shaped cal yx is four- to five-cleft. The tube of the corolla is swollen. its lobes spreading and pointed.

Pollination and Fertilization.- 'Tobacco flowers bear nectaries and are risited by insects. Hence, cross-pollination is probably somewhat frequent. Noreover, observations and experiments show that the flowers are self-fertile-that they will produce viable seed when close-fertilized. The earlier blossoms of an inflorescence are more commonly close-fertilized than are the later ones of the same inflores- 
cence. That the tobaceo plant is, in all probalsility, naturally close-fertilized, is borne out by the fact that self-fertilization (inbreeding) under control has not resulted in a loss of vigor.

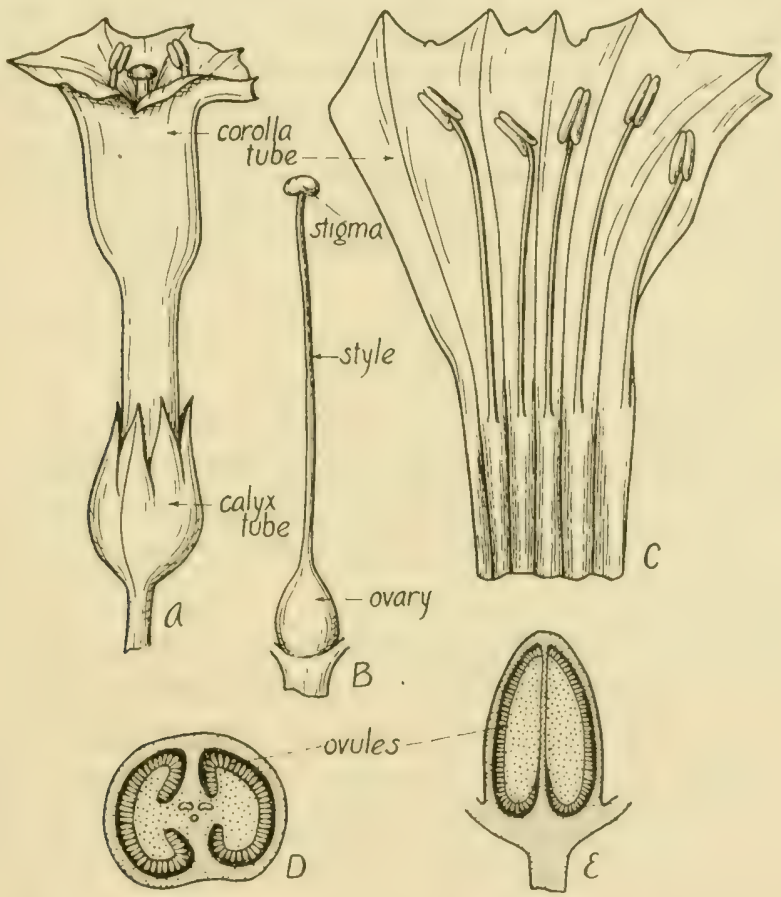

FIG. 244.-Tobacco (Nicotiana tabacum). A, flower; $B$, pistil; $C$, corolla cut open and spread out flat; $D$, cross-section of young fruit; $E$, lengthwise section of young fruit. (After Strasburger.)

Fruit.-The fruit (Fig. 24t) is a two- to four-valved cap)sule, bearing numerous small seeds. A single plant may produce as many as a million seeds.

Geographical.-This species is indigenous to tropical South America. Its varieties are now in cultivation throughout subtropical and even tempcrate climates. It occasionally escapes from cultivation and runs wild. It is grown commercially only in the humid sections of this country. 
Closely Related Species.--There are a number of species of Nicotiana which resemble $N$. tabacum somewhat, and there are several species belonging to other genera besides Nicotiana that go by the name "tobacco."

A. rustica is a "wild tobacco" that was cultivated by the Indians. It is a tall annual with petioled leaves. $N$. quadrivalvis is another plant cultivated by the Indians for tobacco. It is native to the region extending from Texas to California and Oregon. N. persica yields Persian tobacco. "Australian tobacco" is the leaf of Duboisia hoprioddii, a species of Solanacce. "Indian" or "wild tobacco" is a name often given to Lobclia inflata, the dried leaves and tops of which are officinal. It is a member of the bellfower family, Campanulacea. Arnica alpina, a composite, is sometimes known as "mountain tobacco." The most popular ornamental Nicotiana is $N$. alata. In it the flowers are white, open at night and closed in the daytime.

Types and Varieties.- There are two general types of tobacco grown in this country:

I. Cigar lype, the leaves of which are made into cigar wrappers, binders and fillers. The leaves are thin and of fine texture. Common varieties are Sumatra, Connecticut Havana, Connecticut Broadleaf, Cuban, Zimmer Spanish, and Little Dutch.

2. Export and manufacturing type, the leaves of which are used to make smoking tobacco, chewing tobacco, cigarettes, and snuff. The leaves, as compared with those of the preceding type, are thicker, tougher, and of coarser texture. Popular varieties are White Burley, North Carolina Bright Yellow, Maryland Smoking, Yellow Mammoth, Pryors and Orinocos. Export and manufacturing tobaccos are produced on soils and in sections of the country different from the cigar types. The physical and chemical properties of the soil have a marked influence on the quality of the tobacco leaf. Light, well-drained soils, in which there is not too much organic matter, produce a leaf of mild flavor and fine texture. On the other hand, heavy, rich soils produce a leaf of stronger flavor and coarser texture.

Composition.-The tobacco plant is a heavy feeder. It 
removes large quantities of nitrogen, potash, and phosphoric acid from the soil. Consequently, the plant is rich in these valuable plant nutrients. In fact the leaves and stalks make excellent fertilizers, and are so used in tobaccosections.

Curing Tobacco.- This process consists in removing the moisture in the leares and stems in such a manner ats to produce a uniform color and texture in the leaves. Artilicial heat was first employed in the curing of tobaccos in I 812. Wood fires were used up to the year I $S_{2} S$, about which time, flues, and charcoal fires came into use. Flue-curing entirely replaced charcoal fires in 1865 . Flue-curing produces a bright yellow leaf. The green tint is obtained by harvesting the leaf before it is fully ripe. The dark export tobaccos are cured with open hard-wood fires. Light tobaccos may be air-cured, and such are used for pipe smoking. and cigarettes. White Burley tobacco, so highly prized for twist and plug chewing tobaccos, is usually air-cured. The yellow and mahogany tobaccos are cured by flues. The process takes about four days. The broad leaf and Havana seed leaf varieties of the Connecticut Valley are air-cured. They are domestic cigar tobaccos. Curing is often carried on in specially constructed barns with horizontal ventilators. It usually takes about two months to air-cure tobacco, and less time if artificial heat is used. After the leares hare been left hanging for a long time, they are packerl closely in boxes. where they are left undisturbed for several months. When warm weather sets in, a process of fermenlation is set up in the cases, during which process certain important changes take place. Fermentation may be brought about after a shorter period of drying than is used in the preceding method, by placing the leaves in piles in a warm. moist atmosphere. When the temperature reaches $125^{\circ}$ lo $1,30^{\circ} \mathrm{F}$. the piles are opened and heaped up again. The piles are 
thrown down and remade a number of times, until the leaves are ready for the market. During the fermentation the leaf undergoes a number of changes such as a decrease in nicotin, an increase in alkaline reaction, in ammonia, and nitrate, a loss of water and sugar, and a change in the texture, color and flavor. It is not known positively whether fermentation is a result of oxidation by free oxygen of the air, or of bacterial activity, or is due to the action of enzymes.

The Tobacco Industry.-From colonial days the tobacco industry has been an important one in this country. It is interesting to note that tobacco was made legal tender in 1732 in Maryland, where a pound was I penny, and where it was used for the "payment of all debts, including customs, dues, salaries of State officers and ministers of the gospel." In 1777 the tax levy for the county and city of Baltimore was I72 pounds of tobacco per poll.

Virginia and Maryland were long the only tobacco-producing States. The industry has now spread to other States, and the production in $19{ }_{5} 5$ is shown in the following table:

Tobacco: Acreage, Production, and Total Farar Value, Br States, I9I5

State

Kentucky

North Carolina.

Virginia.

Ohio.

Tennessee.

Pennsylvania.

South Carolina............

Wisconsin.

Connecticut.

Maryland.

All other States

United States..
Acres

440,000

320,000

I $92,50 \mathrm{C}$

93,700

92,900

31,400

65,000

4I, 000

22,200

22,000

47,700

I, 368,400
Pounds

$356,400,000$

I $98,400,000$

I $44,375,000$

$84,330,000$

$69,675,000$

42,390,000

$37,700,000$

$36,900,000$

29,907,000

I $6,280,000$

$44,030,000$

I, $060,387,000$
Farm value

Dec. I,

dollars

$23,799,000$

22,221,000

I $3,57 \mathrm{I}, 000$

$7,590,000$

4,990,000

$3,900,000$

2,639,000

$2,214,000$

3,095,000

$\mathrm{I}, 384,000$

I $2,638,000$

$96,041,000$ 
The United States leads all other countries in the production of tobacco. In I9I4, Japan ranked second to the United States, but its output was only about ro per cent. of that in this country.

\section{References}

Applam, C. 'O.: Physiological Behavior of Enzymes and Carbohydrate Transformations in After-ripening of the Potato Tuber. Bot. Gaz., 52: 306-315, I9II.

B.raxes, J.: The Potato (Solanum Tuberosum): Its History, Microscopical Characters, and Structure. Ann. Rep. Trans. North Staffordshire Field, cl, I902-03, pp. 96-106.

Bernard, Noel: Sur la tuberculization de la pomme de terre. Compt. Rend. Acad. Sci. (Paris), r32: 355-357, I901.

Bfrthatlt, PifrRe: Recherches botaniques sur les varieties cultivees du Solanum tuberosum et les especes sauvages de Solanum tuberiferes voisins.

Ann. Sci. Agron., 28: I-59, 87-143, I73-216, 248-29I, Paris, I9I т.

Fitch, C. L.: Productiveness and Degeneracy of the Irish Potato. Colo. Agr. Exp. Sta. Bull. I76: I-r6, I9ro.

Indentification of Potato Varieties. Ia. Agr. Ext. Dept. Bull. 20: I-32, I94.

Fletcher, S. W., and Grfag, O. I.: Pollination of Forced Tomatoes. Mich. Agr. Exp. Sta. Spec. Bull. 39:2-10, I907.

Pollination of Forced Tomatoes. Mich. Agr. Exp. Sta. Spec. Bull. 39 : 294-301, 1907.

G.dBLE, C. H.: 'The Wild Tomato. Jour. Hered., 6:'242, I9r5.

(illinore, Jom $\mathbb{W}_{\text {.: }}$ Quality in Potatoes. Cornell Agr. Exp. Sta. Bull. 2,30: $503-525,1905$.

(sundspen, T. H.: Parthenogenesis, Parthenocarpy and Phenospermy in Nicotiana. Univ. Calif. Pub. Bot., 5: 249-272, I9I5.

Hatstead, B. B.: Notes upon Stamens of Solanacex. Bot. Gaz., 15: 103I06, I890.

Heckil, F.. Sur l'origine de la pomme de terre cultivee et sur les mutations gemmaires culturales des Solanum tuberiferes sauvages. Ann. Fac. Sc. Marseille, 1907, $82 \mathrm{pp}$.

Irisir, H. C.: A Revision of the Genus Capsicum with Especial Reference to Garden Varieties. 9th Ann. Rep. Mo. Bot. Gard., 53-IIo, 1898.

Joxis: Doxiln F.: Natural Cross-pollination in the Tomato. Science, n. s., 43: 509-510, I9I6.

Kimat, f: l̈ber den lsau und die Entwickelung der Solanacenfruchte. Berlin, 1907. 
Matrou, II.: Symbiosis and Tuberization in Potato. Compt. Rend. Ararl. Sci. (Paris), I58: 50-53, I9I4.

Midmeton, R. Morton: Solanum Tuberosum L., and Its dllies. Jour. Bot., 47:228, r909.

ReED, T.: The Anatomy of Some Tubers. Ann. Bot., 24: 537-548, igro (Potato and Jerusalem artichoke).

Rendle, A. B.: Production of Tubers within the I'otato. Jour. Bot., $3 \mathrm{I}$ : 193-195, I893.

Rigdway, Charles S.: (irain of the Tobacco Leaf. Journ. Igri. Research. 7: 269-288, 1916.

Strwikt, F. C.: Observation on Some Degenerate Strains of Potatoes. N. Y. Agr. Exp. Sta. Bull. 422: 319-357, I916.

STrart, Willian: Group Classification and Varietal Descriptions of Some American Potatoes. U. S. Dept. Agr. Bull. I76: I-56, I9I5.

Wiтtacack, L.: Die Stammptlanze unserer Kartofïl. Landw. Jahrl)., js: 55I-605, I909.

Studien über die Stammpflanze der Kartoffel. Ber. Bot. Gesell., 27: 2S42 , I909. 


\section{CHAPTER XXXIX \\ CUCURBITACE $\mathbb{E}$ (Gourd Family)}

There are about 650 species of cucurbits, mainly in tropical regions. All cultivated cucurbits are easily injured by frost, and are distinctly warm season crops.

A number of species are of economic importance. Chief of these are the pumpkin, squash, watermelon, muskmelon, and cucumber. The wild cucumber (Echinocystis lobata) and the star cucumber (Sicyos angulutus) are sometimes planted as ornamental vines. The squirting cucumber (Ecballium claterium) is a fleshy herb containing a cathartic and poisonous principle, elaterin, the main ingredient of elaterium.

Habit.-The members of this family are commonly known as "cucurbits." The majority of them are annual, climbing or trailing herbs, with tendrils, but often reaching a large size.

Stems and Leaves.- The stems are hollow and usually covered with stiff hairs. The leaves are large, alternate, petioled, heart-shaped, palmately lobed or dissected. The tendrils arise as a rule in the axils of leaves. The same tendril may be dextrorse and sinistrorse at different points along its axis and may be simple or forked.

Flowers.-The flowers (Figs. 246 and 247) are axillary, either solitary, paniculate, or rarely racemose or subumbellate. They are monœcious or diœcious, commonly white or yellow, rarely blue or red. The calyx forms a tube which is adnate to the inferior ovary; its limb is tubular or campanu606 
late, and usually hats live imbricated lobes. 'The corolla is livelobed, usually sympetatous, sometimes parted to the batse, inserted on the limb of the calyx, and rotate or campanulate. The stamens (Fig. $2+7$ ) alre fire in number, but they often grow

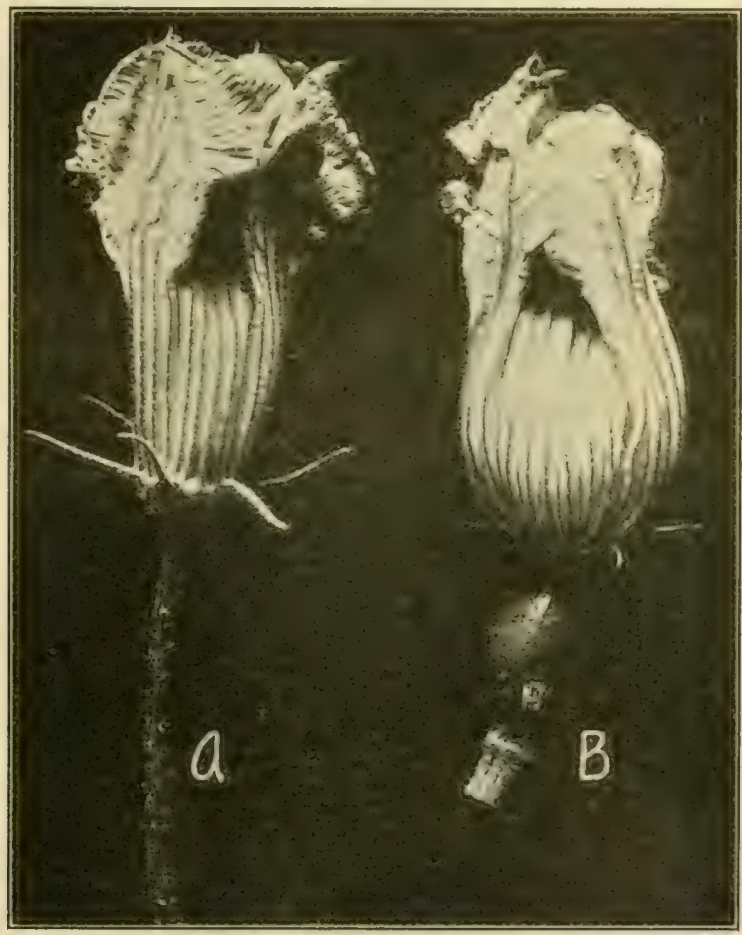

Fig. 2f6.-Field pumpkin (Cucurbita pepo). A, staminate flower; $B$, pistillate flower.

together so that there are apparently three. In case there are three stamens, two of them are broader than the third; the two broad stamens have two-celled anthers, the other has a one-celled anther, thus making in all five anther cells to the androecium. 'The filaments are short, often united, and 
tipped by the worm-like pollen sacs. 'The owary (Fig. 248) is inferior, one- to three-celled, and usually has numerous seeds in each cell or locule; the style is terminal, simple or lobed.

Fruit. The fruit is a pepo, usually indehiscent, or in some

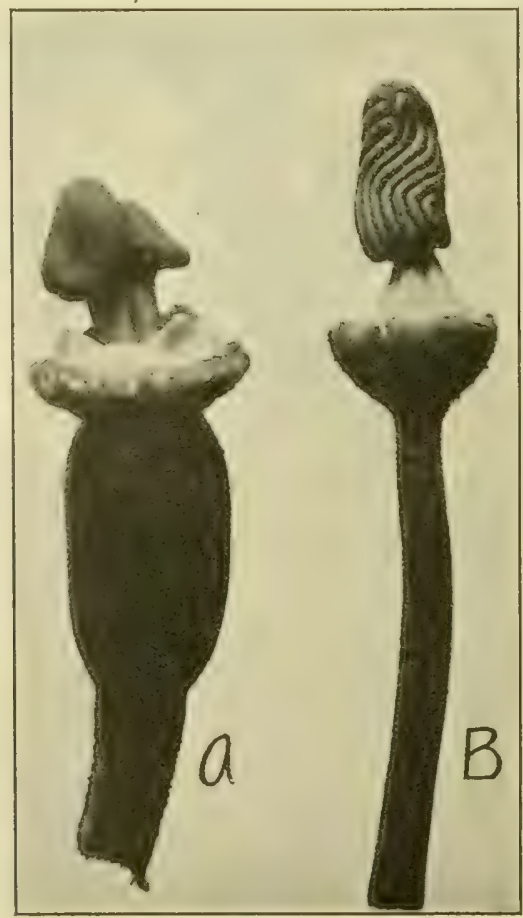

FIG. 247.-Field pumpkin (Cucurbita pepo). A, pistillate flower; $B$, staminate flower; both with perianth removed.

cases (Micrampelis, (yclanthera) dehiscent at the apex or bursting irregularly. In many instances (watermelon. pumpkin, squash), the fruit is of enormous size. The outer part of the fruit is receptacle which has become attached to the exocarp. The flesh of the fruit is chiefly mesocarp and 


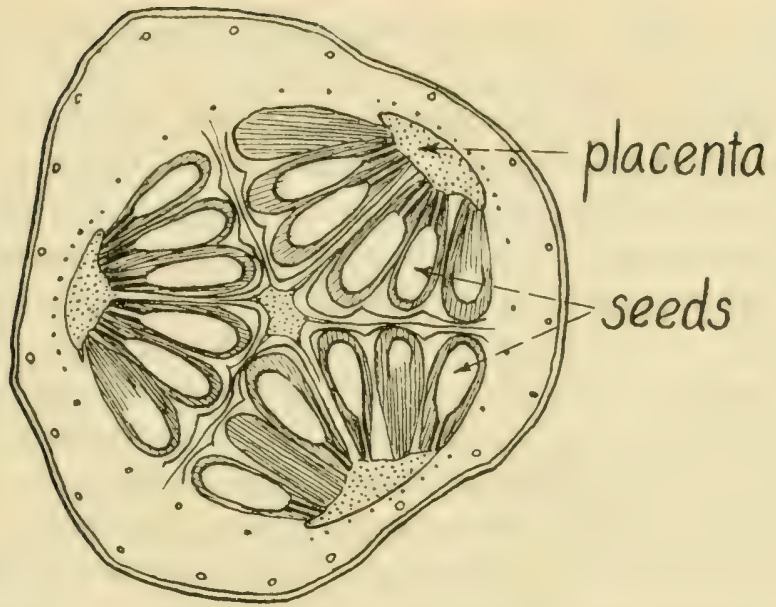

FIG. 248.-Cross-section of mature fruit of cucumber (Cucumis sativus).

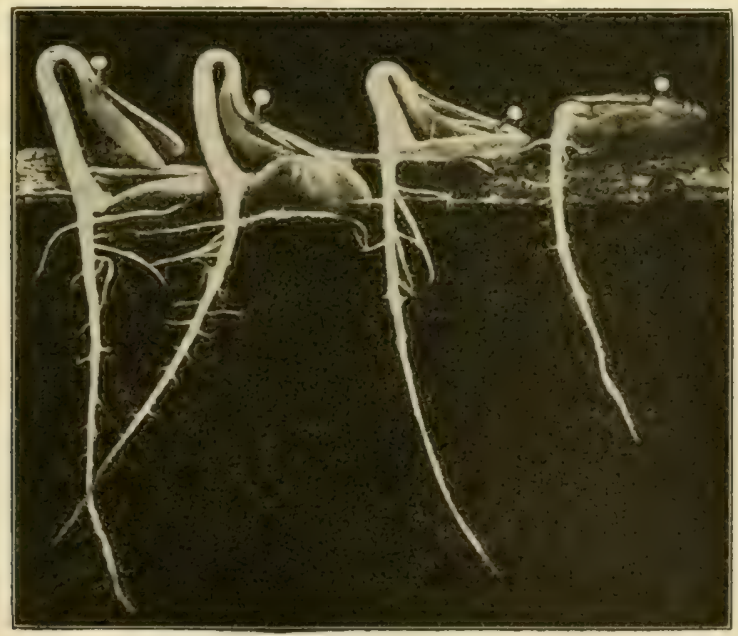

FIG. 249.-Germination of pumpkin (Big Tom) sceds, showing the pegs functioning in the removal of the coats. (After Crocker, Knight and Roberts.) 
cndocarp. Seeds are usually abundant, flat, and without endosperm.

Germination of Cucurbit Seeds.-The cotyledons are epigean in.all the common members of the Cucurbitacex. There are a few hypogean forms, such as Megarhiza californica and Sicyosperma gracilis. The first portion of the seedling to appear above ground is the hypocotyl, which emerges as an arch (Fig. 249). At the base of the hypocotyledonary arch, there is developed a peculiar outgrow th known as the "peg." It is a natural part of the plant, and although it varies somewhat in size in different cucurbits, it has been shown that gravity has no direct effect in increasing peg development or in determining its lateral placement on the hypocotyl. The peg serves to hold the seed coat while the hypocotyl withdraws the cotyledons from the coat. It will be noticed (Fig. 249) that one edge of the seed coat is caught against the peg.

Key to Principal Genera

Corolla rotate or campanulate, five-parted to or almost to the base.

Tendrils often two to three times branched, Citrullus (watermelon, citron).

Tendrils simple, Cucumis (muskmelon, cantaloupe, cucumber).

Coroll a campanulate, five-lobed to or little below middle Cucurbita (gourd pumpkin, squash).

\section{CUCURBITA (Squash, Pumpkin, Gourd)}

Stems, Leaves, Flowers.-Members of this genus are annual, prostrate bushy or trailing vines with rough stems which have a tendency to root at the nodes. The tendency is particularly marked in the long-running varieties of squashes (Turban, Marblehead, Canada Crookneck, Field Pumpkin). The tendrils are branched. The leaves are usually cordate at the base, lobed (C. pepo), or not lobed (C. maxima). The flowers are always solitary in the axils of the leaves, yellow, and monocious: In squashes with a bushy habit 
(early squashes), the staminate flowers are on long peduncles. while the pistillate flowers occur near the base of the plant on comparatively short peduncles. In the longrumning squashes (fall and winter types), the staminate flowers are borne near the center of the plant on long perluncles, while the pistillate occur some distance from the roots, on comparatively short stalks. The flower stalks (peduncles) may be strongly ridged (as in C..pepo and C. moschata) or comparatively smooth (as in C.maxima). In the staminale flowers, the calyx tube and corolla are campanulate and five-lobed; the stamens are three in number, inserted on the calyx tube, the filaments are free, and the anthers large, linear, and more or less united; the ovary is rudimentary. In the pistillate flowers, the calyx and corolla are as described above; the stamens are rudimentary (three staminodia commonly present), pistil one, ovary oblong with three to five manyoruled placenta, style short and thick, and stigmas three to five, each two-lobed and papillose. There are always many more staminate flowers produced than pistillate.

Pollination and Fertilization.-The squashes and pump)kins are usually insect-pollinated. It has been shown that the varieties of $C p c p o$, including the common Crookneck, Scallop, and Pineapple squashes, and the common field pumpkin, will readily cross with one another. However, the above will not cross with varieties of (. maxima, including Hubbard, Marblehead, 'Turbans, and Mammoth Chili and Valparaiso pumpkins. These latter will cross with one another. Varieties of C. moschata will not cross with either of the above species. Cucurbita species do not cross with melons and cucumbers. Squashes and pumpkins ordinarily do not reach any considerable size unless the ovules are fertilized.

Mature Fruit.-The mature fruit is a pepo. In the 
'Turban squashes, the receptacle does not extend over the top of the ovary, while in most other sorts, it is entirely closed at the top. The pericarp is fleshy.
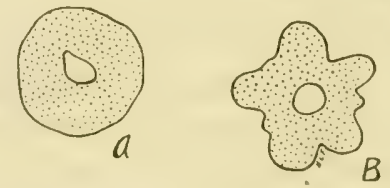

FiG. 250.-A, cross-section of squash (Cucurbita maxima) fruit stalk; $B$, same of pumpkin (Cucurbita pepo).

Geographical.--The genus Cucurlifa has about ro species, natives of tropical America, Asia, and Africa.

\section{Key to Important Species of Cucurbita}

Leaves lobed; stalks of fruit strongly ridged (Fig. 250, B).

Calyx lobes narrow, peduncle not enlarged next to the fruit (Fig. 25 I, B),

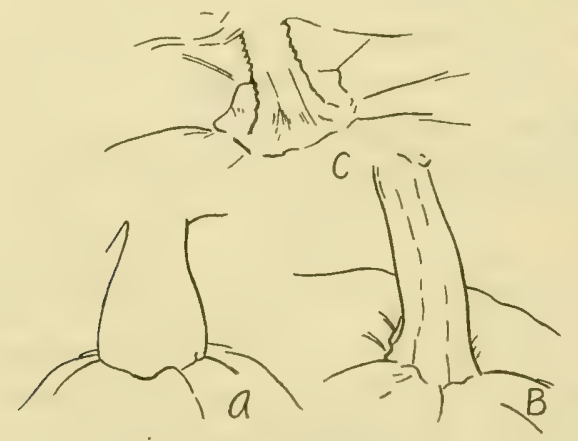

FIG. 25I.-A, fruit stalk of Cucurbita maxima; $B$, of C. pepo; $C$, of C. moschata. (After Bailey.)

Cucurbita pepo (pumpkin, scallop, gourd).

Calyx lobes broad, peduncle much enlarged next to the fruit (Fig. $25 \mathrm{I}, \mathrm{C}$ ), C. moschata (Canada Crookneck and Cushaw).

L.eaves not lobed; stalks of fruit not prominently ridged (Fig. 250, 1), Cucurbila mavima (Marblehead, Turban, Hubbard squashes, etc.). 


\section{CUCURBITA PEPO}

Description.--This is an annual species, with long, running stems; in the so-called "bush-pumpkins," which include the scallops (patty-pans or cymblings) and summer or crookneck squashes, the plants are more compact. The leares are three- to five-lobed. The calyx lobes are narrow. The peduncle is not enlarged next to the fruit. The frutt varies much in size and shape.

Origin.- There is a question as to the origin of the pumpkin. It is considered by some to be of American origin, as it was cultivated by the Indians at the time America was discovered. However, it is claimed by others that its original home is southern Asia.

Types and Varieties.-Cucurbita pepo includes the following groups:

Plants with long, running stems, Truc ficld pumpkins (Connecticut field and Mammoth are common varieties).

Some of the vegetable marrows have long, running stems, while others have a bushy habit. As a group they are relatively unimportant.

Plants bushy, Summer squashes, crooknceks. In these the neck is decidedly crooked and narrow, the distal end is swollen but terminating in a point, the skin is orange-colored and covered with many round excrescences.

Scullop or patty-pan vitutics. These are also known as custard marrows, and in the South as cymblings. The leaves are large, entire, and very slightly five-lobed; the fruit is much broader than long, the edge coarsely scalloped; the flesh is solid and floury; the skin is smooth and of various colors. The pineapple summer squashes are oblong-conical varieties.

Plants with slender, running stems; leaves lobed; fruit small, hard, not edible. of various shapes, Gourds (in part) (C. pepo var. ovifera).

Not all "gourds" belong to the species ('ucurbitu pepo. In addition to this species, they are also referred to Lagenaria sulgaris, Luffa. Cucumis dipsaceus. C'ucumis anguria, and Benincasa cerifera. 


\section{CUCURBITA MAXIMA}

Description.-'This is an annual plant with long, running, cylindrical, somewhat prickly (not spiny) and hairy stems. The leares are large, not lobed, except on young shoots. The peduncles are smooth, i.e., not ridged. The calyx tube is not ribbed. The corolla tube is of equal diameter throughout, the lobes curved outward. The fruit varies in shape and size, but unlike representatives of the preceding species, it never has a light color or a crookneck or bears warty excrescences; the peduncle is not much enlarged next to the fruit.

It is quite agreed that this species is of American origin.

Type and Varieties.-Representatives of the species $C$. maxima are late maturing, as a rule, and hence are quite generally known as "winter squashes." The principal types are as follows:

I. Turban Squashes.-The fruit has the appearance of a turban or "Turk's-cap." This is due to the failure of the fleshy receptacle to completely cover over the ovary, and hence the latter protrudes, forming a fruit the character of which suggests the expression "squash within squash."

2. Hubbard Squashes.-These are the most popular squashes in the Northern States. They are broadly pearshaped, or olive-shaped with very thick, hard, dark green skin and dark yellow, floury flesh. There are varieties of the Hubbard (Red or Golden Hubbard) with orange-red skin.

3. Marblehead Squashes.--These have a gray skin. Otherwise they resemble the Hubbard squashes.

4. Marrow Squashes.-There are a number of varieties of these, only a few of which are very well known. Most of them have a smooth skin and a very floury flesh. The Boston Marrow, a variety with orange-colored skin and flesh, is the best known in the United States. 
5. Mammoth Pumpkins and Squashes.-- These are the largest of the squashes. Some varieties (Mammoth Whale squash, Valparaiso squash, Mammoth pumpkin) attain a diameter of $\mathrm{I}$ to 2 feet and a weight of 100 to 200 pounds. The Mammoth pumpkins are strongly flattened at the ends, while the mammoth squashes are longer than broad, and oblong or narrowly oval in shape.

\section{CUCURBITA MOSCHATA}

Description.-This is an annual with long, running, hairy (never spiny) stems which readily root at the nodes. The leaves are lobed, dark green and with whitish blotches here and there. It is said that these whitish areas are due to a thin layer of air beneath the epidermis. The calyx is deeply lobed. The corolla widens upward. The peduncle is angular, deeply ridged, and swollen where it joins the fruit. The flesh of the fruit usually has a musky flavor.

The species is said to have originated in Eastern Asia.

Types.-The principal types belonging to this species are:

I. Canada Crookneck or Winter Gourd.-The plants are small; the fruit is also rather small, smooth and crooknecked.

2. Cushaw.-This is the "pie pumpkin" or squash of the South and Southwest. It is a crook-necked type of squash, the skin of which may be white, yellow, or striped.

\section{CUCUMIS (Muskmelon, Cantaloupe, Cucumber)}

Stems, Leaves, Flowers.-All of our common species are hispid or rough, trailing, annual herbs. The tendrils are simple. The leaves are simple, palmately three- to five-lobed or dissected. The flowers are monocious. Rane finds that some varieties of muskmelons possess perfect flowers. For 
example, out of 95 varieties examined, 85 had perfect flowers, and only i I had imperfect flowers.

The slaminate flowers are in small clusters, or rarely solitary. The calyx tube is turbinate or campanulate, and its limb five-lobed. The corolla is campanulate, deeply fivelobed or five-parted, the lobes acute. The three stamens are
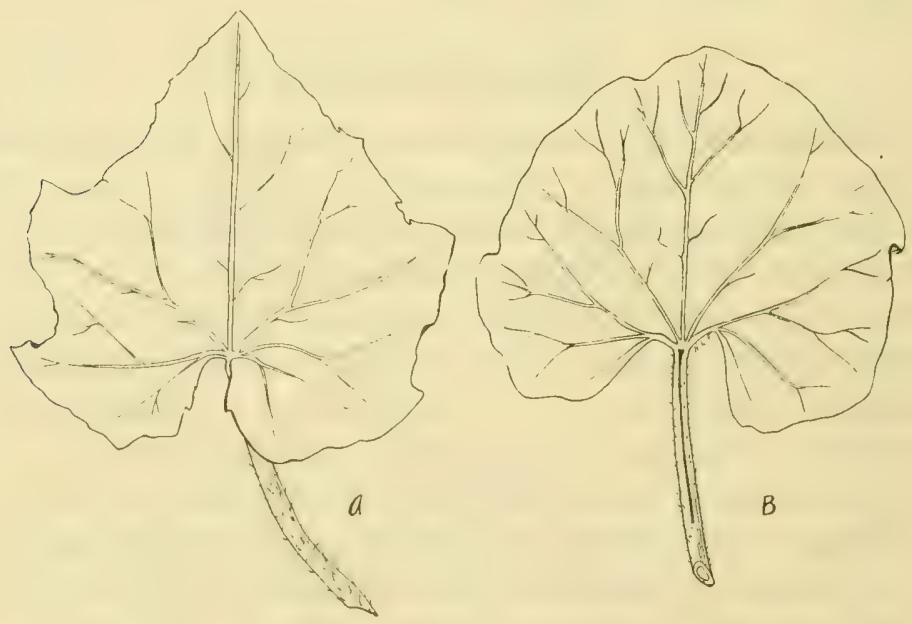

FIG. 252.-Leaves of $A$, cucumber (Cucumis sativus) and $B$. muskmelon (Cucumis melo). $\times 3 / 2$.

separate, with short filaments and oblong anthers. The ovary is rudimentary.

Pistillate flowers are solitary. The calyx and corolla are similar to those described above. The ovary is ovoid or globose, with three to five placenta; the style is single and short, the stigmas obtuse, three in number, and the ovules numerous. The fruit is a pepo varying in shape, size, surface characters, and physical and chemical composition.

Pollination.-Griffin gives data with reference to pollination and fruiting of the cantaloupe. He kept an account of 
the number of flowers produced on each of six vines, from June 27 to July I3, at which latter date the vines became indistinguishable from each other. His data are as follows:

\begin{tabular}{|c|c|c|}
\hline Date & $\begin{array}{l}\text { Number } \\
\text { Staminate }\end{array}$ & $\begin{array}{l}\text { of flowers } \\
\text { Pistillate }\end{array}$ \\
\hline June $27 \ldots \ldots \ldots \ldots \ldots \ldots$ & 203 & $\mathbf{I}$ \\
\hline June $30 \ldots \ldots \ldots \ldots \ldots$ & 338 & II \\
\hline July $3 \ldots \ldots \ldots \ldots \ldots \ldots$ & 474 & 28 \\
\hline July $7 \ldots \ldots \ldots \ldots \ldots \ldots \ldots$ & 755 & 95 \\
\hline$\ldots \ldots \ldots \ldots \ldots$ & 660 & 87 \\
\hline July $\mathbf{~} 3 \ldots \ldots \ldots \ldots \ldots \ldots \ldots$ & 645 & $3 \mathbf{I}$ \\
\hline Total.................. & 3,075 & 25.3 \\
\hline Average to each vine........ & 512 & 42 \\
\hline
\end{tabular}

Vines continue to bloom profusely until late in August in the locality (Rocky Ford, Colorado) where data were obtained. Here, melons may ripen that are set as late as the middle of August; it takes about six weeks for one to mature. Twenty ripe melons per vine is a good crop. In all Cucumis species, the staminate flowers are more numerous and appear earlier than the pistillate ones. Pollination is carried on by insects. Ordinarily, lack of fertilization causes a premature dropping of the fruit, and incomplete fertilization results in misshapen fruit.

Geographical.--There are close to 30 species of Cucumis, most of them belonging to tropical Asia, Africa, and the East Indies.

\section{Key to Principat. Species}

Iruit smooth, not spiny or tuberculate at maturity, C'ucumis melo (muskmelon, cantaloupe, melons).

Fruit spiny or tuberculate at maturity.

Stems (cultivated) 6 to 15 feet long; fruit 6 to 12 inches long, ('utumis sativus (cucumber).

Stems 3 to 6 feet long; fruit a to I 1.2 inches long, C'ucumis anguria (prickly. cucumber, West Indian gherkin, Jerusalem cucumber, gooseberry gourd). 


\section{CUCUMIS MELO (Muskmelon, Cantaloupe, Melons)}

Description.- This is a hirsute or rough annual herb with prostrate stems. The leaves are subcordate, with somewhat rounded angles. The flowers are monocious, or in some varieties the pistillate flowers are with stamens. The fruit varies in shape and size.

Cucumis melo is considered to be a native of southern Asia.

Botanical Varieties of Cucumis melo.--Naudin has monographed the species ('ucumis melo, and according to him, it is divided into a number of botanical varieties, races, or groups which can be fertilized by each other. The principal ones are as follows:

I. Netted Melons (Cucumis melo var. reticulatus).-To this group belong the common muskmelons. These usually have a netted skin, sometimes almost smooth. All of them are shallow ribbed melons, the flesh of which may be green- or salmon-tinted (Jenny Lind, Emerald Green, Netted Gem, Rust Resistant Pollock, Ironclad, Montreal Nutmeg, Cosmopolitan, Ryan's Early Watters). The so-called "Rocky Ford Cantaloupes" are not true cantaloupes; the "Rocky Fords" include a number of varieties (chiefly Rust Resistant Pollock No. 25. Netted Gem), all of which are netted melons (var. reticulatus).

2. Cantaloupes or Rockmelons (Cucumis melo var. cantalupensis).--The true cantaloupes are usually deep-ribbed, hard-rinded, and warty or scaly. The flesh is either greenor salmon-tinter (Hackensack, Nutmeg, Carmes, Long Yellow).

3. Pineapple Melons (Cucumis melo var. saccharinus).These resemble the common netted melons. They are oblong in shape and have a very tender flesh.

4. Suake Melon or Snake Cucumber (Cucumis melo var. flexuosus).- The fruit of this is long and slender, bent and 
twisted, furrowed, and thickest at the distal end. It often reaches a length of 3 feet, and a diameter of $I^{t}$ to 3 inches.

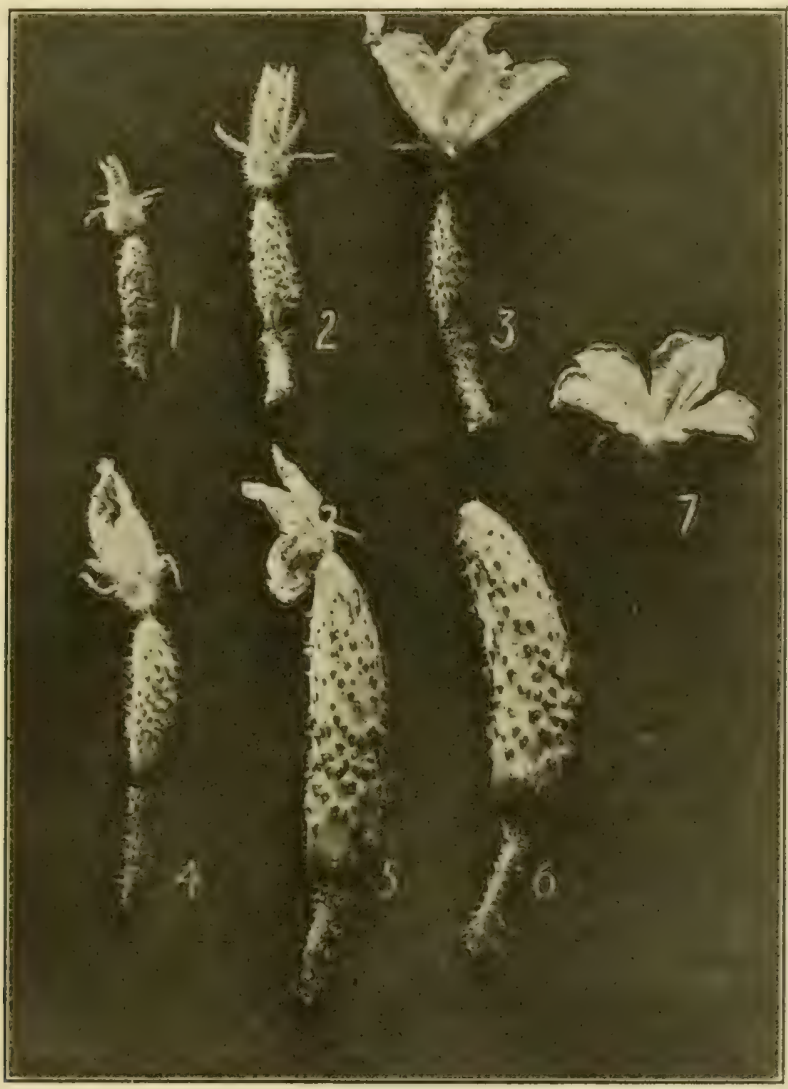

FIG. 253.-I to 6, stages in the development of the cucumber fruit; the flower is unopen in $\mathrm{I}$ and 2 , in 3 it is fully open, in + and 5 it is withering, and in 6 the perianth, stamens and styles have fallen from the enlarged ovary. $\quad 7$. staminate flower of cucumber.

5. Winter Melons (Cucumis melo var. inodorus).-Little known in United States. 
6. Cucumber Melon (Cucumis melo var. acidulus).-Of no economic importance.

7. Orange Melon, Mango Melon, Melon Apple, Vine Peach, Gurden Lemon, Vegetable Orange (Cucumis melo var. chito).Used in making preserves.

8. Dudaim Melon, Pomegranate Melon, Quecn Anne's Pocket Mclon (Cucumis melo var. dudaim).-Inedible.

\section{CUCUMIS SATIVUS (Cucumber)}

Description.-This is an annual plant with rough, hispid stems which reach a length of 6 to 15 feet, and are somewhat branching. The leaves are subcordate, almost as wide as long, and somewhat five-lobed. The corolla is yellow. There is a general impression that the cucumber can be crossed with the melon. Experiments have shown that this crossing is impossible. The fruit is oblong, obscurely threeangled, tuberculate when young, but often becoming smooth (in cultivated forms) at maturity.

Geographical.-Cucumbers have been in cultivation for 3,000 or 4,000 years. They were first cultivated in Asia. The species has not been found growing wild.

Closely Related Forms.-There are a number of " cucumbers" which may be confused (at least in name) with the common cucumber (Cucumis satious). Chief of these are the snake cucumber (Cucumis melo var. flexuosus). West Indian gherkin (Cucumis anguria), musk cucumber ('ucumis moschata), and star cucumber (Sicyos angulatus). The snake cucumber is in reality a melon. It is characterized by the long, narrow, twisted fruit. In the West Indian gherkin the stems are shorter and the fruit much smaller than those of the cucumber. It is a common practice to use young cucumbers as gherkins. 'The musk cucumber is also a melon. 'The 
star cucumber fruit is compresicel, dry and membranous and occurs in head-like clusters.

Types. - There are three principal tyes of cucumbers (Cucumis suliaus): (1) Common ficld cucumbers; (2) English or forcing cucumbers (var. anglicus); and (3) Sikkim cucumbers (var. Sikkimensis). The field cucumbers are divided into black spine varieties and white spone varieties, and these two divisions are further subdivided.

The English or forcing cucumbers differ from the ordinary cucumbers. In the forcing-house, the former do not need artilicial fertilization. while all our common cucumbers must be artificially fertilized. Ilence, the English cucumbers have the habit of producing seedless fruit. The fruit of the forcing cucumber is long and smooth, green in color, and at first corered with a few black spines. Common varieties are Telegraph. Sion House, Kenyon, and Lorne. The Sikkim cucumber fruit is large and reddish brown, marked with yellow.

Pickles.- The growing of cucumbers for pickling is an industry quite different from that having to do with the cultivation of cucumbers for slicing. The pickle industry is mosily restricted to the Northern States, as cucumbers for this inclustry do best in the cooler climate of the north. Cueumbers that are to be pickled are harvested before they reach maturity, and are not allowed to reach a length of more than about 5 inches. They are hauled to the local "salting station," where they are immersed in a brine, which is contained by large wooden tanks, some with a capacity of 1,500 bushels. The pickles are kept in these tanks until ready to be bottled at the factory.

bill pickles are made either from pickles stored in brine or from fresh cucumbers from the vine. The peculiar flator of dill pickles is secured by adding to the brine and 
cucumbers, the stems, leaves, flowering heads, and seeds of dill. and also, sometimes, a spice made from allspice, crushed black pepper, coriander seed, and bay leaves. Some vinegar is added in the later stages of the pickling process.

\section{CUCUMIS ANGURIA (Gherkin)}

Description.-This is an annual, creeping, branching plant. The stems are slender, rough-hairy, and bear simple tendrils. The leaves are deeply sinuate-lobed. Staminate flowers are small, numerous, and on short peduncles, while pistillate flowers are on long stalks. The fruit is about I 1.2 inches long, oval, prickly, and green with whitish streaks. The flesh is thin, and the seeds form a proportionately large percentage of the fruit.

The species is native of the West India Islands.

The genuine gherkins of commerce are the fruit of $C$. anguria. Small cucumbers (C. suticus) are often substituted for them, however.

\section{CITRULLUS (Watermelon, Citron, Colocynth)}

Description.--Citrullus species are coarse, trailing herbs with branched tendrils. The leaves are rotund-cordate, and three- to five-lobed. The flowers are monœcious, and always solitary. In the staminate flowers, the calyx has a broad campanulate tube and a five-lobed limb, and the corolla is five-parted to below the middle; there are three stamens with subsessile anthers, one of which is one-loculed, the other two, two-loculed. In the pistillate flowers, the calyx and coro'la are as described above. The ovary is ovoid with three fleshy placentæ; the style is short, with three large stigmas, and ovules are numerous. The fruit varies widely in form and size, color and thickness of skin, flavor, etc. 


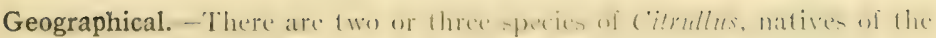
Mediterranean region, lfrica, and leia. The only one wi atgricultural importance is Citrullus vulgaris, which includes the watermelon and citron.

\section{CITRULLUS VULGARIS (Watermelon, Citron)}

Description.-The watermelon is a hairy annual with long, angular, somewhat branching slems, which often attain a length of 15 feet. The leates are lobed. The flowers are pale greenish-yellow. The fruil varies in shape and has a firm fleshy rind and a tender watery pulp), which is usually reddish in color and sometimes purplish. yellowish or white. The skin or rind varies in thickness from ${ }^{1} 2$ inch. in such varieties as White Gem, Gray Monarch, and Hoosier King, to 1 inch in the Black Spanish, Nabob), and colden Gate. The weight of the fruit frequently reaches 23 or 25 pounds.

Geographical.- The watermelon is indigenous to tropical and south lfricat. It has been cultivated for centurie's; Fegptian paintings show that these peoples cultivated them.

Types and Varieties.--The varieties of ('itrullus sulgaris may be divided into two general types:

I. Common Watcrmelon.-Flesh of fruit comparatively tender and watery.

2. Citron.-Flesh of fruit very firm. As compared with watermelons, the citron feels much more solicl. The citron is used for making sweet pickles and preserves. It is not eaten in the raw state. The juice of the citron is arded in equal parts to that of such fruits as peaches, cherries and others whose juices will not "jell" by themselves to make them produce jelly. The citron has a large amount of pectin in the cell walls. This is the substance in fruits which causes their juice to "jell." 
The citron is not to be confused with the true citron (C'itrus medica) (see page 480 ).

Rane divides the varieties of watermelons into six "classes:" ( I) light green (Light Icing, Gray Monarch); (2) medium green (Fordhook Early, Jackson); (3) dark green (Black Spanish, Mountain Sweet, Cannon Ball); (4) light-striped (Golden Gate, Delaware, Hoosier King, Rattlesnake, Santiago); (5) dull-striped (Price of Georgia, Orange, Triumph); and (6) mottled green (Nabob Phinney's Early'). These "classes" are subdivided into "types" according to shape of fruit, and the "types" are each divided into two groups: those with light seeds, and those with dark (black or brown) seeds.

\section{References}

Corbetr, L. C.: Cucumbers. U. S. Dept. Agr. Farmers' Bull. 254: I-30, I 906 .

Crocher, W., Kinght, L. S., and Robert E.: The Peg of the Cucurbitacer. Bot. Gaz., 50: 321-339, 1910.

Griffin, H. H.: The Cantaloupe. Colo. Agr. Exp. Sta. Bull. 62: I-I8, I9or. Pammel, L. H.: Crossing of Cucurbits. Bull. Torrey Bot. Club, 20: $35^{8-359}$, I893.

Results of Crossing Cucurbits. Ia. Agr. Exp. Sta. Bull. 23: 906-9I 7, I894. Rane, F. W.: Fertilization of the Muskmelon. Proc. Soc. Prom. Agr. Sci.. I50-I5I, I898.

II. Classification of Watermelons. N. H. Agr. Exp. Sta. Bull. 86: 95-107, Igor. 


\section{CHAPTER XL}

\section{COMPOSIT E (Thistle Family)}

The composite or thistle family is one of the largest of the plant kingdom, consisting of about 10,000 species in about 760 genera; it has a wide geographical distribution.

Representatives of the family are considered to be among the most complex of plants, and among Dicots, of the highest evolutionary rank. They show a combination of characters which place them high in the scale of evolution. These are: union of petals (sympetaly), inferior ovary (epigyny), seedlike fruit, pappus, united (syngenesious) anthers, head inflorescence, diclinism, and dimorphism.

Comparatively few species of this large family are of economic value. The most important are common lettuce, Jerusalem artichoke, endive, salsify, and dandelion. The following is a short list of the less important representatives of the family: yarrow (Achillea), Chrysanthemum, sage and wormwood (Artemisia spp.), sunflower (Helianthus), Arnica, Aster, goldenrod (Solidago), sow-thistle (Sonchus), Dahlia. marigold (C'alcndula), rabbit-brush (Chrysolhammus), fleabane (Erigeron), everlasting (Antenuaria), Spanish needles (Bidens), and thistle (Carduus).

Habit.- This large family is made up mostly of herbaceous forms; there are a number of shrubs, however, and a few tropical tree species. Many of them, as the dandelion and lettuce, have a milky juice, while in others the sap is watery, resinous, acrid or bitter.

Leaves.- The leaves are either alternate or opposite, rarely in whorls (verticillate), and usually without stipules. 
Inflorescence.-- The inflorescence (Fig. 254, A) is a head, the flowers, usually numerous, being mounted on a common receptacle which is subtended by an involucre. A "sunflower" is not a single flower in the botanical sense, but a group or composite of individual flowers. The receptacle

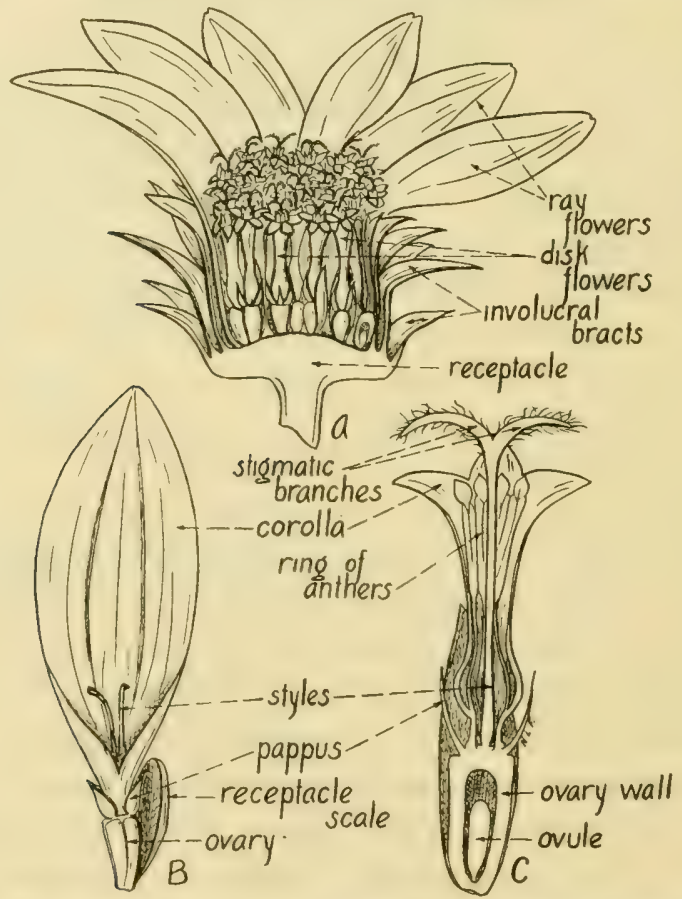

Fig. 254.- Jerusalem artichoke (Helianthus tuberosus). $A$, lengthwise section of head, $\times \mathrm{I} ; B$, ray flower, $\times 6 ; C$, disk flower, cut lengthwise, $\times 6$. (A after Baillon.)

varies in shape from flat to convex or conical. The receptacle is naked or there are chaffy scales subtending the flower; its surface is smooth, pitted, or honeycombed. The involucral bracts also vary widely in shape, from narrow and spinelike to broad and leaf-like; they occur in one or more series. 
Flowers.-The flowers may be perfect, polygamous, monœcious or diøcious. There are two sorts of flowers in the composite family: (I) Disk or tubular, and (2) ray or ligulate.

Disk Flowers (Fig. 254, C).--These are perfect and regular and make up the so-called disk of the composite "flower." For example, the disk of the "sunflower" is the center. The calyx is modified, taking the form of a few or large number of bristles, awns, scales or teeth; this modified calyx is termed a pappus. In some instances, the pappus is entirely wanting. It is attached to the apex of the inferior ovary. The corolla is tubular and five-lobed. The five stamens are attached to the corolla and alternate with its lobes; the anthers are united into a tube. In one genus (Kumia), the anthers are distinct or nearly so. The anthers are often appendaged at the apex and sometimes caudate or sagittate at the base: pollen grains are spherical, often rough or prickly. There is a single pistil, an inferior one-celled and one-seeded ovary, and a single style which is entire (in sterile flowers) or twocleft at the apex; the style branches are often tipped with appendages.

Ray or Ligulate Flowers (Fig. 254, B).-These are usuallyimperfect and irregular. They have a pappus and a strapshaped corolla with either a long or short tube.

The composite family is divided into two large groups, the Liguliflore and Tubuliflora. The dandelion, chicory, and lettuce are representatives of the former, and sunflower. Jerusalem artichoke, daisy, fleabane, aster, and goldenrod typical members of the latter group. In the Liguliflorce. ligulate or strap-shaped flowers are the only sort present; in these, the flowers are perfect and consist of five stamens with their anthers united into a tube, a one-celled, one-seederl ovary, a single style, and a two-lobed stigma; the pappus maty 
be present or wanting. In the Tubuliflore, there are both disk and ligulate flowers, the former occupying the center of the head, while the ligulate ones are at the margin of the receptacle, and are called ray flowers. In the Tubiliflore, the ray or ligulate flowers are very frequently pistillate. In both types of flowers, the fruit (achene) is one-seeded and indehiscent. The pappus is usually persistent at the apex of the fruit, serving as a means of dissemination by the wind.

\section{Key to Important Genera}

Flowers with ligulate corollas only; flowers perfect.

Pappus of plumose bristles, Tragopogon (salsify).

Pappus not plumose.

Pappus of mere chaffs or these reduced and united into a crown, Cichorium (chicory).

Pappus of capillary bristles.

Achenes flattened, Lactuca (lettuce).

Achenes not flattened, Taraxacum (dandelion).

Flowers with tubular corollas or none, or only the ray flowers with ligulate corollas.

Anthers long-tailed at the base and with long appendages at the tip; heads large; rays none, Carduns (thistle).

Anthers not tailed at the base; flowers tubular only, or tubular and ligulate. Receptacle naked.

Ray flowers yellow; involucral bracts scarcely imbricated, Arnica.

Ray flowers never yellow; involucral bracts well imbricated.

Bracts of involucre imbricated in several series, Aster.

Bracts of involucre in but one or two series, Erigeron (fleabane).

Receptacle chaffy.

Bracts of involucre foliaceous, Helianthus (Jerusalem artichoke and sunflower).

Bracts of involucre dry, thin, and papery.

Receptacle chaffy, Achillea (yarrow).

Receptacle not chaffy, naked, or sometimes hairy.

Ray flowers present, Chrysanthemum.

Ray flowers none, Artemisia (sage and wormwood). 


\section{LACTUCA SATIVA (Garden Lettuce)}

Description.-Common garden lettuce is a tall, annual leafy herb, with a milky juice. There is thrown up from a short stem early in the season a cluster of leaves varying considerably in shape, character, and color, in the different varieties. Later in the season, a "seed stalk" is sent up. 'Tracy found that, at Washington, D. C.. the first appearance

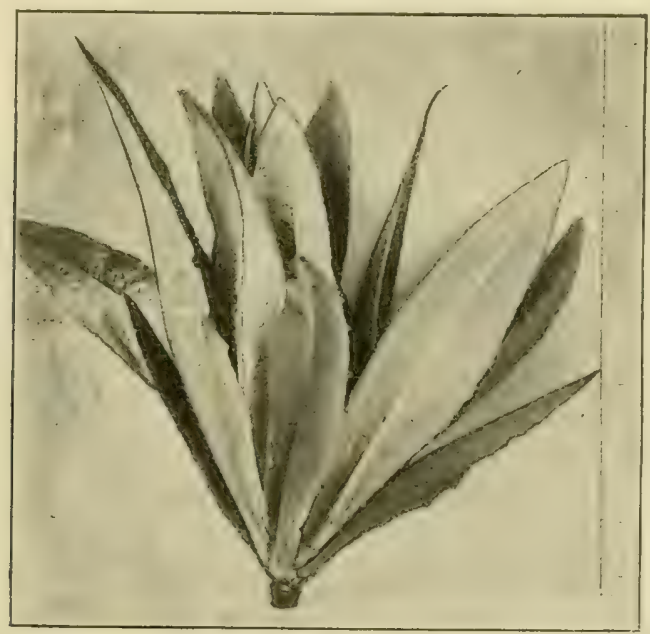

Fig. 255-Asparagus lettuce, var. angustana. (Afler Corbell.)

of the seed stalk after sowing seed, varied from 50 (in Emperor Forcing) to 1 i 2 (in Italian Ice) dass. The leates are alternate, denticulate or pinnatifid, sessile or auriculateclasping, sometimes spinulose-margined, the lowest ones large, and the upper much smaller. The inflorescence is a panicle. The flowers are yellowish or yellowish-white, the involucre cylindric, the bracts of which are imbricated in several series, the outer shorter. The receplacle is flat and n....el. The corollat ralse are truncate and five-teothed at 
the end. The anthers are sagittate at the base. The style branches are slender. The achenes are oval, oblong, or linear, flat, three to five-ribbed on each face, narrowed above or contracted into a narrow beak which bears a large number

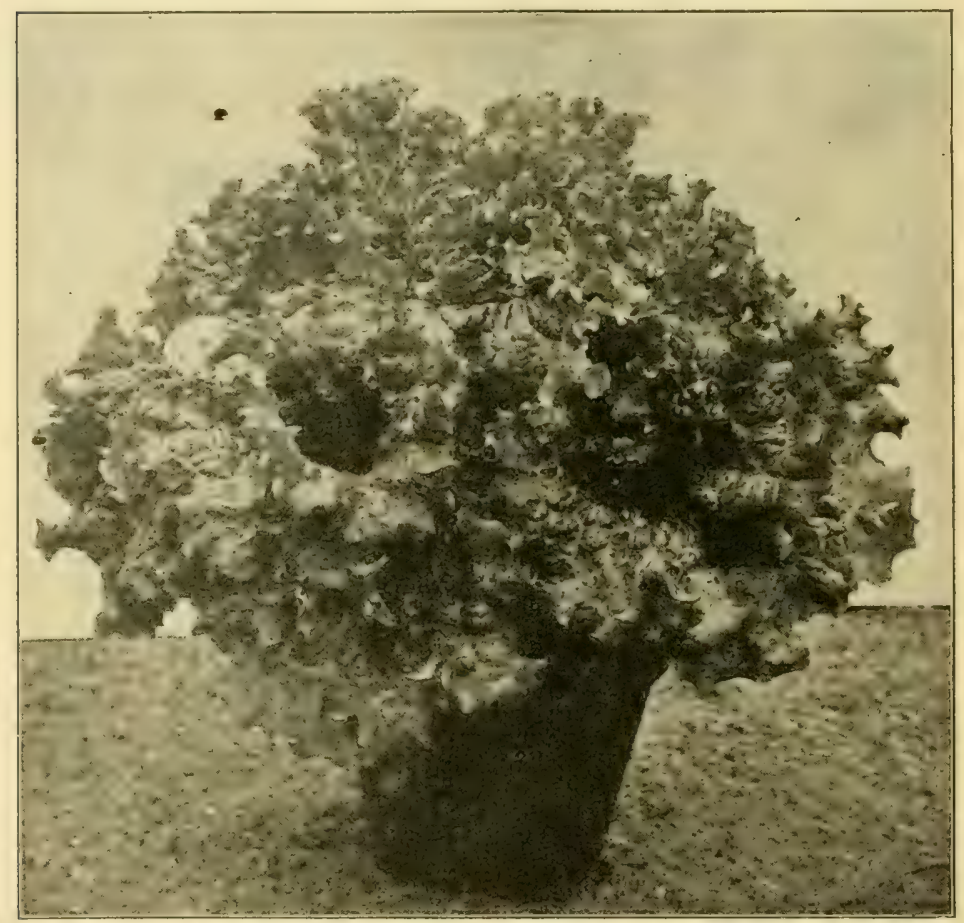

FiG. 256.-Cutting or cut-leafed lettuce, var. intybacea. (After Corbelt.)

of soft, capillary, white or brown pappus bristles. The achenes vary in color: whitish, blackish, yellowish, or brownish.

Origin, and Geographical.-It is quite generally conceded by botanists that our garden lettuce $(L$. sativa) is originated from the wild species, L. scariola. This latter species grows 
wild in Europe, Canary Isles, Madeira, Algeria, Abysinia, and Eastern Asia, and has also become naturalized in the

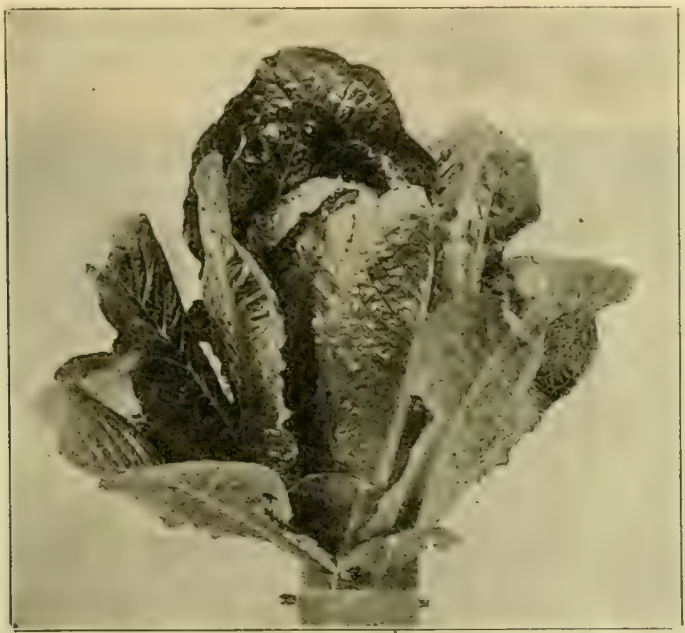

Fig. 257--Cos lettuce, var. romana. (Afler Corbett.)

United States, where it is often a troublesome weed. In this country, L. scariola is distributed from New York to

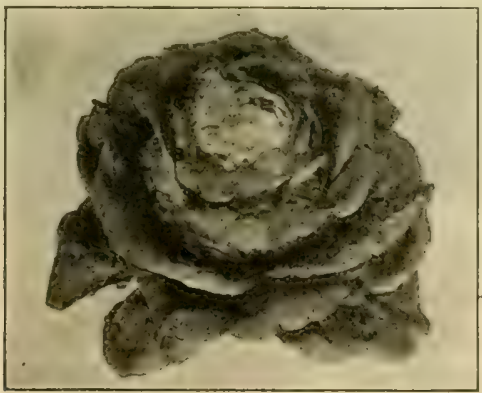

FIG. 258.-Head lettuce, var. capitata. (Afier Corbell.)

Minnesota and Missouri. The close relationship between $L$. sativa and $L$. scariola is shown by the fact that they readily cross. 
There are a number of native species of Lactuca in this country. Britton and Brown mention eight species native of the eastern and northern United States, besides the introluced $L$. scariola. This latter species is commonly known as the "compass plant."

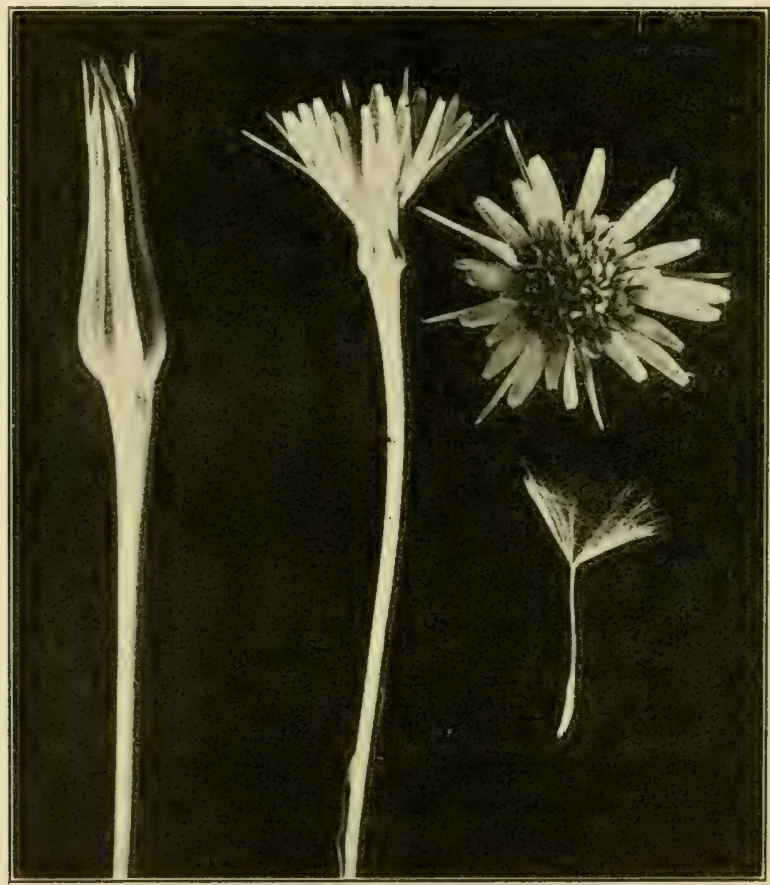

FIG. 259.-Salsify (Tragopogon porrifolius). From left to right: unopen flower head; side view and face view of open flower head; achene with pappus at tip of beak.

Types of Lettuce.-Four types or botanical varieties of cultivated lettuce are recognized. These may be distinguished by the following artificial key:

\section{KEy to Types of LetTuCE}

Basal leaves narrow, distinctly lanceolate, $L$. sativa var. anguslana (asparagus lettuce). 
Basal leates broad, spatulate, oval to roundish, alwaty rounded at the tip.

Leaves deeply cut on the edges, $L$. sativa var. intybacea (cutting or cutleaved lettuce).

Leaves entire or but slightly toothed.

Leaves forming a rather compact roundish or flattish head; leaves never decidedly stiff and flat, $L$. suliod var. capilata (head or cabbage lettuce). Leaves forming at conical or cylindrical-shaped head; leaves straight and stiff, $L$. saliva var. romana (cos lettuce).

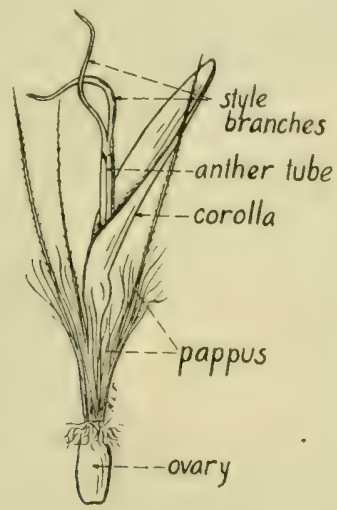

FIG. 260.- Single flower of salsify (Tragopogon porrifolius) $\times 21 / 2$.

Tracy classifies the American varieties of lettuce as follows: (I) butter varieties, (2) crisp varieties, and (3) cos varieties. These three groups are further subdivided.

\section{TRAGOPOGON PORRIFOLIUS (Salsify or "Oyster Plant")}

Description. - Salsify is a hardy perennial plant from a fleshy root. The rools are about 12 inches long with a diameter of about 2 inches at the top; the skin is grayish white. The stems are usually somewhat branched and succulent. When grown from seed, a seed stalk is sent up the second season to a height of 2 to 4 feet. The leates are alternate, entire, linear-lanceolate, clasping at the base, and glaucous. Heards ( Fig. 259) are single at the end of rather long. thickened peduncles, which are often hollow for several 
inches below the head. 'The heads are purple and open early in the morning but usually close by noon. The incolucre is cylindrical, the bracts nearly equal, in one series, linear-lanceolate, and usually much longer than the rays of the flowers. The corollas (Fig. 260) are truncate and five-

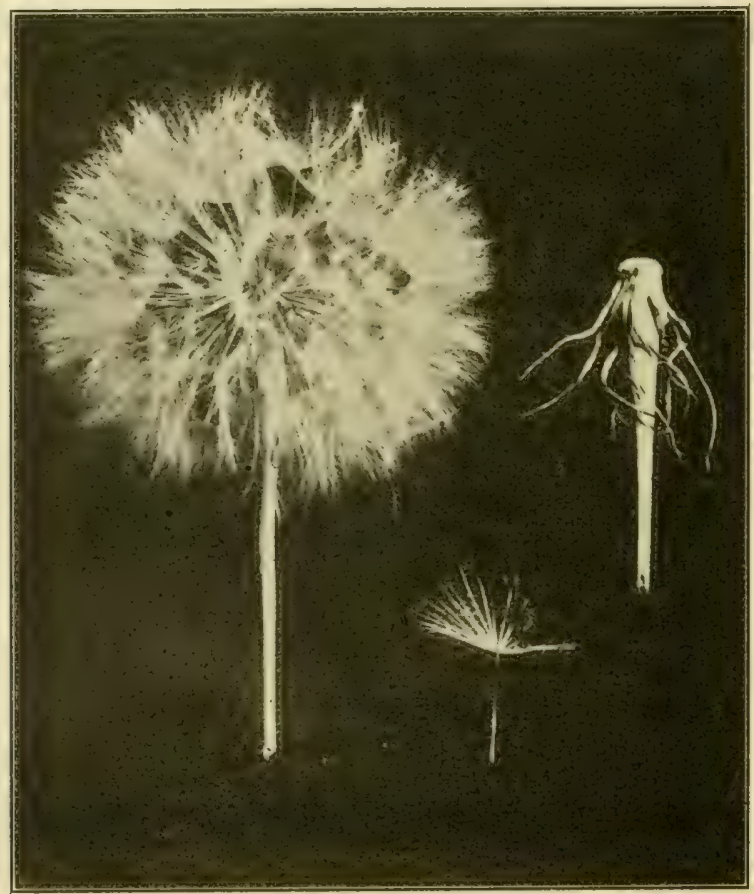

FIG. 26I.-Salsify (Tragopogon porrifolius). Headin fruit; receptacle after having shed the achenes; single achene.

toothed at the apex. The anthers are sagittate at the base. The style branches are slender. Achenes are linear, and terminated by slender beaks, the outer ones being covered with tubercles, particularly on the ribs below. The pappus is grown together at the base, is plumose, and has interwebbed branches (Fig. 26I). 
Geographical, and Closely Related Species.--The species is a native of southern Europe. It is quite widely distributed in this country in fields and waste places, probably as an escape from cultivation. A yellow-flowered salsify ( $T$. pratensis), naturalized from Europe, is also quite widely distributed here. The Spanish salsify or Spanish oyster plant (Scolymus hispanicus), has a root much like that of common salsify, but the plant differs from common salsify in the following respects: the roots are of a lighter color and longer, the leaves prickly, and the flowers yellowish. The black salsify (Scorzonera hispanica), also a member of the Composite family, bears a black, fleshy, edible tap root. It differs from common salsify in that its leaves are broader. flowers yellow, and its involucral bracts are in many series.

Uses.-Salsify is grown for its fleshy roots which have somewhat the flavor of oysters, hence the common name. "oyster plant." They are used both as a cooked vegetable and as a relish.

\section{CICHORIUM (Chicory or Succory, and Endive)}

Description.-All the species of this genus are branching herbs. The leaves are alternate, mostly basal, the cauline ones small and bract-like. The heads are large, and peduncled or in sessile clusters along the branches. The bracts of the involucre are in two series, the outer spreading, the inner erect. The receplacle is flat, naked, or fringed with small hairs. The corolla rays are truncate and five-toothed at the apex. The achenes are five-angled or five-ribbed, truncate, and not beaked. The pappus consists of a number of short scales.

Geographical.- The species of Cichorium are natives of the Old IForld. There are two of economic importance: Cichorium inlybus (chicory) and Cichorium endiva (endive). 


\section{CICHORIUM INTYBUS (Chicory or Succory)}

Description (Fig. 262). - This is a perennial species from a long, deep tap root, which sends up a stiff, rough-hairy, branched stem to a height of I to 3 feet. Radical leaves are numerous, and spreading on the ground; the upper leaves are smaller, lanceolate or oblong, lobed or entire, clasping and auricled at the base. The heads are axillary. The flowers are blue or purplish, and sometimes white.

The species is a native of Europe. It is introduced into the United States, occurring as a ruderal from Nova Scotia to North Carolina, and west to Minnesota and Missouri.

Uses, and Varieties. - The roasted root of chicory has been used as a substitute for, and an adulterant of, coffee. The young roots are sometimes boiled, and the leaves used as "greens" or served fresh as a salad. The plant is sometimes forced in the winter to produce a cluster of loose leaves for use in salads. Such clusters of leaves are called "Barbe de Capuchin." Common varieties of chicory are: Common, Large-rooted Madgebury, Long-rooted Brunswick and Improved very Large-leaved. Witloof chicory is an improved variety of Belgian origin.

\section{CICHORIUM ENDIVA (Endive)}

Description.- Endive is an annual or biennial herb with numerous basal leaves which vary much in character; they may be merely toothed, the teeth large or small and numerous, or pinnatifid; some of the most desirable varieties have the leaf margins very much curled. The upper leaies are smaller, and auricled at the base. The stem often rises to a height of 3 feet; it is hollow, terete, branched, and smooth or slightly hirsute. The flocers are purple and sometimes white. The achenes are angular and ribbed. 


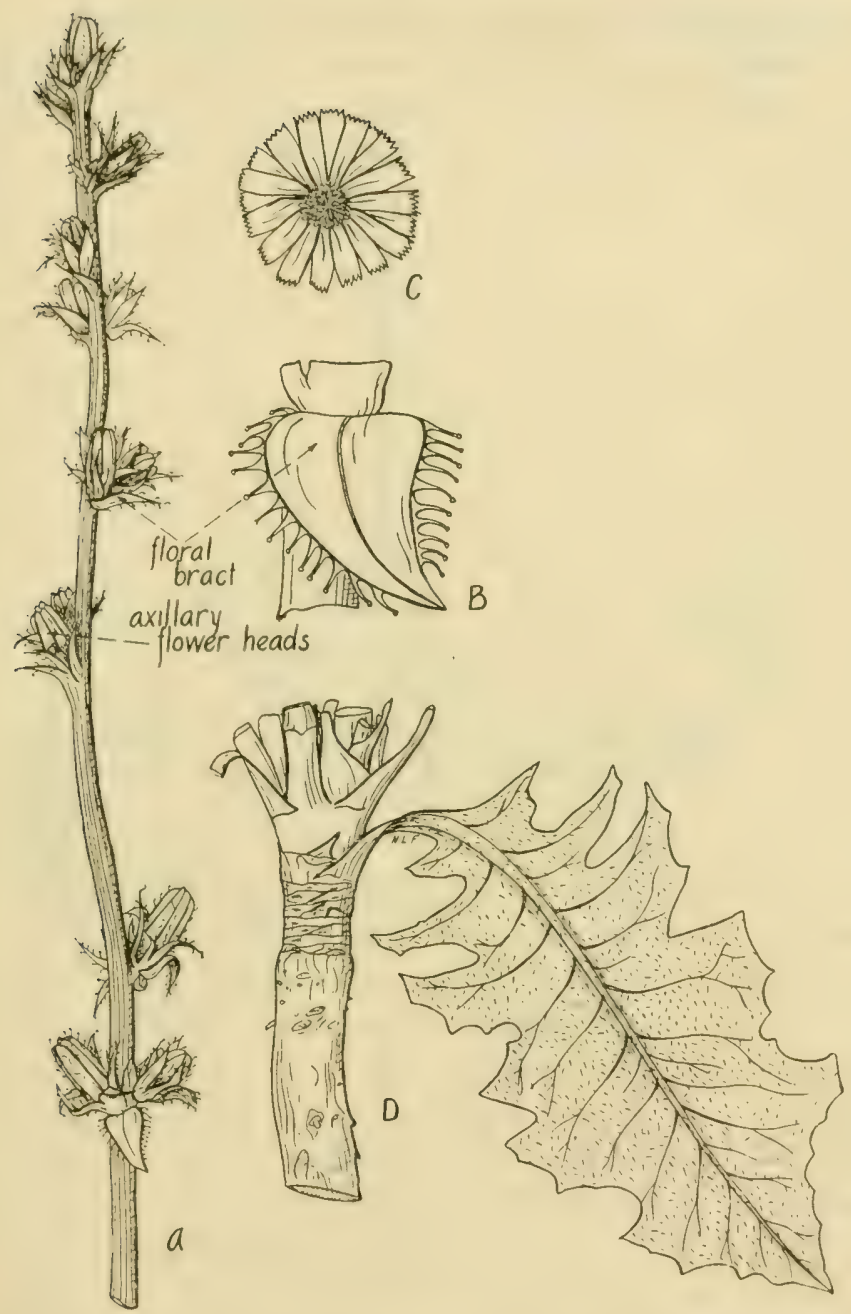

FIG. 262,- Chicory (Chicorium intybus). A, sessile clusters of flowers in axils of bracts, $\times I ; B$, single floral bract enlarged, $\times 4 ; C$, open flotwer, face view, enlarged; $D$, basal leaf, $\times$ I 13 . 
Geographical Distribution, and Economic Uses.-Endive is a native of India. It is cultivated to a great extent in the gardens of European countries and to some extent in

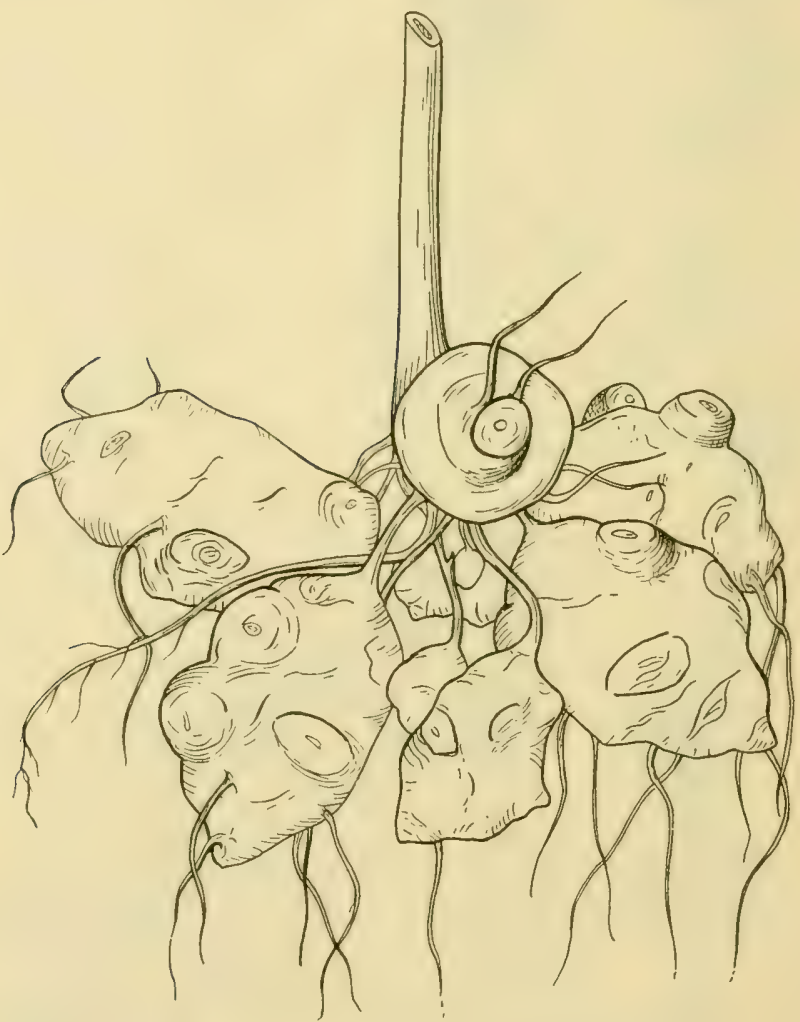

FIG. 263.-Tubers of Jerusalem artichoke (Helianthus tuberosum). (After Vilmorin.)

the United States. The best-known variety grown here is the Green Curled. The plant is cultivated for the young basal leaves which are blanched and used as a salad. 


\section{HELIANTHUS TUBEROSUS (Jerusalem Artichoke)}

Description.-The Jerusalem artichoke is a perennial herb) arising from thick, fleshy rootstocks that bear oblong tubers (Fig. 263). The above-ground slems attain a height of 6 to 12 feet; they are stout, branching, terete and hirsute. The ledies are alternate above, opposite below, simple, ovate or ovateoblong. firm, three-nerved at the base, narrowed, rounded. truncate or slightly heart-shaped at the base, acuminate at the apex, and long petioled. The heuds are solitary or in corymbs. Tubular (disk) and ligulate (ray) flowers are both present; the rays are yellow and the disk is also yellow (Fig. 254). The iniolucre is hemispheric, with lanceolate, acuminate hirsute or ciliate, squarrose bracts. There are 12 to 20 rays. The receptacle is chaffy; the chaff subtends the disk flowers. The achenes are thick, somewhat four-angled, and pubescent. The pappus consists of two deciduous scales.

Geographical.-The Jerusalem artichoke (also called Earth . Apple, Canada Potato, Girasole and Topinambour is native to this country and is found from New Brunsivick and Ontario to Georgia and Arkansas, west and north to Canada. It is grown as a crop more in Europe than in America.

Closely Related Species.-The Jerusalem artichoke is closely related to the "globe artichoke" (C'ynara scolymus) which in fact belongs to the same family, Compositex. Cynara scolymus is sometimes cultivated for the flower heads and leaves. The thick receptacle together with the fleshy bases of the scales of the involucre is used ats a vegetable. The plant may be distinguished further from Jerusalem artichoke by its blue or violet-purple flowers, and its large, wooly, pinnatifid leaves.

Uses.- The tubers of Jerusalem artichole are used both as a vegetable and as a food for stock. Hogs are turned into the field and permitted to root the tubers from the ground.

\section{References}

TRACY, W. W.: American Varieties of Lettuce. U. S. Dept. Agr. Bur. Plant Ind. Bull. 69: $\mathrm{I}-103, \mathrm{I} 905$. 



\section{GLOSSARY}

Abaxile.-Situated off the axis.

Aborlive.-Imperfectly formed or rudimentary.

Acaulescent.-Without an obvious stem.

Accumbent (cotyledons).-Their edges against the hypocotyl.

Achene (akene).- A one-celled, dry, indehiscent fruit in which the testa and pericarp are not firmly attached.

Acropeldl.-Developing from the outside (below) toward the inside (above). Actinomorphic.-Regular, ray-shaped; said of a flower when it can be divided into symmetrical halves by radial planes.

Acuminaie.-Taper-pointed.

Acute--Merely sharp-pointed, or ending in a point less than a right angle. Adnate.-Grown fast to; applied to the growing together of unlike parts. Adentitious. - Out of the ordinary place, as applied to buds or roots.

Aestivation.-The arrangement of parts in the bud.

Alliaceous.-With odor and taste of onions and garlic.

Alternate (buds, flower parts, leaves, etc.). One after another singly at the nodes.

Ament.-Scaly unisexual spike of flowers.

1 mphitrepous (ovules). Half-inverted and straight, with the hilum about the middle, and micropyle terminal.

Anatropous (ovules).--Inverted, straight and with micropyle next the hilum.

Andrecium.--The stamens collectively.

Annual (plant).- Produces flowers, fruit, and seed the same year it is raised from seed, and then dies. Winter annuals germinate in autumn, and produce seed the following spring or summer.

Annular.-Forming a ring or circle, as embryo of beet.

A petalous.-Without petals, as in buckwheat, etc.

Apical.-At the tip or apex.

A pocarpy.-Condition in which the carpels are separate.

A popetaly.-Condition in which petals are separate and distinct.

Arliculated.-Jointed.

Auricle.-Ear-like structure.

A uriculate-Eared; furnished with ear-like appendages.

Aulugumy.-Pollination in which pollen is transferred from the anthers to the stigma of the same flower.

Awn.-Bristle-like structure, or beard. 
Awned.-Furnished with an awn or beard.

Axillary (buds, etc.).-In the axil.

Busal.-Belonging to or attached to the base.

Berry. $-\Lambda$ fleshy fruit, with mesocarp and endocarp fleshy throughout, and seeds imbedded therein, as grape, currant, etc.

Bicnniul.-Of two years' duration; the first year from seed, the second year flowering and fruiting, then dying; as in sugar beet, carrot, etc.

Bipinnate (leaf).-Twice pinnate.

Blade.-Expanded portion of a leaf.

Bloom.-The whitish, powdery, and waxy secretion of epidermal cells.

- Bract.-A reduced scale-like leaf, above the regular foliage leaves.

Bracteclate.-Bearing bractlets.

Bractecle.-A small bract.

Bulbils.-Small bulbs borne underground, as in garlic.

Bulblets.- Small bulbs borne above ground, as in tree onions.

Cambium.-The growing layer in the vascular bundle.

Campanulate.-Bell-shaped.

Campylotropous (ovule or seed).-Curved so as to bring the apex and base near together.

Capillary.-Hair-like in form.

Capitate.-Knob-like; shaped like a head.

Caprification.-The artificial process of pollinating figs.

Capsule (pod).-A dry, dehiscent fruit of two or more carpels.

Carina.-Keel.

Carpoplore.-A slender stalk to which the mericarps of the umbelliferous fruit are attached.

Caryopsis.-Synonym of grain-a dry, indehiscent one-seeded fruit in which the pericarp and testa closely adhere.

Catkin.-Ament. Scaly spike of flowers.

Caudate.-Tailed; with a slender tail-like appendage.

Cauliflorus.-Stem-flowering; trunks bearing flowers, as in figs.

Cauline.-Pertaining or belonging to the stem.

Chasmogamy.-Flowers that regularly open are said to show chasmogamy.

Ciliate.-Fringed with marginal hairs.

Cladophyll.-A leaf-like branch.

Claw:-The narrow or stalk-like base of some petals.

Cleft.-Cut about half way to midrib or median line.

Colesplile.-Leaf sheath in grasses.

Colecrhiza.-A sheath about the root.

Commissure.-The contiguous surfaces of two carpels, as in the fruit of Umbelliferæ. 
Conduplicate.-Folded lengthwise.

Conniven.-Overlapping or brought close together.

Conergenl.-Margins touching.

Convolule.-Rolled lengthwise.

Cordale.-Heart-shaped.

Corneus.-Horny.

Corm.-The swollen, fleshy, and solid base of a stem.

Cortex.-Bark region, from epidermis to endodermis.

Corymb. - An indeterminate type of inflorescence that is flat-toppecl.

Corymbose.-Corymb-like.

Crenate-Margins with rounded teeth.

Crenulale.-With very small rounded teeth; diminutive of crenate.

Culm.-The hollow stem of grasses and sedges.

Cuticle.-A thin covering of a waxy substance called cutin on the outer wall of epidermal cells.

Cyme.-A determinate type of inflorescence, in which the first flowers to open are those toward the inside.

Cymose-Cyme-like, or bearing cymes.

Decompound.--Several times compound or divided, as in leaves of carrot.

Decumbent.-More or less prostrate, but with the tips ascending.

Decurrent (leaf).-Extending down the stem below the point of inscrtion.

Dehiscence.-The opening of a fruit or anther.

Dehiscent.-Splitting open.

Dentale.-Sharp-toothed; teeth directed forward.

Denticulate-Diminutive of dentate; furnished with very small sharp teeth.

Diadelphous (stamens).-United into two sets, as in many legumes.

Diaphragm.-A dividing partition.

Dichogamy.-I condition in which stamens and pistils do not mature simultaneously.

Diclinism.-Stamens and pistils in separate flowers, as in dicecious and monœcious plants.

Digitate-The spreading of segments like the fingers from palm of hand.

Diluted.-Expanded.

Dimorphism.-The occurrence of two distinct forms, as in flowers of buckwheat.

Diacious.-Bearing staminate and pistillate flowers on different individual plants.

Dissected.-Divided into many lobes or segments.

Distichous.-Two-ranked, as the leaves of grasses.

Divergent.--Spreading apart.

Divided.-Segmented to the midline, midvein, or base.

Dorsal.-On the back; surface of member turned away from the main axis. 
Drupe. $-\Lambda$ one-seeded, fleshy fruit in which the endocarp is stony, the mesocarp fleshy, and exocarp skin-like.

Drupelet. - A small drupe, as in raspberry.

Elliplic.-Oval, or the shape of an ellipse.

Emarginate.-Notched at the apex.

Embryo.-Young plant within the seed.

Endocarp.-Inner wall of pericarp (ovary wall).

Endosperm.-The stored food supply in a seed.

Entire--Without divisions, lobes, or teeth; usually refers to margins of leaves, petals, and sepals.

Epicalyx.-Extra bract-like segments below the calyx in the strawberry.

Epigynous.-Ovary inferior; flower parts above the ovary or apparently. growing from its tip.

Epiphyllous.-Borne on leaf surface.

Epiphyte--Growing upon another plant, but gaining from it no nutriment.

Episperm.-Testa; seed coats.

Erose.-With an irregular margin, as if chewed.

Etiolate.-To whiten, or blanch, by the exclusion of light.

Exocarp.--Outer wall of pericarp (ovary wall).

Exserted (stamens).-Extending beyond the other flower parts.

Exstipulate.-Without stipules.

Extravaginal.-Referring to branches in grasses which force their way out through the base of the leaf sheath.

Extrorse.-Turned outwards; usually referring to anthers which shed their pollen towards the outside of the flower.

Falcate.-Shaped like a scythe.

Fascicle - -Bundle or cluster.

Firtile-Capable of bearing fruit or seed; applied to flowers with pistils or to anther with pollen.

Fertilization.-A sexual process in which two dissimilar gametes fuse.

Fibrous.-Fiber-like, usually referring to root system of many small threadlike roots.

Filament.-Thread; stalk of stamen.

Filamentous.-Thread-like.

Fimbriated-Fringed.

Foliaceous.-Leaf-like in form and texture.

Follicle-A dry, dehiscent fruit with one carpel which splits along the ventral suture.

Funnelform.-Funnel-shaped.

Gcitonogamy.-A method of pollination in which pollen is taken from anther to stigma of another flower on same plant. 
Gcniculate-Bent abruptly at an angle, like the bent knec.

Glabrous.-Smooth; without hairs, scales, or bristles.

Glandular.-Furnished with glands.

Glaucous.-Covered with a tine, waxy-like covering (bloom) which rubs off easily:

Globose--Globe-shaped.

Globular.-Globe-shaped.

Glume.-General name for floral bract of grasses and sedges.

Gynacium.-The carpels taken collectively.

II astate.-Halberd-shaped; basal lobes diverging.

Ilcad.- In indeterminate type of inflorescence in which the flowers are in a dense cluster, as in Compositæ.

Herma phrodite (flowers).-Perfect; both stamens and pistils present.

Hyaline.-Thin and very nearly transparent.

IIypocotyl.-That portion of the embryo stem below the cotyledons.

IIypogean (cotyledons).--Remaining underground, as in the pea.

IIypogynous. - Ovary superior; flower parts attached below the ovary.

II ilum.-The scar on a sced, marking the attachment of a seed to its stalk.

Hirsute-Covered with stiff hairs.

Homogamy.-The anthers and stigmas mature at the same time.

Imbricated.-Overlapping.

Incised.-Cut rather deeply into sharp lobes.

Included (stamens).-Not extending beyond the surrounding parts.

Incumbent (cotyledons).-With the backs against the hypocotyl.

Indehiscent.-Not splitting open.

Indigenous. - Native to the region of growth.

Inferior (ovary).-Below the other flower parts.

Inflexed.-Bent inwards.

Inflorescence.-A flower cluster.

Integument.-Skin; coat or protecting layer.

Internode.-The interval between two adjacent nodes.

Intrataginal.--Referring to branches in grasses which grow out between the leaf sheath and the culm (stem).

Introrse.-Turned inwards; usually referring to anthers which shed their pollen towards the inside of the flowcr.

Involucel.-A secondary involucre.

Involucellate-Furnished with involucels.

Involucrate-Furnished with an involucre.

Inwlucre.- I series of bracts that subtend an inflorescence, at in Compositx, cotton, etc.

Irregular (flower).-One or more of the parts of a series are dissimilar. 
Keel.-Ridge, like the keel of a boat.

Laciniate.-Cut into narrow, rather deep segments.

Lamella.-Plate.

Lanceolate.-Lance-shaped.

Lemma.-The bract (glume) at the base of the flower in grasses.

Lenticular.-Shaped like a double-convex lens.

Lignified.-Woody; cell walls impregnated with lignin.

Ligulate--Strap-shaped.

Ligule.-Appendage at juncture of sheath and blade in grasses, or, strapshaped corolla in Compositæ.

Linear.-Long and narrow, its sides nearly parallel.

Lobed.-Divided to about the middle.

Locule.-Cell cavity.

Loculicidal. - Refers to capsules which split lengthwise through the middle of each cell.

Lodicules.-Small scales (inner perianth) surrounding the ovary in grasses.

Lumen.-Cell cavity.

Lyrate.-Lyre-shaped; the end lobe of pinnatifid leaf is much larger than the rest.

Marginal.-Along the edge or margin.

Median.-Middle.

Medulla.-Pith.

Mericarp.-One-half of the fruit of Umbelliferæ.

Mesocarp.-Middle layer of pericarp (ovary wall).

Mesocotyl.-Axis between base of coleoptile and grain, in grasses.

Micropyle. - The opening between the ovule or seed coats.

Microsporangium.-Anther sac; case bearing microspores.

Monxcious.-Staminate and pistillate flowers in different inflorescences on same plant.

Mucronate. - With a sharp and abrupt point.

Nerve--Veins or ribs in bracts, scales, petals, sepals, etc.

Node.-The point on the stem from which a leaf or leaves arise; the junction of two internodes.

Nucellus (megasporangium).-The ovule tissue within the integuments.

Nutlet. $-\Lambda$ small nut.

Ob.-A prefix signifying inversion.

Obcordate.-Heart-shaped, with broad end at the tip. 
Oblate.-Flattened at the ends.

Obovate-Egg-shaped in outline, with the broader end at the tip.

Obsolete-Rudimentary, or entirely absent.

Obluse.-Blunt or rounded at the apex.

Ocrea.-Sheathing stipules in Polygonacex.

Orbicular.-Approximately circular in outline.

Orlhotropous (ovule).- Straight; hilum at one end and micropyle at the other.

Ovale-Egg-shaped in outline; broader end at the base.

Ovoid.-Egg-shaped.

Ovule.-The body which becomes the seed after fertilization.

Palet (palea).-Outer perianth segment of grass flower.

Palmate.-Leaf segments or leaflets radiate from a point like the fingers from the palm of the hand.

Panicle-A compound raceme, as in oats.

Paniculate-Flowers in panicle or panicle-like inflorescence.

Papilla.-A small protuberance.

Papillose.-With papilla.

Pappus.-Bristle-like, awn-like scaly structures (modified calyx) at the tip) of the ovary in Compositæ.

Parenchyma.- I tissue made up of large, thin-walled cells with rather large intercellular spaces.

Parictul.-Pertaining to the wall; ovules that are attached to the wall of the ovary are said to be parietal.

Parled.-Separated into parts nearly to the base.

Parthenocarpy.-A phenomenon in which the fruit matures without iertilization of ovules.

Pedicellate-Possessing a pedicel.

Peduncle.-I stalk, either of an individual flower or of the inflorescence.

Pendant.-Hanging.

Pentamerous (flower).-Parts in fives.

Perfect (flower).--Possessing both stamens and pistils; hermaphroditic.

Perennial.-Living from year to year.

Perianth.-Calyx and corolla taken collectively, or the external floral whorl or whorls.

Pcricarp.-The ovary wall, concisting of three layers: exocarp, mesocarp, and endocarp.

Perigynous.-Calyx, corolla, and stamens borne on a rim of the receptacle such that they appear on the level with the ovary.

Perisperm.-Nucellus.

Petaloid.-Petal-like.

Pctiole-The stalk of a leaf. 
Phlom.-That portion of a vascular bundle which is largely concerned in the transport of elaborated food material.

Phyllotaxy.-The arrangement of leaves upon a stem.

Pileole.-Coleoptile (which see).

Pinnate (leaf).-Leaflets arranged along the sides of an axis.

Pinnatifid.-Pinnately cleft to the middle of the blade, or further.

Pistillate-Bearing pistils only.

Placenta.-The membrane or surface bearing ovules.

Plicate-Plaited.

Plumose--Plume- or feather-like.

Plumule.-The first bud in the young plant.

Polyadelphous (stamens).- Separate, or in more than two groups.

Pclygamo-dicecious.-Bearing both perfect and imperfect flowers on the same plant, with a tendency to become diœcious.

Polygamous.-Both perfect and imperfect flowers present on the same plant.

Pome-A fruit in which the receptacle of the flower enlarges, becomes fleshy and surrounds the carpels, as in apple, pear, and quince.

Prehensile.-Adapted for holding.

Protandry.-In which the anthers of a flower shed their pollen before the stigmas are receptive.

Protogyny.-- In which the stigmas of a flower are receptive before its anthers shed their pollen.

Pubescence.-Fine, soft hairs.

Pubescent.-Covered with fine, soft hairs.

Raceme--Indeterminate type of inflorescence, in which the pedicels are simple and one-flowered.

Racemose.-Raceme-like.

Rachilla.-The axis of a spikelet.

Rachis.--The axis of a spike.

Radical.- Seeming to come from the root. Leaves arising from the base of stem, close to the ground line, are said to be radical, as contrasted with those on the stem (cauline).

Ray.-The branch of an umbel; marginal, ligulate flowers of a composite head.

Receplacle.-The end of the axis to which the floral organs are attached; torus.

Reflexed.-Turned back.

Regular (flower).-The parts of each whorl similar.

Reniform.-Kidney-shaped.

Reticulate.-Netted.

Retrorse.-Turned back or downward. 
Rhisome--Rootstock; underground stem, usually horizontally elongated.

Rotale.-Wheel-shaped.

Ruderal.-Growing in waste places; weed.

Runner.- I prostrate, slender, above-ground stem, such as in the strawberry.

Saccate.-With a sac.

Sagittate- -Shaped like an arrow-head, with the lobes turned downward.

Sulierform (sympetalous corolla).-Tubular with a spreading limb.

Scabrous.-Rough.

Scalc.-Reduced leaf that appears lower on the stem than the foliage leaves.

Scapose--Bearing a nearly leafless flower stalk arising from the base of the plant.

Schizocurp.--A dry, indehiscent fruit, of two carpels, cach one-seeded, - which split apart at maturity into two halves or mericarps.

Silerenchymatous. - Composed of cells that fit closely together and have thick, hardened walls.

Scutcllum.-Morphologically, the cotyledon of the grass embryo.

Segment.-A division of a leaf, fruit or flower.

Scminal.-Belonging to the seed.

Seplum.-Partition or dividing wall.

Serrate.-With sharp teeth that point forward.

Sessile.-Sitting; without a stalk.

Sheath.-A tubular envelope about the stem, such as occurs in the leares of grasses.

Silicle--Similar to a silique, except that it is broader than long.

Silique.-Pod-like fruit of mustards, dehiscent, two-ralved, and with two parietal placentas; longer than broad.

Sinuate.-Wavy along the margin.

Sinus.-The space between two lobes.

Spathe-A large bract or pair of bracts, subtending a spadix or flower cluster.

Spatulate--Shape of a spatula or spoon.

Spicale.-Spike-like.

Spike.-In indeterminate type of inflorescence in which numerous scisile flowers are borne on a rachis.

Spikelet.-The unit of inflorescence in grasses and sedges; a small spike. Spinulose.-With small spines.

Squarrose.-With spreading parts.

Staminal.-Of or pertaining to stamens.

Staminate (flowers).-Bearing stamens only.

Staminodcal.-Pertaining to staminodia, i.e., abortive and sterile stamens. 
Standard.-The large petal in the flowers of Leguminosæ.

Sterile-Unproductive; without the reproductive elements.

Stipitate.-Provided with a stalk or stipe.

Stipules.-Appendages at the base of the petiole.

Stipulate--Bearing stipules.

Stolon.-A trailing stem, above ground, that easily takes root at the nodes when it touches the ground.

Stooling.-Production of secondary branches from lowermost nodes, as in grasses; tillering.

Strobile.-Spike-like pistillate inflorescence of hop; also cone-like group of sporophylls.

Stylar.--Of or pertaining to style.

Stylopedium.-Style-foot. The nectariferous gland at the base of the style in the Umbelliferous fruit.

Sub.-Prefix signifying below, under, or almost, less than normal, in an inferior degree.

Subtend.-To grow under, or be adjacent to, as a bract subtending a flower.

Subulate.-Awl-shaped.

Sucker.-Rapidly growing shoots from roots or from stems underground. Superior (flower).-Ovary appearing above the other parts of the flower.

Sympetaly.-Petals united.

Suture.-A line of splitting.

Sympetalous.-With the petals united to form a tube.

Syncarpy.-Condition in which the carpels are united.

Synconium.--Fleshy fruit, in which the receptacle is hollow, and its inner wall is lined with numerous flowers.

Syngenesious.-With the anthers united, as in Compositx.

Tasscl.-Staminate inflorescence in corn.

Tendril.--Slender, coiled organ used in climbing.

Terete-Cylindrical; pencil-shaped.

Ternate.-Arranged in threes or divided into three divisions.

Testa.-Seed coat.

Tillering.-Production of branches from the lowermost nodes, as in grasses.

Tomentose.-Covered with dense wool-like hair.

Tomentum.-Dense, woolly hair.

Torus.-Receptacle of a flower.

Transhucent.-Partially transparent.

Trifoliate.-With three leaflets, as in clover.

Truncale.-As if cut off squarely at the tip.

Tuberculate--Furnished with tubercles or small projections.

Tuberous.-Swollen and tuber-like.

Tubular.-Tube-shaped.

Turbinate--Top-shaped. 
L'mbel.-An indeterminate type of inflorescence, in which the pedicels arise from the same point.

Umbellate.-Umbel-like.

Umbellet.-Umbel of secondary order.

Undulate.-With wavy margin.

Uiricle. $-A$ one-seeded fruit with a bladder-like covering.

Vilvale (arrangement of parts in the bud).-The segments meet with their edges, without any overlapping.

Valves.-One of the pieces into which a capsule splits. .

Venalion.-The arrangement of veins.

Ventral.-On the lower side; surface of member turned toward the main axis.

Vernation.-Arrangement of leaves in the bud.

Versatile (anther).-Filament is attached near middle of anther, so that it can readily turn in any direction.

Vexillum.-Standard of the flower in Leguminosx.

Viscid.-Sticky.

Villa (pl. vittæ),-Oil tubes in Umbellifer fruit.

Wing.-Lateral petal in the flower of Leguminosx.

II horl.- I group of organs arranged in a circle about a stem, and arising from the same node.

Zygomorphy (flower).-See Irregular. 



\section{INDEX}

Abutilon, 506

Abyssinian oats, I30

Achene, 58

Achillea, 625

Acrospire, I 44

Adjuki bean, 423

Adriatic figs, 275

Aegilops, Iro

African cotton, 517

millet, 213

Agave, 47, 28I

Agropyron repens, 70, 75

Agrostis, 8I

Aino millet, 218, 219

Al $x, 4$ I 5

Albumin, 105

Aleurone layer, IO2

Alfalfa, 442

American, 447

Arabian, 447

Baltic, 447

German, 447

Grimm, 447

Peruvian, 447

sickle, 447

Turkestan, 447

variegated, 447

yellow-flowered, 447

Algæ, 62, 63

Algerian oat, I3I

Allium, 23 I

ascalonicum, 231, 237, 238

сера, 232, 237, 240

bulbellifera, 24I

multiplicans, $24 \mathrm{I}$

fistulosum, 232, 237, 239

sativum, 236, 237

schœnoprasum, 23I, 232, 237, 238
Almond, 4IO

bitter, 4 II

hard-shelled, 4II

oil, 4. I I

soft-shelled, 4I I

sweet, 4 I I

Aloe, 229

Alopecurus, 79

Alsike clover, 433, 434

Althæa, 506

officinalis, 507

rosea, 507

Amarelles, 404

Amaryllidacea, $28 \mathrm{I}$

Amelanchier, 366, 367

American alfalfa, 447

cotton, 5I2, 520

cranberry, 548

black currant, 319,320

crabapple, 379

flowering currant, 319,320

gooseberries, $32 \mathrm{I}$

ivy, 492

laurel, 543

plum, $397,400,401$

red raspberry, 357

upland cotton, 520

Amygdalus persica, 407

Amyris, 475

Andropogon, 87, 88

sorghum, I9I

halepensis, 197

Angelica, 532

Angiospermx, 62

Animated oats, I3I

Annual ring, 40

Annuals, 2I, 70

Antennaria, 625 
Anther, 48, 49

Anthyllis, 429

Antipodals, 50

$\Lambda$ pium, 533, 538

graveolens, 539, 540

rapaceum, 540

key to principal species of, 539

leptophyllum, 539

petroselinum, 539

Apple, 367

American crab, 379

common, 379, 38I

family, 366

flowering crab, 379

narrow-leaved crab, 379

Siberian crab, 379

Soulard crab, 379, 38I

western crab, 379, $38 \mathrm{I}$

Apricot, 405

black, 407

common, 405

Japanese, 407

purple, 407

Siberian, 407

Arabian alfalfa, 447

Arachis, hypogøea, 462

Aragallus, 4I4

Arctostaphylos uva-ursi, 543

Arnica, 625, 628

alpina, 600

Arrhenatherum elatius, 75

Artemisia, 625, 628

Artichoke, globe, 639

Jerusalem, 639

Artificial gums, I 85

Artocarpus communis, 252

Arundinaria, 84

Ascomycetes, 64

Asiatic cotton, 5I I, 5I 2

Asparagus, 244

bean, $422,45^{8}$

falcatus, 244

"fern" 246
Asparagus, laricinus, 244

lettuce, 632

medeoloides, 246

officinalis, 244,246

plumosus, 246

sprengeri, 246

Aster, 625,628

Astragalus, 4I 4

Atriplex, 296

hortensis, 299

Atropa belladonna, 559

Auricle, 78

Australian tobacco, 600

Autogamy, 5I, 94

Autumn wood, 40

Avena, 88, I 23

abyssinica, $\mathbf{I} 30$

algeriensis, $\mathrm{I} 3 \mathrm{I}$

barbata, I3I

brevis, 130

byzantina, I30, I3I

fatua, I28, I30, I3I

nuda, I30, I $3 \mathrm{I}$

orientalis, I25, I30, I $3 \mathrm{I}$

sativa, 89, I 25, I 26, I 28, I 30, I 3 I

sterilis, I3I

strigosa, I3O, I3 I

wiestii, I3I

Awns, 82

Azalea, 543

Bagasse, 227

Baltic alfalfa, 447

Bamboo, 69

Bambusæ, 84

Banner, 4I 4

oats, 130

Banyan, I6

tree, 267

Barbe de Capuchin, 636

Bark, 39, 40

Barley, 72, 88, 89, I35

black, 145 
Barley, bluc, I 45

$$
\text { fan, } 146
$$

four-rowed, 144

hooded, I36, 137, 145, I 46

hull-less Jerusalem, 145

hybrid, I45

medium, I $37, \mathbf{I} 43, \mathbf{I} 45, \mathbf{I} 46$

Nepal, I45

peacock, 146

six-rowed, I 44

two-rowed, I 4.5

bent, 147

erect-eared, 147

naked, I 46

nodding, 147

Barnyard grass, 2 r

millet, $210,219,220$

Basidiomycetes, 64

Basin, 378

Bean, 42I

adjuki, 423

asparagus, $422,45^{S}$

broad, 422, 426, 429

coffee, 456

Dolichos, 422

Dutch case-knife, 423

flowering, 423

hyacinth, 422

Jack, 422

kidney, 423, 426

Lima, 423, 424

locust, 422

Mexican, 424

mung, 423

painted lady, 423

scarlet runner, 423

Sieva, 423, 424

soja, 456

soy, 422,455

velvet, 422

Windsor, 427, 429

Beards, 82

Bect, common garden, 300, 310
Beet, foliage, 3or

leaf, 30 I, 312

ormamental, 301

pulp, 300

sea-kale, 312

seed, 306

multiple-germ, 306

single-germ, 306

silver, 3 I 2

spinach, 3 I 2

sugiar, 300, 301

wild, 30 I

Belladonna, 559

Benincasa cerifera, $61_{3}$

Bergamot, 487

Beriberi, 206

Berry, 59

Berseem, 433

Beta, 298

cycla, 3 I 2

maritima, 30 I

vulgaris, 300

Bidens, 625

Biennials, 2 I

Bigarreaus, 403

Bilberry, dwarf, 546 tall bilberry, 547

thin-leaved, 544

Bindweed, 284

Binomial system, 64

Bird's-foot trefoil, 466

Bistort, 286

Bittersweet, $56 \mathrm{x}$

Black apricot, 405

barley, I 45

bitter vetch, 428

blueberry, 547

-cap raspberry, 357

mulberry, 255, 257

mustard, 327, 339

nightshade, 560

salsify, 635

Blackberry, 354 
Blackberry, dewberry, 354

high-bush, 354 ?

key to principal species of, 354

leafy-cluster, 354

long-cluster, 354

loose-cluster, 354

sand, 354

white, 354

Blade, 42, 77

Blanched asparagus, 250

Blastophaga, grossorum, 27 I

Blitum capitatum, 296

Blood orange, 484

Blue barley, I 45

Blueberry, $55^{\circ}$

black, 547

Canada, 546

high bush, $547,55^{\circ}$

low, 546

black, 546

bush, $55^{\circ}$

Bokhara, 453

Boll, 5 I 4

Bonavist, 422

Brace roots, I6, I59

Bracteole, 80

Bracts, 78

Brambles, $35 \mathrm{I}$

Bran, זо6 layer, I05

Brandy, $5 \circ 3$

Brassica, 326, 327

alba, 327,340

arvensis, 3.39

campestris, 328, 337

juncea, 340

key to species of, 327

napus, 328,338

nigra, 327, 339

oleracea, 328

botrytis, 330, 334

capitata, 329, 33I

caulo-rapa, 330, 333
Brassica, oleracea, gemmifera, 329, 330 viridis, 329,330 rapa, 65, 328, 335

Bread-fruit, 252

Breaking, hemp, 280

Brebas, 275

Brewing process, 149

British gums, 185

Broad bean, 422, 426, 429

Broccoli, 334

Bromus inermis, 76

Broom corn, 88, 196, 197 -corn millet, 210, 213

Brown mustard, 339

Brush, 99

Brussel's sprouts, 329,330

Bryophytes, 62

Buchloe, 70 dactyloides, 76

Buckbean, 4I 4

Buckwheat, 286, 289 common, 289 gray, 294 family, 284 Japanese, 294 notch-seeded, 294 silver hull, 294 Tatary, 293

Bud variation, 25

Buds, 23

accessory, 24

adventitious, 24

alternate, 25

axillary, 24

branch, 23

classification of, 23

dormant, 23

flower, 23

grafting, 23

lateral, 24

leaf, $\cdot 23$

mixed, 23

opposite, 25 
Buds, terminal, 2.4 supernumerary, 24 whorled, 25

Buffalo bur, 561 currant, 319

Bulbs, 32, 229

Bullaces, 400

Bulletin Smyrnas, 275

Bundle scar, 26

Bupleurum, 530

Cabbage, 328

common, 3.3I

key to cultivated types of, 329 types of common head, 332 lettuce, 633

Calamondin orange, 487

Calendula, 625

Callirrhoë, 5o8

Calyx, 48

Cambium, 36 ring, 38

Camelina, 326

Campanulacere, 600

Canada blueberry, 66, 546 crookneck squash, 6I 5

potato, 639

rice, 206

thistle, $2 \mathrm{I}, 28$

Canadian field pea, 420

Cane sugar, production of, 228

Cannabis, 252 indica, $28 \mathrm{I}$ sativa, 276

Cantaloupe, 6 I 8

Caper family, 326

Capparidacex, 326

Caprification, 273

Caprifig, 269, 272, 276

Capsaican, 595

Capsella, 326

Capsicum, 560, 595

annuum, 592
Capsicum, annuum, abbreviatum, 595

acuminatum, 595

cerasiforme, 595

conoides, 595

fasciculatum, 595

frutescens, 595

grossum, 595

longum, 595

Capsule, 58

Caraway, 533

Carbohydrate synthesis, 46

Carduus, 625, 628

Carina, 4 15

Carolina rice, 206

Carpophore, 532

Carrot, 533

family, 530

Carum, 533

Caryopsis, 83

Catawba grape; 5 ㅇ

Catjang, $45^{8}$

Cat-tail millet, 2I 3

Cauliflower, 330, 334

Cavity, 378

Cayenne pepper, 595

Celeriac, 540

Celery, 540

Cell, 4

as unit of structure, 5 of plant activity, 5

Cell sap, 6 wall, 6,8

Celluloid, 526

Central cylinder, 17

Cercocarpus, 348

Cereals, 87

key to groups (genera) of, $8_{7}$ small-grain seedlings of, 88

Chretochloa, 88, 210,2 I I

italica, $211,216,218$ key to principal types of, $2 \mathrm{r} 8$ maximum, 218

moharium, 219 
Chætochloa, viridis, 2II, 2 I9

Chard, 312

Charlock, 339

Chasmogamy, 82

Chenopodiaceæ, 296

key to principal genera of, 297

Chenopodium, 297

Cherry, 4 요

sour, 403

sweet, 402

tomato, 587,590

Chicasaw plum, 401

Chick pea, 467

Chicory, 628, 635, 636

Chilean strawberry, 363,364

Chilli con carne, 596

Chinese cotton, 5 I 7

mustard, 340

pear, 384,385

Chiogenes hispidula, 543

Chives, 237, 238

Chlorophyceæ, 63

Chloroplastids, 8

Chromoplastids, 8

Chrysanthemum, 625,628

Chrysothamnus, 625

Ciboule, 237, 239

Cicer arietinum, 467

Cichorium, 628

endiva, 635,636

intybus, 635,636

Cider, 383

Cinque-foil, 348

Citrange, 489

Citron, 480, 622, 623

Citrullus, 6ro, 622

vulgaris, 623

Citrus, 476

aurantifolia, 480,483

aurantium, 480,487

bergamia, 487

grandis, 480,485

ichangensis, 487
Citrus, key to principal species of, 479 limonia, 479, 48I medica, 479,480

mitis, 487

nobilis, 480,485

deliciỏsa, 485

unshiu, 485

sinensis, $480,48.4$

Cive, 237,238

Cladophylls, 244

Classification and naming of plants, 60

Cleistogamy, 82

Close pollination, $5 \mathrm{I}$

Clover, 66, 432

Alsike, 433, 434

Berseem, 433

crimson, 433, 435

Dutch, 433

hop, 442, 449

giant, 453

Italian, 435

Japan, 465

Ladino, 434

mammoth, 433, 439, 44I

meadow, 44I

medium red, 44I

Persian, 433

purple, 436

red, 433,436

scarlet, 433,435

Shaftal, 433

spotted bur, 442, 449

Swedish, 433, 434

sweet, $45^{2}$

toothed bur, 4.72, 452

white, 433, 44I

zigzag, 433, 44I

Cloudberry, $35^{\circ}$

Club mosses, 62

wheat, III, II 2, II 4

Cob, I63

Coffee bean, 456

Coleanthus, $8 \mathbf{I}$ 
Coleoptile, $x$ o4

Coleorhiza, 10, $\mathrm{ro}_{3}$

Collard, 329, $33 \circ$

Collodion, 526

Colocynth, 622

Columnar epithelium, I04

Commissure, 532

Common apple, $379,38 \mathbf{I}$

apricot, 405

barnyard grass, 210

bread wheat, II I, II 2, II 3, I 44

buckwheat, 289

eggplant, 586

fig, 269, 275

gray buckwheat, 294

hop, 33

millet, 219

onion, 232, 237

pear, 384,385

six-rowed barley, I 44

sugar beet, 300,3 I0

sweet pea, 432

wheat, 65 , III, II 2, II 4

Companion cells, 35

Compass plant, 632

Composite family, 625

Compositæ, 625

key to important genera of, 628

Concord grape, 501

Conium, 532

Convolvulaceæ, 554

key to important genera of, 555

Convolvulus, 554

Cordelia figs, 276

Corchorus capsularis, 28I olitorius, 28I

Core line, 377

Coriander, 533

Corinth currants, $50 \mathrm{I}$

Cork cambium, 38

tissue, 38

Corms, 32

Corn, I 57
Corn, dent, i 78 , i80

flint, $178, \mathrm{I} 8 \mathrm{so}$

fodder, I 85

oil, 184

pod, $\mathbf{I} 78, \mathbf{r} 80$

pop, I 78, I 80

soft, 178,180

starchy sweet, I 78,180

sweet, I 78, I 80

starch, 184

stover, 186

xenia in, 172

Corolla, 48

Coronilla, 429

Cortex, 17

Corymb, 56

Cos lettuce, 633

Cotoneaster, 366

Cottolene, 524

Cotton, 508

African, $5 \mathrm{I} 7$

American, 51 2

Asiatic, 5II, 5I 2

Chinese, 5 I 7

Egyptian, 5 ro

Guatemalan, 512

Nankin, 5I 7

Red Peruvian, 5 I 7

Sea Island, 520

types and varieties of American, $52 \mathrm{I}$

Upland, 510, 520

Wild, 520

Cottonseed hulls, 524

meal, 524

oil, 524

Couloure of Muscat grape, 498

Cowberry, $55^{\circ}$

Cowpea, 460

Crab-apple, American, 379

flowering, 379

narrow-leaved, 379

Siberian, 379

Soulard, 379, 38I 
Crab-apple, western, 379,38 I

Cranberry, 548

American, 548

European, 544

large, $54^{8}$

mountain, 550

small, 548,549

types of, 549

Cratægus, 366,367

Creeping snowberry, 543

wintergreen, 543

Crimson clover, 433,435

Cross pollination, 52

artificial, 95

Crown vetch, 429

Cruciferæ, 323

key to principal genera of, 326

Cucumber, 615, 617, 620

common field, $620,62 \mathrm{I}$

English forcing, 62 I

Jerusalem, 6 I 7

musk, 620

prickly, 6 I7

Sikkim, 62I

squirting, 606

snake, 620

star, 606,620

wild, 606

Cucumis, 6 Iо

anguria, $617,620,622$

dipsaceus, $6 \mathrm{I}_{3}$

key to principal species of, $6 \mathrm{I} 7$

melo, 6i 7,6 г 8

var. acidulus, 620

cantalupensis, 6 I 8

chito, 620

dudaim, 620

flexuosus, 618,620

inodorus, 619

reticulatus, 6r 8

saccharinus, 6 I 8

moschata, 620

sativus, 617,620
Cucumis, sativus, anglicus, 62 i

Sikkimensis, $62 \mathrm{I}$

Cucurbit, 606

Cucurbita, 610, 61 2

key to important species of, $6 \mathrm{I} 2$ maxima, 6I 2,6 I 3

moschata, 612, 613

pepo, 6I 2,6 I $_{3}$

ovipera, 6 工 3

Cucurbitaceæ, 606

key to principal genera of, 6 to

Culms, 72

Currant tomato, 587

Currants, American black, 319, 320

flowering, 319, 320

Buffalo, 3 I9

European black, 319, 320

golden, 319

Missouri, 319

red, 320

white, 320

Cushaw, 6ז 2, 6ז5

Cuticle, 44

Cutting lettuce, $6_{33}$

Cyanophyceæ, 63

Cyclanthera, 608

Cydonia, 388

oblonga, 388

varieties of, 388

Cymopteris, 532

Cynara scolymus, 639

Cyperaceæ, 85

Cyphomandra betacea, 592

Cypress vine, 554

Cytase, 142

Cytoplasm, 6

Dahlia, 625

Dakota vetch, 429

Damson, 400

Dandelion, 628

Dangleberry, 547

Danish ball head cabbages, 332 
Datura, 559

Daucus, 533

carota, 533

varieties of, 535

Delaware grape, 50 I

Dent corn, $178, \mathbf{1} 80$

Dermatogen, 17

Dewberry, 355

blackberry, 354

key to principal species of, 356

northern, 356

Pacific Coast, 352

- southern, 356

western, 356

Dextrins, $I 85$

Diastase, I42

Dichogamy, 169

Dicot stem, 33

stem, growth in thickness of, $3 \mathrm{~S}$

Dicotyledones, 63

Dimorphism, 292

Dioscorea batatas, 556

Dioscoreaceæ, 556

Disk flowers, 627

Distichlis, 55

Dock, 284

Dolichos bean, 422

Domestic onions, 243

Double fertilization, 53

Dracæna, 229

Dried apples, 383

Drosera, 47

Drumhead cabbages, 332

Drupe, 393

Drupacex, 39 I

Duboisia hopwoodii, 600

Duckweed, 2

Dukes, 403

Durra, I96, I97

Durum wheat, 89 , I I I, II 2 , I I 3

Dutch case-knife bean, 423 clover, 433

Dwarf bilberry, 546
Dwarf broom corn, 200

purple eggplant, 587

Dyc-weed, 4 I 4

Ear, 162

Early or forcing radishes, 243

Earth apple, 639

Ecballium claterium, 606

Echinochloa, 88, 2 10

crus-galli, $210,219,220$

frumentacea, 210,220

Echinocystis lobata, 606

Ectoplasm, 6

Edible-podded pea, 4 I 8

Egg nucleus, 50

Eggplant, 585

common, 586

dwarf purple, 587

snake, 587

Egyptian cotton, 510

onions, 24I, 242

millet, 2 I 3

Eichhornia speciosa, I6

Einkorn, 85, I 10

Eleusine coracana, 210

Elodea, 29

Embryo, 96

sac, 50

Emmer, 89, III, II 2, II3

Endive, 636

Endocarp, 58

Endodermis, I 7, 57, 96, 102

English currants, 50 I

Entire wheat, Io8

Epiblast, IO4

Epidermis, 34

Epigæa repens, 543

Epiphyte, 28

Episperm, roI

Equisetales, 64

Erect-eared barley, I47

Ericacea, $5+3$

Erigeron, 625, 628 
Erinocyce figs, 275

Eriogonum, 285, 286

Eryngium, $53^{\circ}$

Euchlæna mexicana, I8I, I82

European black currant, 3I9, 320 cranberry, 544 gooseberries, 32 I

raspberry, 357 strawberry, 363,364

Eurotia, 297

Evergreen or fire thorn, 366

Everlasting pea, 432

Exocarp, 58

"Eyes," 3I

Fagopyrum, 286

emarginatum, 294

tataricum, 293

vulgare, 289

False flax, 326

Solomon's seal, 2I

Tan barley, I 46

Farkleberry, 543

Fennel, 533

Fenugreek, 467

Fermentation, 150

Fern plants, 62

Fertilization, 52

Festuca ovina, 79

pratensis, 76

Fiber flax, 473

of cotton, $5 \mathrm{I} 4$

Ficus, 267

aurea, 267,268

benghalensis, 267

brevifolia, 268

carica, 268, 269

elastica, 252

religiosa, 267

Field cucumber, $62 \mathrm{I}$

pea, 4 I 8,420

Fig, 267

Adriatic, 275
Fig, common, 269, 275

Cordelia, 276

Erinocyce, 275

Golden, 267

Mission, 275

San Pedro, 275

Smyrna, 275

wasp, 27 I

wild, 276

Filament, 48

Filicales, 64

Finger millet, 210

First patent, 108

Five-finger, 348

Flat Dutch cabbages, 332

onions, $24 \mathrm{I}$

-podded pea, 432

Flax, 48, 470

family, 469

fiber, 473

large-seeded, 473

Sicilian, 473

small-seeded, 473

Fleabane, 625,628

Flint corn, $\mathbf{1} 78, \mathbf{1} 80$

Flour, kinds of, 108

Flower, apetalous, 55

complete, 55

hermaphroditic, 55

incomplete, 55

naked, 55

perfect, 55

pistillate, 55

staminate, 55

symmetry of, 53

Flowering bean, 423

crabapple, 379

raspberry, 254

Flowers, 48

incomplete, 55

parts of representative, 48

Fly oats, 13 I

Fœniculum, 533 
Foliage beet, 3 Iо

Follicle, $5^{8}$

Forage crops, I 86

Foreign onions, 243

Fortunella, 476, 487

crassifolia, 489

hindsii, 489

japonica, 489

margarita, 488

Four-rowed barley, I44

Foxberry, 550

Foxtail millets, 21 I, 216, 2 I9

grass, 2 II

Fragaria, 358 californica, $3_{3} 3$

chiloensis, $36_{3}, 364$

glauca, 363

vesca, 363,364

virginiana, 363

Fraxinus, 55I

Fruits, kinds of, 58 dehiscent, 58

dry, 58

fleshy, 59

indehiscent, 50

Fungi, 62

Furrow, I00

Fusarium, 570

Gall flowers, $27 x$

Garden pea, 418.

lemon, 620

radish, 34I

tomato, 590

Garlic, 236, 237

Gaultheria, 543

Gaylussacia, 543, 545, 547

brachycera, 547

dumosa, 547

frondosa, 547

key to North American species of, 547

resinosa, 547
Gaylussacia, ursina, 547

Geitonogamy, 5 r

Generative nucleus, 50

Genista, 4I 4

Geotropism, 73

German alfalfa, 447

celery, 540

millet, 21 8,219

Gherkin, 622

Giant clover, 453,563

Girasole, 639

Gleditsia, 4I 4

Gliadin, 105

Globe artichoke, $\sigma_{39}$

onions, $24 \mathrm{I}$

Globulin, I05

Glucose, 184

Glume, flowering, 80

Glumes, 79, 80

Gluten, I02, I06, I55 meal, 186

Glutenin, Io6

Glycyrrhiza, 4I4

Golden currant, 319 fig, 267

wonder millet, 2 I 8,2 I9

Goldenrod, 625

Goober, 462

Gooseberry family, 3 I 6 gourd, $6{ }^{7} 7$

Gooseberries, 32 I

American, $32 \mathrm{I}$

European, 321

Goosefoot, 296

family, 296

Goose wheats, I 13

Gossypium, 508

barbadense, 5 I 9,520

hirsutum, 517, 518, 520

Gossypol, 524

Gourd, 610, 6r 3

family, 606

gooseberry, 6 I 7 
Gourd, winter, 615

Grafting, 36

Graham flour, 108

Grain, 83

coats, 96

Gramineæ, 69

Granules, 8

Grape, 492

Catawba, 50 I

Concord, 501

Delaware, 5oi

family, 49I

Muscat, 498

Niagara, 50 I

northern fox, 499, 500

Old World, 499

raisin, 499, 50 I

river bank, 499, 500

sand, 499, 500

southern fox, 499, 500

sugar, 185

summer, 499, 500

wine, 499,501

Grapefruit, 485

Grass family, 69

awnless brome, 76

bunch, 76

buffalo, 70,76

quack, 75

rice-cut, 70

tall oat, 75

Grasses, bulbous, 75

rhizome-bearing, 75

stoloniferous, 76

tufted, 76

Greasewood, 297

Green asparagus, 250

foxtail, 2I I, 2I9

gages, 398

Green-weed, 4I 4

Grimm alfalfa, 447

Griottes, 404

Groove, Ioo
Grossulariacex, 3 I6

Ground meristem, 34

Growing point, 57

Guard cells, 45

Guatemalan cotton, 5 I 2

Guinea squash, 585

Gumbo, 527

Gums, artificial, I 85

British, I 85

Guncotton, 525

Gymnospermæ, 62

Hackling, hemp, 280

Hairs, basal, 92

Hairy vetch, 427, 430

Halophyte, 296

Head, 56 lettuce, 633

Hearts, 403

Heath family, 543

Hedysaræ, 4I 5

Helianthus, 628 tuberosus, 639

Hemp, 252, 276 sisal, 28 I tow, 280

Hennequin, 281

Hepaticæ, 64

Herb, 2

Hesperidium, 478

Heterostyly, 292

Hibiscus, 506 esculentus, 507,527 syriacus, 508

High-bush blackberry, 354 blueberry, $547,55^{\circ}$

Hog millet, 213

Hollyhock, 508

Homalocenchrus, 70, 8I

Homogamy, 169

Honduras rice, 206

Hooded barley, I36, I37, I45, I46

Hop, 33, 252 
Hop, clover, 4.42, 449

$$
\text { -meal, } 264
$$$$
\text { -tree, } 475
$$

Hordeum, 88, 135

$$
\text { distichon, } 135, x_{36}, x_{37}, x_{43}, x_{45}
$$
crectum, 147

nudum, 146

nutans, $x_{4} 6, \mathrm{I} 47$

zeocriton, 146

spontaneum, $I_{4} 8$

vulgare, I44,

coeleste, I45

coerulescens, $\mathbf{1} 45$

hexastichon, I36, I37, I43, I44, 146

intermedium, $x 37, x 43,145, x 46$

nigrum, I45

pallidum, I43, I45, I46

trifurcatum, $136,137,145,146$

Horse millet, 213

nettle, 560

Horseradish, 345

Horsetails, 62

Hortulana plum, 400

Hosackia, 429

Hubbard squash, 6 I 4

Huckleberry, 547

black, $547,55^{\circ}$

blue, 546,547

box, 547

bush, 547

Carolina, 547

dwarf, 547

family, 543

high bush, 547

southern black, 544

swamp, 547

Hull-less Jerusalem barley, I 45

oats, 130

Humulus, 252, 258

japonicus, 265

lupulus, $25^{8}$

neomexicanus, 265
Hungarian millet, 219 vetch, 430

Husk tomato, 592

Hyacinth, 229 bean, 422

Hyaloplasm, 6

Hybrid barley, 145

Hydrocotyle, 530

Hypocotyl, 57, 104

Ichang lemon, 487

Imperatrice plums, 399

Incomplete flowers, 55

Indian corn, 88

millet, 213

mustard, 340

tobacco, 600

India rubber plant, 252

Inflorescence, determinate or cymose, 56 indeterminate or racemose, 56

scar, 26

simple, 56

Integuments, 50

Intercellular spaces, 44

Internodes, 72

Intracalicary organs, of cotton, $5 \mathrm{I}_{3}$

Involucre, of cotton; 512

Ipomœa, 554, 555

batatas, 555

bona-nox, 554

pandurata, 554

purpurea, 554

Italian clover, 435

Jack bean, 422

Japan clover, 465

ivy, 33

millet, 2I3

rice, 206

Japanese apricot, 407

barnyard millet, 210,220

buckwheat, 294

hop, 265 
Japanese pear, 384,385

or pot-herb mustard, 340

plum, 400

Jasminium, 55 I

Jerusalem artichoke, 628,639 cucumber, 617

Jessamine, $55 \mathrm{I}$

Jimson-weed, 560

Jumbos, 464

Juncaceæ, 85

Jute, 28I

Kafir, I96, I97

Kale, 329, 330

Kalmia, 543

Keel, 4I 5

Kidney bean, 433, 424

$$
\text { vetch, } 429
$$

King orange, 485

Kinkan, 487

Kinnikinic, 543

Kleinwanzlebener sugar beet, 308

Knaurs, 553

Knotberry, $35^{\circ}$

Knotweed, 284, 286

Kochia, 297

Koeleria, 79

Kohlrabi, 330, 333

Kowliang, I97

Kuhria, 627

Kumquat, 487

Hongkong wild, 489

Marumi, 489

Meiwa, 489

Nagami, 488

oval, 488

round, 489

Lablab, 422

Labrador tea, 543

Lactuca, 628

sativa, 629

angustana, 632
Lactuca, sativa, capitata, 633 intybacea, 633 romana, 633

scariola, 630

Ladino clover, 434

Lagenaria vulgaris, $6 \mathbf{I}_{3}$

Lamb's quarters, 296

Lamella, middle, 375

Lamina, 77

Large cranberry, 548

leaf tomato, 590 -seeded flax, 473

Lathyrus, 4r 4

Lawn grass, 70

Layering, $3 \mathrm{I} 6$

Leaf, beet, 3 OI, $3 \mathrm{I} 2$

floral, 2

foliage, 2

scale, 2

scar, 26

stalk, 42

Leaflets, 44

Leafy-cluster blackberry, 354

Leaves, 42

compound, 44

development of, 42

foliage, 42

kinds of, 42

parts of, 42

simple, 44

structure of, 44

Leek, 232, 236,238

Ledum, 543

Legume, 4 I 3

Leguminos $x$, 4I 3

key to principal genera of, $4 \mathrm{I} 6$

Lemma, 8o

Lemon, 48I

Ichang, 487

Lenticel, 27

Lepidium, 326

Lespedeza striata, 465

Lettuce, 628 
Lettuce, asparagus, 632

cos, 633

cutting or cut-leaved, 633

garden, 629

head or cabbage, 633

key to types of, 632

Leucoplastids, 8

Lianas, 33

Licorice, 4I4

Lignin, 36

Ligulate flowers, 627

Ligule, 78

Liguliflor $x, 627$

Ligustrum, $55 \mathrm{I}$

Lilac, 55 I

Liliaceæ, 229

Lilium, 229

Lily, 229.

family, 229

Lima bean, 423, 424

Lime, 483

Limequat, 483

Linace $x, 469$

Linen, 473

Linoleum, 473

Linseed oil, 473

Linum, 470 catharticum, 469

usitatissimum, 470

Llanos, 69

Liverworts, 62

Lobelia inflata, 600

Lobfigs, 275

Locks, 5 I 4

Loco, 4 I 4

Locust, 4 I 4

bean, 422

Lodicules, 80

Lodging, 72

Loganberry, $35^{8}$

Lombard plums, 399

Long-cluster blackberry, 354

Loose-cluster blackberry, 354
Lotus corniculatus, 466

Low black blueberry, 546

blueberry, 546

bush blueberry, $55^{\circ}$

Luffa, 6 I $3_{3}$

Lupines, 465

Lupinus, 465

Lupulin, 264

glands, 264

Lupuline, 266

Lycium, 559

Lycopersicum, 587

esculentum, cerasiforme, 587

grandifolium, 587,588

pimpinellifolium, 587,588

pyriforme, 587

validum, 587

vulgare, 590

Lycopodiales, 64

Macaroni, I 8

wheats, II3

Macounastrum, 284

Maiz de coyote, I79

Maize, 88, I57

Male nuclei, 50

Mallow family, 505

Malting, I49

Malus, 366,367

angustifolia, 379

baccata, 379

coronaria, 379

floribunda, 379

ioensis, 379,38 I

key to principal species of, 379

soulardi, 379,38 r

sylvestris, $379,38 \mathrm{I}$

Malva, 507,508

Malvacex, 505

key to important genera of, 508

Mamme, 272

Mammoni, 272 
Mammoth clover, 433, 439, $44 \mathrm{r}$ pumpkins and squashes, $6 \mathrm{r}_{5}$

Mandarin orange, 485

Mand's wonder forage plant, 2 I3

Mane oats, I3o

Mangels, $3 \mathrm{I} 3$

Mangel-wurzels, 3 I 3

Man-of-the-earth, 554

Marblehead squash, 6I4

Marigold, 625

Marrow squashes, 6r 4

Marsh mallow, 506

Massecuite, 227

Mayberry, 358

Mazzards, 402

Meadow clover, 44I

fescue, 76

foxtail, 79

Meadows, 69

Mealiness, in apple, 375

Medicago, 44I

arabica, 442, 449

inermis, $45 \mathrm{I}$

falcata, 443,447

hispida, 442,452

confinis, 452

denticulata, 452

reticulata, 452

key to principal species of, 442

lupulina, 442, 449

media, 447

sativa, 442,447

polia, 448

Medics, 44I

Mediterranean oats, I30 orange, 484

Medium barley, I37, I43, I45, I46 red clover, $44 \mathrm{r}$

Medulla, 18

Medullary ray, 35, 39

Megarhiza californica, 6ro

Melilot, 453

Melilotus; $45^{2}$
Melilotus, alba, 453, 454 altissima, 454

gracilis, 454

indica, 454

officinalis, 453,454

speciosa, 454

Melon apple, 620

pear, $56 \mathrm{I}$

Melons, 6i 8

cucumber, 620

Dudaim, 620

Mango, 620

netted, 618

orange, 620

pineapple, 6 I 8

pomegranate, 620

Queen Anne's pocket, 620 snake, 6 I 8

winter, 6r9

Mendelism, 42I

Mendel's law, 42 I

Mericarp, 532

Meristem tissue, 33

Mesembryace $\boldsymbol{x}, 299$

Mesocarp, 58

Mexican bean, 424

grass, I 82

Micrampelis, 608

Micropyle, 50, 57

Middlings, 108

Millet, 88, 2 I

African, 213

Aino, 218

barnyard, 210, 219

broom-corn, 210,213

Egyptian, 213

foxtail, 2II, 2I 6

German, 218

Golden Wonder, 2 I 8

Hog, 2 I 3

Horse, 2 I 3

Hungarian, 2 I9

Indian, 2I 3 
Millet, Japan, 2I 3

Japanese barnyard, 210, 220

key to principal economic types (species) of, 210

pearl, 2 I I

proso, 210, 2 I 3

Siberian, $2 \mathrm{IS}$

true, 2 Io

Milo, 88, I96, I97

Mirabelles, 400

Mission figs, 275

Missouri currant, 319

Monocot stems, 39

Monocotyledones, 62

Monolepis, 297

Moon-flower, 554

Mooting, 73

Moracex, 252

Morellos, 404

Morning glory, 33

family, 554

Morus, 252, 253

alba, 255

tartarica, 255

venosa, 255

key to principal species of, 255

multicaulis, 256

nervosa, 256

nigra, 255,257

rubra, $255,257,258$

Moss plants, 62

Mountain ash, 366

bramble, 35 I

cranberry, $55^{\circ}$

mahogany, 348

sorrel, 284

spinach, 299

timothy, 223

tobacco, 600

Mulberry, 252, 253

black, 255,257

family, 252

paper, 254
Mulberry, red, $255,25 \%, 258$

Russian, 255

white, 255

Mule flowers, 27 I

Multiplier onions, 242

Multipliers, 24I

Mung bean, 423

Muscat grape, 498

Musci, 64

Musk cucumber, 620

Muskmelon, 6rs

Mustard, 327

black, 327, 339

brown, 339

Chinese, 340

family, 323

Indian, 340

Japanese, 340

pot-herb, 340

white, 327,340

Myrobalan plum, 400

Myxomycetes, 63

Naked oats, I30

wheats, I I I, I I 2

Nankin cotton, $5 \mathrm{I} 7$

Nardus, 8I

Narbonne vetch, 429

Narrow-leafed crab-apple, 66, 379

leaved vetch, 428

Navel orange, 484

Nectaries, of cotton, 5 I 2

Nectarine, 4 ro

Nepal barley, I45

Nepenthes, 47

New Zealand spinach, 299

Niagara grape, 501

Nicotiana, 560,596

alata, 600

glauca, 596

persica, 600

quadrivalvis, 600

rustica, 600 
Nicotiana, tabacum, 597 tomentosa, 596 wigandioides, 596

Nodding barley, I47

Node, 22

Nodes, 72

Non-saccharine sorghums, I96

Northern dewberry, 65, 356 fox grape, 499, 500

Nucellus, 50, 102

Nucleoli, 6

Nucleus, 6, 8

Nurse crop, 149

Oats, 88,89 , I23

Abyssinian, I 30

Algerian, I3I

animated, I3I

banner, I30

fly, I3I

hull-less, I 30

mane, I30

Mediterranean, I30

naked, I30

panicle, I3O

rough, $\Upsilon_{3} \mathrm{I}$

short, I 30

side, I 30

single, I 26

sterile, I3I

Tatarian, I 30

twin, $\mathrm{I} 26$

wild, 130

Ochrus, 432

Ocrea, 284

Oil cake, 473

meal, 473

Okra, 527

Old World plums, 397

Oleaceæ, 55 I

Olea europocea, $55 \mathrm{x}$

Oleomargarine, 524
Olive, 55 I

family, $55 \mathrm{I}$

Onion, 231, 240

common, 232, 237

Egyptian, 24I, 242

multiplier, 24I, 242

perennial tree, 243

potato, $24 \mathrm{I}$

top, 24I, 242

tree, 24I, 242

Welsh, 23I, 239

Onions, types of, $24 \mathrm{I}$

composition of, 243

uses of, 244

Onobrychis viciæfolia, 465

Ophioglossales, 64

Orache, 299

Orange, blood, 484

Calamondin, 487

common, 484

king, 485

mandarin, 485

Mediterranean, 484

navel, 484

Satsuma, 485

Seville, 487

sour, 487

Spanish, 484

sweet, 484

trifoliate, 489

Unshiu, 485

Organs, 4

absorptive, 4

reproductive, 4

Ornamental beet, 3 ㅇ

Ornithopus sativus, 465

Oryza, 8r, 87, 88

glutinosa, 204

granulata, 206

officinalis, 206

sativa, 200,206

utilissima, 206

communis, 206 
Oryza, sativa, minuta, 206

Osage orange, 252

Ovary, 48 inferior, 54 superior, 54 wall, xor

Ovules, 48, 50

Oxypolis, 530

Oxyria digyna, 284

Oyster plant, 633

Spanish, 635

Pacific Coast dewberry, $35^{2}$

Painted lady bean, 423

Palea, 8o

Palet, so

Palisade tissue, 4.4

Panicle, 56, 79 oats, 130

Panicum, 2 ro miliaceum, 210, 2 I3 compactum, 215 contractum, 2 I 5 effusum, 2 I 5

Papaveraceæ, 326

Paper mulberry, 252, 254

Pappus, 627

Papyrus papyrifera, 252, 254

Parsley, 539

Parsnip, 536

Parthenocarpy, 374

Parthenocissus, 492

Pastinaca, 533 sativa, 536

Pasture crop, I49

Patent flour, ros

Patanas, 60

Pea, 4I 7 chick, 467 common sweet, 432 edible-podded, 4 I 8 family, 4I 3 everlasting, 432
Pea, field, 4I 8,420

flat-podded, 432 garden, 4 I 8

perennial, 432

shelling, 418

sugar, 4 rS

'Tangier, 432

wild, 432

Peach, 407

Peacock barley, I 40

Peanut, $46_{2}$

butter, 464

meal, 465

oil, 465

Pear, 384

Chinese, 384,385 common, 384,385

Japanese, 384,385 sand, 384,385 tomato, 587

Pearl barley, I 49 millet, 2 I I

Peepul tree, 267

Pencilaria, 213

Pennisetum, 88, 210

spicatum, 2 I I

Penny cress, 326

Pepino, 56r

Pepo, 608

Pepper, 592

Cayenne, 595

Tabasco, 595

vine, 492

Perennial, 20, 70

pea, 432

tree onions, 243

Perianth, 49

Periblem, I7

Pericarp, Ior

Pericycle, I 7

Peridrigon plums, 399

Perisperm, IO2

Perpetual strawberry, 363,364 
Persian clover, 433

tobacco, 600

Persicaria, 286

Peruvian alfalfa, 447

Petals, 48

Petiole, 42

Petunia, 559

Phrophycex, 63

Phaseolus, $42 \mathrm{I}$

angularis, 423

aureus, 423

key to principal species of, 423

lunatus, 423,424

macrocarpus, 424

multiflorus, 423

vulgaris, 423,426

nanus, 426

Phleum, 222

alpinum, 223

pratense, 222

Phloem, I8, 35

elements, functions of, 36

parenchyma, 35

Photosynthesis, 46

Phycomycetes, 64

Phylloxera, 499

Phylogeny, 83

Physalis, 559

Pickles, 621

Pie plant, 286

Pileole, I04

Pistil, 48, 5I

Pistillate inflorescence, 55

Pisum, 4I6, 4I 7

sativum, $4 \mathrm{I} 8$

Pitcher plants, 47

Pitching, 150

Pith, I8, 39

Placenta, 50

Placentation, 53

Plant body, I

fundamental internal structure of, 4

cell, 4
Plant body, cell, discovery of; 4 structure of, 6 nomenclature, $\sigma_{4}$

Plastids, chloroplastids, 8 chromoplastids, 8 leucoplastids, 8

Plerome, I7

Plum, American, 397, 400, $40 \mathrm{I}$

Chicasaw, $40 \mathrm{I}$

family, 39I

hortulana; 400

Japanese, 400

key to principal species of, 397

myrobalan, 400

old world, 397

tomato, 590

Plumy asparagus, 246

Poa pratensis, $7 c$

Poaceæ, 69

Pod, 58 corn, 178, I 80

Polar nuclei, 50

Polish wheat, III, II 2, II 3

Pollen grains, $48,5^{2}$ mother cells, 50 tube, 52

Pollination, 5 I

Polygonacex, 284 key to principal genera, 286

Polygonum, 284

Pomaceæ, 366

key to important genera of, 367

Pome, 366

Pomelo, 485

Poncirus, $476 ; 489$ trifoliata, 489

Pop corn, $178, \mathbf{1} 80$

Poppy family, 326

Pot-herb mustard, 340

Potamogeton, 29

Potato, 561

family, 559

onions, $24 \mathrm{I}$ 
Potentilla, $34 \mathrm{~S}$

Poulard wheat, I1 I, II 2

Prickly ash, 475 cucumber, 6r 7

Privet, 55I

Profichi, 272

Prophyllum, 8o

Prop roots, I6, 159

Proso, 2 I 3

millet, 2 I0

Protandry, 170

P'rotease, I42

Proteose, 105

Protogyny, 170

Protoplasm, 9

Protoplasmic membrane, 6

Protoplast, 6

Prunes, 398

Prunus, 394

americana, 400

amygdalus, 4 Io

angustifolia, $40 \mathrm{I}$

armeniaca, 405

avium, 402

besseyi, 404

cerasifera, 400

cerasus, 402,403

cuncata, 404

dasycarpa, 407

domestica, 398

emarginata, 404

hortulana, 400

insititia, 399

key to main groups of, 394

mahaleis, 404

mume, 407

munsoniana, $40 \mathrm{I}$

nigra, 40 I

pennsylvanica, 404

persica, 407

pumila, 404

sibirica, 407

triflora, 400
Psedera tricuspidata, 33

Pscudomonas radicicola, +13

Psilotales, $\mathrm{O}_{4}$

P'telea, 475

Pteridophytes, 62

P'umpkin, 6 13 field, 6 I $3_{3}$ mammoth, 6I5

Valparaiso, 6 5

Purple apricot, 407

cane rasplerry, 357

clover, 436

vetch, 428

Pyrus, 384

communis, $38_{4}, 3 S_{5}$

serotina culta, 384,385

Quackgrass, 2I, 70

Quamoclit quamoclit, 554

Quince, 388

Rabbit-brush, 625

Raceme, 56, 78

Rachilla, 79

Rachis, 79, 92

Radicula, 344

armoracia, 345

nasturtium-aquaticum, 345

Radicle, 57

Radish, 34I

garden, 34 I

rat-tailed, $3+3$

wild, $34^{2}$

Ragi millet, 2 10

Raisin grape, 499, 500

Raisins, 50I

Raphanus, $34 \pi$

caudatus, 343

raphanistrum, 342

sativus, 34 I

Raspberry, 357

American red, 357

- black cap, 357 
Raspberry, European red, 357

key to principal species of, 357

purple-cane, 357

Rat-tailed radish, 343

Ray flowers, 627

Receptacle, 49

Red cabbages, 332

clover, 433, 435

currant, 320

mulberry, 255, 257, 258

peruvian cotton, 5 I 7

Repeated germination, Io9

Reproductive activity, I

Retting, 279

Rheum, 289

palmatum, 289

undulatum, 289

Rhizoctonia, 569

Rhizomes, 29, 75

Rhododendron, 543

Rhodophyceæ; 63

Rhubarb, 286

Ribes, americanum, 319, 320

aureum, 319, 320

grossularia, 3I9, 32 I

key to important species of, 3I9

nigrum, 319, 320

oxycanthoides, 319, 321

rubrum, 319, 320

vulgare, 319,320

Rice, 88,202

Canada, 206

cultivated, 206

large-kerneled, 206

small-kerneled, 206

wild, 206, 207

River bank grape, 499, 500

Robinia, 4I4

Rockmelons, 6 I 8

Root cap, I 7

crown, 157

hair, effect of external factors upon development of, 20
Root cap, structure of, 20

-hair zone, is

primary, Io

sheath, IO, IO3

system, effect of environment upon character of, I4

primary, 9 I

temporary, 9I

systems, 2, IO

adventitious, I I

development of, Io

fibrous, IO, II

primary, ro

tap, 14

temporary, io

tubercles, 4I3

Roots adventitious, I I

air, $\mathrm{I} 6$

classification of, based upon their medium of growth, I6

general characteristics of, I5

length of life of, 2 I

seminal, Io

soil, I6

structure of, I 6

tap, I4

water, I6

work of, I4

Rootstocks, 29, 75

Rosaceæ, 348

key to important genera of, 350

Rose family, 348

of Sharon, 508

Rough oats, I3 I

Rubus, 350, 353

argutus, 354, 355

bernardinus, 357

chamæemorus, $35^{\circ}$

cuneifolius, 354, 355

glaucifolius, 357

idæus, 357

invisus, 356

key to groups of, 353 
Rubus, leucodermis, 357 microphyllus, $35 \mathrm{~S}$

neglectus, 3.58

nigrobaccus, 354

albinus, 354

sativus, 3.54

occidentalis, 357

strigosus, $357,35^{8}$

trivialis, 356

villosus, 354,356

roribaccus, 356

vitifolius, $35^{2}, 356,35^{8}$

Rue family, 475

Rumex, 284

Runner, I3, 32, 76, $35^{8}$

Rushes, 85

Russian mulberry, 255

thistle, 47,296

vetch, 430

Rutabaga, 337

Rutacex, 475

key to important genera of, 476

Rye, 88, 89, I53

Saccharum officinarum, 225

Sachs, 177

Sage, 625, 628

Sainfoin, $46_{5}$

Sake, 207

Salicornia, 297

Salsify, 628

black, 635

Spanish, 635

yellow-flowered, 635

Salsola, 296

Saltbush, 296

Salt-grass, 55

Salt wort, 47

Samara, 55I

Sand bur, 560

blackberry, 354

grape, 499,500

pear, 384,385
San I'edro figs, 275

Sanicula, 532

Sarcobatus, 297

Sarracenia, 47

Sauerkraut, 332

Satsuma orange, $48_{5}$

Savannahs, 69

Savoy cabbages, 332

Scales, 78

Scallop, 613

Scarlet clover, 433, 435

runner bean, 423

strawberry, 363

vetch, 428

Schizomycetes, 63

Schizophytes, 63

Schuster, 84

Scientific name, 64

versus common name, 66

names, descriptive nature of, 66

Scion, 36

Scorzonera hispanica, 635

Scouring rushes, 62

Scutching, hemp, 280

Scutellum, ro4

Sea Island cotton, 520, 521

Sea-kale beet, 3 I 2

Secale, 88, I 53

anatolicum, I 55

cereale, 89 , I 53

montanum, 155

Second patent, ros

Secondary cortex, 38

Sedges, 85

Seed ball, 306

coats, 57

germination of, 59

leaves, 59

plant body, size and form of, 2 principal parts of, I

Seeds, 57

Seedlings, 57

Self-fertility, 372 


$$
676
$$

Self-sterility, 372,497

Seminal roots, $\mathrm{IO}_{3}$

Semolina, II 8

Sepals, 48

Sequoias, Giant, 2

Serradella, 465

Service berry, 366

Setaria, 2 I0

Seville orange, 487

Shaddock, 485

Shaftal clover, 433

Shallot, 237, 238

Shallu, I96, I97

Shank, I63

Shantz, II 7

Sheath, 77

Sheep's fescue, 79

Shelling pea, $4 \mathrm{I} 8$

Shepherd's purse, 326

Shoot system, 2 development of, 22

Short oats, I30

Shrub, 2

Siberian apricot, 407 crabapple, 379

millet, 218, 219 vetch, 430

Sicilian flax, 473

Sickle alfalfa, 447

Sicyos angulatus, 606

Sicyosperma gracilis, 610

Sieva bean, 423, 424 .

Sieve tubes, 35

Sikkim cucumber, 62I

Silage, 186

Silicle, 325

Silique, 325

Silks, I 7x

Silo, 186

Silver beet, $3 \mathrm{I} 2$

hull buckwheat, 294

Single oats, 126

Sisal hemp, $28 \mathrm{I}$

\section{INDEX}

Sitopyros, I ro

Six-rowed barley, I44

Small cranberry, 548, 549

Small-seeded flax, 473

Smilax, 244

Smith, I75

Smother crop, I49

Smyrna figs, 273,275

Snake cucumber, 620 eggplant, 587

Soapweed, 229

Soft corn, I 78, I80

Soja bean, 456

Solanaceæ, 559, key to important genera of, 560

Solanum, 560 carolinense, 560, 56r chilœnse, 56 I commersonii, $56 \mathrm{r}$ dulcamara, 560, $56 \mathrm{I}$ elæagnifolium, 560 immite, 56I jamesii, 56 I key to important species of, $56 \mathrm{I}$ maglia, 56x

melongena, $56 \mathrm{r}$ depressum, 587 esculentinum, 586 serpentinum, 587

muricatum, $56 \mathbf{I}$ nigrum, 560, 56r rostratum, $560,56 \mathrm{I}$ triflorum, $56 \mathrm{I}$ tuberosum, 560, 56r, $5^{62}$

Solidago, 625

Sonchus, 625

Sophia, 326

Sophora, 4I 5

Sorbus, 366

Sorghum, 88

Sorghums, I9I key to principal types, 197 origin of, I97 
Sorghums, uses of, 199

Sorgo, I96, 197

Soulard crabapple, 379, 38 I

Sour orange, 487

Southern dewberry, 356 fox grape, 499,500

Sow-thistle, 625

Soy bean, 456

Soya, 455 $\max , 456$

Spanish bayonet, 229

moss, 28

needles, 625

orange, 484

sálsify, 635

Spathe, 234

Spelt, 89 , III II 2 , II 3 wheats, III

Sperm nuclei, 50

Spermatophytes, 62

Sphenophyllales, 64

Spike 56,79

Spikelet, 78, 79, 80

Spinacea, 298

oleracea, 298

Spinach beet, 312

common garden, 300

key to groups of, 300

mountain, 299

New Zealand, 299

Spines, 33

Spiræa, 348

Spongy parenchyma, 44

Spotted bur clover, 442,449

Spreading oats, 130

Spur, 23

Spurs, 367

Squash, 6 ro

Canada crookneck, 610, 6I 2

Hubbard, 61 2, 6r 4

mammoth whale, 615

marblehead, 610, 612, 6r4

marrow, 6r4
Squash, summer, $\sigma_{1} 3$

turban, 610, 6I 2, 6I4

Valparaiso, 6I 5

Squirting cucumber, 606

Stages, ripening, 97

Stamens, 48

Staminate inflorescence, 55

Standard, 4I4

broom corn, 200

patent, ro8

Star cucumber, 606, 620

Starches, 177

Starchy endosperm, I03 sweet corn, $I 78$, I80

Strawberry tomato, 592

Stele, 17

Stem, of dicot, 33

Stems, 22

aerial, 2

classification of, based upon their medium of growth, 28

general characteristics of, 26

structure of, 33

underground, 2

work of, $4 \mathrm{I}$

Steppes, 69

Stewart, 167

Stigma, 48

Stipules, 42

Stock, 36

Stolon, 32

Stomata, 45

Stone crop, 47

Stooling, 22, 73

Straight bread flour, ros

Strawberry blite, 296

Chilean, 363,364

European, 363,364

everlasting, $30_{4}$

perpetual, 363,364

scarlet, $36_{3}$

Virginian, $3 \sigma_{3}$

wood, 364 


$$
678
$$

Streamside grape, 66

Streptochæta, 8I, 84

Sturtevant, I59, I67, I78

Stylar canal, I68

Style, 48

Stylopodium, 53I

Succory, 635, 636

Suckers, I60

Sugar beet, 300, 30r

Sugar cane, 225

$$
\text { pea, } 418
$$

Sultanas, 5 이

Summer figs, 275 grape, 499,500 radishes, 243 wood, 40

Sundew, 47

Sunflower, 625,628

Swedes, 337

Swedish clover, 433, 434

Sweet clover, 452 white, 454 yellow, 454 corn, 178,180 orange, 484 pea, leaf, 43 potato, 555 sorghums, I96

Swiss chard, 3I 2

Synconium, 268

Synergids, 50

Systema Naturæ, 6I

Systematic botany, 60

Syringa, 55 I

Tabasco pepper, 595

Tall bilberry, 547

Tangelo, 485 .

Tangerine, 485

Tangier pea, 432

Tangleberry, 547

Tansy mustard, 326

Tap root system, I3
INDEX

Taraxacum, 628

Tares, 429

Tassel, 55,162

Tatarian oats, I30

Tatary buckwheat, 293

Teas' weeping mulberry, 256

Tempering, I07

Tendrils, 33

Teneriffe, 243

Teosinte, I66, I8I, I 82

Testa, Ior

Tetragonia expansa, 299

Thallophytes, 62

Thallus, I plants, 62

Thermopsis, 4I4

Thin-leaved bilberry, 544

Thistle, 625,628 family, 625

Thlaspi, 326

Thorn apple, 366,367

Tillandsia usneoides, 28

Tillering, 22, 73, 74

Timothy, 75, 222

Tissue, 4

Tobacco, 596

Australian, 600

Indian, 600

mountain, 600

Persian, 600

"wild," 600

Tomato, 587

cherry, 587,590

currant, 587

garden, 590

husk, 592

key to types of cultivated, -59 I

large leaf, 590

pear or plum, 587,590

strawberry, 592

tree, 592

upright, $587,59 \circ$

Toothed bur clover, 4.12, 452 
Topinambour, 639

Top onions, 24I, 242

Torch-wood, 475

Torus, 49

Toxylon pomiferum, $25^{2}$

Tracheal tubes, 36

Tracheids, 36

Tragopogon, 628 porrifolius, 633

pratensis, 635

Trailing arbutus, 543

Transpiration stream, 47

Tree, 2

onions, $24 \mathrm{r}, 242$

tomato, 592

Trifoliate orange, 489

Trifolium, 66, 432

alexandrinum, 433

hybridum, 433, 434

incarnatum, 433, 435

key to principal species of, 433

medium, 433, 44I

pratense, 433,436

perenne, 439

repens, 433

suaveolens, 433

Trigonella fœnum-grœcum, 467

Tripping, of alfalfa flowers, 444

Triticum, 88, 9I

œgilopoides, II 2, I I6

xstivum, II I, II 2, I I 4 , II 6

booticum, II 2

capitatum, II 6

compactum, IIII, I I 2, I I 4, II 6

dicoccum, III, II 2 , II 3 , II 6 dicoccoides, II4, II 5 , II 6

durum, III, II $2, I I 3, I 16$

hermonis, II 4

monococcum, IIO, II I, II 2

ovata, IIO

polonicum, III, II 2, I I 3, II6

spelta, III, II 2, II3, II6,

thaoudar, II 2
Triticum, turgidum, III, II 3 , II 6

Tube nucleus, 50

Tuberization, fungus theory of, 569

Tubers, 30,31

Tubulifloræ, 627

Tulip, 229

Turban squash, 6r4

Turkestan alfalfa, 447

Turnip, 65, 335

common, 335

Swede, 337

Turnip-rooted celery, 540

Twin oats, $\mathrm{I} 26$

Two-rowed barley, $\mathbf{4} 45$

Umbel, 56, 234, 530

Umbelliferæ, 530

key to genera of economic importance, 533

Unshiu orange, 485

Upland cotton, 510,520

Upright tomato, 587,590

Utricle, 297

Vaccinium, 543, 545

angustifolium, 546, 550

'arboreum, 543

atrococcum, $547,55^{\circ}$

cæspitosum, 546

canadense, $66,546,55^{\circ}$

corymbosum, $547,55^{\circ}$

key to chief fruit-bearing species of, 546

macrocarpon, 546,548

membranaceum, 544

myrtillus, 546

nigrum, 546,550

ovalifolium, 547

oxycoccus, 546,549

vacillans, 546,550

virgatum, 544

vitis-idan, $546,55^{\circ}$

Vacciniacex, 543 
Vacuole, 7

Variegated alfalfa, 447

Vascular bundles, 35 elements, 35

Vegetative activity, I

Velvet bean, 422

Vetch, 4I4, 426 black bitter, 428

crown, 429

Dakota, 429

hairy, 427,430

Hungarian, 430

kidney, 429

Narbonne, 429

narrow-leaved, 428

purple, 428

Russian, 430

scarlet, 428

Siberian, 430

villous, 430

woolly-podded, 429

Vetchling, 432

Vexillum, 4I4

Vicia, 4I 4, 426

angustifolia, 428

atropurpurea, 428

dasycarpa, 429

ervilia, 428

faba, 427,429

fulgens, 429

key to important species of, 427

narbonnensis, 429

sativa, 427,429

villosa, 427,430

Vigna, $45^{8}$

cat jang, $45^{8}$

sequipedalis, $45^{8}$

sinensis, 458,460

Villous vetch, 430

Vilmorin sugar beet, 308

Vine peach, 620

Vinegar, 383,503

Virginia creeper, $x 6,33$
Virginian strawberry, 363

Vitaceæ, 49I

key to important genera of, 492

Vitis, 492

æstivalis, 499, 500

bourguiniana, 5 ㅇ

labrusca, 499, 500

riparia, 499,500

rotundifolia, 499, 500

rupestris, 499,500

vinifera, 499

Wakefield cabbages, 332

Washingtonia, 532

Water cress, 345

hyacinth, I 6

lily, 29

Watermelon, 61о, 622, 623

types and varieties, 623

Welsh onion, 232, 237, 239

West Indian gherkin, 6I 7

Western crabapple, 379, 38I dewberry, 356

Wheat, 88,89 , 9 I

classification of the types of, IIO

club, III, II 2, II3, II 4

common bread, III, II 2 , II 3 , II 4

durum, 89, III, II 2, II3

grain, microscopic section, I00

hard, 106

naked, III, II 2

Polish, III, II 2, II3

Poulard, III, II 2 , II 3

soft, I06

spelt, III, II 2, II 3

White blackberry, 354

clover, 433, 44I

currant, 320

mulberry, 255

mustard, 327,340

Whorțleberry, 546

Wild barnyard grass, 2 Io

beet, $30 \mathrm{I}$ 
Wild cabbage, 328

$$
\text { cotton, } 520
$$

cucumber, 606

emmer, II 4 , II 5

fig, 276

goose wheats, I I 3

oats, $x_{30}$

pea, 432

radish, 342

rice, 207

tobacco, 600

Windberry, 550

Windsor bean, 427, 429 .

Wine grape, 499,500

Wines, 502

Wings, 415

Winningstadt cabbages, 332

Winter gourd, 6I5

radishes, 243

Wolberry, 550

IVood, 36

elements, functions of, 37

fibers, 36

parenchyma, 36

strawberry, 364

Woolly-podded vetch, 429

Wormwood, 625, 628

Xanthoxylum, 475

Xenogamy, 52, 95
Xylem, I8, 36

Yams, 556

Yarrow, 625

Yellow egg plums, 399

- lowered alfalfa, 447 salsify, 635

Young dicot stem, 33

Yucca, 229

Zanta currants, 50I

Zea, 87, I57

canina, I 79

mays, I58, I 78

amylacea, $178, \mathrm{I} 80$

amylea-saccharata, $\mathbf{I} 78, \mathbf{I} 80$

curagua, 179

everta, I 78, I 80

hirta, 179

indentata, $\mathbf{I} 78, \mathbf{I} 80$

indurata, $178, \mathrm{r} 80$

japonica, I 79

key to "species groups" of, r8o saccharata, I7 8,180

tunicata, $178,180,182$

ramosa, 179

Zigzag clover, 433, 44I

Zizania aquatica, 206

miliacea, 207

Zygote, 52 







\section{LIBRARY OF CONGRESS \\ ||||||||||||||||||||||||||||||||||||||||||||||||

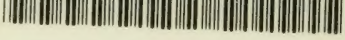

0000933029A 